UNIVERSIDAD POLITÉCNICA DE MADRID

ESCUELA TÉCNICA SUPERIOR DE ARQUITECTURA

\title{
ENTRE: De Repente, Sin Fin, Lo Innombrable
}

\author{
TESIS DOCTORAL
}

EFPRAXIA GIANNOPOULOU

DIRECTORES: Dra. ATXU AMANN ALCOCER, Dr. JAVIER SEGUÍ DE LA RIVA 

UNIVERSIDAD POLITÉCNICA DE MADRID

ESCUELA TÉCNICA SUPERIOR DE ARQUITECTURA

ENTRE: De Repente, Sin Fin, Lo Innombrable

TESIS DOCTORAL

AUTOR: EFPRAXIA GIANNOPOULOU

DIRECTORES: Dra. ATXU AMANN ALCOCER, Dr. JAVIER SEGUÍ DE LA RIVA 

Escuela Técnica Superior de Arquitectura de Madrid.

Universidad Politécnica de Madrid.

Tribunal nombrado por el MagnÍfico y Excelentísimo Sr. Rector de la Universidad Politécnica de Madrid, el día de de 2016 .

Presidente D.

Vocal Dña.

Vocal Dña.

Vocal D.

Secretario D.

Realizado el acto de defensa y lectura de la tesis ENTRE: De Repente, Sin Fin, Lo Innombrable el día de de 2016 en

Calificación_

El presidente

Los vocales

El secretario 

a mi hermano Andrea y mis padres Adamantia y Charalampo Giannopoulo... 
Marina Lampraki Plaka

Pablo Albacete

Luis Ortiz

Angelos Palaskas

Eva Lázaro

Haris Laspas

Katerina Psegiannaki

Eider Holgado

Afroditi Psarra

Ioanna Papageorgiou

Anthi Kosma

Federica Martella
Agradecimientos

Efi Akoumianaki
Raúl Ruano Monge

Ioanna Aggelopoulou

\author{
Kataerina Zamzara
}

Miki Bevilaqua

Vaggelitsa Akoumianaki 


\section{Charalampos Giannopoulos}

Adamantia Giannopoulou

Atxu Amann Alcocer

Gonzalo Pardo

Polyxeni Mantzou

Javier Seguí

Lisetinha Morales
Lola Martínez

Elisavet Mandoulidou
Efstratios Tsougenis

Pepe Alamar

Alexandra Spiratou

Jairo Ciurana Alós
Maria José Gutiérrez

Miriam Arana

Eva Lizón

Anastasia Karampounioti

Konstantina Ganatsiou 
Puede que no esté lejos el día en que planificadores, diseñadores, promotores del desarrollo y otros profesionales, reconozcan el simple becho de que el espacio entre los edificios es tan importante para la vida del hombre urbano como los edificios mismos, y actúen en consecuencia.

Serge Chermayeff, Christopher Alexander. 1963

1 Serge Chermayeff and Christopher Alexander, Comunidady Privacidad: Hacia Una Nueva Arquitectura Humanista (Buenos Aires: Nueva Visión, 1984), 68. 
ENTRE: De Repente, Sin Fin, Lo Innombrable

\section{RESUMEN}

Etiquetamos para reducir nuestra incertidumbre; clasificamos en base a términos opuestos para poder entender. El universo y el espacio construido en particular, se explican desde una arquitectónica dual: dentro - fuera, arriba - abajo, derecha izquierda, día - noche, hombre - mujer. Lo que nos diferencia como grupo, raza o género, distinguiendo los modos de vivir, las ideologías y las teorías, es la relación que establecemos entre los términos opuestos: entre lo individual y lo colectivo, lo privado y lo público, la imaginación y la realidad, la identidad y la otredad, el orden y el caos, el deseo y la saciedad.

El afán clasificatorio dicotómico de la realidad que la modernidad lleva a su extremo, hiere la vida: la mutua exclusión de los opuestos elimina la distancia, el espaciotiempo entre ambos, que es donde la vida se sitúa. La concepción dual que rige nuestro conocimiento contamina también la relación entre los arquitectos y la sociedad, siendo la causa del ambiente tóxico que envuelve al habitante que ya no se identifica con los lugares que habita.

Puede que sea oportuno pasar del pensamiento binario a una lógica de lo intersticial que abandone la dualidad para instalarse en el Entre; los arquitectos serían mediadores entre el poder y la vida, sintiendo el Entre como el transcurso de la vida y la potencia de interacción: los lugares ambiguos e intermedios, es donde sucede el encuentro entre los términos, entre arquitectos y habitantes, entre la imaginación y la realidad, entre tú y yo. 

BETWEEN: Suddenly, Without End, The Unnamable

\begin{abstract}
We label to reduce our uncertainty; we classify based on opposites to understand. The universe and all constructed space in particular, are explained from a dual architecture: inside - out, up - down, right - left, day - night, male - female, black - white. What differentiate us as a group, race, gender, distinguishing the lifestyles, ideologies and theories, is how we draw the relation between the opposites: between the individual and the collective, private and public, imagination and reality, identity and otherness, order and disorder, desire and satiety.

The dichotomous classification of reality that modernity carried to its extreme, hurts life: the mutual exclusion of opposites eliminates the distance, the space-time between the two, which is where life is located. The dual conception that governs our knowledge has also contaminated the relationship between architect and society, being the cause of the toxic environment that surrounds the inhabitant who no longer identify himself with the places he inhabit.

It may be appropriate pass from binary thinking to a logic of the interstitial which abandon duality to settle in Between; architect then will be the mediator between authorities and life, sensing the Between as a flowing of life a potency of interaction rather than a separation between the extremes; ambiguous, in -between, places are where the encounter between opposites happens, between the architect and the inhabitant, between imagination and reality, between you and me.
\end{abstract}




\section{LO OBLIGATORIO EN ANEXO}

Hipótesis...........273

Estructura.....................................275

Justificación del tema de la tesis..............279

Estado de la cuestión.........................281

Estado del arte...............................................291

Objetivos........................................................ 297

Metodología..........................................298

\section{RESUMEN Y CONCLUSIONES EN GRIEGO}

mención europea

307

BIBLIOGRAFÍA 319 


\section{INDICE}

ABSTRACT $13 \quad$ RESUMEN 11

PRO - LOGO 19

DE REPENTE: ENTRE LO FAMILIAR Y LO EXTRAÑO

en el dominio de la letra "O", excluyendo $61 \quad$ Me aburro, en el tedio urbano, 25

con el arquitecto suspendido del siglo XXI $\quad 85$

SIN FIN: ENTRE LA IMAGINACIÓN Y LA REALIDAD

$\begin{array}{llll}\text { la mujer fantasmal en la ciudad fantasma } & 117 \quad \text { vampiros, zombis y slums } & 125\end{array}$

Entre la pared y la espada, el pensamiento binario, 103

$\sin$ fin 147

LO INNOMBRABLE: ENTRE TÚ Y YO

sin techo 211

con los conejos en el Tercer Espacio, en los intersticios

La hierda en terrenos procesionales y estados de excepción 159

fumando en los umbrales de los bares de Madrid 231

dentro de lo Innombrable, desde el Entre 251 

En el otro lado de lo subjetivo, en este lado de lo objetivo, en el límite estrecho donde tú y yo nos encontramos yace el reino del intermedio ${ }^{1}$

Aldo van Eyck 1959

1 On the other side of the subjective, on this side of the objective, on the narrow borderline where I and you meet lies the in-between realm. Aldo van Eyck, Vincent Ligtelijn and Francis Strauven, Aldo Van Eyck: Writings (Amsterdam: Sun, 2008), 54 



\section{PRO - LOGO}

Uno de los momentos más difíciles, pero también de los más emocionantes de la presentación de un pensamiento mediante el lenguaje, es el prólogo. Para el lector, el prólogo parece un umbral, un espacio-tiempo en el que parar, abrir la puerta y decidir si continuar. Para quien escribe, el prólogo es un lugar de decisión sobre el pasado; es el espacio literario donde se presenta y se expone el pasado del pensamiento; el pro-logo, lo que está antes del logo, antes de la formulación de una opinión o el tema de una tesis doctoral. Este pequeño espacio de la introducción no sólo es el encuentro del pasado y del futuro, de lo conocido y lo desconocido y del lector con el autor, también es el lugar donde ocurre el encuentro de lo lógico con lo ilógico: logos no se refiere solo a la expresión, sino también a la lógica. El prólogo es principalmente la narración del camino que uno ha elegido para poder dar una explicación lógica al pensamiento caótico que desencadenó su historia; es la narración del goce y de la lucha para conquistar la esencia del pensamiento ilógico y conseguir presentarlo. El prólogo y el epílogo no son los únicos lugares intermedios del discurso; existen también aquellos huecos, intersticios, en los que uno cae, de repente, mientras escribe o habla: aquellos momentos fuera del tiempo y fuera del lugar donde uno puede permanecer horas petrificado frente al texto, sin poder articular lo que quiere decir; como si Medusa se escondiera dentro del papel en blanco..

Estos estados intermedios, intersticiales y umbrátiles, se desarrollan en esta tesis. La tesis es un conjunto de sensaciones de estar entre dos mundos distintos; son instantes en los que uno tiene la sensación de estar fuera del tiempo y fuera del lugar, en un Tercer Espacio (Žižek), en un estado de excepción donde sucede la transformación silenciosa del mundo; donde y cuando los instantes en que el día se hace noche, lo fuera se hace dentro, lo público privado y el tú se hace yo. Si el mundo, el universo, el conocimiento y la vida están construidos sobre una base dual, en el reino del Entre 
conviven la desestructuración y la estructuración del mundo simultáneamente.

Las dualidades extraño - familiar, imaginación - realidad, tu - yo, se eligen para la investigación del Entre como concepto arquitectónico. Cada dualidad es un capítulo de la tesis y los contenidos de cada capítulo corresponden a estados en los que la dualidad de disuelve.

Entre lo familiar y lo extraño está el de repente: el momento en que lo familiar se hace extraño y lo extraño, familiar; es el momento de la experiencia. Entre lo extraño y lo familiar está el sinsentido, el tedio: un lugar desde donde la vida se desnuda. El capítulo del De Repente aloja el fenómeno social del tedio urbano, la relación del habitante con su entorno y el matiz temporal del concepto del Entre.

Entre la imaginación y la realidad se encuentran los fantasmas, los zombis, los vampiros y todos los seres marginales; entre la imaginación y la realidad está la planificación y la elaboración de plan. Las formas de proyectar son formas de relación entre imaginación y realidad. El capítulo Sin Fin analiza los fenómenos sociales de las ciudades fantasmas y las ciudades informales como resultado de la distancia y la mutua exclusión de los términos imaginación y realidad; describe la función del pensamiento binario y lo relaciona con el pensamiento de Oriente. En Occidente planificamos y pensamos a partir de los términos medio -fin -acción; en China las estrategias y los proyectos se basan en lo sin fin, la transformación - consecuencia -condición evaluación.

Entre tú y yo se encuentra lo Innombrable; aquí tiene lugar el análisis del fenómeno del desencuentro entre los habitantes de las grandes ciudades: un estudio sobre el modo con el que se consigue la comunicación fructífera y el amor. Se clasifican los tipos de estados intermedios y reivindica la filosofía del Entre, que ve al habitante no como sujeto, sino como relación. 
Entre lo familiar y lo extraño

\section{DE REPENTE}


La irregularidad, es decir, lo inesperado, la sorpresa o el estupor son elementos esenciales y características de la belleza

Charles Baudelaire en Flores del Mal 
en el dominio de la letra "O", excluyendo

el arquitecto suspendido del siglo XXI

El pensamiento de "lo uno o lo otro" es lo que domina en los años de la modernidad; un pensamiento binario que divide el mundo en dualidades. La letra "o" indica el estado de la elección y del orden. El orden es la máxima preocupación de la sociedad occidental a partir del Renacimiento. La mente combate lo imprevisto, que transforma el orden caos. La eliminación del “de repente" conduce al ser humano al tedio; la extrañeza es la condición primera de la existencia. (Begout, 2009) 
Me mato porque encuentro el tedio de ir a dormir y el tedio de levantarme insoportables. Me mato porque soy inútil para los demás y peligroso para mí mismo.

Charles Baudelaire en su carta suicida 


\section{Me aburro, en el tedio urbano}

\begin{abstract}
Sólo los animales mejor organizados y más activos empiezan a ser susceptibles de aburrimiento. ¿Qué hermoso tema para un buen poeta es el del aburrimiento de Dios el séptimo día de la creación!" Nietzsche.
\end{abstract}

En 2011, un artículo titulado Hasta que el tedio los separe apareció en la revista Semana. En él, distintos investigadores confirmaban que, hoy en día, la razón principal de la separación de los matrimonios no es la infidelidad - como solía ser los años anteriores - sino el tedio. En la mayoría de los casos de separación por causa del tedio y de la monotonía, las frases más escuchadas por las parejas son "ya no hay sorpresas", "me siento desconectado de la relación", "ya no es excitante", "éramos como hermanos" y "le quiero pero no estoy enamorada de él/ella". El problema con el tedio en las relaciones, como afirman los investigadores, es que es una enfermedad silenciosa que mata la relación mucho antes y más rápido que las peleas. ${ }^{2}$ Uno se pregunta por qué la maravillosa sensación que el enamoramiento provoca se desvanece con el paso del tiempo y por qué se convierte el tedio en la razón principal de las rupturas. En cuanto a la primera pregunta parece que - a parte de un proceso biológico - es el proceso de la familiarización lo que conduce a la reducción del enamoramiento: la transformación de lo nuevo y lo extraño en cotidiano; todo lo que antes fue belleza única y que nos convertía en locamente enamorados, por su familiarización, casi deja de ser visto. La primera fase del amor, la fase en la que sucede el enamoramiento, fue denominada por la psicóloga Dorothy Tennov como limerencia ${ }^{3}$. La limerencia es el estado mental cognitivo que no se elige; no es voluntario, sino que sucede por la atracción que siente una persona hacía

\footnotetext{
1 Friedrich Nietzsche, El Viajero y Su Sombra. Edaf, 1999). aforismo 56, 178.

2 "Hasta Que El Tedio Los Separe - Semana.Com “, accessed 5/31/2015, 2015, http://www.semana.com/vida-moderna/articulo/hasta-tedio-separe/246495-3.

3 Dorothy Tennov, Love and Limerence: The Experience of being in Love (Maryland: Scarborough House, 1998).
}

En siglo XXI, el tedio es la razón principal de la ruptura de las parejas

Limerencia: primera fase del amor, estado cognitivo involuntario 
Vinculo amoroso: segunda fase de la relación.

Equilibrio entre lo familiar y lo extraño: éxito de la relación otra; estado que se convierte en obsesión, necesidad de estar con el otro en cualquier momento. Pero la limerencia es un lugar de paso; es un umbral y como tal, existe solo para permitir la entrada o la salida de la relación futura. Si dura más de lo aceptado, la limerencia se llama enfermedad del amor, porque la larga obsesión hacia una persona o una cosa hacen los tiempos de la vida menos productivos; la obsesión hacia una cosa en concreto, no deja espacio para la experimentación de nuevas cosas.

La limerencia tiene que dar paso a la segunda fase del amor que es en la que se establece el vínculo amoroso; es cuando empezamos a sentir comodidad y seguridad, pero sin dejar que el otro sea un lugar misterioso que nos invita a ser descubierto; un estado del equilibrio entre lo conocido y lo desconocido, entre lo familiar y lo extraño. La diferencia entre la fase de la limerencia - en la que todo nos sorprende y todo sucede por primera vez - con la fase del vínculo amoroso, es que en la primera todo funciona solo; es un proceso involuntario que no podemos controlar y por eso nos dejamos llevar; a diferencia de la segunda fase en la que empezamos a sentir comodidad y no todo se hace solo, sino que la evolución de la relación depende de nosotros. ${ }^{4}$ La segunda fase de la relación es la más frágil porque todo lo desconocido que se conquista, a la vez se desmitifica, pues lo que se familiariza deja de ser asombroso; el asombro habita en lo inesperado y lo extraordinario, lo contrario a lo ordinario y conocido. El proceso de la familiarización es un proceso de doble función: por una parte ofrece lo cómodo y lo seguro de lo familiar, pero a la vez, quita lo asombroso que es propiedad de todo lo que experimentamos por primera vez. Depende de los cuidados de la pareja si esta relación seguirá siendo apasionante, misteriosa y excitante, o se convertirá en un simple afecto que conducirá a su fin o, a su transformación en rutina.

Una relación para no conducir al tedio tiene que encontrar el equilibrio en la sutil línea que separa lo familiar y lo extraño, lo desconocido y lo conocido, lo habitual y lo inhabitual. Si la relación se mueve en una continua extrañeza, no es posible la creación del vínculo amoroso y la familiarización de la pareja. Si la relación cae en lo habitual y se acomoda en lo familiar excluyendo lo extraño y lo repentino, transforma lo cotidiano en rutina y entra en el tedio: en la separación.

4 "La Mirada De Elsa » Te Quiero... Pero no Estoy Enamorado De Ti “, accessed 7/31/2015, 2015, http://www.inteligenciaemocionalysocial.com/828/elsa-escribe/te-quieropero-no-estoy-enamorado-de-ti. 
La diferencia entre las relaciones del pasado y las del siglo XXI es que el proceso que conduce a la ruptura se acelera de manera radical; cuando el enamoramiento se va, cuando aquel que antes era nuevo y desconocido se hace antiguo y conocido, la relación termina. Bauman opina que es la primera vez que nuestras sociedades experimentan el Amor Liquido, un amor que es efímero, ligero e inestable; las relaciones con el otro, el prójimo, son estancias efímeras que a veces se acaban antes de empezar. Bauman recuerda a los habitantes de la Ciudad Leonia de las Ciudades Invisibles ${ }^{5}$, donde los habitantes encuentran la felicidad en estrenar nuevos productos por la mañana y por la noche tirarlos para poder estrenar otros nuevos el día siguiente. ${ }^{6}$. El éxtasis que siente el habitante contemporáneo por el rápido e inmediato consumo de los productos, la satisfacción instantánea y las soluciones rápidas que no requieren esfuerzo, se traslada a las relaciones interpersonales. Los otros no solo se transforman en imágenes, ${ }^{7}$ como sostiene Stavros Stavridis; también se convierten en productos, como afirma Bauman. La promesa de aprender el arte de amar es la promesa (falsa, engañosa, pero inspiradora del profundo deseo de que resulte verdadera) de lograr "experiencia en el amor" como si se tratara de cualquier otra mercancía. Seduce y atrae con su ostentación de esas características porque supone deseo sin espera, esfuerzo sin sudor y resultados sin esfuerzo $0^{8}$.

La necesidad de amar se transforma en necesidad de usar. Baudelaire hace una aproximación violenta a esta necesidad del amar; en Corazón al Desnudo donde escribe cuando el amar se hace usar que, es a este horror de la soledad, a la necesidad de olvidar su yo en la carne extraña, a lo que el hombre llama noblemente necesidad de amar?. Si es así, hoy no hace falta amar para olvidar el yo. Si somos seres humanos- masa que no son capaces de distinguir su individualidad

5 Italo Calvino, Las Ciudades Invisibles (Barcelona: Minotauro, 1983), 125-126.

6 Ibid., 125

7 Stavros Stavridis, en su explicación sobre las maneras con las que el dominio de la imagen - condición de nuestros tiempos - influye en nuestra vida presenta el proceso con el

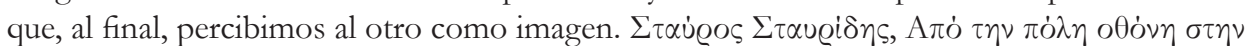

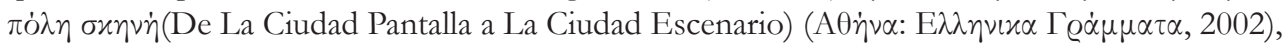
61-70.

$8 \quad$ Zygmunt Bauman, Amor Líquido. Acerca De La Fragilidad De Los Vínculos Humanos (Argentina: Fondo de Cultura Económica, 2005)., 24

9 Charles Baudelaire, "Mi Corazón Al Desnudo.LXVI," in Diarios Íntimos, trans. Rafael Alberti (Buenos Aires: Editorial "Bajel”, 1943). 
de la masa ${ }^{10}$, como Simmel sostiene, si ya hemos olvidado nuestro yo, ya no tenemos la necesidad de amar. Sin la necesidad de amar pero con la necesidad de consumir, el amar se transforma en usar. Los habitantes de la sociedad liquida usan el uno al otro para no ahogarse en la soledad; pero la necesidad de consumir lo nuevo, pronto los hará abandonar la relación para gozar del estreno de una nueva. Las personas - productos se consiguen de manera más fácil y más rápida en las redes sociales donde las relaciones son conexiones de fácil entrada y salida; tienen siempre la ventaja de oprimir el botón delete. $\mathrm{Y}$ aunque relaciones de breve estancia, cuando terminan, en el caso de una implicación sentimental, sus habitantes se sumergen en la tristeza y el tedio como si el amor que sentían fuera algo real. ${ }^{11}$

Esta continua búsqueda de lo nuevo y lo interesante es una de las causas del tedio $^{12}$, según Svendsen. Aristóteles, Charles Baudelaire, Walter Benjamin, Paul Valéry, Lars Svendsen, Søren Kierkegaard, Vladimir Jankélévitch, Maurice Blanchot, Giorgio Agamben y George Steiner son, entre otros, autores que han estudiado la problemática del tedio, pues es la raíz de todo mal ${ }^{3}$. El mal entre todos los males, ese veneno de venenos, como lo llama Valery, anteriormente era una enfermedad que azotaba solo a la burguesía, pero hoy, es el mal de siglo ${ }^{14}$, dice Jankélévitch, y afecta prácticamente a todo individuo ${ }^{15}$.

El tedio: mal de todos los males, el mal del siglo.
Las causas del tedio varían: la destrucción y la pobreza de la experiencia (Agamben, Benjamin), la oposición entre lo imaginado y lo experimentado (Jankélévitch), y la falta del derecho al desorden para Baudelaire. El tedio vital y principalmente con su sentido del Spleen de Baudelaire, fue conectado por Walter Benjamin y Berman con la condición

10 Para Simmel la masa no es la suma de las existencias personales íntegras, sino una configuración nueva, que no se compone de las individualidades completas de sus participantes, sino de aquellas partes del carácter de cada uno en las que coincide con los demás y que no pueden ser otras que las más primitivas y del nivel más bajo en la evolución orgánica. George Simmel, Cuestiones Fundamentales De Sociología (Barcelona, Spain: Gedisa, 2002), 68 .

11 Bauman, Amor Líquido. Acerca De La Fragilidad De Los Vinculos Humanos, 19

12 Lars Fr H. Svendsen, Filosofia Del Tedio (Barcelona: Tusquets, 2006), 34.

13 Søren Kierkegaard, "La Rotación De Los Cultivos. Ensayo Para Una Doctrina De Prudencia Social," in O Lo Uno o Lo Otro: Un Fragmento De Vida I (Madrid: Trotta, 2007), 279.

14 Vladimir Jankélévitch, La Aventura, El Aburrimiento, Lo Serio (Madrid: Taurus, 1989),

15 Lars Fr H. Svendsen, Filosofia Del Tedio (Barcelona: Tusquets, 2006), 14. 
moderna de las calles de Paris en la época de su industrialización ${ }^{16}$ : la época en la que por primera vez miles de personas están en las calles mezclándose, pero siendo extraños; y la época en la que Haussmann derriba barrios enteros a fin de ordenar París y transformarlo en una ciudad excelente para la velocidad, el espectáculo y el consumo que empieza a florecer en las raíces del capitalismo.

Las ciudades son como los amantes y los novios: desarrollamos una relación amorosa con ellas. El amor no es sólo un sentimiento. Es también un arte, dice Honore de Balzac; arte de pensar, construir, habitar. Hay ciudades de una noche, de un fin de semana, de dos semanas; las hay de unos meses o de unos años; las hay para toda la vida. Hay ciudades que son como las estrellas de Hollywood: nos atraen y nos encantan aunque no hemos llegado nunca a vivir con ellas. Si llegamos a ellas, nos pueden decepcionar o nos pueden hacer querer conocerlas más. Si la estancia en ellas dura menos de lo que querríamos, deja aquella sensación que sentimos cuando una relación termina antes de ser cumplida: nos sumergimos en una nostalgia a la escucha de su nombre y pensamos que un día volveremos para vivir en ella. Lo que en este caso sucede es que la ciudad y la vida en ella se idealizan, pues no hemos llegado a conocer lo desagradable que tiene; no existe ni ciudad, ni sociedad, ni personas perfectas; perfecto es, tal vez, solo aquello que no conocemos o lo que ya está muerto, pues lo que no se conoce o lo que está muerto nunca nos decepciona.

Como sucede en una relación amorosa, en la primera fase, todo en la ciudad es mágico, nuevo, admirable y agradable; es también lo desconocido que tiene, que tanto atrae por la curiosidad y el miedo que provoca. El primer tiempo dentro de una ciudad nueva se parece a la fase de la limerencia en la que el trabajo, las obligaciones, las Limerencia; primer tiempo en la ciudad preocupaciones y cualquier cosa que no permite la errancia en sus calles, molesta o se queda en un segundo plano. En esta fase, por una parte todo es extrañante y nuevo, pero por otra parte, la ciudad atemoriza; alguien se encuentra en una continua exposición a lo desconocido sin poder prever lo que podría encontrar en la siguiente esquina.

Con el tiempo lo desconocido es ya conocido y lo que antes era nuevo se hace

16 El Spleen de Baudelaire lo encontramos en varias obras de Benjamin como: Walter Benjamin, Libro De Los Pasajes, Vol. 3Ediciones Akal, 2005), Walter BENJAMIN, "El París Del II Imperio En Baudelaire" y "París, Capital Del Siglo XIX”, Ambos Incluidos En El Volumen,” Iluminaciones II (1972). 
El proceso de la familiarización hace que los edificios desaparezcan

Ser un cuerpo; estar en un cuerpo tan familiar que casi no se ve; los edificios, las plazas y los monumentos desaparecen. Es el proceso de la familiarización lo que hace que los edificios desaparezcan. Las partes de la ciudad que nos dejaban sin palabras, poco a poco - a través su familiarización - empiezan a desaparecer. Y solemos recordar lo extraordinarios que son cuando hacemos de guía a un amigo que viene por primera vez en la ciudad. Las partes de la ciudad mientras se familiarizan dejan de ser asombrosas precisamente porque dejan de ser extrañas. Cuando los edificios desaparecen, es cuando dejamos de ser turistas y pasamos a ser habitantes. Porque el proceso de la familiarización es un proceso de cotidianización; lo que diferencia al turista del habitante de una ciudad, es precisamente que el segundo ha cotidianizado la ciudad porque tiene una cotidianidad. El habitante no es sólo parte del cuerpo de una ciudad como sucede con el turista, sino que ella es parte de su cuerpo. Y como son pocos los momentos en los que paramos y salimos fuera de nuestras actividades para observar nuestro cuerpo, de manera análoga, son muy pocos los momentos en los que salimos fuera de lo que estamos haciendo para observar el lugar donde nos encontramos. Los edificios desaparecen y aparecen de la misma manera que nuestro propio cuerpo lo hace; mientras estamos sumergidos en actividades, en pensamientos o en nuestra comunicación con los otros, olvidamos que estamos dentro de un cuerpo; somos un cuerpo. Pero cuando salimos fuera de cualquier actividad y fuera de cualquier relación interpersonal, cuando miramos nuestros reflejos a espejos o escaparates, o cuando observamos nuestro cuerpo, es cuando dejamos de ser un cuerpo y llegamos a estar dentro de un cuerpo; es cuando el cuerpo vuelve a aparecer. Lo mismo sucede con el cuerpo de la ciudad: cuando salimos fuera del transcurso del día, fuera de nuestras comunicaciones, actividades y pensamientos, la ciudad vuelve a ser un escenario creado por los edificios; los monumentos, las plazas y las luces vuelven a aparecer.

La cotidianidad arrastra consigo cada ladrillo y lo único que deja son nuestras experiencias, es decir, nuestros relatos. La ciudad se transforma, de un espacio lleno de construcciones, en un lugar construido por narraciones cotidianas. Como dice Javier Seguí, es que al final la ciudady la arquitectura sólo serán percibibles las partes de las que se puede 
hablary en la medida en que den que hablar. El resto permanecerá invisible ${ }^{17}$. La familiarización y cotidianización son procesos de integración de lo desconocido en lo ya conocido. No sólo construyen la cotidianidad, sino principalmente a nosotros mismos. Si no existiera el proceso de la familiarización nos quedaríamos siempre obsesionados con una cosa y no tendríamos más que una experiencia en nuestra vida; no evolucionaríamos: el proceso de la familiarización es lo que hace lo que somos. La cotidianidad, al fin y al cabo, es un modo de ser; es una actitud, una toma de posición existencial en la realidad. Creemos que la cotidianidad es una evidencia pero en realidad es, como dice Perec, opacidad, una forma de ceguera, un tipo de anestesia ${ }^{18}$.

Cotidianidad no es lo mismo que cotidiano. El uso arbitrario del lenguaje identifica ambos términos, pero a partir de Lefebvre sabemos que la cotidianidad es un atributo de lo cotidiano ${ }^{19}$. Lo cotidiano es una noción difícil de explicar, pues abarca todo; no hay vida que no sea cotidiana ${ }^{20}$; lo cotidiano es nuestra parte de eternidad ${ }^{21}$, dice Blanchot. Y si es difícil hablar de lo cotidiano, es también porque, como este último autor dice, es algo que se nos escapa ${ }^{22}$; no podemos acceder a ello porque es como la vida, que como expresa Jullien, es algo tan inmediato que se hace inaccesible: aunque nos encontremos inmersos de antemano en la vida, no podemos acceder a ella $(. . .)^{23}$. Bégout define lo cotidiano como todo lo que en nuestro alrededor es inmediatamente accesible, comprensible y familiar, en virtud de su presencia regular ${ }^{24}$ : lo que sucede cada día, lo conocido, lo infra-ordinario ${ }^{25}$ de Perec. Pero lo cotidiano no se puede confundir con lo ordinario; no se puede reducir a lo banal, lo rutinario, lo repetitivo. La banalidad depende de los sujetos. Lo cotidiano

17 Seguí de la Riva, Francisco Javier, “Arquitectura y Narración,” LAU 2006: Segundas Jornadas Sobre Investigación En Arquitectura y Urbanismo, 21-23 De Septiembre De 2006.Sant Cugat Del Vallès: Escuela De Arquitectura Del Vallès, 2006. (2006).. En Internet se puede visitar en “Arquitectura y Narración. Javier Seguí De La Riva,”, accessed 5/30/2015, 2015, http://www. faud.unsj.edu.ar/descargas/LECTURAS/Arquitectura/EXTRA/1.pdf..

18 Georges Perec, Especies De EspaciosEditorial Montesinos, 2003).

19 Javeau Claude, «La Société Au Jour Le Jour. Ecrits Sur La Vie Quotidienne,» Bruxelles: De Boeck-Wesmael (1991)., 11.

20 Francisco Sierra Gutiérrez, "Vida Cotidiana y Filosofía. Pertenencia y Distancia" (Universidad Iberoamericano. Ciudad de México, Junio 13 - 14, 2013). http://www.lonerganlat. org/wp-content/uploads/VIDA-COTI-Y-FIL-MEX-textinprogress.pdf.

21 Maurice Blanchot, La Conversación Infinita (Madrid: Arena Libros, 2008), 312-313

22 Ibid., 305.

23 François Jullien, Filosofía Del Vivir (Barcelona, España: Octaedro, 2012), 14.

24 Bégout Bruce, La Découverte Du Quotidien (2005), 38.

25 Georges Perec, Lo Infraordinario Editorial Verdehalago, 2008).
La cotidianidad no es lo mismo que lo cotidiano

Lo cotidiano no es

lo familiar; es el lugar donde sucede la dialéctica entre lo familiar y lo extraño. 
Somos el modo en el que oscilamos entre los dos términos de las dicotomías de la vida cotidiana. se hace banal, soso, amorfo, rutinario cuando pierde su vitalidad y se hace ordinario. Creemos que lo cotidiano es lo familiar, pero lo cotidiano no es eso: es la dialéctica invisible entre lo familiar y lo extraño ${ }^{26}$. Lo cotidiano es el medio que permite que todo suceda; es el lugar de creación o de perpetuación de todas las significaciones ${ }^{27}$. Lo cotidiano es el lugar donde se trazan los ejes estructurales de la vida cotidiana; es decir, es el lugar que aloja la dialéctica de toda dicotomía. ${ }^{28}$

Lo cotidiano, sostiene Bégout, Sheringham ${ }^{29}$ y otros, oscila entre: la maestría del presente y el descubrimiento de lo nuevo; la seguridad y la aventura; lo endótico y lo exótico, lo cierto y lo incierto; lo familiary lo extraño; la intimidady la exterioridad; lo público y lo privado; lo conocido y lo desconocido, la confianza y la desconfianza, lo normal y lo anormal; lo "informal" y lo "amorfo" Lo cotidiano sólo tiene validez en este movimiento incesante ${ }^{31}$.

La cotidianidad, nuestro modo de ser, es la manera en la que oscilamos entre las dicotomías - ejes estructurales - de la vida cotidiana. Y la dialéctica entre los dos polos de las dicotomías estructurales de la vida es lo que define lo que vivimos y cómo vivimos cada día, decidiendo si nuestra vida cotidiana es amorfa, banal, rutinaria, tediosa o si es excepcional, aventurera, extraordinaria, creativa. Sin embargo, una dicotomía existe solo porque existen dos polos; si no existe uno de los dos, no existe el otro. Sin lo extraño, no existe lo familiar ${ }^{32}$. Existe siempre el territorio natal, familiar, histórico y cultural al que tenemos la sensación de pertenecer, pero lo que nos hace conscientes de lo que es familiar es el encuentro con la extrañeza. Encontrarse con lo extraño es a la vez encontrarse con lo familiar; encontrarse con lo extraño es desorientarse y desordenarse;

\footnotetext{
26 Bruce, La Découverte Du Quotidien, 43.

27 Claude, La Société Au Jour Le Jour. Ecrits Sur La Vie Quotidienne, 2.

28 Ejes estructurales de la vida cotidiana son las dicotomías familiaridad - extrañeza; sentirse en casa - lo público; tiempo ordinario - tiempo excepcional; causalidad y espontaneidad; espíritu arriesgado - prudencia; normalización - anormalidad; hospitalidad - inhospitalidad; causalidad - azar; vida - muerte; resistencia - sumisión; autenticidad inautenticidad. Gutiérrez, Vida Cotidiana y Filosofía. Pertenencia y Distancia, 15.

29 Michael Sheringham, "Everyday Life: Theories and Practices from Surrealism to the Present," (2006).Referencia en Gutiérrez, Vida Cotidiana y Filosofía. Pertenencia y Distancia, 15.

$30 \quad$ Blanchot, La Conversación Infinita, 305.

31 Bruce, La Découverte Du Quotidien, 42.

32 Sin duda, en toda dualidad no hay el uno de los dos términos opuestos sin el otro. François Jullien en su obra ha presentado que en Occidente hablamos de dualidad mientras que en China hablan de polaridad; en el primer caso hablamos de términos opuestos, mientras que en el segundo hablamos de términos complementarios. En occidente usamos el pensamiento de la exclusión, en China aquel de la inclusión.
} 
el encuentro con lo familiar muestra lo que nos orienta y nos ordena. La familiaridad es una experiencia liminal y relativa: liminal porque está en tensión con lo extranjero; relativa porque sólo vive gracias a él y no es absolutamente distinta de la de é $\beta^{3}$. Familiarizamos un lugar cuando sentimos que "estamos en casa". El sentimiento de "estar en casa" no se limita solamente a los límites de nuestro hogar; podemos sentir el mismo grado de comodidad e intimidad en el trabajo, en la calle, o en cualquier sitio. Hay, de este modo, un cotidiano privado y un cotidiano público; el primero es más excluyente de extrañezas, mientras que el segundo está más abierto a ellas.

La familiarización, tanto en el cotidiano privado como en el cotidiano público, es aquel proceso que intenta transformar la incomodidad que provoca la extrañeza en la comodidad que ofrece lo familiar; es el mecanismo que nos permite "sentirnos en casa". La familiarización es un proceso de integración de lo extraño a lo familiar, de lo desconocido a lo conocido. Sin embargo, hay un tipo de extrañeza que es inquietante, porque ella no viene desde el exterior de lo familiar - como sucede con las otras -, sino desde su interior. Esto sucede porque el proceso de la integración requiere un ajuste y una represión: lo extraño se ajusta con lo familiar y se hace parte de ello; se reprime. La inquietante extrañeza ${ }^{34}$, como la llamó Freud, o, el siniestro, como fue traducida en español, es la aparición de algo extraño que a la vez es familiar; lo que había sido conquistado por el mundo de lo familiar, reprimido, de repente vuelve a ser extraño. Heimlich es en el idioma alemán familiar y unheimlich lo oculto ${ }^{35}$; sale a la luz todo aquello que debería baber permanecido oculto ${ }^{36}$. Ejemplos de generadores de la inquietante extrañeza, según Freud, es el animismo de los objetos, y a la inversa, los autómatas, el tema del doble y del otro yo, y más. Tanto para Freud como para Julio Cortázar, la inquietante extrañeza es la esencia de lo fantástico; aperturas sobre el extrañamiento, instancias de una descolocación ${ }^{37}$; desordenan y desestabiliza la cotidianidad

La cotidianización, como la familiarización, es además un proceso de control

33 Ibid., 415-417.

34 Sigmund Freud and Bertrand Féron, L'Inquiétante Étrangeté: Et Autres Essais, Vol. 85Gallimard Paris, 1985). 163-210.

35 Ibid., 173.

36 Ibid., 173.

37 Julio Cortázar, “El Sentimiento De no Estar Del Todo," in, Vol. 1 (México: Siglo XXI, 1967). 25.
Lo que nos hace conscientes de lo que es familiar es el encuentro con la extrañeza

La familiarización es un proceso de integración de lo extraño en lo familiar

Cuando la extrañeza viene desde el interior de lo familiar aparece lo siniestro, la extrañeza inquietante 
La cotidianización es un proceso de organización del flujo del tiempo irreversible: tiempo ordinario y tiempo excepcional

La banalización de lo cotidiano y el puro durar de lo igual: el tedio

El tedio, cuando la vida se ve desnuda. y de organización. El tiempo cotidiano intenta cotidianizar el tiempo irreversible, indefinible; aquel flujo del tiempo incontrolable, siendo a veces tiempo ordinario y otras veces tiempo excepcional. ${ }^{38} \mathrm{El}$ tiempo ordinario es más lento, se ajusta quizás a los ciclos de la naturaleza, es tranquilizador, práctico; un tiempo suave y silencioso, previsible. El tiempo excepcional es el tiempo del "de repente"; el tiempo que pone lo ordinario entre paréntesis; un tiempo intruso, que viene sin preguntar; que viene para desequilibrar y cuestionar lo familiar; imprevisible, irregular, singular. Cuando la singularidad es propiedad solo del tiempo excepcional es cuando hablamos de la banalización de lo cotidiano. Lo que banaliza lo cotidiano es cuando el tiempo ordinario deja de ser singular; lo que banaliza es aquella repetición indigna que borra las diferencias y las singularidades de cada hecho cotidiano. ${ }^{39}$

La banalización es el riesgo que los procesos de la familiarización y cotidianización conllevan. Porque lo que quieren dichos procesos para hacernos sentir en casa es domesticar el espacio - tiempo; acotar lo indefinible y lo imprevisible que tienen. Sentir en casa es sentir tranquilidad y seguridad y, ellas, no quieren a lo extraño y lo excepcional porque las perturban; desorientan y descontrolan. Pero cuando todo es controlado y previsto todo tiempo cotidiano se repite y se eliminan las extrañezas; vivimos en el puro durar de lo igual (langewaile) de lo que habla Blanchot refiriéndose al sentimiento del desasosiego de Fernando Pessoa. ${ }^{40}$ La banalización de lo cotidiano conduce a la experimentación del tedio, del aburrimiento que, para Maurice Blanchot, es lo cotidiano que se hizo manifiesto. Por consiguiente perdió su rasgo esencial-constitutivo- de ser desapercibido ${ }^{41}$. Valery parece haber experimentado el tedio, tal y como revelan sus palabras: el tedio, este absoluto tedio no es en sí más que la vida enteramente desnuda, cuando claramente a si propia se mira. [...] No bay cosa, sin duda, más mórbida en sí misma, no bay cosa más adversa a la naturaleza que ver las cosas como ellas $\operatorname{son}^{42}$. Es el vacío que uno siente frente a la desnudez de la vida; el aburrimiento para vivir, ya que en el vivir no hay ningún sentido. El tedio parece

38 Bruce, La Découverte Du Quotidien, 451-456

39 Ibid., $451-456$

40 María Cecilia Salas, La Escritura Del Desasosiego: Una Poética Del Pensar En Fernando Pessoa (Colombia: Universidad de Antioquia, 2009). 59-62.

41 Maurice Blanchot, El Diálogo Inconcluso, Trad (Caracas: Monte Ávila, 1970), 390.

42 Paul Valéry, El Alma y La Danza: Eupalinos o El Arquitecto (Buenos Aires: Losada, 1958). 40-41. 
ser la experiencia del tiempo infernal, inacabado, homogéneo y vacío, que no nos deja construir ningún recuerdo; el hastío que nos deja fuera de la vida; nos convierte en su observador.

Según Kierkegaard todas las personas son tediosas ${ }^{43}$, pero el tedio que hoy en día se ha convertido en epidemia, la raíz de todo matt4, no es el tedio pasajero, el tedio por fatiga, sino el tedio puro de lo que Paul Valéry buscaba un remedio:

\section{(...) conoces algún remedio especifico, o algún cuerpo exactamente antídoto para ese mal entre} todos los males, ese veneno de venenos, esa ponzoña opuesta a toda la naturaleza (...) que se llama: el tedio de la vida? Me refiero, entiéndelo bien, no al tedio pasajero; no al tedio por fatiga, o aquel cuyo germen se distingue o cuyos hitos se conocen, sino el tedio perfecto, el puro, el que no reclama al infortunio o a la invalidezpor origen, y que se aviene a la condición que dé más gozo contemplar, el tedio, en fin, sin más sustancia que la vida misma ni más causa segunda que la clarividencia del vidente ${ }^{45}$.

Charles Baudelaire usaba el término Spleen ${ }^{46}$ para referirse al sentimiento del tedio que le empujó a su primer intento de suicidio, habiendo escrito unos minutos antes: Me mato porque encuentro el tedio de ir a dormir y el tedio de levantarme insoportables. Me mato porque soy inútil para los demás y peligroso para mi mismo. El spleen baudeleriano fue interpretado con varios modos. George Steiner considera que el spleen es el término más cercano a lo que él llama ennui. Ennui es un término francés, que se suele traducir como aburrimiento; sin embargo, Steiner considera que aburrimiento no es el término adecuado para lo que realmente es el ennui.

43 Søren Kierkegaard, "La Rotación De Los Cultivos. Ensayo Para Una Doctrina De Prudencia Social," in O Lo Uno o Lo Otro: Un Fragmento De Vida I (Madrid: Trotta, 2007), 275. 44 Ibid., 279.

45 Valéry, El Alma y La Danz̨: Eupalinos o El Arquitecto, 40.

46 Baudelaire llama el sentimiento del tedio spleen por la definición que daba Aristóteles sobre la melancolía en el Problema XXX .Pregunta Aristóteles: ¿Por qué razón todos aquellos que han sido hombres de excepción, bien en lo que respecta a la filosofía, o bien a la ciencia del Estado, la poesía o las artes, resultan ser claramente melancólicos, y algunos hasta el punto de hallarse atrapados por las enfermedades provocadas por la bilis negra (...)? La palabra melancolía está compuesta de las palabras melán $(\mu \dot{\varepsilon} \lambda \alpha \nu)$ «negro»y choli ( $\chi 0 \lambda \dot{\eta})$ «bilis». Y la palabra spleen viene de la palabra griega $\sigma \pi \lambda \dot{\eta} \vee \alpha$ (leído, «splina»), que significa bazo. Melancolía, pues, es la bilis negra del bazo; del spleen.
El tedio, raír de todo mal, Veneno de venenos 
En nuestros cerebros bulle un pueblo de Demonios.

$Y$ cuando respiramos, la Muerte a los pulmones

Desciende, río invisible, con sordas quejas.

\section{(...)}

Pero, entre los chacales, las panteras, los podencos,

Los simios, los escorpiones, los gavilanes, las sierpes,

Los monstruos chillones, aullantes, gruñones, rampantes,

En la jaula infame, de nuestros vicios

¡Hay uno más feo, más malo, más inmundo!

Si bien no produce grandes gestos, ni grandes gritos,

Haría complacido de la tierra un despojo

$Y$ en un bostezo tragaríase el mundo:

¡Es el Tedio! - los ojos preñados de involuntario llanto

Sueña con patíbulos mientras fuma su pipa

Tú conoces, lector, este monstruo delicado

-Hipócrita lector-, mi semejante, imi hermano. ${ }^{47}$

Charles Baudelaire en Las Flores del Mal

Extracto de Al Lector 
El tema que deseo precisar es el del ennui. «Boredom» no es una traducciónadecuada, ni tampoco Langweile, salvo quizás, en el sentido en que emplea este vocablo Schopenhauer; noia se aproxima mucho más a lo que quiero decir. (...) Los movimientos repetidos o la inactividad suficientemente prolongada segregan un veneno en la sangre y producen un ácido letargo. Entorpecimiento febril; náusea soñolienta (como tan precisamente la describe Coleridge en la Biografía Literaria) de un hombre que a oscuras pierde un peldaño en la escalera; hay muchos términos e imágenes aproximados. El empleo que hace Baudelaire de la voz spleen es el que más se aproxima al concepto: spleen expresa la combinación, la simultaneidad de un exasperado vago esperar - pero, ¿esperar qué? - y de un grisáceo desfallecimiento. ${ }^{48}$

El spleen representa para Benjamin la experiencia del vacío, un transcurrir del tiempo homogéneo; vacío pero lleno del sinsentido, un tiempo infernal: el 'spleen' hace pasar siglos entre el instante presente y el que se acaba de vivir ${ }^{49}$. En la dualidad que propone Baudelaire, viendo el spleen como lo contrario de lo ideal, Benjamin dice que el ideal dispensa las fuerzas para la reminiscencia (...) el spleen en cambio ofrece la desbandada de los segundos $^{50}$. Los poetas franceses Charles Baudelaire (1821 - 1827) y Paul Valéry (1871 - 1945), vivieron los cambios que sufrió Paris en la época de la Primera Revolución Industrial bajo el urbanismo neoconservador del Barón Haussmann (1809 -1891). Y Walter Benjamin conectó el spleen - el tedio urbano como aquí lo llamamos - con la condición moderna en la que entraba el espacio urbano al principio del siglo XIX. En París, por primera vez, miles de personas coincidían en la misma calle, sin intercambiar ni una mirada. El ciudadano, dice Sennet, en el intercambio con sus conciudadanos, puede mezclarse con ellos, pero no los ve, los toca, pero no los siente, existe sólo en sí mismo y para sí mismo. Y si sobre esta base sigue existiendo en su mente un sentimiento de familia, ya no existe un sentimiento de sociedad ${ }^{51}$. La hipnosis del estado intermedio de tocar sin sentir, mezclarse sin ver, es resultado quizás, de una nueva experiencia de la ciudad, nunca hasta entonces sentida:

48 George Steiner, "El Gran Ennui," in En El Castillo De Barba Azul (Barcelona, España: Editorial GEDISA, 2013). 25.

49 Walter Benjamin, Libro De Los Pasajes, Vol. 3Ediciones Akal, 2005)., 343.

50 Walter Benjamin, Sobre Algunos Temas En Baudelaire, en Poesía y Capitalismo-Iluminaciones II (Madrid, España: Taurus, 1998)., 158.

51 Richard Sennett, Carne y Piedra: El Cuerpo y La Ciudad En La Civilización OccidentalAlianza editorial, 1997), 344.

En las calles de la Metrópolis, mezclarse sin ver, tocarse sin sentir. 
El shock metropolitano: intensificación nerviosa por el continuo cambio de estímulo.
Anonimato de la multitud: amenaza y libertad la experiencia del caleidoscopio ${ }^{52}$, como Baudelaire la nombraba, o la experiencia del shock metropolitano que Benjamín desarrolló. El shock metropolitano, Benjamín lo compara con el shock de la guerra - el shock que analizaba Freud para entender la psicosis provocada de la guerra- sosteniendo que esta experiencia productora de shock del campo de batalla se ha "convertido en norma" en la vida moderna $a^{53}$. El shock metropolitano se debe, según Simmel, a la intensificación de la estimulación nerviosa causada por el rápido y continuo cambio de los estímulos $e^{e x t e r n o s^{54}}$. Frente a la tensión, el yo, dice Buck-Morss, utiliza la conciencia como amortiguador, bloqueando la porosidad del sistema kinestésico, aislando la conciencia actual del recuerdo del pasado ${ }^{55}$. De este modo Benjamin que considera el shock como lo esencial de la experiencia moderna, considera que responder a los estimulos sin pensar, se ha hecho necesario para la supervivencia ${ }^{56}$. Aquí yace el comienzo del individualismo que caracteriza las ciudades del siglo XXI, donde la experiencia del shock conduce a la necesidad de la supervivencia tal y como ocurre en la guerra.

Stavros Stavridis tiene la misma opinión sobre el instinto de la supervivencia que sentía el ciudadano mezclándose en la multitud, pero también presenta lo contradictorio que ella tiene. Por una parte, el habitante, el que antes se encontraba con los otros dentro de condiciones familiares, está rodeado de desconocidos y se siente amenazado, expuesto a riesgos. Pero a la vez, dentro de esta multitud que le amenaza, encuentra tanto seguridad como libertad. Es lo contradictorio que tiene el estado intermedio de mezclarse sin ver y tocarse sin decir. En sus palabras, el habitante de la metrópoli está constantemente expuesto a riesgos que muy a menudo no puede predecir. La mayoría de los que le rodean son desconocidos y por eso sus deseos parecen amenazantes. La seguridad la encuentra participando en el flujo de la multitud pero a la vez se siente solo; "extraño dentro extraños, se siente solo y sin perspectivas de apoyo y comunicación, blindado en su armadura personal, que resuena como toca las armaduras de los otros (...) Parece extraño, pero lo más arraigada que es la identidad de cada uno en

52 Baudelaire habla del hombre que se sumerge en la multitud como una reserva de energía eléctrica. Trazando la experiencia del shock, le llama enseguida caleidoscopio provisto de conciencia. Benjamin, Sobre Algunos Temas En Baudelaire, 147.

53 Susan Buck-Morss and Mariano López Seoane, Walter Benjamin, Escritor Revolucionario (Buenos Aires: Interzona, 2005), 188.

54 George Simmel, “La Metrópolis y La Vida Mental,” Bifurcaciones: Revista De Estudios Culturales Urbanos, no. 4 (2005), 7.

55 Buck-Morss and Seoane, Walter Benjamin, Escritor Revolucionario, 187-188.

56 Ibid., 188 
su soledad más liberadora su bundimiento en el anonimato de la multitud ${ }^{57}$. Berman, a partir del poema de Baudelaire La pérdida de una aureola del Spleen en Paris, presenta también lo contradictorio y lo paradójico del estado intermedio de la hipnosis urbana, pero visto desde otra dicotomía: de una parte la multitud impone el ritmo de su movimiento en las calles pero, a la vez, este ritmo impone formas de libertad.

El hombre de la calle moderna (...) para cruzar el caos en movimiento, debe ajustarse y adaptarse a sus movimientos, debe aprender no sólo a ir al mismo paso, sino a ir al menos un paso por Andar con desconocidos delante. (...) Baudelaire muestra cómo la vida urbana moderna impone estos movimientos a todos; pero muestra también cómo al hacerlo impone también, paradójicamente, nuevas formas de libertad. Un hombre que sabe cómo moverse en, alrededor y a través del tráfico puede ir a cualquier parte, por cualquiera de los infinitos corredores urbanos por donde el mismo tráfico puede circular libremente. Esta movilidad abre un gran número de experiencias y actividades nuevas a las masas urbanas ${ }^{58}$.

El ser humano que sabe moverse en la multitud y disfrutar de la libertad y la seguridad que ella ofrece es el señor G., el hombre de la multitud de Alan Poe; el anciano que observaba Allan Poe en las calles de Londres, quien sentía angustia cuando las calles disfrutar el anonimato y la muchedumbre; hombre libre se vaciaban y buscaba otro lugar lleno de gente, lleno de multitudes. ${ }^{59}$ Baudelaire (18211867) afirma su admiración hacía el señor G que flota en la nueva metrópolis; el crítico y filósofo, según Benjamin, en su El París del Segundo Imperio de Baudelaire; el caminante urbano, el que desciende a las ciudades, ennobleciendo la suerte de las cosas más viles ${ }^{60}$. Según Amendola, en el París de los pasajes y de los grandes bulevares nace el flaneur que bace de la ciudad, convertida en lugar de aventura por excelencia, no tanto su casa, porque no tiene casa, como su escenario. El flaneur, nuevo héroe de la ciudad moderna vive en la muchedumbre sin sufrirla, es capaz de vivir en el instante fugaz, extranjero y ciudadano al mismo tiempo cruza la ciudad sin caminos preestablecidos pero es capaz, de hallar significado en sus propias huellas ${ }^{61}$.

57 Stavros Stavridis, De La Ciudad Pantalla a La Ciudad Escena (Atenas: Ellinika

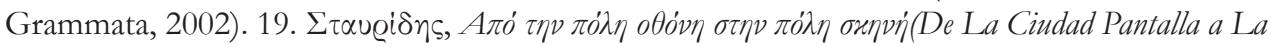
Ciudad Escenario)

58 Marshall Berman, Todo Lo Sólido Se Desvanece En El Aire: La Experiencia De La Modernidad (Buenos Aires, Argentina: Siglo xxi, 1989)., 159-160

59 Edgar Allan Poe, "El Hombre De La Multitud," Cuentos Completos (2005), 247-254.

60 Charles, Las Flores Del Mal, 112.

61 Giandomenico Amendola, La Ciudad Postmoderna: Magia y Miedo De La Metrópolis Contemporánea (Madrid España: Celeste Ediciones, 2000). 190. 
Experiencias marginales, huidas del tedio

Somos diseñados para anbelar lo inesperado.
Causas del tedio: imposición de
orden, eliminación de la contingencia, consumismo, destrucción de la experiencia
La errancia de Baudelaire dentro de la ciudad es una manera de dar significado en sus propias huellas para salir del vacío y del sinsentido que el tedio urbano le lleva. En su obra Las Flores del Mal presenta huidas del hastío vital, del spleen; se entrega al vicio, a los grupos marginales, al alcohol, las drogas, la delincuencia, la prostitución y los juegos. Lo que las experiencias marginales prometen, es la aventura, lo extraordinario, lo diferente, lo inesperado. Baudelaire se dejaba en ellas precisamente porque lo inesperado es el remedio para el tedio. En el idioma griego el término tedio corresponde en la palabra $\pi \lambda \dot{\eta} \xi \eta \eta$ (plixi) y el término sorpresa en la palabra $\dot{\varepsilon} x \pi \lambda \eta \xi ̆ \eta$ (ekplixi), palabra compuesta del prefijo $\varepsilon x-(e k$-) que en español es el prefijo ex que significa fuera - como exterior, éxtasis, éxodos, expandir - y la palabra $\pi \lambda \eta_{\eta} \xi \eta \eta$ (plixi). Es decir, la sorpresa es lo que nos saca fuera del tedio. Según, la neurociencia, cuando algo sorprendente ourre, el centro de placer del cerebro se activa con más fuerza y le sucede un torrente de dopamina, que es el neurotransmisor del bienestar del cerebro. La región se enciende como un árbol de navidad en la resonancia magnética (....) Eso sugiere que las personas están diseñadas para anhelar lo inesperado, dijo el profesor asociado de Dr. P. Read Montague de la neurociencia en Baylor College of Medicine, en Houston ${ }^{62}$. En base a esta observación - que estamos diseñados para la sorpresa - los psiquiatras entienden de otra manera la adicción en las drogas. Hablando sobre el papel de lo imprevisible, de lo sorprendente, de la sorpresa en el uso de las drogas, el doctor Alan Leshner, director del Instituto Nacional sobre el Abuso de Drogas dice que, Sabemos que la gente toma drogas porque les gusta lo que está haciendo a sus cerebros. Pero lo que les gusta es la naturaleza inusual de la experiencia de la droga"*3.

Así que, la causa principal del tedio es la falta del "de repente", de lo inesperado. La ausencia de lo imprevisto en la vida cotidiana equivale a una vida homogénea, indiferenciada, sin experiencias. Si todo está controlado, si nada viene a sorprendernos, nos sumergirnos en la apatía. El tedio vital es el resultado de la perseverante imposición del orden y el incesante combate con la contingencia, lo ambivalente y el desorden: dos

62 Dr. Gregory Berns, profesor asistente en la psiquiatría de Emory University in Atlanta, explica -desde un punto de vista evolutivo - el significado de la imprevisibilidad diciendo que $e l$ cerebro está sintonizado para recoger el cambio. Está ligado a la supervivencia. Cuando algo sorprendente sucede en el entorno esto puede ser la vida o la muerte "Human Brain Gets a Kick Out of Surprises ", accessed 8/14/2015, 2015, http://www.ccnl.emory.edu/Publicity/MSNBC.HTM.

Ibid. 
términos que marcan el comienzo de pensamientos moderno ${ }^{64}$, según Bauman; porque dicho pensamiento intenta, para mantener el orden, excluir lo imprevisto que es lo que perturba el orden impuesto. Causa del tedio es para Svendsen la incesante persecución de lo nuevo e interesante ${ }^{65}$. Jankélévitch, considera que el aburrimiento consiste en la oposición entre lo imaginado y lo experimentado ${ }^{66}$. Walter Benjamin encuentra la causa del tedio precisamente en la pobreza de la experiencia del hombre moderno ${ }^{67}$. Para Agamben la causa del tedio es la destrucción de la experiencia, es decir, la incapacidad en la transformación de la vivencia en experiencia.

En este texto, cuando usamos la palabra experiencia nos referimos a ésta, que es una experiencia. La experiencia ocurre continuamente porque el viviente está en una continua y constante interacción con su ambiente; la interacción de la criatura viviente y las condiciones que la rodean está implicada en el proceso mismo de la vida ${ }^{68}$. Experimentamos el todo, las cosas y los otros, pero no siempre de manera que articule una experiencia. Decimos la experiencia como una experiencia cuando ella es integral; es decir, sigue su curso y llega a su cumplimiento. No toda experiencia llega a un final, a un cumplimiento, como sostiene Dewey; empezamos una actividad pero por causas indefinidas, por distracciones, se interrumpe. Nos ponemos a escribir un texto, por ejemplo, pero por distracciones no cumplimos la actividad; y por eso de alguna manera lo que deseamos no coincide con lo que tomamos o lo que observamos no coincide con lo que pensamos ${ }^{69}$. La experiencia es "una" cuando, como dice Dewey, terminamos un trabajo de un modo satisfactorio: un problema recibe su solución, un juego se ejecuta completamente. Una experiencia es la que espontáneamente llamamos experiencia real, aquellas cosas que al recordarlas decimos que eso fue una experiencia ${ }^{70}$. Puede haber sido algo de gran importancia (la ruptura con la persona querida, una catástrofe, etc.) o algo más ligero - que quizá a causa de su misma ligereza

64 Zygmunt Bauman and Tim May, Pensando SociológicamenteEdiciones Nueva Visión, 1994). 183.

65 Lars Fr H. Svendsen, Filosofia Del Tedio (Barcelona: Tusquets, 2006), 34.

66 Jankélévitch, La Aventura, El Aburrimiento, Lo Serio, 90.

67 Walter Benjamin, "Experiencia y Pobreza," in Discursos Interrumpidos. Vol. I (Madrid, España: Taurus, 1989).

68 J. Dewey, El Arte Como Experiencia (Barcelona, España: Paidós, 2008)., 41.

69 Ibid. 41

$70 \quad$ Ibid. 42
La experiencia se hace una experiencia cuando se termina la interacción de modo satisfactorio

La experiencia es continua interacción con el ambiente; el proceso mismo de la vida 
La experiencia es la relación entre un padecer y un hacer; incorporación del desconocido a lo ya conocido
Destrucción de la experiencia: desequilibro entre padecer y hacer ilustra mejor lo que es una experiencia ${ }^{71}$; una cena con amigos, un viaje, un paseo y cualquier situación de la que decimos eso, es una experiencia; puede haber sido una experiencia previamente organizada o una que apareció, de repente, en el camino.

La pobreza y la destrucción de la experiencia es la causa del tedio vital según Benjamin y Agamben. Para entender la manera en la que sucede la deformación o destrucción de la experiencia, seguimos a Dewey, quien sostiene que cada experiencia es el resultado de una interacción entre la criatura viviente y algún aspecto del mundo en el que vive; de este modo, la experiencia es la relación entre un padecer y un hacer. En cada experiencia hay un elemento de sufrimiento, padecimiento por la incorporación de algo sobre lo previamente conocido; algo de carácter placentero o doloroso. Una experiencia no es solamente un hacer y un padecer que se alterna, sino que consiste en estos y sus relaciones. La interacción de los dos constituye la experiencia total obtenida, y la terminación que la completa es la constitución de una armonía sentida. El desequilibrio entre hacer y padecer (recibir) mancha la percepción de las relaciones y deja la experiencia incompleta. La experiencia se limita por todas las causas que interfieren con la percepción de las relaciones entre padecer y hacer. Cuando hay un exceso en el hacer ninguna experiencia tiene la oportunidad de completarse. El individuo intenta encontrar situaciones en las que pueda hacer el mayor número de cosas en muy poco tiempo. Esta deformación de la experiencia por el exceso del hacer sucede aún más hoy que vivimos en un ambiente apresurado e impaciente. Al otro lado, cuando tenemos un exceso en el padecer la experiencia no se completa sino se queda en un mero padecer. El individuo recibe la mayor cantidad posible de impresiones - que se considera que es la vida - pero que no entra en la percepción ningún significado. Dewey añade que el sentimental, el que sueña despierto o ensueña, deja pasar por su conciencia muchas impresiones, pero la ausencia del hacer y del desequilibrio entre ellos, provoca una experiencia deformada que no es una experiencia ${ }^{72}$. Algo parecido sucede en la experiencia de las actividades automáticas: las actividades automáticas llegan a un fin, a un cumplimiento que es factor principal para considerar algo como una experiencia, sin embargo, no llegan a una consumación en la conciencia porque son demasiado automáticas para proporcionarnos 
un sentido de qué es y dónde se dirige ${ }^{73}$.

Benjamín encontró la pobreza y la destrucción de la experiencia del ser humano moderno en los acontecimientos atroces que sucedieron a principio del siglo XX y en el hecho de que la experiencia dejó de ser comunicable. La cotización de la experiencia ha bajado y precisamente en una generación que de 1914 a 1918 ha tenido una de las experiencias más atroces de la historia universal. (...) las gentes volvian mudas del campo de batalla. No enriquecidas, sino más pobres en cuanto a experiencia comunicable ${ }^{74}$. Cuando la experiencia no se comunica, la experiencia no existe, pues la experiencia se construye mientras se relata. La narración modela no sólo un mundo, sino las mentes que intentan darle sus significados, sostiene Bruner; la manera en que uno habla, llega a ser, con el tiempo, la manera en la que uno representa aquello de lo que babla ${ }^{75}$. Voloshinov coincide con él cuando afirma que no es la experiencia la que organiza la expresión, sino la expresión la que organiza la experiencia; la experiencia fuera de su corporización en signos no existe ${ }^{76}$. Según Agamben, hoy, a la experiencia no le falta una catástrofe o acontecimientos atroces para ser pobre, sino que la cotidianidad pacífica es más que suficiente para eso ${ }^{77}$. Agamben encuentra la destrucción de la experiencia en lo que Dewey nombra como exceso en el padecer; cuando tenemos un exceso en el padecer la experiencia no se completa, sino que se queda en un mero padecer; es decir, recibimos la mayor cantidad posible de impresiones pero no entra en la percepción ningún significado. Dice Agamben que quizás, nunca la existencia cotidiana has ido tan rica como hoy en acontecimientos significativos, pero lo que vuelve hoy la cotidianidad insoportable -como nunca en el pasado- es esa incapacidad de traducirlos en experiencia. El hombre moderno vuelve a casa de noche, extenuado por un fárrago de acontecimientos-divertidos o aburridos, insólitos o comunes, atroces o placenteros- ninguno de los cuales, sin embargo, se ha convertido en experiencia ${ }^{78}$.

\footnotetext{
73 Ibid., 45.

74 Benjamin, Experiencia y Pobreza, 168.

75 Bruner Jerome, Realidad Mental y Mundos Posibles (Barcelona, España: Editorial Gedisa, 2004)., 136.

76 Valentin Nikólaievich Voloshinov and Rosa María Russovich, El Signo Ideológico y La Filosofía Del Lenguaje (Buenos Aires, Argentina: Nueva Visión, 1976). 109

77 Giorgio Agamben and Fabián Lebenglik, Infancia e Historia: Destrucción De La Experiencia y Origen De La Historia (Buenos Aires, Argentina: Adriana Hidalgo, 2007), 8. 78 Agamben and Lebenglik, Infancia e Historia: Destrucción De La Experiencia y Origen De La Historia, 8.
}

Cuando la experiencia deja de ser comunicable no es una experiencia

La experiencia se construye mientras se relata

El individuo contemporáneo vive en un farrago de acontecimientos pero es incapaz de convertirlos en experiencias 


\section{Ciudad Leonia ${ }^{79}$}

La ciudad de Leonia se rehace a si misma todos los días: cada mañana la población se despierta entre sábanas frescas, se lava con jabones apenas salidos de su 50 envoltorio, se pone batas flamantes, extrae del refrigerador más perfeccionado latas aún sin abrir, escuchando las últimas retahilas del último modelo de radio.

En los umbrales, envueltos en tersas bolsas de plástico, los restos de la Leonia de ayer esperan el carro del basurero. No solo tubos de dentifrico aplastados, bombillas quemadas, periódicos, envases, materiales de embalaje, sino también calentadores, enciclopedias, pianos, juegos de porcelana: más que por las cosas que cada dia se fabrican, venden, compran, la opulencia de Leonia se mide por las cosas que cada día se tiran para ceder lugar a las nuevas. Tanto que uno se pregunta si la verdadera pasión de Leonia es en realidad, como dicen, gozar de las cosas nuevas y diferentes, y no más bien el expeler, alejar de sí, purgarse de una recurrente impureza. Cierto es que los basureros son acogidos como ángeles, y su tarea de remover los restos de la existencia de ayer se rodea de un respeto silencioso, como un rito que inspira devoción, o tal vez sólo porque una vez. desechadas las cosas nadie quiere tener que pensar más en ellas. Dónde llevan cada día su carga los basureros nadie se lo pregunta: fuera de la ciudad, claro; pero de año en año la ciudad se expande, y los basurales deben retroceder mis lejos; la importancia de los desperdicios aumenta y las pilas se levantan, se estratifican, se despliegan en un perímetro cada vez más vasto. Añádase que cuanto más sobresale Leonia en la fabricación de nuevos materiales, más mejora la sustancia de los detritos, más resisten al tiempo, a la intemperie, a fermentaciones y combustiones. Es una fortaleza de desperdicios indestructibles la que circunda Leonia, la domina por todos lados como un reborde montañoso.

El resultado es éste: que cuantas más cosas expele Leonia, más acumula; las escamas de su pasado se sueldan en una coraza que no se puede quitar; renovándose cada día la ciudad se conserva toda a si misma en la única forma definitiva: la de los desperdicios de ayer que se amontonan sobre los desperdicios de anteayer y de todos sus días y años y lustros.

La basura de Leonia poco a poco invadiría el mundo si en el desmesurado basurero no estuvieran presionando, más allá de la última cresta, basurales de otras ciudades que también rechazan lejos de sí montañas de desechos. Tal vez el mundo entero, traspasados los confines de Leonia, está cubierto de cráteres de basuras, cada uno, en el centro, con una metrópoli en erupción ininterrumpida. Los limites entre las ciudades extranjeras y enemigas son bastiones infectos donde los detritos de una y otra se apuntalan reciprocamente, se superan, se mezclan.

Cuanto más crece la altura, más inminente es el peligro de derrumbes: basta que un envase, un viejo neumático, una botella sin su funda de paja ruede del lado de Leonia, y un alud de rapatos desparejados, calendarios de años anteriores, flores secas, sumerja la ciudad en el propio pasado que en vano trataba de rechazar, mezclado con aquel de las ciudades limitrofes finalmente limpias: un cataclismo nivelará la sórdida cadena montañosa, borrará toda traza de la metrópoli siempre vestida con ropa nueva. Ya en las ciudades vecinas están listos los rodillos compresores para nivelar el suelo, extenderse en el nuevo territorio, agrandarse, alejar los nuevos basurales.

Italo Calvino. Ciudades Invisibles

79 Italo Calvino, Las Ciudades Invisibles (Barcelona: Minotauro, 1983), 125-126. 
Hoy en día, somos incapaces de traducir las vivencias en experiencias, pero estamos en una continua búsqueda de ellas, de lo nuevo. Dice Lars Svendsen, los intereses de boy en dia se orientan de forma exclusiva hacia lo interesante; y lo interesante es aquello que, tan sólo un momento después, se convierte para nosotros en indiferente y tedioso ${ }^{80}$. El tedio tanto para Svendsen como para Bauman parece ser la consecuencia del espíritu del consumo impuesto por las políticas capitalistas y neoliberalistas de las sociedades contemporáneas. El espíritu del consumo nos ha ubicado en la ciudad Leonia ${ }^{81}$. Si preguntáramos a sus habitantes, dice Bauman, cuáles son sus pasiones ${ }^{82}$, ellos contestarían que gozar de las nuevas cosas y diferentes ${ }^{83}$. Todos los días los habitantes estrenan nuevas cosas y por las noches las tiran, porque el día siguiente quieren gozar de nuevo cosas que no han sido usadas. A lo que lleva el probar cada día nuevas cosas es a tirar cada día nuevas cosas. En esta ciudad los basureros son acogidos como ángeles, y su tarea de remover los restos de la existencia de ayer se rodea de un respeto silencioso pero en esta ciudad, dónde llevan cada día su carga los basureros, nadie se lo pregunta ${ }^{84}$. La vida en la cuidad Leonia es una vida liquida, como la nuestra; en la modernidad liquida ${ }^{85}$, la vida fluye como un líquido: sin forma, sin límites, sin estancia, sin estabilidad, al contrario de los tiempos de la modernidad que fueron tiempos sólidos. Cuando cada día tiramos lo de ayer para gozar del estreno de lo nuevo, no se crea una identidad. El medio donde vivimos ha cambiado. Como dice Bauman, el medio, que era el mensaje, ha cambiado y con ello cambiamos nosotros también. En la modernidad el medio fue el papel fotográfico, en la posmodernidad era la cinta de video y hoy, la memoria y las nubes (cloud); estos últimos son borrables y reutilizables. En los álbumes familiares se creía una identidad, una serie de acontecimientos irreversibles e imposible de borrar; la cinta de video o el pendrive admiten los acontecimientos de hoy pero hay que borrar los de ayer. ${ }^{86}$

Pero no es solo la memoria lo que crea la identidad, sino también el sentido de la pertenencia; sentir que pertenecemos a un lugar y a un grupo social. Madanipour, 80 Lars Fr H. Svendsen, Filosofia Del Tedio (Barcelona: Tusquets, 2006), 34.

81 Italo Calvino, Las Ciudades Invisibles (Barcelona: Minotauro, 1983), 125-126.

82 Bauman, Amor Líquido. Acerca De La Fragilidad De Los Vinculos Humanos, 18.

83 Italo Calvino, Las Ciudades Invisibles (Barcelona: Minotauro, 1983), 125.

84 Ibid., 125.

85 Bauman no usa el termino posmodernidad sino modernidad liquida

86 Zygmunt Bauman, "De Peregrino a Turista, o Una Breve Historia De La Identidad," in Cuestiones De Identidad Cultural (Buenos Aires: Amorrortu Editores, 2003), 40-68.
La continua persecución de lo nuevo e interesante, impuesto por el espíritu de consumismo, conduce al tedio

Los habitantes de la ciudad Leonia, tiran lo de hoy para gozar del estreno de lo nuevo mañana

La falta del sentimiento de la pertenencia en un lugar equivale a la perdida de la identidad 
Las casas se han hecho habitaciones de hoteles; casas que compartimos con desconocidos
No pertenecemos plenamente a ningún lugar y a ninguna sociedad; pertenecemos al "entre"; vivimos solamente en los intersticios pensando en los sin techo, se pregunta cómo la gente que no tiene una casa navega en su mundo, ya que la casa es el punto de referencia a través del cual el individuo encuentra un lugar en el mundo ${ }^{87}$. La sociedad liquida navega sin un punto de referencia; la sociedad liquida no vive en un lugar sino en aquel "entre" que se encuentra entre los varios lugares en los que uno se queda poco tiempo por la reducida demanda del trabajo o por el sentimiento del tedio. En la sociedad liquida vivimos en el "entre" porque a los fluidos, dice Bauman, no les preocupa el espacio, pues como no mantienen por mucho tiempo una forma no les hace falta; los fuidos no conservan una forma durante mucho tiempo y están constantemente dispuestos (y proclives) a cambiarla; por consiguiente, para ellos lo que cuenta es el flujo del tiempo más que el espacio que puedan ocupar: ese espacio que, después de todo, solo llenan "por un momento"s8. Las casas de hoy, cada día se parecen más a las habitaciones de los hoteles. De la casa que la gente construía paulatinamente con esfuerzo, donde vivían generaciones familiares, en la modernidad pasamos a las casas construidas por otros - los arquitectos - para nosotros; y después, en la modernidad liquida, llegamos a la habitación amueblada de una casa, que para poco tiempo compartimos con desconocidos. Vivir en un "entre", en el lugar que está entre las casas y las ciudades, que de manera rápida cambiamos, significa estar en un continuo movimiento, como los fluidos; y la vida se hace más fácil cuando la maleta es mínima: como los recuerdos pesan mucho, los tiramos en cada mudanza. Valeria Luiselli escribía en Papeles Falsos que, quizás, una persona sólo tiene dos residencias permanentes: la casa de la infancia y la tumba $a^{89}$. Sin embargo, parece que a partir de la Generación $Z^{90}$, la única residencia permanente será nuestra tumba, pues los nacidos en el siglo XXI pasan su infancia en las varias casas de una familia que se mueve por el mundo. Al final, hoy en día, no pertenecemos a ningún lugar; vivimos solamente en los intersticios. Como dice Niklas Luhmann, no pertenecemos plenamente a ninguno

87 Ali Madanipour, Public and Private Spaces of the CityRoutledge, 2003). 74.

88 Zygmunt Bauman, Modernidad Liquida (Argentina: Fondo de cultura económica, 2003). 8 .

89 Valeria Luiselli, Papeles Falsos (Madrid: SextoPiso, 2010). 14.

90 Los Sociólogos nombrado las generaciones según las características de su época y de sus actividades: Generación Perdida o Generación 1914, gente nacida entre 1883 - 1900, la Generación Grandiosa nacidos en los años 1901-1924 y vivieron en la Época de la Gran Depresión, la Generación Silenciosa nacida entre 1920-1942, la Generación Baby Boomers entre 1940 - 1960, la Generación X entre 1960-1980, la Generación Y o Generación Millennials entre 1980 -2000, y la Generación Z a partir de 2000. “Generación Z,” Wikipedia, The Free Encyclopedia, 2015 
de los lugares ni a las sociedades que entramos; todos estamos siempre y en todas partes. ${ }^{91}$ Vivimos en links y, por momentos, paramos mirando hacía una dirección; pero en el tiempo que dura un click, entramos de nuevo en otro enlace para encontrar un nuevo sentido. Frente a la amplitud de miras y destinos que se abren en las metápolis contemporáneas, se hace imposible elegir un sentido interesante, y así nos sumergimos en el sinsentido, en un tedio metaurbano.

El tedio urbano nunca ha sido experimentado por los ciudadanos de la ciudad Esmeraldina de las Ciudades Invisibles; el tedio de recorrer cada dia las mismas calles es ahorrado a los habitantes de Esmeraldina ${ }^{92}$. Sin embargo, para los ciudadanos que habitan en las ciudades del Occidente a partir de la modernidad, el tedio se ha hecho una epidemia, una enfermedad que afecta a todos. La diferencia entre los tipos de ciudades - diferencia que revela causas del tedio - es que en la primera la red de pasajes de la ciudad es una red compleja que no se limita a un solo estrato, sino que es combinación de capas de varios niveles que se conectan entre ellas con escalerillas, galerías, puentes convexos, calles suspendidas; mientras, en la segunda, la red de sus pasajes es una rejilla ortogonal de líneas rectas que se expande en un nivel, sin subidas y bajadas. En Esmeraldina, las vidas más rutinarias y tranquilas transcurren sin repetirse, pues cada habitante se permite cada día la distracción de un nuevo itinerario para ir a los mismos lugares. Al otro lado, nosotros no tenemos variedad de itinerarios para ir a los mismos lugares; y los que podemos seguir, tienen la misma forma, ya que el uno resulta de la repetición del otro. La aportación de los urbanistas y los arquitectos en la expansión del tedio yace en el uso exclusivo del sistema hipodámico, un trazado de cuadrícula ortogonal: el plan urbanístico más "fácil", pero desafortunadamente el que crea un paisaje monótono ya que se construye por la repetición de parcelas idénticas; un escenario monótono e indiferenciado, pues la repetición de lo mismo no deja espacio a lo diferente y lo extraño.

91 Referencia en Bauman Zygmunt, En Busca De La Politica (Argentina: Fondo de Cultura Económica, 2001). 169.

92 Italo Calvino, Las Ciudades Invisibles (Barcelona: Minotauro, 1983), 125-126. 
Ciudad Esmeraldina ${ }^{93}$

En Esmeraldina, ciudad acuática, una reticula de canales y una reticula de calles se superponen y se entrecruzan. Para ir de un lugar a otro siempre puedes elegir entre el recorrido terrestre y el recorrido en barca, y como la linea más breve entre dos puntos en Esmeraldina no es una recta sino un zigzag que se ramifica en tortuosas variantes, las calles que se abren a cada transeúnte no son solo dos sino muchas, y aumentan aún más para quien alterna trayectos en barca y transbordos a tierra firme. Asi el tedio de recorrer cada día las mismas calles es ahorrado a los habitantes de Esmeraldina. Y eso no es todo: la red de pasajes no se dispone en un solo estrato, sino que sigue un subibaja de escalerillas, galerías, puentes convexos, calles suspendidas. Combinando sectores de los diversos trayectos sobreelevados o de superficie, cada habitante se permite cada día la distracción de un nuevo itinerario para ir a los mismos lugares. Las vidas más rutinarias y tranquilas en Esmeraldina transcurren sin repetirse.

A mayores constricciones están expuestas, aquí como en otras partes, las vidas secretas y venturosas. Los gatos de Esmeraldina, los ladrones, los amantes clandestinos se desplazan por calles más altas y discontinuas, saltando de un techo a otro, dejándose caer de una azotea a un balcón, contorneando canaletas de tejado con paso de funámbulos. Más abajo, los ratones corren en la oscuridad de las cloacas uno detrás de la cola del otro, junto a los conspiradores y a los contrabandistas; atisban desde alcantarillas y sumideros, se escabullen por intersticios y callejas, arrastran de un escondrijo a otro cortezas de queso, mercancías prohibidas, barriles de pólvora, atraviesan la compacidad de la ciudad perforada por la irradiación de las galerías subterráneas.

Un mapa de Esmeraldina debería comprender, señalados en tintas de diversos colores, todos estos trazados, sólidos y líquidos, evidentes y ocultos. Más difícil es fijar en el papel los caminos de las golondrinas, que cortan el aire sobre los techos, caen a lo largo de parábolas invisibles con las alas quietas, se desvian para tragar un mosquito, vuelven a subir en espiral rozando un pináculo, dominan desde cada punto de sus senderos de aire todos los puntos de la ciudad

Italo Calvino. Ciudades Invisibles

93 Ibid., 125-126 
El pensamiento racional de la modernidad, y principalmente de los CIAM, del Estilo Internacional y del Movimiento Moderno, enfrentó la ciudad como si fuera un espacio cartesiano abstracto y confundió el mapa con el territorio ${ }^{94}$; consideró que la geometría y el dibujo gráfico desempeñan un papel más importante que la estructura propiamente dicha ${ }^{95}$, como Haussmann había dicho. Con el fin de ser fiel frente a los dibujos arquitectónicos, Haussmann no dudó en derrumbar gran parte de la ciudad medieval y renacentista para construir nuevas fachadas uniformes y calles rectas y anchas, capaces de aceptar la velocidad y el consumo; su fidelidad frente a la ciudad del papel era tan fuerte que no perturbó solo a los vivos sino también a los muertos, cuando llegó a dividir el cementerio para realizar el trazado de las calles - calle Caulaincourt- hecho que, según Sennet, expresaba de manera patente cómo la nueva geografía parisina de la movilidad violaba rodas los aspectos de la vida urbana ${ }^{96}$. Todas las ciudades, antes de convertirse en metrópolis, fueron ciudades como Esmeraldina: ciudades de plano irregular, trama cerrada y densa. En las ciudades medievales, las calles estaban formadas por casas de una planta, estrechas; cada una distinta de la otra, sin una geometría pensada, sino construida de manera espontánea, de manera irregular por sus propios habitantes. Sin embargo, una ciudad moderna necesita bulevares, calles anchas, tanto para alojar la velocidad de los vehículos como porque el desorden molesta la vista. Le Corbusier, el representante más importante del pensamiento de la modernidad, en la presentación del Plan Voisin bajo el título, Buenos Aires puede convertirse en una de las ciudades más dignas del mundo, dice: En principio, limpiaremos el terreno: Hay que matar la "calle-pasillo". No se entrará, realmente, en el urbanismo moderno sino después de esta decisión previa. (...)Las "calles - pasillos" hacen las "ciudades - pasillos". iQué aspecto! iQué estética! No decimos nada, pero lo sufrimos. (....). ${ }^{97}$ Creamos así ciudades limpias, esterilizadas, ordenadas, en las que todo está controlado y previsto, pero a la vez impusimos a los habitantes un paisaje homogéneo, indiferenciado, uniforme, en el que cualquier lugar es casi idéntico a los otros; ciudades desnudas, sin

\footnotetext{
94 Miguel Martínez Miguélez, "El Desafío a La Racionalidad Científica Clásica," Paradigma 21, no. 3 (2000), 187-200.

95 “Transformación De París Durante El Segundo Imperio,” Wikipedia, The Free Encyclopedia, 2015

96 Richard Sennett, Carne y Piedra: El Cuerpo y La Ciudad En La Civilización Occidental Alianza editorial, 1997), 354.

97 Le Corbusier, Precisiones Respecto a Un Estado Actual De La Arquitectura y El Urbanismo Trad (Barcelona, España: Apóstrofe, 1999). 194.
}

Confundiendo el mapa con el territorio; el dibujo es más importante que la estructura propiamente dicha,

Le Corbusier: Hay que matar la calle-pasillo...la decisión previa para entrar en el urbanismo moderno 
Le Corbusier: El diseño de la ciudad no debe estar en las manos de sus habitantes:

Del habitante-constructor al usuario - consumidor
Uniformización estandarización de lo cotidiano
La vivienda es como nuestra ropa, rapatos, automóviles; Gropius sorpresas y sin juego, pues el ornamento aquella época era un delito.

Pero no es solo la desnudez de la ciudad y lo uniforme lo que empuja al tedio vital, sino también la transformación del habitante a usuario, que tuvo lugar con el principio del urbanismo moderno. Anteriormente, el habitante de la ciudad no solo vivía en ella sino que era su constructor; la ciudad se hacía por las manos de sus ciudadanos. Pero el urbanismo moderno consideró que, como decía Le Corbusier, la planificación de ciudades es demasiado importante para dejarla en manos de sus habitantes ${ }^{98}$; así que desde entonces su diseño es exclusivamente responsabilidad de los arquitectos de quienes el trabajo es poner el mundo en $\operatorname{orden}^{99}$. De este modo, la ciudad se hizo un producto diseñado por los grandes utopistas y el ciudadano un usuario, que se mueve en un paisaje monótono en el que simplemente consume. Cuando consideramos que la vivienda y la ciudad se administra mejor por otros- arquitectos, urbanistas- que por sus propios habitantes, es cuando empieza la estandarización de la vida y cuando el único objeto de los procesos proyectuales se hace sobre las satisfacción de necesidades. De este modo, lo cotidiano, aquel lugar de creación o de perpetuación de todas las significaciones de todas las relaciones sociales ${ }^{100}$, es visto por los arquitectos como el lugar de la pura satisfacción de funciones, y la ciudad, aquel lugar del encuentro social, se hace un terreno ocupado de objetos, usos y vasos donde la gente habita. Arquitecturar es poner en orden, dice Le Corbusier. ¿Poner en orden a qué? Unas funciones y unos objetos. Ocupar el espacio con unos edificios y con unas carreteras. Crear unos vasos para albergar a unos hombres y crear unas comunicaciones útiles para dirigirse a ellos ${ }^{101}$. La estandarización de lo cotidiano y la uniformización de los hábitos - que podría ser una definición más para lo que el tedio es - es requisito para la planificación urbanística moderna; y lo es, sin duda también, para la producción en serie de las viviendas. Para Gropius, la estandarización y la producción en masa tiene que referirse a los componentes de una casa y no a casas enteras; según él, la mayoría de los ciudadanos de un determinado país tiene requisitos similares en la vivienda y la vida; por tanto, es difícil entender por qué la vivienda que construimos no debe mostrar

98 Peter Geoffrey Hall, Ciudades Del Mañana: Historia Del Urbanismo En El Siglo XX

(Barcelona, España: Ediciones del Serbal, 1996). 219.

99 Ibid., ““'Le Corbusier: Pensamiento Fascista y “ciudad Radiante”' De Joseph Confavreux, Em infoLibro | Tiempos Canallas “, accessed 5/22/2015, 2015, http://www.tiemposcanallas. com/le-corbusier-pensamiento-fascista-y-ciudad-radiante-de-joseph-confavreux-em-infolibro/.

100 Claude, La Société Au Jour Le Jour. Ecrits Sur La Vie Quotidienne, 2.

101 Corbusier, Precisiones Respecto a Un Estado Actual De La Arquitectura y El Urbanismo Trad, 90. 
una unificación similar, como nuestra ropa, zapatos y automóviles. (...) La organización, por lo tanto debe apuntar primero a la normalización y la producción en masa no de casas enteras, sino sólo de sus partes componentes que a continuación se pueden ensamblar en varios tipos de casas (... $)^{102}$. Pero aun así, Gropius sigue viendo al habitante como usuario - consumidor de una casa - producto que podría mostrar una unificación similar, como nuestra ropa, zapatos y automóviles. (...); tal y como en otro momento defiende, la arquitectura debería seguir la estandarización moderna de la prendas ${ }^{103}$.

John F. Turner, aunque está en contra de los estándares, no los anula; sin ellos sería imposible la construcción, sostiene; pero, los estándares no deben ser usados para medir el valor de lo humano. ${ }^{104}$ Turner, autor de los libros Libertad para construir: el proceso habitacional controlado por el usuario (1973) y Vivienda: Todo el poder para los usuarios (1976) pertenece a una línea que se trazaba en paralelo, pero con sentido contrario, con la que fue marcada por Haussmann, Le Corbusier, Mies van de Rohe, Gropius, Estilo Internacional, Giedion, Sert y en general por todos los que comparten esta visión simplista de la vida; la del urbanismo racional, funcionalista o neoconservador ${ }^{105}$ que intenta ordenar la ciudad, simplificar las formas y satisfacer funciones pero poniendo en primer plano la representación de la vida y no la propia vida. ${ }^{106}$ La línea que se extiende en sentido contrario se está trazando por todos los que creen que la vida no puede entrar en rejillas ${ }^{107}$. Camilo Sitte, Aldo van Eyck, Christopher Alexander, Candilis, Team 10, Serge Chermayeff, Constant, los Situacionistas, Stalker, Venturi, Turner, Matta - Clark, los arquitectos activistas contemporáneos y los colectivos activos que encontramos cada vez más en las ciudades que intentan despertarla desde su interior, están entre los que

102 Walter Gropius, The Scope of Total Architecture (New York, Estados Unidos: Collier, 1970), 131.

103 Mark Wigley, White Walls, Designer Dresses: The Fashioning of Modern Architecture (Cambridge MA, Estados Unidos: MIT Press, 2001). 102.

104 John F. C. Turner and Robert Fichter, Freedom to Build: Dweller Control of the Housing Process (New York: The Macmillan Company, 1972). 152.

105 Leonardo Benevolo, Historia Da Arquitetura Moderna (Tradução De Ana M. Goldberger) São Paulo: Editora Perspectiva, 2001). 114.

106 Como se ha dicho anteriormente frase de Haussmann fue era la geometría y el dibujo gráfico desempeñan un papel más importante que la estructura propiamente dicha Wikipedia contributors, Transformación De París Durante El Segundo Imperio

107 Hablando de los desperdicios de la modernidad Bauman escribe: La geometría muestra cómo sería el mundo si fuera geométrico. Pero el mundo no es geométrico. No puede ser metido a presión dentro de rejillas inspiradas geométricamente. Zygmunt Bauman et al., Las Consecuencias Perversas De La Modernidad. Modernidad Contingencia y Riesgo (Barcelona, España: Anthropos, 1996)., 91.
La visión geométrica de la vida hace su representación más importante que ella misma 
Construir ciudades que ofrezcan seguridad y felicidad a los ciudadanos. La felicidad viene por el arte

El urbanismo moderno no bace felices a los habitantes; ha matado lo pintoresco, el arte defienden que la vivienda y la ciudad no se pueden ver como productos: no excluyen lo irregular, el desorden y lo imprevisto, sino que lo incluyen considerándolo como fuente de la vida.

Camilo Sitte fue pionero del urbanismo de lo informal; en la época de la modernidad, en la que la preocupación principal de los urbanistas era la limpieza de la ciudad de las calles - pasillos, trazados de manera irregular por los habitantes, Sitte dio énfasis al carácter informal de la construcción urbana clásica y medieval. ${ }^{108}$ Sitte abría su libro Construcción de Ciudades según Principios Artísticos con las frases de Aristóteles, en relación a que los principios del urbanismo tienen que ser edificar ciudades que ofrezcan seguridad y felicidad a los ciudadanos; y, para lograr la felicidad, el urbanismo debiera ser, no solo un problema técnico, sino, en verdadero y máximo sentido, también de arte ${ }^{109}$. Según Sitte, los tres sistemas urbanísticos de la modernidad - radial, triangular, rectangular y algunas combinaciones de ellos para calles secundarias- son una orientación solamente técnica ya que su fin es siempre la regularización del trazado. De este modo transforman la ciudad en un lugar exclusivo para la circulación de los vehículos mientras que lo que el espacio público siempre ha sido es lugar del encuentro, de los votos y de las celebraciones; el espacio de la sorpresa, de lo inesperado, del romance; la parcelación regular considerada económicamente, se ha desarrollado de tal manera, que sus efectos son ya inevitables... de este modo aniquilase en masa las bellezas que resumimos en la palabra pintoresco ${ }^{110}$. Camilo Sitte, fue un pensamiento único de su época, pues era el único que no abandonó al ciudadano. Años después, Le Corbusier en su libro Cuando las Catedrales eran Blancas fue en contra de sus teorías y Sigfried Giedion habló despectivamente de él: (...) el planificador habia perdido el contacto con su momento histórico. Era como un trovador que salmodiara ineficazmente sus canciones medievales frente al ruido de la industria moderna ${ }^{111}$.

Camilo Sitte pasó desapercibido hasta los años cincuenta cuando los jóvenes

108 George R. Collins, Christiane C. Collins and Camillo Sitte, Camillo Sitte y El Nacimiento Del Urbanismo Moderno: George R. Collins y Christiane C. Collins. Construcción De Ciudades Según Principios ArtísticosGustavo Gili, 1980), 107.

109 Camillo Sitte, Construcción De Ciudades Según Principios Artísticos, trans. Emilio Canosa (Barcelona: Editorial Canosa, 1926). 2.

110 Ibid., 128.

111 Collins, Collins and Sitte, Camillo Sitte y El Nacimiento Del Urbanismo Moderno: George R. Collins y Christiane C. Collins. Construcción De Ciudades Según Principios Artísticos, 107. 
de la última generación de los CIAM - Alison y Peter Smithson, Aldo Van Eyck, Jacob, Bakema, Candilis, Utzon, Coderch, Barragán y más - fueron en contra de sus antecesores por tener una visión fría del mundo y por haber tratado al habitante como un engranaje de una máquina ${ }^{112}$; iban en contra de la estandarización de lo cotidiano, del racionalismo que reivindica la geometría pero abandona la vida; defienden la construcción de situaciones en la ciudad y su transformación en una ciudad lúdica: una arquitectura sin arquitectos. Hay una línea de arquitectos que a partir de los años 50 miraron hacía los estudios antropológicos, para ver, como dice Montaner, que no todas las sociedades pueden ser medidas según los mismos patrones culturales y proponer soluciones que no impongan modelos sino que se aprenda de cada lugar. James M. Richards quien defiende el paso del hombre ideal del modulor al ser humano común, se acerca al habitante, pero el gran cambio se hace con la aparición de los Team $\mathrm{X}$ quienes proponen un nuevo método de trabajo empírico y pragmático ${ }^{113}$, un proyectar desde dentro ${ }^{114}$, desde el interior de la vida; un modo de proyectar contrario al que considera que la planificación de la ciudad es más correcta y más racional si se piensa desde fuera, desde arriba; desde la Vía Aérea de Le Corbusier. Los Situacionistas - movimiento indisciplinar entre filosofía, arquitectura y cultura artística - reconocen el tedio urbano que ha provocado tanto la desaparición de las sorpresas y las extrañezas del espacio público como el espíritu del consumo; proponen la construcción de situaciones capaces de despertar al habitante y propuestas para trasformar la sociedad utilitarista en sociedad lúdica. A partir del final de la década de los sesenta, muchos arquitectos giran alrededor de la frase Arquitectura sin Arquitectos, nombre del catálogo de B. Rudofsky que presenta con sus fotos la incapacidad de la arquitectura de los arquitectos para construir la belleza. ${ }^{115}$ Máximo representante de los que estaban a favor de la arquitectura sin arquitectos es John Turner quien va en contra

112 Si la casa es una máquina como había dicho Le Corbusier, el hombre que habita en su interior puede ser o un engranaje suyo el vacío entre ellos. La frase de Le Corbusier se encuentra en Le Corbusier and Josefina Martínez Alinari, Hacia Una Arquitectura (Barcelona, España: Ediciones Apóstrofe, 1998). XXXI.

113 José María Montaner, Después Del Movimiento Moderno, Arquitectura De La Segunda Mitad Del Siglo XX (Barcelona: Gustavo Gili, 1993). 3-10.

114 Más información sobre el proyectar desde dentro y proyectar desde fuera en Seguí de la Riva, Javier, Desde Dentro y Desde Fuera. Del Todo a Las Parte. Dibujar,Proyectar XVII (Madrid, España: Cuaderno del Instituto Juan de Herrera, 2009).

115 José María Montaner, Después Del Movimiento Moderno, Arquitectura De La Segunda Mitad Del Siglo XX (Barcelona: Gustavo Gili, 1993). 48.
Del ser ideal al ser común; del ojo de Dios a las manos de los habitantes

Arquitectura sin Arquitectos 
El habitante debe construir su casa; es una actividad existencialmente significativa como la de nutrir de la demolición de los slums y sostiene que la construcción de la vivienda por sus habitantes es una actividad existencialmente significativa; en las actividades significativas existencialmente entran aquellas actividades de las que dependen de manera inmediata los fines de la vida como la cultivación y preparación de la comida, cuidar nuestro cuerpo, vestirnos, la crianza de los hijos y el alojamiento de estas actividades; en las actividades no significativas existencialmente entran las que tienen valor pero existencialmente insignificantes en comparación de las primeras como por ejemplo tratar con cualquier objeto producido en masa como operador o consumidor o distribuidor ${ }^{116}$. Presenta las dos formas opuestas de proyectar: aquella que ve la albergación(housing) como sustantivo que conduce a la producción de casas para sus habitantes y aquella que enfrenta la albergación(housing) como verbo es decir como un proceso que se debe realizar por los habitantes de la vivienda. Algunos grupos contemporáneos que están en contra de la demolición de los slums y a favor de la autoconstrucción son Elemental ${ }^{117}$, urban - think tank (U-TT) ${ }^{118}$, Atelier Metropolitano - Jorge Mario Jáuregui ${ }^{119}$. Christopher Alexander, el matemático y arquitecto, después de estudios en los campos de la sociología, la antropología, la psicología y la ecología, introdujo un nuevo sistema de composición, el lenguaje de "patrones":"células" de viviendas que se podían, repitiéndose, ampliarse por sus habitantes. Apoyó que todo ser humano es arquitecto e intentó ayudar a los habitantes a recuperar su capacidad de construir sus entornos. John Turner, Christopher Alexander y todos los que fueron defensores de que el poder de la construcción tiene que volver a las manos del habitante, forjaron la base para lo que hoy en día llamamos urbanismo participativo y Urbanismo Peer-to Peer (P2P): de igual a igual. ${ }^{120} \mathrm{El}$ modo de planificación de las ciudades que usaba el Movimiento Moderno era desde arriba hacia abajo, mientras que el urbanismo participativo es un modo de proyectar desde abajo hacia arriba. La primera es una planificación jerárquica, autoritaria y capitalista que es posible solo con la financiación centralizada de la construcción; el

116 John F. C. Turner and Robert Fichter, Freedom to Build: Dweller Control of the Housing Process (New York: The Macmillan Company, 1972). 153

117 "Elemental - “, accessed 5/15/2015, 2015, http://www.elementalchile.cl/.

118 “Urban-Think Tank - Interdisciplinary Design Studio”, accessed 5/15/2015, 2015, http://www.u-tt.com/.

119 "Jorge Mario Jáuregui “, accessed 5/15/2015, 2015, http://www.jauregui.arq.br/.

120 Nikos A. Salingaros and Federico Mena-Quintero, "Una Historia Breve Del Urbanismo-P2P," 
urbanismo participativo tiene una estructura, diríamos, anárquica, pero que ofrece mejor calidad de vida, pues cada uno sabe mejor lo que necesita que lo que creen los otros que necesita. Resultado de la planificación desde arriba hacia abajo es el gigantismo, la construcción a una escala que no es humana ya que tanto por la financiación - que requiere la gran escala - pero principalmente por el hecho de que la ciudad se ve desde una distancia que no permite ver la vida en su interior, los edificios consiguen grandes dimensiones y el habitante ni se ve. Es como lo describe De Certaeu,

el que sube allá arriba sale de la masa que lleva y mezcla en sí misma toda identidad de autores o de espectadores. (...) Su elevación lo transforma en mirón. Lo pone a distancia. (...)La ciudad-panorama es un simulacro "teórico" (es decir, visual), en suma un cuadro, (...) El dios mirón que crea esta ficción literaria y que, como el de Schreber, sólo conoce cadáveres, (...) Es "abajo" al contrario (down), a partir del punto donde termina la visibilidad, donde viven los practicantes ordinarios de la ciudad ${ }^{121}$.

Si el urbanismo participativo construye ciudades más humanas y más eficaces para las satisfacciones de los ciudadanos, es porque empieza desde abajo hacia arriba; es porque, el habitante decide cómo será su entorno y no un ser divino indispensable que le mira desde arriba. Pero, además, la proyección desde arriba hacia abajo transforma la ciudad en un producto producido por un profesional y al habitante en su usuario; la no participación del habitante en la construcción de su entorno - la eliminación de una actividad significativa existencialmente para él - le deja hipnotizado, apático, es decir, tedioso. Al contrario, el urbanismo participativo o P2P habla del habitante prosumer como aquel que es productor y a la vez consumidor del espacio urbano; un habitante energético, dinámico que para poder construir su entorno busca la educación y su evolución cultural y política.

En el Urbanismo P2P se trata de permitir a la gente diseñar y construir su propio entorno usando información y técnicas que se comparten libremente. ${ }^{122}$ El grupo que fundó oficialmente el Urbanismo P2P, y dio su nombre “peer to peer", se creó en 2010

121 Michel De Certeau and Luce Giard, La Invención De Lo Cotidiano: Artes De Hacer. I, Vol. 1 Universidad Iberoamericana, 2007)., 103-105

122 Salingaros and Mena-Quintero, Una Historia Breve Del Urbanismo-P2P, 1.
Proyectar desde abajo bacia arriba, urbanismo participativo; del igual a igual 
El habitante diseña y construye su entorno: Urbanismo Peer to Peer (P2P); del igual a igual.

Colectivos de Urbanismo Participativo en España con un modo de urbanismo participativo que reúne ideas del movimiento de software libre (opensourse) con ideas nuevas de urbanistas en una disciplina orientada a satisfacer las necesidades humanas ${ }^{123}$. Usa software parecido al de los arquitectos estrellas, pero, en abierto; cualquiera lo puede usar y modificar. La P2P Foundation ${ }^{124}$, fundada por Michel Bauwens, ha organizado y desarrollado muchos conceptos P2P pero la actividad de grupos que se conecta en el mundo virtual para luego reunirse en el mundo real para solucionar problemas urbanísticos ${ }^{125}$ la encontramos mucho antes de 2010, cuando se expandieron las redes sociales. Existen en la actualidad muchos colectivos dentro de esta categoría tal como Recetas Urbanas ${ }^{126}$, Straddle3 ${ }^{127}$, Caldo de Cultivo ${ }^{128}$, esto no es un solar ${ }^{129}$, Paisaje Transversal ${ }^{130}$, Basurama ${ }^{131}$, Todo por la Praxis ${ }^{132}$, Boa Mistura ${ }^{133}$, Left Hand Rotation ${ }^{134}$, Zuloark ${ }^{135}$, Otro Hábitat ${ }^{136}$. Hoy en día, las redes sociales no solo ayudan a la reunión de los ciudadanos para la solución de problemas de su entorno, sino que también ofrece un lugar para la comunicación entre los colectivos de todo el mundo. Las Arquitecturas Colectivas ${ }^{137}$ es una Red Internacional de Colectivos, una página web en la que aparecen los cientos de colectivos que ejercen por el mundo.

Ada Colau, alcaldesa de la ciudad de Barcelona, desde el mayo de 2015 promete en su programa electoral un urbanismo participativo para la ciudad que tome en cuenta 123 Ibid., 1.

124 “P2P Foundation”, accessed 8/14/2015, 2015, http://p2pfoundation.net/Main Page.

125 Salingaros and Mena-Quintero, Una Historia Breve Del Urbanismo-P2P, 4.

126 "Recetas Urbanas :: Santiago Cirugeda :: Arquitectura Social “, accessed 8/14/2015, 2015, http://www.recetasurbanas.net/v3/index.php/es/.

127 "Straddle3 “, accessed 8/14/2015, 2015, http://straddle3.net/.

128 "Caldodecultivo", accessed 8/14/2015, 2015, http:/caldodecultivo.com/.

129 "Esto no Es Un Solar “, accessed 8/14/2015, 2015, http://estonoesunsolar.com/.

130 "Paisaje Transversal Porfolio “, accessed 8/14/2015, 2015, http://www. paisajetransversal.com/.

131 "Basurama“, accessed 8/14/2015, 2015, http://basurama.org/\#2.

132 “Todo Por La Praxis “ , accessed 8/14/2015, 2015, http://www.todoporlapraxis.es/.

133 "Boa Mistura “, accessed 8/14/2015, 2015, http://www.boamistura.com/.

134 "Left Hand Rotation,", accessed 8/14/2015, 2015, http://www.lefthandrotation.

$\underline{\mathrm{com} / .}$

135 “Zuloark Zoohaus “, accessed 8/14/2015, 2015, http://www.zuloark.com/ zoohaus-the-net/.

136 "Otro Hábitat - Colectivo Interesado En Un Urbanismo Participativo y La Mejora Auto-Gestionada Del Hábitat “, accessed 8/14/2015, 2015, http://www.otrohabitat.org/.

137 "Arquitecturas Colectivas | Arquitecturas Colectivas Es Una Red De Personas y Colectivos Interesados En La Construcción Participativa Del Entorno Urbano. “, accessed 8/14/2015, 2015, http://arquitecturascolectivas.net/. 
las propuestas de los ciudadanos y actúe de manera distinta según las necesidades de cada barrio. Según el artículo de Jon Aguirre Such, El urbanismo participativo: una nueva forma de organizar la ciudad, presentado en El País el 10 de Junio de 2015, Ada Colau promete que traerá de vuelta aquella Barcelona de la década de los setenta, donde vecinos y vecinas se reunían para pedir más seguridad en las calles, más servicios y espacios colectivos en el barrio o una mejora en las condiciones de habitabilidad de las viviendas ${ }^{138}$. La misma línea tiene la alcaldesa de Madrid, Manuela Carmena, quien propone en el año 2015 la creación de Planes de Barrio, informes que reflejarán acciones de mejora de cada distrito y que en su elaboración bubieran participado ciudadanos y ciudadanas como también la utilización de los espacios públicos vacíos ampliar el uso de calles, plazas, parques y equipamientos por parte de la ciudadanía ${ }^{139}$. En España, la adopción del urbanismo participativo por parte de los ayuntamientos empieza ya en 2009 cuando los habitantes de Zaragoza pidieron aprovechar los espacios vacíos del casco antiguo; el hecho de que al final se permitiera a colectivos, asociaciones vecinales y culturales, a centros de educación y a personas mayores intervenir al espacio público reanimó el casco con lugares de cultivo, jardines y centros deportivos. ${ }^{140}$ Algo parecido pasó en el barrio madrileño Virgen de la Begoña en 2011 que el colectivo Paisaje Transversal consiguió una financiación para que los habitantes realizaran sus propuestas sobre su entorno que al final condujo a la creación de una ludoteca móvil y una escuela para padres. En Valencia, el ayuntamiento en colaboración con los ciudadanos rehabilitaron un antiguo edificio público que se hizo biblioteca del municipio. Por último, en Girona, el Ayuntamiento de Olot aprobó el Plan de Intervención de Acciones de Mejora para el barrio de Sant Miquel según el cual, los técnicos, políticos y vecinos colaboraron para el mejoramiento de la calidad de vida en el barrio. ${ }^{141}$ Es obvio que algunos ayuntamientos de España se acercan cada vez más al urbanismo participativo, como modelo de organización de la ciudad que no solo requiere un menor coste, sino que principalmente deja a los ciudadanos más satisfechos; es un urbanismo más eficaz no solo porque satisface las necesidades de los ciudadanos, sino también porque los transforma de

138 "El Urbanismo Participativo: Una Nueva Forma De Organizar La Ciudad." Periódico El País, , accessed 8/14/2015, 2015, http://blogs.elpais.com/seres-urbanos/2015/06/ el-urbanismo-participativo-una-nueva-forma-de-organizar-la-ciudad.html.

139 Ibid.

140 Ibid.

141 Ibid.
Ada Colau y Manuela Carmena prometen un urbanismo participativo para los barrios de las ciudades de Barcelona y Madrid

Los ayuntamientos de las ciudades de España apoyan las tácticas del urbanismo participativo desde 2009: Zaragoza, Madrid, Valencia, Girona 
El tedio no se puede curar pero se puede aprender a aburrirse

El ser humano en su combate con la contingencia para mantener el orden olvidó que la condición primera de su existencia es la extrañeza tediosos consumidores a gente activa que evoluciona culturalmente y políticamente, llegando así a tener una mejor calidad de vida.

Es imposible eliminar el tedio pero sí se puede elegir entre admitirlo o inhibirlo ${ }^{142}$, dice Svendsen; aprender a aburrirse. La madurez tiene que ver precisamente con aceptar que los instantes son pasajeros y que la vida consiste en una importante cantidad de tedio distribuida entre uno y otro de estos instantes ${ }^{143}$. Si la sensación del tedio se prolonga, si deja de ser un instante pasajero, se convierte en elpuro tedio vital del que hablaban y sufrían Baudelaire, Blanchot, Valery y más. Aquel que hoy en día se considera como la epidemia de siglo, el veneno que hipnotiza a los habitantes y los empuja al shopping therapy: implica consumir más para llenar el vacío que les crea. La expansión de la enfermedad es resultado del inadecuado uso de la industria y la tecnología y del aumento radical de la población de las ciudades a partir de su industrialización. El descubrimiento de la industria hizo al ser humano entender el poder de su pensamiento, marcando el comienzo de la modernidad en la que el ser humano sintió que él es quien impone el orden en el mundo, mientras que, hasta entonces, la humanidad creía que el orden en el mundo era responsabilidad del Dios o de la Naturaleza. La obsesión con el mantenimiento del orden impuesto obliga a combatir la contingencia, la ambivalencia y lo imprevisto como enemigos del orden, pues transforman el mundo otra vez en caos. Se elimina así lo irregular, las sorpresas, las extrañezas y los acontecimientos que acompañan a lo imprevisto; como dice Lyotard, lo que ya es conocido no puede ser un acontecimiento ${ }^{144}$. Su deseo por ordenar el mundo le hizo olvidar que la condición primera de su existencia es la extrañeza ${ }^{145}$.

142 Lars Fr H. Svendsen, Filosofia Del Tedio (Barcelona: Tusquets, 2006), 182.

143 Ibid. 199.

144 Jean-François Lyotard, "The Inhuman: Reflections on Time, Trans. Geoffrey Bennington and Rachel Bowlby," Cambridge, Polity Press (1991).p.65.

145 Bruce, La Découverte Du Quotidien, 418. 
De repente

Arquitecturar es poner en orden, dice Le Corbusier. Poner en orden ¿qué? Unas funciones y unos objetos, ocupar el espacio con unos edificios y con unas carreteras. Crear unos vasos para albergar a unos hombres y crear unas comunicaciones útiles para dirigirse a ellos ${ }^{t}$

1 Corbusier, Precisiones Respecto a Un Estado Actual De La Arquitectura y El Urbanismo Trad 90 



\section{en el dominio de la letra $\mathrm{O}$, excluyendo}

Vivir es elegir

Ángel Gabilondo

Juan José Millás tuvo una pesadilla mientras dormía: de repente, todos los libros, de cualquier tamaño, peso y temática empezaron a volar; salieron de las estanterías, abandonaron las casas y se alejaron-más y más. En el colegio, de vez en cuanto, algún compañero de Millás levantaba la mano señalando una bandada de libros y el Ministro de Cultura y el de Defensa decían por la televisión que en las clases se trabajarían con apuntes en cuadernos. Los estudiantes empezaron a escribir en ellos pero después de cuatro hojas, los cuadernos temblando entraban en vuelo y les abandonaban. ${ }^{2}$ Finalmente los ministros decidieron cerrar los colegios debido a la imposibilidad de mantener quietas las hojas; todas se volaban. No importaba que las pegaras para que no se escaparan, si lo hacías las letras se deshacían y desaparecerían. En las afueras de las ciudad se podían escuchar historias de luchas entre libros; se extendieron noticias sin confirmar según las cuales un grupo de pesadas biblias encuadernadas en piel, y con remates de latón en las tapas, había atacado a una bandada de libros cientificos, encuadernados en rüstica, que negaban el mito de la creación. También se dijo que en las afueras de la ciudad se libraban espectaculares combates entre novelas policiacas y libros de ensayo; entre textos de literatura juvenil y de adultos; o entre

Cuando las letras se van enciclopedias temáticas y alfabéticas, pero nada de esto se demostró, aunque si quedó patente que tales guerras imaginarias, proyectadas de este modo hacia el exterior, se daban en realidad en el interior de las cabezas de la gente. ${ }^{3}$ La situación incluso se empeoró; la desaparición de las letras dificultó el movimiento y el encuentro en las ciudades. Los carteles informativos de las carreteras 1 Ángel Gabilondo, Artesanos De La Belleza De La Propia Vida / Crafters of the Beauty of the Life itself (Barcelona: CCCB, 2010). 21

2 Juan José Millás, El Orden Alfabético (España: Punto de Lectura, 2010).15

$3 \quad$ Ibid. 17 
iban desapareciendo y la circulación se hacía muy- peligrosa.

Con las palabras, desaparecen los objetos

La desaparición de las letras hace de la ciudad un caos y la sociedad se animaliza

Si perdemos la "o", no existe la vida.

Los nombres de las calles y los números de las casas se borraron, y aunque eso no afectó al reparto de la correspondencia, porque las cartas habian volado ya hacía tiempo de los buzones y oficinas de correos, fue un elemento más de confusión. Pronto advertimos que una ciudad con calles sin identificar y portales sin numeros se transformaba en un verdadero laberinto, en una trampa de la que no era fácil salir. Hubo muchas recomendaciones en el sentido de que la gente no se alejara de su barrio, pues la policía no dejaba de atender llamadas de personas perdidas. Creo que fue entonces cuando alguien, en la radio, comparó lo que estaba sucediendo con un corte prolongado de agua o lu₹, esos bienes de cuya posesión no somos conscientes hasta que faltan. ${ }^{4}$

El padre de Juan José Millás le contó que vivían en una época de animalización por la desaparición de las letras. Cuando la palabra mesa desapareció, con ella lo hizo la mesa como objeto; cuando desapareció la palabra tenedor y cuchara, la gente empezó a comer con las manos. ${ }^{5}$

Si alguien profundiza en el sueño de Millás puede llegar a experimentar, más allá de la animalización de la vida, la propia pérdida de ésta. La letra "o" parece insignificante; cuando está sola dentro del papel no tiene sentido y su presencia dentro de una frase, es mínima. Pero si no existiera la letra “o” no existiría la vida; porque domina los lugares de la elección y la decisión. Cuando la letra "o" va sola en una frase significa que hay una elección: queremos esto o aquello, vamos alli o alli, pensamos una cosa o la otra; si no existiera la letra "o" no existiría la vida, porque sin ella no habría capacidad de elección; como dice Ángel Gabilondo, vivir es elegir . Y en el caso en que uno pudiera sobrevivir con la ausencia de la letra "o" viviría en un caos donde nada podría entrar en un orden, porque la letra "o" no solo indica el acto de la elección, sino también el del orden. El "o" pertenece a la clase de palabras que se llaman conjunciones - que son las palabras desinclinables que sirven para expresar la relación entre las partes de la oración en las

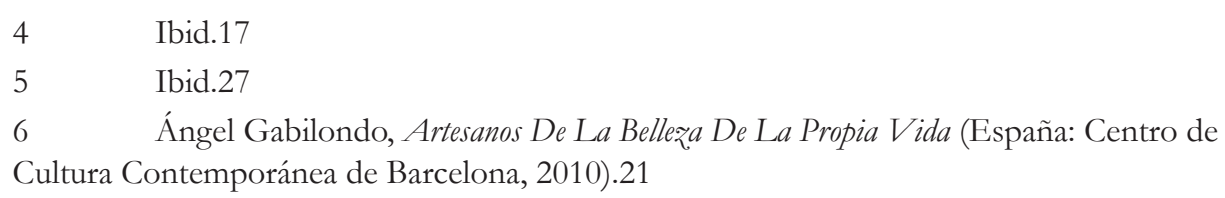


que ésta; dentro de la familia de las conjunciones, está en la categoría nombrada como conjunciones disyuntivas porque sirven para la separación y alternativa de los pensamientos; por esta última acción, la de la alternativa, se llaman también distributivas. ${ }^{7}$ La letra "o" distribuye el espacio, lo pone en orden; la letra "o" es la letra del orden.

La primera modernidad ${ }^{8}$ es la época de la letra “o", del "o bien o", según Beck: la época de la limitación y la seguridad. ${ }^{9}$ Para Bauman, la modernidad empieza cuando la preocupación central del ser humano es el orden, poner el mundo en orden. El orden, para Bauman, es un entorno regular, estable, para nuestra acción; un mundo en el que los grados de probabilidad de los acontecimientos no se distribuyan al azar, sino que se organicen según una estricta jerarquia de modo que determinados acontecimientos tengan grandes posibilidades de producirse, otros sean menos probables y otros prácticamente imposibles ${ }^{10}$. El orden no es algo que se inventa en la modernidad; sin embargo, a partir de la modernidad se convierte en máxima preocupación. El verbo ordenar viene, según el diccionario de Liddell - Scott - del

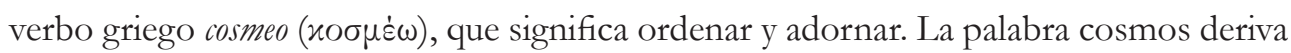
del verbo cosmeo; es el mundo, el cosmos, para los antiguos griegos, el universo como resultado del orden (taxis) y de la armonía perfecta, en contraste con la esencia noformada del Caos, como dice el Diccionario. El cosmos es un término opuesto a caos, porque el cosmos nace en el momento que alguien o algo pone en orden el caos; la introducción del orden en el caos es la responsable de la creación del mundo ${ }^{11}$. Antes de la modernidad el orden fue visto como condición imprescindible para la armonía y la belleza, pero ya en la modernidad el orden existe para evitar la incertidumbre, la ambivalencia y el caos; el orden ya no es lo necesario para llegar a la belleza o la armonía, sino que es lo imprescindible para no sentir la incertidumbre.

7 Vicente Salva y Pérez, Grámatica De La Lengua Castellana. Según Ahora Se Habla (Valencia, España: Librería de los SS Mallen y Sobrinos, 1854).107

$8 \quad$ Para Beck, la primera modernidad empieza con la revolución francesa, 1789

9 Zygmunt Bauman et al., "Modernidad y Ambivalencia," in Las Consecuencias Perversas

De La Modernidad. Modernidad Contingencia y Riesgo (Barcelona, España: Anthropos, 1996), 216

10 Zigmunt Bauman, La Posmodernidady Sus Descontentos Ediciones Akal, 2001).15

11 Platón, Timeo, Introducción, Traducción y Comentarios, Kalfas Basilis, (Atenas: Polis, 1995).
La letra "o" distribuye el espacio, lo pone en orden

La época de la modernidad es el dominio de la letra "o": pensamiento de !o bien o"

A partir de la modernidad, el orden es la máxima preocupación 
Dice Bauman,

La idea del orden como una secuencia regular de eventos, como un conjunto armonioso de partes bien articuladas, como una situación en la que las cosas tienden a permanecer como se espera que lo hagan, no nació con los tiempos modernos. Es claramente moderna, en cambio, la preocupación por el orden, la urgencia por interactuar con él, el temor de que a menos que hagamos algo el orden se degrade hasta convertirse en caos ${ }^{12}$.

Lo novedoso de la modernidad, la existencia de la conciencia del orden

El ser humano descubre que el orden no es natural, sino que depende de él
El propósito más importante de la modernidad es el orden como lo contrario del caos; lo que no es caos; caos como lo que no está ordenado. Orden y caos son los gemelos modernos. Son concebidos a partir del rompimiento y colapso del mundo ordenado por Dios, mundo que nada sabía ni de necesidad ni de accidente $^{13}$. Lo novedoso de la modernidad es que ahora existe la conciencia del orden. Para Stephen L. Collins la conciencia, aparece como la cualidad del orden percibido en las cosas y según la interpretación de Bauman el marco de nacimiento de la conciencia del orden es el marco de nacimiento de la conciencia moderna ${ }^{14}$. Escribe Stephen L. Collins que

Hobbes entendía que el fluir del mundo era natural y que el orden debe ser creado refrenando el flujo natural. La sociedad no es sino un reflejo trascendentalmente articulado de algo predefinido, externo y más allá de la existencia ordenada jerárquicamente. (...) el orden pasó a ser comprendido, no como algo natural, sino artificial, creado por el hombre y manifiestamente politico y social. (...) El orden deviene un hecho de poder, y el poder un hecho de la voluntad, de la fuerza, del cálculo (.... $)^{15}$.

El descubrimiento de que el orden no es natural, es el descubrimiento del

12 Zygmunt Bauman and Tim May, Pensando Sociológicamente Ediciones Nueva Visión, 1994). 183

13 Zygmunt Bauman et al., "Modernidad y Ambivalencia," in Las Consecuencias Perversas De La Modernidad. Modernidad Contingencia y Riesgo (Barcelona, España: Anthropos, 1996), 77 14 Ibid. 784, 6, 7, 28. 29, 32.

15 Stephen L. Collins, "From Divine Cosmos to Sovereign State an Intellectual History of Consciousness and the Idea of Order in Renaissance England," (1989).4, 6, 7, 28. 29, 32 
orden como tal ${ }^{16}$, dice Bauman. La naturaleza, cuya existencia es desordenada, debe ser dominada y organizada para el hábitat humano, según las necesidades humanas. Antes de la modernidad, dice Bauman, el mantenimiento de las divisiones y el orden parecía ser algo dado, natural. Las divisiones de la sociedad, antes de la modernidad, parecían ser intemporales, inmunes a la intervención humana.

En sentido estricto, la 'tradición' implica precisamente esa cualidad institucional 'estructural': el convencimiento de que no hay nada que las personas vivas puedan hacer para cambiar las instituciones que han heredado y de que si, ignorando su impotencia, intentarán trastocar su legado, ese intento les acarrearía desastres inimaginables, causados por el castigo divino o por las leyes de la naturaleza, que no admiten ni toleran ninguna violación ${ }^{17}$.

La postura premoderna hacia el mundo, comenta Bauman, se parece a la de un guardabosque; la del ser humano moderno es semejante a la de un jardinero y la de la posmodernidad, la del cazador. ${ }^{18}$ El trabajo del guardabosques es proteger y defender el territorio frente a cualquier interferencia humana, intentando preservar el equilibrio e organización divina, creación de Dios o de la Naturaleza. La concepción premoderna del mundo es una cadena divina del ser en la que cada criatura tiene su lugar y función adecuada: es mejor que no tocar las cosas ya que la capacidad mental humana no es tan alta como para tocar la armonía y el orden de lo divino. El jardinero del mundo moderno no piensa de la misma manera: para él, el orden no es algo divino sino lo que el ser humano tiene que imponer para mantener el equilibro y la seguridad; ahora el que pone el orden no es Dios o la Naturaleza, sino el jardinero. El jardinero es el ordenador del territorio; primero procesa y elabora las disposiciones adecuadas de las cosas en su cabeza y después intenta traspasar esa imagen tal cual de su cabeza al territorio; en la realidad, decide cuales son las malas hierbas, según sus criterios, e intenta por cualquier medio alejarlas o eliminarlas con el fin de mantener el orden que en principio tuvo en

\footnotetext{
16 Zygmunt Bauman et al., "Modernidad y Ambivalencia," in Las Consecuencias Perversas De La Modernidad. Modernidad Contingencia y Riesgo (Barcelona, España: Anthropos, 1996), 79

17 Bauman Zygmunt, En Busca De La Politica (Argentina: Fondo de Cultura Económica, 2001). 145

18 Bauman Zygmunt, Tiempos Líquidos. Vivir En Una Época De Incertidumbre.Argentina, Editorial Tusquets (2007).139
}

La naturaleza debe ser dominada para el habitat de los individuos

el ser humano premoderno es la figura de guardabosques; la del moderno, el jardinero y en la posmoderidad viene el cazador.

el guardabosques intenta mantener el orden impuesto por la naturaleza o Dios; el jardinero es el que pone en orden el mundo; al cazador no le interesa el orden 
su mente: limpiar la maleza, las plantas invasoras -los intrusos- que han crecido por su propia iniciativa y que han intentado desdibujar el dibujo inicial del jardinero, borrando los límites que existen entre el jardín y el resto del campo; por eso hay que ordenar y vigilar, continuamente, el jardín: los jardineros tratan a la sociedad como un jardín que hay que diseñar y conservar a la fuerza en la forma en que fue diseñado ${ }^{19}$.

La práctica de la jardinería encuentra su máxima expresión en el Estado Moderno, según Bauman. El Estado Moderno parece un jardinero que intenta planificar y estructurar la sociedad, el territorio y la vida; y después, bajo un continuo control, mantener la imagen previa. Dentro de la política nazi, hija del pensamiento moderno, R.W. Darre, Ministro de Agricultura en el Nazismo, comenta:

El que descuide las plantas de un jardín pronto descubrirá sorprendido que el jardín está plagado de malas hierbas y que ha cambiado incluso el carácter básico de las plantas. Si el jardín va a seguir siendo el lugar donde se cultivan las plantas, si, en otras palabras, va a seguir floreciendo a pesar de las fuerzas naturales, entonces es precisa la voluntad modeladora de un jardinero, un jardinero que les proporcionará las condiciones adecuadas para que crezcan, mantendrá aisladas las malas influencias, atenderá amorosamente todo lo que haya que atender y eliminará implacablemente las malas hierbas que pueden privar a las mejores plantas de su alimento, aire, luzy sol. Es decir, comprobamos que estas cuestiones relacionadas con el cultivo no son triviales para el pensamiento politico, sino que tienen que formarparte del núcleo de todas las consideraciones y que las respuestas serán consecuencia de la actitud espiritual e ideológica de un pueblo. Debemos incluso declarar que un pueblo sólo puede alcanzar el equilibrio espiritual y moral si, en el núcleo mismo de su cultura, bay un

En la moderindad, el pensamiento obsesionado por el orden despierta los grandes utopistas y planificadores plan de cultivo bien proyectado ${ }^{20}$.

Los jardineros son los creadores de la utopías; utopía hace referencia a un objetivo soñado y lejano, hacía donde el progreso debe ir para conseguir un mundo

19 Zygmunt Bauman and Tim May, Pensando Sociológicamente Ediciones Nueva Visión, 1994). 23

20 Zygmunt Bauman et al., "Modernidad y Ambivalencia," in Las Consecuencias Perversas De La Modernidad. Modernidad Contingencia y Riesgo (Barcelona, España: Anthropos, 1996), 51-52 
que se adapte mejor en a las necesidades de los humanos. ${ }^{21}$ Aparecen al comienzo de la primera modernidad los grandes planificadores y utopistas que intentan diseñar sociedades y ciudades ordenadas que satisfagan las necesidades humanas haciendo el mundo feliz. Es la época en la que los seres humanos buscan grandes planes para mantener el orden y conseguir las administraciones perfectas de las condiciones humanas para llegar a tener y conseguir una vida ideal. La modernidad es la época de los grandes planificadores, visionarios, constructores de ciudades ideales: de los grandes jardineros. El concepto de la ciudad ideal no tiene su origen en el siglo XIX, sino en los años de Platón, cuando fija pautas de la ciudad perfecta, justa, refiriéndose a menudo a Atlántida. Sin embargo, lo que la diferencia de las de siglo XIX es que las segundas no se

La ciudades ideales se materializan quedan en su aspecto literario, sino que llegan a ser realidad en muchos de sus $\operatorname{casos}^{22}$, desde C.N Ledoux (1736-1806) ${ }^{23}$ a W. Morris ${ }^{24}$.

Robert Owen (1771-1858) elabora un modelo de la convivencia ideal para un grupo determinado de personas que trabajan en el campo y la industria; Charles Fourier (1772-1837), cree que las acciones de los humanos derivan de la atracción pasional y no del provecho económico y habla de los siete periodos de las sociedades, situando la sociedad de su momento a caballo entre el cuarto periodo (barbarie) y el quinto (civilización); el sexto es el de la "seguridad" y el séptimo de la "armonía", en el cual la vida y la propiedad están totalmente colectivizados y los seres humanos viven en los falansterios: un gran hotel, una construcción simétrica con tres patios y varias entradas, edificio que podrá alojar 1620 personas. No consigue trasladar su ciudad ideal a la realidad pero una versión de su proyecto llamada Familisterio es construido por el industrial Jean- Baptiste Godin. ${ }^{25}$ Kenneth Frampton describe que, más tarde, un discípulo de Fourier, Victor Considérant, une la metáfora de Versalles - los falansterios estaban modelados a partir del esquema de Versalles- con la del barco de vapor y esta

21 Bauman Zygmunt, Tiempos Liquidos. Vivir En Una Época De Incertidumbre.Argentina, Editorial Tusquets (2007).145

22 Leonardo Benevolo, Historia Da Arquitetura Moderna (Tradução De Ana M. Goldberger) São Paulo: Editora Perspectiva, 2001).173

23 Claude Nicolas Ledoux, L'Architecture Considérée Sous Le Rapport De l'Art, Des Mcurs Et De La Législation: Tome Premier, Vol. 1 (París: A. Uhl, 1804).

$24 \quad$ William Morris, News from Nowhere (Canada: Broadview Press, 2002).

25 Leonardo Benevolo, Historia Da Arquitetura Moderna (Tradução De Ana M. Goldberger) São Paulo: Editora Perspectiva, 2001). 178 
El pensamiento urbanistico empieza por los higienistas y lo técnico para asegurar el funcionamiento de los sitemas higénicos.
El urbanismo empieza en los años 1830-1850: la primera vez que se se establecen leyes urbanisticas. particular refundición de la comuna y el barco iba a ser retomada por Le Corbusier, más de un siglo después, en su comunidad autosuficiente o Unité d'Habitation, realizada, con alusiones a Fourier, en Marsella entre 1947 y $1952^{26}$. Etienne Cabet (1788-1856), al igual que Fourier, imagina la ciudad Icaria: una ciudad basada en una organización socialista de la propiedad y la producción; una gran metrópoli que reúne las bellezas de todas las ciudades. ${ }^{27}$

En el comienzo de la modernidad es cuando aparecen los grandes urbanistas de la historia; los que intentan poner en orden las ciudades que de manera desordenada e irregular se han construido por los ciudadanos. La revolución industrial provoca un rápido crecimiento de la ciudad, ya que en masa la gente abandona las zonas rurales buscando una nueva vida en las ciudades que, por el avance tecnológico, ofrecen abundancia de trabajo. Se hace necesario poner en orden la ciudad y ser pensada en su totalidad para poder albergar a los ciudadanos y medios de transporte que aumentan rápidamente. Esencialmente, el planeamiento urbanístico había empezado desde la Antigua Grecia, pero, oficialmente empieza con la aparición de la urbanización. Según Sennet, el planeamiento urbanístico comenzó por los higienistas y los técnicos que intentaron buscar soluciones para asegurar el funcionamiento de los sistemas higiénicos de la ciudad. Para Benévolo los orígenes del urbanismo moderno están en los años 18301850 cuando, por primera vez, se establecen las leyes urbanísticas, las leyes sanitarias para la edificación de los barrios obreros ${ }^{28}$. En 1850 es la primera vez que se aprueba una ley urbanística francesa según la cual, los Ayuntamientos son los responsables de la elección de una comisión que ponga las medidas indispensables de sistematización de los alojamientos y dependencias insalubres, alquiladas y ocupadas por personas distintas al propietario. A partir de ella, el Ayuntamiento puede actuar en lugar del propietario o le puede obligar a hacer los trabajos necesarios para el cumplimiento de la ley y para la mejora de las condiciones sanitarias. Para Benevolo,

El diseño urbano del siglo XIX facilitó el movimiento de un gran número de individuos en la ciudad y dificultó el movimiento de grupos, los amenazadores grupos que

26 Jorge Sáinz Avia and Kenneth Frampton, Historia Crítica De La Arquitectura Moderna (Barcelona: Editorial Gustavo Gili, S.L., 2007).22

27 Leonardo Benevolo, Historia Da Arquitetura Moderna (Tradução De Ana M. Goldberger) São Paulo: Editora Perspectiva, 2001). 173-182

28 Ibid.61-75 
aparecieron en la Revolución francesa. Los planificadores urbanos del siglo XIX se basaron en sus predecesores ilustrados, que concibieron la ciudad como arterias y venas de movimiento, pero dieron un nuevo uso a esas imágenes. El urbanista de la Ilustración habia imaginado individuos estimulados por el movimiento de la muchedumbre de la ciudad. El urbanista del siglo XIX imaginó individuos protegidos por el movimiento de la muchedumbre. Tres grandes proyectos marcan este cambio a lo largo del siglo: la construcción de Regenr's Park y Regent Street en Londres, a inicios del siglo XIX; la reconstrucción de las calles parisinas en la época del barón Haussmann a mediados de siglo y la construcción del metro de Londres a finales de siglo. ${ }^{29}$

El prototipo del planeamiento urbanístico que siguen las ciudades europeas a partir de la mitad del siglo XIX son los de Hausmann en París. El historiador David Pinckney escribe: Napoleón le entregó un mapa de París en el que habia trazado con cuatro colores diferentes (que indicaban la urgencia relativa de cada proyecto) las calles que se proponía construir. Este mapa, obra de Luis Napoleón solo, se convirtió en el plano básico para la transformación de la ciudad en las dos décadas siguientes ${ }^{30}$. La transformación de la ciudad de París es necesaria para solucionar la demanda de viviendas, que surge de repente por el rápido aumento de la población en la ciudad y por los nuevos modos de recorrerla, ya que se extiende el uso de los coches. La obra de Hausmann se divide, según Benévolo, en cinco categorías: a) la urbanización de la periferia con varias obras, el trazado de nuevas arterias en los barrios viejos, construyendo edificios a lo largo del mismo, b) la construcción de edificios públicos como bibliotecas, escuelas, puentes, edificios militares, cárceles, hospitales, encargados directamente de la Prefectura y otras entidades públicas, c) la creación de parques públicos d) la nueva red alcantarillado, triplicación de los puntos de luz, organización del transporte público, e)la modificación de la distribución administrativa de la capital: once municipalidades alrededor de Paris se anexionan con la capital, los doce arrondissements (sectores o barrios como parroquias) tradicionales aumentan a veinte, y una parte de las funciones administrativas se descentraliza en las veinte mairies (como prefectura) de cada

29 Richard Sennett, Carne y Piedra: El Cuerpo y La Ciudad En La Civilización OccidentalAlianza editorial, 1997).346

30 David H. Pinkney, Napoleon III and the Rebuilding of Paris, Vol. 78 (Princeton, NJ:

Princeton University Press, 1958).25,
El modelo del urbanismo neoconservador es la reforma de París, en los años de Haussmann 
John Nash es el responsable de la mayor obra urbana de Lóndres arrondissement. ${ }^{31}$ Para la mejora de la circulación, se transportan las estaciones de trenes fuera de la ciudad, conectándolas con una red de grandes y rectilíneas calles y largos bulevares enlazados con plazas circulares. ${ }^{32}$ Para Benévolo, lo importante de la presencia de Hausmann en la reforma de París es más que nada su actividad administrativa porque marca la pauta de cómo planificar y gerenciar una ciudad de tal dimensión ${ }^{33}$.

En Londres, La Nueva Roma de Henri James, -la capital del siglo XIX según Benjamin ${ }^{34}$ - John Nash parece querer una ciudad preparada para la velocidad del siglo XIX. En la Edad Media, en París y Londres, los jardines urbanos servían para refugio, pero, en el siglo XVIII los planificadores crean los parques como pulmones de la ciudad. A mediados de XVIII, el parque público Real de las Tullerías en París es cerrado por las autoridades con verjas porque los parques-pulmones exigen vigilancia; han de proteger las plantas que proporcionan aire saludable a la ciudad. También son valladas las plazas urbanas de Londres al principio de siglo XIX. John Nash es el responsable de la mayor obra urbana de Londres, de Regent's Park y Regent Street y al inicio del siglo XIX

31 Leonardo Benevolo, Historia Da Arquitetura Moderna (Tradução De Ana M. Goldberger) São Paulo: Editora Perspectiva, 2001). 92-98,

32 A partir del siglo XIX la función de las calles en la ciudad cambia. En las ciudades antiguas el plano horizontal de la ciudad se divide en dos partes, una que es utilizada para los peatones y otra para ser usada por animales y vehículos. El plano horizontal. Es uno de los más importantes elementos que define el espacio de la calle. Este es el plano que provee la ubicación física y visual de la forma del edificio, el cual puede ser utilizado para dar unidad, escala y armonía a la calle. Hasta la ciudad medieval los límites entre vehículos y las personas eran difusos pero, como regla general, el centro de la calle era para las personas y en sus bordes se movían los medios de transporte; la analogía entre el ancho de las calles y la altura de los edificios fue generalmente $1 / 2$; la calles eran estrechas como también las cuadras, produciendo tramas principalmente cuadradas. En el Renacimiento se produce la introducción de la perspectiva y a partir de entonces ella es la que organiza las calles; como los puntos de vista, en la ciudad se da énfasis a los cálculos exactos y la geometría; desde la época del neoclasicismo empiezan a aumentar su ancho, con la urbanística neoconservadora iniciada por Haussmann se transforman en bulevares y con Le Corbusier, al principio del siglo XX, dejan de ser mediadores de cultura, del encuentro e intercambio; se transforman en un medio para la circulación de los coches ya que aleja definitivamente al ciudadano del plano horizontal de la ciudad y transporta su vida cotidiana a niveles más altos, dejando las calles para la circulación de los vehículos. En esta época la cuadra se hace desde dentro, organizándose alrededor de su área interna con un edificio alargado con un patio y las calles se crean de manera monumental, dando énfasis al punto de vista. En el periodo neoclásico las calles siguen formas geométricas pero se produce un incremento de la escala de la calle. Las fachadas homogéneas siguen las reglas de la perspectiva; edificios organizados de manera para ser vistos desde varios puntos de vista, direcciones. Jorge A. Negrete, "Utilización De La Cuadra y La Plaza Como Elementos De Diseño Urbano," Trabajo De Ascenso.Universidad Simón Bolivar. Caracas, Venezuela (1986). 87-88.

33 Leonardo Benevolo, Historia Da Arquitetura Moderna (Tradução De Ana M. Goldberger) São Paulo: Editora Perspectiva, 2001). 92-98,

34 Richard Sennett, Carne y Piedra: El Cuerpo y La Ciudad En La Civilización OccidentalAlianza editorial, 1997). 340,344 
basándose en el principio del parque, como pulmón, pero adaptado a una ciudad con más velocidad. Para Regent's Park aunque espacio grande con hierba y árboles - una invitación a acudir al parque en la época victoriana- John Nash quiere impedir dicho uso y protegerlo de los ciudadanos. La calle que rodea el parque, Outer Circle, con un considerable tráfico a gran velocidad supone un muro que lo protege de los ciudadanos. En 1835 el parque abre al público sólo dos días cada semana. ${ }^{35}$

El Plan de Hausmann es el ejemplo de la urbanística neoconservadora; ${ }^{36}$ en Barcelona se encuentra en el trazado del Plan Cerdà en $1859^{37}$ y también, en el de Lindhagen para Estocolmo en $1866 .{ }^{38}$ En Madrid, poco después del Plan Cerdà, se realiza el Plan de Castro, en 1860. La reforma de la ciudad de Madrid era obligatoria por las mismas razones: los límites físicos de la ciudad que habían sido marcados en el siglo XVII por Felipe IV, eran muy reducidos para alojar a las personas que llegaban a la ciudad ante la escasez de las viviendas. Con el plan de Castro la ciudad se extiende fuera de la cerca Felipe IV; además, Castro fija las primeras reglas de la edificación, como la máxima altura de los edificios, la configuración de las manzanas, la anchura de las calles y las leyes para las condiciones higiénicas de las viviendas. Por el ensanche de Castro aparecen los cuatro barrios de Madrid: Salamanca, Chamberí, Retiro y Arguelles. El plan Castro tenía diferencias respecto al de Cerdà, sin embargo era también un plan racional, con calles jerarquizadas y trazado hipodámico. ${ }^{39}$ Una de las diferencias de los trazados yace en la segregación social. Cerda partió de la división de las clases para su ordenamiento de la ciudad: barrio fabril e industrial (Barrio de Chamberí), barrio

\section{$35 \quad$ Ibid.346-347}

36 Leonardo Benevolo, Historia Da Arquitetura Moderna (Tradução De Ana M. Goldberger) São Paulo: Editora Perspectiva, 2001). 114

37 Plano importante sobre el ensanche de Barcelona de la misma época de Cerdà fue el que ganó el primer premio de un concurso que se convocó en aquella época: el plan de Rovira, que no se realizó. El planeamiento del ensanche de Cerdà proponía una ciudad cuadriculada basada en el sistema hipodámico mientras que el de Rovira planteaba una ciudad radial que rodeaba la ciudad antigua amurallada, con centro en la plaza de Cataluña, desde donde se extendían las calles-radios del perímetro circular. Hablamos pues de un planeamiento cercano al de Hausmann o del contemporáneo "ring” de Viena. Sin embargo, el plan de Rovira se consideró un proyecto convencional y poco imaginativo Ibid. 23,-un modelo radioconcéntrico que polarizaba la accesibilidad en un centro privilegiado. "El Caso Del Plan Cerdá | Opinión | EL PAÍS “, accessed 1/12/2016, 2016, http://elpais.com/elpais/2014/02/06/opinion/1391701528 507912.html.

38 Leonardo Benevolo, Historia Da Arquitetura Moderna (Tradução De Ana M. Goldberger)

São Paulo: Editora Perspectiva, 2001). 114

39 Richard Sennett, Carne y Piedra: El Cuerpo y La Ciudad En La Civilización Occidental Alianza editorial, 1997).
En Barcelona, se realiza el Plan Cérda en 1859, en Madrid el Plan Castro en 1860

La diferencia de ambos planes yace en la segregación social 
Garnier optaba por una ciudad ideal en la que no existiría propiedad privada, murallas ni policia
Antonio Sant'Elia redacta el Manifiesto de la Arquitectura y La Ciudad Nueva, una ciudad desnuda
Robert Owen inagura una ciudad -jardin: industria y naturaleza en armonia aristocrático (ambos lados de la Castellana), barrio de clase media para la burguesía (Barrio de Salamanca), barrio de la clase menestral y obrera (al sur de la calle Alcalá) ${ }^{40}$.

Garnier quería construir un mundo donde la naturaleza, los seres y los objetos vivieran con armonía; en 1904 presenta su proyecto de La Ciudad Industrial en la que aparece su creencia de que la ciudad del futuro tiene que ser una ciudad industrial; una sociedad socialista, sin murallas, sin propiedad privada, sin iglesias ni comisaría de policía, ni tribunales de justicia; un lugar donde el espacio no construido es parque público. Sin embargo, una ciudad sin policía y sin tribunales de justicia es una ciudad sin jerarquía, sin clasificaciones; son ciudades de un urbanismo irregular como la propia vida que, sin embargo, es capaz de funcionar con sus contingencias y sorpresas. La ciudad industrial es demasiado jerarquizada y ordenada de un pueblo con un nivel intelectual tan alto como para poder convivir sin vigilancia; la ciudad industrial es una ciudad esterilizada, en la que nada se mezcla con nada y todo tiene su lugar y su uso. ${ }^{41}$

Antonio Sant'Elia proyecta una ciudad desnuda centrada en los nuevos materiales, y la innovación de la estructura y su funcionalidad. Influenciado por Marinetti, redacta su Manifiesto de la Arquitectura Futurista en el que es obvia su necesidad de romper los vínculos con el pasado y convencer a la sociedad y a los arquitectos de las nuevas formas de vida y los nuevos materiales. Ante los valores italianos clásicos, caducos, proclamaba la primacía cultural de un entorno mecanizado que más tarde influiría igualmente en la estética arquitectónica del futurismo italiano y del constructivismo ruso ${ }^{42}$. La Ciudad Nueva está invertida: lo que antes se quedaba oculto, algo que no se debería ver y tenía un carácter utilitario, ahora sale al exterior del edificio, en sus fachadas. En los espacios públicos de la ciudad, las vías adquieren enorme importancia, organizándose en varios niveles y tipos para poder ser la circulación lo más rápidas y cómoda.

Las Ciudades Jardines empiezan con la figura de Robert Owen en su Comunidad Perfecta de la Comunidad Nueva Armonía; una ciudad autosuficiente en la que la naturaleza y la industria están en armonía y la familia encuentra su privacidad en casas unifamiliares con jardín lejos del ruido de la metrópoli. El término ciudad-jardín se

$40 \quad$ Ibid.

41 Jorge Sáinz Avia and Kenneth Frampton, Historia Crítica De La Arquitectura Moderna (Barcelona: Editorial Gustavo Gili, S.L., 2007).

$42 \quad$ Ibid.87. 
encuentra por primera vez en la ciudad ideal y futura de Sir Ebenezer Howard (18501928) en Tomorrow, a peacefulpath to real reform, una ciudad autosuficiente y autogestionada, en la que el terreno es gestionado por una sociedad anónima propietaria del terreno pero no de las viviendas; una ciudad con un equilibrio entre la agricultura y la industria, en una sociedad en la que los ciudadanos son libres para regular sus vidas y negocios. En 1902 se encuentra la primera sociedad en la construcción de la ciudad jardín de Letchworth, a 50 kilómetros de Londres. ${ }^{43}$ La fascinación por la industria, las maquinas, los coches y la velocidad conduce a un pensamiento de la ciudad basado en el transporte más que en la vida de la gente. Progresivamente, la calle es para los vehículos y los peatones pierden el derecho de la calles. Arturo Soria, la Ciudad Lineal del modelo urbanístico lineal, no tiene ningún precedente de un pensamiento nacido en la época Industrial, ya que, nunca antes, la ciudad fue pensada a partir de las carreteras, sino desde el peatón que era la prioridad. La Ciudad Lineal de Arturo Soria, propuesta en 1882, se adapta tanto a la carretera, que se convierte en una carretera; una ciudad de ancho limitado, y longitud ilimitada, dividida en dos, sin profundidad, recorrida por una o varias líneas ferroviarias; en la ciudad lineal, la gente sigue la función.

Le Corbusier en la Ciudad Radiante, centra su interés en la residencia y toda la ciudad se construye en torno a ella. Las construcciones y las autopistas, se elevan sobre pilotis de forma que el terreno queda libre. Le Corbusier está a favor de una nueva arquitectura industrializada, como revela su famosa frase la casa es una máquina para habitar ${ }^{44}$. La Ciudad Radiante verifica la frase de Le Corbusier, pues las viviendas de esta ciudad son tan pequeñas como las de un coche-cama, wagon-lit. Frampton sostiene que la Villa Radiante se orienta en los criterios económicos de la producción en serie mientras que el Immeuble-Villa se basa en el empleo cualitativo de la casa con jardín colgante, con amplia terraza ajardinada y sala de estar de doble altura con dimensiones fijas independientes del número de los miembros de la familia. En la Ciudad Radiante lo fundamental son los parámetros cuantitativos de la producción en serie: un piso flexible de una sola planta, más económico en cuanto al espacio, aprovechando al máximo cualquier centímetro cuadrado de espacio; con cocina y cuarto de baño reducidos al

$44 \quad$ Ibid. 185

La Ciudad Lineal, propuesta por Arturo Soria en 1882 es de ancho limitalado y longtitud ilimitada

En la Ciudad Radiente de Le Corbusier, las casas son maquinas para habitar 
mínimo y tabiques de un espesor tan reducido que son inadecuados para la protección acústica. La Ciudad Radiante supone una innovación en la historia de la arquitectura. ${ }^{45}$ Le Corbusier propone la creación de carreteras anchas para los coches con fácil circulación; el peatón no tiene calles sino un espacio cartesiano, homogéneo e infinito, desde el que puede ver todo y puede ser visto por todos. El espacio público, de encuentro, a partir de Le Corbusier se haya cada vez dentro de los edificios. En sus conferencias Le Corbusier defiende la muerte de la calle, de los pasillos, de los pasajes y de los patios porque las calles son para los coches. Escribe en sus Precisiones, en la presentación del Plan Voisin bajo el título, Buenos Aires puede convertirse en una de las ciudades más dignas del mundo,

Se derruban grandes partes de la ciudad para ponerlas en orden y hacerlas habitables
En principio, limpiaremos en terreno: Hay que matar la "calle-pasillo". No se entrará, realmente, en el urbanismo moderno sino después de esta decisión previa. (...)Las "calles - pasillos" hacen las "ciudades - pasillos". iQué aspecto! iQué estética! No decimos nada, pero lo sufrimos. (...) iPodriamos, podemos suprimir todos los pasillos! (...) empuñando a todo lo que bordea la calle, reduciendo a cero los patios, apilando en altura los edificios, disponiéndolos éstos en cruz. (...) se pueden totalizar las superficies de patios y extenderlas en espacios libres, a la izquierda y a la derecha de las calles. ${ }^{46}$

Poner en orden la ciudad y construir grandes bulevares, requiere una planificación previa. La geometría es el arquetipo de la modernidad, dice Bauman, y la rejilla más que nada: por eso Mondrian es el más famoso de los artistas visuales de la época. ${ }^{47}$ Para Haussmann, la geometría y el dibujo gráfico desempeñan un papel más importante que la estructura propiamente dich $a^{48}$. Para transportar lo diseñado a la realidad con exactitud, el paisajista Jean Pierre Barillet Deschamps no duda en derrumbar gran parte de la ciudad medieval

\footnotetext{
45 Corbusier, Precisiones Respecto a Un Estado Actual De La Arquitectura y El Urbanismo Trad 90

46 Ibid. 194

47 Zygmunt Bauman et al., "Modernidad y Ambivalencia," in Las Consecuencias Perversas De La Modernidad. Modernidad Contingencia y Riesgo (Barcelona, España: Anthropos, 1996), 91 48 «Transformación De París Durante El Segundo Imperio,» Wikipedia, The Free Encyclopedia, 2015
} 
y renacentista para construir nuevas fachadas uniformes con calles rectas y anchas, capaces de soportar la nueva velocidad de la época moderna. Haussmann no perturbó solo a los vivos sino también a los muertos cuando dividió el cementerio para realizar el trazado de las calles como en el caso de la calle Caulaincourt; este proyecto despertó fuertes oposiciones porque expresaba de manera patente cómo la nueva geografía parisina de la movilidad violaba rodas los aspectos de la vida urbana ${ }^{49}$. Construyó grandes monumentos - como la Opera de París - y espacios públicos y rediseñó parques en la ciudad. De la misma manera, John Nash, fijando la prioridad en la rápida circulación de los carruajes, no dudó en eliminar los edificios dispersos que obstaculizaban la fluidez.

Sin embargo, en el comienzo de la modernidad, no solo el factor de la velocidad define el dibujo de la ciudad, sino también el factor del control para que no se perturbe el orden diseñado. En la modernidad, el orden no es otro orden sino tan sólo el es caos; no hay otra alternativa, los tropos orden es la incertidumbre, lo desconocido, lo imprevisible, la confusión, la ambigüedad, lo irregular. Sin embargo, el caos es la pura negatividad del orden; el caos se construye mientras se levanta el orden: sin el uno, no puede existir el otro. Lo que cambia en la concepción del control en la modernidad es que la única alternativa es orden-caos. Para evitar el caos, se hace urgente el diseño. ${ }^{50}$ La modernidad se caracteriza por su constante lucha para mantener el orden y evitar encuentros con lo repentino y lo irregular como enemigos del orden.

Las calles anchas ayudan en el control de la ciudad. Para Haussmann los grandes bulevares dificultan las revoluciones de los ciudadanos y aseguran la tranquilidad. Decía, Hauman,

Asegurar la tranquilidad pública por la creación de grandes bulevares, que dejarían circular no solamente la luz, más las tropas y, por una ingeniosa combinación, darian mejoras al pueblo y menos disposición para la revuelta ${ }^{51}$.

Friedrich Engels en el nombre Haussmann entendía la práctica generalizada de

49 Richard Sennett, Carne y Piedra: El Cuerpo y La Ciudad En La Civilización

OccidentalAlianza editorial, 1997). 354

50 Zygmunt Bauman et al., "Modernidad y Ambivalencia," in Las Consecuencias Perversas De La Modernidad. Modernidad Contingencia y Riesgo (Barcelona, España: Anthropos, 1996), 81

51 «De Las Abrumadoras Calles De Baudelaire a Los Fantasmagóricos Pasajes

De Benjamín (Página 2) - Monografias.Com «, accessed 1/12/2016, 2016, http:/ / www. monografias.com/trabajos55/baudelaire-y-benjamin/baudelaire-y-benjamin2.shtml.
Orden - caos, dualidad moderna

Las calles anchas protegen la ciudad de las revoluciones de los habitantes; facilitan la circulación de la luz y de las tropas. 
abrir brechas en los barrios obreros particularmente en los situados en el centro de nuestras ciudades (...). El resultado es en todas partes el mismo (...), las callejuelas y los callejones sin salida desaparecen, la burguesía se glorifica con un resultado tan grandioso; pero callejuelas y callejones sin salida reaparecen prontamente en otra parte y a menudo en lugares muy próximos. ${ }^{52}$ Sennet dice que Haussmann, para construir las calles, tenía ayudantes -llamados "geómetras urbanos"- que subían a altas torres de madera para poder trazar calles totalmente rectas con compás y regla sobre los antiguos muros de la ciudad. Los geómetras trazaban especialmente el norte y el noroeste, que eran para los obreros, los talleres y las pequeñas fábricas y Haussmann dividía así las comunidades de los pobres con bulevares. ${ }^{53}$

En Londres, en 1863, se instauró el primer metro del mundo de seis kilómetros

En Lóndres, en 1863, se instaura el primer metro del mundo; se aumenta la velocidad del transporte pero el habitante se transforma en topo.

El metro excluye a los pobres del centro de Lóndres de longitud; un medio mucho más rápido que el resto que transportaba a la gente por debajo de la tierra. Para Sennet, los ingenieros habían aprendido de las redes de Haussmann y el objetivo que tenían en la construcción del metro, era tanto llevar a la gente a la ciudad como sacarla de ella. Además de los sirvientes domésticos que vivían en los hogares de sus patrones, había un segundo ejército de trabajadores pobres, como administradores y empleados de menor categoría de la burocracia imperial y la ciudad, o trabajadores que servían a los hogares acomodados pero no compartían la vida familiar con sus patrones, que vivían en congestionados barrios del viejo Londres y en las zonas anteriormente habitadas por delincuentes; eran zonas de miseria masiva donde familias enteras compartían habitaciones individuales de casas pequeñas; casas donde la gente dormía en el mismo piso que en el que comía y donde el olor a orina y de heces impregnaba el interior ${ }^{4}$.

Lo que cambió con el metro -transporte público barato- es que facilitó a los pobres la salida fuera de Londres para poder vivir en casas de mejores condiciones, aunque no de buenas condiciones. Podría parecer que con el metro- funcionando como arteria y como vena - Londres se lograba una ciudad más mezclada, que conectaba a varias clases; pero, según Sennet la mezcla tenía limites bien definidos.

52 Marshall Berman, Todo Lo Sólido Se Desvanece En El Aire: La Experiencia De La Modernidad (Buenos Aires, Argentina: Siglo xxi, 1989). 149-150

53 Richard Sennett, Carne y Piedra: El Cuerpo y La Ciudad En La Civilización OccidentalAlianza editorial, 1997).350-354

54 Ibid. 356 
Durante el dia, la sangre humana de la ciudad fluía bajo tierra hacia el corazón. Por la noche, estos canales subterráneos se convertían en venas que vaciaban el centro, cuando la gente cogía el metro para ir a su casa. Con el tránsito masivo, según el modelo del metro, habia cobrado forma la geografía temporal del centro urbano moderno: congestión y diversidad por el dia, descongestión y homogeneidad por la noche. Y esa mezcla por el día no implicaba un contacto humano significativo entre las clases. La gente trabajaba y compraba, y después regresaba a su casa ${ }^{55}$.

Los grandes bulevares acompañan el distanciamiento entre las personas. Los grandes bulevares rompen los barrios y dividen la ciudad en barrios según clases. Antes la distinción de clases era vertical: más arriba los más pobres. Sin embargo a partir de los grandes jardineros baumanianos la división de la gente se hace de manera horizontal, dejando lejos los unos de los otros. Escribe Angel Ganivet,

la apertura de grandes calles en sustitución de calles pequeñas, trae consigo un encarecimiento artificial de la vida, una penalidad más agregada a las muchas penalidades que, por nuestra desgracia, llevamos ya a cuestas. Si alli donde vivian dos mil pobres edificaron casas que éstos no pueden continuar habitando, dicho se está que se les obliga a huir de aquel centro; y si la operación se repite varias veces, se llega, como si se le diera vueltas a la población dentro de un tamiz, a la separación de clases $^{56}$.

Según Bauman, la sociedad industrial y el orden social burgués pretenden convertir los contextos de la vida en estructuras controlables, tanto a nivel individual como jurídico ${ }^{57}$. Ambos necesitan estructuras controlables para poder mantener el orden. Lo que pone en peligro el orden y tiene que ser controlado es la ambivalencia, la contingencia, lo imprevisto y lo repentino. La mente separa el mundo en dos: el ordenado y el arbitrario, que cuando interviene en el ambiente ordenado lo intenta desordenar. Un mundo ordenado es para Bauman,

\section{$55 \quad$ Ibid. 360}

56 Ángel Ganivet and Miguel de Unamuno, Granada La Bella: Seguido De Las Ruinas De Granada (Madrid: Círculo de Bellas Artes, 2011). 82-83

57 Zygmunt Bauman et al., "Modernidad y Ambivalencia," in Las Consecuencias Perversas De La Modernidad. Modernidad Contingencia y Riesgo (Barcelona, España: Anthropos, 1996), 216
Las calles anchas dividen la ciudad en barrios según las clases sociales.

La mente separa el mundo en dos: mundo arbitrario mundo ordenado 
aquel en el que «uno puede saber cómo conducirse» (o, en el que uno sabe cómo informarse -e informarse para lograr seguridad-respecto a cómo conducirse), en el que uno sabe cómo calcular la probabilidad de un suceso y cómo aumenta o disminuye esa probabilidad; un mundo en el que la vinculación entre ciertas situaciones y la efectividad de ciertas acciones se mantiene constante, de modo y manera que se puede confiar en los sucesos pretéritos como referentes orientativos para el futuro ${ }^{58}$.

El mundo ordenado es aquel en el que uno sabe cómo conducirse. La ambivalencia desordena: distorsiona los calculos que nos ofrecen seguridad.
Venturi elogia la ambigüedad; prefiere el pensamiento de la letra "y" que él del dominio de la letra "o".
Nuestra capacidad de aprendizaje y memorización nos privilegia la capacidad de mantener este orden del mundo. Exactamente por eso, lo contingente, lo ambivalente y lo extraño, lo percibimos como amenaza, porque distorsionan los cálculos que nos ofrecen seguridad. El principal síntoma del desorden es el malestar que uno siente cuando es incapaz de interpretar correctamente una situación y debe elegir entre acciones alternativas; la ambivalencia la concebimos como un desorden porque provoca una inquietud y conlleva una indecisión ${ }^{59}$. Lo contingente (endexomeno) es lo que puede ser de un modo o de otro, lo que no es ni necesario ni imposible, un suceso que pasa de forma inesperada. Para Aristóteles lo contingente se contrapone a lo necesario. En la literatura lógica clásica es frecuente definir la contingencia como la posibilidad de que algo sea y la posibilidad de que algo no sea; en la tesis de Santo Tomás lo contingente es lo que puede ser y no ser (S. theol, I,q. LXXXVI, 3 c) ${ }^{60}$. Lo ambivalente es cualquier objeto, estado o concepto que entra en dos categorías distintas a la vez; lo que puede ser "lo uno y lo otro".

La modernidad es una era de combate encarnizado y despiadado contra la ambivalencia ${ }^{61}$; por eso la modernidad se caracteriza como la época de la letra "o"; en esta época "lo uno y lo otro" es un delito. Para Robert Venturi, la época de la modernidad es la época de la letra "o", comenta en su texto Niveles Contradictorios: El fenómeno "lo uno y lo otro"

\footnotetext{
$58 \quad$ Ibid. 74

$59 \quad$ Ibid. 73

60 José Ferrater Mora, Dicionário De Filosofia. TOMO I (A-K), Vol. 1 (Buenos Aires: Editorial Sudamericana, 1971).

61 Zygmunt Bauman et al., "Modernidad y Ambivalencia," in Las Consecuencias Perversas De La Modernidad. Modernidad Contingencia y Riesgo (Barcelona, España: Anthropos, 1996), 76
} 
en arquitectura $^{62}$. Venturi necesita y elogia la incertidumbre mientras que Le Corbusier busca las grandes formas primarias que no tienen ambigüedad. ${ }^{63}$ Venturi está a favor del fenómeno "lo uno y lo otro": "lo uno y lo otro" es el pensamiento de la inclusión mientras que "lo uno o lo otro" es el pensamiento de la exclusión. Venturi muestra el fenómeno de lo "uno y lo otro" en la escalera principal de la Academia de Bellas Artes de Pensilvania, creada por Frank Furness, en Filadelfia; una escalera demasiado grande en relación con lo que le rodea y dividida en dos por un pilar. Por estos motivos la escalera se podría considerar como un espacio malo pero no lo es porque su función es ceremonial y simbólica aparte de funcional; enfatiza en el acceso al hall y la conexión de este último con el resto del edificio. Si la aislamos de su contexto y analizamos lo que es, diríamos que es un lugar malo mientras que, si la dejamos dentro de su contexto y la vemos desde el todo, es un espacio bueno. Esto es uno de los varios ejemplos que analiza Venturi con el fin de mostrar que no existe ni lo malo ni lo bueno, sino que todo depende del prisma con el que observamos o vivimos las cosas; cuando un observador se mueve a través o alrededor de un edificio, y por extensión a través de una ciudad: en un momento dado un significado puede ser percibido como dominante; en otro momento un significado distinto parece más importante ${ }^{64}$.

El pensamiento de la exclusión, del "lo uno o lo otro", no acepta que una cosa puede ser mala y buena; lo que es malo no es bueno, lo que es grande no es pequeño. Sin embargo, (...) el fenómeno "lo uno y lo otro" (...) puede incluir elementos que son a la vez. buenos y malos, grandes y pequeños, abiertos y cerrados, continuos y articulados, redondos y cuadrados, estructurales y espaciales. ${ }^{65}$ Luis Kahn decía, como escribe Venturi, que la arquitectura debe tener tanto espacios malos como buenos ${ }^{66}$.

Sin embargo, una arquitectura que incluye diversos niveles de significado crea ambigüedad y tensión ${ }^{67}$ y por eso en los años de la modernidad se alejaron de cualquier elemento ambiguo: el "elemento de doble función" rara vez se encuentra en la arquitectura moderna. El fenómeno "lo uno y lo otro" no es lo mismo con el "elemento de doble 62 Robert Venturi, Complejidady Contradicción En La Arquitectura Editorial Gustavo Gili, 1974). 25

63 Le Corbusier, Towards a New Architecture (Londres: The Architectural Press, 1927).31

64 Robert Venturi, Complejidady Contradicción En La Arquitectura Editorial Gustavo Gili, 1974). 25

$65 \quad$ Ibid. 25

66 Ibid. 25

67 Ibid. 25
No existen lugares malos y lugares buenos; todo depende de la escala y el prisma con el que observamos.

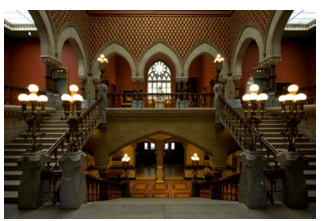

escalera principal de la Academia de Bellas Artes de Pensilvania

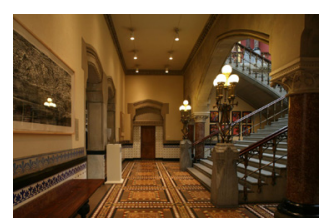

escalera principal de la Academia de Bellas Artes de Pensilvanio

El fenomeno "lo uno y lo otro" y el elemento de doble función crean ambigüedad. 
Elementos de doble función, reminiscente y retóricos son fundamentales para el cambio de la ciudad. Venturi

Forma-función es una dualidad inventada en los años de la modernidad función". El primero se refiere principalmente a los significados mientras que el segundo lo hace a las funciones; el primero se refiere a la relación del parte con el todo mientras que el segundo pertenece a los aspectos de uso y estructura. ${ }^{68} \mathrm{El}$ elemento de doble-función se encuentra en la arquitectura barroca y manierista; cornisas que son umbrales, ventanas que son nichos, cornisas que contienen ventanas, esquinas que son pilastras, arquitrabes que se hacen arcos. ${ }^{69}$ Un ejemplo de elemento de doble-función es la estructura balloon - estructura globo ${ }^{70}$ - de Sigfried Giedion; puede ser muchas cosas a la vez: puede ser tanto armazón como piel.

Venturi considera como elemento de doble función los elementos reminiscentes y los elementos retóricos; el elemento reminiscente es parecido al elemento de doble función: lleva consigo un significado antiguo pero combinado con un significado nuevo que ha conseguido, o le han dado, los nuevos contextos que lo han abrazado; y es un elemento fundamental para el cambio y el crecimiento de la ciudad como se manifiesta en la remodelación de los edificios antiguos a los que se les da unos usos nuevos, tanto de programa como simbólicos (como los palacios que pueden ser museos o embajadas) y en las calles antiguas con nuevos usos y escalas de movimiento ${ }^{71}$. El elemento retórico es un elemento que la arquitectura moderna nombra delito; por ejemplo, la escalera de la Academia de Bellas Artes de Pensilvania, en Filadelfia, es demasiado grande para su contexto inmediato pero es apropiada para su significación como entrada; gran parte de la función del ornamento es retórica. ${ }^{72} \mathrm{Y}$ añade Venturi en este momento, el elemento retórico, que también es estructural, es extraño en la arquitectura moderna, aunque Mies uso retóricamente la viga con una seguridad que hubiese envidiado Bernini ${ }^{73}$.

\footnotetext{
$68 \quad$ Ibid. 25

$69 \quad$ Ibid. 25

70 La estructura globo hasta 1870 se llamaba Construcción de Chicago y es la construcción de tablas delgadas de madera y pies derechos que recorren toda la altura del edificio y se mantienen unidos solo con clavos. Según Sigfried Giedion, la aparición de la estructura globo indica el momento que la industrialización llego a la casa Antes de la industria los clavos cortados de acero y hierro eran muy caros por lo que la construcción de una casa en la que se necesitaran muchos clavos sería muy cara, pero a partir del momento en que aparece ésta el precio de los clavos pasa de 25 centavos el medio kilo, a 3 centavos. De esta manera la construcción de la casa con la estructura globo era mucho más barata y mucho más fácil de construir que la de antes.Sigfried Giedion, Espacio, Tiempo y Arquitectura (Edición Definitiva): Origen y Desarrollo De Una Nueva Tradición, Vol. 17 (Barcelona: Reverté, 2009).352-358 71 Robert Venturi, Complejidad y Contradicción En La Arquitectura Editorial Gustavo Gili, 1974). 60

$72 \quad$ Ibid.62

73 Ibid.62
} 
La invención de la dualidad forma -función, portante-no portante y antiguo -nuevo, tiene lugar en los años de la modernidad. No es que la construcción premoderna desconozca la existencia de partes del edificio imprescindibles para la seguridad y otras que no la proporcionan pero, al no haber pronunciado esta separación, al no haber inventado esta dualidad, ninguna de las dos partes es menos importante. A partir de Derrida es conocido que el pensamiento binario -aquel que divide el mundo en pares de términos opuestos- jerarquiza: siempre uno de los dos polos domina. ${ }^{74}$ En el caso de la modernidad, los términos ganadores son portante, función y nuevo: la forma sigue la función y menos es más, son lemas de la época.

En Ruskin se encuentran las bases de la dualidad forma-función. En Las siete lámparas de la arquitectura pone las bases para el pensamiento de lo inútil, para la búsqueda de la verdad y la pureza. A partir de él empieza la necesidad de la crítica del arte y de la arquitectura bajo el criterio de la honestidad de su creador. ${ }^{75}$ Adolf Loos considera que el único fin verdadero de la arquitectura es la utilidad y que los edificios tienen que prescindir de cualquier ornamento. Años más tarde Adolf Loos denomina el Ornamento como Delito ${ }^{76}$; sus teorías arquitectónicas tendrán una influencia enorme en la profesión. Esta posición de Loos y el Ornamento y Delito llevan a las tácticas de la escuela de Bauhaus, de Le Corbusier, los CIAM y, principalmente, al minimalismo; en un mundo que esperará la desaparición de la arquitectura y del arte ya que no tendrá nada más que decir en un mundo reducido a la pura satisfacción de funciones ${ }^{77}$.

El plan hipodámico es el plan urbanístico más "sencillo" en el sentido de que crea una fácil parcelación del suelo en espacios regulares, ortogonales o cuadrados. Casi siempre los planos hipodámicos contienen calles diagonales para facilitar el acceso más rápido al centro desde la periferia ya que prolonga la longitud de trayectos. Lo inconveniente con el programa hipodámico es que crea paisajes homogéneos. La actividad urbanística de Berlage presenta la peculiaridad de que él siente la necesidad

\footnotetext{
74 Jacques Derrida, La Diseminación (España: Seuil, 2007).

75 Daniel Mielgo Bregazzi, Construir Ficciones: Para Una Filosofía De La

ArquitecturaBiblioteca Nueva, 2008). 281, John Ruskin, Las Siete Lámparas Dela Arquitectura

(Barcelona: Alta Fulla, 1988).

76 Adolf Loos et al., Ornamento y Delito y Otros Escritos (Barcelona: Gustavo Gili, 1972).

77 Daniel Mielgo Bregazzi, Construir Ficciones: Para Una Filosofía De La Arquitectura

Biblioteca Nueva, 2008). 281
}

La raíz de la oposición forma-función está en las Siete lamparas de la arquitectura de Ruskin; instaura el pensamiento de lo inutil, de la verdad y la pureza 
La vida es el desorden; el universo nace no por un Demiourgo que pone en orden el mundo, sino por el Bing Bang que desordena el momento mas ordenado de toda la física

La ambivalencia no se puede eliminar. La ambigüedad fomenta la flexibilidad útili. de huir de las cuadrículas monótonas. Más tarde los arquitectos holandeses criticarán lo inhumano de las planificaciones del Movimiento Moderno que ha creado lugares monótonos, homogéneos, para un hombre ideal. Así que Berlage proyecta un ensanche con red viaria que escapa de las cuadriculas monótonas. Sin embargo, proyecta las fachadas de los edificios con uniformidad y traza grandes ejes con toques monumentales. Ama los grandes ejes, las calles amplias y las perspectivas cerradas por palacios imponentes, escribe Gravagnuolo. ${ }^{78}$

Pero los paisajes homogéneos sin diferenciaciones agotan la vida; la reducen en algo controlable, en el que todo está previsto, sin extrañamientos y, por eso, sin acontecimientos; incita a la aparición del tedio urbano. La calidad de la vida disminuye por lo que la vida es: desorden. Las cosas pasan del orden al desorden y esa es la flecha del tiempo. La naturaleza tiende a desarrollarse siempre a un mayor desorden. Las condiciones iniciales del universo, creían desde antigua Grecia, eran un caos que alguien, el Demiurgo, puso en orden. Pero después del concepto de la entropía, el único momento de baja entropía debe ser el mismísimo principio, el Bing Bang: un momento sumamente ordenado, el momento más ordenado de toda la física. Y así, todo lo que vino después, no es más que un aumento del desorden. Nuestro universo empezó en un estado excepcionalmente ordenado. El rumbo natural es del desorden. Todo lo que vemos en nuestro alrededor, desde la formación de las estrellas hasta nuevas vidas, son todos pequeños epifenómenos, surferos cabalgando en la ola de desorganización creciente en el universo que define la diferencia entre el pasado y el futuro. ${ }^{79}$

La vida es el desorden y junto a ella, nosotros. La ambivalencia y lo contingente no se puede eliminar. El intento de evitar lo ambiguo y lo contradictorio, los elementos retóricos, reminiscentes y la doble función no han conseguido eliminarlo. Los arquitectos quieren evitar la ambigüedad pero la necesitan para dar flexibilidad. En el siglo XVIII, dice Venturi, existian los corredores y las habitaciones de única función pero, a partir de los arquitectos modernos, sucede que en vez de tener tabiques aparecen los muebles que de una parte limitan y definen los usos y de otra parte permiten el cambio; la

78 Benedetto Gravagnuolo, Historia Del Urbanismo En Europa 1750-1960, Vol. 14 (Madrid: Ediciones AKAL, 1998). 227

79 Fabric of the Cosmos: The Illusion of Time, 44, directed by Brian Greene 2011); Brian Greene, The Fabric of the Cosmos: Space, Time, and the Texture of RealityVintage, 2007). 
ambigüedad es la que permite el cambio. La ambigüedad válida fomenta la flexibilidad útißº . La ambigüedad es la que permite los cambios de uso porque, si todo está claro y delimitado, es rígido y no permite el cambio.

Los fenómenos sociales contemporáneos muestran que el pensamiento de la exclusión, del "o bien o", no ha conseguido ofrecer un ambiente seguro, cómodo, organizado, estable y sin accidentes. Al contrario, ha conseguido absolutamente lo contrario; vivimos en tiempos líquidos ${ }^{81}$; sumergidos en la ambigüedad, sin un lugar estable ni raíces. La utopía contemporánea es hacer la incertidumbre menos deprimente; cosa que la distancia de la antigua utopía ya que ésta es una versión liberalizada, privatizada e individual. Lo que diferencia las nuevas utopías de las antiguas es que las antiguas tenían un final, sin embargo, las nuevas son utopías sin fin. Las antiguas anunciaban que el progreso les llevaría a un instante en que el caso quede cerrado y la misión completada: el instante en que se pueda pensar en pasar el resto de la vida «viviendo felices y comiendo perdices, de aqui hasta la eternidad $\rangle^{82}$. Sin embargo, la caza, una vez probada, se convierte en una obsesión, una adicción; el becho de pensar que la cacería puede finalizar no es atractivo sino aterrador en una sociedad formada por cazadores, pues dicho final sólo puede ser entendido como una derrota personal y sólo puede conllevar la exclusión del cazador ${ }^{83}$. La utopía de los cazadores - de los seres humanos posmodernos según Bauman - es una utopía rara, sin final;

Las antiguas utopias adquirían sus magnéticos poderes gracias a que prometian que los duros trabajos tendrían un final; la utopía del cazador es el sueño de un trabajo sin final. Una utopía extraña y poco ortodoxa, pero utopía al fin y al cabo, que promete el mismo premio inalcanzable que propusieron todas las utopias, una solución radical y postrera para las penas y los dolores de la condición humana pasados, presentes y futuros. Es poco ortodoxa, pues ha trasladado el escenario de las soluciones y los remedios del «más allá», al «aquí y ahora». En vez de encaminarse "hacia" la utopia, a los cazadores se les ofrece vivir "dentro" de una utopia. Para los jardineros, la utopia suponía el final del trayecto; para los cazadores, en cambio, es el camino mismo. Los jardineros visualizaban el final del trayecto como la $80 \quad$ Ibid. 53

81 Bauman Zygmunt, Tiempos Liquidos. Vivir En Una Época De Incertidumbre.Argentina, Editorial Tusquets (2007).

$82 \quad$ Ibid. 152

83 Ibid. 152
La utopia contemporánea es hacer la incertidumbre menos deprimente.

Lo que distingue la utopías antiguas de las contemporáneas es que las primeras tienen fin; las nuevas son utopías $\sin$ fin 
vindicación y el triunfo último de la utopía. Para los cazadores, el final del camino sólo puede ser entendido como la derrota ignominiosa y última de la utopía ${ }^{84}$.

Sea o no sea un infierno vivir entre cazadores lo que parece seguro es que es una respuesta que la contesta cada uno. Desde siempre tanto el infierno como el paraíso han sido lugares habitables y, aunque en el primero no se presuponga una buena vida, Italo Calvino da maneras para vivir mejor en él

El infierno de los vivos no es algo por venir; hay uno, el que ya existe aqui, el infierno que habitamos todos los días, que formamos estando juntos. Hay dos maneras de no sufrirlo. La primera es fácil para muchos: aceptar el infierno y volverse parte de él hasta el punto de dejar de verlo. La segunda es riesgosa y exige atención y aprendizaje continuos: buscar y saber quién y qué, en medio del infierno, no es infierno, y bacer que dure, y dejarle espacio» ${ }^{85}$.

La vida, el mundo, la ciudad y la casa se hacen infierno cuando alguien intenta ordenarlas. Ordenar requiere siempre los actos de la inclusión y exclusión; excluir es algo doloroso y, por eso, el pensamiento binario, pensamiento del "o bien o", hiere la vida. La elección de la inclusión en vez de la de exclusión, hace la vida menos dolorosa, más agradable. La ambigüedad no se eliminará con ninguna de las dos; vivir es estar dentro de la ambigüedad continua porque vivir es elegir ${ }^{86}$

$84 \quad$ Ibid. $152-153$

85 Italo Calvino, Las Ciudades Invisibles (Barcelona: Minotauro, 1983).

86 Ángel Gabilondo, Artesanos De La Belleza De La Propia Vida / Crafters of the Beauty of the Life itself(Barcelona: CCCB, 2010). 21 


\section{Con el arquitecto suspendido del siglo XXI}

\begin{abstract}
No hay que escuchar a los arquitectos lo más minimo. Es una profesión respetable, claro, pero no muy creíble. Hemos hecho las ciudades que hemos visto... $O$, por lo menos, hemos sido la punta de lanza del liberalismo más soez. Hay que escuchar al vecino y sus necesidades y transformarlas en elementos, en arquitecturas $y$ en ciudades. ${ }^{1}$
\end{abstract}

Andrés Cánovas

En los centros docentes de España, cuando un alumno no aprueba una asignatura se dice que ha suspendido o está suspenso; suspender, según la Real Academia Española, es levantar, colgar o detener algo en alto o en el aire, detener una acción por un tiempo, privar temporalmente a alguien del sueldo y negar la aprobación a un examinando basta nuevo examen. ${ }^{2}$ En el idioma griego lo suspenso es meteoro ( $\mu \varepsilon \tau \varepsilon \dot{\varepsilon} \omega \varrho o) ;$ los términos meteorito y meteoro derivan de dicha palabra. Para la astronomía, el meteoro es el fenómeno luminoso que se produce cuando un meteroide atraviesa la atmósfera. Suspenso es lo que queda suspendido, detenido en un lugar intermedio, y también lo admirado y perplejo. ${ }^{3}$ Suspender a un alumno significa situarle en un lugar liminal, entre lo desconocido y lo conocido, entre lo correcto y lo incorrecto; en una situación indefinida, en un estado donde yace el des-cubrimiento: lo desconocido no es lo inexistente, es lo que existe cubierto, y espera en el mismo lugar donde el alumno está cuando se le niega el aprobado. El estado de suspensión puede ser de naturaleza liminal o marginal. Lo liminal es, según Víctor Turner, aquello que está fuera de cualquier estructura social porque está entre ellas; el estado en que uno se encuentra cuando no pertenece a ninguna sociedad, saliendo de una y entrando en otra; es el lugar de la potencialidad, donde todo está abierto, todo

1 “Tendiendo puentes entre arquitectura y sociedad. La Ciudad Viva", accessed 1/12/2016, 2016, http://www.laciudadviva.org/blogs/?p=10859.

2 De la Lengua Española, Diccionario, "Real Academia Española," Vigésima 1 (2001).

3 Ibid. 
Gropius suspende a los pioneros del Movimiento Moderno; los caracteriza como monstruos

Le Corbusier: Se piden hombres inteligentes, frios y tranquilos para construir la casa, trazar la ciudad.

Cincuenta años despues de su muerte Le Corbusier se caracteriza como un fascista frances por la falta de sensibilidad frente a la vida humana puede ser y desde donde surgen nuevas sociedades. ${ }^{4}$ La marginalidad se refiere a los grupos que, aun siendo habitantes permanentes del entre, se encuentran fuera de toda estructura social, sin posibilidad de entrar en ninguna.

Los arquitectos, desde Hausman y Nash y hasta los pioneros de CIAM comparten lugar con el alumno suspendido; Gropius caracteriza a los pioneros del Movimiento Moderno, incluyéndose a sí mismo, como monstruos 5 , por no ser sensibles a la vida más allá de lo biológico e intentar glorificar la máquina.

"La casa es una maquina" esboza la imagen de los primeros pioneros como seres bumanos de concepciones rígidas y mecánicas, adictos a la glorificación de la máquina e indiferentes en intimar los valores bumanos ${ }^{6}$.

El arquitecto se transforma a partir de Le Corbusier en una figura fría. Se piden hombres inteligentes, fríos y tranquilos para construir la casa, para trazar la ciudad', escribe en el tratado Hacia una Nueva Arquitectura. Coincidiendo con la conmemoración de los 50 años del fallecimiento de Le Corbusier, realizándose exposiciones en todo el mundo, se publican en Francia tres libros que le presentan como un frio fascista francés. Marc Perelman, arquitecto y filósofo, autor del libro Urbs ex machina, Le Corbusier publicado en 1986, presenta su nuevo libro Le Corbusier, une froide vision du monde; Xavier de Jarcy, periodista especializado en arquitectura en la revista Télérama, publica en Abril de 2015 su libro Le Corbusier. Un fascista francés y Seuil François Chaslin, arquitecto y crítico, publica la obra Un Corbusier. Distintos investigadores, profesionales, filósofos y sociólogos critican el Movimient Moderno por la situación a la que ha dado lugar en las ciudades informales, los slums y las ciudades homogéneas de sociedades tediosas.

Los arquitectos y las arquitectas, en general, no son culpables de la configuración

4 Victor Turner, "Frame, Flow and Reflection: Ritual and Drama as Public Liminality," Japanese Journal of Religious Studies (1979), 465-499.466

5 Walter Gropius, The Scope of Total Architecture (New York, Estados Unidos: Collier, 1970).86

$6 \quad$ Ibid. 86

7 Le Corbusier and Josefina Martínez Alinari, Hacia Una Arquitectura (Barcelona, España: Ediciones Apóstrofe, 1998).100 
de las ciudades ni de su distanciamiento de la sociedad; las ciudades contemporáneas son el resultado de decisiones políticas. Si la política es, según Aristóteles, la ciencia suprema organizadora de la totalidad de la actividad humana ('ciencia arquitectónica') que establece leyes para la ciudad ${ }^{8}$, podríamos claramente decir que la arquitectura es una ciencia supeditada a otra suprema. La culpa de los arquitectos y arquitectas no radica en su falta de conocimiento técnico, sino en quedarse fuera del conocimiento sociológico. Su atención exclusiva a la técnica no les permite tener una visión holística de lo que está sucediendo en la modernidad. El arte de pensar sociológicamente ofrece, al contrario que el sentido común basado en las propias experiencias, una visión mediante redes de relaciones. Cada uno de nosotros es el actor de su propia vida o, como dice Bauman, sabe que es el autor de sus propias acciones. Todo lo que hacemos es efecto de nuestras intenciones, esperanzas y aspiraciones. Hacemos lo que hacemos para alcanzar las cosas que deseamos. Naturalmente, como dice Bauman, la forma de pensar acerca de nuestros actos es el modelo para explicar toda acción que no sea nuestra.

Uno se explica esos actos imputando a los demás intenciones que conoce a partir de su propia experiencia. Esa es la única manera que tenemos de explicar el mundo humano que nos rodea. Tenemos una tendencia a percibir todo lo que acontece en el mundo como la consecuencia de la intención de alguien. ${ }^{9}$

Los seres humanos piensan que detrás de cualquier suceso siempre hay alguien responsable, el efecto de una acción intencional. El poder de la visión personalizada del mundo que nos rodea- que parece ser lo que llamamos el sentido común -depende mucho de lo autoevidente, de lo que consideramos como dado y nunca cuestionamos. Esto yace en la vida rutinaria y repetitiva. Nuestros movimientos habituales y rutinarios no necesitan mucho autoexamen ni autoanálisis. La repetición de las cosas, como dice Bauman, se hace familiar: y lo familiar es autoexplicativo: no presenta problemas, no despierta curiosidad, funciona solo y de alguna manera es invisible. La familiaridad es 8 Aristóteles, Metafísica (Madrid: Editorial Gredos, 1994). A, 2 982a 18

9 Zygmunt Bauman and Tim May, Pensando Sociologicamente Ediciones Nueva Visión, 1994).21
Los arquitectos $\mathrm{y}$ arquitectas no son los responsables de la configuración de las ciudades; los edificios son productos políticos
El Arte de pensar sociologicamente 
La sociología se presenta como un intruso

La figura del arquitecto en la historia representa la evolución del pensamiento .

Todos somos arquitectos enemiga acérrima de la curiosidad y la crítica y, por ende, de la innovación y el coraje de cambiar ${ }^{10}$. La sociología se presenta como un intruso; como un extranjero que hace preguntas que los nuestros, los que son como nosotros, no harían porque son como nosotros; repiten y viven las cosas desde dentro sin salir fuera y sin cuestionamiento; la sociología es, según Bauman, el intruso que viene a desfamiliarizar lo familiar. De pronto la forma de vida habitual es puesta en tela de juicio; y desde ese momento parece ser sólo una de las formas de vida posibles, no la "natural" y tampoco la únical. La incapacidad de salir fuera de las formas políticas de su época dejó a los arquitectos atrapados en sus costumbres, donde domina la letra O; pensar en "o esto o lo otro"; viendo solo una forma de vida en lugar de las posibles, atraído por el orden y la industria. Alejado del habitante, produce en masa, ciudades homogéneas bajo los órdenes de la soberanía.

La figura del arquitecto atraviesa los tres movimientos del pensamiento humano desde su comienzo hasta la actualidad : antes de la modernidad, el arquitecto representa al guardabosques para quien el orden está impuesto por Dios y la Naturaleza y él está para protegerle; en la modernidad, se convierte en jardinero: utopistas y grandes planificadores; consideran que el orden en el mundo no está impuesto sino que ellos son los responsables del orden del mundo; hoy en día, es el cazador que no le interesa el orden sino encontrar lugares inexplorados para construir. El arquitecto, pasa de ser un maestro que intenta organizar y facilitar la vida con su trabajo a ser un constructor de utopías materializadas o no, constructor de ficciones ${ }^{12}$; sale fuera de la ciudad para observarla pero se sale de la sociedad; se limita al espacio físico geométrico abstracto y no atiende a los movimientos y cambios que suceden en la sociedad; en los años contemporáneos es un cazador solitario o miembro de un grupo a la búsqueda de nuevos terrenos para construir.

En un principio la figura del arquitecto era la de un organizador de la vida, por lo que en principio, todo ser humano podía ser arquitecto. El término arquitecto procede de las palabras arche y techne, que significa principio y arte; techne en antiguo

$10 \quad$ Ibid.21

$11 \quad$ Ibid. 21

12 Daniel Mielgo Bregazzi, Construir Ficciones: Para Una Filosofía De La Arquitectura Biblioteca Nueva, 2008). 
griego es producir; según Heidegger,

producir se dice en griego techne. A la raíz tec de este verbo pertenece la palabra techne, técnica. Esto para los griegos no significa ni arte ni oficio manual sino: dejar que algo, como esto o aquello, de este modo o de este otro, aparezca en el presente. Los griegos piensan la techne, el producir, desde el dejar aparecer. La techne que hay que pensar así se oculta desde bace mucho tiempo en lo tectónico de la arquitectura (.... $)^{13}$

En su inicio, el arquitecto parece ser cualquier persona que ejerce una actividad que requiera saber organizador; comienza con la imagen de un maestro, artesano. A partir de Vitruvio y con Alberti el arquitecto debe tener una formación transversal; según Vitruvio,

(...) quien confiese ser arquitecto (...) es conveniente que sea ingenioso e inclinado al trabajo, pues no es posible llegar a ser un diestro arquitecto si posee talento pero carece de conocimientos teóricos, o viceversa. Conviene que sea instruido, bábil en el dibujo, competente en geometría, lector atento de los filósofos, entendido en el arte de la música, documentado en medicina, ilustrado en jurisprudencia y perito en astrología y en los movimientos del cosmos ${ }^{14}$.

Alberti dice,

el arquitecto (architectore) será aquel que con un método y un procedimiento determinados y dignos de admiración haya estudiado el modo de proyectar en teoría y también de llevar a cabo en la práctica cualquier obra que, a partir del desplazamiento de los pesos y la unión y el ensamble de los cuerpos, se adecue, de una forma hermosísima, a las necesidades más propias de los seres humanos ${ }^{15}$.

13 Martín Heidegger, Construir, Habitar, Pensar. Traducción De EUSTAQUIO BARJAU. Conferencias y Artículos, Serbal, Barcelona.1994 (. 127-142

14 Marco Lucio Vitruvio, Los Diez Libros De Arquitectura (Madrid: Alianza Editorial, 1997).

15 Leon Battista Alberti, De Re Aedificatoria (Madrid: Ediciones Akal, 1991). (del Proemio) 
La figura del arquitecto a partir del Renacimiento empieza a aproximarse la del Demiurgo

El Creador-Demiurgo, el ser que habita entre las ideas y la materia

La arquitectura fue pensada como representacion del espacio; a partir del siglo VII es la determinación del espacio.
Del Renacimiento al Barroco la figura del arquitecto empieza a aproximarse a la del Demiurgo, del Creador del mundo: el demiurgo, dios artesano, causa activa, inteligente y productora del cosmos ${ }^{16}$. Hasta los filósofos presocráticos Dios fue visto como la praxis poética que convierte la esencia no formada del caos en el cosmos, de especie material. El Dios (praxis) presocrático se ubica dentro de la naturaleza y desde dentro ordena el cosmos. A partir de El Timeo de Platón empieza la configuración de los mundos desde fuera. Platón "ve" al Creador miniaturizando el cosmos: ubicado fuera y por encima de la naturaleza; él no pertenece al sistema de las interacciones de los entes, que constituye la naturaleza; opera para este sistema pero no sucede eso al revés ${ }^{17}$.

El Creador - Demiurgo es un mediador que se encuentra entre las ideas y las cosas, entre lo inteligible y lo tangible. El creador se ubica en el medio, entre las ideas y la materia y teniendo como modelo el mundo de las ideas, ordena la materia en el espacio siguiendo el modelo eterno $(. . .)^{18}$. El demiurgo, que según Argán es

un hombre que es presa del delirio sagrado puede sufrir visiones - fantasmas - que le permitan superar los limites del conocimiento racional, ya sea que se trate de la adivinación que se refleja en la superficie del hígado, según la obra del demiurgo, o de las visiones bienaventuradas aprehendidas antiguamente por el alma arrastrada a seguir el cortejo de los Dioses. El mito del "soñador", del poeta y del inspirado, visitado por visiones superiores, presa del tormento de lo Ideal, no dejará, a partir de entonces, de acosar nuestra representación del Arte ${ }^{19}$.

Según Argán, la arquitectura hasta principios del siglo VII es pensada como representación del espacio; después, se plantea como determinación del espacio. El

16 Pablo Melogno, "La Cosmología y Teoría De Los Poliedros En Platón [En Línea]. Cibernous. 2002. Disponible En Web: Ht Tp," Cibernous.com/autores/platon/teoria/ciencial cosmolog.Html [Consultado En Linea: Febrero 2012] (. s/e, s/1, s/f. Pág. s/n. Se han quitado las mayúsculas a demiurgo y dios artesano.

17 Platón, Timeo, Introducción, Traducción y Comentarios, Kalfas Basilis, (Atenas: Polis, 1995).

18 Melogno, La Cosmología y Teoría De Los Poliedros En Platón [En Linea]. Cibernous. 2002. Disponible En Web: Ht Tp s/n.

19 François Jullien, La Urdimbre y La Trama, Vol. 1009 Katz Editores, 2008). 122 
arquitecto considera que está representando en su edificio una realidad que existe por fuera de sí mismo, una realidad objetiva; a partir del siglo VII el arquitecto no representa el espacio sino que es el que lo hace. ${ }^{20}$

En la época de los manifiestos arquitectónicos, a principios del siglo XX, es cuando la figura del arquitecto aparece como el indispensable, comenta Bregazzi. Los manifiestos son escritos que, a diferencia de los tratados renacentistas que aspiraban a sentar las bases de un consenso universal, cultivan la diferencia; cada vez intentan, a través de principios personales, presentar una arquitectura a diferencia de otra ${ }^{21}$. Previamente a los manifiestos de principios del siglo XX está el tratado urbanístico de Ebenezer Howard titulado Mañana: un camino pacifico a la reforma real (Tomorrow: a peaceful path to real reform) donde presentaba la utópica e ideal ciudad-jardín como solución al caos urbano moderno y al capitalismo. De esta forma, dice Bregazzi, Howard no solamente diseñaría una ciudad ideal sino también su funcionamiento politico interno, viendo en el caos de la urbe moderna y en el capitalismo la raíz de los males de la modernidad ${ }^{22}$. Este texto, es inicio de las siguientes presentaciones de ciudades ideales como La Ciudad Industrial de Tony Garnier (1917), La Corona de la Ciudad(1919) de Bruno Taut y más tarde los proyectos de Frank Lloyd Wright y Le Corbusier. Los ejemplos más representativos de los manifiestos arquitectónicos son los futuristas. Sant'Elia, con el Manifiesto de Arquitectura Futurista (1914), dice que el arquitecto debe romper con la suprema imbecilidad de la arquitectura moderna ${ }^{23}$. De muy similar ideología fue el tratado de Le Corbusier, Hacia una Nueva Arquitectura (1923), en el que celebraba la estética industrial y establecía cánones para la construcción como sus cinco puntos para la producción de viviendas a gran escala ${ }^{24}$. A lo largo del siglo XX se publican varios escritos en la misma línea como la de Adolf Loos, Crimen y Ornamento y la obra escrita de Frank Lloyd Wright. Los arquitectos ya no son sólo maestros; tienen que publicar sus obras, sus principios y llegar a crear algo diferente a los anteriores; no solo construyen

20 Giulio Carlo Argan and Liliana Rainis, El Concepto Del Espacio Arquitectónico Desde El Barroco a Nuestros Días (Buenos Aires: Ediciones Nueva Visión, 1973). 17- 18

21 Daniel Mielgo Bregazzi, Construir Ficciones: Para Una Filosofía De La Arquitectura Biblioteca Nueva, 2008).150-151

$22 \quad$ Ibid. 145

$23 \quad$ Ibid. 147

$24 \quad$ Ibid.149
Cuando aparecen los manifestos arquitectonicos el arquitecto se transforma en ser indispensable;capaz de ordenar el mundo.

Mañana: un camino pacifico a la reforma real ,la Arquitectura Futurista, Hacia una Nueva arquitectura, Crimen y Ornamento 
La figura de arquitecto según Gropius es la de un coordinador de distintas actividades
Arquitecto: Sirviente o Lider. La respuesta es simple: pon un "y" en el lugar del "o". sino que deben poder explicar sus principios en base a los cuales eligen las formas con las que producen. A partir de los manifiestos, el arquitecto se convierte en una profesión distinta del resto de la sociedad; como si Dios bubiese seleccionado al arquitecto para llevar a cabo una misión divina en un mundo decidido a anegar su talento, escribe Bregazzi a la escucha de La verdad contra el mundo por Frank Lloyd Wright.

Con Gropius la imagen del arquitecto se aleja de aquella del creador y se transforma en un coordinador de las distintas actividades que implica la construcción de los edificios ${ }^{25}$; con Gropius, la distancia entre sociedad y arquitecto disminuye. Esta idea social contrasta fuertemente con el trabajo del egocéntrico arquitecto prima donna que obliga a su fantasia personal sobre un cliente intimidado, creando monumentos solitarios de significación estética individual $^{26}$. W. Gropius se pregunta sobre la función del arquitecto, Arquitecto: Sirviente o Líder. La respuesta es simple: pon un "y" en el lugar del "”"27. Sostiene que en todo hay un camino intermedio: ni líder ni sirviente, sino los dos a la vez; líder y sirviente son momentos interdependientes. El arquitecto bueno, dice Gropius, debe servir a las personas y simultáneamente mostrar un verdadero liderazgo, tanto para guiar el cliente, como al propio grupo de trabajo. Utiliza la metáfora del médico y del paciente para explicar la relación arquitecto - usuario; los arquitectos tienen que hacer un diagnóstico para comprender las verdaderas necesidades que pueden estar detrás de los vagos sueños del cliente e intentar guiarle hacía una aproximación coherente y global. Cuando un hombre está enfermo desde luego no insistiría en decir a su médico como tratarle, pero, si esperamos tal confianza de nuestro cliente, aprendemos que los arquitectos son raramente tratados con el respeto otorgado a la profesión médica ${ }^{28}$. Y el arquitecto, para ganar tal confianza, tiene que ser lo suficientemente competente. Con Gropius, la distancia entre arquitecto y usuario se reduce, pero no se elimina.

En los años 50, con la tendencia hacia el humanismo, el interés se dirige hacia el individuo común. James M. Richards defiende el paso del hombre ideal al hombre

25 Walter Gropius, The Scope of Total Architecture (New York, Estados Unidos: Collier, 1970).76

$26 \quad$ Ibid. 85

$27 \quad$ Ibid. 87

28 Ibid. 85 
común; superar el modulor de Le Corbusier (1942), del hombre ideal, y centrarse en el hombre común de la cotidianidad. ${ }^{29}$ A finales de los 50 , los jóvenes arquitectos del CIAM: Alison y Peter Smithson, Aldo Van Eyck, Jacob, Bakema y Candilis, se posicionan en contra de las anteriores generaciones de CIAM (Le Corbusier, Sert, Van Eesteren, Gropius, Giedion) ${ }^{30}$. Consideran su modo de proyectar funcionalista; la función es prioritaria a la vida de los habitantes y el futuro usuario es un engranaje más de una máquina por diseñar. La aparición de los Team X supone un gran cambio: proponen un método de trabajo empírico y pragmático; los arquitectos se acercan a la sociedad y proyectan desde su interior. ${ }^{3 l}$ Ya no se generan manifiestos sino fragmentos, opiniones y ensayos de cada uno de los participantes.

En los años 50 comienzan a aparecer movimientos que están a favor de una arquitectura "bazlo tú mismo" y arquitectura sin arquitectos; el ambiente urbano es visto como obra de arte colectiva, sintesis creativa de todas las actividades bumanas ${ }^{32}$. El catalogo Arquitectura sin arquitectos (1964) de B. Rudofsky, intenta mostrar que, la arquitectura de los arquitectos no es capaz de construir la belleza de la arquitectura popular. Archizoom, Superstudio y el grupo UFO niegan el exclusivismo del arquitecto, renuncian a la producción e imposición de modelos de comportamiento e invocan a las capacidades creativas del usuario. Joseph Beuys y las propuestas de arte povera, afirman que todo el mundo es artista y están a favor de la participación de los habitantes. Christopher Alexander, con los patterns, parte de la idea de que todo el mundo puede ser arquitecto de su propio espacio; su objetivo es recuperar la capacidad individual y colectiva del hombre para diseñar su medio ambiente armónicamente con él mismo y la naturaleza circundante. John

29 José María Montaner, Después Del Movimiento Moderno, Arquitectura De La Segunda Mitad Del Siglo XX (Barcelona: Gustavo Gili, 1993).

30 a. Primera generación Protagonistas del Movimiento Moderno (1880-1894): W. Gropius, E. G. Asplund, Mies, Le Corbusier, E. Mendelsohn, G. T. Rietveld, H. Meyer, J. J. P. Oud, J. Duiker, R. Neutra, H. Schmidt, H. Scharoun, A. Lurgart... b. Segunda generación. (1894-1907). Alvar Aalto, J. H. Van der Broek, Buckminster Fuller, J. L. Sert, L. Costa, M. Breuer, A.Jacobsen, A. Roth, G. Terragni, E. Eiermann, J. Sakakura, K. Mayekawa, P. Johnson, O. Neimeyer, M. Brill.

c. Tercera generación. (1907-1923). La característica es conciliar voluntad de continuidad. Sir John Leslie Martin, A. E. Reidy, E. Saarinen, Kenzo Tange, G. Candilis, Coderch, Soltan, Bakema, Erskine. Ibid.

$31 \quad$ Ibid.10

$32 \quad$ Ibid. 48
A partir de los años cincuenta varios arquitectos buscan acercarse a la sociedad; trabajar desde dentro.

A favor de una Arquitectura sin arquitectos 
Arquitectura de la Información: nueva disciplina a partir de 1976
Arquitecto de Información: persona que crea la estructura para que otras encuentren sus trayectorias personales.
F.Turner estudia la ocupación ilegal del suelo y la autoconstrucción de nuevos poblados cerca de las grandes ciudades de Latinoamérica, y defiende el sentido común de una arquitectura en la que el habitante interviene en su configuración: un posible modelo autogestionario.

En 1976, cien años después de la primera conferencia del Instituto Americano de Arquitectos (AIA), el tema central fue la Arquitectura de la Información, presentado por Richard Saul Wurman, arquitecto, diseñador gráfico y fundador del conjunto global de conferencias $\mathrm{TED}^{33}$, quien en esta época era el máximo directivo de la conferencia anual del Instituto ${ }^{34}$; en el mismo año publica el libro Arquitectos de Información. Según Wurman,

\section{el arquitecto de información es el individuo que organiza los patrones inherentes en datos, haciendo claro lo complejo. Una persona que crea la estructura o el mapa de la información que permite que otras encuentren sus trayectorias personales al conocimiento. ${ }^{35}$}

La arquitectura de la información se refiere al proceso de visualización de la información mediante mapas, diagramas, sistemas de signos, websites y multimedias. ${ }^{36}$ Wurman usa el término de manera amplia, englobando todos los lenguajes de la ciudad y la ciencia de la señalética que, según Joan Costa, es una disciplina proyectual del diseño de comunicación visual que tiene por objeto hacer los espacios de acción de los individuos inteligibles y fácilmente utilizables ${ }^{37}$. Según Wuman, la arquitectura de la información es una

33 TED Tecnología, Entretenimiento, Diseño (en inglés: Technology, Entertainment, Design) es una organización sin fines de lucro dedicada a las "Ideas dignas de difundir" (del inglés: Ideas worth spreading) es ampliamente conocida por su congreso anual (TED Conference) y sus charlas (TED Talks) que cubren un amplio espectro de temas que incluyen ciencias, arte y diseño, política, educación, cultura, negocios, asuntos globales, tecnología y desarrollo, y entretenimiento. "Holometabolismo," Wikipedia, The Free Encyclopedia, 2016, https://es.wikipedia.org/wiki/Holometabolismo.

34 "Richard Saul Wurman: Technology, Entertainment, Design | Roy Christopher " , accessed 1/12/2016, 2016, http://roychristopher.com/richard-saul-wurman-technologyentertainment-design.

35 Peter Bradford and Richard Saul Wurman, Information ArchitectsGraphis Press Corporation, 1996).

36 "I+diseño ", accessed 1/12/2016, 2016, http://www.diseno.uma.es/i diseno/i diseno 6/carmen grisolia.htm.

37 Joan Costa, Señalética Corporativa (Barcelona: Costa Punto Com, 2007).18 
combinación de diseño gráfico, tecnología y redacción/periodismo. ${ }^{38}$ A partir del libro de Louis Rosenfeld y Peter Morville, Information Architecture for the World Wide WebDesigning Large-scale Web Sites en 1998, la arquitectura de la información está asociada con la construcción de websites. El urbanismo open source, código abierto, es un término que proviene del ámbito del software: se refiere al software y hardware que es accesible y modificable libremente; el usuario puede transformar y modificar la fuente del programa. Desde el urbanismo participativo y de código abierto, el arquitecto no es el autor de una estructura; es parte de ella junto a todos los ciudadanos que se interesen en construir su entorno; ciudadanos y profesionales entran al código fuente de la planificación urbana y pueden rectificar errores que la administración no repara. El arquitecto tiene hoy todas las herramientas y facilidades para promover el urbanismo participativo y configurar la ciudad desde abajo hacia arriba (bottom-up).

Entre el veintisiete de septiembre de 2012 y el tres de febrero de 2013, tiene lugar en la Pinacoteca Moderna de Múnich (Pinakothek der Moderne), la exposición El arquitecto: historia y presente de una profesión en la que se muestra la imagen pública del arquitecto y sus representaciones desde Egipto. El arquitecto en Egipto representa al sumo sacerdote Bekenkhons, gran promotor de templos del Antiguo Egipto; una escultura anterior a 1239 representa al arquitecto como Atlas en el coro de una catedral; un retablo de 1470 con la representación del maestro de Marienlebens del siglo XV, en $1567^{39}$ El buen arquitecto, en 1804 el Grabado de Claude-Nicolas Le-doux titulado El ojo del arquitecto, en 1850 aparece el Cuadro alegórico sobre la arquitectura del pintor alemán del siglo XIX Wilhelm von Kaulbach, en 1956 el Retrato de Le Corbusier y hoy la imagen de FOSTER + PARTNERS.

38 “- Arquitectura De La Información “, accessed 1/12/2016, 2016, http://www. bibliodigital.udec.cl/index.php?option $=$ com content\&task=view\&id=39.

39 "Presentan Al Arquitecto Como "Intéprete Global" De Todas Las Disciplinas Artísticas - 20minutos.Es “ , accessed 1/12/2016, 2016, http://www.20minutos.es/ noticia/1614197/0/arquiecto/interprete-global/artes-exposicion/.

A partir de 1998 la Arquitectura de la Información se asocia con la construcción de websites.

Siglo XXI: urbanismo participativo y de código abierto

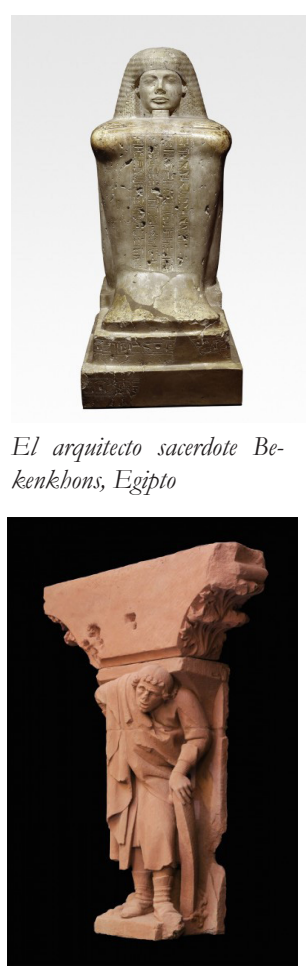

El arquitecto Atlas en el coro de un catedral

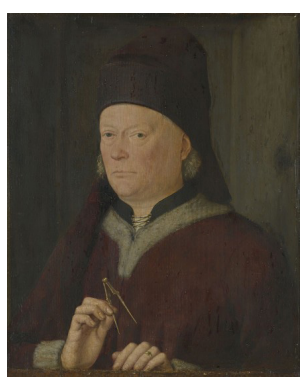

Retablo de 1470, el maestro de Marienlebens 


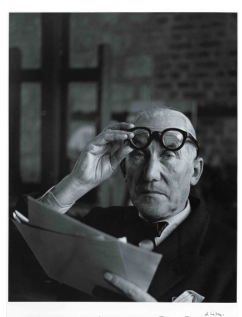

Retrato de Le Corbusier

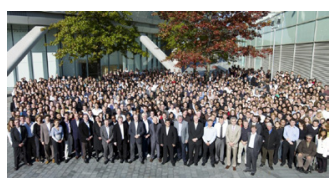

El Arquitecto-grupo. Imagen de Fosters+Partners.

El arquitecto facilitador, mediador entre la sociedad y la soberania,

Con las nuevas tecnologías lo invisible se hace visibile y el espacio se hace espectro
La imagen del arquitecto desde maestro o artesano hasta el siglo XXI, parece haber hecho un viaje desde abajo hacia arriba y desde arriba hacia abajo: del artesano al demiurgo, el utopista y la estrella, vuelve a la tierra en su estado original, dentro de la sociedad: facilitador ${ }^{40}$ de herramientas para la comunicación de estructuras distintas; vínculo entre habitantes, constructores, disciplinas y vínculo entre el poder y la sociedad. En este espacio del umbral, en el que se encuentra, como mediador entre profesiones y estados, como fue en su origen, tiene la oportunidad de influir en la promoción del urbanismo participativo que devuelve a los habitantes su derecho de, como mínimo, opinar en la construcción de su entorno. Como habitante del lugar que está entre la soberanía y el ciudadano, el poder y la vida, y con la presencia de los nuevos medios, la figura del arquitecto consigue ser un facilitador de la naturaleza del holometábolo ${ }^{41}$.

Los rápidos cambios en la tecnología prometen nuevas transformaciones en la estructura del arquitecto. Las gafas Microsoft Hololen son el primer equipo holográfico libre que construye imágenes tridimensionales basadas en el empleo de la luz, sin necesidad de cables, teléfono y conexión a un ordenador, y que reaccionan según la voz y las manos frente a ellas. ${ }^{42}$ La holografía es una técnica de fotografía que crea imágenes tridimensionales mediante el uso de un rayo láser que registra una película fotosensible. A primeros de noviembre de 2015, sale la red Li-Fi, la nueva red que sustituirá a la Wi-Fi. La red Li-Fi es cien veces más rápida que la Wi-Fi; la Wi-Fi transmite a frecuencias bajas, como el microondas, y la Li-Fi utiliza la parte visible del espectro radioeléctrico para enviar datos. De este modo en un futuro cercano existirán lámparas que, además de iluminar una zona, podrán ofrecer conectividad. Otra diferencia entre las $40 \quad$ “Offlinecity | En Construcción “, accessed 1/10/2016, 2016, https:// offlinecity.wordpress.com/.

41 El holometabolismo, holometabolía o metamorfosis completa o complicada es un tipo de desarrollo característico de los insectos más evolucionados, en el que se suceden las fases de embrión, larva, pupa e imago(adulto). Los insectos con este tipo de desarrollo se denominan holometábolos. Wikipedia contributors, Holometabolismo

42 “Arquitecto De Sueños, 'Biohacker'... y Otras Profesiones Del Futuro | Economía | EL MUNDO “, accessed 1/12/2016, 2016, http://www.elmundo.es/ec onomia/2015/04/22/55368164e2704e7e608b4580.html. 
dos redes es que, Li-Fi, al utilizar la luz visible, no interfiere con otras frecuencias y puede ser usada en más zonas, como el avión. Con Li-Fi da comienzo un nuevo tipo de comunicación, la comunicación por luz visible. ${ }^{43}$ Con las nuevas tecnologías el entorno invisible se hace visible; aquel espacio aparentemente vacío del mundo, la energía oscura y misteriosa que constituye el $70 \%$ del universo ${ }^{44}$ será material del arquitecto.

En 2045, el setenta por ciento de los bebés que hoy en día vienen al mundo tendrán profesiones que todavía no se han inventado, concluye la jornada organizada por Startup Academy, en 2014, bajo el título Un futuro lleno de oportunidades, ¿estás preparado ${ }^{45}$ Entre el nanomédico, el trabajador social de redes, el ingeniero de órganos, agricultor vertical, meteopolicia, médico personalizado, conductor de drones, técnico de domótica, se encuentra el arquitecto de los sueños; constructor de los escenarios de los sueños de los habitantes; de forma similar quizás a la construcción de sueños que aparece en la película cinematográfica El Origen. Esta profesión, después de treinta años, instaurará un nuevo camino para la compresión de la construcción de ficciones. ${ }^{46}$

43 “Li-Fi, La Nueva Red Cien Veces Más Rápida Que El Wi-Fi,”, accessed 1/12/2016, 2016, http://www.lavanguardia.com/tecnologia/innovacion/20151127/30426722928/red-lifi. html.

44 Fabric of the Cosmos: The Illusion of Time, 44, directed by Brian Greene 2011); Brian Greene, The Fabric of the Cosmos: Space, Time, and the Texture of RealityVintage, 2007).

45 Arquitecto De Sueños, Biohacker'... y Otras Profesiones Del Futuro | Economía | EL MUNDO

46 Daniel Mielgo Bregazzi, Construir Ficciones: Para Una Filosofía De La Arquitectura Biblioteca Nueva, 2008). 
La vida es lo que te pasa mientras estás ocupado baciendo otros planes' John Lennon

$1 \quad$ John Lennon, "Beautiful Boy (Darling Boy)," Song Lyrics.on Album Double Fantasy.New York: Geffen Records (1980). 


\section{SIN FIN}

Entre la imaginación y la realidad 



\section{entra la espada y la pared, excluyendo}

\section{Sin Fin}

\section{vampiros, zombis y slums}

El fin es el final, el limite; pero es también la meta, los objetivos por alcanzar. Occidente piensa en base a los términos medio, fin y acción; China piensa en la condición, la consencuencia y la transformación. En Occidente para llegar al fin se hace un plan previo según el que se actua; las estrategia de Oriente se basan en la evaluación: la búsqueda desde dentro de las condiciones facilitadoras. Cuando todo está planificado nacen estructuras rígidas que el imprevisto puede derrumbar; cuando no existe el fin, las estructuras se hacen flexibles para poder transformarse infinitamente. Las ciudades fantasmas y las ciudades informales son el resultado de una planificación que no evalúa las condiciones y la potencia de la vida: la ve desde arriba, como una maqueta, un modelo y un plan que llevar a cabo 



\title{
Entre la espada y la pared, el pensamiento binario,
}

\author{
A veces vivo y a veces pienso \\ Paul Valery
}

Los modismos cotidianos españoles, griegos y europeos en general, muestran el sustrato dramático del pensamiento occidental. En España se dice estoy entre la espada y la pared para mostrar la difícil situación en la que se debe elegir entre dos opciones, cuando ninguna de ellas es satisfactoria y deseada. La situación es menos dramática si cambiamos de escala; si nos alejamos para verla desde lejos, con el fin de tener otros puntos se puede ver más de una opción. El pensamiento binario (pensamiento del "esto o lo otro") es lo que enmarca asuntos en base a términos opuestos: malo-bueno, dentro fuera, público, privado y cualquier par de términos contrarios. ${ }^{2} \mathrm{El}$ pensamiento trivalente es aquel que encuentra un tercer término y se centra en él; el pensamiento polivalente es el que se aleja y ve más de tres opciones; de este último hablan autores como Bauman (pensamiento "esto y lo otro"), Edgar Morin (pensamiento complejo), Gilles Deleuze y Félix Guattari (pensamiento rizomático), Judith Butler (pensamiento queer o trans-), Edward de Bono (pensamiento lateral) y Bart Kosko (pensamiento borroso, difuso)

El pensamiento y la filosofía occidental trabajan en modo binario: dividen el mundo y la vida en antónimos, en pares de términos opuestos; la filosofía oriental tiene un pensamiento polar: divide la vida en dos, pero no son pares de términos opuestos, sino complementarios de un todo; el pensamiento occidental es el pensamiento de la exclusión y el de Oriente, el pensamiento de la inclusión. En Occidente pensamos en base al

la filosofía occidental se ha basado en una arquitectónica dual desde siempre Sery en Oriente en base a la Via, al Tao. Según la teoría del Ser, A no puede ser a la vez no-A; para la teoría de la vía, A es a la vez no - A; la primer excluye la contradicción, la segunda la incluye. Para el pensamiento binario el mundo es un todo dividido en dos; en 1 François Jullien, Filosofía Del Vivir (Barcelona, España: Octaedro, 2012).

2 Peter Elbow, “The Uses of Binary Thinking," Journal of Advanced Composition (1993), 51-78. 
No solo en Grecia pensaron en modo dual; desde las sociedades semicivilidades se observa la dicotomía. varias son las explicaciones que se dan para el fenómeno de pensamiento polar que se observa en todas las sociedades

El protipo de toda oposición es la contrariedad del sexo. el mundo oriental todo es continua transformación; todo es lo mismo, pero diferente.

La polaridad no es exclusiva de la cultura de la antigua Grecia y China; existe también en sociedades primitivas, antiguas y modernas, de diferente ordenación y situadas en distintas partes del mundo. En las tribus sudamericanas, en la época de las lluvias, la tribu se divide en dos grupos, la gente de la plaza y la gente de las afueras. Esta división da lugar a una clasificación dicotómica general de la naturaleza. La naturaleza entera dice Nimuendaju "queda dividida por vía de antitesis en dos grupos: este oeste, sol luna, día noche, y más. Esta dicotomía dice Nimuendaju "no envuelve la oposición de sexos, pero se extiende a los animales y las plantas" . Las divisiones dualistas las encontramos también en algunas tribus de Indonesia, como la tribu ampoya, donde según J. M. van de Kroef, la aldea(...) está dividida en dos partes: cada parte no solo constituye una unidad social, sino una categoría de una clasificación cósmica que abarca todos los objetos y acontecimientos que tienen lugar en el mundo que rodea a los habitantes de la aldea. Tabla de opuestos, según R. Needham, encontramos en las creencias de los meru de Kenya. Para E.W.Gifford la sociedad de los mikwok de Norteamérica adopta una clasificación dualista donde "toda naturaleza está dividida en tierra y agua". ${ }^{4}$

Lévi Strauss sostiene que todas las sociedades que han sido clasificadas como dualistas son más complejas de lo que podría sugerir esta clasificación; no podemos dudar de la abundancia de las sociedades que han basado sus teorías en términos de opuestos y que reflejan la organización social y urbanística de las sociedades. ${ }^{5}$ Es un hecho digno de investigación estudiar el porqué los humanos de distintas partes de la tierra han aprendido y construido nuestro mundo basándose en una estructura dualista. Son muchas las aportaciones que se han dado para explicar la prevalencia del pensamiento binario. Cornford sugiere que el prototipo de toda oposición o relación de contrariedad es la contrariedad del sexo $0^{6}$. Burnet, propuso una explicación diferente: dado que el punto de vista desde el que los antiguos contemplan el mundo es el del ciclo de crecimiento y decadencia, la oposición entre día y noche, estío e invierno, con su sugestivo paralelismo en sueño y

\footnotetext{
3 GER Lloyd, Polaridady Analogía. Dos Tipos De Argumentaciónen Los Albores Del Pensamiento Griego (Madrid: Taurus, 1987).38

$4 \quad$ Ibid. 40

5 Ibid. 41

6 Francis Macdonald Cornford, "From Religion to Philosophy," (1957).68
} 
vigilia, nacimiento y muerte es el prototipo de toda oposición ${ }^{7}$. Para Lloyd, existen muchos factores que contribuyen al notable dominio de las teorías basadas en opuestos; muchos fenómenos naturales exhiben una suerte de dualidad: el día alterna con la noche, el sol sale y se oculta. ${ }^{8}$

La neurociencia también habla de esta dualidad; Francisco J. Rubia Vila, neurocientífico, Catedrático de la Facultad de Medicina de la Universidad Complutense de Madrid, dice que el pensamiento dual se debe a un operador binario que se encuentra en el hemisferio dominante; hay teorías que consideran que los seres humanos primitivos no tenían este operador ya que surgió con la evolución del cerebro; otras afirman que sí existía aunque los primitivos no lo usaban. Los avances de la ciencia cognitiva y de la neurociencia plantean que el pensamiento binario o dualista es una función innata de nuestro cerebro y nos acompaña desde los años primitivos. Sin embargo, según el Prof.esor F. J. Rubia Vila, es una función evolutiva. El operador binario del cerebro está ubicado en el hemisferio izquierdo; intenta encontrar un orden en el desorden de la experiencia, así que simplifica la realidad para poder entenderla9.

La polaridad en la argumentación especulativa griega, está presente desde las principales teorías cosmológicas de los presocráticos. Es bien conocida la Tabla de los Opuestos de los Pitagóricos y la afirmación del Alcmeón: la mayoría de las cosas humanas van en pareja ${ }^{10}$. La medicina se basa en las teorías de los opuestos de los tratados Hipocráticos en los que las enfermedades y los remedios se encuentran en sus opuestos. La contribución de Parménides fue el Ser y no Ser; es el momento decisivo de la filosofía occidental y el alejamiento del pensamiento chino y griego. Hasta Platón, los términos opuestos pertenecían a la misma naturaleza (frío-caliente, seco-húmedo); a partir de Platón se habla de mundos opuestos: el Ser y el Devenir.

Aristóteles dice de sus predecesores: Todos ellos identifican los elementos, y los que llaman principios, con contrarios, aun sin dar razones para proceder así, sino como si se vieran compelidos por la verdad misma ${ }^{l 1}$. Sin embargo, él también, siguió la tradición del pensamiento binario;

7 GER Lloyd, Polaridady Analogía. Dos Tipos De Argumentaciónen Los Albores Del Pensamiento Griego (Madrid: Taurus, 1987).38

$8 \quad$ Ibid. 81

$9 \quad$ Ibid. 81

$10 \quad$ Ibid. 81

11 Ibid.23
Las dualidades dia-noche, invierno -verano y sueño vigilia desencadenaron el pensamiento binario.

La neurociencia encuentra un dispositivo binario en el hemisferio dominante.

La polaridad empieza con la teorías cosmologicas de los presocráticos. 
En la caverna de Platón nace la dualidad cuerpo -mente

La caverna es el cuerpo, la prisión de la mente su teoría está basada en los opuestos: lo caliente y lo frío, lo húmedo y lo seco, la Forma y la Privacidad.

El símil de la Caverna de Platón, considerado el mito fundamental de la filosofía occidental, reúne la visión dualista epistemológica (Doxa, Episteme), la visión ontológica o metafísica (mundo sensible - mundo inteligible) y la visión antropológica (alma-cuerpo). El "símil" de la Caverna de Platón, que encontramos en el libro VII de la República (514a-516d), es según el propio Platón una metáfora o alegoría de nuestra naturaleza respecto de su educación y de su falta de educación (517a 8 hasta 518d 7); expresa su doctrina sobre la paideia (educación). Plantea que la Filosofía y la Episteme son las que nos pueden transportar de la realidad umbrátil, como la llama Heidegger, a la realidad verdadera; salir del mundo de los reflejos percibidos por el cuerpo y las sensaciones, al mundo del Ser y lo Verdadero que es perceptible solamente por la Inteligencia (Episteme).

Platón cuenta a Glaucón ${ }^{12}$-a través de las palabras de Sócrates- una historia sobre los habitantes de una caverna imaginaria; la caverna representa lo que nos rodea: de "ese bien asentado dominio que, al da una mirada en redondo, por la vista se nos muestra" ${ }^{3}$. La bóveda de la caverna el cielo, y bajo ella la Tierra, donde sus habitantes viven presos. En la entrada de la caverna hay un fuego, que sus habitantes no pueden ver por estar atados de espaldas a un muro que los separa de la salida. Otros, entran y salen de la caverna cada con sus objetos. Lo único que los presos pueden ver es el muro del fondo de la caverna, donde se proyectan las sombras de los objetos y de los cuerpos que pasan alrededor del fuego. Para los presos lo que les rodea es lo real y, como dice Heidegger, en tal cavernoide morada se sienten como "en mundo", y cual "en casa"; y en ella encuentran lo de confianza. ${ }^{14}$

Fuera de la caverna se hacen visibles lo que en el interior eran solo sombras; según Heidegger, los objetos en el exterior de la caverna son las imágenes de aquello que es el propio ser: son la imagen de las Ideas.

12 Martin Heidegger, "La Doctrina De Platón Acerca De La Verdad," Eikasia: Revista De Filosofía, no. 12 (2007), 261-284. 2

13 Ibid. 5

14 Ibid. 2 
Si según Platón, no tuviera el hombre a la vista "ideas", esto es: un "aspecto" peculiar en cada cosa, -vivientes, hombres, números, dioses-, no podría jamás percibir esto o aquello como casa, hombre o dios. Suele pensar el hombre que es esta casa o aquel árbol lo que precisa y directamente ve, y asi de los demás seres; todo lo que pasa, natural y corrientemente, por ser a sus ojos "lo real", lo está viendo, siempre y únicamente, a la luz de "ideas". Tales realidades inmediatas, $y$, con todo, umbrátiles, es todo lo que a diario tiene el hombre en su puño. Vive en prisión; a sus espaldas, todas las "ideas". Y justamente porque no cae en cuenta de que es prisión donde se halla, toma tal campo de acción diaria, bajo la bóveda celeste, por campo adecuado a la experiencia y al juicio, que son los que, exclusivamente, fijan a todas las cosas y relaciones su medida, y a enderezos y aderezos la regla ${ }^{15}$.

Para Platón, el Sol es lo que hace todo visible, incluso las Ideas; es la Idea de todas la Ideas; es la Idea del Bien ${ }^{16}$. Y así, de la alguna manera, se introduce la dualidad de lo Bueno y lo Malo, que domina nuestro pensamiento occidental hasta nuestros días.

En Platón, según su alegoría de la prisión para el alma, éstas perdieron sus alas y cayeron en un cuerpo sólido. El cuerpo es un vehículo que transporta el alma inmortal y divina; recibieron el principio inmortal del alma, construyeron el cuerpo mortal, que dieron a aquélla como un carro para que la llevara ${ }^{17}$. La caverna, que es nuestro cuerpo, es una cárcel; las Ideas y el Bien están fuera y "mientras tengamos nuestro cuerpo, y nuestra alma esté sumida en esta corrupción, jamás poseeremos el objeto de nuestros deseos; es decir, la verdad"18 La dualidad cuerpo-alma se extiende a la esfera ontológica y se traduce en mundo sensible y mundo inteligible; el mundo de las Ideas y del Bien y el mundo del cuerpo y de la corrupción. El mundo sensible es el que percibimos por nuestros sentidos; el mundo umbrátil, el de las sobras, el mundo inestable y cerrado, generado, siempre cambiante y que surge por la opinión unida a la percepción sensible ${ }^{19}$, el Suceder. El mundo de las Ideas o el mundo del Ser es lo inmutable, no generado e indestructible; lo estable invisible y no perceptible por los sentidos.

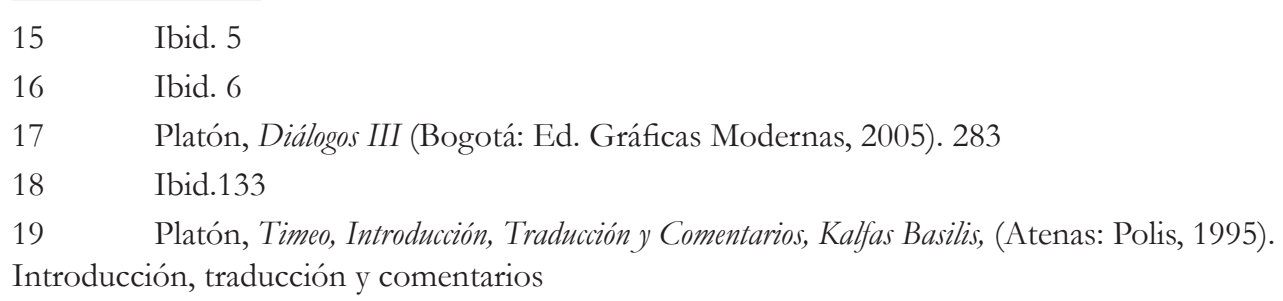

De la dualidad cuerpomente nace la de mundo inteligible - mundo tangible 
La base de todas las dualidades parede ser la de cuerpo-mente

La separación mente cuerpo duplica la vida.
En él se encuentra la ignorancia de lo real; el conocimiento que alguien alcanza a partir de los sentidos y de la opinión (Doxa); y donde yace el error. El exterior es lo real, lo verdadero y el Bien; lo que alguien consigue a través de la ciencia (Episteme). La opinión es nuestro conocimiento a partir de la contemplación de las sombras, de esta copia imperfecta del mundo inteligible; y nuestro conocimiento del mundo sensible se estructura en la imaginación (Eikasia) y en la creencia (Pistis), y donde yace la posibilidad del error. La ciencia es el conocimiento verdadero donde la razón no da posibilidad al error y lleva a la esencia de los entes. Tal conocimiento constituye el pensamiento (Dianoia) que capta la esencia y la razón (Noesis), la idea del Bien²0; y, sólo la educación (Paideia) puede liberar del mundo, de la prisión del cuerpo y transportar al mundo verdadero del Ser y de la esencia.

Platón con sus teorías establece una exclusión mutua y exhaustiva entre los opuestos; opuestos de cualquier índole, elementos, términos, cosas o mundos. Legitima la contrariedad y la incompatibilidad entre lo estable y lo inestable, lo invisible y lo visible, la imaginación y la realidad, la cosa y la idea, lo sensible y lo inteligible, lo interior y lo exterior, el alma del cuerpo: ninguno de los contrarios consciente de suyo, mientras siga siendo el que es, venir a ser al mismo tiempo su contrario, sino que se distancia o perece (Fedon, e 7 y ss) ${ }^{21}$. Por último, Platón, a través de las palabras de Sócrates, establece la ley general del Cambio, del Devenir: los opuestos nacen de opuestos (Fedon 70d dd) y llega a concluir que el llegar-a-ser, en su conjunto, está entre opuestos ${ }^{22}$.

Esta separación conduce a la duplicación de la vida. De un lado la vida de nuestro cuerpo y de otro lado la vida de nuestra mente; la vida de nuestros deseos y aspiraciones, la vida que siempre intentamos alcanzar pero nunca la llegamos. Vivir y pensar se convirtieron en términos antagónicos cuando se separaron en lugares opuestos: en el cuerpo y en la mente. Pero, oponer el pensamiento con la vida, es crear una segunda vida; duplicarla; crear un lugar donde el dolor, el hambre y el deseo están ausentes, ya que, allí, en la vida ideal, se encuentra la saciedad, la satisfacción y la libertad absoluta; y la tentación de la filosofía, desde los, ha sido duplicar la vida: oponer al vivir repetitivo,

20 Cfr. República 511d - e. También en 533a y ss.

21 Lloyd, Polaridady Analogía. Dos Tipos De Argumentaciónen Los Albores Del Pensamiento Griego133

22 Ibid.31. 
biológico, eso otro que ella denomina, proyectándolo al Ser, la "vida verdadera".(...)A veces vivo y a veces pienso $^{23}$, escribe Paul Valery, e ilumina la tradición del pensamiento occidental: dividir la vida en polos opuestos. Como vivir es lo más elemental, lo que compartimos con la ameba, pero también el lugar donde colmamos nuestras aspiraciones; y como estos dos extremos nos desgarran, siempre ha existido la tentación de duplicar la vida, dice François Jullien, dando una posible razón por la que la filosofía occidental decidió dividir la vida en dos: en la vida meramente metabólica y absurdamente repetitiva y en la vida eterna, que escapa al tiempo, que se desarrolla en el más allá; la vida verdadera. ${ }^{24}$

Esta división radical del vivir nos condujo a una contradicción dramática: aunque que la vida es lo más inmediato, lo más íntimo y cercano, jamás conseguimos alcanzarla plenamente, ni acceder a ella; y por eso, se nos escapa y sentimos una nostalgia infinita $^{25}$. Cada vez que pensamos en la palabra vida nos fundimos en las más profunda melancolía dice François Jullien; porque la saciedad nunca alcanza el deseo. Sócrates usaba la metáfora del tonel agujereado para hablar de lo que es vivir; el tonel agujereado es nuestro cuerpo; un cuerpo que no se satisface nunca porque nuestros deseos son ilimitados; la vida es estar continuamente intentando llenar una vasija que nunca se llena porque el agua escapa por sus agujeros. El cuerpo que nunca se satisface - la vasija agujereada- no nos deja nunca descansar; no nos permite estar nunca en paz. Sin embargo, la vida de los sabios, según Sócrates, son toneles sin agujeros porque ellos han conseguido dominar a sus deseos, cerrar los agujeros y sentirse siempre llenos. Y eso es, según Sócrates, a lo que la gente tendría que aspirar: dominar sus deseos y convertir su cuerpo en un tonel sin agujeros que se podrá llenar definitivamente, descansar y estar en paz consigo mismo. Pero, según Calicles, la condición misma de estar vivo es tener que llenar continuamente nuestro cuerpo que nunca se satisface completamente; nuestra vida se sitúa en este "entre"; entre el deseo y la saciedad, entre el estado que se afirma y el estado al que se aspira. Solo los muertos, dice Calicles, tienen sus toneles llenos, ya que la falta de agujeros no permite ninguna interacción de lo interior con el exterior; de la tristeza con la alegría, del hambre y la saciedad, con cualquier estado y

23 François Jullien, Filosofía Del Vivir (Barcelona, España: Octaedro, 2012). 15

24 Ibid. 13

$25 \quad$ Ibid.15

La división entre vida metabólica y vida eterna nos conduce al drama de no poder acceder nunca a la vida.

El cuerpo corre siempre detrás de un ideal que no alcanza nunca y pierde el Entre de la vida

En Occidente el sabio es el que cierra los agujeros de los toneles de Danaides 
La exclusion mutua del cuerpo con la mente endurece la vida.

China baso sus teorías en el par de términos positivo - negativo, mientras Occidente, en el malo -bueno su contrario. ${ }^{26}$ Platón, según Jullien, no llega a dar contenido al entre (entre el deseo y la saciedad), al transcurso de la vida entre llenar y vaciar pero encuentra la plenitud y el placer en la satisfacción de la carencia. Eso se explica por el dualismo alma-cuerpo que inventa donde el cuerpo es una cárcel y el placer verdadero está en el más allá, en un mundo ideal.

Según François Jullien, esta exclusión mutua de los dos polos ha endurecido la vida que está siempre en una continua lucha entre lo malo y lo bueno, entre lo biológico y lo ético, lo prohibido y lo permitido; siempre persiguiendo la verdad y la perfección reprimiendo, muchas veces, los deseos. La vida es así una condena; las hijas de Danaos - las Danaides- fueron condenadas a estar eternamente llenando vasijas agujereadas por haber matado a sus quinces primos. Llenar un tonel agujereado es un castigo según el mito, sin embargo para Calicles o el pensamiento chino no es una condena, sino la oportunidad de la propia vida.

China basó todas sus doctrinas en el par positivo - negativo; ni uno ni otro pueden existir por separado; encontramos los opuestos Yin y Yang, donde Yin es la parte sombreada de una colina o una casa y Yang la parte expuesta al sol; yin: la oscuridad, el frío, el sexo femenino, la noche, la luna, la tierra, el oeste, el norte, lo blando, lo pesado, lo débil, lo situado detrás, lo situado debajo, la derecha y la muerte; Yang: la luz(la claridad diurna), el calor, el sexo masculino, el día, el sol, los cielos, el oeste, el sur, lo duro, lo ligero, lo fuerte, lo situado delante, lo situado encima, la izquierda y la vida.

Al contrario de la filosofía occidental, el pensamiento Chino no vivió la Caída, de las almas, según Platón; ni tampoco la pérdida de la inocencia con la exclusión de Adán y Eva del paraíso. Por eso la vida y la ética chinas, no se encuentra dividida entre Bueno y Malo, entre Alma y Cuerpo. El pensamiento chino nunca espera la salvación. En lugar de lo Malo-lo Bueno se centra en lo Negativo y lo Positivo. Lo negativo no es lo Malo, sino la sombra en el cuadro de la vida que ilumina y eleva lo positivo.

"Es una sombra en el cuadro" es una expresión francesa que se dice de un ligero defecto que no borra las bellezas de una sombra o las buenas cualidades de las personas. Decir que hay una sombra en el cuadro supone indicar que algo desentona, que nos quejamos por 26 François Jullien, La Sombra En El Cuadro. Del Mal o De Lo Negativo (Madrid: Arena Libros, 2009). 71-93 
encontrarlo. Esta sombra percibida en el cuadro de la vida será la muerte, el sufrimiento, la enfermedad, la guerra, la injusticia, etc, que deseariamos no tener que afrontar. ${ }^{27}$

Al contrario del dualismo occidental que opone trágicamente el mal y el bien, china enfoca en lo positivo y lo negativo, el yin y el yang, que se instalan frente a frente $y$ cooperan (...) acoplados como lo están el anverso y el reverso, y si uno tiende a prevalecer, estamos seguros

El mal depende de la moralidady de un debe -ser que el otro no desaparece sino que prepara su vuelta ${ }^{28}$.Vivir a partir de la dualidad negativopositivo es muy distinto que a través del malo-bueno. El mal depende de la moralidad (sufrimiento, imperfección, pecado) y de un "debe - ser" siempre supuesto; lo negativo depende de una funcionalidad del curso del mundo; el mal remite al punto de vista de un sujeto, lo negativo es un momento en el continuo cambio del mundo; el mal depende de una singularidad, se produce según la figura de una persona o historia; lo negativo remite a lo global, es una relación con un conjunto del cual participa; el negativo remite a un proceso, lo malo a una acción o pasión. En la dualidad Mal- Bien, los términos son extremos y se excluyen mutuamente: bien "o" mal; lo negativo - positivo son diferentes pero no contrarios, no se excluyen sino que se incluyen. Lo negativo no opone lo real a lo ideal, lo que el escinde está al mismo tiempo pareado y coordinado: lo negativo es lógico. ${ }^{29}$ Lo malo se orienta hacia la Salvación, lo negativo hacia la Sabiduría; de una parte el maniqueo y de la otra el estoico. ${ }^{30}$

Según Jullien, "grandes concepciones" de la "vida" o de la "existencia se acomodan a su distribución entre estos polos: los del mal o de lo negativo, de la salvación o de la sabiduría, y no los de profano y lo sagrado (de lo laico o lo religioso). La salvación necesita de Dios, y la sabiduría del Sabio; la salvación se concibe mediante el punto de vista del "alma", la sabiduría se concibe en relación al mundo. La salvación viene de mythos, de un Gran Relato, la Sabiduría del logos; el Gran relato, desde la Caída en el Mal hasta el ascenso doloroso fuera de la Tinieblas, a diferencia de la falta de un relato en China, donde no están a la espera del cumplimiento de grandes sorpresas. ${ }^{31}$

27 François Jullien, La Sombra En El Cuadro. Del Mal o De Lo Negativo (Madrid: Arena Libros, 2009).11

$28 \quad$ Ibid. 89

$29 \quad$ Ibid.23

$30 \quad$ Ibid. 28

$31 \quad$ Ibid.28

\footnotetext{
lo negativo depende de la funcionalidad del curso del mundo
} 
Dicho con brevedad: el pensar de la salvación, que libera el mal, por este hecho, bace que surja la tensión, hace que vibre la pasión: organiza y dirige una dramaturgia y se convierte en heroico; mientras el de la sabiduría, disolviendo el mal negativo, justifica una armonía: por un lado se juega (trágicamente) el destino de un alma y por el otro se piensaserenamente- el orden del mundo, o mejor, lo que Plotino denomina "sintaxxi"."32

El Gran Relato depende del modo que nos posicionamos frente a la dualidad malo-bueno y ético-biologico

La dualidad en los procesos creativos se traduce como lo imaginado y lo experimentado
Las historias de la humanidad, el Gran Relato, y los pequeños, dependen del modo en el que nos colocamos frente a la dualidad malo-bueno y ético-biológico (mente-cuerpo): la separación de los términos en pares conduce a la invención de un Dios que salva el mundo de la maldad y lleva al más allá, al mundo de las Ideas donde yace la verdad y aparece al paraíso. La historia de la vida individual y colectiva depende del modo en que nos movemos entre los términos de los pares: la vida se sitúa en este espacio intermedio. La calidad de la vida depende del modo de relacionarlos; el lugar donde se desarrolla la vida es el que se traza mientras estamos entre el deseo y la saciedad, lo dentro y lo fuera, lo individual y lo colectivo, lo desconocido y lo conocido. Según Jullien, la indeterminación del entre, de la forma que está entre los opuestos, del vivir, molestó a Platón, quien incapaz de determinarlo, le dio la espalda y buscó la vida en lo más allá, en el meta del metafísico. ${ }^{33}$ La vida real se ha transportado al lugar del más allá, en lugar de lo Ideal; así el entre del vivir se queda vacío; cuando uno siente el vacío, el tedio y la depresión es porque no puede llegar a la vida Ideal; la oposición imaginado - experimentado es lo que endurece la vida según Jankélévitch ${ }^{34}$; cuanto mayor es la distancia entre lo imaginado y lo experimentado, más profunda es la tristeza, la decepción y la insatisfacción.

En los actos creativos, la distancia entre lo imaginado y lo experimentado define el proyecto. La mutua exclusión de los opuestos, el pensamiento binario, agota al creador y le priva de posibilidades inesperadas. Lo imaginado no se identifica nunca con lo experimentado y el dibujante siempre queda insatisfecho; su lucha es siempre

$32 \quad$ Ibid. 25

33 François Jullien, Filosofía Del Vivir (Barcelona, España: Octaedro, 2012). 13

34 Vladimir Jankélévitch, La Aventura: El Aburrimiento. Lo Serio (Taurus Ediciones, 1989). 90 
llegar a realizar lo que está imaginado. En el camino, corriendo detras de sus ideales, se encuentra con nuevas e inesperadas posibilidades que le pasan desapercibidas mientras la única meta es llegar lo más rápido y lo más cerca a la Idea. En el caso del arquitecto, la distancia entre lo imaginado y lo experimentado no está solo en relación a su acto de dibujar, sino que también influye en la relación que tiene con el habitante: la vida de los habitantes que el arquitecto imagina y la que finalmente los habitantes tienen. Los slums y las ciudades fantasmas son el resultado de un pensamiento que ha excluido la imaginación de la realidad; los planificadores sumergidos en los ideales e ideas no pudieron evaluar la potencia de las ciudades ya que no las habitaron desde su interior sino a través de los planos; construyeron estructuras rígidas que no se podían adaptar al aumento de la población obligándola a construir una ciudad informal paralela; construyeron estructuras estandarizadas que no satisfacían a los habitantes y se quedaron abandonadas.

Cuando la distancia entre lo imaginado por el arquitecto y lo experimentado por el habitante es excesiva, puede llegar a la locura del habitante. Žižek encuentra un ejemplo en la película El resplandor, donde la explosión de la locura llega por la tensión entre la pequeña familia y el gigantesco edificio vacío que ocupan; también en la obra de Hitchcock Psicosis, la locura habita entre las dos casas: el moderno motel horizontal y la vertical casa gótica entre los que el protagonista corre constantemente sin encontrar un lugar propio. En obras contemporáneas todavía existe esta oposición, aunque el principal objetivo de la posmodernidad fue confundir los opuestos. Si el motel lo hubiera construido Gehry, dice Žižek, la historia sería diferente, la locura no existiría; como suele hacer, combinaría directamente la casa vieja y contemporánea y llegaría a una nueva entidad hibrida; el asesino no hubiera matado las víctimas, ya que hubiera quedado liberado de la insoportable tensión que le impulsa a correr entre los dos lugares; bubiera tenido un tercer lugar de mediación entre los dos extremos. ${ }^{35}$

La arquitectónica del pensamiento occidental está estructurada sobre una base dual que arrastra toda la actividad arquitectónica y constructiva. Los arquitectos, dibujando crean relaciones entre términos opuestos; sus trazos son líneas que conectan y separan términos antagónicos. El lenguaje que se usa durante la proyectación, el diseño
Los slums y las ciudades fantasmas son resultados de la distancia entre lo imaginado y lo experimentado
La base dual de la filosofía y lógica define la actividad arquitectónica 
y la construcción, concentra gran variedad de dualidades, como son:

\author{
Arquitecto - Usuario
}

Invisible - Visible

Invisible -Visible

Privado - Público

Todo - Parte

Antiguo -Nuevo

Útil - Inútil

Vacío - Lleno

Bueno - Malo

Luz - Oscuridad

Teoría -Praxis

Abierto - Cerrado

Transparente - Opaco

Natural - Artificial

Orden - Desorden 
Hacer edificios es crear relaciones entre los términos opuestos y los modos de proyectar, dependen de la manera de relacionar los opuestos. Según Peter Elbow existen cinco modos de enfrentar los pares de términos opuestos: pensando en el modo de la Hacer edificios es relacionar términos exclusión "esto o lo otro", encontrar una dialéctica entre ellos y un término tercero, considerando que no existe ninguna diferencia entre ellos, o que los dos polos son iguales y reales, y volver a enmarcar el asunto, alejarse y encontrar más de dos variantes. Este último es el modo más difícil: el pensamiento complejo o borroso. Sin duda, el pensamiento racional de "lo uno o lo otro" ha conseguido lo contrario de lo que quiso y a la vez ha hecho la vida más difícil. Según Venturi, el pensamiento de la exclusión es una actividad mental mucho más fácil que el pensamiento de la inclusión. Según Jullien el pensamiento de la inclusión, es la única forma de acercarse en la vida, no sentir melancolía por escucha de su nombre, conciliando e integrando los polos de los pares de términos; tener un pensamiento borroso o polar en vez que dual, para poder captar el vivir, cada concepto debe abrirse a su contrario. ${ }^{36}$

Antes que oponer trágicamente lo uno a lo otro, de buir de uno y de echar de menos al otro, será un sabio el que perciba que lo uno no va sin lo otro y que, bajo lo uno apunta ya lo otro: que uno contiene lo otro en si para existir. ${ }^{37}$

36 François Jullien, Filosofía Del Vivir (Barcelona, España: Octaedro, 2012).

37 François Jullien, La Sombra En El Cuadro. Del Mal o De Lo Negativo (Madrid: Arena Libros, 2009). 90 



\title{
con la mujer fantasmal en la ciudad fantasma
}

\author{
El espanto es el signo del fantasma. ${ }^{1}$ \\ Pascal Quignard.
}

Existe cierto paralelismo entre la evolución del modo de vida de la mujer y las narraciones de fantasmas en la literatura de lengua inglesa del siglo XIX. Desde la primera vez que los fantasmas aparecen hasta el siglo de su apogeo en el siglo XIX y hasta hoy en día; esta similitud se aprecia en la evolución del uso del espacio donde los fantasmas habitan: espacios liminales e intermedios, como puertas, ventanas, y escaleras que como el fantasma están en el Entre, entre arriba y abajo, entre dentro y fuera ${ }^{2}$.

La identificación del ser y del estar de la naturaleza de los fantasmas y la de los lugares que habitan, es según Gullon, debido a que el estar determina el ser: los escritores siempre se han preocupado de la relación que se establece entre el ser y estar ${ }^{3}$; yo soy el espacio donde estoy, dice Arnaud. ${ }^{4}$ Distintos investigadores se han dedicado a la razón de la atracción de las mujeres escritoras y lectoras hacía las narraciones de fantasmas: Lynette Carpenter y Wendy K. Colmar (1991), Michael Cox y R.A Gilbert (1991), Vanessa D. Dickerson (1996), Kathleen Brogan (1998) ${ }^{5}$. La mujer siempre ha sido vista por la sociedad algo cercana al estado y al ser de los fantasmas; dice Cixous, siempre la mujer ha sido vista como presente ausente, en una condición espectral, que tiene que comportarse como un espectro, buscar vías alternativas para hacerse presente e intentar romper un orden preestablecido: ser bruja, volar, mover y romper muebles, desorientar ${ }^{6}$ En los primeros textos góticos escritos por mujeres los fantasmas aparecen 1 Pascal Quignard, El Sexo y El Espanto, 2005).

2 Debbie Felton, Haunted Greece and Rome: Ghost Stories from Classical Antiquity (University of Texas Press, 1999). 93-94

3 Ricardo Gullón, Espacio y Novela Editorial Bosch, 1980). 28

4 Atxu Amann Alcocer, El Espacio Doméstico: La Mujer y La Casa (2005).46

5 Mercedes Arriaga Flórez, Mujeres, Espacio y Poder ArCiBel Editores, 2006). 253

6 Hélène Cixous, Keith Cohen and Paula Cohen, "The Laugh of the Medusa," Signs 1 , no. 4 (1976), 875-893.

Yo soy el espacio donde estoy.

La mujer siempre se ha visto como un ser espectral. 
En la literatura gótica los fantasmas viven en los castillos; pero a partir del siglo XIX los fantasmas se domestican

La domesticación se debe a que la casa es también un espacio liminal, entre la cultura y la naturaleza.

El cambio del lugar donde habitan los fantasmas, es una metáfora del progreso de la vida de la mujer

De los castillos, al espacio domestico, a los lugares de las secretarias, de las enfermeras, hasta la calle. en lugares como castillos, edificios marcadamente góticos y cementerios; los críticos ven la literatura gótica como una vuelta a las premodernas sociedades patriarcales donde las mujeres viven sujetas a amenazas, violencia y peligros. Cuando avanza el siglo XIX los fantasmas se hacen más famosos; ya no viven en castillos, sino en el espacio doméstico como el lugar que principalmente habita la mujer: sucede la domesticación de los fantasmas. ${ }^{7}$

El traslado de los fantasmas a la residencia es también porque, según David Felton, la casa es un espacio liminal, entre la dicotomía cultura y naturaleza, el margen entre la vida y la muerte, donde las almas inquietas se encuentran consigo mismas; además, los que más nos inquietan son los que se cuelan en la cotidianidad. ${ }^{9}$ Para Lynette Carpenter y Wendy Colmar, el cambio del lugar donde habitan los fantasmas es una metáfora del progreso de la vida de la mujer; la casa, su lugar por excelencia poco a poco se llena de amenazas, dificultando su vida; la vida de las mujeres está encadenada dentro de la casa, como sucede a los fantasmas que las habitan: no existe salida. En el siglo XX, los fantasmas no habitan solo dentro de la casa, sino en los nuevos lugares que se permite a la mujer habitar: surgen las secretarias, las enfermeras y las trabajadoras en las lavanderías; los fantasmas salen a las calles, al tiempo que las mujeres empiezan a deambular. Beborah Parsons escribe que no solo se habla del flaneur, sino de la figura flaneusse: en la literatura a partir de la industrialización de las ciudades ${ }^{10}$, para la mujer, la calle es un camino hacia la independencia, pero sin duda, está lleno de obstáculos ${ }^{11}$.

Las mujeres siempre han sido ubicadas por la sociedad patriarcal en el detrás; la mujer tradicional pasa solo dos horas fuera de la casa mientras que el hombre está dentro solo dos horas, fuera del espacio público; la mujer está escondida; en una casa prisión donde se le priva de todas las actividades que pueden conducir a una formación y actividad creativa que es la que conduce a la poesía, vehículo hacia la esencia de lo vital. ${ }^{12}$ La ciudad se diseña por y para los hombres; el espacio se divide en dos y lo

7 Mercedes Arriaga Flórez, Mujeres, Espacio y Poder ArCiBel Editores, 2006). 253

8 Debbie Felton, Haunted Greece and Rome: Ghost Stories from Classical Antiquity (University of Texas Press, 1999). 95

9 Michael Cox, Victorian Ghost Stories: An Oxford AnthologyOxford University Press, USA, 1991). 15

10 Mercedes Arriaga Flórez, Mujeres, Espacio y Poder ArCiBel Editores, 2006). 260

11 Atxu Amann Alcocer, El Espacio Doméstico: La Mujer y La Casa (2005). 52

12 Ibid. 45 
privado se dedica a la mujer mientras que lo que se entiende como ciudad, está para la vida del hombre -ciudadano; la mujer vive en ventanas reales y metafóricas y disfruta el exterior a través de la experiencia del hombre, las ventanas y la televisión; la mujer vive una realidad mediada y vivida por otros, una realidad que no le corresponde; ${ }^{13}$ el entramado de las calles es ocupado por los hombres, mientras el plano de las cubiertas es ocupado por las mujeres: la unica opción es saltar. ${ }^{14}$ Sin embargo, los fantasmas tienen algo de lo que carecen los humanos: siendo criaturas liminales de lugares liminales, ambiguos, están llenos de potencialidad. El espacio liminal es, según Turner, el lugar lleno de potencia y potencialidad; ${ }^{15}$ entre lo conocido y lo desconocido, que es donde yace el descubrimiento y la innovación.

Las mujeres, aunque fantasmas invisibilizados, están presentes de manera activa en toda la historia de la humanidad y, por consiguiente, en la formación de las sociedades y espacios urbanos. Daphnes Spain en How Women Saved the City expresa lo imprescindible que es el papel de la mujer para la mejora de la calidad de la vida en las grandes ciudades de Estados Unidos en el cambio del siglo XIX al XX. En el desarrollo del movimiento City Beautiful, las mujeres muestran cómo la ciudad real es invisible; carecen de higiene, de espacio de cuidado y juego para los hijos de las mujeres trabajadoras; por ello llevaron a cabo campañas para la construcción de baños públicos, la limpieza de las calles y la adecuación de los solares vacíos para el juego de los hijos. Las aportaciones más significativas como cuerpos de conocimiento que influyen en el pensamiento urbanístico se recogen en el libro de Jane Jacobs en 1961, Muerte y vida en las Grandes Ciudades. La aportación de Denise Scott Brown en Aprendiendo de las Vegas en colaboración con Venturi y Massey Doreen en Space, Place and Gender donde escribe que (...) espacio y lugar, los espacios y los lugares, así como el sentido que tenemos de ellos se estructuran recurrentemente sobre la base de género (...). Esta estructura genérica del espacio y el lugar simultáneamente refleja la manera como el género se construye y entiende en nuestras sociedades, y tienen Los lugares y los espacio se estructuran sobre la base de género. afectos sobre ellas, ${ }^{16}$ son también aportaciones significativas.

13 Josep Maria Montaner and Zaida Muxí, Arquitectura y Política: Ensayos Para Mundos AlternativosGustavo Gili, 2011). 198

14 Atxu Amann Alcocer, El Espacio Doméstico: La Mujer y La Casa (2005). 48

15 Victor Turner, "Frame, Flow and Reflection: Ritual and Drama as Public Liminality," Japanese Journal of Religious Studies (1979), 465-499. 466

16 Doreen Massey, Space, Place and GenderJohn Wiley \& Sons, 2013). 202 
En España, la figura de la arquitecta aparece en la década de los ochenta

A partir de los noventa las mujeres arquitectas aumentan exponencialmente en España

El edificio Margarette Schutte en Viena, hecho por mujeres, $1993-1997$
En España, la influencia de la mujer en el pensamiento urbanístico empieza en la década de los 80 a partir de la I Jornada de Feministas Independientes de Barcelona en 1980, proponiendo un nuevo enfrentamiento al espacio urbano, mostrando que el entorno se está construyendo según una estructura patriarcal. En 1984, en las jornadas organizadas por el Seminario de Estudios de la Mujer de la Universidad Autónoma de Madrid se habla del uso del espacio y la mujer; la antropóloga Teressa del Valle con su libro Las Mujeres en la Ciudad e Isabel Segura con Guía de Mujeres de Madrid, se dedican a la investigación de las aportaciones de las mujeres en la ciudad, desde los años romanos. A partir de los noventa, los trabajos de mujeres arquitectas y urbanistas aumentan exponencialmente; en 1997 se realiza los primeros encuentros de mujeres en Arquitectura a cargo de la asociación La mujer Construye de Madrid. En 1999 se publica el Manual de Recomendaciones para la concepción de los aglomerados urbanos desde la perspectiva de género, resultado del proyecto europeo Las Mujeres y la Ciudad realizado por Anna Bofill, Isabel Segura y Rosa M. Dumenjo. En 2005 se realizan en Barcelona las I Jornadas de Urbanismo y Género por la diputación de Barcelona y coordinadas por Isabel Velasquez. ${ }^{17}$ En los mismos años se publica la tesis doctoral por Atxu Aman Alcocer El espacio doméstico: la mujer y la casa, primera tesis de género de la ETSAM en la que establece los vínculos entre las formas de pensar, de ver el mundo y de las formas de vida y la vivienda, mostrando cómo en la relación arquitectura-familia la mujer está ausente; la misma autora, en el Primer Congreso de Investigación en Arquitectura y Género de ArquitecAs en Sevilla en 2014 expone los Espacios diferentes en un mundo desincronizado. La velocidad de las arquitectas en la Universidad: ETS AM. ${ }^{18}$

Desde el punto de vista del proyecto, hay que destacar el edifico de Margarette Schutte -Lihotzy Hof en Viena, hecho por y para mujeres entre 1993-1997, el proyecto de 350 unidades de viviendas elaborado por las arquitectas Franziska Ullman, Gisela Podreka, Elsa Prochazka y Liselotte Peretti, aportando una gran variedad de tipologías flexibles. Cada uno de estos edificios cuenta con un espacio comunitario cuyo uso se decide por la comunidad, con abundancia de espacios intermedios que no solo sirven de conexión sino también de espacios para juegos alternativos, almacenaje en cada planta

17 Montaner and Muxí, Arquitectura y Política: Ensayos Para Mundos Alternativos 197-204

18 Atxu Amann Alcocer, El Espacio Doméstico: La Mujer y La Casa (2005). 
y estancias diversas. ${ }^{19}$

La exclusión de la mujer de la relación familia-arquitectura es una de las razones de las ciudades fantasmas que aparecen en las sociedades contemporáneas. La sociedad puso a la mujer en el interior de la vivienda y dedicó el exterior para el hombre; los hombres proyectaron urbanizaciones viendo la vivienda desde fuera, ya el funcionamiento del interior de la casa era desconocido para ellos. La visión desde fuera de los hombres ha conducido a la creación de interiores inhabitables. El arquitecto obtuvo un punto de vista de la vida de la ciudad contrario al que el habitante tiene; el primero observa la ciudad desde arriba, desde fuera mientras que el segundo vive la ciudad desde dentro. La proyección de lugares o edificios desde fuera requiere la estandarización de lo cotidiano y la uniformización de los hábitos, ya que desde arriba, desde lejos, no se distinguen personas y solo se ve una masa.

El programa Los Imprescindibles emitido en 26 de Diciembre de 2014 en La 2 de la Televisión Española, bajo el título No te mueras sin ir a Ronchamp (Sáenz. de Oíza) está dedicado a la vida y al trabajo de Francisco Javier Sáenz de Oíza. En este documental a partir del momento 47.00 de emisión aparece la conversación que el arquitecto tuvo con los habitantes que acababan de entrar en las viviendas sociales conocidas con el nombre de el Ruedo, situadas en el tercer cinturón de circulación M-30 de la Comunidad de Madrid, entre las calles Félix Rodríguez de la Fuente y la avenida Doctor García Tapia, en Moratalaz. Construido en el periodo 1986 - 1989, las viviendas realojaron 350 familias que aún lo ocupan, sin ser los propietarios de las casas. Todos los habitantes de las viviendas están insatisfechos con el diseño de Oiza. Después de casi 15 años no se sienten identificados con su casa; alguien mira en su interior y parece un espacio abandonado aunque habitado.

Habitante: El curvo, curvo que, por desgracia, me ha tocado a mí...

Oiza: Se dice "por suerte"...

Habitante: No por suerte, eh. jPor desgracia! Yo tengo tres hijos y no me caben dos camas.

Y más adelante empieza la conversación con otro habitante más enfadado.

Oiza: Pero es que el pilar se completa con un armario que va entre el pilar
La exclusión de la mujer de la construcción es una de las razones de la existencia de las ciudades fantasmas.

El hombre proyecta viviendas pero no las habita.

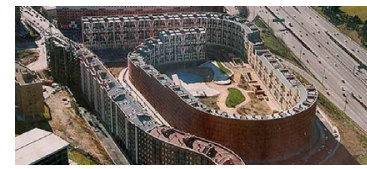

Vivienda social, M-30, Madrid.

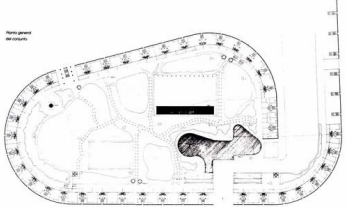

Vivienda social, M-30, Madrid. 


$$
\text { y la pared. }
$$

Habitante: No queremos armario

Oiza: Es que eso está para poner un armario abí.

Habitante: ;Ah, Usted! 'Ahí va a llevar las medallas! ¡De oro!

Oiza: Cuando nosotros hicimos no era de ustedes...

Habitante: Usted ha becho apartamentos porque esos son apartamentos. No son pisos para gente del Pozo del Huevo...

Otro habitante: ¿Y la televisión? Si la pongo alli, ¿cómo la pongo?

Y, Oiza enfadado ya contesta: Mira, lo mejor es que dejes la casa jy te hagas arquitecto! $^{20}$

Proyectar desde fuera, desde el espacio o desde dentro, desde la ocasión 
lo ambivalente. Cuando el tiempo no se evalúa y lo único que importa es la geometría del espacio, las construcciones son rígidas, incapaces de transformase y adaptarse a los cambios que la vida conlleva.

Existen muchas urbanizaciones fantasmas que surgieron por la incapacidad del Estado y de los arquitectos para evaluar la potencialidad de la vida y que a partir de la crisis económica de 2008 se expandieron. En España, es famosa la urbanización de Seseña en Toledo, las de Villalbilla en la comunidad de Madrid, la ciudad Valdeluz a pocos kilómetros de Madrid en Guadalajara, Orihuela en Alicante, la urbanización Costa Miño Golf en el ayuntamiento de Miño, en Galicia. Pero fuera de España, Ordos es una ciudad fantasma extraordinaria, una de las principales ciudades de Mongolia interior, cerca del desierto Ordos en el Norte de China. Se fundó en 2001 y tiene en su totalidad mil quinientos de habitantes. En 2003, las autoridades de Ordos decidieron construir a las afueras de la ciudad un nuevo distrito, Kangbashi; un distrito en medio de las estepas de Mongolia - una ciudad en el lugar de la nada - en la que vivirían millones de personas. La empresa Ordos Jiangyuan Water Engineering Co. Ltd quiso construir este nuevo barrio e invitó a 100 arquitectos de todo el mundo para construir cada uno un edificio para la nueva ciudad. Para la realización del proyecto se colaboró con el artista Ai Weiwei y los arquitectos suizos Herzog y De Meuron quienes fueron los responsables para la elección de cien jóvenes arquitectos de todo el mundo. El planteamiento de la ciudad se realizó siguiendo los principios del movimiento moderno; un planteamiento racional que se aleja de la creación de vecindades con calles estrechas y se enfoca en los grandes bulevares y edificios - objetos situados en un espacio homogéneo - y en este caso, literalmente desierto. El sueño del empresario es crear una ciudad exposición de la capacidad de cien arquitectos, un nuevo Dubái. Hoy en día, la ciudad es un museo de la arquitectura contemporánea; un museo que no tiene habitantes ya que es una ciudad vacía- ciudad fantasma - que fue construida para 1.000.0000 de habitantes, de los que solo 100.000 viven en sus edificios. El proyecto empezó el 2008 y hoy en día todavía la ciudad no está construida en su totalidad ya que el proyecto se abandonó antes de acabar. Aunque Ordos iba a ser mundialmente famosa por la calidad de sus edificios, al final ha conseguido ser famosa para los aficionados al skateboarding. Los
Urbanizaciones fantasmas en España

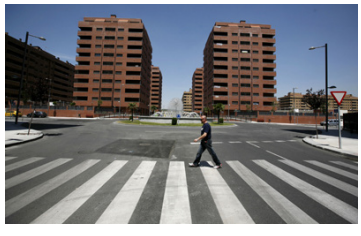

Seseña en Toledo

Ordos es una ciudad museo. Cien arquitectos jóvenes de todo el mundo, elegidos por Herzog y DeMeuron, han diseñado cada uno de los edificios de la ciudad pero en la ciudad no existen habitantes

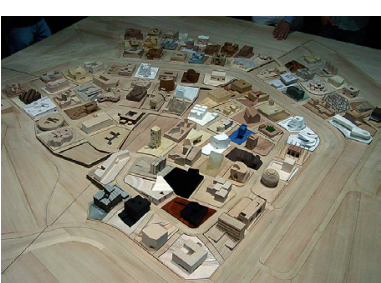

Ordos, Norte de China

Ordos, ciudad diseñada para un millón de habitantes de los que sólo cien mil, viven en sus edificios.

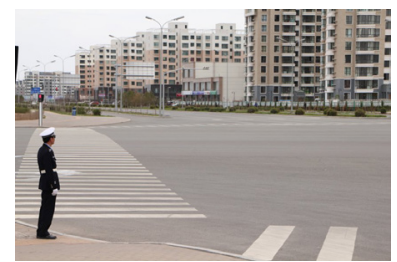

Ordos, Norte de China 


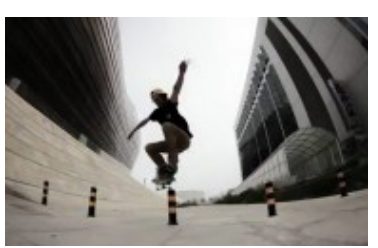

skaters escriben: Ordos: Skating in Modern Chinese Ghost town ${ }^{23}$ y consideran que Ordos es el país de la maravillas de skateboarding, pues todo es hormigón y mármol con calles, pavimentos y plazas nuevas, solo para el skateboarding ya que nadie vive en Ordos. La ciudad de Ordos satisface a los únicos habitantes que los arquitectos no tuvieron en cuenta: en las ciudades sucede todo lo que no fue pensado por los urbanistas y los políticos. $^{24}$

La distancia que se ha creado a partir de la modernidad entre la vida de los habitantes imaginada por los arquitectos y la vida real es fruto del proyecto desde fuera, desde arriba; proyectar desde fuera se fundamenta en un pensamiento binario que ha conducido también a la dicotomía hombre - mujer. El ser humano ha dividido el mundo en dos y como Jacques Derrida dice, el gran problema con el pensamiento binario es que siempre, uno de los polos domina; siempre uno es más fuerte que el otro.

Lejos del pensamiento binario está el pensamieto queer o trans-, analizado por Butler.

La identidad es del aquí y del ahora
Siempre el hombre ha sido superior a la mujer. Hélène Cixous, la feminista francesa profesora universitaria, poetisa y filósofa, encuentra el mismo conflicto: siempre que encontramos la polaridad existe la jerarquía. En otro lado, el pensamiento queer o transde los estudios de género de Judith Butler va más allá de las etiquetas y no acepta el concepto de la esencia; la identidad es del aquí y el ahora y no algo inmutable.

23 "ORDOS - Skateboarding through a Modern Chinese Ghost Town : Salty Peaks “, accessed 5/16/2015, 2015, http://www.saltypeaks.com/blog/2012/10/ordos-skateboardingthrough-a-modern-chinese-ghost-town.html.

24 Michel De Certeau and Luce Giard, La Invención De Lo Cotidiano: Artes De Hacer. I, Vol. 1Universidad Iberoamericana, 2007). 


\section{Vampiros, Zombis y Slums}

Las personas infelices son peligrosas ${ }^{1}$

J.W. Goethe

Adán y Eva, al comienzo de la historia de la humanidad vivían en el paraíso, en un lugar donde todo era fácil. La preferencia hacia lo prohibido, hacia lo que está fuera de las reglas impuestas por Dios, les excluyó del paraíso y los llevó a la tierra: un lugar donde, visto desde el paraíso, uno tiene que sufrir para conquistar la felicidad. En Solo los amantes sobreviven $^{2}$ de Jim Jarmuch, Adán y Eva son vampiros. No han vuelto al paraíso, pero tampoco han ido al infierno; se quedan entre la muerte y la vida: inmortales, liminales, asesinos pero a la vez sabios, conocedores de toda la historia de la humanidad, creativos y con potencia de superhéroe. Los zombis son criaturas del intermedio, como los vampiros, pero sin pasiones, ni pensamientos ni reflexiones; en continua caza, alimentándose de los que quedan vivos. Los vampiros y los zombis son de la categoría de los no-muertos (undead) que permanecen en un estado intermedio: no están vivos pero tampoco están muertos, como ocurre desde el Monstruo de Frankenstein, Hyde, Dorian Gray, Drácula hasta los vampiros y zombis del siglo XXI. ${ }^{3}$

El vampiro aparece en los diccionarios de Europa en el siglo XVIII, en Alemania, Inglaterra y Francia. Arnold Paole fue el primero estipulado como tal, según el informe médico sobre su muerte en 1732 en Medreya, Serbia. El pueblo desenterró

El vampiro aparece en el diccionario en el siglo XVIII su cadáver, los de sus allegados y los de aquellos a quienes dio muerte; les atravesaron el corazón con una estaca y los quemaron. ${ }^{4}$ La imagen del vampiro en la literatura aparece

Los Adan y Eva, contemporaneos son vampiros que viven en Detroit

\footnotetext{
$1 \quad J o h a n n$ Wolfgang Goethe, Fausto (Madrid: Alianza Editorial, 2006).

2 Solo Los Amantes Sobreviven, directed by Jim Jarmusch (España: Paramount Television \& Digital Distribution SpainS.L, 2014)

3 Jorge Martínez Lucena, Vampiros y Zombies PosmodernosEditorial GEDISA, 2011). 15

4 Santiago Lucendo Lacal, El Vampiro Como Imagen-Reflejo: Estereotipo Del Horror En La Modernidad Universidad Complutense de Madrid, Servicio de Publicaciones). 52
} 
El vampiro en la literatura aparece en 1797 con la novela El Vampiro de Polidori traspasa lo folclorico y sigue conVarney Vampire de Sheridan y Drácula de Bram Stoker.

Después del éxito de Drácula en 1927, en Broadway la fama del vampiro se expande

A partir de la década de los ochenta, el vampiro empieza a humanizarse.

El vampiro posmodernose se concibe como un ser ideal, con fuerza, belleza y creatividad en el siglo XVIII, en 1797, con Goethe y su Novia de Corinto, pero es desde The Vampyre (El Vampiro), la novela escrita por John William Polidori en 1815, cuando la imagen del vampiro traspasa lo folclórico. Su leyenda se sigue ampliando en el XIX gracias a la novela Varney the Vampire y Carmilla de Sheridan Le Fanu y Drácula de Bram Stoker. ${ }^{5}$ El éxito de este último marca un cambio en la vida de los vampiros, consolidando su figura en el siglo XX. Las varias adaptaciones de Drácula en el teatro y cine, entre las que destacan el éxito de Broadway en 1927 y la película de Tod Browning estrenada en 1931, ambas con el actor Bela Lugosi como protagonista, contribuyen a ello. A partir de 1973, año en el que Anne Rice escribe la novela Entrevista con el vampiro, - que más tarde en 1994 fue realizada en versión cinematográfica de Neil Jordan - la imagen del vampiro cambia de manera definitiva: el vampiro, según Lucena, empieza a humanizarse.

Ahora los vampiros son personajes que sienten melancolía de su existencia como humanos y lamentan tener que asesinar. Desde Los viajeros de la noche (Kathryn Bigelow, 1987) o Los jóvenes ocultos (Joel Schumacher, 1987), los vampiros buscan una vida pacífica. Más tarde, con Besos de Vampiro (Robert Bierman, 1988) se concibe al vampiro como una severa enfermedad mental. Drácula (Francis F. Coppola, 1992), es una versión de Stoker, transformada en una historia de amor eterno y verdadero. Aunque desde entonces siguen existiendo películas que ven a los vampiros como asesinos de tipo clásico, sin sentimientos, como Abierto hasta el amanecer (Robert Rodríguez, 1996), Vampiros (John Carpenter, 1998) o Vampiros: los muertos (Tommy Lee Wallace, 2002), la imagen del vampiro posmoderno se ha humanizado, llegando a concebirse como un ser ideal, con fuerza, belleza, creatividad y conocimiento; atractivo, siempre joven y diferente del resto de la humanidad. El vampiro posmoderno, descendiente del Drácula de Stoker es una criatura entre humano y antihéroe como los que aparecen en Crepúsculo (Catherine Hardwicke, 2008) y su saga, Underworld (Len Wiseman, 2003), Blade (Stephen Norrington, 1998), Déjame entrar (Tomas Alfredson, 2008), Sangre fresca (Allan Ball, 2008), Daybreakers (Michael Spierig y Peter Spierig, 2009), The Vampire Diaries (Crónica Vampiricas en español, 2009) ${ }^{6}$ o Solo los Amantes Sobreviven (Jim Jarmusch, 2013).

$5 \quad$ Ibid. 71

6 "Portal De La Comunicación InCom-UAB · Dossiers · Vampiros En La Cultura Audiovisual · Tiempo y Vampirización: Del Asesino Al Superhéroe “ , accessed 1/13/2016, 2016, http:/ /www.portalcomunicacion.com/monograficos txt.asp?id=168\&txt=116. 
Los protagonistas de esta última son seres de alto nivel intelectual que pueden controlar la necesidad de sed de sangre y buscan vivir rodeados de conocimiento y creatividad. Ambos consiguen ser incluidos en la civilización, pero sienten la necesidad de salir de ella, excluirse de nuevo; en esta sociedad, los vampiros son peligrosos no por su condición de animales que se alimentan de sangre humana sino por sus características intelectuales. El vampiro de Jim Jarmush es el ser no-ser que vuelve a corromperse para poder vivir en una sociedad animalizada, dominada por zombis.

El zombi, entre la muerte y la vida, un ser no ser, un muerto viviente, es una figura con una condición contraria a la de los vampiros. El zombi es un muerto resucitado, que ha vuelto a la vida sin mente ni alma. Es un cadáver que se mueve por el hambre de cerebros. El zombi tiene su origen en algunas leyendas de Haití: el término proviene del haitiano zombi que en la religión vudú se refiere al muerto resucitado por bokor o mago que lo controla. Los esclavos negros llevaron estas creencias a las colonias europeas en Caribe y, según la investigación de Davis sobre el mito de los zombis en 1982, estos son víctimas de un engaño: después de introducir a la víctima tetrodotoxina que pone el cuerpo en estado de catatonia, el bokor puede manipular el cuerpo y hacerle creer que ha muerto y ha vuelto a la vida. Además, para intensificar el proceso, enterraban y desenterraban el cuerpo. Según Davis, esas conductas provienen de las creencias culturales y religiosas grupales pero, en cualquier caso, el individuo reconstruía su identidad como zombi y su papel en la sociedad haitiana, era la que decidía el bokor, que le explotaba principalmente en plantaciones de caña de azúcar, como se ve en la primera película de zombis, White Zombie (Victor Halperin, 1932). ${ }^{7}$ Según Roman Gubern, el mito del muerto viviente se asienta en la Europa medieval de las grandes epidemias en las que las víctimas son enterradas precipitadamente- y los más afortunados consiguen escapar de sus tumbas y provocar así el terror a sus conocidos. ${ }^{8}$ A partir de las películas de Romero, el zombi cambia: detrás del zombi ya no hay el rito vudú, epidemia o guerra;

la amenaza no tiene causa (...) el zombi no tiene razón de ser ni discurso (...) Romero nos presenta el terror de lo indecible, la masa persistente y enloquecida.

$7 \quad$ Àngel Ferrero and Saúl Roas, "El” Zombi" Como Metáfora Contracultural,"

Nómadas.Revista Crítica De Ciencias Sociales y Jurídicas 32, no. 4 (2011), 97-220. 5

8
En la pelicula Solo los amantes sobreviven, los vampiros Adan y Eva son seres - no seres, de alto nivel intelectual marginados por no poder coincidir con la sociedad posmoderna de los zombis

El zombi es de naturaleza contraria del vampiro; un cuerpo resucitado que ha vuelto sin mente y sentimientos.

El zombi en Europa empieza con las grandes epidemias en las que la victimas eran enterradas precipitadamente 
Los zombis, a partir Romero, son seres sin discurso; el terror de lo indecible

Hoy en día, los zombis y los vampiros son una pandemia
Los no-muertos vienen de la literatura gótica de siglo XIX; la época en la que tiene lugar el movimiento gothic revival architecture que rechaza lo racional y lo neoclásico y busca las formas góticas de la Edad media
Los famosos zombis de Romero no eran tales, sino una masa de hombres alienados, probablemente renacidos de la muerte o atravesados por una oscura maldición espacial, con un apetito monstruoso por la carne y desprovistos de su capacidad de raciocinio.9

Los zombis y los vampiros se han convertido en una pandemia; los lectores y espectadores seguidores de narraciones de vampiros, zombis, fantasmas y, en general, de aquellas criaturas que se quedan en un entre, aumentan. Hay una extraordinaria producción de series, películas, video games, comics y novelas sobre las criaturas intermedias de la oscuridad. Los no-muertos no solo conquistan el espacio cinematográfico o literario sino el de la sociedad y el de la ciudad creando un fenómeno social que va desde los simples seguidores de la saga de Crepúsculo, Sangre Fresca o Crónicas Vampíricas hasta posiciones más extremas como la de las nuevas tribus urbanas: los góticos y los darks, adolescentes y adultos muy delgados con uñas largas, piel mortecina, a quienes les gustan los cementerios y la literatura romántico-tardía más fantástica. Estos jóvenes no habitan en castillos, en las calles de Transilvania o dentro de edificios góticos, sino en las calles de las grandes ciudades. Según Lucena, la invención de los no-muertos es una manera de ir en contra del racionalismo que acababa de empezar en el siglo XIX. Los no-muertos vienen de la literatura gótica que florece en el siglo XIX: el estilo literario de terror de ambiente romántico que toma lugar en castillos, cementerios, sótanos, criptas, laberintos, ruinas y, en general, en un paisaje de edificios góticos en los que aparecen personajes extraordinarios: demonios, vampiros y monstruos. La narrativa gótica sucede en el momento en el que tiene lugar el movimiento de gothic revival architecture (en Español, el movimiento neogótico) cuando se revaloran las formas góticas de la Edad Media Baja, entre los siglos XII y XV, y se rechaza lo racional y lo neoclásico, con su máximo representante en Eugène Viollet-le-Duc. De la misma manera, la novela gótica también rechaza lo racional y busca en sus narraciones lo irracional ${ }^{10}$; es, según Lucena,

un dispositivo mítico para afrontar la angustia generada por algo que la ciencia del siglo XIX y empezaba a postular: que el alma podía ser reducida cientificamente a cuerpo,

9 Jorge Fernández Gonzalo, Filosofía Zombi Anagrama, 2011). 19

10 Santiago Lucendo Lacal, El Vampiro Como Imagen-Reflejo: Estereotipo Del Horror En La Modernidad Universidad Complutense de Madrid, Servicio de Publicaciones). 75 
a cerebro, a sistema nervioso, y que el único destino del hombre era, por tanto, su tumba. ${ }^{11}$

En principio la mentalidad estrictamente materialista es de las clases cultivadas y, por eso, los no muertos son pocos y de clase alta, pero a lo largo de siglo XX la mentalidad de lo racional, lo que reduce el alma al sistema nervioso, se difunde de manera masiva. Aparecen los zombis, una masa de no-muertos y la imagen del vampiro clásico pierde su credibilidad haciéndose humano; se ha producido una suerte de desencantamiento del no-muerto porque en nuestra cultura se ha asumido acríticamente que no somos más que materia, y por ello resulta cada vez menos atractivo reflexionar sobre este miedo, porque el materialismo es la lente a través de la que ineluctable e inapelablemente nos miramos ${ }^{12}$.

Según Cinto Niqui Espinosa, la preferencia hacia las ficciones de vampiros y zombis-puede ser una metáfora del hecho de estar presentes en un mundo material y otro inmaterial, aquel de los entornos digitales ${ }^{13}$; es quizás la identificación con el presente-ausente habitante contemporáneo que está a la vez en todos los lugares corriendo a la velocidad de la luz entre las redes de la sociedad, con un cuerpo sin reflejo y por eso inmaterial, transparente. Hoy en día los ciudadanos según el medio de transporte y de comunicación que usan pueden elegir si quieren un cambio de lugar (desplazamiento) o un cambio de tiempo (desincronización); ${ }^{14}$ pueden estar ahora pero no aquí, tal y como los vampiros.

La identificación de los habitantes con los vampiros amplía el significado del gótico; comienza designando a los pueblos bárbaros, los godos, Goths, ${ }^{15}$ y hoy en día identifica, principalmente, la subcultura y tribu urbana antes referida que vive en las calles y los espacios marginales de las ciudades. El vampiro que anteriormente se excluía de la cotidianidad ya que la luz del día le eliminaba, hoy intenta humanizarse

\footnotetext{
11 Jorge Martínez Lucena, Vampiros y Zombies Posmodernos Editorial Gedisa, 2011).

12 Portal De La Comunicación InCom-UAB · Dossiers - Vampiros En La Cultura Audiovisual . Tiempo y Vampirización: Del Asesino Al Superhéroe

13 Cinto Niqui Espinosa, La Comunicación Es Vida: Reflexiones Eclécticas Sobre Ticsy Contenidos Audiovisuales, Vol. 191Editorial UOC, 2011).162

14 François Ascher and María Hernández Díaz, Los Nuevos Principios Del Urbanismo: El Fin De Las Ciudades no Está a La Orden Del DíaAlianza editorial, 2004).61

15 Santiago Lucendo Lacal, El Vampiro Como Imagen-Reflejo: Estereotipo Del Horror En La Modernidad Universidad Complutense de Madrid, Servicio de Publicaciones). 75
}

La novela gótica rechaza lo racional y busca narraciones de lo irracional; no puede aceptar que el alma pueda ser reducida cientificamente al cuerpo

Quizas, hoy la gente se identifica con los nomuertos, porque vive en un mundo aumentado, entre lo material y lo inmaterial. 
El vampiro abandona los castillos y se pierde en las calles de la grandes ciudades como un Flâneur

El vampiro es el ser marginado, excluido.

Los zombis no son excluidos de la sociedad: son los que están dentro y han perdido su humanización y el acto de pensar y entrar en la civilización, eliminando el estigma del ser peligroso que la historia le ha dado. El vampiro, a partir de la película de Francis Ford Coppola, abandona los lugares oscuros, los castillos y los cementerios para perderse como un flâneur en las calles de las grandes ciudades. El vampiro encarna la exclusión: el habitante apartado de las estructuras de la sociedad, habitante de espacios liminales y marginados; Adán y Eva, los excluidos del paraíso, de los paisajes y estructuras divinas, ahora son excluidos de la sociedad, criaturas marginadas que viven en Detroit, en una ciudad fantasma. Son seres que han intentado civilizarse, aprender, amar el arte y la filosofía y vivir en la eternidad alimentando su pensamiento. Sin embargo, cuando lo consiguen observan la animalización de la sociedad, su transformación en zombis ${ }^{16}$. Adán y Eva están obligados a aislarse de la sociedad o a entrar en sus reglas contemporáneas, transformarse de nuevo en un ser que se mueve por su sed, en una continua necesidad de consumir. Los zombis no son gente que se han quedado excluida de la sociedad, al contrario, los que están dentro de las estructuras socio políticas y económicas son los que se transforman en zombis: gente que pierde su humanización, la empatía, los sentimientos y todo lo que nos convierte en inhumano. La figura de zombi y de los zombis alineados es aquella de los seres humanos- masa de Simmel:

no la suma de las existencias personales integras, sino una configuración nueva, que no se compone de las individualidades completas de sus participantes, sino de aquellas partes del carácter de cada uno en las que coincide con los demás y que no pueden ser otras que las más primitivas y del nivel más bajo en la evolución orgánica ${ }^{17}$.

Los zombis, el ser-masa, cuerpo incompleto, con ronas expuestas a la mirada y vacios que nos entregan la visibilidad del fondo (...) seres sin razón de ser, ni discurso, ni tan siquiera recibe el privilegio de la denominación. ${ }^{18}$

Los zombis; no son como los vampiros que antes de transformarse mueren y se quedan entre la vida y la muerte melancólicos y reflexionando desde el entre, sino

$16 \quad$ Jarmusch, Solo Los Amantes Sobreviven

17 George Simmel, Cuestiones Fundamentales De Sociología (Barcelona, Spain: Gedisa, 2002), 68 .

18 Jorge Fernández Gonzalo, Filosofía Zombi Anagrama, 2011). 13-19 
se transforman contagiándose; la transformación en zombi es provocada por un virus que se expande a alta velocidad y canibaliza a quien contagia; los transforma en una masa anónima, como la de las sociedades contemporáneas que no piensa sino con un alto grado de egoísmo e intenta satisfacer sus apetitos de inmediato. ${ }^{19}$ Los zombis contemporáneos son los seres humanos que han dejado de pensar y por eso no hablan, no saben qué decir y han perdido su humanidad. Sin embargo los zombis no son solo monstruos sino también víctimas: han sido manipulados, infectados y lo que realmente hacen no es por su propia voluntad. El zombi es víctima porque no puede ni escapar de sus instintos ni del contagio, y es monstruo porque aparentemente nadie le obliga a actuar de ese modo. Es monstruo y víctima porque ni es consciente de su maldad, como sí ocurre con Drácula u otros monstruos, ni es consciente de su lamentable situación, ${ }^{20} \mathrm{y}$, sin ser consciente de su maldad, la contagia.

El serde los vampiros y de los zombis se representa en el estar; en español ser y estar es algo distinto aunque en inglés y griego designa lo mismo. El paisaje urbano se contagia y se moldea de los distintos tipos de habitantes que envuelve. El pensamiento contemporáneo obliga al retorno de lo primitivo, al instinto del consumo y el abandono del pensamiento y del arte. Como dice Miguel Suarez, lo que parece una distopía, en la ciudad contemporánea es una realidad: se cierran cines y teatros y en su lugar se construyen centros comerciales y aparcamientos ${ }^{21}$-en Madrid, el caso de H\&M de Gran Vía es de los más conocidos. De una parte los ambientes marginales, ciudades informales que están excluidas de las estructuras sociopolíticas de las ciudad legítima y, de otra parte, la ciudad proyectada, planeada anteriormente por los Estados, con las manos de los urbanistas, de manera racional: ciudades ordenadas, en las que todo está bajo un continuo control para que no se altere el paisaje urbano por cualquier contingencia no pensada; homogénea, uniforme, construida bajo las reglas de la estandarización y producción en masa; ambientes en los que los habitantes se han transformado en usuario, pasivo consumidor del producto-casa. De otra parte las ciudades informales, construidas con las manos de sus propios habitantes, pero, infortunadamente, sin el apoyo del Estado: las autoridades o demuelen las ciudades no legítimas, los slums, 19 Àngel Ferrero and Saúl Roas, "El” Zombi" Como Metáfora Contracultural," Nómadas. Revista Crítica De Ciencias Sociales y Jurídicas 32, no. 4 (2011), 97-220.

20 Ibid.

21 "El Círculo Del Vampiro Contemporáneo - Croco Magazine ", accessed 1/13/2016, 2016, http://www.crocomag.com/item/el-circulo-del-vampiro-contemporaneo/.
El zombi no nace de la muerte como el vampiro; se transforma por un virus que canibaliza a la gente y la hace y masa anómima

El paisaje urbano se transforma según sus nuevos habitantes: los vampiros y los zombis

Ciudades fantasma, ciudades informales y zonas marginadas 
Ciudades planificadas bajo un pensamiento racional por los urbanistas, ciudades informales levantadas por sus habitantes

Proyecto PREVI. Construcciones que asumen la espontaneidad de los habitantes. o no las apoyan, mostrándose pasivas en la mejora de las condiciones de higiene e instalaciones.

Dependiendo de la relación que se establece entre el Estado, el urbanista, el arquitecto y el usuario, se pueden construir tres tipos de edificios o ciudades: aquellas pensadas, diseñadas y construidas por el arquitecto que son ofrecidas al usuario como un producto, la famosa casa llave en mano. Un modo de proyectar en el que el arquitecto sabe lo que el habitante necesita y le deja fuera de la construcción de su casa, transformándole en usuario. El segundo sería aquel que considera que el arquitecto podría asumir y racionalizar la construcción espontánea. El tercer modo apoya la autoconstrucción y autogestión de una vivienda ya que se administra por los que la van a habitar, sin que el arquitecto o el Estado intervengan.

En el caso de la construcción que puede asumir la espontaneidad de los habitantes encontramos el PREVI (Proyecto Experimental de Vivienda). PREVI como una utopía del Movimiento Metabolista- es un proyecto que empezó a gestionarse en Lima en 1967 como un concurso internacional para la construcción de quinientas viviendas que buscaba dar una solución a la situación de las ciudades informales que se construían en Lima. El PREVI contó con la ayuda de las Naciones Unidas debido a que esta problemática se extendía más allá del territorio de Lima, llegando a todos los países atrasados que empezaban a estar en vías de desarrollo. En este concurso, en un principio se iban a construir sólo una minoría aunque, al final, el jurado decidió construir la mayoría de los proyectos que se presentaron posibilitando que cada equipo construyera veinte viviendas. Entre los arquitectos internacionales que participaron están Atelier 5 (Suiza), Aldo van Eyck (Holanda), Christopher Alexander (USA), Candilis, Josic and Woods (Francia), José Luis Íñiguez de Ozono y Vázquez de Castro (España), James Stirling (Reino Unido), Toivo Korhonen (Finlandia), Esguerra Saenz Urdaneta Samper (Colombia), Fumibiko Maki, Kionori Kikutake (Japón), Charles Correa (India), Herbert Obl (Alemania), Knud Svenssons (Dinamarca), Oskar Hansen y Svein Hatloy (Polonia).

En las bases del concurso se hallaba la petición de proyectar lugares tomando en cuenta las actividades edificatorias de los habitantes y, así, poder presentar no un resultado acabado, sino construir un proyecto en proceso, viviendas hechas para ser ampliadas y modificadas por los habitantes. Se generó un tejido urbano no de 
construcciones, sino a base de técnicas constructivas, en el que las viviendas no estaban acabadas sino empezadas: una vivienda social dinámica que aporta la base para la futura autoconstrucción de las viviendas. Esta iniciativa viene a cambiar los modos proyectuales de forma que el factor tiempo entra a formar parte del proyecto; el tiempo, entendido bajo el concepto de la eternidad, construye lugares sólidos, fuertes, para que perduren. Sin embargo, a partir de los años sesenta, después del fracaso del Movimiento Moderno y tras la revolución de la tercera generación en Europa, se produce un cambio en el modo con el que se usa el espacio-tiempo en los proyectos arquitectónicos.

Importantes, en este sentido, son las investigaciones del matemático Hermann Minkowski y de Albert Einstein por las que se llega a partir de 1915 a ver el espacio y el tiempo no como dos entidades separadas sino como una sola. A partir del nuevo espaciotiempo de Minkowski, el punto se reemplaza por el suceso y la longitud por el intervalo, ya que suceso e intervalo son conceptos espaciotemporales. A partir de la Relatividad de Einstein, la noción del espacio como un receptáculo -como lo escribían Platón y Aristóteles - o como un escenario en el que suceden historias -que es la concepción newtoniana del espacio- es abolida. El tiempo ya no es un escenario o un receptáculo, es un actor. ${ }^{22}$ Esos cambios -aunque difícilmente interiorizados por la sociedad de los sesenta- provocan cambios en los pensamientos sociológicos, antropológicos, biológicos y arquitectónicos, pues todo es relativo y relacional. Desde la época de los sesenta parte de la nueva generación de arquitectos se aleja de la concepción clásica del espacio y empieza a planificar teniendo en cuenta que el espacio no es algo fijo sino que se construye dentro de la vida.

El Estado de Perú en 1966 tiene un pensamiento innovador, más que ninguno otro país en el mundo, ya que los arquitectos que participan en el concurso no son los que ponen las bases del mismo, sino el arquitecto y presidente de Perú Fernando Belaúnde Terry que, con el apoyo de las Naciones Unidas y bajo la dirección de Peter Land, ${ }^{23}$ consigue crear un tipo de viviendas que se expanden por el mundo. La construcción del proyecto experimental dependía obviamente del uso de la tecnología de la época ya

22 Brian Greene, The Fabric of the Cosmos: Space, Time, and the Texture of RealityVintage, 2007).

23 "PREVI: The Metabolist Utopia “, accessed 5/15/2015, 2015, http://www. domusweb.it/en/architecture/2011/04/21/previ-the-metabolist-utopia.html.
Cambio en los modos de proyectar; distinta concepción del tiempo

A partir de Minkowski y Einstein el espacio deja de ser un receptáculo y se hace un actor

Nueva generación de arquitectos que planifica viendo el espacio no como algo estable, sino como algo en continua construcción 
La comparación entre PREVI 1970 y 2015 expone que existe preferencia por el crecimiento vertical, rechazo de la producción en serie y búsqueda de una identidad

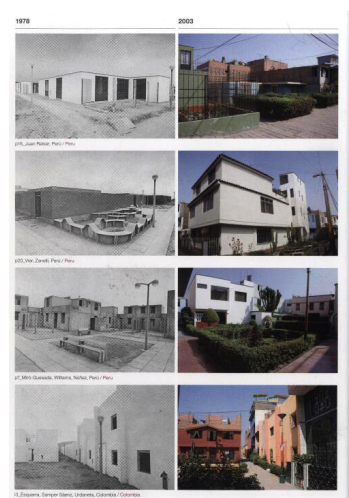

Previ 1979 y 2015

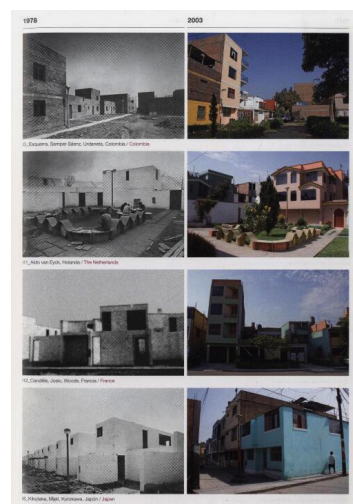

Previ 1979 y 2015

que además se quería construir un barrio flexible que se seguiría autoconstruyendo, para gente de ingresos escasos. Los modos de construcción de las casas tenían que ser de bajo coste y por ello el Estado necesitaba un uso de la tecnología innovador que pudiera ser usado por cualquier habitante para la construcción de su casa.

Hoy en día la Unidad Vecinal Experimental -resultado de la ejecución de las propuestas de PREVI- es un barrio de la ciudad de Lima que ocupa un terreno mucho más amplio y está completamente trasformado por las viviendas que construyeron sus habitantes. La comparación del barrio de PREVI de 1970 con el de 2015 permite asumir que la vida no se puede encerrar en una construcción sólida y también analizar cuáles son las tipologías usadas más satisfactorias para sus habitantes. Hay una preferencia por el crecimiento vertical -las casas que estaban proyectadas para tener hasta dos plantas, ahora tienen tres o cuatro. Además, se produce la mezcla de los usos de lo residencial con lo comercial y la individualización de las formas -los habitantes rechazan la construcción en serie y buscan cada uno su estilo. ${ }^{24}$ Otra cosa que funcionó en el desarrollo de este barrio - y que sus habitantes confirman- es la separación del automóvil y del peatón; el grupo de desarrollo había propuesto la creación de varias plazas que serían interconectadas entre ellas por pasajes peatonales. La propuesta se realizó y los habitantes las mantuvieron, construyendo plazas gestionadas por los vecinos: cuidan su vegetación, crean condiciones de silencio y tranquilidad y, en general, consiguen un ambiente que favorece una vecindad que desapareció en los años del movimiento moderno con calles anchas y espacios libres homogéneos que crean distancia entre las personas. ${ }^{25}$ Otro de los elementos importantes en esta pequeña ciudad- barrio es el patio, que llega a ser el núcleo de ampliación de la casa y plaza más cerrada de socialización de la familia o de las varias familias que lo podrían compartir. ${ }^{26}$

En su totalidad, viendo el proyecto experimental 45 años después, realmente el Estado Peruano y sus participantes consiguieron construir una plataforma que facilitara condiciones de higiene e instalaciones propias para la construcción de casas según los 24 P. Lucas, J. Salas and R. Barrionuevo, "Cuarenta Años Del PREVI-LIMA: Algunas Enseñanzas Para La Industrialización De La Vivienda De Bajo Coste En Latinoamérica,” Informes De La Construcción 64, no. 525 (2012), 51-62.

25 Stavros Stavridis, De La Ciudad Pantalla a La Ciudad Escena (Atenas: Ellinika Grammata, 2002).

26 Samper Esquerra et al., "PREVI Lima: 35 Años Después," Arq, no. 59 (2005), 72 76. 
criterios y las necesidades de cada familia. La plataforma da un muestrario de casas de bajo coste y las familias deciden si quieren repetir y adaptar cada tipo o transformarlo totalmente. Se presenta el patrón Instalación / Densificación / Diversificación; en relación a la instalación, el grupo familiar puede hacer cambios para definir su propia casa según sus gustos y necesidades; en la densificación, la familia puede añadir nuevos núcleos en Instalación /Densificación/ Diversificación la casa según su variación en el tiempo; la diversificación se refiere a la posibilidad de subdividir la casa en varios departamentos para varios grupos. Las reglas del juego para el habitante giran en torno a dos conceptos: permanencias y holgura/ rigidez. Las permanencias son aquellos elementos que perduran en las transformaciones y no cambian; la dialéctica entre la holgura y la rigidez depende del habitante, de los elementos estructurales y de los espacios que el habitante tiene para la incorporación de nuevas estructuras. ${ }^{27}$

Los 35 años de PREVI, dice Rodrigo Pérez de Arce, merecen ser celebrados como lección de arquitectura: de humildad, porque los derroteros del proyecto jamás quedarán congelados a la visión original del autor en todos sus aspectos; y de confirmación, por cuanto las obras iniciales, estrategias, postulados y la convicción de sus autores y gestores dieron inicio a la formación de un barrio urbano desde muchos puntos de vista destacable ${ }^{28}$.

Desde entonces parece que no ha sucedido nada parecido. Se han realizado prácticas similares pero incomparables a la sociedad de PREVI porque nunca existe un apoyo estatal o humanitario detrás. Se pueden encontrar colectivos que mejoran la tecnología y la plataforma de la autoconstrucción pero siempre a escala pequeña.

El tercer modo de relación entre el arquitecto y el habitante es la que promociona la autoconstrucción; encuentra sus raíces en los años 60; es la más radical de todas y defiende la vivienda construida por sus habitantes. En palabras de John Turner:

Cuando los usuarios controlan las decisiones más importantes y son libres para aportar su propia contribución al diseño, construcción y administración de su vivienda, ambos, proceso y medio ambiente producidos, estimulan el bienestar individual y social. Cuando los

27 Ibid.

28 Ibid. 
Soberania - habitantes, la autoconstrucción
Housing como verbo y como sustantivo. La casa como proceso y como objeto usuarios no tienen control sobre las decisiones clave ni son responsables de ellas, el rededor de alojamiento puede convertirse en un impedimento para la realización personal y una carga para la economía ${ }^{29}$.

Los títulos de los libros Libertad para construir: el proceso babitacional controlado por el usuario (Freedom to Build, Dweller Control of the Housing Process), publicado en 1973 y Vivienda: Todo el poder para los usuarios (Housing by People: Towards of an autonomy in building environments) publicado en 1976 revelan la aproximación radical del arquitecto nacido en 1927, John F. C. Turner. Alguien podría pensar que defiende la muerte del arquitecto, sin embargo Turner no se queda en los modos proyectuales - formales y conceptuales - sino que profundiza en la propia actividad arquitectónica, llegando a la política de la vivienda social. Es distinto, como dice, pensar en la vivienda (housing) como sustantivo o como verbo; cada aproximación -verbo o sustantivo- conduce a dos caminos muy distintos. Cuando la palabra vivienda se usa como sustantivo, la vivienda es un objeto mientras que el verbo define un proceso y una duración de continuidad infinita. En sus palabras: In English, the word 'bousing' can be used as a noun or as a verb. When used as a noun, housing describes a commodity or product. The verb 'to house' describes the process or activity of housing $(. . .)^{30}$. En castellano las palabras que terminan en -ción tienen este doble sentido, siendo a la vez sustantivo y verbo; edificación, habitación, construcción, albergación. En cualquier caso, respecto al termino housing, pensar en verbo o en sustantivo conduce a lugares distintos. Desde el habitante, si ve la construcción como un producto es el usuario del producto, si ve la construcción como acción, entonces él es actor. A la vez, si el arquitecto o el Estado perciben la construcción como un producto, el habitante es usuario del producto, y si afronta la vivienda como verbo, entonces ve al que vive dentro de ella, quién la hace, como una construcción que se construye mientras se vive.

Para Turner, el territorio de América Latina, en el que las ciudades informales se multiplican rápidamente, ha de encontrar una solución para el problema de la vivienda que lejos de ver la casa como un objeto incorpore los conceptos de la vivienda progresiva

29 John F. C. Turner, Vivienda, Todo El Poder Para Los Usuarios: Hacia La Economía En La Construcción Del Entorno (Madrid: Hermann Blume, 1977), 18.

30 John F. C. Turner and Robert Fichter, Freedom to Build: Dweller Control of the Housing Process (New York: The Macmillan Company, 1972). 151 
y procesos autogestionados. Según Turner, cuando la satisfacción de las necesidades de los habitantes es considerada como un producto el valor de la casa se estima según su cualidad material y no según lo que ofrece en la vida de los habitantes. La lógica de demoler los slums o las viviendas que no siguen los estándares preestablecidos de un sistema central, viene de que la gente fracasa en distinguir lo que son las cosas y lo que hacen en las vidas de los habitantes. Turner, aunque va en contra de los estándares, no los anula; sin ellos sería imposible la construcción, sostiene; pero, los estándares no deben ser usados para medir el valor de lo humano. ${ }^{31}$

A Turner le interesa el impacto de la actividad de la albergación (housing activity). Hace una nueva clasificación de las actividades en actividades significativas y no significativas existencialmente; en la primera categoría entran aquellas actividades de las que depende de manera inmediata los fines de la vida como la cultivación y preparación de la comida, cuidar nuestro cuerpo, vestirnos, la crianza de los hijos y el alojamiento de estas actividades; en la segunda categoría entran las que tienen valor pero existencialmente insignificantes en comparación de las primeras como, por ejemplo, tratar con cualquier objeto producido en masa como operador o consumidor o distribuidor ${ }^{32}$. Housing - la construcción de la casa - es una actividad que entra en la primera categoría que afecta de manera inmediata a los fines de la vida. Afrontar la vivienda como sustantivo significa que las agencias ofrecen un producto para las necesidades de los habitantes, transformando a los habitantes de la casa en consumidores o pasivos beneficiaros - gran ejemplo es hoy en día las agencias de casas llave en mano. Si se entiende la vivienda como actividad existencial para la vida de los habitantes, éstos ya no son usuarios pasivos de un producto, sino personas activas que tienen el poder de tomar decisiones ${ }^{33}$. Turner propone, por tanto, la eliminación en el vocabulario arquitectónico del término usuario ya que solo usarlo significa enfrentarse a la vivienda como producto y al habitante como pasivo consumidor, como zombi. Lo importante es encontrar un modelo que considere la vivienda como actividad y al habitante como actor.

La diferencia entre la vivienda como verbo y como sustantivo tiene otra interpretación. En el caso del verbo hablamos de personas que usan organizaciones para hacer una actividad; en el segundo caso, hablamos de organizaciones que usan personas.

$\begin{array}{ll}31 & \text { Ibid. } 152 \\ 32 & \text { Ibid. } 153 \\ 33 & \text { Ibid. } 154\end{array}$

Contra la demoloción de las ciudades informales, a favor de los conceptos de la vivienda progresiva y los procesos autogestionados

Actividades significativas existencialmente y no significativas; construir una casa es una necesidad existencial del habitante

La vivienda como sustantivo es ofrecer un producto y transformar al habitante en su consumidor. La vivienda como verbo ofrece procesos a un habitante activo que toma descisiones sobre su entorno 
Housing como verbo: personas que usan organizaciones, housing como sustantivo, organizaciones que usan personas

Sistema abierto de construcción: el habitante elige los modos y las combinaciones

Sistema de construcción cerrado: las decisiones se toman por un cuerpo central
Estos dos modos generan dos sistemas de viviendas, dos sistemas de construcción completamente distintos; el primero es un sistema cerrado, el segundo es un sistema abierto. En los dos sistemas los servicios necesarios básicos están institucionalizados y son los mismos; lo que cambia son los modos en los que se usan, las combinaciones que se hacen de ellos y las personas que deciden su organización. Estos servicios, su complejidad y su número depende del contexto en el que se va a construir la vivienda: el terreno donde se apoyará la casa, las herramientas y los materiales que se van a usar, la mano de obra que tiene el conocimiento, la experiencia o la habilidad para construirla-y un sistema de intercambio que permite a los habitantes tener los recursos que no tienen.

En el caso de estos cuatro servicios, en un sistema abierto, el habitante elige los modos y las combinaciones a realizar según los recursos que puede tener y las leyes existentes. En el ejemplo de Turner, si hay cuatro maneras para utilizar cada servicio (cuatro sitios distintos, cuatros modos de financiación, cuatro grupos de materiales y herramientas y cuatro modos de concesión de su construcción) el habitante es libre y puede elegir entre seiscientas veinticuatro combinaciones. ${ }^{34} \mathrm{El}$ otro sistema de construcción que Turner llama sistema cerrado es aquel en el que las decisiones se toman por un cuerpo central de corporaciones privadas o instituciones públicas. En este sistema autoritario existe inevitablemente una jerarquía en la que un cuerpo toma las decisiones desde el principio y elige la combinación de los servicios y, al final, la persona que se aloja en la vivienda tiene muy pocas opciones (a veces, ninguna). Este esquema, según Turner, representa un típico proyecto de viviendas promocionado por el sector público.

En general, la manera tradicional para solucionar los temas de la vivienda muestra su fracaso tanto en los terrenos ya desarrollados como en los que se acaban de empezar a desarrollar; principalmente, dificulta la vida de aquellos que viven con bajos ingresos. El sistema político autoritario de la vivienda es un sistema menos económico que el sistema abierto, satisface menos a sus habitantes y les priva de la existencial actividad de la albergación. Las personas no son libres para hacer combinaciones y elegir los hogares que abrazan sus actividades; el único criterio es conseguir lo máximo -materialmente hablando- pagando lo menos posible. Un sistema abierto no es el que 
corresponde a un sistema que favorece a los okupas y que permite que cada familia pueda construir y habitar como quiera y donde quiera, sino un sistema que combina los estándares y las instituciones pero de forma no autoritaria. No se puede jugar sin reglas; siempre hay una autoridad que pone las reglas pero éstas, en la política de la vivienda, deben estar en continua revisión y cambiar para adaptarse cada vez a los contextos distintos. Según Turner, hay dos cosas que pueden hacer frente al problema de la vivienda: dejar de imponer nuestra voluntad a los otros pretendiendo saber mejor lo que los otros necesitan y ayudar a los que han perdido la autoridad de la actividad de la vivienda -de vivir- ya que ha sido reducida por las instituciones públicas y las corporaciones privadas. ${ }^{35}$

La postura de Turner, el famoso Modelo Turner, caracterizado por Emilio Duhau como una visión neoanarquista, ${ }^{36}$ aceptó muchas críticas, principalmente por los que tenían una perspectiva histórico-estructural y neomarxista ${ }^{37}$ quienes estaban en contra de la ciudad informal y, de alguna manera, en contra de la autonomía y viendo la producción informal como un modo precapitalista de producción ${ }^{38}$. Años atrás el derecho de una persona para construir su casa según sus ingresos, sus recursos y sus materiales era un derecho evidente. La perspectivita de Turner más que nada es un método para que cualquier habitante pueda tener derecho a hacer una actividad tan básica como la de vestirse o alimentarse. Ivan Illich, en sus pensamientos sobre la Industria de la Construcción, explica:

La mayoría de la gente no se siente realmente en su casa, sino cuando una parte significativa del valor de ella es fruto de su propia labor. Una política convivencial se ocuparía primero de definir lo que es imposible que alguien obtenga por sí mismo, cuando se construye su casa. En consecuencia, aseguraría a cada uno el acceso a un minimo de espacio, de agua, de elementos prefabricados de herramientas convivenciales, desde el barreno hasta el montacargas y, probablemente, también el

\footnotetext{
$35 \quad$ Ibid. 175

36 Emilio Duhau, Hábitat Popular Y Política UrbanaUniversidad Autonoma Metropolitana Unidad Azcapotzalco, 1998), 40.

37 Ibid.

38 Raúl Fernández Wagner, "Los Asentamientos Informales Como Cuestión. Revisión De Algunos Debates," Los Mil Barrios (in) Formales. Apuntes Para La Construcción De Un Observatorio Del Hábitat Popular Del Área Metropolitana De Buenos Aires, Cravino MC (Organizadora), UNGS, Provincia De Buenos Aires (2008), 13-14.
}

El sistema cerrado es menos económico que el sistema abierto

El sistema abierto no está a favor de un sistema de okupas; no se puede jugar sin reglas

El Modelo Turner es un método para que cada habitante pueda construir su casa

La gente se siente en casa solo si una parte significativa del valor de ella es fruto de su propio labor. 
Christopher Alexander es defensor de la misma idea:

El ser humano se siente en casa cuando está profundamente implicado en su construcción.
La privación de los habitantes de la actividad de construir transforma la huella de la vida en un producto para el alojamiento
Sólo hay un único modo de construir atemporal. Tiene mil años, y todavía hoy es como era entonces. Los grandes edificios del pasado, los pueblos, las tiendas y los templos en los que el ser humano se siente en casa, son los realizados por personas que están profundamente implicadas en su construcción. No podemos construir edificios importantes, ciudades y lugares bellos, en los que nos sentimos nosotros mismos, donde estamos vivos, si no se sigue esta vía. Como se verá, esta llevará a cualquiera que la esté buscando a hacer edificios que sean ellos mismos, tan antiguos en su forma como los árboles y las colinas y como nuestros mismos rostros ${ }^{40}$.

John Turner fue duramente criticado y se le consideró como un ex anarquista que estaba a favor de programas anarco-liberales, tanto por su colaboración con el Banco Mundial entre 1983 y 1990 para planteamientos de viviendas para pobres como también por sus visiones en las que el poder tiene que ir a las manos de los habitantes, enfrentándose con las teorías marxistas. Como dice Illich, la privación de los habitantes de la actividad de construir su propia casa hace que ésta pase de ser un lugar para ser habitado que transforma la huella de la vida a convertirse en un producto para el alojamiento. También sostiene Illich que antes de la modernidad, antes del comienzo de la industrialización, la casa no era un producto sino un proceso que no acababa nunca. Hay gran diferencia entre las palabras habitante y usuario: para el primero el mundo es habitable, para el segundo el mundo es usable. La casa hoy es un producto que espera ser usado; es un producto que construyen los profesionales y que dan la llave en mano.

En muchas lenguas, en vez de habitar puede decirse también vivir. “DDónde vive usted?", preguntamos cuando queremos saber el lugar en el que alguien habita. "Dime cómo vives y te diré quién eres". La equiparación de habitar con vivir procede de una época en la que

39 Ivan Illich, La Convivencialidad (México: Joaquín Mortiz /Planeta, 1985), 107.

40 Christopher Alexander, El Modo Intemporal De Construir Editorial Gustavo Gili, 1981) 
el mundo era habitable y los seres humanos habitantes (...) La vivienda tradicional nunca estaba acabada en el sentido en que hoy decimos que un bloque de pisos o de apartamentos se entrega "llave en mano"(...)Un barrio de una ciudad nunca estaba terminado: hasta la época de los soberanos absolutos, en el siglo XVIII, los barrios residenciales de las ciudades europeas eran el resultado no planificado de la interacción de numerosos artistas constructores (...)Sólo en una medida muy limitada se nos permite aún habitar a los seres humanos de la era industrial. Por lo general, en vez de habitar, somos simplemente alojados. Los La vivienda tradicional nunca estaba acabada; hoy se entrega llave en mano. alojamientos se nos dan ya planificados, construidos y equipados; en el mejor de los casos, podemos instalarnos entre cuatro paredes alquiladas o compradas mientras no clavemos en ellas ningún clavo ${ }^{41}$.

La pérdida del derecho a construir es la pérdida del derecho a habitar; una condición defendida por Heidegger: habitar es construir. El mundo después de siglo XIX se ha transformado de habitable a usable, aunque siempre existen voces de arquitectos, filósofos, sociólogos, pedagogos y, en general, de cualquier oficio que defienden los derechos de los habitantes como constructores de su propia casa.

Cuando los politicos debaten hoy este tema se dividen las opiniones. Para unos, quizá los más en nuestros países industrializados, se trata de promover el derecho de los ciudadanos a un alojamiento en vivienda-garaje. El derecho de habitar significa para ellos que todo ciudadano disponga de su parte de metros cuadrados bien situados y acondicionados, construidos por, profesionales. Pero otros muchos quieren algo muy distinto: para ellos se trata de instaurar el derecho a un hábitat comunal en el que cada comunidad pueda asentarse y vivir de acuerdo con su propio arte y su propia capacidad ${ }^{42}$.

En la década de los setenta surgen nuevas políticas alternativas en las que el papel del habitante en la construcción es fundamental, estando a favor de la

$41 \quad$ "La Reivindicación De La Casa | Edición Impresa | EL PAÍs “, accessed 5/21/2015, 2015, http://elpais.com/diario/1983/06/05/opinion/423612014 850215.html. $42 \quad$ Ibid. 
A partir de los setenta surgen nuevas políticas a favor de la autoconstrución planificación participativa. En Vancouver, en 1976, se realiza la Cumbre Hábitat I, ${ }^{43}$ en donde se reconocen estas políticas. En los principios de los 80 tiene lugar una gran financiación por el Banco Mundial para la realización de programas de mejora de la vivienda que involucraban la participación de los habitantes en el planteamiento y la gestión de los barrios por las comunidades. En las conferencias del primer Hábitat en Vancouver se propone un alejamiento de las políticas habitacionales de una primera generación que veían deseable la erradicación de los asentamientos. Son destacables tres políticas habitacionales de tres generaciones: las de los 50 y 60 que están a favor de la demolición de los barrios informales y que al final llegan acompañadas de un sistema de vivienda de "llave en mano"; la segunda generación que aparece en los años setenta, en las que hay un giro hacia la radicalización, la mejora de la vida de los barrios urbanos y la participación de los habitantes en los procesos, encontrando casos en los que hay grandes subvenciones en programas de mejora en los que están directamente involucrados los habitantes, siendo gestionados por ONGs y comunidades. Finalmente, en los años 80 y 90, la pobreza aumenta y se producen cambios estructurales en las sociedades de América Latina. El Estado se trasforma en facilitador del mercado y empieza la rápida expansión de las hipotecas; distintas organizaciones nacionales e internacionales se centran en la vivienda y abandonaron la escala urbana. ${ }^{44}$

Hoy en día, cada vez se encuentran más grupos de arquitectos a favor de la autoconstrucción. Son los proyectos de soluciones $a d h^{45}$ y aquellos que ven la ciudad, los barrios y las viviendas, como procesos y no como objetos. Prácticas parecidas son 43 En el 1976, en Vancouver, se realizó la primera conferencia de Naciones Unidas sobre los Asentamientos Humanos (Habitat I). En esta primera conferencia la Fundación Habitat cambió su nombre en Centro de las Naciones Unidas para los Asentamientos Humanos (CNUAH) y en 2002 obtuvo el nombre que hoy conocemos, Programa de las Naciones Unidas para los Asentamientos Humanos, ONU-Habitat. Dichas conferencias se realizan cada 20 años. El Habitat I tomó lugar en Vancouver en 1976, el Habitat II en Estambul, Turquía, y la tercera conferencia, Habitat III, tomará lugar en el próximo año, de 17 a 20 de Octubre de 2016, en Quito, Ecuador. “ONU-HABITAT :: Oficina Regional Para América Latina y El Caribe “, accessed 5/19/2015, 2015, http://www.onuhabitat.org/.

44 Raúl Fernandez Wagner, "Elementos Para Una Revisión Crítica De Las Políticas Habitacionales En América Latina," en Asentamientos Informais e Moradia Popular: Subsidios Para Políticas Habitacionais Más Inclusivas. (Brasilia, Brasil: Instituto de Pesquisa Econômica Aplicada (IPEA), Ministério de Planejamento, Orçamento e Gestão., 2008).

45 La Real Academia Española define el término ad hoc como lo que se dice o lo que se hace solo para un fin determinado. Literalmente significa "para esto". Es una solución elaborada solo para un problema y no puede ser universalizada; es lo contrario a las soluciones que proponía los CIAM, el Estilo Internacional y, en general, el Movimiento Moderno que tendía a generalizar las soluciones considerando que todas las personas tienen las mismas necesidades. (Gropius) 
las del grupo Elemental (Chile) ${ }^{46} \mathrm{y}$, entre sus proyectos, el de las viviendas en Quinta Monroy, en Iquique de Chile en 2004 y la Villa Verde en Constitución en Chile, en 2010; del equipo_urban - think tank (U-TT) ${ }^{47}$ como la intervención Hoograven, Urban Rehab en el vecindario de Hoograven, en Utrecht, Holanda, la Vivienda Social El Carmen en Guarenas- Guatire, Venezuela, en 2010 y más. Hay que mencionar el proyecto de los U-TT ${ }^{48}$, Torre David / Gran Horizonte, ${ }^{49}$ ganador del premio León de Oro en la Bienal de Arquitectura de Venecia, la propuesta para la mejora del uso de la Torre David en Caracas construido por el arquitecto venezolano Enrique Gómez en 1993 y que fue abandonado poco antes de ser acabado, tras la muerte de su propietario. Desde entonces Torre David se va ocupando de familias de manera informal y hoy se considera un barrio informal vertical habitado por 750 familias. En el mismo camino se encuentra el estudio Atelier Metropolitano - Jorge Mario Jáuregui ${ }^{50}$ que se dedica, entre otros proyectos, a la rehabilitación de las favelas de Brasil con varias estrategias y métodos. Jorge Mario Jáuregui, arquitecto argentino autor del programa Favela Barrio, también es el creador del teleférico del Complexo do Alemão, en Sao Paolo, que facilita la comunicación interna en las favelas, como también entre ellas y la ciudad, creando así una interconexión aérea entre la ciudad formal e informal integrando la una a la otra. El grupo U-TT también construyó el Metro Cable Caracas, integrado en el Metro de la ciudad, conectando lo informal con lo formal. ${ }^{51}$ 46 "Elemental - ", accessed 5/15/2015, 2015, http://www.elementalchile.cl/.

47 "Urban-Think Tank - Interdisciplinary Design Studio", accessed 5/15/2015, 2015, http://www.u-tt.com/.

48 La importante aportación del U-TTT en el ámbito de la investigación y la pedagogía; U-T'T en colaboración con Columbia University han creado el S.L.U.M LAB. (Sustainable Living Urban Model), una empresa nómada mundial que reúne a estudiantes, planificadores y arquitectos de todo el mundo para trabajar hacia una comprensión de los vinculos entre la arquitectura, el urbanismo, la planificación urbana, y el alivio de la pobreza. (traducción libre).

S.L.U.M. Lab is a global nomadic enterprise bringing together students, planners, and architects worldwide to work towards an understanding of the links between architecture, urban design, urban planning, and poverty alleviation. Working from the pedagogical context of Columbia University's Graduate School of Architecture, Planning, and Preservation, the Lab challenges prevailing notions about urban improvement, searching for innovative methods to optimize the energy of the vernacular and the informal. It works to expand the role of the politically engaged architect and planner, while also breaking down rigid definitions and valuations of urban typologies. "Columbia GSAPP “, accessed 5/15/2015, 2015, http://www.arch.columbia.edu/ $\underline{\text { labs/more-labs. }}$

49 “Torre David “, accessed 5/15/2015, 2015, http://torredavid.com/.

50 “Jorge Mario Jáuregui “, accessed 5/15/2015, 2015, http://www.jauregui.arq.br/.

51 "Metro Cable Caracas / Urban-Think Tank | Plataforma Arquitectura " , accessed 5/15/2015, 2015, http://www.plataformaarquitectura.cl/cl/02-96696/metro-cable-caracasurban-think-tank.
Grupos contemporaneos a favor de la autoconstrucción

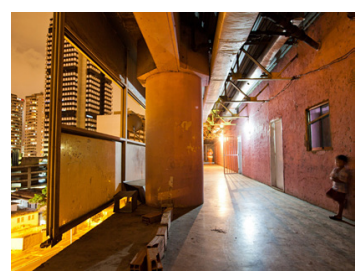

Torre David, Caracas 
Las exposiciones Design for the Other $90 \%$ en 2007 y Design the Other 90\% Cities
Madrid y Atenas ocultan en su interior ds pequeñas ciudades informales
Las soluciones delos arquitectos activistas sorprenden y revelanlagrandeza delacreatividad, que consigue utilizar elementos baratos y/o residuales con gran sensibilidad frente a lo sostenible y frente a la calidad de la vida de los que viven en el límite entre la muerte y la vida.

Las exposiciones Design for the Other 90\% que se realizó en 2007 y su segunda parte Design with the Other 90\%: Cities; exposiciones de proyectos que se realizan en todo el mundo e investigan y encuentran soluciones para $90 \%$ de la población de la tierra, que es el porcentaje de población que vive en barrios y ciudades informales construidas por ellos mismos. ${ }^{52}$ La segunda exposición con sesenta proyectos está dividida en seis partes: acceder, adaptar, intercambiar, revelar, incluir, prosperar. En la unidad de acceder están las soluciones que se centran en el acceso a la sanidad, la educación, la higiene y el transporte; en adaptar se dan soluciones a los problemas que encuentran las comunidades de los asentamientos informales; en intercambiar se concentran los proyectos que construyen puentes para el intercambio de conocimiento de diseño entre ciudades formales e informales; incluir aloja las soluciones que se relacionan con la inclusión de personas consideradas marginadas y excluidas por la ciudad establecida; prosperar es la unidad que incluye proyectos que intentan crear oportunidades de trabajo en las ciudades informales; revelar concentra los proyectos que quieren visibilizar las situaciones y las condiciones de los asentamientos informales; que casi siempre quedan fuera de la luz los mapas oficiales: el mapa no es el territorio.

Madrid y Atenas disponen de una pequeña ciudad informal en su interior, en el centro: zonas que fueron construidas o transformadas por sus habitantes de manera ilegal e irregular. El siglo XVI, en 1561, Felipe II trasladó toda su corte a Madrid. Como la ciudad no estaba preparada para acoger a la gente del monarca, Felipe II hizo la ley de Regalía de Aposento, que duró hasta la mitad del siglo XIX, según la cual todas las casas que tenían más de una planta debían dejar la segunda a la Corte y convivir así con un extraño. Los madrileños con casas de más de una planta intentaron ocultar el segundo piso de la fachada de distintas maneras. Ésto modificó las fachadas de las casas madrileñas: colocación de las ventanas a distintas alturas de manera desordenada para que no se viera si era de una o de dos plantas, tejados muy inclinados con buhardillas

\footnotetext{
52 "About - Design Other 90\% Network | Smithsonian Cooper-Hewitt National
} Design Museum, accessed 5/16/2015, 2015, http://www.designother90.org/about/. 
secretas o plantas intermedias que no se podían considerar como segunda planta. Estas casa son hoy conocidas como casa a la malicia.

La ciudad de Atenas, en Grecia, tres años después de la revolución contra los otomanos y su liberación, aprobó el primer plano urbanístico en su historia moderna trazado por los alumnos del arquitecto alemán Karl Friedrich Schinkel, Stamatis Kleanthis y Eduard Schaubert, en 1833. ${ }^{53}$ El esbozo de los arquitectos revelaba un pensamiento arquitectónico muy avanzado para su época en relación a la organización de las calles, hablando de una combinación de una retícula rectangular con conexiones radiales desde los puntos céntricos y con grandes espacios abiertos teniendo siempre de referencia la Acrópolis y los palacios; ${ }^{54}$ prohibía la construcción en la colina de la Acrópolis; las calles serían anchas y los espacios comunes ocuparían grandes superficies, de conformidad de las normas europeas para una capital, todo se orientaba hacia el Pireo, el estadio y principalmente hacia Acrópolis. Al contrario al resto de los países europeos, cuando la gente se dio cuenta de los cambios necesarios para la construcción de los grandes bulevares, los propietarios de las zonas que se iban a expropiarse protestaron, salieron a la calle e impidieron su ejecución..$^{55} \mathrm{El}$ proyecto fue suspendido. Atenas aprobó en 1834 un nuevo plan urbanístico del arquitecto Leo von Klenze que mantuvo las calles estrechas, hizo los espacios públicos pequeños y permitió la construcción en la colina de Acrópolis con el fin de silenciar las protestas. El resultado es el caótico e inhumano estado de la ciudad de Atenas, aunque el Barrio de los Dios o Plaka, construido por los habitantes de la ciudad en las colinas de Acrópolis, es el barrio más caro, famoso, turístico y, a la vez, posiblemente el más humano y sano para vivir en Atenas.

La belleza y el interés se centran hoy en día en lo irregular, lo informal, lo que sale fuera de las normas de las sociedades. El Calendario Pirelli, en 2013, abandonó la belleza del desnudo para encontrarla en las favelas del Rio de Janeiro ${ }^{56}$.

El intento de normalizar la formas y controlar el orden de la ciudad para la mejor convivencia de los ciudadanos tiene como resultado, de una parte, la creación de

53 K. Biris, The First Athens Plans..., op. cit., passim

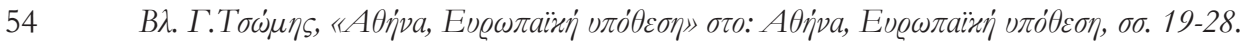

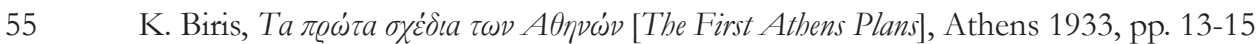

56 "Pirelli Presenta El Calendario Pirelli 2013, Fotografiado Por Steve McCurry ",

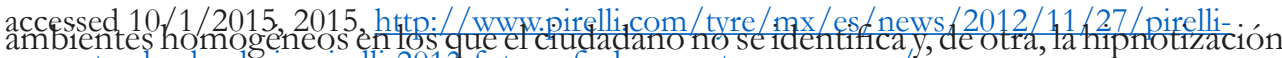
presenta-el-calendario-pirelli-2013-fotografiado-por-steve-mccurry

La situación urbanistica actual de Atenas se debe, entre otras razones, a que ningún plan urbanistico fue permitido por los habitantes

El barrio informal de la colina de Acrópolis: Barrio de los dioses o barrio de Plaka

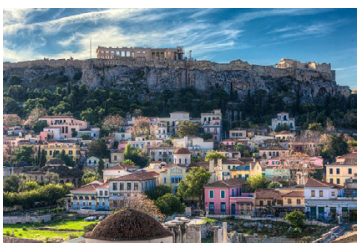

Barrio de Plaka, Atenas

La belleza se centra, hoy en día, en lo informal. 


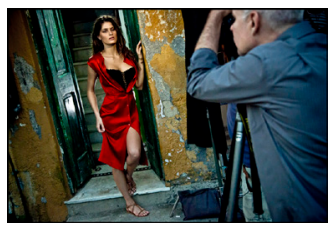

Calendario Pirelli, Rio de Janeiro, 2013

La normalización de las formas y su rigidez conduce a la construcción de ambientes en los que los habitantes se transforman en consumidores de su propia casa producto

Cualquier orden y clasificación, deja residuos, nuevos conceptos que no pueden entrar en ninguna estructura del habitante y su transformación en consumidor -zombi que no tiene palabra acerca de la construcción de su entorno. Además, parece ser que el pensamiento racional es el que ha conducido a las ciudades informales hacia lo marginal: el mundo nunca ha sido geométrico y, por eso, no se puede categorizar de manera absoluta; cualquier clasificación produce nuevos residuos, es decir, nuevos conceptos y lugares que no pueden entrar en ninguna categoría y estructura y, por eso, lugares marginales, excluidos; los desperdicios se producen mientras sucede el diseño del orden y de la clasificación. ${ }^{57}$ Al otro lado, un pensamiento más complejo, pensamiento de la inclusión, del “esto y lo otro”, según el que un concepto entra en varias categorías o en ninguna pero se incluye como diferente y no se excluye como residuo, es más eficaz en la organización de la ciudad: la aparición de lo marginal, lo monstruoso y lo diferente no desordena la ciudad ya que está siempre incluido en su planeamiento, sino que ofrece otro tipo de orden, nuevas posibilidades de innovación y descubrimiento ya que lo nuevo y lo desconocido no está clasificado, es lo que está entre las categorías. Según el director de El Laberinto del fauno, Guillermo del Toro Gómez, la actual pandemia de vampiros sirve para recordarnos que no tenemos un auténtico control sobre nuestros cuerpos, nuestro clima o incluso nuestras almas. Los monstruos siempre nos proporcionarán la posibilidad del misterio en nuestro mundano reality show ${ }^{58}$.

57 Zygmunt Bauman et al., "Modernidad y Ambivalencia," in Las Consecuencias Perversas De La Modernidad. Modernidad Contingencia y Riesgo (Barcelona, España: Anthropos, 1996), 73 119. 94

58 "El Misterio Del Otro | Actualidad | Móvil EL PAÍS “, accessed 1/13/2016, 2016, http://elpais.com/m/diario/2009/08/06/revistaverano/1249509602 850215.html. 


\section{Sin Fin}

No hay cosa más útil que no hacer nada

Lao Zi.

Cuando los seres bumanos hacen planes, los dioses rien, dice una frase griega desde la época de los dioses del Olimpo. Aparece algo, de repente, hace que todo lo esperado se desvanezca en el aire antes de ser vivido; el pensamiento queda a la espera de lo que podría haber pasado. Lo repentino viene, si no a destrozar el plan por completo, como mínimo a desestructurarlo. La desestructuración es más dolorosa. Lo acabado, lo muerto, lo que nunca volverá a suceder no se puede arreglar y no decepciona nunca; lo que ha quedado a medias tiene la posibilidad de estructurarse de nuevo y con formas distintas. Lo inacabado y lo abandonado siempre invitan a volver, a comenzar de nuevo y dar un nuevo matiz. La destrucción de una Idea-proyecto, sin haber sido vivida, provoca miedo en la realización de las siguientes porque es posible volver a encontrar en el camino el dolor de lo incumplido

La relación de la imaginación con la realidad, percibida como un lugar intermedio, es similar a la que se siente cuando estando en el mar se mira hacia el horizonte. Una piensa que tiene fin, que un día se sumergirá en el mar y nadará hasta tocarlo; otro entra con el mismo fin, pero sabe desde el principio que eso no pasará nunca y esto le permite disfrutar del viaje, porque sabe hacia dónde quiere ir pero sin preocuparse de si llegará o no. Otra opción es darse la vuelta e irse; no intentar aproximarse al horizonte, negar su existencia. En el primer caso realidad e imaginación son términos opuestos; tener como meta llegar al horizonte no permite estar a la vez en la realidad y disfrutar del camino: el único objetivo visible es el horizonte, el fin. En el segundo, llegar al horizonte no es una obsesión, sino algo deseado; si no se llega, hay muchas otras oportunidades en el

1 “El Arte De no Actuar “, accessed 1/13/2016, 2016, http://www.lavanguardia. com/cultura/20140730/54412610993/arte-actuar.html.

Cuando los ser humanos hacen planes los Dioses rien

Destrucción y desestructuración de una Idea

La relación de la imaginación y la realidad espacialmente es la relación que uno tiene frente al horizonte 
El término fin tiene dos significados: fin como final, fin como meta, como objetivo

A partir de los cincuenta, arquitectos defienden que no se debe proyectar del todo

Detrás de la perfección y de la necesidad de acabar está el pensamiento binario

En la grieta, brecha que aparece entre la realidad y la imaginación, entre praxis y teoría, aparece lo inesperado y desconocido camino. En el tercer caso, no existe separación entre la realidad y la imaginación porque no existe el horizonte y no existe un fin.

El fin tiene dos significados: por una parte es de naturaleza espacial (fin del mundo) y por otra, se refiere a alcanzar una meta. La metáfora del mar y el horizonte sirve para explicar las diferentes formas de acercamiento a un proyecto, a una creación, a una producción. Tres modos de proyectar: partiendo de una idea previa transcribiendo el pensamiento en dibujo para después transformar el terreno fielmente a lo dibujado, proyectar teniendo una idea de lo que uno quiere sabiendo que nunca se conseguirá. Y por último, proyectar sin proponerse un fin, una meta.

En Occidente, durante la modernidad, los planificadores proyectan desde una idea previa. Observando la ciudad desde fuera, deciden lo más necesario, lo más económico y lo más sano; y transcriben sus decisiones en planos. Entre los años cincuenta y los ochenta aparecen algunos arquitectos que se plantean la posibilidad de no tener todo planificado. Dos son los factores que definen el proyecto: la evaluación y la organización; evaluar la situación desde dentro y no desde un mapa y centrarse, no en las distancias espaciales, sino en los cambios culturales y politicos. Este tipo de proyecto no tiene un fin; está pensado para que pueda ser implementado por los habitantes. El tercer modo de proyectar es el no planificar; simplemente crear las condiciones para que las cosas se hagan de manera natural.

Cada modo de proyectar parte de distintas formas de pensamiento. El primero es resultado del pensamiento binario; separa la imaginación y la realidad (xorismos) en dos y la ve como términos opuestos. En el pensamiento binario, cualquier asunto puede estar o en la imaginación, o en la realidad. Así, nace la teoría, la praxis y la brecha entre ellas: se inventa una teoría (teoría) o un Ideal y se proyecta y dibuja en un plano (praxis) para que llegue a ver construido (meta). La brecha es una grieta en la que se encuentra lo inesperado y lo imprevisible, a la espera de intervenir en la realización de la teoría. El pensamiento de la inclusión conlleva otro modo de proyectar: se trabaja con elementos y formas que podrían ser modelados, repetidos o eliminados en el tiempo, sin que eso destruya la construcción. Se centra en el tiempo, no en el espacio; capta los cambios que suceden en las sociedades, no en las dimensiones de los espacios. Los materiales del primer modo son la distancia, la altura, la longitud, el ancho y los materiales no se pueden 
desestructurar sino solo destrozar, como el hormigón. El segundo modo de proyectar se centra en la construcción de procesos: crear una plataforma que sea capaz de cambiar y adaptarse según la evolución de los años, como es el caso del proyecto PREVI. El tercer modo, parte de un pensamiento borroso: no ve el horizonte, ni ve límites, ni clasifica, ni pone metas, sino que deja que las cosas lo encuentren.

Las sociedades que más experimentan con las dos últimas formas de dibujar son las orientales. La filosofía de Oriente y principalmente de China es una filosofía del Entre, donde no hay forma, y cuando la tiene es porque se adapta a los movimientos de lo que envuelve. La cosmología China no piensa en el comienzo de la historia de la humanidad y del mundo, sino en la vía, el tao, que es el camino y el vacío que nos envuelve. ${ }^{2}$ En Occidente pensaron en el Demiurgos, que puso en orden el caos; desde entonces todo tiene un principio y un fin. En China, no existe principio ni fin; todo tiene un ritmo cíclico que está en continua trasformación; no se cree en la eternidad sino en la duración; ${ }^{3}$ dibujan pensando que nada dura para siempre y tienen en cuenta el modo en el que lo imprevisto favorece el proyecto inicial. La filosofía griega es la filosofía del Ser, del límite; el ser existe porque tiene forma: la forma la definen los límites.

Un modo de proyectar que se basa en un pensamiento borroso no dual es la técnica de wu wei: la estrategia de no actuar (wu wei) ${ }^{4}$. No hay cosa más útil que no hacer $n a d a{ }^{5}$ dice en el libro de Dao, Lao Zi. La estrategia o el arte de no actuar se basa en la frase de no bacer pero no dejar nada sin hacerse. ${ }^{6}$ No se refiere a adoptar una actitud pasiva, como se entiende en Occidente, sino a dejar que las cosas pasen de forma natural. La estrategia del no actuar es mucho más eficaz que las de Occidente - según las que todo tiene que estar planificado y programado antes de su comienzo - si se observa que, China, por esta estrategia, no ha sido conquistada. ${ }^{7}$ Mientras que aparentemente no existe una metodología, de repente, las cosas están hechas sin darse cuenta cómo se hicieron. Este modo de trabajar conduce a la quinta clase de ambigüedad que William 2 François Jullien, La Sombra En El Cuadro. Del Mal o De Lo Negativo (Madrid: Arena Libros, 2009).

3 Ibid.

4 François Jullien, Conferencia Sobre La Eficacia (Buenos Aires: Katz Editores, 2007).

5 "El Arte De no Actuar ", accessed 1/13/2016, 2016, http://www.lavanguardia. com/cultura/20140730/54412610993/arte-actuar.html.

6 François Jullien, Conferencia Sobre La Eficacia (Buenos Aires: Katz Editores, 2007).

7 Ibid.
En China, se encuentra la filosofía del Sin Fin, del Entre; en Oriente no pensaron nunca en un principio y un fin

No hay cosa más útil que no bacer nada. Lao Zi 
La quinta clase de ambigüedad, William Empson

Hallazgos valiosos que se producen de manera casual, serendipia y el trabajo preliminar del consciente

El azar no favorece más que a los espiritus preparados. Luis Pacal
Epson - ampliamente citado por Venturi. Una confusión afortunada, como dice Epson, en la que el autor está descubriendo su idea mientras está escribiendo. ${ }^{8} \mathrm{O}$, crear a partir de estados de epifanías o, de estados de serendipia.

Estos momentos repentinos que conducen a hallazgos valiosos (Arquímedes, Newton, Fleming), son denominados desde 1754, serendipia, término acuñado por el arquitecto, político y escritor Lord Horace Walpole. La 23a Edición del Diccionario de la Real Academia Española, define la palabra serendipia como hallazgo valioso que se produce de manera accidental o casual. ${ }^{9}$ Sin embargo, quizás ese momento en el que sucede la inspiración, no es algo accidental o casual, sino que es el trabajo del periodo preliminar del consciente que siempre precede a todo trabajo fructífero del inconsciente, como lo describe Henry Poincaré. ${ }^{10}$ Plantea las combinaciones de nuestra mente como si fueran los átomos de Epicuro. Cuando nuestra mente está en un estado de reposo completo, los átomos no se mueven; están enganchados en las paredes de nuestra mente. Cuando estamos trabajando, se mueven en la habitación de la mente de pared a pared. Sin embargo, a menudo sucede que mientras en el aparente estado de reposo, algunos dejan la pared y hacen nuevas conexiones sin tener un previo orden. Esto es posible si antes ha tenido lugar el trabajo consciente preliminar, que es una danza por las numerosas combinaciones de la búsqueda de ensamblarlos para encontrar soluciones. Y mientras se cree que no se ha hecho nada porque no se ha llegado a soluciones satisfactorias, y se deja de trabajar, los átomos no vuelven a engancharse a las paredes, sino que siguen su danza pero esta vez de manera libre; y así, vienen de repente nuevas combinaciones y aparece una inspiración o un descubrimiento por azar. ${ }^{11}$ Pero sea o no, aunque es algo que pasa por azar, en el campo de la investigación el azar no favorece más que a los espíritus preparados, como dice Louis Paster. Para llegar a experimentar el maravilloso momento de la epifanía, inspiración o serendipia, alguien tiene que estar muy preparado y haber trabajado mucho previamente. El período de inspiración sucede sólo durante el baile libre de los átomosconexiones de nuestra mente. La única manera de llegar allí es dejar que las cosas sucedan, creando a partir de aquellos hallazgos valiosos que se producen de manera accidental o casual. 8 William Empson, Seven Types of Ambiguity, Vol. 645Random House, 2004). 2 9 De la Lengua Española, Diccionario, "Real Academia Española," Vigésima 1 (2001). 10 Brewster Ghiselin, The Creative Process: Reflections on Invention in the Arts and Sciences (California: Transformationial Book Circle, 2005). 22-31

11 Ibid. 22-31 
La técnica del wu wei, se basa en la actividad de la evaluación; es la técnica que China usa en las guerras, que tienen la misma base que las que se usan en la planificación urbanística y en el diseño arquitectónico. Tanto en la guerra, como en la actividad arquitectónica, uno proyecta y hace un plan previo a la acción. Sin embargo, esto sucede sólo en Occidente; en Oriente no existe un plan previo de sus acciones; no modelizan. El Tratado de la Guerra, dice Jullien, no empieza con lo que la planificación es, sino que se habla de la evaluación. El arte de la guerra en China empieza con la evaluación del potencial de la situación. No se elabora un plan de operaciones sino un diagrama de potencial de situación. Elpotencial de situación consiste en determinar la variable en función del beneficio ${ }^{12}$.

La diferencia entre la planificación y la evaluación radica en que la primera se apoya en algo elaborado mientras que en la evaluación lo importante es el potencial de la situación; los planos elaborados, en algún momento caducan; cuando uno capta la potencialidad y consigue captar sus ritmos y la manera en la que se renuevan, puede administrar cualquier situación. En Occidente se modeliza y se sigue un plan: cuando aparece una circunstancia que está fuera de él, se crea la brecha entre la teoría (lo anteriormente observado) y la praxis (el momento de la acción). Cuando las estrategias y las planificaciones no consiguen su fin es porque, en el medio, en el camino, algo imprevisto aparece que no estaba dentro del plan; la falta de reacción adecuada en el momento de lo improvisto, pierde la batalla. En Occidente, dice Jullien, se llama golpe de genio cuando alguien consigue reaccionar en una circunstancia imprevista y dejar de lado el plan, el modelo.

La diferencia entre el pensamiento chino y el europeo es el modo en que cada cultura percibe el concepto de la eficacia. En Europa entendemos la eficacia en términos de medio -fin:

La forma ideal que sirve de plan es percibida como el objetivo; luego hay que encontrar los medios que deben ponerse en práctica para alcanzar ese objetivo. El mejor medio es el que conduce de manera más directa al objetivo deseado (...) Esta sería la formulación más densa, que resume lo esencial, de la exigencia estratégica: una vez que la forma modelizada
Occidente planifica, Oriente evalua.

La planificación se basa en algo fijo, un plan; la evaluación se apoya en el potencial de la situación

En Occidente pensamos y planificamos teniendo un fin $y$ un medio

12 François Jullien, Conferencia Sobre La Eficacia (Buenos Aires: Katz Editores, 2007).10 
China no piensa en el fin ni en el medio, sino en la consecuencia y la condición.

En China la transformación, en Occidente la acción

La acción es momentanea, local y remite a un sujeto.

La transformación es global , progresiva y no remite a un sujeto

Organizar y ordenar

\section{se establece como objetivo, buscamos el medio. ${ }^{13}$}

La arquitectura del pensamiento chino es muy distinta a la hora de proyectar. El termino objetivo no existe en el idioma chino clásico. En la cultura oriental no se desarrolló nunca el concepto de la forma ideal, por eso no se pensó en un fin, como tampoco en el medio que conduce a ello: la finalidad es un concepto griego. En China no se piensa en términos de medio-fin sino en condición - consecuencia. La estrategia intenta anticipar los elementos que favorecen el proceso para sacar beneficio de ella. En la guerra, la estrategia china busca las condiciones facilitadoras; agotarlas para el enemigo y aumentarlas a su favor. La gran diferencia entre las dos culturas es que Grecia pensó en la acción y China en la maduración: el fin y el medio necesitan la acción; la condición y la consecuencia remiten a la maduración. Después de la modelización y la definición del fin y del medio, es necesaria la acción del sujeto. Teoría- Praxis es una dualidad griega. En China no actúan sino que transforman; la transformación como concepto es muy distinto de la acción aunque estén cerca; el estratega y el Sabio chino transforman el mundo. La acción es momentánea, aunque ese momento puede durar un tiempo; es local, ocurre aquí y ahora, y remite a un sujeto que puede ser colectivo o no. ${ }^{14}$ La transformación es global: se transforma todo el conjunto; no puede ser momentánea, sino progresiva y continua; por último, no remite a un sujeto sino que procede discretamente, por influencia: $1 a$ transformación no se ve, sólo se ven los resultados (...) no se ve el fruto mientras está madurando sino un día se comprueba que está maduro. ${ }^{15}$

En el pensamiento de la inclusión, la representación es inspiración y la planificación es evaluación. No se piensa en representar un ideal sino en inspirar el aire de la vida: evaluar, expirar. Organización y orden son sinónimos con matices diferentes. Detrás de la palabra orden está oculto un mandato; el orden no es sólo la disposición de las cosas sino el mandamiento. Al contrario, la organización es sinónimo de ritmo. Órgano en griego es el instrumento, organosi es la organización y concentración de la gente; órgano es una parte del cuerpo, y también un instrumento musical. En el idioma español se dice orden jónico, orden dórico y orden corintio. Sin embargo, en griego se

13 Ibid. 11

14 Ibid. 18

15 Ibid. 23 
sustituye orden por ritmo: ritmo jónico, ritmo dórico y ritmo corintio. Es muy diferente crear orden a crear ritmo; es más fácil poner en orden los edificios y la ciudad, pero es mucho más difícil intentar dar un ritmo melódico y dejar a los habitantes bailando, cambiándolo continuamente.

En cualquier modo de proyectar, la vida se sitúa entre la imaginación y la realidad. Los modos de proyectar son los modos de vivir. La calidad de la vida depende del estilo con el que nos movemos dentro de ellas: estar continuamente planificando para llegar a un fin, planificar para que las cosas no tengan fin y a esperar que las cosas se hagan solas, de manera natural. 



\title{
LO INNOMBRABLE
}

\author{
Entre tú y yo
}



Dentro de lo Innombrable, desde el Entre

la hiedra en terrenos procesionales y estados de excepción

\section{Sin Techo}

Entre tú y yo existe el no - objeto: el vago y difuso fondo de las cosas, aunque fuente de ellas. Entre tú y yo existe lo innombrable: lo que nunca encontrará un nombre; lo sin forma, lo que está entre los edificios. El lugar intermedio se puede encontrar como un tiempo alargado. Las vías y los elementos procesionales son la ritualización del Entre. El intersticio se parece a una grieta, a un hueco que rompe el ritmo y a un lugar de manera radical, como las fronteras o los estados de excepción. La naturaleza umbrátil es algo intermedio, entre el tiempo alargado y el tiempo perpendicular del de repente.

los conejos en el tercer espacio, en los intersticios 



\section{La hiedra en terrenos procesionales y estados de excepción,}

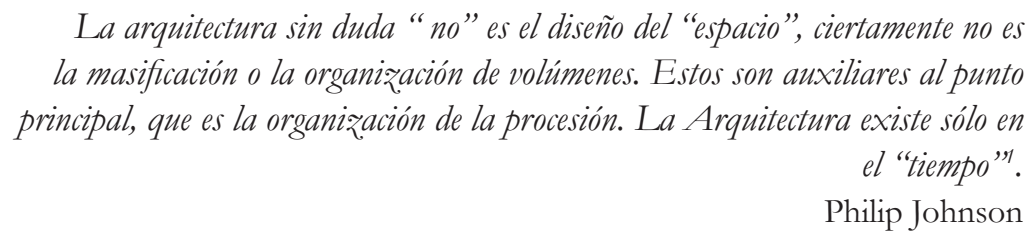

El 6 de Octubre de 2006 fue un día que marcó la historia de la humanidad: las puertas del limbo se cerraron de forma definitiva. ${ }^{2}$ El cierre del limbo no fue un acto fácil; fue un proceso que empezó 31 años antes. En el año 1984, Benedicto XVI expone que el limbo es solo una hipótesis teológica a la que la Comisión Teológica Internacional ha llegado ante la incapacidad de dar una explicación sobre el lugar al que va la gente cuando muere, cuando no ha sido, ni mala, ni buena. ${ }^{3}$ La Biblia o Dios nunca han hablado del lugar que está entre el cielo y el infierno; en aquella época la gente solo podía ser mala o buena; la buena iba al paraíso y la mala terminaba en el infierno. Sin embargo, aparece, en el paso del tiempo, gente que no puede entrar en una de estas dos categorías, como por ejemplo los niños que mueren antes de ser bautizados, los que fallecen antes de la bajada de Cristo o, también, los suicidas. Aparece así la obligación de construir un tercer espacio para estas criaturas inclasificables. San Agustín de Hipona (354 d.C - 430 d.C) es el primero que estudia el caso de los niños no bautizados. Considera que van al

1 Architecture is surely "not" the design of "space", certainly not the massing o organizing of volumes. These are auxiliary to the main point which is the organization of procession. Architecture exists only in time. Philip Johnson, "Whence \& Whither: The Processional Element in Architecture," Perspecta (1965), 167-178.

2 "El Papa Cierra Las Puertas Del Limbo | Edición Impresa | EL PAÍS “, accessed 7/27/2015, 2015, http://elpais.com/diario/2006/10/07/sociedad/1160172012 850215.html. 3 Ibid.
En octumbre de 2006 se cierran las puertas del limbo 
El limbo: lugar que no está en el cielo pero tampoco en el infierno; una zona itermedia donde los niños no bautizados son felices

Lugares intermedios divinos

infierno, pero allí tienen un castigo más suave. ${ }^{4}$ San Alberto Magno (1193 d.C - 1280 d.C) es quien introduce la noción del limbo - del latín limbus que significa la orla del vestido, su reborde o limite final ${ }^{5}$ - como espacio limítrofe del infierno. ${ }^{6}$ Santo Tomás de Aquino considera que los niños no bautizados no van al infierno, ni son castigados; van al lugar intermedio, el limbo, que no está ni en el cielo - cerca de Dios - ni en el infierno; un lugar en el que están simplemente felices. Con Santo Tomas de Aquino, la naturaleza del limbo cambia y ya no es solo un lugar, sino también un estado. ${ }^{7}$ El lugar del limbo empieza a colapsar, en 1984 cuando Benedicto XVI afirma que éste es una hipótesis teológica y no un lugar. Su clausura empieza en 1992, con un texto de Juan Pablo II en el que no se cita el lugar intermedio de los niños que no gozan de Dios pero tampoco sufren. ${ }^{8}$

El limbo es un lugar construido entre el paraíso y el infierno, como también lo es el purgatorio: un lugar de paso para todos los habitantes de la muerte: la sala de espera para el juicio de los que van a ser conducidos al paraíso, al infierno o al limbo. Benedicto XVI cierra las puertas del purgatorio en el año 2011 cuando afirma que el purgatorio no es lugar del espacio, sino un fuego interior?. Juan Pablo II, antes de Benedicto XVI, también afirma que el purgatorio no es un lugar o una prolongación de la situación terrenal sino el camino hacia la plenitud a través de una purificación completa ${ }^{10}$. Cuando el limbo y el purgatorio dejan de ser lugares físicos, el paraíso y el infierno también dejan de serlo. El paraíso y el infierno existen, pero no son lugares sino estados de espíritu, dice el Papa Juan Pablo $\mathrm{II}^{11}$. Sin embargo, la concepción del purgatorio como un estado de espíritu no es algo de lo que la iglesia fuera consciente a partir del siglo XX, sino desde los años de Catalina de Génova (1447 - 1510) que jamás presentó el purgatorio como un lugar en el universo, sino como un imaginario colectivo creado simbólicamente.

\footnotetext{
$4 \quad$ San Agustín, Obras Completas (Madrid: BAC, 1975)., 504.

5 P. Ángel Peña Benito and Agustino Recoleto, El Destino De Los Niños Muertos Sin Bautismo (Lima, Peru: , 2003)., 17. 
La más famosa presentación alegórica del infierno, del purgatorio y del paraíso en el siglo XIV, antes de los años de Catalina de Génova, es la que Dante Alighieri diseña en su Comedia, años más tarde nombrada como Divina Comedia por el escritor humanista italiano Giovanni Boccaccio, debido a su desarrollo en espacios no terrenales. La Divina Comedia es el viaje de Dante a los lugares del inframundo descrito en sus tres partes: Infierno, Purgatorio y Paraíso. El Infierno, para Dante, es una especie de cono de nueve círculos con el vértice hacia abajo. El Paraíso está constituido por nueve círculos concéntricos (los nueve cielos) que tienen como centro la tierra. Pero lo más interesante, es la descripción de los lugares intermedios divinos que conforman los umbrales para el Infierno o el Paraíso. El Purgatorio es un lugar contradictorio; una isla que es montaña - un cono simétrico al de infierno - de nueve terrazas con una puerta de acceso. El Purgatorio es el umbral extendido que conecta el Paraíso y el Infierno, pero no es el único umbral del inframundo. Antes del primer círculo del Infierno, se encuentra el Rio Aqueronte que conecta la vida con dicho círculo, el Limbo, al que pasan todos los que terminan en el Infierno; y donde quedan para siempre los niños no bautizados. El Limbo y el Rio Aqueronte son lugares contradictorios: el Limbo es un lugar del Infierno, pero los niños están felices; y el Rio Aqueronte está fuera y dentro del Infierno. En la entrada del Paraíso y la salida del Purgatorio, se inserta el primer cielo - cielo de la Luna - como lugar de las mutaciones, los cambios y los reflejos. El primer cielo es el lugar de los débiles, donde las almas aparecen como reflejos en espejos o en aguas tranquilas. ${ }^{12}$

La construcción del más allá de Dante es una mezcla de los elementos del imaginario colectivo cristiano y del de la antigua Grecia. Sin embargo, los misteriosos lugares que están en las fronteras entre los vivos y los muertos y, en general, el inframundo griego, están construidos de manera muy distinta. En el cristianismo, el infierno se edifica en la profundidad de la tierra y el paraíso en el aire, pero en Grecia, el inframundo no es un lugar abstracto, sino un país como el de los vivos. Las dos concepciones espaciales de la vida después de la muerte son distintas porque las bases de las dos creencias son completamente opuestas: el Dios de la religión cristiana es un ser inimaginable, sin forma y sin límites; su reino no es un lugar rígido y estable, sino un espacio indefinido y difuso; está construido de aire. Al otro lado del Dios inequívoco,
La representación más conocida de los lugares divinos es la de Dante Alighieri, en la Divina Comedia

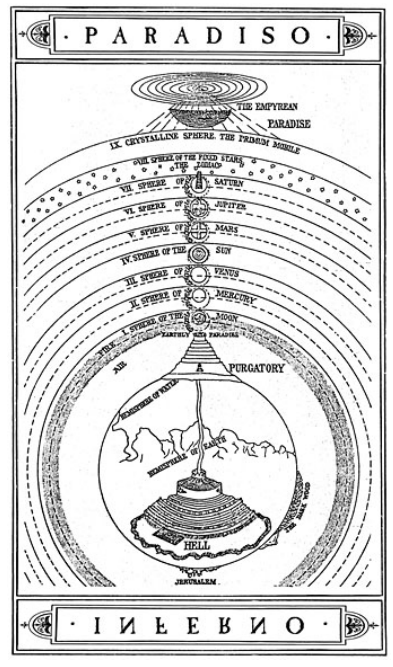

El más allá de Dante

Los lugares divinos del cristianismo están en el aire, los de Antigua Grecia en la tierra. El Dios ser abastracto en la primera, el Dios de naturaleza humana en la segunda 
La antromórfica naturaleza de los dioses griegos conduce a la construcción de un inframundo inspirado en la naturaleza

El viaje entre la vida y la muerte en la Antigua Grecia están los dioses griegos, que son una creación antropomorfa; su vida es como la de los mortales: cometen errores, se enamoran y odian. Así el lugar donde los dioses griegos habitan y el inframundo griego son como los de los mortales, con ríos, océanos, cuevas, islas y reinos. La antropocéntrica concepción de los dioses como mortales - dioses con cuerpos - conduce a la construcción de un inframundo inspirado por la naturaleza. Un equipo de arqueólogos estadounidenses, en 2012, recupera y apoya la hipótesis del arqueólogo Giorgos Papathanassopoulos, quien 1970 encontró la cueva que, según él, fue la inspiración para la creación del mundo de Hades. Es la cueva de Alepotrypa-hoyo de zorro- de un tamaño de cuatro campos de futbol en la que encontraron herramientas, cerámica y artefactos de hace 9.000 años. Como dijo el arqueólogo Michael Galaty, es el Hades completo con su propio Rio Estigia ${ }^{13}$.

Hades - nombre que significa invisible, contrario al de Zeus que significa brillo del día ${ }^{14}$ - era un lugar definido y delimitado por ríos. El inframundo griego, descrito tanto por Homero, Hesíodo y más tarde por Virgilio, se dividía en regiones por medio de cinco ríos: Aqueronte (tristeza), Cocito (lamentos), Flegetonte (fuego), Lete (olvido) y Estigia (odio). Sus combinaciones construían las tres regiones del Hades: los Campos Elíseos donde vivían las almas con una vida ejemplar - el Paraíso de Dante-, los Campos Asfódelos donde reposaban las almas de los que tuvieron una vida equilibrada y Tártaro que corresponde al infierno cristiano. En la geografía del Hades había más regiones pero eran menos conocidas: Erebos o la Antesala de Hades era la región que los muertos atravesaban acompañados por Hermes para llegar a las orillas del Río Aqueronte ${ }^{15}$, lugar donde los muertos esperaban a Caronte para que en su barco los llevase a las puertas de Hades. Para cruzar el Río Aqueronte las almas tenían que pagar a Caronte de uno a tres óbolos; motivo por el que a todos los muertos les ponían sus familiares un óbolo debajo de la lengua para poder pagar el viaje último y definitivo. Los que no tenían dinero o algún familiar que los ayudase, se quedaban en las orillas de Aqueronte, entre la vida y 13 "Arqueólogos Descubren Cueva Donde Podría Haberse Ubicado El Hades, El Inframundo Griego," , accessed 8/16/2015, 2015, http://pijamasurf.com/2012/11/ arqueologos-descurben-cueva-que-podria-haber-inspirado-el-hades-el-inframundo-griego/. 14 Mike Dixon-Kennedy, Encyclopedia of Greco-Roman Mythology (Santa Barbara, Califronia: Abc-Clio, 1998)., 143.

15 Según Pausanías y Dante el rio que era el límite entre muertos y vivos era el Rio Aqueronte, mientras que para Virgilio era el Rio Estigia. JC Fernández Corte and A. Espinosa Pólit, Virgilio: Eneida (Madrid: Cátedra Madrid, 1993)., Christian Habicht, Pausanias' Guide to Ancient Greece, Vol. 50 (California, USA: Univ of California Press, 1998). 
la muerte, durante cien años hasta que Caronte volvía para llevarlos sin pagar. Una vez atravesado el río, los muertos-vivos llegaban a una zona parecida al purgatorio: entraban al antepatio del palacio de Hades y Perséfone donde los tres jueces Minos, Radamanto y Éaco decidirían el último destino de las almas. El paso de la vida a la muerte no era, según la mitología griega, un transporte instantáneo, sino una lenta transición; un viaje en el que la vida se despide y el alma se prepara para el cambio de su estado. Las almas, para encontrar su lugar último, han de atravesar una zona intermedia, lugar de paso que no pertenece plenamente ni al mundo de Hades, ni al de Zeus.

La construcción de los lugares de paso divinos, de las regiones situadas entre la vida y la muerte, se realizan en base a la organización ritual que presentan los actos mágicoreligiosos: son una manifestación espacial de las tres fases que componen los ritos de paso de lo profano a lo sagrado: ritos de separación, ritos de margen y ritos de agregación, también nombrados como ritos preliminares, ritos liminares y ritos postliminares. ${ }^{16}$ La transición de lo profano a lo sagrado afecta tanto a los muertos como a los vivos; los ritos de paso suceden no solo en el viaje de los que han muerto, sino también en el de los que quedan atrás, los parientes. Ellos también realizan los actos necesarios para su entrada, estancia y salida en una sociedad diferente; los parientes entran en un periodo marginal en el que su vida se queda en un estado de suspensión donde sociedad les impone una serie de prohibiciones y un atuendo especial como protocolo de reintegración en la sociedad. Para el antropólogo van Gennep la vida del ser humano es una sucesión de etapas que tiene que pasar como miembro de una sociedad. Según él, los ritos de paso son las ceremonias, las fiestas o ritos de transición de un estado y situación determinada a otra. El mismo hecho de vivir, demanda los pasos sucesivos de una sociedad especial a otra y de una situación social a otra ${ }^{17}$. Los ritos de paso se encuentran en todas las culturas, tanto como indicadores, como vehículos para el paso de un estado y estatus sociocultural a otro: de la infancia a la madurez, de la virginidad al matrimonio, de la enfermedad a la salud y de la paz a la guerra ${ }^{18}$.

La transición metafórica - simbólica que sucede se manifiesta espacialmente.

\footnotetext{
16 Arnold Van Gennep, Los Ritos De Paso Alianza, 2008). 25

17 Ibid. 13-15,

18 Victor Turner, "Frame, Flow and Reflection: Ritual and Drama as Public Liminality," Japanese Journal of Religious Studies (1979), 465-499. 466
}

Los lugares de paso y las zonas divinas entre la vida $\mathrm{y}$ la muerte se construyen en base a una organización ritual; los ritos de paso de lo profano a lo sagrado

La vida del ser humano es una sucesión de etapas; los ritos de paso son las ceremonias y las fiestas que acompañan los pasos de una a otra 
Los ritos de paso se materializan espacialmente en los límites, las fronteras, los umbrales, los pórticos y las zonas sagradas

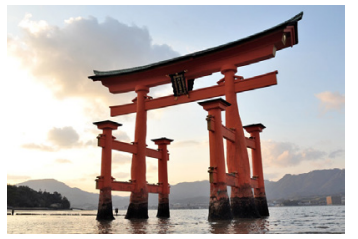

Torii de Miyajima

Para los semicivilizados el paso ideal es un paso material ${ }^{19}$. En muchos ritos se materializa el paso bajo un umbral, o un pórtico; y el viaje de la transición de las almas de la vida a la muerte, en la mayoría de las sociedades, presenta obstáculos materiales tales como muros, puertas y ríos. Los ritos de paso se materializan espacialmente en los límites y las fronteras, los umbrales, los pórticos, en las zonas sagradas, acompañados o no de divinidades de $\operatorname{paso}^{20}$. Las tres fases de los ritos de paso - preliminar, liminar, postliminar - se traducen espacialmente en entrada, margen o aproximación y salida. Entre la salida y la entrada de cualquier estado o lugar hacia otro, existe una zona neutra que puede tener varias dimensiones y varias razones de materialización; razones religiosas, políticas ó económicas. La zona neutra, que aloja la fase liminar del rito de paso, se estrecha y se alarga según el acto que se realiza en ella; puede estar entre países, territorios, ciudades, barrios y casas, y puede reducirse hasta a una simple piedra, una viga, un umbral, una poterna de las murallas, una puerta de un muro, de un barrio, o de una casa. ${ }^{21}$

La manifestación espacial de los ritos de paso crea monumentos y ciudades con templos impresionantes; y en la fase de margen llega a construir umbrales autónomos. En el caso de la transición de lo profano a lo sagrado, existen ejemplos de pórticos que se convierten en monumentos independientes como las puertas aisladas de Oriente. Los Torii, icono de Japón que significa alli donde están los pájaros ${ }^{22}$, son las puertas hacía el mundo espiritual de los santuarios sintoístas. En principio se hacían con piedra y madera pero después se incorporaron más materiales como acero inoxidable y hormigón reforzado. Normalmente existe solo un Torii por cada indicación del paso hacia lo

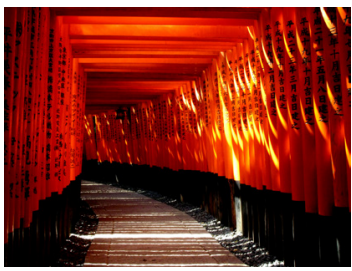

Fushimi Inari Taisha Torii sagrado, pero a veces, se alinean varios, uno detrás de otro, creando largos túneles, como el famoso templo Fushimi Inari en Kioto. Existen varios tipos de Torii, según lo que representan pueden incluir: postes inclinados o perpendiculares, dinteles superiores derechos o curvos y vigas que sobresalen o no de los postes. Torii deriva de Torana ${ }^{23}$, el pilón monumental de la construcción budista e hindú que separa el mundo sagrado

19 Arnold Van Gennep, Los Ritos De Paso Alianza, 2008). 276

20 Ibid. $31-44$

21 Segalen Martine, Ritos y Rituales Contemporáneos (Madrid: Colección El libro de bolsillo, Antropología, Alianza Editorial, SA, 2005), 47

22 David Young and Michiko Young, The Art of Japanese Architecture (Singapore: Tuttle Publishing, 2007). 54

23 Francis DK Ching, Mark M. Jarzombek and Vikramaditya Prakash, A Global History of Architecture (New Jersey: John Wiley \& Sons, 2010). 384 
del mundo profano en India; un pórtico que en la mayoría de los casos, tiene dos o tres dinteles entre dos postes. ${ }^{24}$ De los mejores ejemplos de la riqueza artística de India son las Toranas de las estupas del complejo budista Sanchi creado el siglo VI a. C., con cuatro toranas que se levantan más de diez metros. Es también importante la sensación de entrada y aproximación, de los arcos Paifang o Pailou de China, en este caso para distinguir los distritos de la ciudad, los $\mathrm{Fang}^{25}$, y no para indicar el paso del profano a lo sagrado.

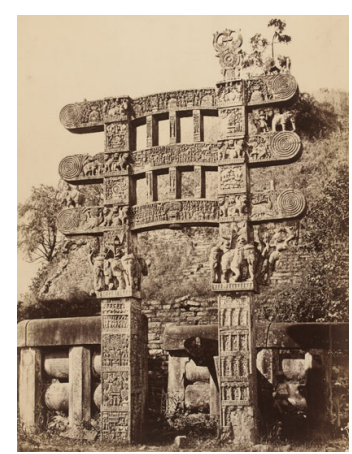

Torana, Sanchi, India

Los arcos de triunfo romanos son un ejemplo más de la materialización espacial de esta fase liminar de los ritos de paso: separarse del mundo del enemigo y, acompañado por los rituales establecidos, pasar al mundo romano. ${ }^{26}$ En Madrid, la materialización de este ocurre en el Arco de la Victoria, o Puerta de Moncloa como se suele llamar, construida en la mitad del siglo XX (1950-1956) como conmemoración de la victoria del ejército sublevado contra la República en la batalla de la ciudad universitaria. En el año 1888 se construye la Puerta - Arco de Triunfo - de Barcelona, que permite el acceso al consumo, hacia la feria de la Exposición Universal, lo que se podría ver como la entrada de la ciudad en la modernidad. El icono de Barcelona no llega a las dimensiones del monumento más representativo de París, construido para celebrar las victorias del ejército francés bajo las órdenes de Napoleón. Su construcción duró 30 años desde su comienzo en 1806 y es una puerta que han atravesado los restos mortales de Napoleón ${ }^{27}$ y los desfiles militares de las dos guerras mundiales en 1919 y 1944. La Puerta de Brandenburgo, que fue inspirada por los Propileos de Atenas, es un arco de triunfo y unos de los símbolos del poder militar y la ciudad de Berlín. Esta Puerta no pudo ser atravesada durante treinta años, formando parte de la separación del Berlín este - oeste. Fue inaugurada en la última década del XVIII como Puerta de la Paz y cuando cayó el muro de Berlín se consideró emblema de la libertad y de Berlín unificado.

Los ritos de paso no son responsables solamente de la construcción de puertas autónomas sino también de la construcción de edificios y vías procesionales. En Egipto

\section{$24 \quad$ Ibid. 384}

25 Javier Ruiz Barreto, "La Evolución De La Puerta En La Arquitectura Civil y Sus Códigos En La Idiosincrasia De La China Imperial” 2015).

26 Arnold Van Gennep, Los Ritos De Paso Alianza, 2008). 38

27 “Arco Del Triunfo - El Monumento Más Representativo De París “, accessed 1/13/2016, 2016, http://www.paris.es/arco-triunfo.
Los arcos de triunfo

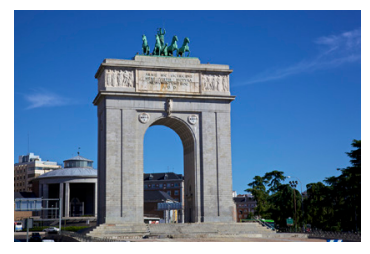

Arco de la Victoria, Madrid

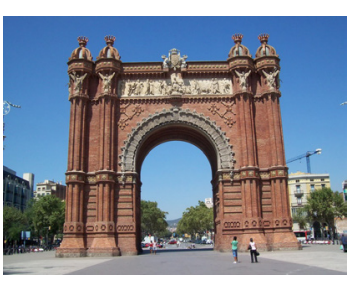

Arco de la Triunfo, Barcelona

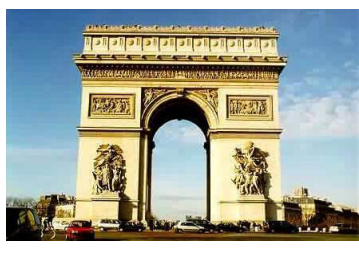

Arco de la Triunfo, París 
La materialización espacial del rito de paso es el Pilón de Egipto y el dromos

El dromos es la vía procesional flanqueada por esfinges

Dromos es, para los sepulcros minóicos y micénicos, la vía que conecta la tierra con el sepulcro que está fundido dentro de ella el paso espiritual de lo profano a lo sagrado, está enfatizado en todos los templos. El Pilón o pilono es una entrada alargada con sus paredes pintadas o esculpidas con escenas de faraones, diosas y dioses; enfrente del Pilón están los obeliscos y las grandes estatuas del faraón. El pilono se hace por pares de muros de forma piramidal que flanquean la entrada de los templos. Detrás de estas grandes puertas, en la mayoría de las veces y como en la arquitectura griega, existe un patio interior, porticado en varios de sus lados. En Egipto, la importancia de la transición de un mundo a otro, se aprecia por el amplio uso de este tipo de entradas monumentales. En el complejo de templos de Karnak están los diez pilonos que abren el camino hacia el interior de los templos. En el caso de Karnak los pilonos están precedidos por los dromos, término griego que alude a las calles procesionales flanqueadas de esfinges, que sirven para conectar los templos entre ellos y a todo el complejo de los templos con el rio Nilo. En Karnak, el dromos daba lugar a la procesión que se realizaba en la fiesta de Opet, la ceremonia partía del templo de Karnak, tres sacerdotes transportaban sobre sus hombros las tres barcas sagradas de Amón Ra, su mujer Mut y su hijo Jonsu, para visitar Amón Min de Luxor; mientras atravesaban el dromos para llegar a Nilo, acróbatas, danzantes, cantantes, músicos animaban la fiesta. Dromos es, en la creta minoica, el pasillo estrecho e inclinado que conectaba la tierra con el sepulcro que estaba hundido dentro de ella. Los cretenses no tenían un tipo definido de sepulcro sino que experimentaron varias formas, la más importante, sin embargo, es la tumba colmena o tholos que tenía una cúpula apuntada, aunque de estructura en voladizo. Basados en la combinación dromos - tholos evolucionaron los sepulcros micénicos, llegando a las formas de los Tesoros de Atreo, de Minyas y la Tumba de Clitemnestra; los dromos, como los tholos, también se engrandecieron llegando a tener hasta treinta metros de largo y nueve de ancho. ${ }^{28}$ En Atenas, dromos es la vía Panatenaica que empieza en Dípilon y culmina, cruzando en diagonal el Ágora, en la estatua de la diosa Atenea en la Acrópolis.

La Acrópolis de Pericles fue un programa de construcción que tenía como fin la reconstrucción de la Antigua Acrópolis, anterior a la guerra con los persas ${ }^{29}$. Según

28 Marvin Trachtenberg and Isabelle Hyman, Arquitectura, Vol. 24 (Madrid: Ediciones Akal, 1990). 89-90

29 Robin Francis Rhodes, Architecture and Meaning on the Athenian Acropolis (U.K:

Cambridge University Press, 1995). 42 
Robin Rhodes, el lugar sagrado pre-persa fue una construcción que fue apareciendo gradualmente en el curso del sexto y quinto siglo a. C, sin un planeamiento previo. Por el contrario, el Programa de Pericles constituyó una unidad: los cuatro edificios Propileos, el Templo de Atenea Niké, el Partenón y el Erecteion fueron construidos según analogías pre-establecidas, tal y como lo indican los ejes paralelos este - oeste de Propileos y Partenón, la correlación de la altura proporcional entre las columnas del peristilo del Partenón y la de la fachada de Propileos, la relación 2:1 entre la altura de los órdenes jónicos en Propileos y el templo de Atenea Niké, la relación 2:1 entre espacio axial de las columnas del pórtico norte del Erecteion y aquel de las columnas de Atenea Niké, la inclinación hacía el interior de las columnas jónicas del templo de Atenea Niké y del pórtico norte del Erecteion, era característica del orden dórico pero rara vez se encuentra en el jónico. ${ }^{30}$

Sin embargo, para Rhodes, el programa de construcción de Pericles no es el resultado de una narrativa solamente de geometría simétrica sino de una más profunda, ritual y religiosa; los ritos de la victoria y la procesión son los elementos que han unificado y han creado el programa de construcción de Pericles. ${ }^{31}$ La Acrópolis arcaica no era solo la casa de los dioses y las diosas, sino el lugar donde culminaban festivales y procesiones de las Grandes Panateneas. La vía procesional, dromos, salía del Dípilon, atravesaba en diagonal el Ágora, y subía en rampa, a los Propileos, que es el edificio que sirve de puerta al Partenón. Es un umbral extendido, convertido en un monumento autónomo, de transición, de paso, que permite la entrada a lo sagrado y a la vez conecta el lado oeste de la Acrópolis, con la parte posterior de los témenos. Para la arquitectura griega el este es la dirección sagrada que se enfrenta el sol naciente. Los Propileos alojan la transformación de historias y explicaciones humanas en narrativas de lo inexplicable, desconocido y sagrado ${ }^{32}$

Este paso que separa y conecta lo profano y lo sagrado es lo que delimita los Propileos; la transición en sí, la electricidad detrás del instinto monumental, se convierte en una componente casi literal de la monumentalidad, como el individuo se transforma en lo genérico, lo genérico
En el complejo de la Acrópolis, los cuatro edificios se conciben como una unidad

La configuración de la Acrópolis por Pericles no es el resultado solamente de una narrativa geométrica, sino ritual y procesional

$\begin{array}{ll}30 & \text { Ibid. } 43 \\ 31 & \text { Ibid. } 43 \\ 32 & \text { Ibid. } 44\end{array}$


El paso de lo profano a lo sagrado es lo que configura la Acrópolis

El orden jónico es un elemento procesional; enfantiza lo horizontal e invinta al interior

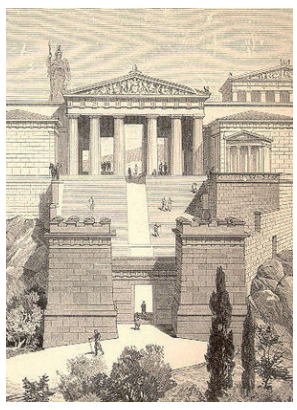

Los Propileos, Atenas
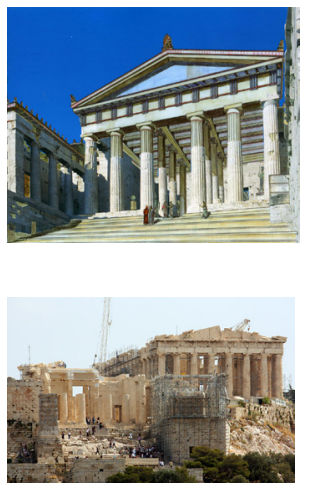

Los Propileos, Atenas

Para Philip Johnson la arquitectura es una organización procesional a lo ideal, lo ideal a lo divino " (p. 7). ${ }^{33} \mathrm{La}$ intención de Mnesicles de enfatizar la transición se revela en los techos de distinta altura que elevan el edificio de la parte oeste, repitiendo el modo en el que el suelo sube y el diálogo entre el orden jónico y dórico. Según Rhodes, Mnesicles podría haber elegido levantar la base del edificio o tener una línea continua de techo pero eligió reflejar el nivel del suelo en su techumbre para enfatizar el paso a la Acrópolis; ${ }^{34}$ podría haber usado solo el orden dórico que era lo más habitual, pero prefirió usar columnas de orden dórico en la fachada y jónico en el interior del pórtico oeste. El dórico es un orden simétrico, destinado a ser experimentado desde lejos; es un orden que da énfasis a lo vertical, separa el templo de su ambiente y deja claro el límite entre ellos. El orden jónico enfatiza la horizontalidad, invita a su interior borrando los límites entre el interior y el exterior. Neil Asher Silberman dice,

todo en el orden jónico, empezando por las plataformas (estilóbato) de escasa elevación que en consecuencia enfatizan la horizontalidad, las dobles y triples columnatas, el muro posterior ciego, la gradación espacial y la axialidad potenciada por la columnata frontal, difuminaban las fronteras entre exterior e interior y conducian al peregrino hasta la fachada, su eje y finalmente hacia el interior. Este estilo era diametralmente opuesto al Dórico clásico, una arquitectura esencialmente de exterior, que presentaba pórticos simétricos delantero y trasero, cuya plataforma de mayor altura y gradación decorativa de abajo a arriba, subrayaba la verticalidad frente a la horizontalidad y separaba el templo de los elementos circundantes y de cualquier tipo de aproximación al mismo. ${ }^{35}$

Para Philip Johnson la arquitectura es la organización de una procesión organización procesional - y no la de espacios o volúmenes - organización espacial - porque la arquitectura existe solo en el tiempo. ${ }^{36}$ Las experiencias del aproximar y entrar son, según

33 B. A. Sparkes, "Decoding the Acropolis," The Classical Review 47, no. 1 (1997), 149-151. 149. 'Indeed, the transition itself, the electricity behind the monumental instinct, becomes an almost literal component of monumentality, as the individual is transformed to the generic, the generic to the ideal, the ideal to the divine'

34 Robin Francis Rhodes, Architecture and Meaning on the Athenian Acropolis (U.K: Cambridge University Press, 1995). 54

35 Neil Asher Silberman, The Oxford Companion to Archaeology (U.S.A: Oxford University Press, 2012). 648

36 Johnson, Whence \& Whither: The Processional Element in Architecture, 167-178 
Philip Johnson, los puntos principales de la arquitectura; la fotografía ha influido en el descuido de estas experiencias por parte de los arquitectos; la fotografía congela el tiempo y presenta la arquitectura como un edificio de tres dimensiones. ${ }^{37} \mathrm{Su}$ texto $D e$ dónde y Adónde: El Elemento Procesional en Arquitectura (Whence and Whither: The Processional Element in Architecture) es un estudio comparativo de plazas o edificios según la sensación de aproximación y entrada que ofrecen; es decir, según su organización procesional. Uno disfruta la aproximación a la Acrópolis; la entrada al Partenón se hace excepcional por la presencia de los Propileos y lo mismo sucede en San Pedro por la imponente columnata de Bernini.

Entre los ejemplos que Johnson analiza, está la Plaza Seagram de Mies van der Rohe en la que la vía procesional es una línea recta que culmina en los corredores de los ascensores; el visitante tiene el tiempo de sentir la aproximación a la entrada desde lejos, esperando uno de los ascensores, ubicados en una línea directa con la calle - la mayoría de las veces los ascensores se prefieren menos visibles; teniendo también tiempo para mirar atrás y despedir Park Avenue. Sin embargo, Mies van de Rohe pierde la belleza de lo procesional por culminar la vía frente al ascensor, cortándola bruscamente. En el Guggenheim de Wright, la belleza de la organización procesional está presente en su entrada: se hace de manera diagonal como la de Mies van del Rohe, pero es una experiencia totalmente contraria de la del Seagram, ya que el visitante percibe en el hall del edificio un vacío de veintiocho metros de altura, a través de una minúscula entrada en relación con las dimensiones del edificio. La torre Kline Science Tower de Yale y la Casa en New Canaan están pensadas a partir del elemento de la procesión, explica Johnson para su obra, y concluye que la organización procesional es la que considera el "De Dónde" y "Adónde" como elementos principales del proyecto arquitectónico proponiendo una aproximación diagonal a la entrada y nunca frontal; lo diagonal ofrece la perspectiva de la profundidad del edificio. ${ }^{38}$

La procesión de las Panateneas en Atenas, que de manera diagonal atravesaba el Ágora y aproximaba al Partenón, no solo define las formas y las narrativas de la Acrópolis, sino también, la propia forma urbana de la ciudad. Todas las adiciones
La arquitectura existe solo en el tiempo. La fotografía congela el tiempo y presenta la arquitectura como un edificio.

Los elementos procesionales en la obra de Mies van de Rohe y Wright, según Philip Johnson

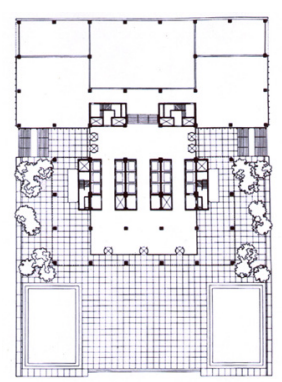

Plaz̧a Seagram, Park Avenue, New York. Mies van der Robe

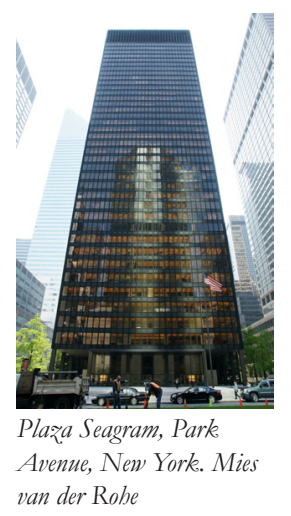

$37 \quad$ Ibid.

38 Ibid. 
La Procesión de las Panateneas de Atenas no solamente configura la Acrópolis sino también la forma urbana de Atenas.

Los ritos de paso, los festivales y las procesiones transforman el espacio urbano que se suceden en el tiempo, parece que se hacen de manera que enmarcaran el lugar donde sucede el movimiento de la victoria y la procesión. El desarrollo del Ágora, de los edificios dentro de ella y de los que están en el camino, podría ser una mejora de la celebración del festival de las Panateneas. La importancia de la procesión para los griegos se muestra también en el edifico Pompeion - "edificio de la procesión" en griego - que ocupaba el lugar entre el Dípilon y la Puerta Sacra. El Pompeion, lugar donde se almacenaba lo necesario para las procesiones, constituía el punto de partida de las procesiones de las Panateneas que conducían a la Acrópolis y de la de los Misterios que conducían al Eleusis. ${ }^{39}$ La evolución de la forma urbana de Atenas, tuvo como referencia la vía procesional, tal y como sucede en algunas formas urbanas de Roma, donde el movimiento en la ciudad se desarrolla siguiendo el camino de los peregrinos, la razón primordial del edificio de calle. ${ }^{40}$

La influencia de los ritos de paso, los festivales y las ceremonias en el contexto urbano es indudable, pudiendo transformar hasta el lugar más prosaico en extraordinario. Sin embargo, el modo en el que forman y organizan el espacio urbano se puede apreciar en las procesiones, ritos de paso participativos y colectivos, que circulan a través del asentamiento, mientras que otros actos festivos solo implican la idea de reunirse en un lugar. Éstos enfatizan una ubicación, mientras que la procesión contiene todo el asentamiento: lo importante es el conjunto. La peregrinación también influye en la forma urbana pero la diferencia entre las dos está en que la procesión tiene que ser un evento participativo colectivo, mientras que la primera es individual. Según los estudios de Kanekar, los rituales procesionales pueden vincular varios puntos importantes de la ciudad según criterios religiosos o políticos, como el viacrucis - camino de la cruz - en Jerusalén, donde se conectan varias estaciones que Jesús hizo en su camino hacia la cruz; además, pueden trazar las fronteras y los límites de las ciudades y conectar varias zonas de la ciudad generando una entidad coherente en la celebración de un festival, como la carrera de caballos, el Palio de Siena. ${ }^{41}$

Las procesiones formalmente se pueden entender como una ruta de la circulación

39 Aarati Kumar Kanekar, Celebration of Place: Processional Rituals and Urban Form (1992).

$41 \quad$ Ibid. 26 
prescrita que podría ser de circunvalación; un circuito cerrado debido a un punto de importancia que encierra el espacio creando un límite imaginario que tiende a eliminar el valor especial del comienzo y del final, como suele suceder en los templos del sur de la India; podría ser axial, debido a la presencia de dos o más puntos de importancia; implicando irreversibilidad y enfocando el final como una catarsis; o podría basarse en un diagrama fijo principalmente cósmico en origen, tal y como en India se plantean las ciudades de templos basadas en el patrón de mandala o, en estupa, que es un diagrama cosmológico que enlaza el cuerpo de Buda con el $\operatorname{cosmos}^{42}$. En vez de estar prescrita, la circulación puede ser marcada por varios elementos que motivan la secuencia dependiendo de las culturas. La procesión puede ser también organizada según jerarquías, en algunos casos la circulación puede estar enmarcada por edificios, como los edificios de Atenas que se desarrollan alrededor de la vía Panatenaica; o por cuerpos como sucede en el encierro de los toros de Pamplona. A veces, la ruta de circulación es la que pone los límites de la ciudad: no podemos decir si primero vinieron las fronteras o los rituales, dice Kanekar, pero habitualmente van de la mano. ${ }^{43}$

Frontera, ritual, dromos, pilón, portal son términos que, hoy en día, remiten a estructuras distintas de lo que significaban antes de la industrialización. La palabra pilón se usa para referirse a la torre de electricidad (electricity pylon) y el poste de publicidad; portal tiene también un nuevo significado: el sitio de internet de la estructura global que permite al usuario-habitante el acceso a la comunicación; como Yahoo!, iGoogle, MSN, etc. Dromos en griego corresponde a la palabra calle del idioma español; las calles de Atenas y de Grecia se llaman dromos; todas las calles del mundo se llaman dromos; quizás, todas las calles pueden ser un pasaje ritual de un estado a otro o, los ritos de paso se han convertido en algo insignificante. Habría que evitar dos escollos, dice Senegal, el de reforzar un decadencia de los rituales y el de verlos por todas partes. ${ }^{44}$

42 Es una estructura redonda; la masa central se compone de un montículo hemisférico de barro enfrentado con ladrillos y esto se franquea por una balaustrada de piedra (védica) que replica una construcción de madera. Parikrama es la circunvalación, el acto ritual de moverse alrededor de algo sagrado. El propósito de la védica es dar una presentación y definición espacial de parikrama que junto con mandala y esvástica siguen siendo fundamentales para la expresión arquitectónica de India. Ching, Jarzombek and Prakash, A Global History of Architecture 168

43 Aarati Kumar Kanekar, Celebration of Place: Processional Rituals and Urban Form (1992)

28-50

44 Segalen Martine, Ritos y Rituales Contemporáneos (Madrid: Colección El libro de bolsillo, Antropología, Alianza Editorial, SA, 2005), 16-17
La procesión se puede entender como una ruta de circulación; un circuito cerrado que podría ser axial o basarse en un diagrama fijo

Los términos frontera, ritual, dromo, pilón y portal, hoy en día, remiten a estructuras muy diferentes 
El pensamiento racional elimina los antiguos Dioses y Diosas e inventa unos nuevos

La forma urbana a partir del siglo XIX se define por la velocidad de los medios de transporte

La historia del pensamiento occidental se revela en la historia en la Puerta de San Vicente
Sin duda, el pensamiento racional que ha dominado a partir del Renacimiento aleja la sociedad de lo religioso y la acerca a lo racional. El pensamiento racional elimina unos dioses/as e inventa otros nuevos/as: el progreso, la velocidad, el control, la utilidad son unos/as de los/las que la sociedad más admira. Una de las características más representativas de la historia moderna es el progreso constante de los medios de transporte. ${ }^{45} \mathrm{El}$ progreso es sinónimo de aumento de la velocidad y este concepto del progreso cambia la forma de las calles y las ciudades. Hasta la ciudad medieval, los límites entre los vehículos y las personas son difusos, siendo el centro de la calle para las personas, mientras que en los bordes circulan los medios de transporte. En el Renacimiento se produce la introducción de la perspectiva y a partir de entonces ésta organiza las calles dando importancia a los cálculos exactos y a la geometría, aunque la referencia de la escala sigue siendo el peatón. A partir de este período, el centro de la calle es ocupado por los vehículos y el peatón se mueve en los bordes. ${ }^{46} \mathrm{La}$ ciudad deja de ser un lugar que sucede de manera espontánea, irregular, alrededor de lugares religiosos y vías procesionales y se piensa y planea en su totalidad para poder albergar el aumento de la población de las ciudades industrializadas y los medios de transporte. La historia de la Puerta de San Vicente de Madrid ${ }^{47}$ muestra el cambio del pensamiento urbanístico no solamente en Madrid o en España, sino en el mundo occidental. La Puerta de San Vicente fue derribada poco después de que cayera la Cerca construida en el XVII por Felipe IV (1868). Sin Cerca, la Puerta perdió su utilidad y se transformó en un obstáculo para los movimientos de los vehículos que empezaban a conseguir mayor velocidad. En un principio, se pensó en trasladarla a otro lugar, pero según los cálculos del arquitecto José López Salaberry era más económico utilizar sus piezas para otras funciones y necesidades, tales como farolas monumentales para la glorieta de Cibeles. Alrededor de 1891 fue derribada y, la de hoy en día, es una reconstrucción realizada en 1994-1995.

De manera análoga, ocurrió en algunas formas urbanas del resto de las

\footnotetext{
45 Bauman Zygmunt, “La Globalización. Consecuencias Humanas,” Fondo De Cultura (1999). 23

46 Jorge A. Negrette, "Utilización De La Cuadra y La Plaza Como Elementos De Diseño Urbano," Trabajo De Ascenso.Universidad Simón Bolivar.Caracas, Venezuela (1986).87-88 47 Félix San Vicente, Reconstrucción De La Puerta De San Vicente Año 1994-1995 (Madrid: Ayuntamiento, 1995).
} 
ciudades de Occidente. En Londres - la capital del siglo XIX según Benjaminn ${ }^{48}$ John Nash, teniendo como prioridad la rápida circulación de los carruajes, no dudó en eliminar los edificios dispersos que obstaculizaban la fluidez de la ronda; además, usó las calles anchas, los bulevares, no solo como ejes de circulación de vehículos, sino también como muros: la calle que rodeaba Regent Park, Outer Circle, constituyó un muro que lo separaba de los ciudadanos. ${ }^{49}$ De la misma manera, en la calle Regent's Street, se construyó un gran bulevar que empezaba en el extremo sur del parque y cuya creación requería la demolición de los edificios-obstáculos: calle tanto peatonal como con inmensas manzanas uniformes de vehículos ${ }^{50}$ Las mismas características tenían las intervenciones de Napoleón III y Haussmann en el ensanche de París, el mayor proyecto de renovación de los años de la modernidad. ${ }^{51}$. Haussmann no dudó en derribar gran parte de la ciudad medieval y renacentista para construir nuevas fachadas uniformes y calles rectas y anchas. Las calles de alta velocidad eran las nuevas fronteras entre los pobres y los ricos; los bulevares dejaban fragmentados los distritos pobres y su anchura permitía circular a dos carros del ejército en paralelo, para poder, en caso necesario, disparar a ambos lados de la calle. Por otra parte estaban delimitados por edificios uniformes continuos, con tiendas a la altura de la calle y encima de ellas, viviendas: los ricos más cerca de la calles, lo pobres más cerca del cielo. ${ }^{52}$

Los grandes bulevares rompieron los barrios y los planeamientos urbanísticos dividieron la ciudad en barrios según las clases. Escribe Angel Ganivet, la apertura de grandes calles en sustitución de calles pequeñas, trae consigo un encarecimiento artificial de la vida; si alli donde vivian dos mil pobres edificaron casas que éstos no pueden continuar habitando, dicho se está que se les obliga a buir de aquel centro ${ }^{53}$. Por una parte, las ciudades tenían grandes bulevares con aceras, con árboles y bancos, delimitados por restaurantes, tiendas, cafés; por otra parte, la gente pobre se acumulaba en bolsas congestionadas de la antigua

48 Richard Sennett, Carne y Piedra: El Cuerpo y La Ciudad En La Civilización Occidental Alianza editorial, 1997). 340,344

$49 \quad$ Ibid.346-347

$50 \quad$ Ibid.349

51 David Pinckney, Napoleon III and the Rebuilding o/ París (Princeton: Princeron University Press, 1958), p. 25. carne piedra 351

$52 \quad$ Ibid. $350-354$

53 Ángel Ganivet and Miguel de Unamuno, Granada La Bella: Seguido De Las Ruinas De Granada (Madrid: Círculo de Bellas Artes, 2011).90
La forma urbana de París y Londres del siglo XIX se define por la velocidad 
ciudad, en lugares que, algunas veces, para cumplir la ley del planeamiento de fachadas, no se podían cumplir las condiciones higiénicas del interior de las viviendas. Las grandes calles de circulación rápida con aceras para los cafés comerciales de los burgueses, frente a espacios encogidos con malas condiciones de habitabilidad para los obreros. Por una parte los ensanches burgueses para las casas ajardinadas individuales con trama urbana abierta y plano regular y por otra, el plano irregular, de trama cerrada y densa. La introducción de la velocidad dio un nuevo significado social a la circulación. La utilización del tráfico para aislar y descongestionar el espacio, como sucedió en Regent's Park, impidió la reunión de una muchedumbre con un fin determinado. La presión del movimiento peatonal lineal en Regent Street dificultó, y aún lo sigue haciendo, que, por ejemplo, se reuniera una muchedumbre para escuchar un discurso. Por el contrario, tanto la calle como el parque privilegiaron el cuerpo individual en movimiento ${ }^{54}$.

La organización de la ciudad según el criterio de la velocidad distancia a sus habitantes mientras, que la organización procesional los reúne; los bulevares impiden la reunión de la muchedumbre y privilegian el cuerpo individual en movimiento, las procesiones requieren un cuerpo colectivo: son un acto que sin la participación de los ciudadanos no se puede cumplir. La organización procesional es un programa de construcción que empieza desde dentro, desde abajo; la sociedad traza las vías según sus ámbitos, fiestas, ceremonias o hábitos; al contrario, la velocidad necesita un esbozo contemplado desde fuera, desde arriba; la primera piensa en el tiempo y en la duración, mientras que la segunda piensa en el fin: llegar lo más rápido posible a la meta. La organización procesional se centra en el Entre.

Sin embargo, existe algo lo contradictorio en el diseño de la velocidad. Por

El aumento de la velocidad comprime el espacio-tiempo una parte necesita calles anchas o bulevares que aumenten la distancia; por otra parte, comprime el espacio - tiempo: si la transición, trasportación o pasaje de un punto a otro se hace de manera instantánea, el espacio entre se reduce, se hace pequeño o se elimina. Pero, como dice Stavridis, no es que las nuevas tecnologías hagan el mundo más pequeño sino que lo que han cambiado, es la experiencia de la distancia. ${ }^{55} \mathrm{El}$ constante

54 Richard Sennett, Carne y Piedra: El Cuerpo y La Ciudad En La Civilización Occidental Alianza editorial, 1997). 349

55 Stavros Stavridis, De La Ciudad Pantalla a La Ciudad Escena (Atenas: Ellinika Grammata, 2002). 
aumento de la velocidad hace que el medio se aísle de su entorno; lo desconecte. Lo que permanece en la percepción de la distancia son imágenes del entorno que corren de manera tan rápida que nadie consigue incorporarlas en un hilo conductor con sentido. ${ }^{56}$ Muchos medios de transporte, para poder llegar a la máxima velocidad, intentan librarse de los obstáculos que el terreno ofrece: el metro, el avión, los trenes que se mueven en varios niveles. Así cada vez más, el viajero tiene la experiencia de una inmovilidad que no es perturbada por las vibraciones debidas a los obstáculos y las condiciones del camino; como tampoco cambia la imagen del espacio, parece que la distancia que separa el origen de la llegada, se anula. ${ }^{57}$ La transportación instantánea, la eliminación del espaciotiempo, es más fácil cuando falta el cuerpo; el nuevo modo de comunicación y encuentro entre las personas, facilitado por las nuevas tecnologías, no requiere la participación de un cuerpo individual o colectivo; la información se desplaza independientemente de sus portadores corpóreos y de los objetos en los que se forma; información, cuerpo y objeto tienen velocidades diferentes, siendo la mayor la de la información. Así, a partir de la World Wide Web, llega el fin del concepto de la distancia: la información está disponible instantáneamente en todo el globo. ${ }^{58}$

Dentro de la evolución de los medios de transporte y comunicación, los significados de los términos pilón o pilono y portal se han expandido: no son material solo de manera geográfica, sino que se encuentran en las fronteras electrónicas; los portales, hoy en día, también designan los sitios web que permiten al usuario el acceso a la comunicación como son Internet Explorer, Yahoo! Google, Bing: umbrales de la infraestructura global que permiten la entrada y la salida inmaterial. La extensión de las redes de internet está constituida por novecientos mil kilómetros cables que conectan los cinco continentes; infraestructura gigante que Telegeography es responsable de representar en un mapa anualmente. Los portales, de los países son los Puntos Neutros o Puntos de Intercambio de Internet; es una infraestructura física a través de la cual los proveedores de servicio de internet conocidos como ISP (Movistar, Orange, Vodafone, entre otros) intercambian la información entre sus redes. Se llaman Neutros porque están

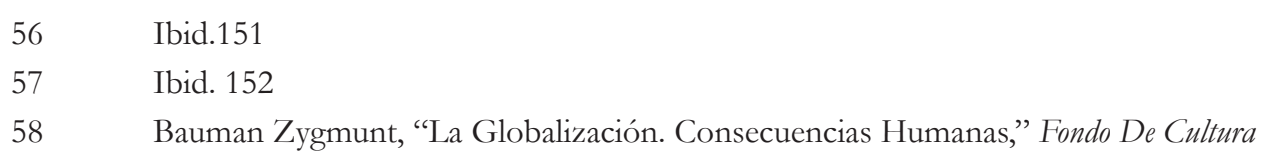

Los nuevos medios de transporte para llegar a la maxima velocidad se aislan del terreno; el viajero tiene una experiencia de la inmovilidad; la distancia que separa el origen y la llegada parece que se anula 
Los Pilones conteporáneos son las torres de transmisión eléctrica

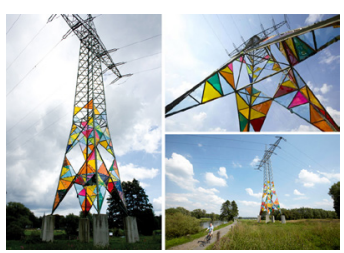

Leuchtturm por estudiantes de Klasse Löbbert, Alemania

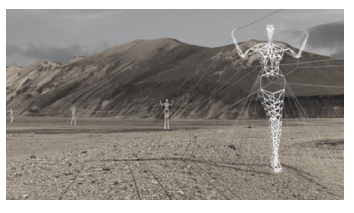

The Land of Giants: Propuesta Landsnet, Iceland. Arquitectos Choi and Sbine gestionados por empresas independientes - no vinculadas directamente con los ISP. El principio de neutralidad se basa en un alquiler por la gestión, uso y mantenimiento de estos puntos por los proveedores que se conectan en él. De este modo todos los ISP son clientes del Punto Neutro y no hay prioridad entre ellos o sus redes. ${ }^{59} \mathrm{El}$ punto neutro de España, ESPANIX, se encuentra en Madrid en la Avenida de la Comunidad de Madrid de Las Rozas.

Los Pilones contemporáneos son las torres de transmisión de electricidad; de dimensiones monumentales crean las fronteras entre los barrios, las ciudades, las regiones y los países. Las redes de electricidad definen los límites de las ciudades desde la aparición del primer pilón que tuvo lugar fuera de Edimburgo en 1928. El diseño inicial de los gigantes esqueléticos fue desarrollado por el americano Milliken Brothers, bajo la dirección del arquitecto Sir Reginald Blomfield. ${ }^{60}$ Con altas aspiraciones bautizó la torre de transmisión con el mismo término, pilón, que se utiliza en los templos egipcios y griegos. El pilón ha inspirado a los británicos modernistas Day-Lewis y Stephen Spender, el último de los cuales escribió con nostalgia: "Pilones, esos pilares / Chicas gigantes desnudos que no tienen ningún secreto ${ }^{61}$. Los pilones son parte del paisaje cultural de la humanidad, puertas que indican, ya no las fronteras entre lo profano y lo sagrado, sino entre la civilización y la no civilización. Los últimos años, se han realizado concursos arquitectónicos con el fin de encontrar nuevas formas. Uno de los más famosos es el concurso arquitectónico que se realizó en 2011 por la iniciativa de Instituto Real de Arquitectos Británicos, el Departamento de Energía y Cambio Climático y la Red Nacional, que supuso un desafío para arquitectos, diseñadores, ingenieros y estudiantes para llegar a estructuras que equilibraran la energía necesaria con el impacto visual ${ }^{62}$. Además, muy a menudo, se encuentran intervenciones artísticas en los pilones en las 59 "Puntos Neutros De Internet: Presentamos a Los Grandes Desconocidos | Interxion " , accessed 1/13/2016, 2016, http://www.interxion.com/es/blog/puntos-neutrosde-internet-presentamos-a-los-grandes-desconocidos/.

60 "Loved and Loathed - the Armoured Knights of the National Grid | Art and Design | the Guardian “, accessed 1/13/2016, 2016, http://www.theguardian.com/ artanddesign $/ 2011 / \mathrm{may} / 22 /$ national-grid-pylons-design.

61 "Are Electricity Pylons really such a Blot on the Landscape? | Oliver Wainwright | Opinion | the Guardian “, accessed 1/13/2016, 2016, http://www.theguardian.com/ commentisfree/2014/nov/11/electricity-pylons-landscape-national-grid-bury.

62 "The Winner of a New Generation of Electricity Pylons is Announced | Environment | the Guardian “, accessed 1/13/2016, 2016, http://www.theguardian.com/ environment/gallery/2011/sep/14/shortlist-designs-electricity-pylons-in-pictures. 
carreteras que separan y conectan los países de manera más transparente pero que son quizás más peligrosos que las fronteras anteriores, ocasionando en varias ocasiones la muerte de pájaros, a los que no se permite entrar en el mundo urbano. Pilones destacables como soportes artísticos son la pieza diseñada y construida por los alumnos de Klasse Lobbert, del colectivo de arte urbano DOMA, las series de Richard Box, de los arquitectos Choi y Shine, y el proyecto Land of Giants llevado a cabo por el estudio ruso Design Depot. ${ }^{63}$ Famosas torres de transmisión eléctrica en España son los Pilones de Cádiz diseñados por el ingeniero italiano A.M. Toscano en 1957.

Si ha llegado el fin del concepto de la distancia ${ }^{64}$ y si el ritual es una celebración de lugar y del tiempo ${ }^{65}$, tal vez podríamos hablar de desritualización o decadencia de los festivales, los rituales y las procesiones. Puede tener una base estable la consideración de la época contemporánea como la decadencia de lo ritual; pero no sorprende ver ritos en tantos lugares de los comportamientos repetitivos del ser humano ${ }^{66}$. Lo ritual no es simplemente algo ceremonial o litúrgico de la transición de lo profano a lo sagrado sino algo básico en la existencia del hombre. El ritual, no es solo un acto repetitivo, sino un acuerdo y una forma relevante de comportamiento social con una dosis extra de pasión e intensidad. ${ }^{67}$ Los ritos son normas de conducta que prescriben cómo debe comportarse el hombre ante las cosas sagradas. ${ }^{68}$ Son actos simbólicos; el ser humano en cuanto animal social es animal ritual: sin las cartas de pésame, los telegramas de enhorabuena, y sin postales de vez en cuando, la amistad de un amigo distante no constituye una realidad social. No tiene existencia sin los ritos de la amistad. ${ }^{69}$ El rito no puede desaparecer porque en su base, es una necesidad existencial del ser humano.

De este modo, Senegal propone que en vez de hablar de decadencia de lo

63 Flores En El Ático » Torres Eléctricas Como Soporte Artístico „, , accessed 1/13/2016, 2016, http://floresenelatico.es/torres-electricas-como-soporte-artistico/11696.

64 Bauman Zygmunt, "La Globalización. Consecuencias Humanas," Fondo De Cultura (1999). 23-24

65 Aarati Kumar Kanekar, Celebration of Place: Processional Rituals and Urban Form (1992)

22

66 Segalen Martine, Ritos y Rituales Contemporáneos (Madrid: Colección El libro de bolsillo, Antropología, Alianza Editorial, SA, 2005), 35

67 Aarati Kumar Kanekar, Celebration of Place: Processional Rituals and Urban Form (1992)

13

68 Segalen Martine, Ritos y Rituales Contemporáneos (Madrid: Colección El libro de bolsillo, Antropología, Alianza Editorial, SA, 2005), 16-17

69 Ibid. 28
El fin del concepto de la distnacia no anula la ritualización

Los ritos no sonsimplemente algo ceremonial sino una forma relevante de comportamiento 
En vez de hablar de decadencia de lo ritual o de la desritualización, hablamos de desplazamiento del campo ritual

Los festivos y ritos de paso siguen existiendo pero ha cambiado el tipo de transición que sucede; se abandona lo sagrado y lo profano y se habla de lo extraordinario-ordinario

El tiempo festivo, tiempo fuera del tiempo, estado de excepción ritual o de desritualización, sería mejor hablar de desplazamiento del campo ritual desde el corazón de lo social hacia sus márgenes: en el ámbito deportivo o en la periferia del trabajo; las fiestas de jubilados, celebraciones de cumpleaños; el futbol, las fiestas de Navidad, los árboles de Navidad en los halls de los edificios. ${ }^{70}$ Los maratones y las grandes carreras colectivas contemporáneas ritualizan y cambian el espacio urbano y su repetición hace un ciclo anual pseudoreligioso; actividades colectivas de fuerte intensidad emocional que llenan el espacio público con signos rituales. ${ }^{71}$ No se puede hablar de desritualización cuando se observa la tendencia de la revitalización de los rituales y de las celebraciones: en las escuelas se enseña a los niños a celebrar la navidad, el día del padre, de la madre y los estados intentan reincorporar y celebrar carnavales y fiestas religiosas. ${ }^{72}$ Las manifestaciones se pueden considerar también un nuevo ritual. El comportamiento ritual remite (...) a formas de ser, formas de comunicación exterior entre dos o más individuos. Se convierte en lenguaje del comportamiento y un rasgo esencial de este tipo de lenguaje es que «sus simbolos unitarios tienen un significado comin, tanto para el que los manifiesta como para su público» (E. Leach, p. 331). ${ }^{73}$

Los ritos de paso siguen existiendo pero lo que ha cambiado es el tipo de transición que sucede; en vez de una transición de lo profano a lo sagrado, los rituales acompañan la transición del tiempo ordinario al tiempo extraordinario, incluyendo asî todas las transiciones posibles entre los términos de cualquier dicotomía de antónimos. Más importante que el campo o la forma espacial de los ritos es la experiencia del tiempo festivo. Alessandro Falassi nombra el tiempo de un ritual o festival como

tiempo fuera del tiempo $;^{74}$ porque (...) el tiempo festivo es cualitativamente distinto del tiempo ordinario, mundano y precisamente en esos tiempos está permitido lo que fuera de sus límites no sería. Es un mundo fuera del mundo, en un tiempo fuera del tiempo. Esta diferencia crucial entre el tiempo ordinario y el tiempo festivo yace lo ritual de lo festivo ${ }^{75}$.

$70 \quad$ Ibid. $16-17$

71 Ibid. $75-76$

$72 \quad$ Ibid. 169, 36-37

73 Ibid.

74 Scott T. Cummings, "Recent Writing on Interculturalism," Performing Arts Journal 11/12 (1989), 240-242. 4

75 Aarati Kumar Kanekar, Celebration of Place: Processional Rituals and Urban Form (1992) 
El tiempo festivo - como el tiempo del extrañamiento, de la sorpresa, del de repente - es una forma de estado de excepción: entramos en una situación y estado excepcional, fuera de lo ordinario. La estructura topológica del estado de excepción es, según Agamben, estar-fuera y, no obstante, pertenecer ${ }^{76}$. El estado de excepción es llamado por Victor Turner, estado de liminalidad. Liminalidad literalmente significa "estar en un umbral", 77 entre lo profano y lo sagrado, lo ordinario y lo extraordinario, entre cualquier término y su opuesto. El término fue usado por primera vez por Van Gennep, para describir el estado de la segunda fase de los ritos de paso- la fase liminar - en la que el individuo está en un "entre”; cae en un limbo entre el estado que deja detrás y en el que va a entrar. Turner amplia el significado de la liminalidad o limbo: es cualquier condición que está fuera o en la periferia de la vida cotidiana ${ }^{78}$. El tiempo de la liminalidad, es para Turner, un tiempo y lugar de alejamiento de los procedimientos normales ${ }^{79}$. Fuera de lo normal significa fuera de la normalidad, es decir, fuera de las normas de una sociedad, que son las que estructuran el orden social ordinario; la estructura del orden social se entiende como una organización de posiciones, oficios, roles jurídicos, políticos y económicos ${ }^{80}$.

De este modo, si la liminalidad es el estado de estar fuera de las normas de la sociedad pero perteneciendo a ella, es también la situación en la que el ser humano se escapa de las clasificaciones sociológicas. ${ }^{81}$ Para Mary Douglas, la liminalidad, los estados de excepción, son peligrosos; el peligro reside en el estado de la transición porque la persona no está ni un estado ni el otro, es indefinido. En el estado de excepción, la interacción y comunicación entre las personas es espontánea, no racional, ya que escapa de las jerarquías sociales establecidas; el rasgo que caracteriza la comunicación e interacción en un estado de excepción es la igualdad entre sus miembros. La liminalidad 76 Giorgio Agamben, "Estado De Excepción, Trad," Flavia Costa e Ivana Costa.Buenos Aires (2003). 75

77 Victor Turner, "Frame, Flow and Reflection: Ritual and Drama as Public Liminality," Japanese Journal of Religious Studies (1979), 465-499. 465

78 Victor Witter Turner, Dramas, Fields, and Metaphors: Symbolic Action in Human SocietyCornell University Press, 1975).4

79 Victor Witter Turner and Beatriz García Ríos, El Proceso Ritual: Estructuray Antiestructura Taurus Ediciones, 1988). 171

80 Victor Turner, "Liminality and Communitas," The Ritual Process: Structure and AntiStructure (1969), 94-130. 177

81 Segalen Martine, Ritos y Rituales Contemporáneos (Madrid: Colección El libro de bolsillo, Antropología, Alianza Editorial, SA, 2005), 53-55

En los estados de excepción y las fases liminares el ser humano está fuera de las estructuras sociales porque está entre ellas.
Estado de excepción: estar-fuera y, no obstante, pertenecer. Agamben

Liminalidad y fase liminar: cualquier condición que está fuera o en la periferia de la vida cotidiana. Turner 
La sociedad es una casa con habitaciones y pasillos y es peligroso el paso de una a otra; la transición de un estado a otro es indefinible. Van Gennep

Lo urbano es una dimensión liquida de la ciudad que puede verse circular en los espacios intermedios a veces llega a la creación de una antiestructura social; estructuras que se resisten a apoyarse en la clase social y rechazan el orden social: la comunitas (....) siempre se trata de grupos efimeros, ad $h o c^{82}$. El peligro de la fase de la liminalidad está en que es un tiempo fuera del reloj, incontrolado; y, por eso, todo podría pasar; en el proceso sociológico, dice Turner, lo liminal se parece al modo subjuntivo de los verbos mientras que las actividades mundanas se parecen al modo indicativo. ${ }^{83}$ Van Gennep, para explicar espacialmente la fase de la liminalidad, la consideró como el tiempo de paso por los pasillos de una casa entre las habitaciones:

(..) vió a la sociedad como una casa con habitaciones y corredores en los que resulta peligroso el paso de unos a otros. El peligro reside en los estados de transición; sencillamente porque la transición no es un estado ni el otro, es indefinible. La persona que ha de pasar de uno a otro está ella misma en peligro y emana peligro para los demás. El peligro se controla por el rito, que precisamente lo separa de su viejo estado, lo hace objeto de segregación durante un tiempo y luego públicamente declara su ingreso en su nuevo estado. ${ }^{84}$

Quienes se desplazan en estos corredores, en esta zona umbral o limen de los ritos de paso, quienes se trasladan entre estados -estancias, se les llama pasajeros, dice Manuel Delgado; estos ámbitos intermedios, que son obstáculos o puentes entre estructuras, se definen por la incertidumbre, la inestabilidad y la intranquilidad porque estando fuera de las estructuras es difícil ser vigilados y controlados. ${ }^{85}$ En la sociedad urbana, sigue Delgado, los lugares intermedios se identifican con la calle y los espacios públicos;

todo lo que constituye la dimensión más líquida e inestable de la ciudad (vehículos, personas, energías, recursos, servicios, información...) puede verse circular en estos espacios-movimiento o territorios

$82 \quad$ Ibid. $53-55$

83 Victor Turner, "Frame, Flow and Reflection: Ritual and Drama as Public Liminality," Japanese Journal of Religious Studies (1979), 465-499. 466-467

84 Segalen Martine, Ritos y Rituales Contemporáneos (Madrid: Colección El libro de bolsillo, Antropología, Alianza Editorial, SA, 2005), 52

85 Manuel Delgado, El Animal Público: Hacia Una Antropología De Los Espacios Urbanos:[XXVII Premio Anagrama De Ensayo]Ed. Anagrama, 1999). 
circulatorios. Por ello todo sistema-ciudad pone el máximo cuidado en mantener en buenas condiciones de, equilibrio, de presión y de densidad su red de condiciones, evitando las zonas termas, pero también asegurando un permanente drenaje que evite los espacios pantanosos. Sin embargo esta práctica nunca llega a ser del todo resolutiva ni efectiva. ${ }^{86}$. Lo liminal, el estado de liminalidad, es lo urbano. La diferencia entre la ciudad y lo urbano es que la ciudad es algo estático, mientras que lo urbano es dinámico, es un continuo movimiento, cambio y transformación. La ciudad está en la ciudad, dice Delgado: son las familias, las estructuras, los palacios, las instituciones, las estaciones, pero lo urbano trasciende de las fronteras físicas. ${ }^{87}$ Lo urbano está constituido por todo lo que se opone a cualquier cristalización estructurab8; es el desequilibrio permanente, momento de lo lúdico y lo imprevisible ${ }^{89}$.

La inestabilidad, el desequilibrio, lo peligroso y lo imprevisible son sensaciones que uno experimenta en la fase liminal; pero, a la vez, está dentro de la extrema libertad, ya que es un ambiente que funciona fuera de jerarquías y normas establecidas; puede estar en plena creatividad porque en este momento es cuando los opuestos se encuentran: cuando lo definido se hace indefinido o lo indefinido se define, lo familiar se extraña pero se familiariza lo extraño; cuando uno se hace otro y cuando el otro es él. La liminalidad está llena de potencialidad y potencia. ${ }^{90} \mathrm{El}$ terreno de la liminalidad está en el "Reino de la Contradicción": todos los conceptos son al mismo tiempo sus términos contrarios; los choques de los antónimos en su encuentro lo hacen un terreno inestable, peligroso con muchas vibraciones que desorientan. Por eso, los estados intermedios deben siempre ser de paso: si alguien se queda atrapado en su interior pierde su identidad y su capacidad de elegir; y vivir es elegir ${ }^{91}$. Es como si alguien intentase vivir dentro de un ascensor: subir y bajar, abriendo la puerta en todos los niveles de una estructura,

86 Ibid.

87 Ruiz Delgado, "Manuel:“Ciudad Líquida, Ciudad Interrumpida"," Editorial Universidad De Antioquia (1999).9

88 Manuel Delgado, El Animal Público: Hacia Una Antropología De Los Espacios Urbanos:[XXVII Premio Anagrama De Ensayo]Ed. Anagrama, 1999).25

89 Lo urbano, al mismo tiempo que lugar de encuentro, convergencia de comunicaciones e informaciones, se convierte en lo que siempre fue: lugar de deseo, desequilibrio permanente, sede de la disolución de normalidad y presiones, momento de lo lúdico y lo imprevisible. Henri LEFEBVRE, "El Derecho a La Ciudad: Historia, Ciencia, Sociedad,” Barcelona.Penísula (1978). 16

90 Victor Turner, "Frame, Flow and Reflection: Ritual and Drama as Public Liminality," Japanese Journal of Religious Studies (1979), 465-499. 466

91 Ángel Gabilondo, Artesanos De La Belleza De La Propia Vida (España: Centro de Cultura Contemporánea de Barcelona, 2010).
Lo urbano es lo liminal.

La liminalidad es sinónimo de la inestabilidad y la incertidumbre pero a la vez los es de la potencialidad y de la potencia

Los lugares liminales tienen que ser siempre espacios de paso; si se hace lugar permanente uno se hace marginado de la sociedad 
Uno no puede estar en un estado liminal de manera permanente, sin embargo, según Agamben, el estado de excepción se ha hecho norma mirar pero no entrar y seguir. A través de la metáfora de van Gennep, según la que la estructura social se parece a una casa que tiene habitaciones y pasillos, cada cambio de estado es pasar de una habitación a otra, salir al pasillo para encontrar la siguiente habitación que uno abrirá; pero este tiempo si dura más de lo necesario es peligroso, porque el ser humano no tiene un estado concreto; tiene y no tiene raíces, tiene y no tiene memoria. Dentro de los pasillos se pueden formar anti-estructuras, estructuras efímeras y adhoc; las comunitas, seres liminares. Pero si alguien se pierde en el interior de los pasillos de las habitaciones sociales, pierde el camino, se convierte en marginado.

No se puede vivir en los pasillos de las casas sin entrar en ninguna habitación, pensaría van Gennep; es decir, no se puede estar continuamente en la fase de la liminalidad, en el lugar que está fuera del tiempo, fuera de normas y principios; no se podría estar en continuo estado de excepción. Sin embargo, un cambio importante en los umbrales del siglo XXI es que el estado de excepción se ha hecho norma; como dice Agamben, hoy no hay ya manera de pensar ni de actuar en función de un escenario fijo, inamovible(...) sólo queda lugar para pequeñas intervenciones, gestos, maniobras realizadas sobre la marcha, inmediate $2^{92}$. El estado de estar fuera pero permanecer, hoy en día, es lo habitual y lo normal mientras que en otros tiempos esto era cualidad solo de un momento excepcional: cuando alguien sale fuera de las estructuras de lo ordinario. Hoy no pertenecemos plenamente a ningún lugar y a ninguna sociedad en la que entramos; ${ }^{93}$ pertenecemos al "entre"; vivimos entre los pasillos y los links de las estructuras sociales, en los intersticios. Con o sin cuerpo, el ser contemporáneo está siempre a todas horas en todas partes. Bourdieu dice que la

92 Agamben explica la forma del estado de excepción definido por un Estado: lugar donde normas y leyes no valen y por eso la que impone es la gestión y la figura central es la policía: es excepcional, no existen principios, seguridad y estabilidad. Los nazis no hicieron más que servirse de una figura jurídica, la del estado de excepción, para crear un espacio en el que todo estaba permitido, donde no habia delitos porque no existian leyes. Intenté comprender Auschwitz. como modelo, no como hecho bistórico. Y ese modelo, el del estado de excepción, es el que se está convirtiendo en norma (...) Estado de excepción es donde las leyes no valen, donde no hay formas fjias ni principios que los acepten todos, lo que se impone es la gestión, el resolver los problemas de la manera que sea, y la policia se convierte en la figura central. A la policía se le permite hacer cosas que la ley no autoriza porque se entiende que se enfrenta con situaciones excepcionales. Pero cuando toda forma parte de un estado de excepción, se generalizan los métodos policiales (...) Y cuando no hay principios de referencia, la pregunta ya no puede ser "¿qué quiero hacer?”, sino "¿quépuedo hacer?”. Hoy no hay ya manera de pensar ni de actuar en función de un escenario fijo, inamovible (...)sólo queda lugar para pequeñas intervenciones, gestos, maniobras realizadas sobre la marcha, inmediatez: "'El Estado De Excepción Es Hoy La Norma” | Edición Impresa | EL PAÍS “, accessed 1/13/2016, 2016, http://elpais. com/diario/2004/02/03/cultura/1075762801 850215.html.

93 Referencia en Bauman Zygmunt, En Busca De La Política (Argentina: Fondo de Cultura Económica, 2001).169. 
figura del siglo XXI es la del inmigrado, exiliado, turista y errante urbano ${ }^{94}$; situación que se percibe como un ser humano sin raíces, y por eso sin identidad: la raíz es lo que define la diferencia con los otros, con la raíz de los otros. ${ }^{95}$ Lo contradictorio es que el fenómeno del desarraigo va de la mano con la uniformización. La uniformización por la sobreproducción de objetos e información de culturas y lenguajes cambia el paisaje urbano: cada vez se hace más liso, sin pliegues, por la uniformización y por tanto neutralización de los espacios; hay que decir, expresa Bourdieu, que la cultura contemporánea se fabrica en lugares aparentemente similares en todo el mundo - los no lugares de Auge: aeropuertos, shopping malls, etc.; allí sucede un choque y encuentro de diferencias culturales importadas. ${ }^{96}$

Dentro de la uniformización y a la vez, de la pérdida de identidad, ¿quiénes son los otros?, pregunta Bourdieu: todos los que se encierran dentro de las costumbres que no se pueden trasladar al país de recepción. ${ }^{97}$ La creación del gueto es la defensa más común de los desarraigados frente a lo uniforme y lo global; ir en contra de las fuerzas que te cortan la raíz e intentar encontrar ritos o tradiciones para salvar la raíz ${ }^{98}$. Lo que sucede en el mundo contemporáneo es la reivindicación de la raíz como medio y remedio para la identidad rechazada o mitificada; si antes, en la modernidad, dice Bourdieu, la raíz representaba el reinicio radical y la nueva humanidad para el ser humano que vino en la cultura después de ellos es su asignación para una identidad, sentir que pertenecen a un lugar social o espacial estable, a un marco natural y de seguridad. ${ }^{99}$ Así, en el nombre de la raíz se desarrollan el racismo y las ideologías tradicionalista, la exclusión de los otros. ${ }^{100}$

Son las raíces las que hacen sufrir a los individuos: en nuestro mundo globalizado, persisten a la manera de esos miembros fantasmas cuya amputación provoca un dolor imposible de combatir, ya que afecta a una sustancia que ya no existe. 101 "Estaba bastante contento
94 Nicolas Bourriaud and Michèle Guillemont, Radicante Adriana Hidalgo Buenos Aires, 2009). 56

$95 \quad$ Ibid. 21

96 Ibid. 19

$97 \quad$ Ibid. 21

$98 \quad$ Ibid. 21

$99 \quad$ Ibid. 55

100 Ibid. 21

101 Ibid. 21
Años de contradicción: el fenómeno del desarraigo va de la mano de la uniformización

La formación del gueto es la defensa frente a la pérdida de la identidad y la uniformización 
Maneras para habitar lo liminal y la incertidumbre sin vértigo
Para vivir dentro de la incertidumbre hay que ser un organismo radicante, como la hiedra

\begin{abstract}
por ser alguien sin raices — confesaba-Marcel Duchamp hacia el final de su vida. Porque precisamente, temía la influencia de la raíz en mí. Cuando me encontré del otro lado, no babía raíz. ninguna porque habia nacido en Europa. Asi que resultaba fácil. Estaba inmerso en un baño agradable porque podía nadar tranquilamente y no se puede nadar tranquilamente cuando bay demasiadas raíces, ¿sabe?"'0234
\end{abstract}

Ciento setenta y cinco millones personas en el mundo, viven en el exilio, voluntario o no, y esto es una razón importante para desarrollar un nuevo pensamiento sobre el concepto de la identidad. ${ }^{103}$ Habitar en lo liminal de manera equilibrada y estable se puede hacer de varias maneras; una sería evitar moverse en los pasillos de las sociedades, alejarse de la incertidumbre de la manera más fácil que es no asumir riesgos, pertenecer a una sociedad plenamente, mirar la globalización como lo malo de la época y evitar moverse y estructurase dentro de él; esto tiene el coste de estar en minoría, que a veces es sinónimo de marginal; y lo marginal es el otro lado de lo liminal, su cara negativa; o se podrían aceptar las condiciones de la liminalidad y aprovecharlas; porque, como ya se ha dicho, la liminalidad está llena de potencialidad y potencia; ser el modo subjuntivo de los verbos, significa que todo puede ser y podría ser; en un lugar indefinido, sin reglas que llevan a definir y ordenarse, familiarizarse, con infinitas opciones y personas. Hay algo más que el estado de la liminalidad ofrece: la experiencia de lo intersticial, de estar dentro y fuera a la vez. Estar en el "entre" privilegia al ser humano con una visión holística de las estructuras sociales y de él mismo: está en el tiempo - fuera del tiempo ordinario, que permite ver desde varios puntos de vista todas las facetas de los términos entre los que está; ver tanto las negativas como las positivas. Sin embargo, el limbo, aunque lugar de juego, de creatividad, del podría ser, no deja de ser un lugar inestable, indefinido, de incertidumbre, sin estructuras, sin identidad y sin orden. Sentirse bien en los terrenos de lo liminal, sentirse bien dentro de lo urbano, requiere la capacidad de contradecir; ser contradictorio, un ser humano sin raíces pero a la vez con raíces, con identidad pero sin identidad, con ideología pero sin ella. Para vivir y establecerse en la incertidumbre hay que ser un organismo radicante: un organismo

$102 \quad$ Ibid. 21

103 Ibid. 21 
que hace crecer sus raices a medida que avanza ${ }^{104}$. La metáfora de la hiedra es la que ayuda a Bourdieu a explicar cómo estaría cómodo el ser humano dentro de un espacio -tiempo excepcional, inestable, indefinido y sin normas, sin normalidad. La hiedra es de la familia El organismo radical es lo opuesto al organismo radicante de los radicantes que, al contrario de la familia botánica de los radicales que nacen de una raíz y su evolución depende de ella, son capaces de producir y echar raíces en los nudos que está en el suelo, contrariamente a los radicales cuya evolución viene determinada por su arraigamiento en el suelo. El Modernismo pertenece a la categoría de los radicales: querer volver al origen, a la raíz para depurarla y volver a crecer hacia arriba, hacia una nueva humanidad. Los artistas, arquitectos, los creadores del siglo XXI, empiezan a mostrar la tendencia de ser radicantes: hacer crecer sus raíces a medida que avanza. ${ }^{105}$ Dice Bourdieu,

\section{El radicante se desarrolla en función del suelo que lo recibe, sigue sus circunvoluciones,} se adapta a su superficie y a sus componentes geológicos: se traduce en los términos del espacio en que se encuentra. Ser radicante: poner en escena, poner en marcha las propias raíces en contextos y formatos beterogéneos, negarles la virtud de definir completamente nuestra identidad, traducir las ideas, transcodificar las imágenes, transplantar los comportamientos, intercambiar en vez. de imponer. ${ }^{106}$

El radicante, es atormentado entre la necesidad de vinculo con su entorno y las fuerzas del desarraigo, entre la globalización y la singularidad, entre la identidad y del aprendizaje del Otro. El adjetivo radicante, define el sujeto como negociador o mejor dicho, traductor del diverso; el radicante es el éxota de Senegal: el que logra volver a sí mismo luego de haber atravesado lo diverso. ${ }^{107}$

El peligro de la fase liminal del rito de paso es la desorientación en esta zona intermedia; perderse en lo indefinido, en los pasillos. La persona que ha de pasar de uno a otro está ella misma en peligro y emana peligro para los demás. El peligro se controla por el rito, que precisamente lo separa de su viejo estado, lo hace objeto de segregación durante un tiempo y luego

El peligro de la fase liminal, del paso de una estructura a otra, se controla por los ritos de paso

$\begin{array}{ll}104 & \text { Ibid. 22 } \\ 105 & \text { Ibid. 21 } \\ 106 & \text { Ibid. 22 } \\ 107 & \text { Ibid. 73 }\end{array}$


La etimología del término rito conduce al orden. Los ritos organizan

La manifestación de los hologramas, por primera vez realizada en Madrid y en el mundo, es un fenómeno y ritual radicante

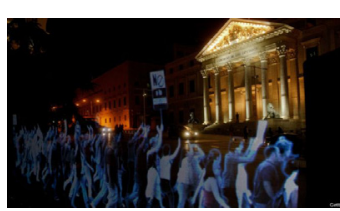

Manifestación de Hologramas, Madrid, 2015

públicamente declara su ingreso en su nuevo estado. ${ }^{108}$ Los ritos son herramientas organizadoras de los espacios - tiempos y, precisamente, de los espacios-tiempos liminales. La etimología del rito significa orden establecido; está asociado a términos griegos como artus (ordenanza), ararisko (armonizan, adaptan), y arthmos, que evoca el vínculo, la unión; la raíz ir se deriva del indoeuropeo védico (rta, arta). La etimología de la palabra parece definirle como el orden del cosmos, el orden de las relaciones entre los dioses y los hombres, el orden de los hombres entre si. ${ }^{109}$ Lo urbano, es decir, la sociedad que se forma cotidianamente en los pasillos, en los lugares de paso entre las estructuras de la ciudad, puede habitar como un desarraigado que se mueve en espacios uniformes, sin poder distinguirse de los otros, sin identificarse con su entorno y por eso, en la continua búsqueda de una identidad; o elegir, en lugar de sentir la ausencia de raíces, crear raíces nuevas y no buscar una identidad: interconectadas con las lejanas pero sin que ninguna le llegue a definir plenamente; en vez de buscar una identidad intentar no definirla; no ver un espacio-tiempo-sociedad uniforme sino mirar hacia la potencialidad del suelo indefinido e inestable en que está arraigado.

Un importante acontecimiento que muestra el significado del adjetivo radicante es la manifestación de hologramas que tuvo lugar por primera vez en la historia de la humanidad en la ciudad de Madrid, el 10 de Abril de 2015; atravesando las calles de Madrid, con la ausencia de sus cuerpos pero con su imagen digital, más de diecisiete mil personas de todo el mundo, se manifestaron contra la ley mordaza que, a partir de Julio de 2015, prohíbe las manifestaciones en las calles de la ciudad sin autorización previa. La ley, violación de la libertad en la expresión, no puede funcionar en el lugar liminar de las redes de internet: aunque exista la ley de la prohibición de la concentración masiva en el espacio público y de realización de manifestaciones-procesiones, no existe una ley que prohíba la manifestación de hologramas. Los manifestantes fueron participando desde España, Rusia, México, Argentina, Chile, Reino Unido y Francia, entre otros países, diciendo que ya sólo podrás manifestarte como un holograma. ${ }^{110} \mathrm{El}$ aprovechamiento del espacio liminal no solo ha conducido a la invención de un nuevo modo del uso del

\footnotetext{
108 Segalen Martine, Ritos y Rituales Contemporáneos (Madrid: Colección El libro de bolsillo, Antropología, Alianza Editorial, SA, 2005), 52

109 Ibid. 13

110 “Es Esta La Primera Manifestación De Hologramas De La Historia? - BBC Mundo “, accessed 1/13/2016, 2016, http://www.bbc.com/mundo/noticias/2015/04/150413 manifestacion hologramas espana jm.
} 
espacio público y de identidad, sino también a la creación de vínculos y raíces entre ciudadanos de varios países.

El ritual es importante no solo para la creación de raíces y vínculos sociales, ${ }^{111}$ sino también para poetizar los pasajes. El rito significa más para la sociedad que las palabras significan para el pensamiento. Pues es muy posible entrar en conocimiento de algo y hallar luego palabras para ello. Pero es imposible mantener relaciones sociales sin actos simbólicos ${ }^{112}$. Los ritos son más que actos simbólicos: son intensificadores de la experiencia de estos mismos actos simbólicos; les dan color, pasión, drama, es decir los poetizan: lo ritual, como la poesía, puede tomar las cosas ordinarias y a través de la metáfora aumentar su significado por encima de lo mundano. Los espacios urbanos más prosaicos pueden ser totalmente transformados en un grado irreconocible durante un ritual.. ${ }^{113}$ Si lo urbano es lo dinámico de la ciudad, su dimensión más liquida e inestable, la sociedad que se está formando y trasciende las fronteras de la ciudad, lo que está en continuo cambio, la sociedad del paso, ${ }^{114}$ entonces sería razonable hablar de ritualización del tiempo urbano en lugar de renovación del espacio urbano; el espacio sería renovado y revitalizado según la manifestación espacial de los ritos. Ritualizar en el sentido de organizar - el rito, dicho anteriormente, significa orden cósmico - probar una organización procesional en los ámbitos de lo urbano: en los lugares de paso, lugares intermedios y liminales.

La organización procesional se diferencia de la organización de la velocidad, que es la que suelen usar los urbanistas y los políticos a partir del Renacimiento, en que la primera busca el retraso mientras que la segunda intenta eliminarlo; la primera se localiza hacia lo que sucede en el "entre": los eventos que pueden tomar lugar en el momento de la procesión o cualquier rito de paso, juegos o celebraciones. La segunda se centra en el fin del trayecto; llegar lo más rápido posible al lugar de terminación y, si es posible, sin moverse del punto de partida. La organización procesional aspira a que el viajero sienta el cambio y la transformación que sucede en el paso de un estado a otro, de una estación

111 Segalen Martine, Ritos y Rituales Contemporáneos (Madrid: Colección El libro de bolsillo, Antropología, Alianza Editorial, SA, 2005), 115

112 Ibid. 28 (p. 89).”

113 Aarati Kumar Kanekar, Celebration of Place: Processional Rituals and Urban Form (1992) $17-18$

114 Manuel Delgado, El Animal Público: Hacia Una Antropología De Los Espacios Urbanos: [XXVII Premio Anagrama De Ensayo]Ed. Anagrama, 1999).
El rito significa más para la sociedad que las palabras significan para el pensamiento. Senegal

La organización procesional le interesa al Entre, al proceso; la organización de la velocidad se centra en el fin del trayecto. La organización procesional enfoca el cambio y la transformación; la de la velocidad se centra en la transición 
A China le interesa el cambio, la transformación, lo constante, lo cambiante. Occidente enfoca en el movimiento, la transición y el tiempo abstracto

El concepto del tiempo en China no se analiza a partir del movimiento, sino a partir del cambio a otra; la organización de la velocidad piensa en la transición: transportar de la manera más rápida posible un sujeto de un punto a otro. La organización basada en los ritos de paso deriva de un pensamiento intersticial, que parte del Entre; lo primordial no es el sujeto, el fin y el principio del trayecto, sino lo que sucede entre ellos. La conquista de la máxima velocidad es fruto del pensamiento racional, binario, abstracto, que parte del Ser: piensa en el tiempo que necesita un ser para pasar de un punto a otro. El pensamiento racional entiende el concepto del tiempo de manera muy distinta que lo de lo mágico-religioso o el pensamiento chino.

El pensamiento chino no concibe el tiempo y el espacio como algo abstracto, geométrico; el vocabulario chino no incluye el término tiempo. China se ha interesado por el cambio, la duración y las estaciones, la transformación, lo constante y lo cambiante; Occidente ha sido atraída por el movimiento, la transición, el tiempo abstracto, lo eterno y lo temporal. Aristóteles pudo concebir el tiempo a partir del movimiento; después, para entender el movimiento, pensó en el lugar en el que se produce el movimiento y el tiempo que sirve como medida; el tiempo se percibe entre dos puntos sucesivos del movimiento de un cuerpo; por ello se representa con más comodidad en relación al espacio, según la trayectoria de un móvil que se mueve de un punto a otro, el transporte local (phora). ${ }^{115} \mathrm{~A}$ través de la metafísica, la invención del Ser y del más allá, orientó el pensamiento hacia la dualidad eterno - efímero. Además, la búsqueda del origen del mundo condujo a la creación de un principio y un fin de los actos. La concepción china entiende la naturaleza y el tiempo en términos de factores correlativos, yin y yang, y no en términos de cuerpos en movimiento. En China el concepto del tiempo no se examina a partir del movimiento sino a partir del cambio; en vez de transición o travesía se percibe la transformación. ${ }^{116}$ En la historia de China no se piensa la Creación y el Fin de los tiempos, ni el tiempo eterno y lo temporal, sino lo constante y lo cambiante.

Las palabras eterno y constante las dos dicen de la permanencia, las dos se oponen a las efemérides, pero lo hacen de modo distinto. Lo eterno está separado de lo temporal mientras

115 François Jullien and Miguel Lancho, Del» Tiempo»: Elementos De Una Filosofía Del VivirArena Libros, 2005). 25

116 Francois Jullien and José Miguel Marcén, Las Transformaciones Silenciosas Bellaterra, 2009). $43-45$ 
que lo constante se manifiesta "por medio" de lo cambiante. (...). Ambos denotan una permanencia pero dispuesta de modo distinto: mientras que la permanencia de lo eterno está adosada al ser y se ofrece a la contemplación (teoría), la de lo constante se refiere a la marcha de las cosas, como dicen los chinos, a su funcionamiento. Lo eterno nos remite una "identidad" de esencia mientras que lo constante es del orden de la "capacidad", es lo que asegura el proceso de las cosas, transformándose sin cesar, lo que constituye su "viabilidad"(...) mientras que lo eterno está fuera del tiempo, lo constantes lo que no se interrumpe jamás. ${ }^{117}$

Occidente, reivindicando la finalidad, el "hacia qué" y el destino se ha centrado en el Fin y ha abandonado el intermedio, la transición o la transformación. ${ }^{118}$ Si el fin, la finalidad y el origen de la filosofía griega, dejan fuera el tercer término, el entre, es porque la Filosofía del Ser y la lógica binaria no pueden explicar los momentos del cambio y transformación; la lógica binaria cree en los términos opuestos: las cosas son o no son; así que el momento de la transformación, cuando las cosas son y no son, es inexplicable ${ }^{119}$ La filosofía del Ser es la filosofía del Fin, es decir, del Límite, que necesita limitar, delimitar, definir para entender el mundo. La filosofía del Entre es la Filosofía de la Vía: considera esencial los momentos en los que suceden las transformaciones, aquellos en que una cosa es y a la vez no es y por eso le interesa lo indefinido, lo sin límites, lo que no tiene identidad.

El pensamiento lógico, racional, que se manifiesta desde Platón, se afirma con Aristóteles bajo el principio de la no contradicción y del tercio excluso, y se intensifica en los años de la Modernidad cuando se privilegia el orden, lo bien definido, la claridad y se excluye lo indefinido y lo inesperado. ${ }^{120}$ Lo que el pensamiento griego evitó pensar, el entre, el intermedio, lo contradictorio, ${ }^{121}$ es lo que ha construido: un estado en continuo cambio y transformación donde todo es y no es: todo está un poco después de nacer y 117 François Jullien and Miguel Lancho, Del» Tiempo»: Elementos De Una Filosofía Del VivirArena Libros, 2005). 23-24

118 Francois Jullien and José Miguel Marcén, Las Transformaciones Silenciosas Bellaterra, 2009).

119 Ibid. 22-23

120 Zygmunt Bauman et al., "Modernidad y Ambivalencia," in Las Consecuencias Perversas De La Modernidad. Modernidad Contingencia y Riesgo (Barcelona, España: Anthropos, 1996), 73 119.

121 Francois Jullien and José Miguel Marcén, Las Transformaciones Silenciosas Bellaterra, 2009).
La filosofía del Ser es la filosofía del limite y del fin. La filosofía del Entre es el pensamiento de lo sin fin

El pensamiento racional, desde Aristóteles y hasta la modernidad, intenta excluir lo contradictorio, lo intermedio y lo liminal

El pensamiento racional conduce a una epoca en la que el estado de excepción es la norma, creando la época de lo liminal 
Revitalización o renovación del espacio público vs Ritualización del tiempo urbano un poco antes de aparecer; un entorno de verbos en modo subjuntivo y por eso lleno de potencia; todo está en potencia, virtual. El pensamiento racional, al final, orienta quizás hacía una época liminal, que no es postmoderna, ni contemporánea, porque ya el tiempo, el espacio, la distancia y cualquier término han alterado sus significados. De la prehistoria a la historia y ahora, en una fase liminal, entre la historia y la metahistoria, del lenguaje a metalenguaje.

Los ritos de paso cuidan y protegen precisamente esta fase liminal del paso de un estado a otro, de una época a otra, de un ambiente a otro. ${ }^{122}$ En vez de revitalización o renovación del espacio urbano sería quizás más fácil intentar la ritualización del tiempo urbano: proyectar pensando en el cambio y no el movimiento, en la transformación y no la transición, en las relaciones y no en los sujetos; abandonar la velocidad y aprovechar el retraso. La prisa es el otro nombre del miedo ${ }^{123}$, andar despacio es tranquilidad, reflexión, comunicación; el retraso indica un encuentro inesperado, una sorpresa y lo imprevisto que no permitió la llegada a tiempo. Es humano retrasarse. La arquitectura debería, en mi opinión, tenerlo más en cuenta ${ }^{124}$.

122 Segalen Martine, Ritos y Rituales Contemporáneos (Madrid: Colección El libro de bolsillo, Antropología, Alianza Editorial, SA, 2005), 52

123 Ángel Gabilondo, Artesanos De La Belleza De La Propia Vida (España: Centro de Cultura Contemporánea de Barcelona, 2010).9

124 Aldo van Eyck, Vincent Ligtelijn and Francis Strauven, Aldo Van Eyck: Writings (Amsterdam: Sun, 2008). 62 


\section{los conejos en el Tercer Espacio, en los intersticios}

....cuando hagáis vuestros planes, pisad con suavidad, porque pisáis sobre los sueños de la gente que vivirá dentro y que contemplará vuestros edificios. ${ }^{1}$

Slavoj Žižek

El conejo común o europeo es miedoso por naturaleza; a veces huye incluso por simple sospecha. ${ }^{2}$ A esta circunstancia influye la estructura que tiene: entra en la categoría de los animales víctimas, al contrario que el ser humano, que está en la categoría de cazador. Los animales víctimas tienen los ojos laterales; los cazadores frontales y con visión estereotópica, necesaria para el cálculo de distancias en el espacio y la detección de los objetos. Las víctimas, que tienen desarrollada la visión periférica, no pueden ver en profundidad pero tienen un campo visual de $350^{\circ}$ para poder controlar el entorno; los cazadores de ojos frontales tienen un campo visual de $180^{\circ}$ pero con gran área binocular. ${ }^{3}$ Sin embargo, aunque víctimas y destinados a ser cazados, el conejo pertenece a las cien especies exóticas invasoras más dañinas del mundo, de la lista elaborada por el Grupo Especialista de Especies Invasoras (GEEI) de la Comisión de Supervivencia de Especies (CSE) de la Unión Internacional para la Conservación de la Naturaleza. ${ }^{4}$ Los conejos que vivían en la Plaza Potsdam de Berlín después de la Segunda Guerra Mundial, estaban acostumbrados a ver las vallas que los berlineses levantaban para proteger sus verduras porque después de la Segunda Guerra mundial la ciudad carecía de alimentos. De repente en la noche del 12 al 13 de Agosto de 1961,

1 Slavoj Žižek, Viviendo En El Final De Los TiemposEdiciones Akal, SA, 2012). 289

2 Mauerhase, directed by Bartek Konopka, Piotr Rosolowski and Anna Wydra Icarus Films, 2009)

3 Polyxeni Mantzou, "Utilización De Medios Audiovisuales Como Modificadores Del Espacio Arquitectónico” Arquitectura), .385

$4 \quad$ Sarah Lowe et al., 100 of the World's Worst Invasive Alien Species: A Selection from the Global Invasive Species DatabaseInvasive Species Specialist Group Auckland,, New Zealand, 2000).
Los conejos son victimas y miedosos por naturaleza, pero pertenecen a las cien especies invasoras más dañinas del mundo 
Los conejos berlineses se quedan atrapados dentro de la franja de Nadie, entre los dos muros que dividen Berlín

La franja de 120 kilometros que separa el mundo en dos, Oriente-Occidente, es el país paradisíaco de los conejos las vallas empezaron a expandirse, no solo para cubrirlas de plantas, sino por todo el área del prado. Después, las vallas dieron lugar a construcciones más y más sólidas: una alambrada de 155 kilómetros. Los conejos nerviosos veían a los seres humanos en un comportamiento extraño y se escondieron en sus madrigueras. Cuando todo parecía más calmado, después de varios días, los conejos salieron de sus madrigueras y no pudieron reconocer su entorno, el prado. Había un muro. Corrieron para encontrar la salida. En todos los lados había soldados y perros; los conejos recorrían kilómetros sin hallar una salida. Después de varios días corriendo a lo largo del muro, se encontraban otra vez en la plaza Potsdam. Fueron conscientes de que estaban atrapados; se habían quedado dentro de la franja entre los dos muros que rodeaba Berlín occidental. Había guardias que hacía turnos en torres levantados: durante ocho horas al día no hacían más que mirar la franja y observaban todo el día la vida de los conejos; si les dispararan tendría consecuencias ya que estaba prohibido. Casi 300 torres de vigilancia en una franjacarretera de cuatro metros de ancho y tres puntos de control: Alfa, Bravo y Charlie paso soviético y americano.

Los conejos seguramente creían que los seres humanos deseaban protegerles y ofrecerles un paraíso; protegidos de otros enemigos, de los perros, de los gatos y de los propios seres humanos. Los conejos empezaron a tener confianza con los soldados; en la plaza Potsdam había unos mil conejos. Después de unos años los conejos se multiplicaron y se asentaron en toda la franja de 120 kilómetros. La franja de 120 kilómetros que separó el mundo en dos, oriente - occidente, era el país de los conejos. Todas las familias tenían sus madrigueras siempre con una salida oculta en la sombra de los bloques blindados de los muros. El país de los conejos se hizo famoso y los que habían construido la pradera invitaban a la gente a observar la vida de los conejos. El paraíso empezó a convertirse en tedio para los conejos: no tenían miedo de nada, no tenían que buscar y encontrar comida, no tenían que hacer nada; tenían lo que querían, siempre estaban felices y, por eso, entraron en pasividad. Para los conejos, el nuevo gerente de aquella época era amante de los conejos, más que nadie. Aumentó la pared en altura y cerró los últimos huecos que quedaban con bloques de hormigón; puso farolas que iluminaban más lejos e instaló nuevos sistemas de control. La vida de los conejos se desarrollaba en paz y armonía, con comida en abundancia y protegidos, 
sin embargo, la gente de fuera de los muros, descubrió unos grandes túneles que los conejos cavaban para huir del paraíso por debajo del muro al Oeste. El gerente quedó decepcionado y limpió la pradera a fondo; los guardias observaron a los conejos, taparon las madrigueras que parecían conducir fuera del muro, quitaron la hierba para ver con más claridad. Finalmente exterminaron los conejos poniendo productos químicos en la hierba y envenenándolos. Los soldados veían a los conejos por la noche venir y pedir comida. Muchos de ellos se los llevaron a casa o les pusieron una cinta en el cuello para que todos supieran de quien era cual. La caza ya no estaba prohibida. Los soldados los disparaban para llevarlos a casa. Los conejos vivían en un miedo continuo porque en cualquier momento podían morir. El muro cayó y los conejos pudieron dejar la pradera y llenar la plaza. Vieron gente nueva que no eran soldados y más sabores, fuera de la pradera. La gente cazaba todos los días. Los conejos eran muchos y eran una plaga como antes; por todas partes eran expulsados. ${ }^{56}$ La caída del muro fue un gran acontecimiento para el pueblo Alemán, pero fue como un éxodo dramático principalmente en Alemania occidental, una sentencia de muerte para los pisoteados por los eufóricos alemanes que trataban encontrar a sus seres queridos en la franja de nadie.

El documental no histórico, sino alegórico de Konopka, da un punto de vista desde el entre que ningún ser humano pudo vivir. La historia ha sido contada por las dos partes políticas, por los soldados que vigilaban la zona de nadie y por los pocos que consiguieron vivir después de haber atravesado la zona de la muerte. La historia nunca fue contada desde el entre, desde el intersticio, desde el tercer espacio: solo los conejos berlineses eran los legítimos habitantes del muro, de la zona de Nadie o de la Vergüenza. ${ }^{7}$ Hoy en día quedan tramos no edificados de la zona de la muerte, como la calle Bernauer Strasse, donde el muro corría justo enfrente de los edificios. El 9 de noviembre de 2014, la Canciller Angela Merkel inauguró The Berlin Wall Memorial que está localizado en la mitad de la capital, en la Bernauer Strasse, que tantos años dividió la ciudad en dos. Se extiende alrededor de 1,4 kilómetros y contiene la última pieza del

5 Mauerhase, directed by Bartek Konopka, Piotr Rosolowski and Anna Wydra Icarus Films, 2009)

6 Ibid. En español el documental tuvo el titulo Conejo a la Berlinesa

7 "Rabbits in Berlin's Death Zone | Film | the Guardian ", accessed 1/13/2016, 2016, http://www.theguardian.com/film/2010/mar/11/rabbit-a-la-berlin.
El paraiso de los conejos se hizo infierno cuando el ser humano decedió extreminarlos

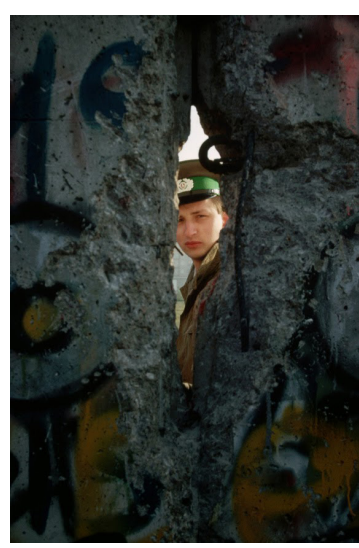

La historia del Muro de Berlín nunca fue contada desde el entre. Solo el documental de Konokpa no da un punto desde el interior de la franja de Nadie o de la Verguenza 
Las dos ciudades creadas por el muro de Berlín siguieron cada una distintas formas urbanas

La franja de los dos muros es la materialización espacial de un diálogo muro de Berlín. ${ }^{8}$ Axel Klausmeier, director del museo, recuerda que esta es la única pared que se ha construido no para impedir la entrada, sino para impedir salir; quedan pocos metros, dice Klausmeier, porque aquella noche lo único que se escuchaba eran la piquetas de cuando los vecinos rompían y se llevaban una pieza del muro.

El muro de Berlín dividió la ciudad en dos; la parte estadounidense, británica y francesa, La República Federal Alemana, RFA y la del control soviético, la República Democrática Alemana, RDA. Las dos partes de la ciudad siguieron distintos caminos en la evolución de la forma urbana. Las Reformas que suceden en la RDA impulsadas por Gorbachov secretario general de URSS provocan un éxodo de los orientales, viendo en occidente mejores condiciones de vida. Así, el muro se levantó para impedir a los ciudadanos de oriente pasar al otro lado. El trazado del muro dividió la estructura y la dinámica urbana de cada una de las ciudades alemanas; los ciudadanos tenían dos líneas de metro, con dos mapas de líneas distintas. En Mayo de 1990, se firmó la unión monetaria económica y social de los de las dos Alemanias y empezó la reunificación de Berlín: se volvieron a conectar las calles que el muro había cortado por la mitad. Entre los años 1990 al 2000 la ciudad aceptó extraordinarias edificaciones; se instalaron muchas empresas y hubo grandes inversiones. A partir de 1990, Berlín fue una fiesta de arquitectura; se levantaron grande edificios institucionales, reurbanizaciones y centros comerciales. Hoy en día el trozo de Muro más grande, con un total de 1,3 kilómetros es una gran colección de murales al aire libre: en total 100 obras de artistas de 21 países. ${ }^{9}$

El país de los conejos, la franja entre los dos muros de Berlín, consistía en el lugar de encuentro y división no solamente de las dos partes de Berlín, sino de todo el mundo y de todo el pensamiento humano: occidente - oriente, Estados Unidos - Rusia, capitalismo-comunismo, izquierda -derecha, individual -colectivo, nosotros y los otros. Este espacio, con un ancho de veintisiete hasta noventa metros y una longitud de ciento cincuenta y cuatro coma cinco kilómetros, el Tercer Espacio, aquel que permanece fuera del exterior pero fuera del interior, la tierra de nadie, es la materialización espacial de un diálogo, de una conversación que ha conducido a la separación del mundo en dos. Los

8 "Berlin Wall Memorial “, accessed 1/13/2016, 2016, http://www.berliner-mauergedenkstaette.de/en/.

9 "Urban Networks: Berlín Reunificado Tras La Caída Del Muro y El Final De

La Ciudad Doble. “, accessed 1/13/2016, 2016, http:// urban-networks.blogspot.com. es/2013/04/berlin-reunificado-tras-la-caida-del.html\#more. 
conejos como habitantes de nadie, pudieran hablar, se preguntarían por qué una raza de animales de ojos frontales, nacidos cazadores todo el día hacen la mismo: mirando una zona de nadie. Desde el interior del tercer espacio la pregunta que cualquiera haría es por qué existen las fronteras: sería la pregunta de un conejo; para el ser humano las fronteras son algo tan natural que nunca se cuestionan.

Según el Derecho Internacional, una frontera es la línea que marca el límite exterior de un Estado; el lugar donde un Estado ejerce su soberanía. La definición de las fronteras entre dos Estados se hace en dos pasos: la delimitación y la demarcación. La delimitación fronteriza es una operación intelectual en la que se elige el emplazamiento de la frontera; delimitación se refiere a una definición abstracta y en papel, y esta operación está contenida en el tratado de límites o fronteras de los países como instrumento jurídico. ${ }^{10}$ En la comunicación y negociación entre los dos países, éstos tienen dos opciones o principios de la delimitación: encontrar un nuevo límite, cuyos criterios más utilizados son los naturales; (la geomorfología del terreno: cadenas de montaña, divisoria de aguas) y los artificiales, que son proyectados sin pensar en la topografía del terreno, como por ejemplo limites astronómicos o geométricos. Los geométricos pueden ser una línea recta que conecta dos puntos o un arco con un punto establecido o las construcciones humanas. Otro modo para trazar los límites radica en encontrar un nuevo límite tomando en cuenta un trazado antiguo de límites preexistentes. La implantación de límites internacionales preestablecidos sucede cuando tenemos una sucesión de Estado; el nuevo Estado surgido debe respetar y mantener las fronteras coloniales heredadas existentes en el momento al acceso a la independencia. ${ }^{11}$

La segunda operación es la demarcación que es la parte material de la definición de las fronteras: es la labor material y la técnica de verificación; demarcación es trasladar los términos de una delimitación previamente hecha en el terreno. ${ }^{12}$ La demarcación, es decir, la marca visible de las fronteras, se puede efectuar de varias formas. Según Ruiz y Molinos el tipo básico de configuración de fronteras es la delimitación en barrera y en cadena, del tipo Gran Muralla China que es el caso del cierre absoluto, mediante puntos

10 Ana Gemma López Martín, "Frontera. Criterios De Delimitación,” in Diccionario Crítico De Ciencias Sociales, Vol. I (Madrid y México: Ed. Plaza \& Valdés, 2007).

11 Ibid.

12 Ibid.
La delimitación de fronteras entre dos Estados se hace en dos pasos: delimitación y demarcación

Delimitación es una operación intelectual en la que se elige el emplazamiento de la frontera; es una definición abstracta y en papel

La demarcación es la parte material de la definición de las fronteras; es la marca visible de las fronteras 
Existen fronteras vivas $y$ fronteras muertas

Las fronteras de Creta Minoica eran mar que produce riqueza.

La civilización de Creta Minoica se distingue de otras por su espontaneidad. fluidez y libertad

Palacios sin fachadas y sin límites, multiples entradas, rechazan lo monumental y lo axial y crean una atmósfera informal y pintoresca de control que crean una red visual. Las fronteras no se forman únicamente cuando hay tierra de por medio, sino que también existen aéreas, fluviales, marítimas, lacustres y hoy en día, inalámbricas. Las fronteras de un Estado no se clasifican sólo según los tipos de construcciones territoriales o aéreas, sino que existen además fronteras político-sociales, históricas y económicas; para la economía, en relación con la interacción de la gente, las fronteras son vivas cuando existe intercambio y dinámica económico-social entre las regiones fronterizas, o muertas si no existe contacto de poblaciones como las fronteras en regiones desérticas o deshabitadas. Realmente las construcciones fronterizas son materializaciones físicas y espaciales, del diálogo como operación intelectual que tiene lugar entre los Estados. Y por esta razón, las fronteras muestran la relación de los Estados como relación con la otredad, ya que la relación de dos Estados no es solo geográfica, sino una relación entre culturas, lenguaje, costumbres.

Cuando entre los Estados existe un mal diálogo, la relación y el encuentro entre ellos es más difícil cuando los separa el mar que la tierra, pero aunque parezca ilógico, es posible que suceda un encuentro verdadero y fructífero. La gente que vive en islas parece ser más relajada que la que vive en la tierra, posiblemente porque las dos partes de la relación tienen tiempo para sentir la otredad; el barco se aproxima con lentitud y esta distancia permite un tiempo para la preparación psicológica de un encuentro; además, el mar entre ellos, lo sin fin, les recuerda la insignificancia del ser humano en el mundo y su pertenencia a la misma especie; abrir nuevos horizontes, decimos, y nos referimos a la ampliación del conocimiento, de la libertad y de las posibilidades. Los límites y las fronteras de los cretenses minoicos no eran desiertos o fortalezas, dice Trachtenberg, sino el mar, que produce riqueza: por eso los cretenses se distinguen de otras civilizaciones por su espontaneidad, fluidez y libertad .Es una sociedad extraña en la que entre el hombre y la mujer no hay diferencia o jerarquía sino solo colaboración: los dos participan en la organización del hogar y en el negocio familiar, en las actividades deportivas públicas y en las reuniones sociales de temas de la comunidad, en las que se tiene en cuenta la opinión de todos sin excepción. La sociedad minoica tenía un pensamiento irracional e informal. Sus palacios, tenían límites difusos, sin fachadas, ya que lo dentro y lo fuera no se diferencia, tenían múltiples entradas pero sin que realmente una fuera la principal, rechazaban conscientemente la monumentalidad que 
el Este con lo axial, la simetría y la abstracción conseguía y creaban una atmosfera informal, cómoda, pintoresca y animada. ${ }^{13}$

Hoy en día los países se tocan el uno al otro, pero en los años de las tribus semicivilizadas, incluso en la época en la que Europa no toda era cristiana, entre las sociedades había una zona neutra que no pertenecía a ninguna. Esta zona es el desierto o el pantano pero principalmente es selva virgen en la que cada uno puede viajar o cazar con todo derecho. La marcación de los límites de las sociedades, que son los que dan forma a la zona neutra, no se hace solo por razones políticas, jurídicas o económicas sino también mágico religiosas. Los musulmanes, los cristianos y los budistas no pueden entrar en el lugar de otras creencias, entrar en sus territorios. Para quien está dentro de la zona neutra los dos territorios que separan la zona son sagrados, y para los habitantes de los dos territorios, la zona es sagrada; para quienquiera que pase de uno a otro se halla así materialmente y mágico-religiosamente, durante un tiempo más o menos prolongado, en una situación especial: flota entre dos mundos ${ }^{14}$. Esta zona tiene un papel importante en la antigüedad clásica, principalmente en la Antigua Grecia que era el lugar del mercado o el lugar de combate. El aumento de la población y el progresivo abandono del pensamiento mágico religioso, cambia la forma y las características de la zona intermedia: o desaparece, o se hace inmaterial o, de manera material se divide, dejando de ser sagrada y se hace zona de conflictos, zona que no es de nadie y la presencia de alguien en su interior le puede costar la vida. Es el caso del muro de Berlín y la zona llamada franja de la muerte o franja de nadie.

La forma de las zonas fronterizas depende siempre de las sociedades y de la comunicación entre los dos países. Fronteras en las que la palabra civilización y evolución encuentra su significado son las fronteras de Austria, Hungría y Eslovaquia: una mesa de picnic para tres es lo que marca el cambio de los países. Las banderas conectan y separan Alemania, Polonia y República Checa. Lo que conecta a Alemania, Países Bajos y Bélgica es un monumento conmemorativo. La cercanía entre Polonia y Ucrania es decorada cada año en el festival del arte local en honor a la tierra. Macao y China se separan por una construcción que produce un cambio de carril. La frontera de Canadá y EE.UU es la frontera más larga del mundo pero sin una defensa militar.

13 Marvin Trachtenberg and Isabelle Hyman, Arquitectura, Vol. 24 (Madrid: Ediciones Akal, 1990). 86-90

14 Arnold Van Gennep, Los Ritos De PasoAlianza, 2008). 32
En la época de las sociedades semicivilizadas los paises no se tocaban entre sí. Entre ellos había una zona sagrada

Para los habitantes de los territorios de la zona neutra es sagrada, y para quienes están dentro de la zona, los dos territorios son sagarados

Fronteras extraordinarias

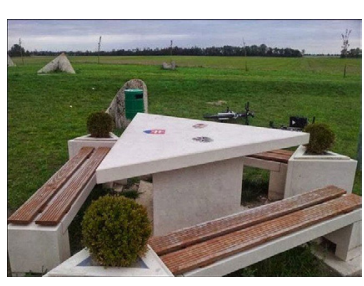

Austria, Hungría y Eslovaquia

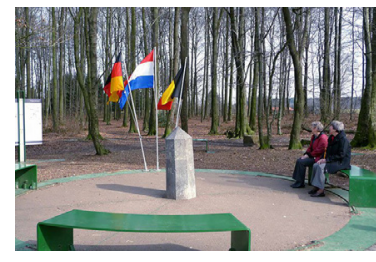

Alemania, Polonia y República Checa. 


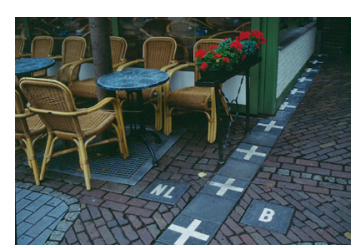

Baarle-Nassau

La progresiva desaparición de las fronteras entre los paises de la Unión Europea crea nuevos tipos de ciudades: las eurociudades

La Linea Verde de la isla de Chipre divide la isla de Chipre en dos desde 1974. La franja de Nadie que está entre los dos muros son partes de la ciudad antigua de Nicosia

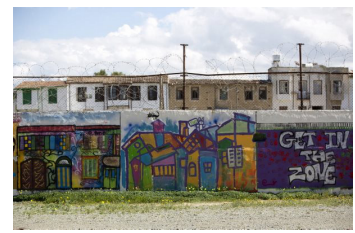

Linea Verde, Nicosia, Chipre

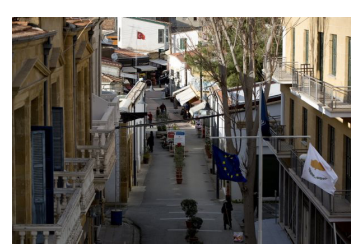

Linea Verde, Nicosia, Chipre
En el pueblo fronterizo de Le Perthus francés, se comparte la calle principal con el Els Limits español, uno aparca su coche en Francia y baja andando a España: los coches están aparcados en Francia, los bolardos y la cabina de teléfonos están en España y el supermercado llamado Frontera es de los dos países. ${ }^{15}$ En el pueblo Baarle compartido por Bélgica y Holanda, las fronteras son extremadamente complicadas y por eso se marcan por una linea divisoria dentro de la ciudad. La progresiva desaparición de las fronteras entre los países europeos a partir de la Unión Europea crea nuevos tipos de ciudades, las eurociudades; son ciudades que pertenecen a dos países distintos, pero ambos lados de la frontera crean convenios de cooperación y colaboración en proyectos comunes (colaboración en el sector de turismo, la organización de infraestructuras y del transporte). Ejemplo de ello es la eurociudad Vasca Bayona - San Sebastián, región urbana transfronteriza entre España y Francia y las eurociudades que España comparte con Portugal: Eurociudad Badajoz-Elvas, Ayamonte (Huelva) y Vila Real de Santo Antonio, Verin (Orense) - Chaves, Tuy (Pontevedra) y Valença do Minho. La Gran Muralla China, desde 1987, es Patrimonio de la Humanidad por UNESCO; es una muralla de veintiuno mil kilómetros, construida y reconstruida entre el siglo VIII a. C y el siglo XVI d. C como frontera norte del imperio chino con Mongolia. Hoy en día, se está construyendo la Gran Muralla Verde China, obra monumental que empezó a construirse en 1978 y está previsto que acabe en 2050. Es la nueva frontera de China hacia el norte, hecha con cien mil millones de árboles, para protegerse del polvo y de la arena del norte. ${ }^{16}$ La Línea Verde de la isla de Chipre no está construida de árboles: es una zona que divide Nicosia en dos desde 1974, cuando los turcos invadieron y ocuparon la mitad de la isla en su parte norte. La franja entre los muros son partes de la ciudad que se han encontrado dentro de la zona de nadie, intocables desde entonces; aunque el paso de un lado a otro se hace a través solamente de dos Check - Points, en 2007 el gobierno grecochipriota empezó a romper partes del muro como símbolo de buena voluntad, para abrir el antiguo casco de Nicosia que lleva sin vida 41 años. ${ }^{17}$ 15 "Ciudades Divididas: Le Perthus y Els Limits - “, accessed 1/13/2016, 2016, http://fronterasblog.com/2008/11/24/ciudades-divididas-le-perthus-y-els-limits/.

16 "La Gran Muralla Verde | Planeta Futuro | EL PAÍS “, accessed 1/13/2016, 2016, http:/ / elpais.com/elpais/2014/08/08/planeta futuro/1407493132 336973.html.

17 "El Gobierno Grecochipriota Comienza a Derribar El Muro Que Divide La Ciudad De Nicosia | Internacional | EL PAÍS “, accessed 1/13/2016, 2016, http://internacional. elpais.com/internacional/2007/03/09/actualidad/1173394805 850215.html. 
Desafortunadamente, en 2015, todavía existen fronteras de conflictos y se siguen construyendo más. En 2012, Grecia ha levantado una valla alambrada de doce kilómetros y medio con cuatro metros de altura en la frontera con Turquía. EE.UU y México tienen sus fronteras en conflicto aunque en Naco de Arizona y Naco de México usan el muro para jugar voleyball. La Valla de Melilla define los límites entre España y Marruecos; su construcción empieza el 1998 como una solo valla, después dos vallas de tres metros de altura; en 2005, las vallas alambradas tienen cuchillas y la altura se eleva a seis metros; en 2007 debido a las manifestaciones de algunos colectivos, el gobierno español retira las cuchillas, pero en 2013 vuelve a ponerlas y en 2014 la malla metálica se cambia por una que no permite la introducción de los dedos para treparla. Hoy, son doce kilómetros de un elemento arquitectónico de dos vallas paralelas de seis metros de altura con alambres de púas, acompañado con luces de alta intensidad, videocámaras de vigilancia y cables bajo el suelo que crean una red de sensores electrónicos de ruido y de movimiento. ${ }^{18}$ El muro de Israel que lo separa de Cisjordania y en general la forma de las fronteras de Israel con el Estado Palestino, demuestra su incapacidad de comunicación y los conflictos con las fronteras más complicadas del mundo con un barrera aprobada por el Estado Israelí en 2002; en 2015 sigue en construcción y se prevé que mida setecientos kilómetros de largo y cien metros de ancho. La Zona Neutra, la zona desmilitarizada, de Corea del Norte y de Corea del Sur, es de cuatro kilómetros de ancho y doscientos treinta y ocho de longitud; en algunos tramos, delimitan la frontera los cuerpos humanos, como en Panmunjom, la última aldea de Corea de Sur; en Panmunjom están las fronteras reales de las dos Coreas donde los dos límites están marcados con dos líneas en el suelo a pocos metros de distancia entre ellas: el paralelo 38; soldados enemigos se miran cara a cara, sin moverse, sin intercambiar ninguna palabra: un gesto que mantienen todo el día, sin perder de vista a los militares de enfrente; si un día se tienen que hablar por algo importante, existe un teléfono rojo en las dos partes de Corea pero, como dijo el capitán norteamericano Agee, en mayo de 2015, este teléfono lleva siete años sin soñar. ${ }^{19}$ Lo especial de estas fronteras, no es sólo la imparable tensión del eterno enfrentamiento 18 “El ‘blindaje’ De Ceuta y Melilla | Política | EL PAÍS “, accessed 1/13/2016, 2016, http://politica.elpais.com/politica/2014/03/05/actualidad/1394046257 447524.html.

19 "Zona Desmilitarizada De Turistas | Internacional | EL MUNDO “, accessed 1/13/2016, 2016, http://www.elmundo.es/internacional/2015/05/13/5543ac23268e3e70568b 456b.html.

En el paralelo 38, en Panmunjom, los soldadosenemigos se miran cara a cara sin moverse

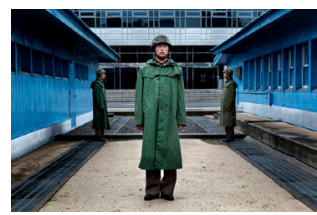

Paralelo 38, Panmunjom, Corea 
Las fronteras de Corea son un punto turístico importante para los dos paises.
A través de un ventanal de un teatro de Corea del Sur, la zona neutra entre las dos Coreas consigue una condición fantasmagórica

El Tercer Espacio: lo que permanece perdido en la división en el Exterior y el Interior, Žižek de los cuerpos con la mirada sin interacción, sino el hecho de que ocurra en los lugares más turísticos de las dos partes de Corea. Antes de penetrar en la zona neutral de la parte de Corea de Sur, existe un parque de atracciones, parecido a un parque de Disney, que incluye un mirador, cafeterías, tiendas de souvenirs y excursiones que cuentan la historia por la que Corea se dividió. En la parte de Corea del Norte, desde el mirador se ve el pueblo de propaganda, como los surcoreanos nombran al pueblo nortecoreano Gijeondong, que consideran que está construido con altos edificios para mostrar la inexistente prosperidad de Corea del Norte; este pueblo es el antagonismo del pueblo surcoreano Daesong-dong donde viven doscientos treinta habitantes que el estado subvenciona para que vivan allí. Hay un silencio tenso en aquel lugar que se ha convertido en un punto macabro de interés turístico, dice la periodista Rocío Galván, enviada especial del periódico el Mundo. Slavoj Žižek cuenta que en el lado Sur de Corea existe un teatro en cuya fachada se recorta un gran ventanal hacia el norte; desde allí los visitantes miran la zona neutra, con sus muros y alambradas y a lo lejos Corea de Norte; los del Norte han construido, según Žižek, una maqueta de una ciudad con casas preciosas; cuando anochece, se encienden las luces y los ciudadanos están obligados a dar un paseo en la ciudad ficticia para simular un ciudad con vida. De este modo, dice Žižek, este espacio de las fronteras, la zona neutra desmilitarizada, y todo lo que se crea consigue una condición fantasmagórica que la convierte en un espectáculo que se ve a través de una pantalla- ventanal; los dos lados que se comunican visualmente se hacen espectáculos sublimes: Corea del Norte es un espectáculo sublime para los que están en el lugar seguro de Corea del Sur y espectáculo sublime es la democracia para los que están en el lado del Norte, con un régimen totalitario. ${ }^{20}$

Lo que sucede en la zona liminar entre las dos Coreas es uno de los ejemplos que Žižek usa para referirse al Tercer Espacio; dice Žižek, que el Interior y el Exterior nunca ocupan el espacio completo: siempre queda un Tercer Espacio, que permanece perdido en la división en el Exterior y el Interior. En las construcciones humanas existe un espacio intermedio del que se reniega. Todos sabemos que está abi pero, en verdad, no aceptamos su existencia, permaneciendo como una realidad ignorada y casi siempre innombrable. ${ }^{21} \mathrm{El}$ Tercer Espacio es una condición difícil de nombrar porque el exterior y el interior no son términos que se refirieran

20 Slavoj Zizek, Viviendo En El Final De Los TiemposEdiciones Akal, SA, 2012). 269

21 Ibid. 270 
solamente al lugar abierto o cerrado, sino que tienen significados muy amplios; fuera y dentro evoca en general lo que está fuera y dentro de las categorías que la mente humana construye; hace mención a lo que está dentro y fuera de una definición, delimitación y el tercer espacio es lo que se queda entre lo definido y lo indefinido, entre lo conocido y lo desconocido, entre lo privado y lo público, entre lo interior y lo exterior.

El Tercer Espacio, no se refiere sólo a un lugar físico material intermedio, como sería la zona neutra entre los países, las murallas o las puertas, sino a algo que no está del todo definido. Žižek describe a través de una serie de ejemplos varias formas que puede tener el Tercer Espacio; ejemplo del Tercer Espacio es el exterior enmarcado por el interior, como sucede en el caso del ventanal que se abre hacia Corea del Norte o en la tercera planta del nuevo museo de Acrópolis de Bernard Tschumi en Atenas frente a la colina de Partenón, desde donde a través de un marco de una gran ventana se ve la cosa en sí misma, el Partenón. En los dos casos lo que sucede es que viendo a través del marco, y no directamente, la cosa en sí, Partenón y la zona neutra, se realza lo sublime de su apariencia ${ }^{22}$ transportándolo a un tercer espacio. Lo que vemos a través de la ventana es un paisaje enmarcado que es otro exterior de lo que está fuera del edificio: el exterior donde está Partenón es una circundante unidad, que nos envuelve; pero el exterior que vemos por la ventana, no es simplemente dicha unidad que contiene el interior, sino que ella misma simultáneamente está encerrada por el interior. El interior podría ser falso, dice Žižek, hablando del Centro de Arte y Medios Tecnológicos de Karlsruhe; existe una pantalla de televisión en la entrada que conduce a los aseos que muestra en continuo el interior de un pequeño cuarto de baño con inodoro desocupado; Žižek siente el alivio del que el baño está desocupado y no tendrá que esperar pero luego piensa que cuando esté dentro, todo será visible desde fuera y se da cuenta de que el video está pregrabado y no proyecta lo que está ocurriendo en el aseo en tiempo real. ${ }^{23}$

Otra clase de tercer espacio es el lugar que vemos en el espejo y en el vidrio, donde simultáneamente aparecen el exterior, interior y el tercer espacio donde está el reflejo de nuestro cuerpo; un espacio que se ha quedado fuera de la división entre lo exterior y lo interior prisionero en el intermedio.
El Tercer Espacio no es solamente un espacio físico

Viendo a través de un marco, y no directamente la cosa en si, el exterior se transporta en un Tercer Espacio donde se hace sublime

Tipo de Tercer Espacio es el lugar del espejo o de cristal

El Tercer Espacio es el vacío que queda entre la estructura y la piel 


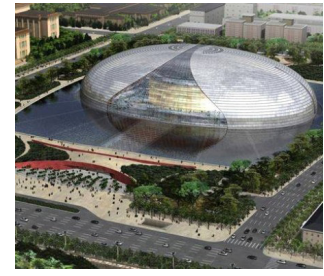

En Teatro Nacional de China, en Beijing. Paul Andreu

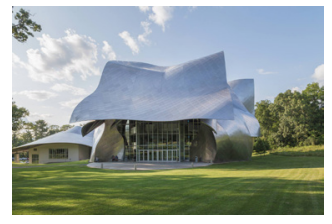

Performing Arts Center, Bard College, Estados Unidos. Frank Gehry

El Tercer Espacio como edificio - tierra
El vacío que queda entre la estructura y la piel, este lugar intersticial que aparece con varias formas, es un tercer espacio para Žižek. El vacío que está en la Bibliotheque Nationale de Francia de Koolhaas entre la envoltura y los múltiples espacios funcionales que flotan en el interior es un ejemplo de la apariencia del tercer espacio. Desde que la forma y la función se disociaron, la característica que tienen en común los centros para las artes escénicas contemporáneos, es el espacio vacío que está entre la piel y la estructura, y que aparece con distintas versiones. En el proyecto de Koolhaas antes referido, la envoltura es una enorme caja neutral que en su interior alberga varios espacios funcionales. Existen otros casos en los que la caja deja de ser una caja neutral y se convierte en un armazón que protege la joya del interior, como el Teatro Nacional de China, en Beijing del arquitecto Paul Andreu parecido, según Žižek, al huevo Kinder-Sorpresa - que esconde en su interior una sorpresa. ${ }^{24}$ En las obras escultóricas de Frank Gehry existe otro tipo del vacío entre la estructura y la piel: en este caso, la envoltura deja de ser un armazón que protege y se transforma en una escultura con sentido por derecho propio, como por ejemplo el Performing Arts Center, en Bard College, el Walt Disney Concert Hall, y el Pritzker Pavilion. El espacio intersticial, vacío, entre la piel y el contenido se encuentra de otra forma, según Žižek, en los edificios-terreno, aquellos en los que la piel -superficie se construye como continuación de la tierra: la Terminal Internacional del Puerto de Yokohama, por Foreign Office Architects, cuya cubierta funciona como una plaza abierta que extiende la superficie del terreno ${ }^{25}$. Si esto se lleva al límite, de algún modo, todo el Interior del edificio se reduce a su espacio intersticial entre la piel/ envoltorio (la superficie de hierba omadera) y sucuerpo en la tierra, condensado en el aplanado dominio entre ambos(...) el efecto real de estos edificios sea lo verdaderamente opuesto a su pretendida «naturalización» (la aparente inmersión en los entornos naturales): la propia naturaleza se ve de ese modo desrealizada, es decir, parece como si una superficie «natural» de hierba fuera una piel artificial que oculta una compleja maquinaria ${ }^{26}$

El Tercer Espacio es también el espacio intermedio de las construcciones humanas, que sabemos que existe pero no aceptamos su existencia: como el $24 \quad$ Ibid. 272

25 Ibid. 273

26 Ibid. 273 
espacio invisible de los desechos viajando por las bajantes, la compleja red de instalaciones (electricidad, nodos digitales, etc.) que está en los huecos que quedan entre las paredes y bajo los suelos y las infraestructuras en general. En el tercer espacio están los lugares del espacio basura, término usado por Rem Koolhaas, para los espacios sobrantes urbanos; todos los lugares, dice Žižek, que existen en la ciudad y que no son parte de su ego - ideal, es decir espacios disociados de su idealizada imagen, como las favelas de Brasil, son lugares de desregulación y de mezcla caótica de materiales de deshecho. En el tercer espacio está el paisaje que está entre las construcciones de las favelas y la imagen idealizada de la ciudad; en un tercer paisaje está la arquitectura ordinaria que construye los bloques de apartamentos o los garajes y los centros comerciales concebidos solo para funcionar o para ganar dinero. En general, la condición primaria del tercer espacio parece ser la de la enjuta:

En la arquitectura, la enjuta prototípica es el espacio triangular «que queda» en lo alto cuando una pared rectangular está perforada por un corredor coronado por un arco redondeado. Por extensión, una enjuta es cualquier configuración geométrica del espacio que inevitablemente aparece como consecuencia de otras decisiones arquitectónicas. Así, el espacio entre el suelo y el primer peldaño de una escalera o el recorrido horizontal entre los dinteles de una linea horizontal de ventanas y la parte de abajo de la bilera de ventanas en el piso superior también se llaman enjutas. Generalizando (...) una enjuta es cualquier espacio necesario y predeciblemente forjado de una determinada manera que no está diseñado explícitamente como tal, sino que surge como una inevitable consecuencia colateral de otra decisión arquitectónica (agujerear una pared con un arco redondeado, construir un peldaño a cierta altura del suelo, construir un edificio de varias plantas con ventanas en bileras.). ${ }^{27}$

Según Žižek, el tercer espacio como espacio intersticial, abierto por la desconexión entre la piel y la estructura, tiene un papel decisivo, como por ejemplo en el Kimmel Center para las Artes Escénicas de Filadelfia o el Centro de Artes Escénicas Esplanade en Singapur, donde el espacio intersticial, espacio abierto interior, exterior que es interior, está lleno de cafés, espectáculos y actividades similares. ${ }^{28}$ Un nombre para
En el Tercer Espacio están todos los lugares de la ciudad que no son parte de su ego-ideal, como las favelas

La condición primaria del Tercer Espacio es la de la enjunta

Un nombre para el Tercer Espacio es, para Žižek, el de poche 
El poche, es un espacio sólido representado con tinta que indica a todos los espacios raros ignorados en el plan general de un edificio.
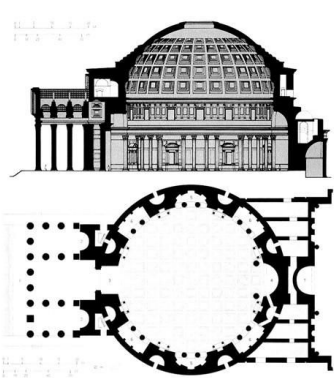

Pochcé en el plano de Pantheon, Roma.

El Tercer Espacio, en Occidente surge como consecuencia necesaria de otra decisión, indepentiente del diseño este espacio intersticial que aparece entre la piel y el contenido del edificio es según Žižek el de poche (bolsa, bolsillo, en francés), palabra empleada en las antiguas escuelas beauxartianas del siglo XIX para referirse al espacio solido representado con tinta, aguadas o rallados que indica la masa construida inaccesible, que la tinta cubre en los espacios auxiliares, complementarios o indignos de ser reseñado; el poche indica, según Žižek, a todos los espacios «raros» ignorados en el plan general de un edificio ${ }^{29}$. Dice Žižek,

\section{El poche se refiere principalmente a un plano o a un dibujo de un edificio en el que los objetos} sólidos están pintados de negro para hacerse una mejor idea de la geometría del espacio físico que se esboza; de manera más general se refiere a todos los espacios «raros» ignorados en el plan general de un edificio. Sin embargo, también tiene un significado mucho más preciso, que recoge el término badiouniano de «sustracción»: el ensanchamiento de las paredes para crear un «espacio sustractivo»; este espacio se crea tallando a través de un gran muro, recortando en él vestíbulos y salas. El poche permite la creación de singulares movimientos a través de un edificio; no solo es útil para dar forma a la planta de una estructura y para diseñar tanto el techo como el suelo, también nos permite cortar una estructura horizontalmente para crear un flujo de movimiento (por ejemplo, una de las maneras de introducir la luz en una estructura es cortar el techo, dejando aberturas que permitan que entre más luq). Expresándolo en tosco hegelés, el poche refleja la dialéctica de la envoltura y el cuerpo en la propia ensanchada envoltura: la propia envoltura explota sobre el cuerpo, tallando nuevos interiores. ${ }^{30}$

Este tercer espacio en occidente, de alguna manera, surge como consecuencia necesaria de otra decisión, independiente del diseño, y no como adaptación nacida por propia voluntad ${ }^{31}$, considerado como espacio sobrante, como enjuta, en la filosofía y arquitectura china y japonesa es el espacio primordial. La concepción del vacío y de lo que está "entre" es radicalmente distinta en la filosofía occidental y la oriental. Para occidente lo importante es lo que está presente y no lo ausente, siendo por eso que la ausencia es la que carece de esencia pre-esencia, au- sencia. ${ }^{32} \mathrm{Al}$ contrario, para Oriente, el vacío no es algo carente de sentido sino lo que hace posible que las cosas tengan

$\begin{array}{ll}29 & \text { Ibid. } 287 \\ 30 & \text { Ibid. } 287 \\ 31 & \text { Ibid. } 288 \\ 32 & \text { Francois Jullien, La Gran Imagen no Tiene Forma (2008). }\end{array}$


sentido. La gran diferencia entre la pintura china y europea es que la primera intenta presentar el vacío, el fondo de las cosas, lo que no tiene forma, el no-objeto de Jullien, mientras que en Occidente se intenta representar lo presente. Occidente se ha interesado por lo que las cosas son, sobre el ser y la esencia, mientras que en Oriente reflexionaron sobre lo que está entre las cosas, lo que las pone en relación y permite que existan. Aristóteles dejo excluido el tercer espacio con su principio de no contradicción y del tercio excluido; en la Antigua Grecia evitaron reflexionar sobre el espacio contradictorio en el que todo es y no es a la vez, en el que cada término es a la vez su contrario; a partir de Aristóteles, como dice Kosko, cuanto mejor dibujamos las líneas entre los opuestos, entre la cosa y la no-cosa, entre el $A$ y no- $A$, más lógica es nuestra mente y más exacta nuestra ciencia ${ }^{33}$. $\mathrm{Al}$ contrario, en China es exactamente este lugar de la contradicción el que es punto de reflexión. Tanto en Occidente como en Oriente dividen el mundo en dos, en pares de términos opuestos, como lleno - vacío, abierto - cerrado, contenedor - contenido; pero para el pensamiento occidental estos términos son contrarios, mientras que en Oriente, son complementarios; en un espacio tiempo en el que los dos son lo mismo a la vez, la relación de los dos, momento intermedio en el que uno transforma al otro.

Según el budismo, todo está en continua transformación, como también decía Heráclito, y dentro de esta transformación, existe un estado transitorio entre dos formas diferentes en el cual las dos coexisten pero no se sintetizan; el estado de la contradicción, de lo uno y lo otro o ni lo uno ni lo otro. Este estado denominado en la cultura japonesa ma, que según el diccionario japonés significa espacio entre las cosas que existen una cerca de la otra, intersticio entre ellas; en términos espaciales el "ma" es la distancia natural entre dos o más cosas, mientras que en términos temporales, "ma" es la pausa natural o el intervalo entre dos o más fenómenos que se suceden; el "ma" no es un espacio generado mediante la composición de elementos, sino lo que sucede en la conciencia del individuo, el espacio que se percibe por medio de la experiencia. ${ }^{34}$

El ma es ese momento libre de cualquier contradicción que lo someta, por ejemplo la oposición 33 Bart Kosko, Fur2y Thinking, the New Science of Furzy Logic. (New York: Hyperion, 1993). 68

34 Eider Holgado García, La Casa Del Vacio. Espacios De Interacción En La Arquitectura Doméstica De Sejima y Nishizanwa. Escuela Técnica Superior de Arquitectura, Universidad Politécnica de Madrid). 48
Aristóteles deja excluido el Tercer Espacio con el principio de la no contradición y del tercio excluido

En la filosofía china no excluyeron la contradicción sino que se basaron en ella.

El Tercer Espacio en Japón es el Ma; el estado de la contradicción 
Las viviendas japonesas son flexibles, de paneles que se mueven, para crear el vacío que será configurado según los habitantes
Desde el Tercer Espacio proyectan Camilo Sitte, Alison y Peter Smithson, Christopher Alexander, Serge Chermayeff entre las partes y el todo. Es el momento en que puedes ser consciente de tu entorno sin dejar de formar parte del mismo ${ }^{35}$. El Ma subraya que la forma es vacío y el vacio es forma.

Al término Ma le corresponden muchos conceptos: entre, amplitud, tiempo, pausa, intermedio, vacío lleno de significación. El Ma son espacios de significación espiritual o filosófica que responden a la necesidad de reposo mental y desapego. ${ }^{36}$ Para los arquitectos japoneses el espacio vacío no es un espacio sobrante, sino un lugar lleno de significación que da sentido a los edificios. Por esta razón las viviendas japonesas son flexibles con paneles que se mueven, para crear este vacío sin función específica en el que el individuo puede decidir su espacio según las posibles acciones; este vacío es un espacio de interacción donde se relacionan varias posibilidades. ${ }^{37}$ La arquitectura japonesa se organiza según la manera en la que el habitante recorre el espacio; es una arquitectura no construida sino que está en continuo cambio y transformación: se está construyendo según los movimientos de sus habitantes. La puerta, tal y como la conocemos, es un elemento fijo que divide dos estancias entre si y se construye dentro de un muro, pero en la arquitectura japonesa los paneles que delimitan las estancias se pueden mover fácilmente transformando el espacio ${ }^{38}$

En occidente, en los últimos años cada vez se habla más de este tercer espacio, intersticial. De los primeros en hablar sobe este vacío "entre”, en el sentido japonés del ma, son Camilo Sitte, que iba en contra del urbanismo moderno, porque según él no pensaba en lo que está entre los edificios, sino solamente en los edificios. Alison y Peter Smithson hablaron del in-between, del intervalo entre los edificios que es lo que organiza el urbanismo americano al contrario que el urbanismo europeo en el que las conexiones entre los espacios de las ciudades se hacen con escaleras y calles estrechas. Aldo van Eyck defendía que la arquitectura debía concebirse como una configuración de lugares intermedios, como lugares de transición y transformación donde sucede la interacción y el encuentro entre la gente. Christopher Alexander y Serge Ivan Chermayeff apoyaban lo

35 Michihiro Matsumoto, The Unspoken Way Kodansha International, 1988). 38

36 Casa Asia, Los Arquitectos De La Nada (Barcelona: Casa Asia, 2014)..27

37 Eider Holgado García, La Casa Del Vacio. Espacios De Interacción En La Arquitectura

Doméstica De Sejima y Nishizawa. Escuela Técnica Superior de Arquitectura, Universidad Politécnica de Madrid). 32

$38 \quad$ Ibid. 54 
mismo. Alison y Peter Smithson hablan de una lógica infraestructural que encontramos también en las obras Fumihiko Maki en Investigations in Collective Form, Reyner Banham en Megastructure, o Shadrach Woods en The Man in the Street, Stan Allen en Points + Lines, Edward Soja en Postmetropolis y Frei Otto en Occupying and Connecting;

Robert Venturi habla del modo en el que los arquitectos ven el espacio entre opuestos; de los distintos modos de composición, del pensamiento de la exclusión y de la inclusión; se posiciona a favor de la contradicción, de los estados transitorios, intermedios, ambiguos, de doble función, frente al estado de la rígida organización de las cosas. Bernard Tschumi habla de los espacios inclasificables o inprogramados que surgen cuando los pares de opuestos están en conflicto; los lugares que surgen entre ellos a veces considerados residuales, son lugares en los que pueden suceder eventos no planeados. Eisenman habla de los procesos de lo intersticial o de la intersticialidad; como un nuevo concepto de espacialidad; Eisenman en sus Procesos de Intersticial publicado en Croquis, No. 83, habla de una nueva dualidad forming - spacing: forming es el modo tradicional de los procesos arquitectónicos que fundamenta el espacio en el concepto de contenedor propio de sistemas clásicos de valores y usos. El spacing no tiene estas leyes, por lo que eso es un proceso que debe proveer formas de autorregulación. El proceso de lo intersticial es una forma del spacing. ${ }^{39}$ También de lo intersticial habla Colin Rowe en la Ciudad Collage, en la Crisis del Objeto, cuando expresa que se debe encontrar correspondencia entre lo sólido y lo vacío porque de otra forma aparece el caos de la ciudad medieval o el despótico orden de la ciudad del CIAM. El vacío es el espacio intersticial generador de dinamismo.

El tercer espacio y su gestión por los arquitectos marcan dos posturas distintas y contrarias filosofías en las conjeturas arquitectónicas: por una parte la Filosofía del $\mathrm{Ser}^{40}$, que es la que necesita delimitar las funciones para ordenar el espacio, es una razón rígida según la cual una cosa o concepto puede ser solo una cosa. Se corresponde con el pensamiento binario de "o lo uno o lo otro", usado en la época de la modernidad por los funcionalistas y los racionalistas, en donde lo contrario del orden es el desorden. Por otra parte, la filosofía del Entre, según la que, como dice Venturi, lo contrario del orden

39 Peter Eisenman, "Procesos De Lo Intersticial," Croquis, no. 83 (1997), 21-35.

$40 \quad$ Ivan Flores Arancibia, "Pensar El Entre, Contribuciones Para Una Crítica De La Razón Intersticial” 2010).
El Tercer Espacio toma los nombres de espacios in clasificables o inprogramados por Bernard Tschumi

El tercer espacio como creador de espacio: los procesos de lo intersticial de Eisenman

La filosofía del Ser y la filosofía del Entre en la configuración arquitectónica 
La configuración de lo intersticial empieza desde el Tercer Espacio, como lugar abierto a todas posibilidades $y$ encuentros. La filosofía del Entre ve el ser humano como relación y no como sujeto
La utopía arquitectónica es el Tercer Espacio. no es el caos sino otro tipo de orden; ${ }^{41}$ es la filosofía que no divide la vida en contrarios sino en relaciones entre términos, en las posibles interacciones y por tanto en los posibles distintos órdenes. La filosofía del Entre es la que empieza sus conjeturas y trazos desde el entre, desde el tercer espacio; ve al vacío y a los intersticios como lugares abiertos a todas las posibilidades, a los posibles lugares de interacción y encuentro. La filosofía del Ser, ve el ser humano como sujeto que se mueve entre otros sujetos y objetos, mientras que la de la razón intersticial, considera el individuo como relación que no tiene esencia, porque está en continua interacción con el mundo cambiando continuamente. El ser humano - sujeto se mueve entre los lugares construidos, el individuo - entridad construye su entorno mientras se relaciona con ello. Para la filosofía del Ser los acontecimientos suceden dentro del espacio; para la del Entre, los acontecimientos no ocurren en el espacio ni en el tiempo; el espacio y el tiempo no son matrices previas, a priori; no son recipientes que envuelven objetos, cuerpos y acontecimientos. El espacio-tiempo es una propiedad del acontecimiento. ${ }^{42}$ Para Aristóteles (filosofía del Ser) el lugar parece ser una superficie, como si fuera un recipiente, algo que contiene; para Zhuang $\mathrm{Zi}$, los lugares son nombres de las cosas que han pasado. ${ }^{43}$ La razón intersticial, sin duda, da una visión más holística de las relaciones entre los lugares y las posibles interacciones; los intersticios por estar entre dejan ver de manera simultánea el dentro y el fuera, las partes y el todo, lo cerrado y lo abierto; posibilita la visión de la dinámica de los encuentros.

Para Žižek, el tercer espacio es la utopía arquitectónica; los espacios entre los pilares del puente pueden ser utilizados por personas que no tienen hogar para dormir aunque no fueran diseñados para ello; como también las enjutas de las iglesias pueden convertirse en centro de decoración. Pregunta Žižek,

¿No abren entonces las enjutas el espacio para las exaptaciones arquitectónicas? ¿No son estas enjutas los «espacios intersticiales» (...) funcionalmente espacios vacios abiertos para la exaptación? Aqui la lucha está planteada, la lucha sobre quién se apoderará de ellos.

\footnotetext{
41 Robert Venturi, Complejidad y Contradicción En La ArquitecturaEditorial Gustavo Gili, 1974).

42 Emmánuel Lizcano, Metáforas Que Nos Piensan: Sobre Ciencia, Democracia y Otras Poderosas Ficciones (2006). 144
}

$43 \quad$ Ibid. 144 
Estos «espacios intersticiales» son, así, el espacio adecuado para el sueño utópico; nos recuerdan la gran responsabilidad ético-politica de la arquitectura, en la que hay muchas más cosas en juego de lo que en principio puede parecer. Recordemos los conocidos versos de William Butler Yeats: «He extendido mis sueños bajo vuestros pies. / Pisa con suavidad, porque pisas sobre mis sueños». Ya que esos sueños también se refieren a la arquitectura, la advertencia para los arquitectos es: cuando hagáis vuestros planes, pisad con suavidad, porque pisáis sobre los sueños de la gente que vivirá dentro y que contemplará vuestros edificios. ${ }^{44}$ 

sin techo

El vagabundo que está llamando a tu puerta tiene puesta la ropa que tú llevaste una veẓ̌.

Bob Dylan

A finales de abril de 2015, un poco antes de las elecciones locales y autonómicas de España, Esperanza Aguirre, la candidata del Partido Popular para la alcaldía de Madrid, prometió que iba a estudiar a fondo si se debía o no dormir en la calle. Exactamente dijo que no entendía por qué no estaba sucediendo lo que sucedía antes: "venia el Samur Social, ofrecía a las personas que querian dormir en la calle ir al albergue, y si estas personas no querian ir, el Samur Social se las llevaba; les hacia no sé exactamente qué, supongo que una valoración sanitaria o lo que fuera, y después de eso se limpiaba toda esa zona². Esperanza Aguirre cree que tanto la gente que duerme en la calle, como las manifestaciones, son un obstáculo para el turismo, y por consiguiente, para la propia economía del país; así que intentó limitar el derecho constitucional de reunión en el centro de la capital'. Como apareció en este mismo artículo del periódico El País en el año 2006, el alcalde de Madrid Alberto Ruiz-Gallardón (PP) consideró necesario aprobar una ley estatal que establez̧ca que, cuando hay recursos públicos gratuitos, sea obligatorio abandonar la vía pública. Estoy absolutamente a favor de eso. Es necesario un debate profundo sobre los usos de la vía públicat. En el caso de Gallardón su preocupación era que, como los ciudadanos pagan impuestos para que la gente "sin techo" tenga casa, debería ser obligatorio ir al albergue que ofrece el Estado. Por su lado, Esperanza Aguirre añadió otro matiz a la situación de la gente sin hogar: ahora el problema es que la presencia de los indigentes en las calles de Madrid degrada la imagen 1 Letras en la canción It's All Over Now, Baby Blue (en español, Todo se acabó, Chica Triste), incluida en el álbum Bringing It All Back Home publicado el Marzo de 1965 por Bob Dylan.

2 “Aguirre Quiere Sacar a Los 'sin Hogar’ De La Calle Para Impulsar El Turismo | Madrid | EL PAÍS “, accessed 6/7/2015, 2015, http://ccaa.elpais.com/ccaa/2015/04/27/ madrid/1430144657 879791.html.

3 Ibid.

4 Ibid.

Esperanza Aguirre: el sinhogarismo degrada la imagen de la ciudad

Las manifestaciones ensucian la ciudad 
40.000 sin hogar en España

Sinhogarismo y urbanismo

Sin techo: cuando la dualidad público - privado desaparece. de la ciudad y expulsa a los turistas, porque la ensucian de forma literal y metafórica. De manera análoga cualquier manifestación enturbia las calles de la ciudad y estorba los desplazamientos en ella, reduciendo el grado de generación de turismo. Sin embargo, lo que no se ha dicho, ni por Esperanza Aguirre, ni por Alberto Ruiz-Gallardón, es que la expulsión de los indigentes de las calles de la ciudad es extremadamente necesaria porque revela el fracaso de la arquitectónica política que ha conducido a las continuas insurrecciones de sus ciudadanos y a que se queden más de un millón y medio de personas en infraviviendas y alrededor de cuarenta mil ciudadanos sin hogar ${ }^{5}$.

Las frases de Esperanza Aguirre dan que pensar sobre el fenómeno del sinhogarismo y sobre los modos en que la ciudad y su planificación cambian según las políticas que se siguen frente a este fenómeno; porque el planeamiento y el diseño de la ciudad se definen desde la política y la economía que dominan en cada época. El urbanista, el arquitecto y el paisajista, les guste o no, como dice Bregazzi, están comprometidos políticamente y, frecuentemente, se afilia a los intereses a los que sirve. ${ }^{6}$ Sin duda, a la política, a la que interesa la imagen de la ciudad y el turismo más que la vida de los habitantes de la calles, conduce a un diseño urbanístico completamente distinto al de una política que olvida la imagen de la ciudad frente a la calidad de la vida de los ciudadanos. La gente sin techo, aunque sean vistos por muchos como personas inútiles para la sociedad, siguen siendo habitantes del espacio público como el resto de los ciudadanos, y las leyes que se toman para la desaparición de los indigentes de las calles de la ciudad afectan a todos y a la calidad del espacio público.

Los indigentes son las únicas personas para las que la esfera pública y privada significa lo mismo. La división entre esfera pública y esfera privada no existe ya que para ellos la única opción espacial es el espacio público. ${ }^{7}$ El espacio público, para Madanipour, nos permite experimentar la presencia de otras personas y conocer sus puntos de vista; (...) es el espacio que compartimos y por lo tanto nos permite compartir una experiencia del mundo que nos rodea. Sin embargo, esto es algo temporal y limitado. Pero para el sin techo que vive en el espacio público, toda

5 "España Cuenta Con 40.000 Personas Sin Hogar ", accessed 6/8/2015, 2015, http://www.lavanguardia.com/vida/20140406/54404697303/espana-cuenta-con-40-000personas-sin-hogar-y-un-millon-y-medio-de-familias-en-infraviviendas.html.

6 Daniel Mielgo Bregazzi, Construir Ficciones: Para Una Filosofía De La Arquitectura. Biblioteca Nueva, 2008, 199.

7 Ali Madanipour, Public and Private Spaces of the City. Routledge, 2003, 46. 
experiencia es inevitablemente y continuamente compartida con los demás ya que el espacio privado para él no existe ${ }^{8}$. La única casa que los indigentes tienen es su cuerpo y la falta del segundo cuerpo - de la casa-, hace de su cuerpo el único lugar que tienen para protegerse de los peligros del mundo exterior. Pero el cuerpo no es suficiente para la creación de la identidad porque esta última parece necesitar del sentido de la pertenencia, de un lugar, para desarrollarse. Madanipour considerando la casa como el punto de referencia a través del cual el individuo encuentra un lugar en el mundo se pregunta sobre la posición de la gente sin hogar. ¿Cómo las personas que se ven privados de este punto de referencia navegan en su mundo?? Los sin techo están en continuo movimiento, no porque intenten llegar a un lugar, sino precisamente por no tener ningún lugar donde ir. El único destino real es el final del día ${ }^{10}$, dice un indigente. Ir a ninguna parte a la vez significa encontrarse en ninguna parte; ser sin techo no solo significa vivir sin hogar, sino en general sin lugar ${ }^{11}$. Y carecer de lugar implica un continuo e interminable andar. Andar es no tener un lugar. Se trata del proceso indefinido de estar ausente y en pos de algo propio. El vagabundeo que multiplica y reúne la ciudad hace de ella una inmensa experiencia social de la privación de lugar $(. . .)^{12}$. El cuerpo del indigente habita en el limbo, encarnando la ausencia. Está siempre en un continuo e indefinido proceso de estar ausente, como lo describe De Certeau: inexistente en la esfera pública, pero, a la vez, constantemente presente en el espacio público. Cualquier persona que tiene un hogar, en su cotidianidad, usa la frase salir a la calle. Pero para el indigente la frase es salir de la calle. Miguel Fuster, ilustrador que pasó quince años viviendo en la calle sin tener un hogar, en una entrevista habla de sus intentos de salir de las calles de Barcelona; si para muchos la calle puede representar la libertad, para Miguel la calle fue una cárcel de la que no podía escapar; una infinita cárcel por la que deambulaba atrapado ${ }^{13}$. Y dentro de esta cárcel, dice Miguel, alguien vive con un miedo permanente a lo desconocido, a lo que sea ${ }^{14}$.

$8 \quad$ Ibid. 166

$9 \quad$ Ibid. 74

10 Samira Kawash, “The Homeless Body,” Public Culture 10, no. 2 (1998), 328.

11 Ibid. 327. Traducido desde el idioma ingles por el investigador: Going nowhere is simultaneously being nowhere; homelessness is not only being without bome, but more generally without place.

12 Michel De Certeau and Luce Giard, La Invención De Lo Cotidiano: Artes De Hacer. I, Vol. 1. Universidad Iberoamericana, 2007, 116.

13 "Miguel Fuster Cuenta Sus 15 Años De Indigente En Cómic - RTVE. Es A La Carta “, accessed 7/21/2015, 2015, http://www.rtve.es/alacarta/videos/programa/miguelfuster-cuenta-15-anos-indigente-comic/763527/.

14 Ibid.
Indigente: la encarnación de la ausencia 
El sinhogarismo no es un fenómeno de nuestros días; tiene sus raíces en la antigüedad, desde los años de la antigua Grecia y Roma. Ejemplo de ello es el filósofo Diógenes el Cínico (412 a. C - 323 a. C) que vivía en las calles, dentro de una tinaja. Sin embargo, en la época de Grecia y Roma vivir en la calle y no tener un trabajo era una elección de la gente vaga y el fenómeno de sinhogarismo no consistía en un grave problema social para los líderes. ${ }^{15} \mathrm{El}$ sinhogarismo empieza a ser un fenómeno urbano en los albores del capitalismo, la industrialización y la urbanización, es decir, a partir del siglo XVII; pero el tiempo en el que por primera vez los historiadores dedican líneas a dicho fenómeno en Estados Unidos y Europa, es en la década de los sesenta, abarcando la época desde la Edad Media hasta hoy en día. ${ }^{16}$ En el siglo XX después del crac del 1929 y la Gran Depresión que duró hasta la década de los treinta, el número de los sin techo se triplica. En Estados Unidos el problema del sinhogarismo se enfrenta con las políticas "New Deal" (Nuevo Trato) - las reformas que propone el presidente estadunidense Franklin Delano Roosevelt para la lucha contra los resultados que provocó la Gran Depresión - pero también con el reclutamiento de la gente sin hogar para la Segunda Guerra Mundial ${ }^{17}$. Las guerras dentro y fuera de las fronteras en Estados Unidos creaban nuevas olas de gente sin hogar: soldados veteranos que, después de la guerra, heridos corporal y psicológicamente, vivían en las calles sin un trabajo, porque el Estado no les ofrecía un bienestar social. ${ }^{18}$

A partir de los años setenta sucede una transformación evidente en las prácticas políticas, económicas y culturales que conduce al aumento de los sin techo y de los desempleados. En este periodo la desindustrialización causa altos niveles de desempleo, a la vez que se estabiliza la teoría política del neoliberalismo: el desempleo es el factor necesario para el funcionamiento de la economía ya que ella mantiene los sueldos en 15 A. L. Beier and Paul Ocobock, Cast Out: Vagrancy and Homelessness in Global and Historical Perspective (Athens, OH, Estados Unidos: Ohio University Press, 2009, 4.

16 Andreas Skraparlis, «Paisaje Urbano Contemporáneo, Espacio Público y Sin Techo» (Programa Interdepartamental del curso de posgrado, Arquitectura de Paisaje, Escuela de Arquitectura - Facultad de Agricultura, Universidad Aristóteles de Salónica. 13

17 Kenneth L. Kusmer, Down \& Out, on the Road: The Homeless in American History. Oxford University Press, 2003, 19-32.

18 Patrick Markee, War and Homelessness. How American Wars Create Homelessness among United States Armed Forces Veterans (New York: Coalition for the Homeless, 2003, 1-3.

"War and Homelessness. How American Wars Create Homelessness among United States Armed Forces Veterans,", accessed 7/15/2015, 2015, http://www.csun.edu/ bashforth/155 PDF/ME2 Fall SI/AmericanWarsCreateHomelessness.pdf. 
bajos niveles. ${ }^{19}$ Dentro del marco del neoliberalismo, según Harvey, la mente empresarial se acompaña con la amplificación de la competitividad; el individualismo competitivo, por una parte provoca una explosión de energía y a la vez conduce a redistribuciones significativas de ingresos que favorecen a los privilegiados. ${ }^{20} \mathrm{El}$ empleo regular se desplaza hacia los contratos o subcontratos de trabajo temporal de media jornada; dicho cambio es, según Harvey, una de las razones que debilitan la organización de la clase obrera. ${ }^{21}$ Y esta falta de organización permite la degradación del Estado de Bienestar, ya que no está para impedir la debilitación de la seguridad social, la salud pública, la educación y en general para defender y mantener las regulaciones estatales que aseguraban la protección de la sociedad..$^{22}$ Pero el Estado de Bienestar no se desvanece solo por la debilitación de la organización de la clase obrera; en el contexto neoliberalista, lo que interesa es principalmente el desarrollo de la capital y, como las dotaciones asistenciales cuestan y no generan ganancias, el Estado deja de apoyar a los miembros de la comunidad que han dejado de ser sanos o preparados para enfrentarse al reto de la vida. Según Bauman, esta nueva perspectiva queda expresada en la nueva frase de moda: "Estado de Bienestar? Ya no podemos permitírnoslo"23. El Estado de Bienestar era, según Bauman, una herramienta que ayudaba a los miembros de la comunidad temporalmente insanos y sin preparación y además alentaba a los que estaban sanos y preparados. Las dotaciones asistenciales eran una red de seguridad tendida por la comunidad que aseguraba a todos sus miembros que los desempleados tuvieran salud y herramientas para volver a incorporarse a la

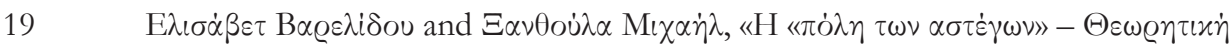

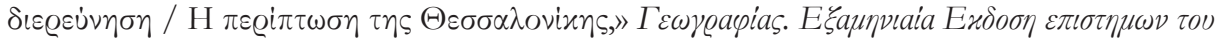

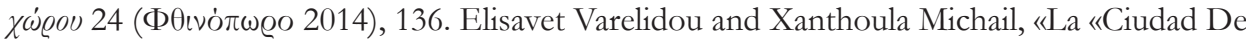
Los Sin Techo» - Investigación Teórica / El Caso De Salónica,» Geografías. Edición Bianual De Ciencias Del Espacio. 24 (Otoño 2014), 136.

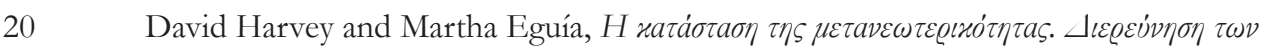

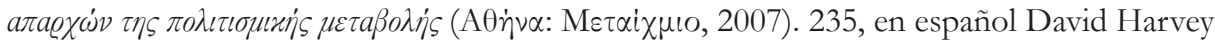
and Martha Eguía, La Condición De La Posmodernidad: Investigación Sobre Los Orígenes Del Cambio Cultural (Buenos Aires: Amorrortu, 1998). 196

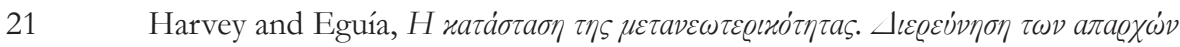

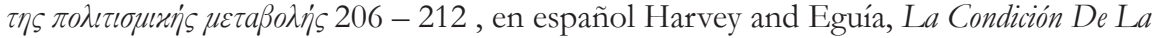
Posmodernidad: Investigación Sobre Los Orígenes Del Cambio Cultural. 173

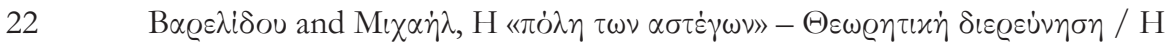

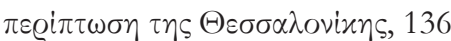

Varelidou and Michail, La «Ciudad De Los Sin Techo» - Investigación Teórica / El Caso De Salónica, 136 . La «Ciudad De Los Sin Techo» - Investigación Teórica / El Caso De Salónica, accessed 7/15/2015, 2015, http://akea2011.com/2014/03/04/ipolitonastegon/\# ftnref2.

23 Zigmunt Bauman, La Posmodernidady Sus Descontentos. Ediciones Akal, 2001). , 51
Desindustrialización y neoliberalismo

Debilitación de la clase obrera

Colapso del Estado de Bienestar 
Causas de sinhogarismo: modelo individual y modelo estructural

Considerando

el sinhogarismo como un problema personal estigmatizamos a los indigentes producción. ${ }^{24}$ ElEstado de Bienestar se concibió no como caridad, sino como un derecho del ciudadano, no como suministro de limosnas individuales, sino como una forma de aseguramiento colectivo ${ }^{25}$. Sin embargo, hoy, hay una parte de la población que paulatinamente se aumenta que tiene nulas posibilidades de reincorporación a la producción; las dotaciones asistenciales ya no pueden cubrir sus necesidades que consideran como un gasto de la comunidad. Por consiguiente, las dotaciones asistenciales han pasado de ser un ejercicio de derechos ciudadanos a convertirse en el estigma de los impotentes y los incautos ${ }^{26}$.

Las causas del sinhogarismo, según Wyly \& Hammel, se encuentran en dos modelos distintos: el sistema de la responsabilidad personal (individual model) según el que las causas que conducen a la pérdida del hogar se encuentran en fracasos y conductas personales - modelo que se adopta por los economistas neoclásicos y neoliberalistas -, y el modelo de motivos sociales (structural model) que encuentra las causas del sinhogarismo en causas sociales. ${ }^{27}$ En el primer caso, las causas principales son las discapacidades físicas, las enfermedades mentales y el abuso de sustancias. En el segundo, la causa del sinhogarismo es el fracaso de la economía política que los Estados siguen. Las razones quizás son combinación de los dos modelos; las víctimas del fracaso de la economía y la política son los que no fueron preparados frente al reto de la vida y la producción. Cuando la sociedad no entiende el sinhogarismo como resultado de las políticas que fracasaron en el bienestar de los ciudadanos sino que lo percibe como resultado de las conductas inapropiadas personales, percibe el sinhogarismo no como un problema social sino como un problema personal; no intentan encontrar su raíz para solucionarlo, sino disminuir las molestias que provoca ${ }^{28}$, e intentan ocultarlo de la cotidianidad urbana. La consideración de que el sinhogarismo no es responsabilidad de la sociedad sino el resultado de las elecciones personales e inapropiadas estigmatiza a los indigentes como personas inútiles; las nuevas políticas y economías, en vez de ayudarlos, los excluyen. Si antes el Estado de Bienestar intentaba incluir a los desempleados, los

\footnotetext{
$24 \quad$ Ibid. , 51

$25 \quad$ Ibid., 51

26 Ibid. , 52

27 Elvin K. Wyly and Daniel J. Hammel, "Mapping Neo-Liberal American urbanism1," in Routledge, 2004), 18.

28 Bálint Misetics, "Criminalisation, Discourse and Symbolic Violence," Homeless in Europe, Invierno 2012/2013.
} 
enfermos y no preparados en la producción, hoy, en el marco del neoliberalismo y de la sociedad del consumo, el Estado intenta excluirlos, como gente fuera de lo normal, fuente de la criminalidad y del miedo.

Sin embargo, la norma más importante que los pobres violan y que es la que les hace "anormales", según Bauman, es la que obliga estar capacitado para consumir, no la que impone tener un empleo. En la actualidad, los pobres son ante todo "no consumidores", ya no "desempleados"29. La presencia de los sin techo no permite a los consumidores disfrutar su tiempo en las calles comerciales y por eso deben alejarse. Si alejamos a los sin techo de las calles de las ciudades, ¿Qué lugar les toca?, se pregunta Bauman. La respuesta más concisa es: fuera de la vista. Primero hay que sacarlos de la calle y de los otros lugares públicos que usamos nosotros, los residentes legítimos del valiente mundo consumista ${ }^{30}$. La razón por la que los sin techo - los ciudadanos anormales- deben alejarse de las calles es porque obstaculizan el consumo y provocan miedo a los ciudadanos legítimos de la ciudad y su presencia estropea la imagen de la ciudad provocando problemas en el turismo y la economía. Como escribe Bauman, se arroja a la gente a la marginalidad porque se la considera definitivamente inútil, algo sin lo cual todos los demás viviríamos sin problemas. Los marginales afean un paisaje que, sin ellos, sería hermoso; son mala hierba, desagradable y hambrienta, que no agrega nada a la armoniosa belleza del jardín pero priva a las plantas cultivadas del alimento que merecen. Todos nos beneficiariamos si desaparecieran ${ }^{31}$.

La exclusión de la clase marginal de los espacios públicos se intenta con varias tácticas y políticas. Una de ellas es la de la criminalización de las personas sin hogar. Según Doherty, durante las décadas de los sesenta y setenta, la legislación que de alguna manera criminalizaba a los mendigos y vagabundos, era característica de la mayoría de las sociedades Europeas. Estas legislaciones fueron abandonadas a partir de los años noventa, pero en la actualidad hay una tendencia para volver a introducir leyes que impiden una variedad de actividades en el espacio público y se asocian directamente con las vidas de los sin techo. ${ }^{32}$ Esta legislación que se caracteriza como "anti-homeless laws"

29 Zygmunt Bauman and de los Ángeles Boschiroli, Victoria, Trabajo, Consumismo y Nuevos PobresGedisa Barcelona, 2003), 139-140.

30 Zygmunt Bauman, Vida De Consumo. Fondo de cultura económica, 2008)., 171

31 Ibid., 104

32 Joe Doherty, “The Changing Role of the State: Homelessness and Exclusion: Regulating Public Space,” (2006)., 9
Bauman: Para las autoridades, el lugar de los indigentes es aquel que está fuera de la vista, pues afean el paisaje.

Para las autoridades los sin techo son inútiles que ensucian la belleza de la imagen de la ciudad

Técnicas de expulsión; criminalización de los indigentes. 
Anti- bomeless laws: intentando borrar los mendigos de la imagen de la ciudad

Urbanismo frente al sinhogarismo: hostil $y$ amable

Indigentes: habitantes auténticos de los intersticios urbanos no son leyes que se refieren de manera directa a los sin techo, pero de manera indirecta indican y señalan. Son leyes que abordan el comportamiento urbano a fin de que el espacio público sea agradable y limpio para todos: pero las actividades que prohíben son actividades que los que tienen un hogar no harían en el espacio público; se hace ilegal, por ejemplo, el acampamiento en los parques de la ciudad, la mendicidad, sentarse en las aceras, dormir en los bancos, beber en la calle, orinar y bañarse en aguas públicas, entre otras. Así, los sin techo de alguna manera se criminalizan. ${ }^{33}$ Las personas físicas autorizadas y las nuevas tecnologías de vigilancia consiguen el desplazamiento de los sin techo fuera del campo de visión del ciudadano medio y el turista.

Sin embargo, no solo son con las legislaciones con las se consigue el alejamiento de los indigentes de las calles de la ciudad; también por la gestión y la configuración de un espacio público por los arquitectos, paisajistas y urbanistas que no permita su utilización por los sin techo. De manera consciente o inconsciente, estos profesionales proyectan de manera hostil o a veces de manera amable hacia los sin techo ${ }^{34}$. Configuración hostil es aquella que intenta obstaculizar la permanencia de los sin techo en los espacios públicos, mientras que configuración amable enfrenta el sinhogarismo como un fenómeno social e intenta apoyar y ofrecer lugar a aquellos que viven en las calles de las ciudades. El modo con el que se enfrentan los sin techo por el diseño arquitectónico se revela en el modo con el que estos piensan en los intersticios, en los espacios intermedios, pues allí es donde los sin techo habitan. Los indigentes tanto para protegerse del desconocido, de las condiciones climáticas como para obtener una cierta privacidad, eligen lugares intermedios de la ciudad que estén entre lo público y lo privado, lo abierto y lo cerrado: las entradas de las estaciones de metro, los pasos de peatones subterráneos, los lugares entre las dos puertas de la entrada de los sucursales de bancos, los pórticos, lo porches, los ingresos y cualquier hueco de los edificios, los umbrales, los callejones sin salida, debajo de los puentes, los espacios para sentarse, son todos ellos los lugares intermedios de las ciudades que los indigentes eligen como hogar.

El modo de proyectar los lugares intermedios de la ciudad y el inmobiliario

33 Juliana M. Zanotto, Public Spaces, Homelessness, and Neo-Liberal Urbanism: A Study of'Anti-Homeless' Strategies on Redeveloped Public Spaces (2012)., 36.

34 Andreas Skraparlis, «Paisaje Urbano Contemporáneo, Espacio Público y Sin Techo» (Programa Interdepartamental del curso de posgrado, Arquitectura de Paisaje, Escuela de Arquitectura - Facultad de Agricultura, Universidad Aristóteles de Salónica. 131 
urbano revela la sensibilidad del arquitecto frente al problema del sinhogarismo y de la pobreza. Los espacios de sentarse (sitting space) ${ }^{35}$ son espacios fundamentales de una ciudad y principalmente para los indigentes quienes los usan para dormir. Según William H. Whyte, la calidad de cualquier ambiente urbano se mide según la comodidad que ofrecen los espacios hacia los peatones que los usan. ${ }^{36}$ Dichos espacios, que tienen un papel decisivo en la relación social y en la interacción de los peatones, para los indigentes son espacios de extrema importancia. Pensar en la pobreza y el sinhogarismo es proyectar y diseñar lugares cómodos, accesibles y capaces en facilitar la vida de los que viven en la calle, pensar no solo en los ciudadanos legítimos de las ciudades sino también en la clase marginal. Sin embargo, el urbanismo sensible frente a la pobreza y el sinhogarismo, desvanece. La sociedad del consumo pide calles limpias de la pobreza e indigentes para poder consumir con conciencia limpia y así, el propósito del diseño urbanístico deja de ser la habitabilidad de la ciudad para ser la imagen de la ciudad. Según Mike Davis, reflexionando sobre la ciudad de Los Ángeles, a partir de los 90 sucede la militarización del espacio urbano; es decir, tenemos un arsenal de sistema de seguridad y una obsesión con la vigilancia de las fronteras sociales a través de la arquitectura ${ }^{37}$. Los procesos de la gentrificación urbana, el cercado de espacios públicos y el diseño de edificios e mobiliarios urbanos incómodos para los indigentes son prácticas efectivas para la exclusión de la clase marginal de las calles de la ciudad.

La gentrificación es un concepto que la socióloga Británica Ruth Glass acuñó en 1964 para describir los cambios que se realizaban en los barrios londinenses cuando a un barrio de residentes de un nivel educativo, social y económico bajo, llegaban nuevos residentes de la clase media urbana. El resultado de este desplazamiento era el alejamiento de la clase baja y su sustitución por la clase media, pues el precio de la vida por la presencia de los nuevos residentes se incrementaba demasiado para la clase baja. Según escribe Sassen Saskia, la gentrificación en un principio fue entendida como la rehabilitación de

35 William H. Whyte realiza un análisis extenso sobre los espacios para sentarse (sitting space) del espacio urbano y presenta tanto la importancia que dichos lugares llevan en las relaciones sociales pero también la manera que los arquitectos los enfrentan.

William Hollingsworth Whyte, The Social Life of Small Urban Spaces. (New York: Project for Public Spaces, 1980).

36 Referencia en Mike Davis, "Fortress Los Angeles: The Militarization of Urban

Space," Variations on a Theme Park (1992), 154-180., 160.

37 Ibid. 154.
La calidad del espacio público depende de los espacios de sentarse

Urbanismo de la exclusión: militarización del espacio público.

Gentrificación urbana: desplazamiento de los habitantes pobres. 
El diseño urbanístico hostil frente al fenómeno de sinhogarismo: planeamiento de la exclusión
Bajo los términos revitalización, renovación urbana está la gentrificación viviendas deterioradas o de bajos ingresos por forasteros de media clase en ciudades centrales, pero a partir de los finales de la década de los setenta la conceptualización de los procesos de la gentrificación fue ampliando. La conceptualización del proceso de gentrificación como proceso de rehabilitación residencial - como se entendía a los finales 1970 - a partir de los ochenta era una sola faceta evidente de un proceso mucho más amplio relacionado con la transformación que sucedía por el capitalismo avanzado; un proceso de restructuración social, económica y espacial. ${ }^{38}$ La gentrificación urbana es un proceso de rehabilitación y renovación de la ciudad de manera que ella misma responde a las normas establecidas por el capitalismo avanzado y el neoliberalismo. Obviamente, la gentrificación urbana sucede, principalmente, en zonas de la ciudad donde ha existido una falta de inversión previa que crea oportunidades a las clases económicamente más saludables para hacer una reurbanización rentable según sus necesidades, a costa de los habitantes primarios de bajo nivel económico y social. ${ }^{39}$ La gentrificación es el principal factor del desplazamiento y exclusión de los ciudadanos de nivel económico, educativo y social bajo. Hoy en día, según Smith, Lees, Hammel y Wyly encuentran, son cada veces más las soluciones urbanísticas que se proponen bajo los nombres de la "revitalización", "renovación”, "revitalización”, pero que, llegan siempre a los procesos de la gentrificación. Algunos autores, entre ellos Tom Slater, sostienen que no existe gentrificación sin el desplazamiento de los grupos de clase baja por los de clase media y media -alta, mientras que para otros, como Freeman, Hammett y Whitelegg, la gentrificación del espacio urbano es posible sin la realización de desplazamientos de

38 Saskia Sassen, The Global City: New York, London, Tokyo. Princeton University Press, 2001). 261

39 Tom Slater, "Gentrification of the City," The New Blackwell Companion to the City (2011), 571-585., 572 
grupos. ${ }^{40}$

Como se ha escrito anteriormente, además de la gentrificación urbana, un modo para limpiar las calles de las ciudades de los indigentes y en general de la clase marginal es a través de aquel diseño militarista del que habla Mike Davis que es un consciente endurecimiento de las superficies de la ciudad para que no sea posible su uso por los indigentes. Es el de diseño de mobiliario urbano anti-mendigos o del diseño de antilugares. Los artistas franceses Survival Group ${ }^{41}$ llevan nueve años desarrollando un proyecto fotográfico que bajo el nombre Anti Sites (Anti Lugares) ${ }^{42}$ coleccionan lugares de ciudades, entre ellas Francia, Estados Unidos, Brasil, Canadá, Japón, Londres en los que se han puesto obstáculos para que la gente no pueda acostarse o patinar. José Manuel Caballol de la Fundación contra la exclusión social RAIS ${ }^{43}$ considera que esta arquitectura disuasoria es un tipo de violencia indirecta contra las personas sin hogar ${ }^{44}$. Y, como opina Eva García Pérez, urbanista del Observatorio Metropolitano $^{45}$, son estrategias para desplazar lo que la ciudad no quiere vert6. Los obstáculos más agresivos que se usan en las ciudades para la expulsión de los indigentes son pinchos, forjas y espinas.

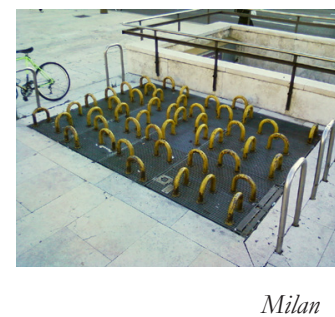
En la fuente central en Plaza Sol de Madrid, lo que antes fue un banco circular en lo que

40 Referencia en Óscar Muñoz Carrera, "Gentrificación, Segregación y Reestructuración Social En Madrid.” Direito Da Cidade 6, no. 1 (2014).. Aquí no se puede desarrollar más el proceso de la gentrificación urbana. Pero una información extensa de sus procesos y sus resultados encontramos en las siguientes obras: Neil Smith, "On 'the Eviction of Critical Perspectives'," International Journal of Urban and Regional Research 32, no. 1 (2008), 195-197., Elvin K. Wyly and Daniel J. Hammel, "Gentrification, Segregation, and Discrimination in the American Urban System,” Environment and Planning A. 36 (2004), 1215-1242. Tom Slater, “The Eviction of Critical Perspectives from Gentrification Research," International Journal of Urban and Regional Research 30, no. 4 (2006), 737-757. Loretta Lees, "Gentrification and Social Mixing: Towards an Inclusive Urban Renaissance?" Urban Studies 45, no. 12 (2008), 2449-2470. Chris Hamnett and Drew Whitelegg, "Loft Conversion and Gentrification in London: From Industrial to Postindustrial Land use," Environment and Planning A 39, no. 1 (2007), 106. Ruth Lazarus Glass, London: Aspects of Change, Vol. 3MacGibbon \& Kee, 1964). Lance Freeman, "Displacement Or Succession? Residential Mobility in Gentrifying Neighborhoods," Urban Affairs Review 40, no. 4 (2005), 463491.

41 "Survival group/accueil", accessed 7/24/2015, 2015, http://www.survivalgroup.

org/.

42 “Anti Lugares,", accessed 7/24/2015, 2015, https://www.flickr.com/ photos/7211263@N02/.

43 "RAIS Fundación | RAIS Fundación ", accessed 7/24/2015, 2015, https://www. raisfundacion.org/.

44 "Ciudades Que Pinchan | Sociedad | EL PAÍS“, accessed 7/24/2015, 2015, http:// sociedad.elpais.com/sociedad/2014/06/13/actualidad/1402683725 100674.html.

45 "Observatorio Metropolitano “, accessed 7/24/2015, 2015, http://www.

observatoriometropolitano.org/.

$46 \quad$ Ciudades Que Pinchan | Sociedad | EL PAÍS 


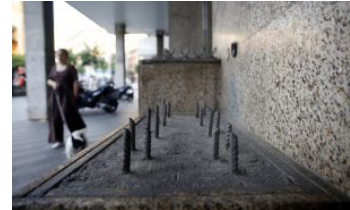

Pinchos en la plaza Soledad Torres Acosta de Madrid.

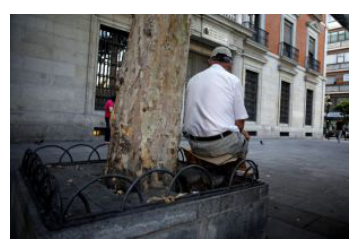

Plaza de Jacinto Benavente, Madrid

Mobiliario urbano anti-mendigos

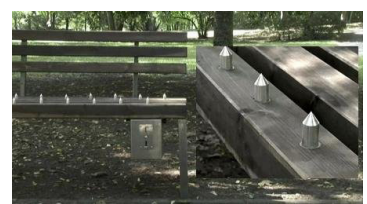

Banco con pinchos, China. Fabian Brunsing

Ana Botella, en 2014, pide mobiliario urbano anti-mendigos para la ciudad de Madrid la gente se sentaba, hoy en día, es un elemento sin uso. Lo mismo sucede en plaza Jacinto Benavente en Madrid con los bancos que rodeaban a los árboles y a ahora existen sillas de los bares de la plaza. Los pinchos se usan también en los soportales de los edificios que son lugares de descanso de los indigentes como por ejemplo los que se han puesto en la plaza Soledad Torres Acosta en Madrid o el ejemplo más representativo que provocó olas de protestas en Londres de los dieciséis pinchos metálicos que colocó en su soportal una comunidad de vecinos para alejar a los indigentes que solían dormir en esto; caso extremadamente decepcionante ya que no fue iniciativa de las autoridades de la ciudad sino de sus ciudadanos. Famoso se ha hecho también el puente de la ciudad Guangzhou en China debajo del cual las autoridades, en 2012, pusieron afiladas púas de cemento de altura de más de 20 centímetros para la liberación del espacio de los mendigos.

La imaginación de los diseñadores sorprende con las soluciones de bancos antimendigos como los bancos en los que las nuevas tecnologías han conseguido controlar el tiempo en el que hay alguien se puede sentar. El ejemplo más representativo es el banco urbano creado por el artista Fabian Brunsing que es un banco con parquímetro: el banco está cubierto por pinchos y para sentarse alguien tiene que abonar dinero; los pinchos desaparecen y cuando pasa el tiempo correspondiente al dinero abonado de repente vuelven a salir; un proyecto que muestra que quizás en el futuro los únicos que podrán sentarse en los espacios públicos serán los ricos. En las grandes ciudades encontramos de manera más frecuente bancos antimendigos como aquellos que tienen separaciones amplias como los asientos de Warrior Square Gardens en Essex, en Reino Unido diseñados por Gillespies Landscape Architects en $2011^{47}$ que se usan también en Madrid; bancos de forma semicilíndrica como los de Los Ángeles o bancos tubulares famosos en Tokio y Osaka. En Madrid, el colectivo de los jóvenes de Moratalaz Distrito 14 protestaron a través de la iniciativa \#ArreglaTuMarquesina cuando Ana Botella, en los finales del verano de 2014, empezó a cambiar las marquesinas del sistema de transporte EMT - Madrid cuenta con alrededor 4000 marquesinas $^{48}$ - y los bancos de

47 "Warrior Square Gardens by Gillespies Landscape Architects « Landscape Architecture Works | Landezine “, accessed 7/23/2015, 2015, http://www.landezine.com/ index.php/2011/11/warrior-square-gardens-by-gillespies-landscape-architects/.

48 “'Tanto Urgía La Renovación De Las Marquesinas De Autobús? | Madrid | EL MUNDO “, accessed 7/24/2015, 2015, http://www.elmundo.es/madrid/2014/09/01/540361 44e2704ed8158b457e.html. 
la ciudad. El diseño fue de la multinacional francesa JC Decaux Y consiste tanto de bancos redondeados, bancos de asientos separadores para que se separen las personas que se sienten, bancos extremadamente estrechos o con separadores. Con asientos en los que nadie se puede acostar, Madrid adopta el urbanismo neoliberalista que intenta expulsar los indigentes de sus calles para limpiar y dejar el espacio urbano a los turistas y los consumidores. Al otro lado, son escasos los ejemplos de investigaciones y de los arquitectos-urbanistas y paisajistas que se dedican al diseño a partir de la vida de los sin techo en las calles de las ciudades. Encontramos ejemplos de profesionales y de colectivos que intentan ayudar a los sin techo a volver a construir su vida y a salir de los intersticios de las ciudades; proyectos que, en vez de excluir a los indigentes de la vida social, intentan incluirlos. Los refugios - edificios hechos de materiales alternativos de bajo coste que su construcción no requiere manos profesionales, los refugios móviles individuales, los campamentos de casa pequeñas en el espacio público y los workshop y talleres relacionados con casas para indigentes que en los últimos años se organizan por universidades y colectivos con proyectos que hacen a los indigentes participes en la construcción.

Sin duda, los Estados de los países europeos intentan la construcción de centros de acogida temporal y, precisamente en España en los últimos años, se ha inaugurado gran número de ellos, pero nunca son suficientes porque el número de las personas sin hogar aumenta de manera radical por la prevalencia del liberalismo económico desenfrenado de la sociedad de consumo y del colapso del Estado de Bienestar. ${ }^{49}$ Además, la gente sin hogar evita ir a estos centros, porque los edificios no están pensados para que la gente salga de las calles. La mayoría de los centros de acogida se constituyen como espacios uniformes en los que pueden llegar a tener en un cuarto de pocos metros cuadrados gran número de camas dando un efecto peor que lo de la estancia en un hospital. Si los indigentes evitan los centros de acogida es precisamente porque ellos no necesitan un techo sino construir su techo, sentirse útiles. Los refugios temporales que el Estado ofrece serían más afectivos si los indigentes fueran participes en su construcción. La única manera para que la gente sea participe en la construcción

49 Andreas Skraparlis, «Paisaje Urbano Contemporáneo, Espacio Público y Sin Techo» (Programa Interdepartamental del curso de posgrado, Arquitectura de Paisaje, Escuela de Arquitectura - Facultad de Agricultura, Universidad Aristóteles de Salónica. 13

En España se construyen cada vez más centros de acogida pero muchos de los sin techo los evitan
El planeamiento de la inclusión: participación de los indigentes en la construcción de su techo. 
Cuando los sin techo construye su techo con sus manos, construyen su vida de nuevo

La construcciones levantadas por las manos de los mendigos tienen un coste mucho menor que la de los centros de acogida

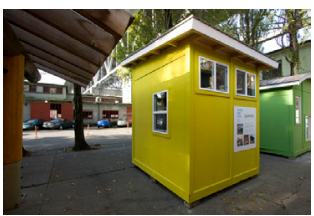

Home for Less, Vancouver, Canadá

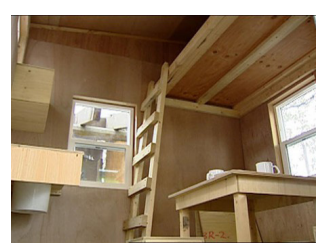

Home for Less, Vancouver, Canadá de su techo es enfrentando la vivienda (bousing) como verbo y no como sustantivo. Según Turner, cuando la enfrentamos como verbo consideramos que la construcción de la vivienda por su habitante es una actividad fundamental para él y por eso pensamos proyectos que le involucran en su diseño y construcción. ${ }^{50} \mathrm{El}$ coste medio de los centros de acogida llega a los seis millones de euros como es el caso del Centro de Acogida Princesa Letizia en Santander que tuvo un presupuesto de 6,5 millones de los cuales los 5,7 era aportación del Ayuntamiento. El Centro de Acogida Juan Luis Vives en Madrid de ciento treinta y dos plazas se diferencia de sus similares ya que consiste en un edificio construido por módulos prefabricados que se puede adaptar al número de la gente sin hogar con un contrato con la Junta de Gobierno para dos años, desde 2014 hasta 2016, de un coste de 4, 3 millones. ${ }^{51}$ Pero, aun así, sigue siendo un lugar llega a tener sesenta camas en un solo espacio.

Propuestas para la participación de los indigentes en la construcción de su techo encontramos en varios proyectos experimentales como el proyecto Home for Less que se realizó en Vancouver, en Canadá, y fue diseñado por alumnos de la Universidad Emily Carr. Son pequeñas casas de madera de 6 metros cuadrados con un coste de 1.750 euros cada uno. Hacen un barrio dentro de la ciudad de 10-12 casas que compartan cocina y baños. En un principio se construyeron por los alumnos pero su fácil modo de construcción permite la construcción por cualquier persona. Otro proyecto que intenta dar soluciones a la gente que no tienen casas y viven en las calles de las ciudades es el Tiny House Movement que se está realizando por los miembros del grupo Occupy Madison ${ }^{52}$. El Occupy Madison ${ }^{53}$ está activo desde el 2011 y con la gente sin hogar organizaron el movimiento Tiny House que construyen casas pequeñas y baratas en

$50 \quad$ John F. C. Turner and Robert Fichter, Freedom to Build: Dweller Control of the Housing Process (New York: The Macmillan Company, 1972). 151

51 “4,3 Millones Para El Centro De Acogida Juan Luis Vives - Ayuntamiento De Madrid “ , accessed 6/13/2015, 2015, http://www.madrid.es/portales/munimadrid/es/Inicio/ Ayuntamiento/Medios-de-Comunicacion/Notas-de-prensa/4-3-millones-para-el-Centro-deAcogida-Juan-Luis-Vives? vgnextfmt= default\&vgnextoid=3ea14c1396a03410VgnVCM1000000 b205a0aRCRD\&vgnextchannel $=6091317 \mathrm{~d} 3 \mathrm{~d} 2 \mathrm{a} 7010 \mathrm{VgnVCM} 100000 \mathrm{dc} 0 \mathrm{ca} 8 \mathrm{c} 0 \mathrm{RCRD}$.

52 Occupy Madison es uno de los grupos de carácter local que se formaron después del agotamiento del movimiento Occupy Wall Street, rama del Movimiento 15-O que fue una protesta pacífica que se realizó en forma de manifestaciones en 1051 ciudades de 90 países en 15 de Octubre de 2011.

53 “Om - Tiny Houses \& More!”, accessed 7/9/2015, 2015, http://occupymadisoninc. $\underline{\mathrm{com} / .}$. 
espacios de la ciudad. Los habitantes de estas casas- los sin techo - no pagarán alquiler pero están obligados a ayudar en su construcción. Ejemplos para el Occupy Madison son los de Opportunity Village y Emerald Village en Eugene, Oregón y Quixote Village en Olympia, Washington. El Tiny House Movement no es solo un movimiento que intenta dar solución para la gente sin hogar sino es un movimiento social que aboga por la vida simple en casas pequeñas: porque son soluciones que respetan el medio- ambiente, soluciones más económicas tanto para los estados como para sus habitantes y soluciones con las que se crean comunidades pequeñas donde la gente comparte terreno y actividades. Ejemplos de este tipo de comunidades empiezan a aparecer después de 2007; algunos son realizados y habitados, otros consisten en pueblos pilotos y fase experimental. Algunos de los más famosos son Boneyard Studios fundado en 2012 en Washington, D.C., Dignity Village, en Portland, Oregon, en Estados Unidos, Dome Village, en Downtown L. A, Village of Hope, en Frenso, California, River Haven en Ventura California, Quixote Village en Olympia, Washington, y más. Los módulos-casas móviles independientes en la ciudad es una solución más frente al problema del sinhogarismo. Ejemplo es el caso de las construcciones del diseñador americano Gregory Kloehn quien construye casas usando residuos. Hablamos de su proyecto nombrado Homeless Homes ${ }^{54}$ que es una iniciativa colaborativa que intenta juntar gente creativa que quiere ayudar en la creación de refugios móviles para la gente sin techo de las calles de California usando materiales de dumping ilegal, de residuos u objetos domésticos. En este tipo de soluciones entra la mayoría de los proyectos que se presentan en los talleres, workshops y concursos arquitectónicos que se realizan con el objetivo de la vida de la gente que no tiene hogar. Sin embargo, las propuestas que se presentan se quedan en un nivel teórico y rara vez se realizan y, desafortunadamente, el problema que surge en estos casos es que los arquitectos se centran en conseguir soluciones inteligentes y en la innovación arquitectónica y olvidan los problemas reales de los indigentes. Ejemplos de soluciones inteligentes de hogares de indigentes que de manera fácil se hacen y se deshacen son la tienda propuesta por la empresa Zo -loft, el banco que se transfora en capsula de dormir diseñade por Peter O’ Brien, las casas -camas transportable de Kacey Wong y más. 54 "Homeless Homes Project " , accessed 7/9/2015, 2015, http://www. homelesshomesproject.org/.
Tiny House Movement: casas construidas por indigentes

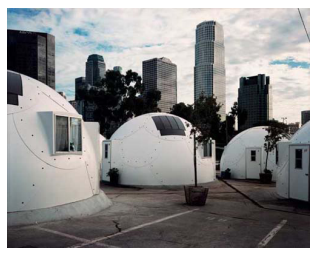

Dome Village

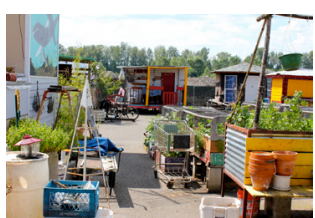

Dignity Village

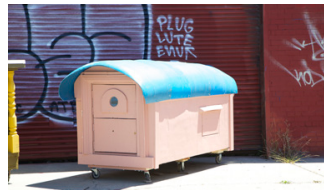

Homeless Homes por Gregory Kloehn

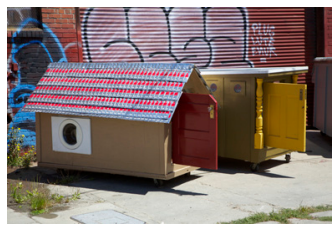

Homeless Homes por Gregory Kloehn 
Construcciones de materiales no convencionales y de bajo coste

Shigeru Ban:
construyendo con
cartón

Shigeru Ban, arquitecto activista, construye ad hoc soluciones para las situaciones extremas y de emergencia y catástrofes naturales

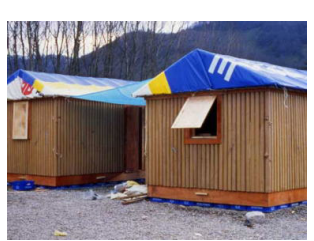

Construcción de cartón, Turquia. Shigeru Ban

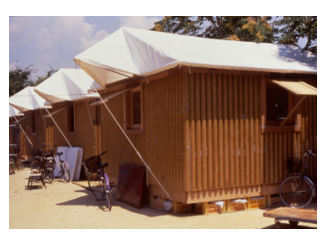

Construcción de cartón, Kobe. Shigeru Ban
Variedad de soluciones se presentaron en la Tabacalera y el blog bl $^{55}$ del Workshop de Construcción Experimental que se realizó de 7/06/2012 hasta el 9/06/2012. Las construcciones que usan materiales no convencionales de bajo coste y que se levantan sin la necesidad de manos de obra especializadas son efectivas en el problema del sinhogarismo. Otro ejemplo representativo de este tipo de soluciones es el barrio construido por contenedores de barco por el arquitecto Shigeru Ban - premiado con el premio Pritzke en 2014 - para 500 desplazados de la tragedia de tsunami y terremoto sucedido el marzo de 2011 en Japón. Las autoridades de la pequeña localidad de Onagawa permitieron a Ban la construcción de casas temporales de hasta tres pisos, fabricadas de contenedores de 6×2.5 metros, en un antiguo estadio de béisbol. Más de cien familias están alojadas en el barrio de contenedores que se levantó en solo tres meses; estructuras baratas y fáciles de montar y desmontar, edificadas a pruebas de terremotos.

La obra del arquitecto Shigeru Ban, arquitecto bumanitario, activista se distingue por sus soluciones innovadoras en las situaciones extremas y de emergencia. Es un arquitecto que trabaja con materiales de bajo coste no convencionales (cartón, contenedores, bambú, etc.) y en colaboración con voluntarios y estudiantes dando ad hoc soluciones en las áreas de desastres después de catástrofes naturales para la construcción de refugios o edificios comunitarios de bajo coste. Otra obra de Ban que merece ser mencionada es la de las casas de cartón después del terremoto de Kobe, en Japón en 1995. Son casas de rollos de papel reciclables que posteriormente serían reciclados o reusados por el arquitecto para otras construcciones posteriores; construcciones fácil de hacerse y deshacerse sin la necesidad de mano de obra especializada y por eso autoconstruible por sus propios usuarios. Hablamos de casas de $16 \mathrm{~m} 2$ y de un coste 1800 euros; como base de cimentación tenían cajas de cervezas llenas de arena y una cubierta textil que se levantaba el verano para la ventilación y cubrirse el invierno para mantener el calor; las fachadas eran un doble pared de tubos de cartón prensado e impermeabilizado con espuma aislante entre ambos paramentos y el techo de lona de tiendas de campaña. Casas de cartón diseñadas por Ban encontramos también en Turquia tras el terremoto de 2000, en Bhuj, en India después del seísmo en 2001, en

55 “iVive La Calle!”, accessed 7/9/2015, 2015, https://vivelacalle.wordpress.com/. 
Puerto Principe en Haití en 2010 y en Cebu, Filipinas en 2014. El uso de cartón por Ban no se limita en la construcción de refugios y casas sino se usa en edificios comunitarios. Algunos son la iglesia de papel o Templo de Takatori en Kobe, montado en 1995 y desmontado el 2005, Escuela de Primaria Temporal en Hualin - Chengdu, China, 2008, Hall de Conciertos Temporal de Papel - L'aquila, Italia, 2011, Catedral de Cartón Christchurch, Nueva Zelanda, 2013, Centre Pompidou-Metz, France, 2010 y más obras que se pueden encontrar de manera detallada en la página web del arquitecto ${ }^{56}$.

Estructura de materiales no convencionales de bajo coste que permiten su construcción por mano de obra no especializados es el pabellón de latas de aluminio que fue presentado en la Bienal de Urbanismo de Paisaje Bat Yam del año 2008 por los diseñadores Young Designers. Las botellas de plástico PET fueron el material de la construcción de la escuela primaria nacional Day-Asan ubicada en la provincia de Surigao en Asia construida por Illac Diaz y la Fundación MyShelter. Las botellas en ocasiones se colocan vacias y en ocasiones llenas de adobe, material mucho más resistente que el concreto. Mencionamos un proyecto más de los varios que usan materiales alternativos, el Wedding Chapel en la Villa Escamp, en Holanda. Un proyecto diseñado y construido por los DUS Architects en 2011. Es un "dome" de seis metros de longitud y tres metros de altura que puede alojar 50 personas y está construido por dos kilómetros de tubos de ventilación flexibles. La asignatura Especulaciones impartida por la arquitecta Atxu Amann Alcocer, profesora de la Escuela Técnica Superior de Arquitectura de Madrid, fortalece la creatividad de los alumnos a través de intervenciones y ejercicios de descontextualización de materiales y acciones con el fin de crear estructuras y lenguajes alternativos. En los años académicos de 2013-2014 y 2014-2015 los alumnos tuvieron la oportunidad de organizar y levantar en el patio de la Escuela estructuras de bajo coste, sostenibles, construidas por residuos: en el primer año tuvo lugar el levantamiento de un invernadero de botellas de plástico usadas, y en el segundo, fue la construcción de una casa con el uso de latas vacías.

Las estructuras neumáticas del arquitecto español José Miguel Prada Poole podrían ofrecer también soluciones para la estancia temporal de los indigentes. Son estructuras que usan el aire como elemento de construcción; estructuras soportadas 56 "Works | Shigeru Ban Architects", accessed 7/9/2015, 2015, http:/ /www. shigerubanarchitects.com/works.html.

Talleres, workshop y concursos arquitectónicos para la vida de los sin techo
C r e a t ivid a d, descontextualización y sostenibilidad

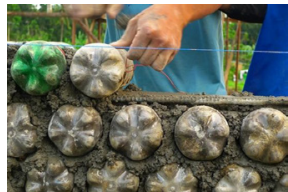

Escuela Day-Asan, Asia

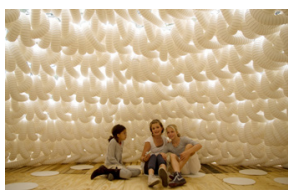

Wedding Chapel. Holanda 
José Miguel Prada Poole: construyendo con el aire
El Director de ETSAM en 1974 quita la estructura Elipsoide del jardín de la escuela: los alumnos no se pueden dedicar a hacer casas para hippies y gitanos

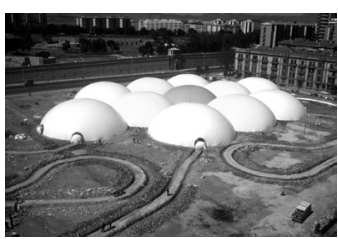

Estructura Elipsoide. Prada Poole o hinchadas por aire de membranas impermeables de plástico o látex que por una presión mayor de la de la atmosfera pueden ofrecer alojamiento para los varios usos del espacio. Para Miguel Prada Poole el aire es el mejor elemento de construcción; el material constructivo estructural más económico, de menos peso, más baja densidad, que existe abundantemente en cualquier lugar de la tierra y cuyo coste económico, hoy por hoy, es nulo, y se puede adquirir sin necesidad de instancia o permisos o crear problemas de propiedad (hoy, 1974) es el aire. ¿Por qué no construir con aire? $?^{57}$ Prada Poole es uno de los pocos arquitectos que defienden las estructuras que no dejan buellas ${ }^{58}$, arquitecturas inexistentes ${ }^{59}$ : evanescentes, inmateriales, sostenibles, efímeras; arquitecturas instantes.

Entre los pioneros de las estructuras neumáticas, Prada construye en 1968 la cúpula hinchable Alcudia, cúpula a partir de colchones de baja presión sin armadura de soporte ${ }^{60}$ En 1969, Prada construye Elipsoide: la primera grande estructura neumática en España con la ayuda de empresas y alumnos en el jardín de la Escuela Técnica Superior de la Arquitectura de Madrid; estructura que permanecerá seis años hasta su demolición porque el Director de la Escuela dijo que tienen que desaparecer porque los arquitectos de la escuela no se podian dedicar a hacer casas para bippies y gitanos, y que eso no eran ni estructuras ${ }^{61}$. La Arquitectura Jonás de 1970 fue una estructura en forma de gusano que se podía mover; un animal gigante viviente que es capaz de convivir con sus habitantes. La Ciudad Instantánea de 1971 fue una ciudad de módulos neumáticos que se construyó para el alojamiento

57 José Miguel de Prada Poole, "La Arquitectura Perecedera De Las Pompas De Jabón,” El Urogallo 25 (Enero - Febrero 1974), 72-78.

Referencia en Prada Poole, José Miguel de and Fabián López Ulloa, "José Miguel De Prada y Las Estructuras Neumáticas En España, 1960-1980," Geometría y Proporción En Las Estructuras (2010), 374-387.

58 Patricia Gosálvez, “Arquitecto De Burbujas y Arcoíris,” El País28 Mar, 2011.

"Arquitecto De Burbujas y Arcoíris | Edición Impresa | EL PAÍS “, accessed 7/13/2015, 2015, http://elpais.com/diario/2011/03/28/madrid/1301311464 850215.html.

59 Prada expone los tres escalones de la arquitectura inexistente: el primero, el de la desmaterialización urbanística; el segundo, el de la constitución de la ciudad y la sociedad planetaria; el tercero, el desarrollo de la ciudad mágica, evanescente e inmaterial recorrida por olas estimulares y energéticas, que semejarían una ebullición solar. En ella, pasado presente y futuro se confundirían para constituir un instante único y múltiple, individual y universal. Prada Poole, La Arquitectura Perecedera De Las Pompas De Jabón, 72-78 Referencia en Prada Poole, José Miguel de and López Ulloa, José Miguel De Prada y Las Estructuras Neumáticas En España, 1960-1980, 374-387

60 Thomas Herzog, Gernot Minke and Hans Eggers, Construcciones Neumáticas: Manual De Arquitectura HinchableEditorial Gustavo Gili, 1977)., 50.

Referencia en Prada Poole, José Miguel de and López Ulloa, José Miguel De Prada y Las Estructuras Neumáticas En España, 1960-1980, 374-387

61

Ibid. 
temporal de los alumnos que participaban en el congreso ICSID en Ibiza. Era una ciudad que se iba aumentando o disminuyendo según el número de sus habitantes y que habría debates y reflexiones sobre la autoconstrucción: el diseño de la ciudad a partir de sus habitantes y no de los arquitectos. En el evento de los Encuentros de Arte de Pamplona en 1972, Prada presentó un Recinto Neumático de superficie cubierta de 8.500 metros cuadrados constituida por 11 semiesferas de un diámetro de 25 metros y de 12 metros de altura que, como dice, es una urbanística efímera, espacio-puente entre los varios locales en los que se desarrollaban los encuentros y que alojaba las exposiciones programadas de los Encuentros.

Alguien se preguntaría si las estructuras neumáticas o las construcciones con elementos alternativos de bajo coste o las comunidades Tiny Houses son soluciones para la erradicación del sinhogarismo. Ni las tácticas presentadas anteriormente y tampoco aquellas convencionales de construcción de edificios rígidos son capaces de eliminar el fenómeno del sinhogarismo, pues éste es un fenómeno social que depende de las estrategias políticas y económicas de cada país. Sin embargo, los arquitectos y urbanistas pueden aportar en la mejora de la vida de los indigentes. Propuestas urbanísticas sensibles hacia los indigentes, soluciones que construyen procesos y no edificios rígidos, estructuras de materiales de bajo coste que podrían levantarse de las manos de sus propios habitantes abren la posibilidad a los sin techo a construir su hogar, es decir, su vida. Además, planificar pensando en el bienestar de los indigentes conduce a una ciudad más agradable, más cómoda y más viva para todos sus habitantes; cada planificación que ayuda a la exclusión de los sin techo de las calles afecta la calidad de los espacios públicos y de este modo, a la vez, expulsa todos los ciudadanos. La expulsión de los indigentes de los intersticios urbanos para la mejora de la imagen de la ciudad requiere proyectos que intentan convertir el espacio público en un lugar inaccesible, pues es la única manera para que los indigentes desaparezcan. Cuando en la ciudad no hay espacios para sentarse los habitantes están obligados a estar en un continuo movimiento; el espacio público deja de ser un espacio de reposo y de dialogo y se hace un no lugar o un anti lugar, pues andar es no tener un lugar ${ }^{62}$.

62 Michel De Certeau and Luce Giard, La Invención De Lo Cotidiano: Artes De Hacer. I, Vol. 1. Universidad Iberoamericana, 2007, 116
Construcciones con aire por Prada Poole

La expulsión de los indigentes del espacio público significa la expulsión de todos los ciudadanos 



\section{Fumando en los umbrales de los bares de Madrid}

Es humano retrasarse. La arquitectura debería, en mi opinión, tenerlo más en cuenta ${ }^{1}$

M Aldo van Eyck

Desde 2013 hasta la actualidad se observa en la ciudad de Madrid una reforma masiva de los interiores de sus bares; la mayoría de los sitios de encuentro (bares, restaurantes, panaderías, tabernas, discotecas, residencias) permanecen cerrados poco tiempo y vuelven a abrir con sus umbrales extendidos; alargan el espacio que ocupa la puerta y crean un lugar intermedio entre la acera y el interior del bar; en muchos casos, este lugar intermedio llega a tener casi la misma dimensión que el interior. La extensión del tamaño de los umbrales parece ser el resultado del llamado fenómeno del cigarrón, por el que decenas de personas que están en los umbrales de los bares y las discotecas fuman, ya que en su interior está prohibido. El cigarrón es el resultado de la segunda ley antitabaco que, en España, entra en vigor el 2 de Enero de 2011². La primera ley, de 2006, daba la opción a los locales de elegir si querían tener un establecimiento para fumadores o no; el 95\% permitió el tabaco, a pesar de que el 65\% de los ciudadanos no fuma. ${ }^{3}$ Juan José Rodríguez Sendín, miembro de la Organización Médica Colegial, defendió que es mejor no tener ley que hacerla descafeinada, refiriéndose al hecho de que no pueden convivir dos tipos de locales: los de fumadores y de no fumadores. La ley sería más eficaz si solo existieran lugares en los que no se puede fumar; aquellos que

1 Aldo van Eyck, Vincent Ligtelijn and Francis Strauven, Aldo Van Eyck: Writings (Amsterdam: Sun, 2008).62

2 "El Congreso Aprueba La Ley Antitabaco Que Prohíbe Fumar En Los Espacios Públicos Cerrados | Sociedad | EL PAÍS “, accessed 1/13/2016, 2016, http://sociedad.elpais. com/sociedad/2010/12/21/actualidad/1292886011 850215.html.

3

Ibid.
Reforma masiva de interiores en los barres de Madrid: Ampliación de los umbrales

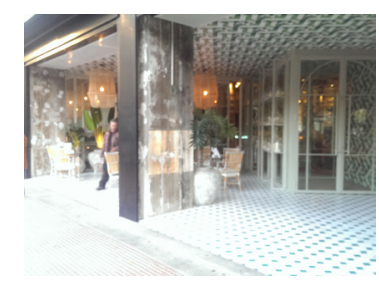

Bar en calle Eloy Gonzalo, Madrid

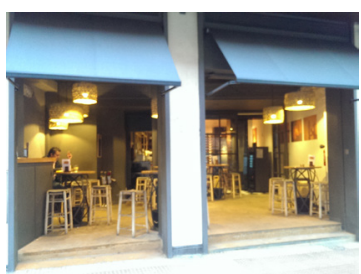

Bar en calle Santa Engracia, Madrid

La ley antitabaco y el fenomeno cigarrón 
En el umbral, que está fuera y dentro a la vez, no entra la ley
El umbral, espacio liminal, materialización del encuentro están en contra de la ley, defienden que esta medida no ayuda a abandonar al habito, perjudicando además al sector de la hostelería. El fenómeno del cigarrón provoca, por una parte, las quejas de varios vecinos, para quienes es una contaminación acústica y por otra parte, es lo que decide el éxito del local, ya que la gente elige los bares según el tamaño de sus umbrales

El Estado ha elegido poner en vigor esta ley y decidir por sus ciudadanos, pero los madrileños encontraron una solución intermedia para el fenómeno del cigarrón: extender aquel lugar que no se puede gobernar, el espacio liminal del umbral, entre lo que está dentro y lo que está fuera. Dentro del bar se puede beber, estar, hablar y escuchar música sin tener frio; fuera se puede fumar pero no se puede beber y además hace frio; pero en el lugar en el que está la puerta, un espacio que casi siempre ocupa un portero, se permite todo: el espacio del umbral no está dentro, así que se puede fumar pero tampoco está fuera, así que también se puede beber; pero como está a la vez dentro y fuera se puede escuchar a la vez la música y no tener frio. El umbral es una estructura liminal, según Victor Turner y Van Gennep, un Tercer Espacio, según Žižek, que queda fuera de lo dentro y fuera de lo fuera. La palabra umbral, deriva de la palabra umbrío que significa sombra; un lugar protegido que se encuentra a la luz del exterior y en la oscuridad del interior creando así sombra. El ideograma que se corresponde con el umbral en el idioma japonés son dos ideogramas: el del portón y el de la luna, que crean entre ellos la sensación del entre. ${ }^{4} \mathrm{El}$ umbral es la materialización del encuentro y a la vez, de la separación; es aquel momento en el que sucede la transformación de términos opuestos. Cuando lo dentro se hace fuera, lo individual se hace colectivo, el cuerpo se hace mente y tú se hace yo: es el pasaje de un mundo a otro. El umbral es un lugar metafórico y teatral, un escenario;

¡(...) una simple puerta viene a dar las imágenes de la vacilación, de la tentación del deseo, de la seguridad, de la libre acogida, del respeto! Diriamos toda nuestra vida si biciéramos el relato de todas las puertas que hemos cerrado, que hemos abierto, de todas las

\footnotetext{
4 Stavros Stavridis, De La Ciudad Pantalla a La Ciudad Escena (Atenas: Ellinika Grammata, 2002).308.
} 
puertas que quisiéramos volver a abrir ${ }^{5}$.

Es importante, según Aldo van Eyck, que los arquitectos se centrenen el umbral para dar importancia a la transición entre los mundos del exterior al interior y viceversa. Según él,

la puerta no es una superficie plana con bisagras y una cerradura que constituye una dura aterradora frontera (...). La realidad más grande de la puerta es el establecimiento localizado de un maravilloso gesto humano: la consciente entrada y salida. Es algo que marca su iry venir, una experiencia vital, no sólo para aquellos que lo hacen, sino también para los que se encuentran o se dejan atrás 6 .

Dar importancia a entrar o salir, quedarse o marcharse, dejar el hogar e irse del hogar, son transiciones a veces dolorosas alternativas. Los arquitectos tienen que tener en cuenta estos acontecimientos a la hora de sus configuraciones, propone Aldo van Eyck, quien además sostiene que la arquitectura no puede evitar este hecho. Eso es posible cuando se intenta que las transiciones no sean abruptas - transiciones que causan ansiedad- indicando el camino por etapas; ${ }^{7}$ suavizar el salto psicológico que se produce en la transición de lo interior a lo exterior y viceversa. Para la suave transición de un mundo a otro, Aldo van Eyck en el orfanato, transforma una plaza interior en exterior para anclar la gran casa-pequeña-ciudad de los niños con la esfera pública, lo que consiste así en un elemento de transición entre la realidad de afuera y la de dentro ${ }^{8}$. Aldo van Eyck expande los umbrales a lo máximo posible. La línea que dibuja el umbral es algo más; es un tiempo dilatado en el que el ser humano toma el tiempo que necesita para su transición entre los distintos mundos que conecta. La transición suave del mundo exterior con el mundo interior, van Eyck lo hace con el uso de la calle interior. Es un elemento usado también por Herman Hertzberger principalmente en escuelas y en

5 Gaston Bachelard, La Poética Del Espacio: Gaston BachelardFondo de Cultura Económica, 1983). 261

6 A door is a localized setting for a wonderful human gesture: conscious entry and departure. Something that frames your coming and going, for it's a vital experience not only for those that do so, but also for those encountered or left behind. Aldo van Eyck, Vincent Ligtelijn and Francis Strauven, Aldo Van Eyck: Writings (Amsterdam: Sun, 2008).62

$7 \quad$ Ibid. 62

$8 \quad$ Ibid. $312-323$
La puerta es el establecimiento de un marivilloso gesto bumano.

Cuidar la transición entre dentro y fuera, entre los dos mundos.
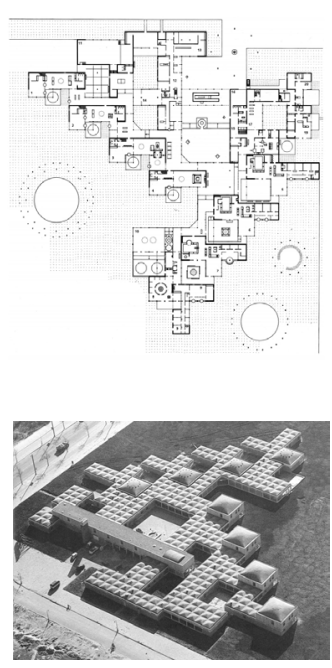

El Orfanato de Aldo van Eycke.

La expansión de los umbrales 
La calle interior

Los umbrales y los lugares de paso pierden significado en la modernidad

Comienzo de la filosofía del umbral. Alison y Peter Smithson colegios. Lo que sucede a partir de ellos es que un elemento exclusivamente urbano, el elemento de la exterioridad, entra en el interior del edificio; lo que cambia con este gesto no es solo el grado de reciprocidad del interior con el exterior sino también que el hall, el lugar centralizado del edificio, pierde su importancia. La calle interior es también un elemento de articulación que a veces se transforma en plaza; es una herramienta más para la aproximación a la reciprocidad. La calle interior es un espacio intermedio como lo es el umbral en el que estar dentro todavía significa estar fuera.

En la modernidad, los umbrales, y en general los lugares intermedios, están abandonados; existen solo porque son necesarios para la conexión y la separación de los lugares principales. La visión simple y únicamente técnica del espacio - tiempo del entre, del entretien - de los arquitectos de la modernidad, hace considerar las tácticas de Aldo van Eyck como inhumanas; el pensamiento racional y la obsesión por el orden y la velocidad hace olvidar el "entre" de la vida como transición entre los mundos y el encuentro constante con el prójimo. Los Smithson, Aldo van Eyck, el Team X y en general, la mayoría de la tercera generación de los CIAM, proponen dejar la utilidad que transforma al ser humano en máquina e usuario para centrarse en el Entre; en los lugares intermedios donde sucede la transición entre los estados y el encuentro de uno consigo mismo y con el otro. En el IX CIAM, realizado el 1953 en Aix-enProvence, Alison y Peter Smithson, miembros del grupo británico MARS, criticaron la actitud de la arquitectura moderna, según la que el hábitat se simplifica y se divide en organización de funciones de la vivienda, trabajo, transporte y ocio, apoyando que lo que los arquitectos tienen que hacer es organizar sus intenciones proyectuales según las posibilidades de interacción de los habitantes; los Smithson, como Aldo van Eyck y TEAM X, se concentran en configurar lugares que favorecen la relación entre la gente. Con Alison y Peter Smithson empieza la filosofía del umbral en los ámbitos arquitectónicos que es extendida más tarde por Aldo van Eyck. Según los Smithson, lo que es abandonado por los CIAM es la calle; la calle que como exponen en el texto de presentación en el IX Congreso en Aix-en-Provence bajo el título Urban Re-Identification, es una oportunidad de relaciones entre la familia y la comunidad exterior de la casa: 
Debemos empezar nuestro pensamiento desde el momento en que el se humano o el niño pisan fuera de su casa (...) tratar de encontrar de qué manera este contacto básico tiene lugar, cuantas casas poner juntas, cuales son las instalaciones que comparten, cuestionando continuamente la arbitrariedad de las soluciones existentes. Este es el principio básico del enfoque ecológico sobre el problema del hábitat 9

La filosofía del umbral es extendida por Aldo van Eyck más allá del lugar entre la casa y la calle y de la transición entre ellos. Sin embargo, la influencia de los Smithson en el desarrollo de sus creencias es crucial:

Hay una cosa más que ha estado creciendo en mi mente desde que los Smithson dieron con la palabra 'umbral' en Aix. No la be olvidado desde entonces. He estado reflexionando sobre esto, expandiendo su significado tanto como he podido. He ido incluso tan lejos como para identificarlo como símbolo de lo que la arquitectura debe alcanzar. Establecer el "intermedio" significa reconciliar las polaridades conflictivas. Proporcionar el lugar donde se pueden interactuar $(. . .)^{10}$.

Así, Aldo van Eyck introduce el concepto del lugar y lo distingue del espacio. El lugar es allí donde los extremos se reconcilian. El lugar es donde el ser humano se identifica. Las dualidades para Aldo van Eyck son falsas realidades; son realidades mentales y la mente está equilibrada en su reconciliación. No son realidades polares sino realidades ambivalentes ${ }^{11}$. Construir lugares donde el interior - exterior, individual colectivo, cerrado - abierto dejan de ser polaridades y se hacen realidades ambivalentes que se mezclan entre ellas, creando lugares que respiran, de manera que el ser humano lo hace; es construir lugares que son el espejo de la naturaleza humana y, por eso, el hombre en ellos reconoce su reflejo; se identifica ${ }^{12}$. Entonces, para Aldo van Eyck el espacio y el tiempo son abstracciones congeladas para entender el mundo; en sus

$9 \quad$ Alison Smithson and Peter Smithson, “The Built World: Urban Re-Identification," Architectural Design.No6 (1955), 185-188.

10 Aldo van Eyck, Vincent Ligtelijn and Francis Strauven, Aldo Van Eyck: Writings (Amsterdam: Sun, 2008).61

11 On inside outside, Ibid.

$12 \quad$ On inside outside Ibid.
Empezar desde el umbral.

El umbral extendido es lo que la arquitectura debe alcanzar.

Las dualidades son falsas realidades; el intermedio es donde el ser humano se identifica. 
El lugar y la ocasión son más importantes que el espacio y el tiempo

Los pares de términos opuestos y los fenomenos gemelos de Aldo van Eyck

Principio de la reciprocidad y de la respiración palabras, el espacio en la imagen del hombre es el lugar y el tiempo en la imagen del hombre es la ocasión ${ }^{13}$. A los arquitectos no les tiene que preocupar el espacio o el tiempo, sino el lugar y la ocasión; sea el que fuere el significado de espacio y tiempo, el lugar y la ocasión significan más ${ }^{14}$. El intermedio es para Aldo van Eyck el lugar donde realidades distintas se pueden encontrar y unificar; el intermedio es el lugar donde las dualidades se hacen fenómenos gemelos; se reconcilian. ${ }^{15}$

Fenómenos gemelos son los pares de opuestos que para Aldo van Eyck, no son opuestos sino precisamente gemelos. El pensamiento de Aldo van Eyck es un pensamiento de la reconciliación de los conceptos opuestos - principalmente se refiere a los conceptos unidad-diversidad, individual - colectivo, parte - todo, grande - pequeño, poco - mucho, dentro - fuera, abierto - cerrado, movimiento - reposo, orden - $\operatorname{caos}^{16}$, pasado - presente, clásico - moderno, arcaico - avantgarde, constancia -cambio, simplicidad - complejidad, orgánico - geométrico, etc. ${ }^{17}$ - que en vez de términos opuestos llaman gemelos, pues consideran que el proceso arquitectónico se tiene que basar en la exploración de las relaciones de las parejas de los fenómenos gemelos y la reciprocidad entre ellos. Aldo van Eyck, profundamente influenciado por Heráclito, quien cita en el comienzo de su texto $A$ home for Twin Phenomena ${ }^{18}$ - que es su discurso pronunciado en el último congreso CIAM en Otterlo en 1959 -, considera que los fenómenos gemelos individual - colectivo, parte - todo, cerrado - abierto se tienen que entender en términos de respiración; y la arquitectura moderna, según él, intenta de manera dura la aproximación de la relación y de la reciprocidad entre dichos fenómenos gemelos no se refiere solo a ellos sino a cualquier término que se puede encontrar en las prácticas arquitectónicas. Todos los fenómenos gemelos están interconectados entre ellos; tan pronto como uno se

\footnotetext{
$13 \quad$ Ibid. 61

14 Ibid. 50

15 Francis Strauven, "Aldo Van Eyck. Shaping the New Reality from the in-between to the Aesthetics of Number," Study Centre Mellon Lectures. California: College of the Arts 24 (2007). 15

16 Aldo van Eyck, Vincent Ligtelijn and Francis Strauven, Aldo Van Eyck: Writings (Amsterdam: Sun, 2008).

17 Francis Strauven, "Aldo Van Eyck. Shaping the New Reality from the in-between to the Aesthetics of Number," Study Centre Mellon Lectures. California: College of the Arts 24 (2007).

18 Aldo van Eyck, Vincent Ligtelijn and Francis Strauven, Aldo Van Eyck: Writings (Amsterdam: Sun, 2008). 58
} 
refiere a uno de ellos, descubrirá asi mismo tratar con el próximo - con todos ellos ${ }^{19}$.

La incapacidad de aplicar el principio de la reciprocidad - de la respiración - en las dualidades mucho - poco y grande - pequeño conduce a la mera separación arbitraria de la configuración del hábitat en dos disciplinas - arquitectura y urbanismo - dando como resultado el terrible panorama del urbanismo, según Aldo van Eyck.

La dualidad arbitraria arquitectura - urbanismo
El fracaso al gobernar la multiplicidad creativamente y bumanizar el número a través de la articulación y configuración (el verbo 'multiplicar' debería coincidir con el poco utilizado 'configurar') ha llevado al descalabro de la mayoría de nuevos asentamientos ${ }^{20}$.

Aldo van Eyck explica que, en el paso del siglo XIX al XX, todo pensamiento creativo, desde el poeta hasta el científico, del pintor al antropólogo, del arquitecto al psicólogo, del filósofo al compositor, derriba paredes entres polaridades incompatibles. A partir de la teoría de la relatividad, dualidades como espacio y tiempo, energía y materia, reposo y movimiento, micro y macrocosmos, consciencia e inconsciencia, entre otras, se reconcilian y el mundo objetivo de la ciencia deja de ser opuesto al mundo subjetivo del arte; sujeto y objeto se han mezclado alegremente. Pero aunque arte, ciencia y filosofía a partir de la teoría de la relatividad rompen barrearas entre ellas, arquitectura y urbanismo se alejan entre ellos. A la luz de los logros de otros campos creativos-un concepto distendido de la relatividad - lo que los arquitectos y urbanistas han hecho podría llegar a considerarse una traición ${ }^{21}$. Aldo Van Eyck sostiene que tenemos que concebir la arquitectura urbanísticamente y el urbanismo arquitectónicamente (jeso hace lo absurdo de las dos palabras!), es decir, de llegar a lo singular a través de lo plural, y viceversa. ${ }^{22}$ La ciudad es como una casa grande y la casa es como una ciudad pequeña. La ciudad tiene que ser vista como un hogar de la misma manera que la casa lo es; y la casa y la ciudad tienen que impartir una sensación de ir (volver) a casa independiente del sentido del camino; hacia la ciudad o hacia la casa. ${ }^{23}$

19 ....as soon as you are concerned with one of them, you'll discover yourself concerned with the nextwith all of them.... Ibid.

$20 \quad$ Ibid. $312-323$

$21 \quad$ Ibid. $312-323$

22 (...)conceive of architecture urbanistically and urbanism architectonically(this makes the right nonsense of both words) Ibid.60

23 Ibid. 62
La arquitectura debe romper sus barreras y relacionarse con otras disciplinas

La ciudad es una casa grande y la casa es una ciudad pequeña.

La configuración desde el Entre 
El lugar intermedio no es simplemente un margen.

El intermedio es el lugar que como el ser humano inspira y expira.

El concepto del reino del intermedio de Aldo van Eyck
El concepto del intermedio es para Aldo van Eyck la base de todo su desarrollo arquitectónico. La arquitectónica de Aldo van Eyck, es decir, el modo con el que organiza sus intenciones en sus diseños arquitectónicos, es una organización desde el intermedio; no desde dentro y tampoco desde fuera sino desde el lugar que conecta a esos dos términos.

El reino del intermedio para Aldo van Eyck no es un espacio concreto o delimitado que se encuentre entre las cosas - como los Smithson lo ven. No es un improvisado o un insignificante margen, sino algo tan importante como los propios opuestos reconciliados. El intermedio es una ocasión;

es un momento en el que las tendencias contrarias entran en equilibrio que constituye un espacio lleno de ambivalencia, y por lo tanto el espacio que corresponde a la naturaleza ambivalente del hombre. El intermedio es (...) es el lugar, que como el ser humano, inspira y expira ${ }^{24}$

El concepto tanto del reino intermedio como de los fenómenos gemelos nace para Aldo van Eyck - hijo del poeta y filósofo Pieter Nicolaas van Eyck - de la influencia que tienen en él físicos como Albert Einstein, Niels Bohr, Werner Heisenberg and Louis de Broglie y filósofos como Martin Buber, Henri Bergson y Merleau -Ponty. Antes de la teoría de los fenómenos gemelos, se encuentra aquella que acepta que las entidades y las cualidades son relativas, y no se pueden medir si no están relacionados con nosotros y no pueden existir (tener un significado) sin sus opuestos - también para la gente que las percibe. Dice van Eyck que Einstein, de Broglie, Planck, Bohr, Heisenberg y otros han dejado muy claro que, en última instancia, no podemos medir lo que no puede estar relacionado con nosotros mismos ${ }^{25}$. Los fenómenos gemelos se identifican en el espacio con la noción del intermedio. Aldo van Eyck llama este concepto como "in-between realm": la casa de los Fenómenos Gemelos ${ }^{26}$. Según Lammers, el concepto del intermedio aparece por primera

24 Being the moment where contrary tendencies come into balance, it constitutes a space filled with ambivalence, and thus space that corresponds to the ambivalent nature of man. The in-between is 'space in the image of man', a place that, like man, 'breathes in and out'. Strauven, Aldo Van Eyck. Shaping the New Reality from the in-between to the Aesthetics of Number

25 Harm Lammers, "Potentially...Unravelling and Reconnecting Aldo Van Eyck in Search of an Approach for Tomorrow" Eindhoven University of Technology). 46

26 Aldo van Eyck, Vincent Ligtelijn and Francis Strauven, Aldo Van Eyck: Writings (Amsterdam: Sun, 2008). 58 
vez en una pequeña observación que Aldo van Eyck hace después de dos viajes que realiza al Sahara; escribía, Sahara se extiende entre dos mundos: el mundo de Mahoma y el mundo del Negro. Tanto en la imaginación como en la realidad, este océano de piedra y arena es un mundo intermedio ${ }^{27}$. El siguiente concepto del intermedio con el que Aldo van Eyck trabaja, es provincia intermedia, un término que utiliza en sus textos sobre la construcción de las escuelas que construye en el pueblo de Nagele. ${ }^{28}$ Es en el proceso de la configuración del orfanato en el que Aldo van Eyck consigue entender y formular el concepto del reino del entre como la equivalencia espacial de los fenómenos gemelos; el lugar donde los opuestos se complementan. El reino del intermedio deriva de la combinación de la noción del umbral de los Smithson introducida en el IX CIAM, en Aix-en-Provence en1953, y la noción del Zwischen - término alemán de intermedio - introducida por el filósofo Martin Buber; la esfera del entre o el auténtico tercero. ${ }^{29}$

Martin Buber habla de lo que está entre el tú y el yo, pero, no usa la palabra intermedio; habla del entre, de la esfera del entre o del auténtico tercero. La introducción del término in - between en el vocabulario arquitectónico es posible gracias a la filosofía del "entre" de Martin Buber que usa el termino das Zwischen ${ }^{30}$. Las teorías de Buber sobre la dualidad individual - colectivo, entre el tú y el yo y la relación entre los polos de los términos opuestos, son las que más influencia tienen en la filosofía del "entre" de Aldo van Eyck. Según Buber, el ser humano moderno ha creado la dualidad individual colectivo pero lo individual y lo colectivo no existe; son formas abstractas para separar el Tú y el Yo. El se humano es relación. Es relación con un Tu y es relación con un Ello. Y cuando el ser bumano dice Yo, quiere decir uno de los dos ${ }^{31}$. No bay Yo en sí, sino solamente el Yo de la palabra primordial Yo-Tuy el Yo de la palabra primordial Yo-Ello ${ }^{32}$. Para Buber existen tres esferas en donde surge el mundo de la relación: la primera esfera es la de nuestra vida con la naturaleza, una relación oscuramente recíproca, como la llama Buber, y que está por 27 "The Sahara spans between two worlds: the world of Mohammed and the world of the Negro. Both in the imagination and in fact, this ocean of stone and sand is an in-between world." Lammers, Potentially... Unravelling and Reconnecting Aldo Van Eyck in Search of an Approach for Tomorrow 47 $28 \quad$ Ibid. 47

29 Carlos Díaz, Introducción Al Pensamiento De Martin Buber (Madrid: Instituto Emmanuel Mounier, 1990).

$30 \quad$ Harm Lammers, "Potentially...Unravelling and Reconnecting Aldo Van Eyck in Search of an Approach for Tomorrow" Eindhoven University of Technology).

31 Martin Buber, Tuy Yo (Buenos Aires: Nueva Vision, 1984).8

32 Ibid. 8
Del mundo ntermedio al reino del intermedio. La influencia de Martin Buber

El reino del Entre de Martin Buber

El ser humano es relación; cuando dice Yo quiere decir o Tú o Ello. 
Las tres esferas de la realación

Diferencia entre la persona y el individuo debajo del nivel de la palabra ${ }^{33}$; la segunda es nuestra vida con el otro, relación que se manifiesta y adopta la forma del lenguaje 34 y la tercera esfera, que Buber denomina como la "esfera del entre", es en la que sucede la comunicación con las formas inteligibles ${ }^{35}$.

La primera esfera es la relación del ser humano con su entorno y es principalmente su relación con el Ello; pero, puede suceder también la relación con un Tu. En esta esfera, el entorno es un objeto; podemos observarlo, nombrarlo, clasificarlo. Yo de la palabra primordial Yo- Ello aparece como un ser aislado y adquiere conciencia de sí como de un sujeto (el sujeto del conocimiento práctico y de costumbre) ${ }^{36}$. Sin embargo, alguien puede enfrentar en su entorno, objetos o animales o vegetales como un Tú; cuando nos capta la potencia de su exclusividad ${ }^{37}$. En la segunda esfera, en relación del ser humano con el ser humano la diferencia es que el Yo de la palabra primordial Yo- Tu aparece como una persona y adquiere conciencia de sí como de una objetividad (sin genitivo dependiente) ${ }^{38}$. En esta esfera no solo encontramos la relación Yo- Tú sino también el Yo- Ello; el Tú se hace Ello cuando el otro se hace objeto, es decir, cuando lo vemos como un objeto o cuando lo ponemos en un lugar de interés o utilidad. Buber hace una distinción fundamental que es la que existe entre los conceptos del individuo y de la persona.

La individualidad aparece en la medida en que se distingue de otras individualidades. La persona aparece en el momento en que se entra en relación con otras personas. La una es la forma espiritual de una separación natural; la otra, la de la unión naturaß39.

Más adelante, Buber explica que la persona contempla su sí mismo, el individuo se ocupa de lo que es suyo ${ }^{40}$. Sin embargo, ningún ser humano es puramente persona o puramente individuo; cada cual vive en el interior de un yo doble. Pero existen seres humanos en los cuales resulta

\footnotetext{
33 Carlos Díaz, Introducción Al Pensamiento De Martin Buber (Madrid: Instituto Emmanuel Mounier, 1990).18

$34 \quad$ Ibid. 18

$35 \quad$ Ibid. 18

$36 \quad$ Ibid. 19

37 Martin Buber, Tu y Yo (Buenos Aires: Nueva Vision, 1984).11-12

38 Carlos Díaz, Introducción Al Pensamiento De Martin Buber (Madrid: Instituto Emmanuel Mounier, 1990). 19

$39 \quad$ Ibid.19

$40 \quad$ Ibid.20
} 
tan preponderante lo personal, que cabe llamarlos personas, y otros en quienes la Individualidad es a tal punto preponderante, que cabe llamarlos Individuos. Entre aquéllos y éstos se juega la verdadera historia $^{41}$. En esta esfera, Buber distingue el concepto del encuentro y de la relación. Alguien suele creer que primero ocurre el encuentro y luego la relación pero, según Buber, primero es la relación y luego el encuentro. La relación es actitud mental o estado psicológico, mientras que el encuentro es algo que sucede, un evento. ${ }^{42}$ El verdadero encuentro entre dos personas sucede, según Buber, cuando no existe ninguna mediación; cuando la relación con el tú es directa; cuando entre el Yo y el Tú no se interpone ningún sistema de ideas, ningún esquema, ninguna imagen previa (...); cuando entre el Yo y el Tú no se interponen fines, ni placer ni prejuicio; y el deseo mismo se transforma, pues pasa de sueño a presencia. Todo medio es obstáculo. Sólo cuando todo medio está abolido acaece el encuentro ${ }^{43}$.

El verdadero encuentro, la conversación verdadera - la conversación espontánea -, el abrazo verdadero y no lo que se basa en la formalidad, el duelo verdadero y no su simulación, todo eso sucede en la "esfera del entre"; lo que se sucede no ocurre solo en uno de los participantes, ni tampoco en el mundo que abarca a los dos y a todas las demás cosas, sino en el sentido más preciso, "entre" los dos, como si dijéramos, en una dimensión a la que sólo los dos tienen $\operatorname{acces}^{44}$. El lugar donde sucede esta reciprocidad verdadera es la tercera esfera de la relación, la "esfera del entre" o del "auténtico tercero".

La relación está allí envuelta en nube, pero se desvela poco a poco; es muda, pero suscita una voz. No distinguimos ningún Tú, pero nos sentimos llamados y respondemos, creando formas, pensando, actuando. Todo nuestro ser dice entonces la palabra primordial,

En la esfera del Entre la relación está envuelta en nube, no distinguimos un Tú

La "esfera del entre" es lugar donde se crea entre dos personas.

"Algo me pasa", y cuando digo esto me refiero a algo concreto que puede distribuirse

\footnotetext{
$41 \quad$ Ibid. 19

42 Martin Buber, Tuy Yo (Buenos Aires: Nueva Vision, 1984) 11-12

43 Carlos Díaz, Introducción Al Pensamiento De Martin Buber (Madrid: Instituto Emmanuel Mounier, 1990).15

$44 \quad$ Ibid. 23

$45 \quad$ Ibid. 18
}

El encuentro verdadero sucede en la tercera esfera de la relación: la esfera del Entre

Primero sucede la relación y después el encuentro. 
exactamente entre el mundo y el alma, entre el proceso "exterior" y la Impresión "interna", pero cuando otro y yo "nos pasamos uno al otro" la cuenta no se liquida como en el caso anterior, queda un resto, un como lugar donde las almas cesan y el mundo no ha comenzado todavia, y este resto es lo esencial.

La esfera del Entre se capta en sucesos menudos, momentáneos que apenas se asoman a la conciencia.

El reino del Entre no es ni objetivo, ni sujetivo: es mas allá del individualismo, mas acá del colectivismo
Según Carlos Díaz,

Podemos captar este hecho en sucesos menudos, momentáneos, que apenas si asoman a la conciencia. En la angustia momentánea de un refugio contra bombardeos las miradas de dos desconocidos tropiezan unos instantes, en una reciprocidad como sorprendida y sin conexión; cuando suena la sirena que anuncia el cese de la alarma aquello ya está olvidado, y sin embargo "ocurrio" en un ámbito no más grande que aquel momento. En la sala a oscuras se establece entre dos oyentes desconocidos, impresionados con la misma pureza y la misma intensidad por una melodia de Mozart, una relación apenas perceptible y, sin embargo, elementalmente dialógica, que cuando las luces vuelven a encenderse apenas si se recuerda. (...) Más allá de lo subjetivo, más acá de lo objetivo, en el "filo agudo" en que el "Yo" y el "Tú" se encuentran, se halla el ámbito del "entre"

Según Buber, el Entre es un reino que no es ni objetivo ni subjetivo ni la suma de los dos. Si alguien quita todo lo que pertenece al objeto y todo lo que pertenece al sujeto, todavía quedaría el Entre ${ }^{47}$. En palabras de propio Buber, más allá de lo subjetivo, más acá de lo objetivo, en el "filo agudo" en que el "Yo" y el "Tú" se encuentran, se halla el ámbito del "entre". El reino del Entre va más allá del individualismo y más acá del colectivismo. Individualismo y colectivismo son formidable abstracciones, como dice Buber; son estructuras imaginarias que el ser humano inventa y por eso fracasan según Aldo van Eyck. Buber explica que,

El hecho fundamental de la existencia bumana no es ni el individuo en

\footnotetext{
$46 \quad$ Ibid. 22

47 Robert E. Wood, Martin Buber's Ontology: An Analysis of I and ThouNorthwestern University Press, 1969). 41

48 Carlos Díaz, Introducción Al Pensamiento De Martin Buber (Madrid: Instituto Emmanuel Mounier, 1990). 23
} 
cuanto tal ni la colectividad en cuanto tal. (...) El individuo es un hecho de la existencia en la medida en que entra en relaciones vivas con otros individuos; (...) El hecho fundamental de la existencia humana es el hombre con el hombre. Lo que singulariza al mundo humano es, por encima de todo, que en él ocurre entre ser y ser algo que no ocurre parigualmente en ningún otro rincón de la naturaleza $a^{49}$.

Y más adelante Buber para dar la definición de lo que es la esfera del Entre o del auténtico tercero, dice que las raíces del ser humano están en que un ser busca a otro ser tratando de contactar con él en una esfera común a los dos pero que sobrepasa el campo propio de cada uno $^{50}$.

A esta esfera, que ya está dada con la existencia del ser humano en cuanto ser humano, pero que todavia no ha sido conceptualmente dibujada, la denomino la esfera del Entre. Constituye ella una protocategoría de la realidad humana, aunque es verdad que se realiza en grados muy diferentes ${ }^{51}$.

Según Robert Wood, la noción del Entre conlleva dos elementos significativos. Primero apunta al carácter auto-trascendente del acto cuando uno se relaciona con el Tú. Segundo, apunta a la inaccesibilidad última, i.e, la real otredad del Tứ${ }^{52}$. El Entre es un lugar en el que, como más adelante dice Wood, el Yo - que es auto conciencia-y el Otro manifiesto aparecen simultáneamente ${ }^{53}$. El Entre es el lugar y soporte reales de las ocurrencias interhumanas ${ }^{54}$; el Entre es el lugar de lo interhumano. Y este Entre ocurre y se construye cuando sucede el encuentro verdadero que parece que para Buber es posible a través del amor. El encuentro verdadero sucede cuando no existe ninguna mediación; cuando no se interpone ningún sistema de ideas o imágenes previas o prejuicios; cuando todo medio está abolido acaece el encuentro. Y eso sucede

\footnotetext{
$49 \quad$ Ibid. 22

$50 \quad$ Ibid. 22

51 Buber Martin, “¿ Qué Es El Hombre,” México, Fondo De Cultura (1973).147

52 Wood, Martin Buber's Ontology: An Analysis of I and Thou 41

53 Ibid. 41

54 Carlos Díaz, Introducción Al Pensamiento De Martin Buber (Madrid: Instituto Emmanuel Mounier, 1990). 22
}

La esfera del Entre es la esfera dada con la existencia humana pero todavia no conceptualmente dibujada

El Entre es el lugar de lo interhumano 
El verdadero encuentro sucede cuando las personas son capaces de crear el reino del Entre

cuando existe el amor; porque lo que sucede cuando existe el amor es que se aprecia la totalidad de un ser; se reconoce la alteridad del otro - la otredad - de la misma manera que se reconoce a sí mismo, como ser humano. El lugar del Entre es el lugar donde habita y construye el amor; y el ser humano habita en su amor. En palabras de propio Buber,

A los sentimientos se les "tiene"; pero el amor ocurre. Los sentimientos habitan en el hombre; pero el hombre habita en su amor. No es una metáfora, sino la realidad: El amor no se adbiere al Yo haciendo del Tú un "contenido", un objeto, sino que está entre Túy Yo. Quien no sepa esto, quien no lo sepa con todo su ser, no conoce el amor, aunque atribuya al amor los sentimientos que experimenta, siente, goza o expresa. El amor es una acción cósmica. Para quien habita en el amory contempla en el amor, los hombres se liberan de todo lo que les enlaza a la confusión universal; buenos y malvados, sabios y necios, bellos y feos, todos, uno tras otro, se tornan reales a sus ojos, se convierten en otros tantos Tú, esto es, en seres liberados, definidos, únicos; los ve a cada uno cara a cara. ${ }^{55}$

Es decir, el verdadero encuentro sucede cuando dos personas son capaces

Marcharse uno de si mismo para encontrarse con la otredad en un lugar intermedio

Teatralidad: capacidad de dejar el yo para visitira la otredad. Stavridis de crear el lugar del Entre, el lugar donde habita el amor y se acepta la otredad de cada uno. Dice Buber que únicamente cuando el individuo reconozca al otro en toda su alteridad como se reconoce a si mismo, como hombre, y marche desde este reconocimiento al encuentro del otro habrá quebrantado su soledad en un encuentro riguroso y transformador ${ }^{56}$. Es necesaria, pues, la construcción de un lugar de encuentro con el otro, pero también la transición de un Yo en el espacio común del Entre donde se encuentra otro Yo que es capaz de salir para encontrarse en el espacio creado entre ellos. Dice Stavridis, que uno nunca puede entrar en el lugar del otro; aunque a veces decimos si me pongo en tu lugar nunca entramos al lugar del otro; lo único posible es trazar un lugar entre los dos y conseguir transportarnos en este lugar para encontrar al otro.

Stavridis usa la noción de la teatralidad para describir la manera con la que sucede el encuentro verdadero; el término teatralidad parece que, por primera vez, se 
usa por Barthes quien dice que la teatralidad es el teatro menos el texto ${ }^{57}$; pero, este término en el paso del tiempo tiene muchas interpretaciones y, Stavridis, la usa más bien como la capacidad que uno tiene en salir de su Yo, marcharse, para visitar la Otredad, sea ésta otro u otra cara, otro lado, del mismo para luego volver al lugar de donde empezó. El acto teatral del actor que deja su Yo para encontrarse con Otro y luego volver al suyo. ${ }^{58}$ La teatralidad de Stavridis es la transportación del actor de la que habla Schechner: el actor en su acto se transporta a otro lugar y luego vuelve a su lugar, a sí mismo, a su Yo y a su vida diaria ${ }^{59}$; esta transportación es una habilidad social que permite el verdadero encuentro de lo que habla Buber, pues la persona es capaz de dejar su Yo y fabricar un Yo intermedio que no es ni el suyo ni el del Tú, capaz de habitar en el Entre en el que se encuentra el Tú que no es el Tú sino un Tú intermedio fabricado del Yo del otro lado.

En realidad, la teatralidad de la que habla Stavridis es la capacidad y la habilidad que cada uno tiene de marcharse de su Yo para poder distanciarse tanto de él mismo y reflexionar desde fuera, ver lo que podría ser, como también para crear un espacio común en el que puede comunicarse con otras personas. La teatralidad de Stavridis está defendida en otras palabras por Todorov y Bajtín; Todorov habla de la exotopía y Bajtín de la extraposición; la exotopía es una noción distinta de la extraposición ${ }^{60}$ pero es la palabra que más acerca, según Todorov, al término vnenajodimost de Bajtín. Los dos coinciden en la existencia del tercero: hablan del Yo y del Otro pero creen en la existencia del Tercero; lo interhumano. Escribe Todorov,

Bajtín empieza por la cuestión más simple: nosotros nunca nos vemos a nosotros mismos como un todo; el otro es necesario para lograr, aunque sea provisionalmente, la percepción del yo, que el individuo puede alcanzar sólo parcialmente con respecto a si mismo. Las objeciones posibles se plantean en seguida: ¿acaso en el espejo no se encuentra la visión completa del yo? ¿O, en el caso de un

57 Roland Barthes, Ensayos Críticos Seix Barral, 2002).

58 Stavros Stavridis, De La Ciudad Pantalla a La Ciudad Escena (Atenas: Ellinika Grammata, 2002). 233- 242

$59 \quad$ Ibid. 235

60 Karine Zbinden, "El Yo, El Otro y El Tercero: El Legado De Bajtín En Todorov," Acta Poética 27, no. 1 (2006), 325-339.
Teatralidad: transportación del actor en otro lugar, en otro Yo

La exotopía de Todorov y la extraposición de Bajtín. El lugar del Tercero 
pintor, en un autorretrato? En los dos casos, la respuesta es: $n o^{61}$.

Lo que uno cree que es, no es lo que es

El Tercero no es un ser real sino una instancia trascedental que hace posible la comunicación. Bajtín
Cuando observo a un hombre integro, que se encuentra afuera y frente a mi persona, nuestros horizontes concretos y realmente vividos no coinciden. Es que en cada momento dado, por más cerca que se ubique frente a mi el otro, que es contemplado por mí, siempre voy a ver y a saber algo que él, desde su lugar frente a mí, no puede ver: las partes de su cuerpo inaccesibles a su propia mirada (cabeza, cara y su expresión, el mundo tras sus espaldas, toda una serie de objetos y relaciones que me son accesibles a mí e inaccesibles a él). Cuando nos estamos mirando, dos mundos diferentes se reflejan en nuestras pupilas. Para reducir al minimo esta diferencia de horizontes, se puede adoptar una postura más adecuada, pero para eliminar la diferencia es necesario que los dos se fundan en uno, que se vuelvan una misma persona ${ }^{62}$.

Bajtín más tarde habla sobre la noción del tercero o supradestinatario en su Estética de la creación verbal ${ }^{63}$; en cualquier situación de comunicación el tercero no es un ser real, sino una instancia trascendental, un "ideal" que hace posible y garantiza la posibilidad de comunicación y compresión mutua. Explica Bajtín sobre lo que el tercero es,

El Tercero es la capacidad de ponerse fuera de la posición hermenéutica de uno mismo
El autor del enunciado, con una mayor o menor concientización presupone la existencia de un supradestinatario (tercero), cuya comprensión reciproca, absolutamente justa, se plantea o en una lejanía metafísica, o en un tiempo histórico remoto (el destinatario de escapatoria) ${ }^{64}$

61 Tzvetan Todorov, The Morals of HistoryU of Minnesota Press, 1995). 95

62 Mijaíl Bajtin, "El Autor y El Héroe En La Actividad Estética," M.Bajtin.Hacia Una Filosofía Del Acto Ético.De Los Borradores y Otros Escritos.Barcelona: Anthropos (1997). 28

63 Mihail Mihajlovič Bahtin, Estética De La Creación Verbal Siglo xxi, 1982). 305

64 Mihail Mihajlovič Bahtin, Estética De La Creación Verbal Siglo xxi, 1982).305 
La extraposición o exotopía o el Tercero es la capacidad de ponerse fuera de la posición bermenéutica de uno mismo con el fin de aprehender el problema desde un punto de vista distanciado ${ }^{65}$. Todorov explica el proceso que se requiere hacía el tercero o hacia la exotopía. Es un proceso de cuatro fases distintas: la primera fase es la salida, el primer paso el abandono del yo; el motivo de la salida es la necesidad de uno de salir de su sociedad y de su yo. El segundo paso es la primera aproximación de la otra sociedad; uno se sumerge en su interior e intenta comprender y comunicar, pero lleva el peso de su modo de pensar y actuar y la compresión de la otredad no es fácil. El tercer paso es la vuelta a su lugar, a su yo; pero ahora en su lugar está un extranjero, no es el mismo que él fue antes; si consigue no sucumbir en la esquizofrenia que esta experiencia provoca, dice Stavridis, da la oportunidad a la conciliación con la otredad. ${ }^{66}$ En el cuarto y último paso el nuevo yo, hace una nueva aproximación del otro, distinta de la primera porque los otros ya no son extranjeros, no son algo exótico de su sociedad y con otros principios; desde esta lugar intermedio en el que el ser humano se ha encontrado puede estudiar tanto su sociedad como la de los otros. Así, comenta Todorov, el conocimiento de la otredad no es solamente una posible vía hacia el autoconocimiento, sino la única. ${ }^{67} \mathrm{El}$ encuentro verdadero y la comunicación fructífera sucede cuando los dos seres humanos que participan, son capaces de dar estos cuatro pasos, que conducen a la formación de un espacio intermedio común en el que los dos se identifican. Sin embargo este proceso no se hace de manera instantánea. La teatralidad no es como la imitación; en la primera el ser humano necesita tiempo para hacer los cuatros pasos mientras que en la segunda repite sin reflexionar.

Aldo van Eyck defiende que es humano e importante retrasar y que los arquitectos deben pensar en eso cuando proyectan; ${ }^{68}$ cuando alguien piensa desde el retraso, los umbrales se extienden porque lo deseado es el retraso; el retraso en los lugares donde suceden los encuentros de los varios mundos, sociedades, persona, da

65 Zbinden, El Yo, El Otro y El Tercero: El Legado De Bajtín En Todorov, 325-339 333

66 Stavros Stavridis, De La Ciudad Pantalla a La Ciudad Escena (Atenas: Ellinika Grammata, 2002). 261

$67 \quad$ Ibid. 262

68 Aldo van Eyck, Vincent Ligtelijn and Francis Strauven, Aldo Van Eyck: Writings

(Amsterdam: Sun, 2008). 62
Los cuatro pasos del Tercero, los cuatro pasos del encuentro y de la comunicación con la otredad

La velocidad elimina los lugares del encuentro

La filosofía del umbral comienza después de la aparición de la figura del desconocido 
Extranjero, extraño, y desconocido son figuras intermedia: no son ni amigos ni enemigos

El extranjero perturba la resonancia entre la distancia física y psiquica. tiempo a los participantes para construir el lugar intermedio, el reino del Entre. Al contrario, la velocidad - que puede llegar a una transportación instantánea- elimina el espacio -tiempo intermedio de la comunicación y del encuentro. El comienzo de la filosofía del umbral se debe principalmente a la aparición de la figura del extranjero o del desconocido; antes la otredad podía ser o enemigo o amigo, pero el extranjero no es ni amigo ni enemigo; es una figura intersticial que según Bauman, uno teme más a los extranjeros que los enemigos ${ }^{69}$. Amigos - enemigos es una oposición que deriva de la interior-exterior, y amistad - enemistad son las formas arquetípicas de toda socialidad. Constituyen la estructura dentro de la que la socialidad es posible; delimitan la posibilidad de «ser con otros". ${ }^{70}$ El extranjero entra en la familia de los innombrables de Derrida: aquellos no pueden ser incluidos dentro de la oposición (binaria) filosófica, a la que niega y desorganiza, sin constituir un tercer término sin dar salida a una solución bajo la forma de dialécticas especulativas ${ }^{71}$. Los innombrables, como el extranjero es una amenaza para el orden del mundo y del ambiente seguro. A los amigos uno necesita tenerlos cerca, a los enemigos lejos; pero el extranjero llega a tener una intimidad corporal de grado mayor que con un amigo; en los medios de transportes, ascensores, salas de espera, los cuerpos no se pueden separar entre ellos; pero, aunque se tocan no se sienten, aunque se mezclan no se ven. ${ }^{72}$ Según Bauman,

El extranjero socava el ordenamiento espacial del mundo --de la lucha por la coordinación entre la proximidad moral y topográfica y del estar-juntos de los amigos y del alejamiento de los enemigos. El extranjero perturba la resonancia entre la distancia física y psíquica: él está ffísicamente cerca mientras que espiritualmente se encuentra muy lejano(...) La clasificación binaria desplegada en la construcción del orden no puede recubrir totalmente la experiencia no discreta, continúa de la realidad. La oposición, producida por el horror a la ambigüedad deviene el principal foco de ambivalencia. El esfuerzo de clasificación supone inevitablemente la producción de anomalias. Difícilmente se da una anomalía más anómala

69 Zygmunt Bauman et al., "Modernidad y Ambivalencia," in Las Consecuencias Perversas De La Modernidad. Modernidad Contingencia y Riesgo (Barcelona, España: Anthropos, 1996), 73 119. 94

70 Ibid. 94

71 Gayartri Chakravorty Spivak, “Jacques Derrida of Grammatology,” (1974). 143

72 Richard Sennett, Carne y Piedra: El Cuerpo y La Ciudad En La Civilización

OccidentalAlianza editorial, 1997).344. 
que el extranjero. Este se sitúa entre el amigo y el enemigo, entre el orden y el caos, entre el interior y el exterior ${ }^{73}$.

La anomalía del extranjero conduce a un encuentro anómalo, que es y no es encuentro: el desencuentro, término que es utilizado por primera vez por Buber. ${ }^{74} \mathrm{El}$ desencuentro es la relación de los cuerpos extraños de la ciudad que no es la del enemigo, tampoco la del amigo, sino una relación de lo indiferenciado. El desencuentro sucede cuando uno intenta evitar el otro, enviarle a la esfera de desatención. La técnica del desencuentro es llegar a enviar al otro a la esfera donde se evita cualquier contacto consciente; la esfera de desatención es

el ámbito del no - compromiso, del vacio emocional, inhóspito, tanto para la compansión como para la hostilidad; un territorio inexplorado, desprovisto de letreros; una reserva de vida silvestre dentro del mundo que se desarrolla la vida. ${ }^{75}$

Dentro de las técnicas del arte del desencuentro es evitar el contacto visual con los extraños; poder llegar al estado del ver, pero a la vez pretender no estar viendo; conseguir una mirada inofensiva, que no da paso a un encuentro; no provoca respuesta, reciprocidad; mirada indiferente que no presupondrá derechos y obligaciones mutuas. ${ }^{76} \mathrm{El}$ arte del desencuentro es según Bauman una de las primeras y principales técnicas que sirven para deseticalizar la relación con el Otro. ${ }^{77}$

La ciudad es, para Bauman, un lugar de desencuentros. La técnica del desencuentro, usada por el ciudadano contemporáneo, para su mejor convivencia con el extraño, no permite que un espacio físico se transforme en un espacio social. La arquitectura tampoco ayuda en esa transformación. El espacio físico urbano es tan organizado que los encuentros no intencionalmente buscados se pueden evitar, y si

73 Zygmunt Bauman et al., "Modernidad y Ambivalencia," in Las Consecuencias Perversas De La Modernidad. Modernidad Contingencia y Riesgo (Barcelona, España: Anthropos, 1996), 73 119. 101 - 103

74 Zygmunt Bauman, Ética Posmoderna Siglo XXI, 2005).

75 Ibid. 176

76 Ibid. 176

77 Zygmunt Bauman et al., "Modernidad y Ambivalencia," in Las Consecuencias Perversas De La Modernidad. Modernidad Contingencia y Riesgo (Barcelona, España: Anthropos, 1996), 73 119. 97
El fenomeno y la técnica del desencuentro

Al otro lado de la esfera del Entre, la esfera de la desatención

La ciudad, según Bauman, es hoy un lugar de desencuentros

La arquitectura contemporánea crea lugares de desencuentro. 
En la modernidad, el ambito de los arquitectos no analiza la figura del extranjero y desconocido
El fenomeno del desencuentro elimina los lugares umbratiles; la falta de los lugares de umbral, intermedios, aporta en la expansión del desencuentro

La arquitectura debería concebirse como una configuración de lugares intermedios. no es posible, si son inevitables son de poca importancia. Según Sennet la arquitectura moderna urbana crea lugares de desencuentro; áreas inmensas de espacio vacío, áreas para cruzar, no para usarse, áreas por donde uno pasa, no dentro de las cuales uno permanece ${ }^{78}$; Lever House, en Nueva York, Brunswick Centre, en Londres, la Defensa, en Paris son ejemplos para Sennet. Arquitectos de la tercera generación de los CIAM consideran la arquitectura racional y funcionalista inhumana, precisamente porque no empieza el proyecto desde el encuentro sino desde la función; las necesidades de los seres humanos se estandarizan pero dentro de ellas no está incluida la relación con el extraño. En la modernidad, la naturaleza de la relación con el extranjero no es analizada en los ámbitos arquitectónicos. Esto es porque la arquitectura racional es un pensamiento dual que excluye el intermedio, lo que está entre los términos opuestos. El extraño se queda excluido porque es la encarnación de la ambivalencia y de la contradicción que la modernidad quiso eliminar: no es ni amigo, ni enemigo.

El descuido de la relación que está entre la identidad y la otredad se traduce materialmente en el abandono de los lugares umbrátiles que es donde sucede el encuentro con lo Otro, con lo desconocido y lo extraño; a su vez, el descuido de los lugares intermedios fortalece el fenómeno del desencuentro ya que no deja lugar al encuentro; elimina el lugar donde se encuentran los términos gemelos; reduce el lugar donde se encuentra el tú con el yo. Por eso,

La arquitectura debería concebirse como una configuración de lugares intermedios claramente definidos. Esto no implica una transformación continua o un aplazamiento interminable del lugar y la ocasión. Por el contrario, implica un rompimiento con el concepto contemporáneo (digamos enfermedad) de la continuidad espacial y la tendencia a borrar todas las articulaciones entre espacios, es decir, entre el exterior y el interior, entre un espacio y otro (entre una realidad y otra). En su lugar la transición debe articularse por medio de lugares intermedios definidos que permiten el conocimiento simultáneo de lo que es significativo al otro lado. Un espacio intermedio en este sentido proporciona el terreno común donde las polaridades conflictivas pueden ser fenómenos gemelos ${ }^{79}$.

78 Zygmunt Bauman, Ética Posmoderna Siglo XXI, 2005).179

79 Aldo van Eyck, Vincent Ligtelijn and Francis Strauven, Aldo Van Eyck: Writings (Amsterdam: Sun, 2008). 


\section{Dentro de lo Innombrable, desde el Entre}

\author{
Lo Sin-Nombre es el comienzo del Cielo y de la Tierra \\ Lo que tiene nombre es la madre de todos los seres ${ }^{1}$
}

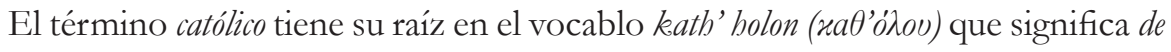
acuerdo con el todo, del todo, universal. Lo especial que tiene esta palabra griega es que significa "del todo" pero a la vez significa no del todo, para nada, de acuerdo con nada; aunque las dos palabras tienen la misma pronunciación, la única diferencia que existe en la escritura de las palabras del todo y para nada, es que en la primera hay un pequeño espacio vacío entre $\theta$ y la $o^{\prime}$,junto con un pequeño símbolo insignificante del lenguaje, la apostrofe ': katholou (rató̀̇ou) significa de nada, kath' holon (rat'ó̀ou) es del todo. El lugar blanco entre las letras $\theta$ y $o ́$ es el que decide cual es la nada y cuál es el todo: cuando falta, estamos en la nada, pero, cuando este insignificante intersticio literal existe, estamos en un todo. Parece tan insignificante el lugar blanco entre letras y las palabras que se leen, pero sin estos intersticios, sería imposible la existencia de una palabra y, si no existieran las palabras, no habría nada que nos distinguiera de los animales; no habrían calles, ni plazas, quizás edificios.

El blanco del papel que soporta las palabras pasa desapercibido pero es lo que permite su construcción; como también pasa desapercibido el blanco del papel que soporta los dibujos arquitectónicos, ya que la mirada se centra en las líneas; interesa el vacío que las líneas crean pero no las líneas que el vacío crea. El modo de sentir el vacío, es decir, la relación presencia-ausencia, es uno de los ejes fundamentales que separa la filosofía china y occidental. Para François Jullien, la originalidad e historicidad del pensamiento europeo se debe a la distancia y la tensión que los griegos crearon entre la

1 Francois Jullien, "La Gran Imagen no Tiene Forma," (2008).45
El todo y la nada distingue el lugar intersticial entre dos letras

El modo de sentir el vacío distingue la filosofía oriental y occidental 
En las palabras presencia y ausencia se escucha la palabra esencia

En Occidente, lo ausente es lo que no tiene esencia, en Oriente es el fondo y fuente de las cosas ausencia y la presencia, lo visible y lo invisible. En la palabra presencia (parousia) y ausencia (apousia) se escucha la palabra esencia (ousia), el Ser, la diferenciación entre presencia y ausencia se refiere a la diferencia entre el ser y el no-ser. Los griegos, según Heidegger, comprendieron la definición de la esencia (ousia) como presencia (parousia); es decir, la presencia consiste en una forma más clara de la esencia ${ }^{2}$ en pocas palabras, lo esencial en Occidente es lo que está presente, visible; lo invisible, ausente, es lo que carece de esencia. En Oriente, lo invisible, aparentemente el vacío de las cosas, es el Fondo de las cosas; Fondo y a la vez Fuente de todos los seres. Fondo: a la vez fondo y fuente, fons y fundus; es lo Sin-forma lo que sirve de fondo a la pintura. (...) lo sin forma no solo precede a lo que tienen forma, como su punto de partida y origen, sino que representa también el fundamento operador, generador, del que procede continuamente ${ }^{3}$.

En la pintura china existen dos términos fundamentales: aquello que posee una figuración (you xiang) y aquello que no tiene forma (wu xing); lo que posee una figuración manifestándose en tanto que "instauración", estableciéndose físicamente, y lo sin forma, de manera previa, en tanto que puro "engendramiento"; lo sin forma constituye el fondo, de donde emana, actualizándose, el despliegue de las figuraciones. Hay que recordar las leyes articuladas por la Gestalt respecto a la figura y el fondo, según las que el campo visual se divide en un Figura significativa y el Fondo insignificante. ${ }^{4}$ Existen algunos filósofos occidentales -principalmente después de Hegel- que ven el vacío como lleno de significación. Platón, aunque padre de dualismo filosófico que empezó años después ${ }^{5}$, habló del concepto de la Khora, que en idioma griego contemporáneo significa espacio pero también el país. La Khora de Platón es el tercer género donde aquí se encuentra todo lo que podría ser; el estado donde una cosa es pero no es; el momento un poco antes de la aparición, los verbos en subjuntivo. Hegel habla de la mediación que es el devenir, el pasaje; entiende que la vida y lo real está en la mediación. El fundamento de lo real no está en el ser sino en su negativo; la identidad para Hegel es mediación. Jacques Derrida habla de un tercer

\footnotetext{
$2 \quad$ Ibid. $24-25$

$3 \quad$ Ibid.43-44

4 Polyxeni Mantzou, "Utilización De Medios Audiovisuales Como Modificadores Del Espacio Arquitectónico” Arquitectura), 397

5 José Ferrater Mora, Dicionário De Filosofia. TOMO I (A-K), Vol. 1 (Buenos Aires: Editorial Sudamericana, 1971).
} 
género - Différance - que es la fuerza que distingue las cosas. ${ }^{6}$

En China, el término vacío no fue nunca entendido como carente de sentido; porque los chinos nunca piensan y hablan en términos de presencia-ausencia; para ellos la vida y las entidades están basadas en el acto de la respiración. En Oriente, el ser y el no-ser no son conceptos u objetos diferentes, visible e invisible no son términos opuestos, el mundo no consiste en una dualidad. La distinción entre el ser y no-ser, entre el hay y no-hay, remite a una diferencia de fase en el advenimiento del proceso de las cosas. Wang Bi en el siglo III comenta que (...) todo lo que hay tiene su comienzo en el no-hay;(...) El hecho de que ese "no-hay" originario del fondo indiferenciado, sea, no ya la nada, sino aquello de donde no dejan de proceder, diferenciándose, las individualidades particulares (...) lo convierte en punto de partida de sabiduría. Según Laozi; el hay y el no hay, poseen el mismo origen y esta comunidad del origen expresa lo Indiferenciado, allí donde se encuentran lo actualizado y lo que aún no lo está. 7

\section{En el mundo, todos los seres nacen del hay}

$Y$ el hay nace del no-hay ${ }^{8}$

China, considerando fundamental el fondo, fuente del todo, presenta lo indefinido, lo sin forma, en el fondo en su pintura. En occidente se intenta, durante mucho tiempo la fiel representación de lo visible; por eso, se usa más el término representación que presentación. La mayoría de pintores occidentales, en el dibujo de sus paisajes, se interesan por los momentos del día en los que el sol está en un lugar desde donde su luz define los límites entre las cosas perfectamente: el paisaje del mediodía, cuando los contornos son definidos, las sombras precisas y los trazos se destacan. ${ }^{9}$ En el paisaje griego las formas se recortan por la luminosidad transparente que crea una identidad esencial propia. En China, la pintura quiere presentar, hacer presente, lo que está invisible entre las cosas y los sujetos; Se interesa por los momentos transitorios del paisaje, en los que sucede el cambio y la transformación, cuando un estado se va

6 Ivan Flores Arancibia, "Pensar El Entre, Contribuciones Para Una Crítica De La Razón Intersticial” 2010)..

7 Francois Jullien, "La Gran Imagen no Tiene Forma," (2008).46

$8 \quad$ Ibid. 46

$9 \quad$ Ibid. 20
China no piensa en la ausencia y la presencia; el ser y el no-ser no se distinguen

La pintura occidental en su comienzo intenta pintar las cosas, las formas claras, y no lo que está entre las cosas, el fondo. 
China pinta la transformación, los momentos transitorios.

China pinta el no -objeto, el difuso fondo de las cosas

El no-objeto, como elemento arquitectónico, sería lo que está entre los edificios y viene otro: los momentos del atardecer y del amanecer, donde sucede el encuentro entre los términos opuestos del día - la noche, la luz -la oscuridad. En estos momentos, los límites se diluyen, lo de-finido se hace in -definido: las formas adquieren tonos nimbados y oscuros a la ver, y poco a poco se vuelven indecisas. ${ }^{10} \mathrm{El}$ pintor chino dibuja el mundo sumergiendo y emergiendo, o en su quietud; pinta entre el haber y no-haber, you y wu; no intenta inmovilizarlo como Ser y determinarlo como objeto; ${ }^{11}$ busca aproximarse al no-objeto, que es:

(...) de lo que la búsqueda es vana e inconcebible; eso que es demasiado borroso -vago-difuso-evanescente-confuso para dejarse inmovilizar y aislar; que se halla sumido en lo indiferenciado, que no es ni asignable ni tampoco representable, que no puede tener por tanto la consistencia de un en sí, que no puede constituirse de "ser", y, Gegenstand, no puede "erguirse delante" - recortando su perfil - del Ojo o del Espíritu; eso que experimentamos sin cesar y que nos reconduce a la indefinición de lo innato, pero que la ciencia y la filosofía abandonaron muy pronto en su empeño por tratar lógicamente las cosas; en su empeño de construir un "esto", manipulable por el pensamiento, con vistas a responder al interrogante "¿Qué es?(...)"; es lo inobjetivable "fondo de las cosas", que abandonado por la ciencia y la filosofía, se ha vuelto tan difícil recuperar en la gran lengua europea.(...) es aquello que no puede ser referido, no pudiendo describir(lo), ni concebir(lo), sino solamente delimitar(lo): giro a su alrededor. (...) lo fundamental, pero que no es nunca lo mismo (pues carece de esencia) $)^{12}$

El no-objeto, lo que está entre nosotros aparentemente ausente, lo que experimentamos sin cesar, lo que está entre los edificios es una de las razones por las que el urbanista Camilo Sitte se sitúa en contra del el Movimiento Moderno y el urbanismo neoconservador que empieza en el siglo XIX. A Sitte le interesa lo que está entre los edificios y no sólo la forma que tienen. Según él, en el pasado lo que estaba entre los edificios, lo invisible de la superficie no edificada, lograba efectos de unidad y de encuentro; los lugares vacíos libres son más importantes que los edificios porque es

$10 \quad$ Ibid. 20

$11 \quad$ Ibid.21

12 Ibid.11-13 
donde los habitantes se encuentran; son los lugares de votos y de celebraciones que el urbanismo racional considera espacios sobrantes;

En la urbanización moderna resulta inversa la relación entre superficie edificada e inedificada. Antes, el espacio libre era un conjunto cerrado, que se calculaba teniendo siempre como fin lograr efectos de unidad. Hoy parcelanse los solares en figuras regulares cerradas y a lo que sobra, llamamos calles y plazas (... $)^{13}$.

En la modernización, según Sitte, las plazas dejan de ser el lugar del encuentro y de las celebraciones para convertirse en un lugar para el aire y el descanso de las masas. En sus propias palabras:

\section{(...) la significación de las plazas abiertas en medio de la ciudad, hoy se} las emplea muy poco para las grandes fiestas públicas, y cada vez. menos en el uso diario, siendo con frecuencia su fin único, procurar más aire y luz̧ interrumpir la monotonía de la masa de casas, y quizá hacer resaltar plenamente algún edificio monumental, permitiendo su libre contemplación ${ }^{14}$

Todo en la ciudad parece depender de la geometría. Como comenta Sitte, ya nadie piensa en cómo tiene que colocar los monumentos para que tengan un sentido para los ciudadanos y la historia de la ciudad, como lugar para el encuentro de los habitantes; las disposiciones de los monumentos, las plazas y los edificios se hace de manera geométrica. A Sitte, no le parece importante el espacio geométrico sino el espacio existencial y el espacio del encuentro; percibe que el nuevo urbanismo diseña y construye la ciudad según líneas rectas dentro de una retícula; líneas que pueden producir lugares cómodos para los coches pero los habitantes son abandonados. Sobre los espacios amplios y vacíos escribe Sitte:

(...) un espacio libre en el interior de una ciudad evolucionó hasta formarse en plaza (...) pero desde el punto artístico, un trozo de terreno vacio no es aún una plaza (...) las enormes plazas con su desolador vacio y su tedio deprimente, contagian aún a los

13 Camillo Sitte, Construcción De Ciudades Según Principios Artísticos, trans. Emilio Canosa (Barcelona: Editorial Canosa, 1926).

14 Ibid.
Para Camilo Sitte, la arquitectura del siglo XIX no piensa en lo que está entre los edificios

Las plazas dejan de ser lugar de encuentro y se hacen lugares para el aire.

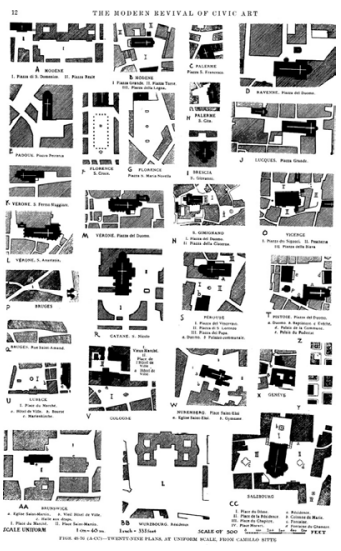

Sitte: dibujando lo que está entre los edificios

El urbanismo neoconservador se centra en la geometría y no en el encuentro. 
moradores de las ciudades cómodas y discretas, de la tan en boga agorafobia ${ }^{15}$.

La esencia de los planteamientos de Sitte está en la importancia que da a lo informal en la vida, a lo que está entre los edificios más alla de la geometría, la función de la plaza y la calla como lugar de encuentro

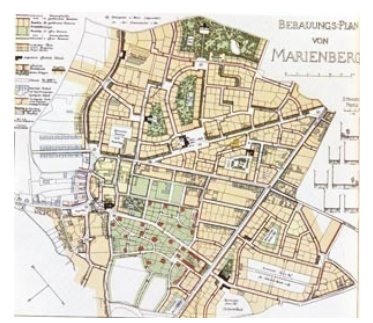

ampliación de la ciudad Marienberg por Camilo Sitte
Hasta hoy en día, pocas obras escritas se podían encontrar sobre los planeamientos, las investigaciones y las teorías de Sitte. En estos pocos libros se pueden hallar detalles de sus obras y de los arquitectos seguidores de Sitte que desarrollaron su planeamiento sensible, abierto, democrático y romancista. George Collins y Christiane Collins, realizaron una investigación exhaustiva por su gran interés sobre Camillo Sitte buscando los criterios y las "reglas" de Camillo Sitte, como ellos dicen, y la publicaron de 1965 - en 1980 en español - bajo el título Camilo Sitte y el Nacimiento del Urbanismo Moderno/ Construcción de Ciudades según Principios Artísticos. En este libro se presenta al arquitecto finlandés Eliel Saarinen (1873-1950) que hizo un resumen del libro de Sitte antes de que apareciera la edición en Estados Unidos en 1945. Saarinen compara los planeamientos totalitarios de Haussmann con el planeamiento humanista de Sitte y concluye que la esencia de los planeamientos de Sitte se concentran en la importancia de lo informal en la vida de los habitantes, en la importancia de lo que está entre los edificios intentando encontrar una coherencia entre las unidades edificadas más allá de la relación geométrica entre ellas y finalmente, la importancia de la función de las plazas y las calles de la ciudad frente a los grandes espacios. Saarinen, en su introducción a la versión de 1945 insistió que Sitte habia sido pionero al situar la expresión de los condicionantes actuales por encima de cualquier estilo formal en particular; (algo) que Sitte realmente babia dicho (... $)^{16}$. Parece que las teorías de Sitte hoy son la base para muchos proyectos humanistas que empiezan desde la caída del planeamiento racional y son los primeros trazos para el desarrollo del movimiento de las ciudades jardines. De las obras de Sitte, se pueden mencionar la ampliación de la ciudad de Marienberg y de Lubin y la Ringstrasse en Viena, así como sus dibujos sobre la disposición de los edificios en el espacio urbano según el espacio que se queda entre ellos.

Los planeamientos de Sitte son acogidos por urbanistas alemanes creando una escuela que se distancia de los planeamientos racionalistas de la época. Cornelius

\footnotetext{
$15 \quad$ Ibid. 2

16 George R. Collins, Christiane C. Collins and Camillo Sitte, Camillo Sitte y El Nacimiento Del Urbanismo Moderno: George R. Collins y Christiane C. Collins. Construcción De Ciudades Según Principios ArtísticosGustavo Gili, 1980).107
} 
Gurlitt, T. Goecke, K. Henrici, T. Fischer son seguidores de Sitte. ${ }^{17}$ Es reseñable el proyecto del sittesco Friedrich Puetzer (1871-1922), alumno de Henrici, para una ciudad jardín en Darmstad. Collins pone los dos dibujos el uno al lado del otro, para mostrar en primer plano la diferencia que hay entre el trazado provocado por la ley del mínimo esfuerzo, la que siguió el proyectista encargado oficialmente del trazado del barrio y al lado, el plano de Puetzer por el que se queda tan fascinado, que escribe - después de una extensa descripción del proyecto. No es posible mencionar todos los detalles bellos que hay en este Plan, por lo que es mejor dejar al lector que los descubra por si mismo. Como cada calle tiene su propia personalidad, sería demasiado largo describirlas una por una. ${ }^{18} \mathrm{El}$ autor del planeamiento considera que como el barrio no tendrá mucho tráfico en su interior, es adecuado dejar curvas pintorescas y dar más ancho a las vías principales que lo rodean. Como dice Collins, todo su arte está en la disposición de las plazas; añadimos, que también está en el hecho de permitir que cada calle tenga su personalidad: ninguna es exactamente igual que la otra. No existen edificios aislados - edificios objetos dentro de una amplitud infinita, tan característicos del movimiento moderno - sino que se unen en parcelas. La alienación de las viviendas no sigue de manera estricta la calle sino que la calle hace una alineación cóncava, despegándose de las casas y así se ven mejor las fachadas y se logra calidad de espacio. Tampoco los paseos arbolados son exagerados, sino que los árboles se plantan en lugares donde mejor pueden crecer y como dice Collins, (...) se han planeado en los lugares donde los árboles pueden crecer mejor y serán plantados con el espesor suficiente para que visualmente presenten masas compactas de follaje y den una sombra acogedora a los que circulen por aquéllos ${ }^{19}$. El planeamiento del barrio según principios artísticos y finales pintorescos es obvio según Collins, por el diseño de las calles en diálogo visual con los edificios. Gracias al ingenioso diseño de las calles, sólo cuando se llega a poca distancia se puede ver toda la iglesia y su aguja, que surge por encima de la nave y de las mansiones que la rodean; será un final pintoresco para más de una calle ${ }^{20}$.

17 Paolo Sica et al., "Historia Del Urbanismo" INAP, 1981). 46

18 Collins, Collins and Sitte, Camillo Sitte y El Nacimiento Del Urbanismo Moderno: George R. Collins y Christiane C. Collins. Construcción De Ciudades Según Principios Artísticos107

$19 \quad$ Ibid.107

$20 \quad$ Ibid. 107
Seguidores de Sitte

El caso del proyecto de una ciudad de jardín en Darmstad de Friedrich Puetzer

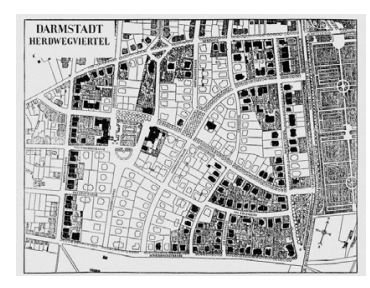

ciudad de jardin en Darmstad de Friedrich Puetzer 
La calle para los Smithson no es solo un espacio para la circulación sino un espacio de estancia

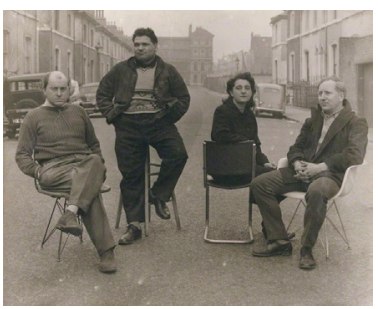

Los Smithson con Nigel Henderson y Eduardo Paolozzi. Imagen - participación en la Exposición This is tomorrow, Whitechapel Art Gallery, 1956

El Espacio -Entre, the Space Between, de los Smithson
El concepto que los Smithson tenían sobre el papel de la calle, se hace explícito en la imagen en la que participan con Nigel Henderson y Eduardo Paolozzi en la exposición This is tomorrow en Whitechapel Art Gallery en 1956: en la mitad de la calle Limerston de Londres, cuatro personas sentadas en sillas, como si la calle fuera un espacio de la casa, un salón. Para los Smithson la calle tiene que ser vista no como un espacio necesario para la circulación de vehículos y habitantes, sino como un espacio de estancia, un espacio intermedio. Alison y Peter Smithson se interesaron no en los objeto, sino en lo que está entre los objetos; entre los edificios. Un poco antes del último congreso de los CIAM en Otterlo, los Smithson envían un texto nombrado Statement of problems regarded as central to architecture in the present situation en el que presentan los problemas básicos de las ciudades de la época y se refieren de manera indirecta al no-objeto, a lo que está entre los objetos. Hablan de las infraestructuras de la ciudad - espacio entre los edificios - mostrando su admiración hacía los diagramas de trafico de Luis Kahn para la ciudad de Filadelfia y sostienen son como fuerzas unificadoras. En general, la definición de técnicas de edificios-ciudad puede hacer una comunidad más comprensible. Estas técnicas consisten en desarrollar las carreteras y los sistemas de comunicación como infraestructuras urbanas o autovias como una fuerza unificadora ${ }^{21}$.

Es en 1974 cuando por primera vez los Smithson utilizan el término espacio entre o espacio intermedio (space in-between) en un texto dedicado a trabajo de Luis Kahn nombrado The Space Between en la revista Opossitions. En este texto los Smithson hablan del misterio y de la extrañeza como un factor importante en la arquitectura; consideran que el aire vacío - el que está entre nosotros - está cargado de energía y de misterio que se mueve hacia el interior y hacía el exterior. Los editores de la revista Oposiciones, acompañan el texto de los Smithson con una introducción que muestra la transición del interés por parte de los Smithson de los edificios -su preocupación en la primera modernidad - al espacio que está entre ellos. Si la arquitectura moderna puede tener algún efecto sobre la construcción del futuro debe ser mirada desde la capacidad de regeneración de sus ideas. Una de esas ideas es la potencial mediación de los nuevos edificios con los viejos a través de lo que puede

21 Smithson, Alison y Peter: Statement of problems regarded as central to architecture in the present situation, Architectural Archives of the University of Pennsylvania, 1959, Louis I. Kahn Collection. Antonio Juárez Chicote and Fernando Rodríguez Ramírez, "El Espacio Intermedio y Los Orígenes Del TEAM X," (2014). 
ser llamado "el espacio intermedio"22. Más tarde, en 1981, en el texto Space is de American Mediator or The Blocks of Ithaca: Especulations ${ }^{23}$ presentan de forma más clara lo que el "espacio entre" o espacio intermedio es: el distanciamiento, el intervalo. Ellos dicen que la diferencia del urbanismo americano con el urbanismo europeo, yace en que el segundo usa como elementos de conexión muros, escaleras, columnatas, mientras que, para el urbanismo americano, la mediación entre los edificios depende de la variación del intervalo. ${ }^{24}$ La filosofía del "entre" es obvia en el edificio de la revista The Econimist en Londres terminado en 1965 - edificio cuya demolición fue autorizada por el London Country Council. En la urbanización Robin Hood Gardens - terminada en 1962 y con su demolición programada ${ }^{25}$ - se encuentran las calles en el aire (streets in the air). Se traslada la calle a la altura de los accesos de las viviendas del edificio, considerando siempre que la calle no es solamente un medio de acceso, sino también un escenario para la expresión social?" extienden de alguna manera los umbrales de las casas y empiezan así su "filosofía del umbral"'.

Las infraestructuras y las megaestructuras trabajan a partir del entre, del vacío en el que estamos sumergidos. El interés por las infraestructuras es común a toda la generación de arquitectos que heredan la fascinación de sus maestros por el tamaño y la velocidad derivados de la industrialización. La condición del espacio infraestructural como espacio no atendido por la disciplina revela su incorporación casi obligada a este listado inicial de espacios intermedios. Su operatividad puede ser objeto de estudios posteriores $^{27}$ Fumiko Maki trabaja con el "entre" cuando busca las tres formas de las ciudades en su Collecti. Form. Three Paradigmes. La lógica infraestructural se halla en las obras Fumihiko Maki en las Investigations in Collective Form, en Reyner Banham en Megastructure, o en Shadrach Woods en The Man in the Street durante los 60 y 70;

22 Nota introductoria de los redactores de la revista Oppositions, que abre el texto de Smithson, Alison y Peter: “The Space Between”. En Oppositions. Octubre, 1974. Nueva York: Insitute for Architecture and Urban Studies. 1974. Ibid.

23 Fernando quesada, Comunidad Común Comuna (España: Asimétricas, 2015).173

$24 \quad$ Ibid. 173

25 "MP Calls for Robin Hood Gardens’ Demolition After Failed Listing Bid “, accessed 1/12/2016, 2016, http://www.dezeen.com/2015/08/05/politician-calls-immediatedemolition-robin-hood-gardens-listing-bid-fails-historic-england-brutalism/.

26 Alison Smithson and Peter Smithson, Urban Structuring Studio Vista London, 1967).15

27 Ibid. 15 
El vacío en la arquitectura japonesa es el campo de posibilidad del mundo

Los términos Ma y $\mathrm{Ku}$

El fondo indiferenciado, lo sin forma, es lo innombrable más recientemente, en Stan Allen en Points + Lines, en Edward Soja en Postmetropolis o Frei Otto en Occupying and Connecting.

La lógica infraestructural como lógica relacional o la lógica de la movilidad de los Team X, de Toyo Ito y en general de toda la cultura japonesa se centra en el vacío como la vacuidad como el campo de posibilidad del mundo, el campo de posibilidad del ser de las $\operatorname{cosas}^{28}$.(...) El vacio representa para Japón la estructura relacional o no-substancial de las cosas del mundo la condición de posibilidad de todas las cosas, es la fuente del movimiento. ${ }^{29}$ Palabras claves de la filosofía y arquitectura japonesa es el Ma y Ku. En dicha arquitectura japonesa el espacio Kukan significa un lugar vacio, agujero en el universo o el cielo. Ku en japonés significa el fondo, el vacio, lo abierto, pero este vacio no es simplemente lo negativo de las cosas sino el modo originario del todo, la condición a que debemos aspirar ${ }^{30}$. Ma se define como la distancia natural entre dos o más cosas que existen en una relación de continuidad y también como pausa o intervalo entre dos o más fenómenos que ocurren en continuidad. Ma y Ku en la cultura japonesa expresan el territorio intermedio entre espacios temporales, físico y espirituales. El Ma son espacios de significación espiritual o filosófica que responde a la necesidad de reposo mentaly desapego. ${ }^{31}$ El Ma subraya la forma es vacio y el vacio es forma.

El Ma y Ku son el fondo Indiferenciado de las cosas, el no-objeto de François Jullien: el no-hay, lo sin-forma pero fuente de todo lo que hay. Laozi nombra el Fondo indiferenciado, de lo invisible, desde donde salen y se pierden las figuras como innombrable, ${ }^{32}$ el fondo, lo sin -forma, escapa de todas las determinación de esencia y se pierde en cuanto aparecen la especificaciones que conducen a las disyunciones (ser/ no-ser, hay / no-hay, etc.); no se trata de un Ser sino de la Via, Tao, porque las formas y los seres adviniendo y reabsorbiéndose, "actualizándose" y "regresando", siguen la vía de esta inmanencia:

Lo Sin-Nombre es el comienzo del Cielo y de la Tierra

Lo que tiene nombre es la madre de todos los seres ${ }^{33}$

$\begin{array}{ll}28 & \text { Casa Asia, Los Arquitectos De La Nada (Barcelona: Casa Asia, 2014).27 } \\ 29 & \text { Ibid. } 27 \\ 30 & \text { Ibid. } 28 \\ 31 & \text { Ibid. } 27 \\ 32 & \text { Jullien, La Gran Imagen no Tiene Forma } 44 \\ 33 & \text { Ibid. } 45\end{array}$


¿Cuál es la naturaleza del sin forma de la que depende la forma pictórica, sobra la que ésta se apoya y que se insiste en imitar? ${ }^{34}$ pregunta Jullien. Lo invisible de lo fundamental no puede gozar de un estatus ontológico puesto que "no tiene forma", y, por consiguiente, no da lugar a la determinación de la esencia, eidos (...) lo sin forma no corresponde a lo in-forme- no puede ser considerado solamente como lo a-morfo, o la nada, o lo abierto, caos $^{35}$.

El no-objeto, el fondo indiferenciado no puede tener un nombre, no tiene forma y escapa a todas las de - limitaciones, es decir las de-finiciones. Lo sin forma es lo que no tiene fin, no tiene una definición; no se puede delimitar por no tener límites, forma; lo innombrable, porque no tiene nombre. El vocablo definición en griego es, orismós (o@ıбuós). Orismos tiene la misma raíz que la palabra orio (ó@ı), que en español significa límite; óros (ó@os) que equivale a término; sínoro (oúvo@o) que significa frontera; etimológicamente la frontera en griego es la síntesis de dos límites, el lugar del encuentro de ambos: sin - oro y sin -tesis. La definición (orismos) tiene la misma raíz que la palabra orizontas, que en español es horizonte. El horizonte en griego (orizontas) tiene dos significados: el del idioma español, pero además, horizonte es el gerundio del verbo delimitar, definir; el gerundio conlleva una acción que no está definida ni por el tiempo, ni el modo, ni el número ni la persona. ${ }^{36} \mathrm{El}$ horizonte, es un acto: que consiste en trazar continuamente un cerco gnoseológico o lingüístico en el seno del cualpuede haber conocimiento y hablar con sentido, indicándose asimismo, aquel ámbito allende el confin en donde el conocimiento incurre necesariamente en antinomias y paralogismos y el lenguaje en proposiciones carentes de sentido. Este cerco es, el propio mundo. Y el límite que define lo que puede conocerse o decirse es, por lo tanto, el límite del mundo. Más allá subsiste aquello en donde no hay ya lugar a conocimiento ni a decir con sentido (...) lo que desborda el cerco y el confin: el otro mundo ${ }^{37}$.

El límite que define lo que puede conocerse o decirse es el límite del mundo

El horizonte, el límite que divide lo conocido y lo desconocido, el sentido con el sin

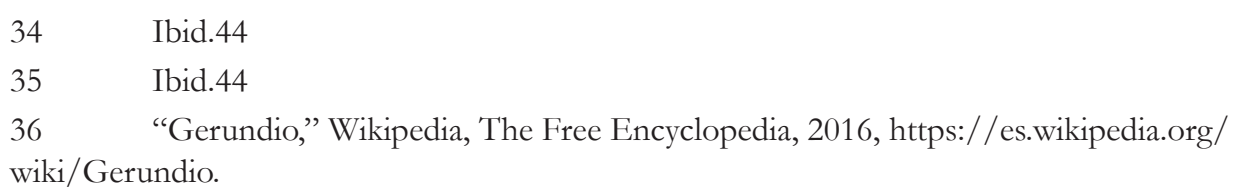


Los limites del mundo somos nosotros.

En el límite sentimos vertigo; el lenguaje clasifica para reducirlo

Clasificar es trazar límites, de-finir sentido es el cerco gnosiologico y linguistico que trazamos nosotros; somos el límite del mundo.

Los limites del mundo somos nosotros, con un pie implantado dentro y otro fuera. Somos los límites mismos del mundo ${ }^{38}$.

Como habitantes del límite sentimos vértigo: de una parte está el hogar y de otra el abismo. ${ }^{39} \mathrm{El}$ lenguaje (nosotros) para eliminar la ambivalencia (vértigo) clasifica, dice Bauman. La clasificación intenta eliminar la ambivalencia: su realización es verificada en virtud de las nitidas divisiones en clases, de la precisión de sus limites definitorios y de la univocidad con la que los objetos pueden ser distribuidos por clases $^{40}$. En la ambivalencia algo puede pertenecer a más de una categoría; la posibilidad de referir un objeto o suceso a más de una categoría, es el correlato lingüistico especifico del desorden: es el fracaso del lenguaje en su dimensión denotativa (separadora $)^{41}$. El lenguaje se esmera en mantener el orden y negar la arbitrariedad inesperada y la contingencia ${ }^{42}$. Clasificar significa crear límites dentro de los cuales entran entidades de mundo distintas; clasificar es definir, delimitar; dibujar lugares que alojan entidades similares y que se separan de otras diferentes.

clasificar dice relacionar patterns diferenciales de acción con diferentes clases de entidades (la evocación de un específico patrón de conducta se convierte en el criterio de definición de la clase). Clasificar, en otras palabras, es dotar al mundo de una estructura: manipular sus probabilidades; hacer algunos sucesos más verosímiles que otros; comportarse como si los sucesos no fueran casuales o limitar o eliminar la arbitrariedad de los acontecimientos ${ }^{43}$.

\footnotetext{
$38 \quad$ Ibid. 45

$39 \quad$ Ibid. 44

$40 \quad$ Zygmunt Bauman et al., "Modernidad y Ambivalencia," in Las Consecuencias Perversas De La Modernidad. Modernidad Contingencia y Riesgo (Barcelona, España: Anthropos, 1996), 73 119. 75

$41 \quad$ Ibid. 73

$42 \quad$ Ibid. 74

$43 \quad$ Ibid.74
} 
Clasificar, supone poner aparte, excluir e incluir ${ }^{44}$.En occidente las clasificaciones son propias de una arquitectónica dual; dividir el mundo en términos opuestos; en dos entidades: las que corresponden al nombre y las que no. Determinadas entidades pueden ser incluidas en una clase -hechas una clase- sólo en la misma proporción en que otras entidades son excluidas, apartadas ${ }^{45}$.

Los innombrables de Derrida son los inclasificables; ${ }^{46}$ los que no pueden entrar en ninguna de las categorías y se quedan entre ellas. Un innombrable para Derrida es la palabra Pharmakon cuyo significado en griego es tanto remedio como veneno, pero no es ni remedio ni veneno, ni Dios ni diablo, ni interior ni exterior(...)es algo poderoso en virtud de su ambivalencia y ambivalente en virtud de su poder ${ }^{47}$. Otra palabra de esta familia, es la palabra griega bymen que significa tanto membrana como matrimonio, se refiere al mismo tiempo a la virginidad y a su violación. La palabra suplemento, que en francés significa adición y sustitución; no es un más o menos, ni un exterior ni el complemento de 'un interior, ni acción, ni esencia, etc. ${ }^{48}$ Los innombrables, dice Bauman, son todos los ni esto/ ni aquello. Su indeterminación es su poder; no son nada y pueden ser todo. Las oposiciones proporcionan conocimiento y acción; los innombrables las paralizan ${ }^{49}$.

Innombrable, en el ámbito arquitectónico, puede referirse a elementos de doble función, los elementos reminiscentes, los elementos retóricos y los edificios multifuncionales de los que habla Venturi. El edificio multifuncional es aquel que es complejo en el programa y en la forma, aunque es fuerte en su totalidad. Lo "aunque" es para Venturi siempre una indicación de la ambigüedad. El edificio multifuncional es un edificio ambiguo. El edificio multifuncional por antonomasia llevado al extremo es, para Venturi, el Ponte Vecchio: el puente más antiguo de Florencia sobre el que se construyeron viviendas. Este puente es utilizado por comerciantes, ya que las tiendas
En Occidente domina la clasificación dual

Los innombrables de Derrida: lo que no se puede clasificar, nombrar

Innombrables, puentes habitables

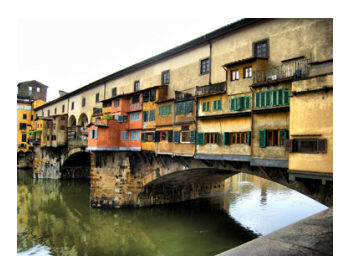

Ponte Vecchio, Florencia

44 Gayartri Chakravorty Spivak, "Jacques Derrida of Grammatology," (1974).143

45 Zygmunt Bauman et al., "Modernidad y Ambivalencia," in Las Consecuencias Perversas

De La Modernidad. Modernidad Contingencia y Riesgo (Barcelona, España: Anthropos, 1996), 73 -

119. 75

$46 \quad$ Ibid. 100

47 Jacques Derrida, Dissemination, trans. Barbara Johnson (London: Athlone, 1981).

71,99

48 Jacques Derrida, «Positions. Trad. Alan Bass,» (1987). $42-43$

49 Zygmunt Bauman et al., "Modernidad y Ambivalencia," in Las Consecuencias Perversas

De La Modernidad. Modernidad Contingencia y Riesgo (Barcelona, España: Anthropos, 1996), 73 119. 96 


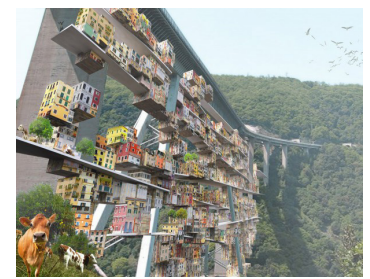

Modern Pont Vecchio, Ja Studio

Lo innombrable es el elemento que no debería existir; cuestiona el mundo

Lo innombrable no se puede eliminar

Zoe viene del idioma griego y significa Vida. La Ciudad Vida de Italo Calvino es la Ciudad de lo Innombrable

que están ubicadas en el puente están libres de impuestos. Hoy en día el Ponte Vecchio sigue siendo un pasaje comercial en el que las casas están destinadas a como joyerías y talleres. Existe una gran variedad de puentes habitables, como el puente-castillo de Chenonceau; el Krämerbrücke de la ciudad Turingia de Erfurt, en Alemania; el Pont de Rohan,en Landerneau, al noroeste de Francia; el puente habitado cubierto en la ciudad de Lovech, en Bulgaria; el Pont des Marchands en Narbonne, en Francia y el puente Pulteney en Reino Unido, diseñado por Robert Adam; propuestas de ciudades informales como el Modern Pont Vecchio de Ja Studio. Dentro de los Innombrables están el Dadaismo, la Internacional Letristas, Henri Michaux.

Los innombrables son el tercer elemento que no debería existir, pues el pensamiento racional, binario y aristotélico excluye el tercer lugar. Ellos no cuestionan sólo esta oposición aqui y abora: cuestionan las oposiciones, el principio de la oposición, la plausibilidad de la dicotomía que sugiere y la posibilidad de separación que demanda. Desenmascaran la frágil artificialidad de la división. Destruyen el mundo $0^{50}(. .$.$) no pueden ser incluidos dentro de la oposición (binaria)$ filosófica, a la que niega y desorganiza, sin constituir un tercer término sin dar salida a una solución bajo la forma de dialécticas especulativas ${ }^{51}$. Pero los innombrables no se pueden eliminar; la ambivalencia no es una patología del lenguaje, sino más bien una de las principales funciones del lenguaje: la de nombrar y clasificar $^{52}$. La ambivalencia es inevitable en el acto de la clasificación; y si no lo fuera, todo permanecería igual. La vida es ambigüedad que el lenguaje intenta clasificar para superar el vértigo que cuando muestra sus límites.

En la Ciudad de Zoe, dice Italo Calvino no existe clasificación; carece de topónimos y cualquier lugar puede transformarse para otro uso. La falta del “entre lo de dentro y lo de fuera" hace que no haya ningún lugar estable ni permanente; todo en esta ciudad es y a la vez no-es. La palabra Zoe es griega, y significa $V i d a$. La vida y el entorno no se hacen de dualidades; en la vida no existe ni arriba, ni abajo, ni dentro, ni fuera ni tu ni yo. Como dicen Aldo van Eyck y Martin Buber, las dualidades y las clasificaciones

\footnotetext{
$50 \quad$ Ibid. 100

51 Spivak, Jacques Derrida of Grammatology143

52 Zygmunt Bauman et al., "Modernidad y Ambivalencia," in Las Consecuencias Perversas De La Modernidad. Modernidad Contingencia y Riesgo (Barcelona, España: Anthropos, 1996), 73 119.73
} 
son abstracciones de la mente. ${ }^{53}$ La vida es lo que está entre las clasificaciones que uno hace; formar una vida, se dice en español; formar una vida es dar forma al uniforme fondo de las cosas; clasificarlo, definirlo y nombrarlo.
La vida es lo que está entre las clasificaciones, entre las dualidades

\section{La Ciudad Zoe (Vida)}

El hombre que viaja y no conoce todavía la ciudad que le espera al cabo del camino, se pregunta cómo será el palacio real, el cuartel, el molino, el teatro, el bazar. En cada ciudad del imperio cada edificio es diferente y está dispuesto en un orden distinto; pero apenas el forastero llega a la ciudad desconocida y echa la mirada sobre aquel racimo de pagodas y desvanes y cuchitriles, siguiendo la maraña de canales, huertos, basurales, de pronto distingue cuáles son los palacios de los príncipes, cuáles los templos de los grandes sacerdotes, la posada, la prisión, el barrio de los lupanares. Así--dice alguien-- se confirma la hipótesis de que cada hombre lleva en la mente una ciudad hecha sólo de diferencias, una ciudad sin figuras y sin forma, y las ciudades particulares la rellenan. No es asi en Zoe. En cada lugar de esta ciudad se podría sucesivamente dormir, fabricar arneses, cocinar, acumular monedas de oro, desvestirse, reinar, vender, interrogar oráculos. Cualquier techo piramidal podría cubrir tanto el lazareto de los leprosos como las termas de las odaliscas. El viajero da vueltas y vueltas y no tiene sino dudas: como no consigue distinguir los puntos de la ciudad, aun los puntos que están claros en su mente se le mezclan. Deduce esto: si la existencia en todos sus momentos es toda ella misma, la ciudad de Zoe es el lugar de la existencia indivisible. ¿Pero por qué, entonces, la ciudad? ¿Qué línea separa el dentro del fuera, el estruendo de las ruedas del aullido de los lobos? ${ }^{54}$

53 Aldo van Eyck, Vincent Ligtelijn and Francis Strauven, Aldo Van Eyck: Writings (Amsterdam: Sun, 2008).

54 Italo Calvino, Las Ciudades Invisibles (Barcelona: Minotauro, 1983). 
La pintura china tiene como objeto el no-objeto porque la vida es lo que está transformándose, lo que está entre las cosas.

En los paisajes de la pintura china las fronteras entre presencia -ausencia se reducen; el paisaje está siempre en el estado de "como si"
El entre de la vida, el vivir, que es el no - objeto, es donde se sitúa la vida para la filosofía China. Su pintura intentó captar el no objeto, en contradicción con oriente, que intenta representarlo. Para captar el no-objeto del paisaje y reflejar sus matices, la pintura china se interesó por los momentos transitorios del paisaje: aquellos en los que sucede el cambio y la transformación: los momentos de atardecer y el amanecer, donde se encuentran términos opuestos, día -noche, luz -oscuridad, y el uno da su lugar al otro; los momentos en que los limites se diluyen, en que lo de-finido se hace in -definido. Al contrario, la pintura en Grecia, se ha interesado por los momentos del día en los que la luz del sol traza perfectamente los límites entre las cosas: el paisaje del mediodía, donde los contornos son definidos, las sombras precisas, los trazos se destacan y se imponen a la atención. ${ }^{55}$ En el paisaje griego las formas se recortan por la luminosidad transparente y parecen tener identidad propia; en las horas del atardecer y del amanecer los límites desaparecen: las formas adquieren tonos nimbados y oscuros a la vez, $y$ poco a poco se vuelven indecisas. Los vapores emergentes diluyen las lineas y el paisaje entero comienza a sumergirse en la penumbra al tiempo que esas formas que van confundiéndose apuntan a supera sus individuaciones temporales para fundirse en el fondo indiferenciado de las cosas ${ }^{56}$ : el no-objeto; las cosas ya no se imponen ni se exponen; el pintor chino dibuja el mundo sumergiéndose - emergiendo de él y no en su quietud; lo pinta entre el haber y no-haber, you y wu; no intenta inmovilizarlo como Ser y determinarlo como objeto sino en curso, de acuerdo con un proceso continuo. ${ }^{57}$

El paisaje de la pintura china está siempre en el estado de "como si", como si fuera, como si hubiera y a la vez, como si no hubiera; el paisaje está entre entre el es y no-es, entre el bay y no-hay; en un tiempo subjuntivo en el que: podría ser o podría no ser. En este paisaje, las fronteras entre la presencia y la ausencia se reducen o se igualan; las cosas se abren a su ausencia y el pintor no las pinta más que en sus indicios de manera que sean a la vez presentes-ausentes. La estructura de "emergencia -inmersión” y "aparición desaparición" se muestra en los tratados de pintura china como lo que despliega todo el paisaje y le confiere su profundidad. ${ }^{58} \mathrm{El}$ pintor, al abrir las formas hacia su evasión,

55 Jullien, La Gran Imagen no Tiene Forma 20

56 Ibid. 20

$57 \quad$ Ibid.21

$58 \quad$ Ibid.31-32 
al hacerlas indecisas, y sumergirlas en la confusión, convierte en visible esa reciprocidad constantemente operativa. El pintor chino que pinta entre el "hay" y el "no-hay", ese "no hay" (wu), es evidentemente lo contrario de un negativo, el oren del no-ser o de la nada; de hecho representa este Fondo de inmanencia a partir de la cual el "hay" puede advenir desmarcándose al igual que un trazo a-parece o una forma existe. ${ }^{59}$

Occidente eligió la filosofía del Ser, la filosofía de la presencia, de la forma, del límite y del fin; Oriente se centró en el Entre, en lo sin fin, lo indefinido, lo ausente, lo sin forma y sin nombre. El modelo de la respiración (inspiración-expiración) es lo que construye el pensamiento chino frente al de la representación, que da forma al pensamiento occidental. El esquema oriental neutraliza la brecha entre la presencia y la ausencia; promueve la transición; la entrada dirige a la salida y viceversa. En lugar de oponer categóricamente la presencia y la ausencia bajo el esquema de la respiración, inspiración-expiración- se dirigen mutuamente y permiten su tránsito indefinidamente. De esta manera se logra un mundo que no tiene fin. En este mundo, la presencia y la ausencia se mezclan continuamente y lejos de tratar de excluirse de la ausencia, la presencia se extiende y se elogia a través de esta. ${ }^{60}$

En los diseños arquitectónicos para captar y diseñar lo urbano, y no la ciudad, el modelo de la respiración parece ser más efectivo que el de la representación. Lo urbano, dice Manuela Delgado, no es lo mismo que la ciudad; la ciudad está en la ciudad (los edificios, las instituciones, los palacios) y lo urbano es lo dinámico, lo que está entre; la dimensión más liquida e inestable de la ciudad. ${ }^{61}$ La filosofía y pintura china han experimentado y reflexionado más sobre el dibujo de lo liquido, de lo sin forma; ellos,

Lejos de contribuir a la construcción de la perspectiva en la pintura al designar una linea de fuga gracias a la cual se traduciría la disminución progresiva y proporcional de los objetos, el sendero de la pintura china que desaparece-reaparece favorece el desarrollo de un paisaje en contante transformación. ${ }^{62}$

\section{$59 \quad$ Ibid. 47}

$60 \quad$ Ibid. 34

61 Manuel Delgado, El Animal Público: Hacia Una Antropología De Los Espacios Urbanos:

[XXV II Premio Anagrama De Ensayo]Ed. Anagrama, 1999).

62 Jullien, La Gran Imagen no Tiene Forma 33
El pintor chino dibuja el mundo sumergiéndose - emergiendoy no en su quietud.

China se ha basado en el modelo de la respiración, Occidente en el modelo de la representación.

Lo que está entre los edificios de la ciudad, el noobjeto, es lo urbano

El modelo de la respiración parece más efectivo para captar lo urbano en la configuración arquitectónica 



\section{Des-enlace}

Acuérdate de morir ${ }^{1}$

¿Cómo hay que vivir? Esta es la pregunta que los griegos se planteaban (pos bioteon); la pregunta oportuna es ¿Cómo acceder al vivir? El vivir, lo cotidiano, es nuestra inmediatez; es en lo que estamos sumergidos, desde donde viene toda actividad y plenitud, que por ser inmediatas, las perdemos de vista ${ }^{2}$.

A lo largo de la historia, parece que se han dado dos respuestas: la primera es la que los europeos eligieron, como Platón, crear la distancia duplicando la vida y transportándola a un más allá: la distancia que existe entre la vida del cuerpo y la vida de la mente. La vida del otro lugar se convierte en un fin y es la que nos asigna un camino infinito que recorrer, es aquella que nos permite avanzar con entusiasmo, como viajeros impacientes por llegar al puerto ; la vida de aquí es un medio hacia la otra. Acuérdate de morir (memento mori) dicen los platónicos y los cristianos, esperando encontrar la otra vida, a la que se accede de manera definitiva por la muerte. ${ }^{4}$ Así, Aristóteles reduce la vida a la finalidad y más tarde a la utilidad:

Todas las artes, todas las indagaciones metódicas del espíritu, lo mismo que todos nuestros actos y todas nuestras determinaciones morales, tienen al parecer, siempre por mira algún bien que deseamos conseguir.

Todos los relatos, como paseos, valen solo si llegan a un fin; como sucede con el Gran Relato. Un relato, que espera la salvación y la vuelta al origen, a la vida verdadera; y pensar en la salvación que libera del mal esto hace que surja tensión, pasión: organiza y dirige una dramaturgia y se convierte en heróico ${ }^{6}$. Así, todos los pequeños dramas y tragedias que están envueltos en el Gran Relato son de la misma naturaleza: necesitan la catarsis, la purificación de la tensión que los espectadores sintieron durante la tragedia vivida. La catarsis es la liberación de la perplejidad en la que se encuentra el espectador sometido a requerimientos

\footnotetext{
1 François Jullien, Filosofía Del Vivir (Barcelona, España: Octaedro, 2012). 153

$2 \quad$ Ibid. 149

3 La República VI-VII, referencia en Ibid. 150

$4 \quad$ Ibid. 153

5 Aristóteles, Moral, a Nicómaco, trans. Patricio de Azcárate (Madrid: Espasa Calpe, 1992). Jullien, Filosofía Del Vivir 152

6 François Jullien, La Sombra En El Cuadro. Del Mal o De Lo Negativo (Madrid: Arena Libros, 2009). 25
} 
opuestos. ${ }^{7} \mathrm{El}$ desenlace es distinto que la catarsis, aunque tienen la misma finalidad, que es la de la finalidad, el fin del relato. El desenlace (ysis) se difiere en que éste desenlaza, libera, desliga, mientras que la catarsis separa; catarsis es un corte. Característico de la lysis es desanudar una confusión, una aporía; la catarsis en vez de deshacer el nudo, se deshace de él, cortándolo. En la poética la lysis figura como el desenlace, la catarsis es el corte de las tensiones experimentadas por el público ${ }^{8}$. Morales supone que el desenlace, la lysis, corresponde a la catarsis requerida, para volver a ser quien es; le permite la salida hacia el logos convirtiéndose así en la verdadera finalidad de la tragedia, según el pensamiento aristotélico, dado que el verdadero desenlace de la obra no se halla en la conclusión de ella sino en la catarsis, que libera al público de las tensiones y de las ataduras que sufrió en la tragedia.

Cada pequeño relato cotidiano tiene como fin la finalidad: llegar a la meta planificada. Sin embargo, cortar o desenlazar son distintos modos de acabar, pero los dos son actos dolorosos: desenlazan o cortan el hilo del camino que se ha convertido en vida, pero que ahora tiene que cortarse ya que ha llegado a su fin.

$\mathrm{Al}$ otro lado del planeta, en China, no pensaron nunca en la finalidad; no duplicaron la vida, sino que prefirieron aceptar su infinitud,

el vivir solo se experimenta cuando dejamos de buscar algo detrás, cuando libramos el vivir de la finalidad y dejamos que sea contemporáneo de si mismo; cuando evitamos el truco de tirar el palo para poder correr a tras de él. El vivir solo se vive cuando no se abandona su inmediatez, cuando nos mantenemos en su inocencia, es decir, cuando aceptamos su incompletitud: solo cuando conseguimos pasear, ya no para favorecer la salud o cualquier otra cosa, sino simplemente para pasear; incluso este para es excesivo: solo cuando, al pasear, paseamos. ${ }^{9}$

Sin finalidad, se crea un mundo sin fin, donde todo se transforma pero nada se acaba; sin un fin, todo sucede de manera natural, sin esfuerzo. Xiaoyaoyou, palabra clave de Zhuang Zi, significa evolucionar cómodamente, sin destino, al gusto de cada cual..$^{10}$

7 José Ricardo Morales, Las Artes De La Vida: El Drama y La Arquitectura, Vol. 35Anthropos Editorial, 1992). 18-20

8 Ibid. $18-20$

9 François Jullien, Filosofía Del Vivir (Barcelona, España: Octaedro, 2012). 153 Ibid. 153 
LO OBLIGATORIO EN ANEXO 



\section{HIPO-TESIS}

La hipótesis de esta investigación es que los arquitectos en general, a partir de la modernidad y de manera inconsciente, se enfrentan al proyecto arquitectónico al margen del transcurso de la vida: por una parte, el planeamiento y la planificación que pone en orden el mundo y de otra, el desorden y lo imprevisible de la vida ${ }^{1}$. Dicha posición del arquitecto, observando la vida desde fuera para ponerla en orden, es la responsable de la aparición de las ciudades fantasmas y las ciudades informales; porque desde fuera se ve y se organiza el espacio pero el tiempo se capta solamente desde el interior de la vida. La falta de la evaluación de la potencialidad del tiempo en los proyectos arquitectónicos ha conducido a construcciones no preparadas para adaptarse a los cambios que el transcurso de la vida conlleva; estructuras que por ser incapaces de transformarse según las circunstancias fueron abandonadas o nunca habitadas y obligaron la presencia de las ciudades informales, ya que no pudieron alojar el aumento de la población de las ciudades.

Hipótesis de la investigación es también la raíz de la incapacidad del arquitecto de captar el tiempo y de proyectar que el interior de la vida yace en el exclusivo uso del pensamiento racional y binario que organiza el mundo en pares de términos opuestos como espacio -tiempo, arquitecto - usuario o fuera - dentro. Sin embargo, el arquitecto, en su intento de clasificar lo que le rodea según la lógica del ser o no ser, pierde lo que está entre los polos de los pares de opuestos, que es donde la vida sucede, y se centra en lo

1 Arquitecturar, decía Le Corbusier, es poner en orden. Le Corbusier, Precisiones Respecto a Un Estado Actual De La Arquitectura y El Urbanismo Trad (Barcelona, España: Apóstrofe, 1999), 90. La ciencia arquitectónica es, según Aristóteles, la ciencia suprema organizadora de la totalidad de la actividad bumana (Metafísica, A, 2 982a 18) Aristóteles, Metafísica (Madrid: Editorial Gredos, 1994).. Pero, aunque considerábamos que la vida sucedió de la misma manera, del orden del desorden, después del concepto de la entropía de Boltzmann conocemos que nuestro universo empezó en un estado excepcionalmente ordenado y, en el evento de Bing Bang, empezó el gran desorden; nuestras vidas son partes de la desorganización creciente en el universo y la vida se debe al desorden. Brian Greene, The Fabric of the Cosmos: Space, Time, and the Texture of RealityVintage, 2007). Brian Greene, "Fabric of the Cosmos: The Illusion of Time," Nova, Https:/ / mww. Youtube. com/watch 44 (2011). 
que los edificios son o no son y olvida que la vida se desenvuelve en el espacio que está entre ellos.

Esta tesis doctoral no empieza con una hipótesis, es una investigación cualitativa que dibuja su camino desde la observación participativa con cuaderno de campo. El método cualitativo, el más adecuado para la investigación arquitectónica interesada en lo humano y su cotidianidad ${ }^{2}$, no prueba hipótesis ni teorías, sino que las genera. La conjetura de la mutua exclusión entre arquitectónica y vida nace tanto de la observación del que el proceso arquitectónico se basas en pares de términos opuestos como, desde las lecturas del ámbito sociológico relativas al interés de los grandes planificadores de la modernidad para poner en orden el mundo; un orden que para ser mantenido, ha requerido un continuo combate contra la arbitrariedad inesperada, la ambivalencia y la contingencia ${ }^{3}$ : contra la vida ${ }^{4}$.

$2 \quad$ Linda Groat and David Wang, "Architectural Research Methods," New York (2002). 3 Zygmunt Bauman et al., "Modernidad y Ambivalencia," in Las Consecuencias Perversas De La Modernidad. Modernidad Contingencia y Riesgo (Barcelona, España: Anthropos, 1996), 73 - 119.

4 Según É. Boutroux, si no bubiese tal contingencia no podría haber en el mundo novedad y, de consiguiente, no podría haber realidad. José Ferrater Mora, Dicionário De Filosofia. TOMO I (A-K), Vol. 1 (Buenos Aires: Editorial Sudamericana, 1971). 


\section{ESTRUCTURA}

El cuerpo principal de la tesis se estructura en tres capítulos; cada uno de ellos se centra en uno de los tres problemas sociales que la investigación analiza: el tedio, las ciudades fantasmas y los slums y el desencuentro. Dicha división coincide con la que se hace también según tres tipos de relaciones: la relación habitante: la relación del habitante con su entorno, consigo mismo y con el otro. Coincide, además, con los tres fundamentos de la vida a través de las que se intenta entender el concepto del Entre: lo temporal (de repente), lo espacial (sin fin) y del lenguaje (innombrable).

La investigación es transversal; intenta hacer un catastro $^{5}$ de los lugares del Entre y de sus figuras intersticiales, generados tanto por arquitectos como por sociólogos y filósofos. Se abren muchos temas y se categorizan según las dualidades en las que se encuentran; como es imposible analizar todos en profundidad, se desarrollan los más importantes para la investigación y el resto se queda en notas, esperando su futura elaboración. Las notas son textos comprensibles pero escritos y estructurados de manera rizomática, de forma que pueden suceder eventos no programados, al permitir al lector que llene los intersticios entre los párrafos según el hilo que él elige.

En relación con la elaboración de los textos y el formato de la investigación, la tesis doctoral respeta el cambio que sucede en el acto de leer por el creciente uso de la red, que no es profundizar o leer de manera lineal, sino escanear u hojear descartando de manera rápida lo que no interesa. Por eso cada capítulo es autónomo, aunque hay un fino hilo entre ellos que es la influencia del pensamiento binario y el lugar del Entre. Cada subcapítulo es, a su vez, autónomo y no necesita los otros para ser comprendido, sin embargo están conectados entre ellos por el fenómeno social que se analiza en el capítulo donde se encuentran. La tesis puede además ser recorrida también por la lectura de los textos pequeños que están en los intersticios de la página al lado del texto principal, que son resúmenes de los temas que el texto principal desarrolla.

En concreto, el primer capítulo, De repente. Entre lo Familiar y lo Extraño, se dedica al fenómeno social del tedio, considerado por la psicología, la filosofía y 
la sociología como el mal del siglo, una epidemia que azota a casi todos los habitantes. Como la mayoría de los autores investigadores de este fenómeno lo relacionan con el cambio que han sufrido las ciudades después de su industrialización, el tedio se suele llamar en la investigación tedio urbano. En principio, a partir de lecturas de los campos de la filosofía, la sociología y la psicología, se analiza el fenómeno del tedio y las razones de su presencia en el subcapítulo bajo el nombre Me Aburro, en el tedio urbano. Después, la parte del capítulo denominado De Repente se centra en la importancia del estado de la sorpresa, del extrañamiento, de lo irregular y de lo imprevisto para la cotidianidad de los habitantes, que es abordado desde el prisma de la filosofía, la neurociencia, la filosofía y la literatura. El texto En el dominio de la "O" es un intento de narrar una breve historia del urbanismo, desde el modo en el que los arquitectos afrontan lo repentino y lo irregular, enfrentando la dualidad orden - desorden y familiar - extraño. La parte El Arquitecto Suspendido es el epílogo del primer capítulo, en el que se concluye que la imagen del arquitecto como profesional responsable - indispensable para el planeamiento de ciudades, entre el mundo de las Ideas y la realidad, ha de desaparecer. Aún más hoy en día, el arquitecto, después de la Revolución Digital, las TIC y la Realidad Aumentada, es un simple mediador entre varias disciplinas, que aporta en la construcción del entorno, lo mismo que cualquier habitante.

A parte del papel del arquitecto en el fenómeno social del tedio, el primer capítulo está dedicado a la relación del habitante con su entorno. Se analiza el modo en el que el habitante percibe los edificios, se estudian los procesos de la familiarización, los modos con los que se construye la experiencia y el modo en el que funciona lo cotidiano y los ejes estructurales de la vida, hasta llegar al habitante que construye su propio entorno. Este primer capítulo es una reivindicación hacia lo irregular, lo imprevisto y el desorden y una reivindicación de los trabajos de los arquitectos que consideran el desorden y la autoconstrucción como necesidad existencial del habitante, desde Camilo Sitte hasta los arquitectos activistas contemporáneos.

El segundo capítulo que se titula Sin Fin. Ente la realidad y la imaginación está dedicado al fenómeno de las ciudades fantasma y las ciudades informales. Éste es una colección de estos tipos de ciudades y explica las ciudades fantasma y los slums como un fracaso de los arquitectos que revelan la construcción de lugares inhabitables 
y demuestran que las construcciones rígidas y poco flexibles no pueden adaptarse a los cambios de la vida. Según la investigación, la responsabilidad de los arquitectos se sitúa en proyectos realizados desde arriba, desde fuera, desde los ojos de un dios desde donde no se puede evaluar el potencial y la dinámica de la vida. La primera parte, titulada Entre la Espada y la Pared, analiza la principal razón de este fenómeno que es el pensamiento binario en el que está basada toda la filosofía, el planeamiento y la vida occidental. Es la parte de la investigación en la que se analiza la historia del pensamiento dual y sus consecuencias en la vida y en los proyectos arquitectónicos. Hace una pequeña historia de la evolución de este pensamiento dentro de una lista breve de los tipos de pensamiento hasta ahora registrados. La segunda parte denominada Fantasmas, Vampiros y Zombis, colecciona ciudades fantasmas, describiendo su historia y buscando los fundamentos de su existencia. Examina los modos de construcción de los slums y concentra todos aquellos proyectos que van en contra de su demolición. No interesa la vivienda en sí, sino la política que hay detrás de las construcciones de las viviendas colectivas y las ciudades. La parte de título En el Espejo Negro, se dedica al cambio de la relación de los polos de la dualidad imaginación - realidad a partir de la evolución de la tecnología, de la Revolución Digital, de las nuevas Tecnologías de Información y Comunicación y de los Ambientes Aumentados. En esta parte de la investigación se describen de manera breve algunos de los cambios negativos en la ciudad y la sociedad dentro del nuevo paisaje urbano, pero presenta también lo positivo que aparece en la posibilidad que los nuevos medios abren al habitante al ser partícipe en todo lo que sucede en su entorno. Este capítulo cierra con la parte de Sin Fin en la que se propone una nueva metodología de trabajo, importada de la cultura China: No Actuar (wu wei) es una estrategia en la que la imaginación y la realidad no se dividen, un estado en el que alguien cree que no está trabajando, una situación de fluir que el trabajo se hace solo.

El último capítulo Lo Innombrable. Entre Tú y Yo es la parte de la investigación que se dedica a la introducción y la definición del concepto de la "filosofía del Entre” y de la razón intersticial en el ámbito arquitectónico. En principio, de nuevo se realiza una colección de los filósofos que hablan y se preocupan, no sobre las cosas, sino sobre lo que está entre ellas. Después se aborda un listado de los arquitectos que reflexionan sobre el "entre", incluyendo una serie de términos y teorías que cada uno aporta sobre 
dicho concepto. La filosofía del Entre es aquella a la que no se interesa por la entidad sino por la entridad en la que el ser humano no es un sujeto sino una relación. La razón intersticial en el ámbito arquitectónico está compuesta precisamente por los modos de trabajar y proyectar, focalizando el interés no en lo que los edificios y los lugares son, sino en lo que está entre ellos; una lógica que no percibe el habitante como sujeto que se relaciona con otros sujetos y objetos, sino como relación. La parte En el Tercer Espacio es el ámbito de los lugares intermedios- ambivalentes (umbrales, proscenios, pórticos, puentes,..) donde se registran todos los términos que los arquitectos dan en este "lugar del entre", las teorías que cada uno desarrolla sobre él y los modos con los que trabajan con él. El texto titulado Sin Techo está dedicado al fenómeno social del sinhogarismo, considerando a auténticos habitantes de los intersticios de la ciudad la gente sin hogar. A partir del análisis de este fenómeno, se exponen las maneras en las que los arquitectos influyen en este fenómeno. La última parte de este tercer capítulo, Lo Innombrable, se dedica al puro Entre, que no tiene forma, que no se ve, sino se capta; se dedica al vacío que está entre los edificios, al concepto del Ma japonés, al no - objeto que es el fondo de las cosas; se dedica al amor; a lo que está entre tú y yo: la vida. 


\section{JUSTIFICACIÓN DEL TEMA DE LA TESIS}

El principio de la investigación se sitúa mucho antes de su comienzo, en el tercer año de la carrera de Arquitectura, en un primer intento de trazar un espacio público. El detonante para su comienzo fue la contradicción existente hallada en los espacios públicos: por una parte se llaman públicos, pero parecen no tener libre acceso; es decir, no están accesibles en cualquier momento al público. El ejercicio trataba de construir un mercado municipal en un lugar vacío de un barrio en el que ya había uno construido provisionalmente por los ciudadanos. La pregunta que aparecía en aquella época es de qué manera los proyectos de los arquitectos y sus construcciones influyen en la cotidianidad de los habitantes. Empezó la pasión y las preguntas sobre los lugares que delimitan a la vez un concepto y su contrario; entre lo privado y lo público, entre lo abierto y lo cerrado, entre lo interior y lo exterior, entre unos y otros.

Las preguntas planteadas hicieron presente la ausencia explicita de un documento, una investigación o un libro que presentase la influencia que las construcciones de los arquitectos tienen en el bienestar de los habitantes, lo que los arquitectos deben saber sobre las razones de la felicidad de los habitantes, y base de información sobre todos aquellos lugares - los terceros espacios de Žižek- que quedan siempre fuera del exterior y fuera del interior, por lo que en ocasiones, son considerados como residuales.

La realización de esta tesis intenta contestar preguntas básicas para el trabajo de los arquitectos, que les hagan conocer que lo que distingue las teorías y los movimientos en la historia de la arquitectura es tanto las nuevas dualidades que aparecen en distintas etapas (forma - función, lugar -ocasión, real - virtual) como el modo en el que se gestiona la relación entre los dos polos de dichas dualidades. La investigación visibiliza los lugares intermedios - casi siempre vistos como espacios sirvientes, necesarios solamente para conexión de los lugares principales o residuales - como protagonistas de la historia del planeamiento arquitectónico, pues los trazos de los arquitectos son el dialogo que se establece entre los términos opuestos. Al estar toda la vida y la filosofía occidental basada en pares de términos opuestos, la manera en la que uno vive, su cotidianidad, 
depende del modo con el que maneja los términos antagónicos.

La tesis es una investigación interdisciplinaria que entra y sale de las escuelas de arquitectura con la sociología, la filosofía, la filología y más disciplinas, creando vínculos entre ellas. Desde el umbral se puede considerar como una investigación sobre los procesos arquitectónicos a través de referencias que vienen de otros campos o se puede entender como una investigación relacionada con los fenómenos sociológicos contemporáneos desde la disciplina de la arquitectura.

Respecto a su valor teórico, la investigación ofrece la introducción de la filosofía del Entre y de la razón intersticial - que hace poco fue introducida en las escuelas de la filosofía- en el ámbito arquitectónico; ofrece una colección de los términos que se han usado para describir el lugar del Entre y también las teorías que lo fundamentan. A través del análisis de tres fenómenos sociales - el tedio, los slums, el desencuentro- llega a mostrar la forma en la que los arquitectos influyen en la mejoría o el empeoramiento de la vida de los habitantes. Intenta plantear un nuevo modo de proyectar desde el Entre, donde la dualidades desaparecen. La utilidad metodológica que esta investigación ofrece es la de crear un nuevo instrumento o analizar datos en el encuentro de las oposiciones binarias. 


\section{ESTADO DE LA CUESTION}

En Grecia, cuando entramos en el avión, en el teatro o en cualquier espacio donde nos queremos sentar y no sabemos cuál es nuestro asiento preguntamos a alguien ¿cuál es mi tesis? mostrando los asientos o butacas que están en nuestro alrededor o, decimos, perdón, ha ocupado a mi tesis cuando alguien se ha sentado en el lugar que estaba destinado para nosotros. Tesis es un vocablo que viene de la palabra griega $\theta \dot{\sigma} \sigma \eta$ (thesis). La palabra tesis en griego se traduce como el lugar, el sitio y el asiento. La palabra tesis en griego tiene el significado que da la Real Academia Española a la palabra tesis solo cuando se usa de manera metafórica; la opinión de alguien sobre algo, la proposición que se mantiene con razonamientos y la disertación escrita que presenta a la universidad el aspirante al título de doctor en una facultad. Para la tesinanda - de origen griego

- literalmente hablando, una tesis doctoral es el lugar que el investigador elige para sentarse y observar el campo de investigación en el que se encuentra; el campo que ha sido cultivado por otros, cada uno por su lugar, su tesis.

La tesis para la recopilación y clasificación de los tipos del "entre" el primer lugar visitado fue el diccionario ya que allí están concentrados todos los tipos de lugares; los límites del mundo son los límites del lenguaje (Wittgenstein). Lugares intermedios son aquellos que empiezan con los prefijos pro-, hipo - , semi -, inter -, dia-, trans - por, intro -, epi -, medio -; pero también lugares que se encuentran de manera más difícil; nombres de lugares que derivan de verbos que revelan transición como por ejemplo puertos, puertas, puentes que vienen de la palabra portus (de esta palabra derivan las palabras oportunidad, importuno, portar) y esta última del verbo portar. De esta búsqueda de los lugares intermedios en los diccionarios, se detectaron palabras que no se consideran exactamente espacios o lugares pero que indican el medio o el intermedio como el diálogo o la introducción o aquellos términos que empiezan con los prefijos meta- como metáfora, metafísica, que viene de la palabra griega metapherein que meta (mas allá) y pherein (llevar, trasladar). Los diccionarios como fuente de investigación abrieron más su campo, lo extendieron. Para entender mejor la cuestión principal de 
la tesis diríamos que si esta tesis se realizara en la escuela de filología su objetivo sería tanto la función de las preposiciones como la función del blanco de las páginas que las soporta y permite su existencia.

François Jullien es de las referencias fundamentales de la investigación al ser el primer autor que la investigadora encontró en su camino que hablaba directamente de lo que el "entre" es y cómo el pensamiento binario funciona. Jullien compara el pensamiento de occidente con lo del oriente y encuentra su diferencia en que lo primero es un pensamiento binario - para entender el mundo lo divide en pares de términos opuestos - mientras que en oriente usan un pensamiento polar - dividen el mundo en pares de términos complementarios. Hay gran distancia entre los dos tipos de pensamiento ya que en lo primero intentamos suprimir la una parte de la dualidad mientras que en oriente saben que si se elimina uno de los dos polos desaparecerá el otro.

Un extenso análisis sobre el pensamiento polar lo encontramos en la Polaridad y Analogía en Antigua Grecia por G.E.R Lloyd que observa la evolución del pensamiento binario desde las sociedades primitivas. Aristóteles ya apuntó que todos los filósofos y todas las cosmoteorias conocidas hasta su tiempo estaban basadas en pares de términos opuestos. Sin embargo según Jullien, hasta la época de Platón las teorías estaban basadas en polaridades pero los pares de los términos no se veían como opuestos entre ellos sino como complementarios. Pensamiento de pares de términos complementarios fue lo de Heráclito que insistía que todo fluye entre los pares de los términos y la verdad no está en una de los dos sino en el "entre". A partir de Platón los términos de los pares se transforman en contrarios, opuestos: una cosa no puede ser y a la vez no ser. Aristóteles nombró los términos de los dos polos como contrarios cuando articulo el Ley de la no contradicción y del Tercio Excluido. Como hoy dice Bart Kosko - defensor del pensamiento borroso que no divide el mundo en dos valores sino en más, polivalente - dice que a partir de Aristóteles cuando más clara es la separación de los límites de los términos opuesto más exacta la ciencia.

Hasta la aparición de Hegel la lógica y la filosofía occidental seguían estando basadas en un pensamiento binario. Hegel fue en contra del pensamiento binario, aceptando que la verdad está en la contradicción. Hablaba de la mediación, que es el devenir, el pasaje; entendía que la vida y lo real está en la mediación; que el fundamento 
de lo real no está en el ser sino su negativo. La identidad para Hegel es mediación. Para Hegel los términos de las polaridades son la misma cosa que se encuentran en continuo cambio. Jacques Derrida sigue el pensamiento de Hegel con quien diríamos que termina el concepto de la verdad absoluta. Jacques Derrida habla de un tercer género - Différance - que es la fuerza que distingue las cosas y que eso conduce a un pensamiento binario, pero los pares de los términos opuestos es una abstracción. Jacques Derrida apoya la opinión que el gran problema con el pensamiento binario es que siempre uno de los polos domina; siempre uno es más fuerte que el otro - lo mismo apoyaba Hegel. El ejemplo más representativo es la dualidad hombre-mujer donde siempre el hombre ha sido superior a la mujer. Hélène Cixous, la feminista francesa profesora universitaria, poeta y filósofa, apoya la misma idea: siempre que encontramos la polaridad existe la jerarquía. Edgar Morin habla del pensamiento complejo que es una capacidad de hacer interconexiones entre dimensiones distintas de lo real y no reducirlo en términos opuestos. Complejo significa pensar el mundo y la vida como una red que entrelaza sus partes con hilos finos. Gilles Deleuze y Félix Guattari hablan del pensamiento rizomático y apoyan que el pensamiento binario crea estructuras jerárquicas; hacen la distinción entre árbol y redes: el primero es una estructura jerárquica mientras que la otra parece a la lógica del internet, de la red. Bauman nos dice que el pensamiento binario es el pensamiento de la exclusión; lo describe la frase "o esto o lo otro" y es el pensamiento en la que se basó la modernidad; el pensamiento de la posmodernidad es de la inclusión; lo describe la frase "esto y lo otro". La época de la modernidad es la época de la "o" mientras que la posmodernidad es la época de la "y". Si el pensamiento binario acompaña la frase "o esto o lo otro", el pensamiento rizomático la describe la frase "esto y esto ... $\mathrm{y}_{\ldots} . \mathrm{y} \ldots \mathrm{y} \ldots \mathrm{y} \ldots$... El pensamiento queer o trans- de los estudios de género de Judith Butler es el pensamiento que va más allá de las etiquetas porque no acepta el concepto de la esencia; la identidad es del aquí y el ahora y no algo inmutable. El pensamiento lateral es otro tipo de pensamiento presentado por Edward de Bono y es un pensamiento creativo que busca lo absurdo; es decir, busca soluciones que el pensamiento racional abandonaría. Es un pensamiento que acepta el pensamiento binario pero hace el uso contrario. El pensamiento de lo que habla Bart Kosko, el pensamiento borroso o difuso o polivalente, diríamos que es lo contrario de lo racional; 
en vez de blanco o negro piensa los grises. Este pensamiento según palabras de Kosko ve la verdad en términos de precisión; todo tiene una calificación de 0 a 100\%. Sin embargo lo curioso de este pensamiento que mientras que alguien espera que la verdad corresponde a 100\% de precisión una declaración que 100\% de precisión no describe el mundo; porque la imprecisión es la elaboración principal de la ciencia; es decir según el pensamiento borroso lo que describe el mundo no es precisión sino imprecisión.

Del otro lado, de la parte de los estructuralistas está Levi Strauss quien apoya que el pensamiento binario es el único modo de pensar, hecho inherente de la mente humana (1987). Así un tema cuestionable es si al final el pensamiento que marca los asuntos en pares de términos (contrarios u opuestos) es el único modo de pensar o son posibles los modos de los que hablan los autores anteriormente mencionados. Parece que Lloyd - sin decirlo claramente - apoya con su trabajo que el pensamiento binario es la única manera de pensar cuando dice que pensamos así quizás porque la naturaleza está dividida en dos polos; dos géneros, dos manos, etc. George Lakoff y Mark Johnson dicen que la naturaleza y nos invitan a tener dicho pensamiento. De la neurociencia también hay esta división; si lo binario es el único modo de pensar. Francisco J. Rubia Vila, neurocientífico Catedrático de la Facultad de Medicina de la Universidad Complutense de Madrid, apoya que el pensamiento dual se debe a un operador binario que se encuentra en el hemisferio dominante; hay teorías que consideran que los primitivos no tenía este operador y que es algo que surgió con la evolución del cerebro y otras que firman que sí que existían pero los primitivos no lo usaban. La tesis no dio respuesta de si el pensamiento polar es el único modo de pensar pero terminó su viaje entre las referencias de campos distintos de lo de los arquitectos con Peter Elbow que propone que hay cinco modos de enfrentar los pares de los términos opuestos a) pensando con el modo de la exclusión "esto o lo otro" b)encontrar una dialéctica entre ellos y encontrar un término tercero c) considerar que no hay ninguna diferencia entre ellos d) considerar que los dos polos son iguales y reales y e) volver a enmarcar el asunto, alejarse y encontrar más de dos variantes; este último modo de pensar es modo más difícil- el pensamiento borroso.

La mayoría de los arquitectos que fueron en contra de las oposiciones arquitectónicas fueron de la filosofía y lógica del deconstructivismo. El deconstructivismo 
no es nada más que el continuo intento de llegar a la ruptura con las jerarquías que el pensamiento binario crea. Sin embargo, todos ellos aunque hablaron de la deconstrucción de las dualidades tradicionales y defendieron un modo de pensar distinto, al final no escaparon de lo binario, pues crearon nuevas dualidades. Para cada uno de ellos la ruptura con las dualidades era de máxima importancia pero para cada por distintas razones.

Aldo van Eyck es referencia importante para la investigación y sus teorías sobre el pensamiento binario no se pueden comparar con las de deconstructivistas, ya que él fue más allá de la edificación y los procesos proyectuales. Concepto básico para sus teorías fue la teoría de los fenómenos gemelos. Según él, toda actividad arquitectónica está basada en la relación de términos opuestos pero el problema es cuando estos términos se ven como opuestos y no como gemelos. Criticaba el pensamiento racional porque trabajaba según pares de términos opuestos hecho que conduce a la construcción de lugares inhumanos, fuera de su naturaleza. La naturaleza del ser humano está en la respiración y los términos tienen que ver con el proceso de la respiración; inspirar -expirar; la vida está en la combinación de los dos. Para Aldo van Eyck las dualidades arquitectónicas son abstracciones fuera de la naturaleza del ser humano. El enfrentamiento de las polaridades como dualidades conduce al distanciamiento de las personas, al desencuentro, razón por la que Aldo van Eyck considera que el Movimiento Moderno piensa poco en la felicidad de los ciudadanos

Robert Venturi tanto en Complejidad y Contradicción, pero principalmente en Niveles Contradictorios: El fenómeno "lo uno y lo otro" en arquitectura nombra la época de la modernidad como la época del pensamiento de "o lo uno o lo otro", del pensamiento de la exclusión. Al contrario, la posmodernidad es la época de "lo uno y lo otro" pensamiento de la inclusión. Según Venturi el pensamiento binario agota el mundo porque la vitalidad se encuentra en la ambigüedad y la contradicción. El pensamiento de la exclusión es un pensamiento muy fácil que simplifica la vida pero lo de la inclusión es un pensamiento mucho más difícil ya que incluye muchos parámetros.

Bernard Tschumi también observa que los arquitectos construyen dualidades y aprecia que una arquitectura postbumanista tiene que romper con las dualidades antiguas establecidas. Su pensamiento se revela en sus libros Arquitectura y Disyunción y en las 
serie de Event Cities. Tschumi, podríamos decir que no escapa del pensamiento binario, pues rompe con las dualidades antiguas pero crea nuevas; en vez de forma - función adopta forma-concepto, y la más famosa del espacio-tiempo, espacio - eventos. Tschumi estudia y profundiza más en el pensamiento binario y, a través de la dualidad espacio - eventos, propone tres modos de enfrentar las dualidades: apoyar uno al otro, estar en conflicto o, ignorar el uno al otro. Tschumi escapa de la dualidad del pensamiento cuando en Event Cities 3 propone un pensamiento trivalente, tres variables a través de las cuales enfrenta la construcción: concepto -contexto-contenido.

Peter Eisenman, desde las conclusiones de su tesis doctoral, intenta la aproximación a un pensamiento borroso centrado en los matices. Introduce la dualidad de lo genérico-especifico y piensa en el intermedio al hablar de los diagramas y recurre a la noción de la Khora de Platón, al tercer género, del que ya habla Deleuze para describir el caos germinal o lo que está en potencia.

El concepto de Aldo van Eyck, el "in - between realm", "el reino del entre", surge bajo la influencia de la "esfera del entre" estudiada por Martin Buber. La "esfera del entre" es el lugar donde sucede la comunicación con las formas inteligibles. La relación del Tú con el Yo, como dice Buber, en el lugar de "la esfera del entre" está envuelta en nube, dice Buber, pero se desvela poco a poco. El "reino del entre" es para Aldo van Eyck el lugar donde se encuentran las distintas realidades de los términos opuestos que para él son gemelos. Aldo van Eyck fue más allá del resto de los arquitectos que hablaron del intermedio o del intersticial ya que para él, el "entre" no es solamente un lugar intermedio físico, sino el encuentro de todas las dualidades posibles. Los lugares intermedios son, como él dice, la casa de los fenómenos gemelos.

Sobre el estado de la cuestión del "entre" hoy sabemos que hay una filosofía del "entre". Es decir tenemos la "filosofía del ser" y la "filosofía del entre". La filosofía del ser es la que viene del pensamiento binario; es decir, una cosa es o no es. La filosofía del ser acepta el ser humano como sujeto, mientras que para la filosofía del entre el ser humano es relación; en la primera existe el Yo, en la segunda no existe Yo sino la palabra Yo - Tu, de la que habla Martin Buber; la primera acepta que existe una verdad y la segunda que no existe una verdad sino muchas; todo es relativo y relacional. La filosofía china es una filosofía del entre, la de occidente es de ser. El Entre empezó a ser un tema cuestionable 
oficialmente a partir de Hegel que hablaba de la mediación; lo real está en la mediación, en el pasaje; el fundamento de lo real no está en el ser sino en su negativo. La filosofía del entre empieza oficialmente con Hegel pero su principio está en Heráclito para quien era imposible saber del mundo porque no existe nada permanente; todo está en un continuo cambio, todo fluye, todo es un "entre". Este pensamiento es lo que encontramos en las teorías contemporáneas de Kosko que, como dijimos anteriormente, si algo es 100\% preciso no describe el mundo ni la verdad porque el mundo es impreciso. Platón, aunque padre de la filosofía del Ser y de la filosofía dualista que empezó años después, hablo de la Khora - que en griego es el espacio - como el tercer genero donde allí se encuentra todo lo que podría ser, el estado donde una cosa es pero no es; el momento un poco antes de la aparición. De la Khora hablo también Derrida, como vimos anteriormente, para apoyar su teoría de Différance; allí es donde recurrió Eisenman para hablar del lugar del diagrama. Heidegger también se podía considerar participe de la filosofía del Entre cuando en Sery Tiempo dijo que en cuanto cuidado, el dasein es el 'entre'. Según Deleuze, en su artículo La queja y el Cuerpo donde hace una reseña del libro de Pierre Fedida, L'absence, y dice que la gran novedad de este libro es la invención de toda clase de inter- conceptos que señalan lo que está "entre”; el intermediario, el mensajero, intermezzo. Deleuze habla del entre a través de su "aire de la época", la teoría del umbral. William Desmond en su Being and In-between distingue la lógica del ser y la lógica del "entre". Foucault habla del espacio del entre como el espacio de saber. Peter Sloterdijk habla del pensamiento en un mundo intermedio.

El "entre" se ha descrito por muchos filósofos pero cada uno le daba un distinto nombre: Heidegger habla de "pliegue" (Zwiefalt), "umbral” (Schwelle) y “entre” (Zwischen), Deleuze de "Lógica del Y”, “umbral”, “medio” y el intermezzo, Nancy del "entre” y del "con”. En Michel Serres encontramos el "tercer incluido", en Derrida el "entre". Foucault habla del "intersticio" y Agamben de la "excepción". Blanchot se refiere al "entredós” y "el tercer género"; Emmanuel Levinas sobre el intervalo. Sloterdijk sobre el "ser-contenidos-en-un-entre" y Maurice Merleau-Ponty sobre el trastorno intersticial. Paul Ricœur habla de lo liminar y Eugenio Trías Sagnier de la lógica del límite; Jacques Rancière sobre el "estar-entre". Levi -Strauss habla de la ciencia intersticial y Mijaíl Bajtín y Tzvetan Tódorov de la extraposición y de la 
exotopía. François Jullien sobre el “entre” y el no-objeto. El no-objeto es quizás la mejor descripción de lo que está entre nosotros que parece el vacío pero está lleno. El noobjeto, según François Jullien, es el objeto de la pintura china. La pintura del occidente basada en la visión intentaba representar de los objetos mientras que la pintura china, basada en la respiración, captar el entre, el fondo de las cosas; la transición.

La filosofía del "entre" en el ámbito arquitectónico, oficialmente, parece que empieza con los Alison y Peter Smithson, empero, su principio está en las teorías de Camilo Sitte. Camilo Sitte iba en contra del urbanismo moderno porque según él lo que sucedido en la modernidad es que relación superficie edificada e inedificada se ha hecho inversa es decir, antes empezaban del espacio libre viéndolo como un conjunto cerrado y buscando maneras de lograr efectos de unidad, mientras en la modernidad hacemos solares en figuras regulares y lo que sombre lo llamamos plazas y calles. Y en general, en toda su obra Construcción de ciudades según principios artísticos habla del abandono de lo que está entre los edificios. Alison y Peter Smithson hablaron del umbral; palabra que disparó el interés de Aldo van Eyck que con la influencia de Martin Buber llegará al "reino del entre" y del umbral extendido; extender los umbrales lo máximo posible porque allí es donde sucede la "esfera del entre", el verdadero encuentro. Por eso Aldo van Eyck dirá que la arquitectura debería concebirse como una configuración de lugares intermedios claramente definidos. Para Alison y Peter Smithson la modernidad abandonó las calles y para ellos el pensamiento de los arquitectos tiene que empezar en el momento que el hombre pisa fuera de su casa, en el umbral. Los Smithson hablaron nombraron como "entre" (in between) el vacío que está entre los edificios. Para ellos el "entre" es el distanciamiento, el intervalo. La diferencia del urbanismo americano con el urbanismo europeo yace en el que el segundo usa como elementos de conexión muros, escaleras, columnatas, mientras que para el urbanismo americano la mediación entre los edificios depende de la variación del intervalo. Christopher Alexander y Serge Ivan Chermayeff, en Comunidad y Privacidad de alguna manera afirman que los arquitectos han abandonado el "entre" cuando que no va a tardar la época que los arquitectos verán que lo que está entre los edificios tiene la misma importancia que los edificios. Toyo Ito y, en general, toda la cultura japonés, trabaja con el concepto del $M a$ y Ku que muchos relacionan con el in - between realm de Aldo van Eyck; Ma se describe de la frase la forma es vacio y el vacio es 
forma. Las infraestructuras y megaestructuras son otras figuras intersticiales del "entre". De las infraestructuras hablaban Alison y Peter Smithson después de ver los diagramas de tráfico de Luis Kahn. La lógica infraestructural trabaja empezando por el vacío. La lógica infraestructural la encontramos en las obras Fumihiko Maki en Investigations in Collective Form, Reyner Banham en Megastructure, o Shadrach Woods en The Man in the Street, Stan Allen en Points + Lines, Edward Soja en Postmetropolis y Frei Otto en Occupying and Connecting; la lógica infraestructural parece a la lógica de la movilidad de los Team X.

Robert Venturi hablaba del fenómeno "lo uno y lo otro", anteriormente dicho, pero hablaba también del elemento de doble función; la diferencia entre lo primero y lo segundo es que lo primero se refiere en los significados mientras que el segundo en las funciones; ejemplos encontramos en la arquitectura barroca; cornisas que son umbrales, ventanas que son nichos. Bernard Tschumi habla de los espacios inclasificables o inprogramados que surgen cuando los pares de opuestos están en conflicto; los lugares que surgen entre ellos a veces se consideran residuales pero son lugares en los que pueden suceder eventos no planeados.

Eisenman habla de los procesos de lo intersticial o de la intersticialidad; el concepto de la intersticialidad como un nuevo concepto de espacialidad. Eisenman en sus Procesos de Intersticial publicado en Croquis, No. 83, habla de una nueva dualidad forming spacing. Para Eisenman forming es el modo tradicional de los procesos arquitectónicos que se fundamenta el espacio en el concepto de un contenedor con un significado anteriormente establecido; tiene sistemas clásicos de valores y usos. Al contrario el spacing no tiene estas leyes, por lo que eso es un proceso que debe proveer formas de autorregulación. El proceso de lo intersticial es una forma del spacing. De lo intersticial habló Colin Rowe en la Ciudad Collage en la Crisis del Objeto diciendo que se debe encontrar correspondencia entre sólido y vacío porque de otra forma tenemos o el caos dela ciudad medieval o despótico orden de la ciudad del CIAM. El vacío es el espacio intersticial generador de dinamismo. De Rem Koolhaas hablamos del espacio basura y los espacios de la nada en su Imaging Nothingness. Cerramos con el Tercer Espacio de Slavoj Žižek del que habló en Arquitectura Viva en 2011. Según él, el espacio interior y exterior nunca ocupan el espacio completo: siempre queda un Tercer Espacio, que permanece perdido en la división en el Exterior y el Interior. 
De gran interés son las investigaciones que se dedican a las consecuencias que tiene la disolución de los límites de los términos opuestos a partir de la Revolución Digital y aún más después de las nuevas Tecnologías de Información y Comunicación y el Ambiente Aumentado; experimentamos el cambio de las nociones del local, profesional, público. De alguna manera lo que sucede es que la experimentación del espacio público se personaliza y se domestifica; es decir se interioriza mientras que a la vez la vida íntima y personal se publica y se exterioriza. El cambio del espacio público y su interiorización lo encontramos en las obras de Marshall Mcluhan, Manuel Castells Oliván, Lev Manovich. También, en Jean-Luc Nancy en su obra La ciudad a lo lejos, en Los Nuevos Principios del Urbanismo de François Ascher, en los No - Lugares de Marc Augé, en Privacidady Publicidad: La Arquitectura Moderna como Medio de Comunicación de Masas de Beatriz Colomina como también en las obras de Richard Sennett. Autores que han hablado de la influencia del Ambiente Aumentado en las dicotomías arquitectónicas son Zygmunt Bauman, Trevor Boddy, Jordi Borja y Zaida Muxi, Keiichi Matsuda, William Mitchell, y Eduardo Roig. 


\section{ESTADO DEL ARTE}

Empezando del entorno más cercano de la tesis, investigaciones realizadas o que están realizando, libros, conferencias o ponencias en España y Grecia, no se ha encontrado ninguna tesis de estructura y objetivo similar; es decir, no se ha encontrado ningún intento ni de una clasificación de los tipos de "entre" con los que nos encontramos en las actividades arquitectónicas ni de un análisis extensa del pensamiento binario y los pares de términos opuestos del lenguaje arquitectónico. Tampoco se ha encontrado algo parecido en el entorno muy lejano; una extensa investigación en las universidades de arquitectura por el mundo no consiguió encontrar algo parecido. Sin embargo, sí que se ha encontrado la misma intención - la clasificación de los tipos del "entre" - pero solamente en el ámbito filosófico. Hablamos de la ponencia Pensar el entre, contribuciones para una crítica de la razón intersticial por Iván Flores Arancibia en el XLVII Congreso de Filosofía Joven de la Universidad de Murcia de 28 abril, 2010 - 30 abril, 2010. Arancibia introduce el concepto de la entridad y de las figuras intersticiales y hace un catastro - como lo llama - de figuras intersticiales usados por filósofos; ponencia que fue de gran ayuda para esta tesis doctoral porque le ofreció un resumen de todos los modos que se ha visto el "entre" en la filosofía. Lo más cercano a la investigación desde el ámbito de la arquitectura es el trabajo literario del arquitecto griego Stavros Stavridis; toda su obra se centra en la "filosofía del entre" pero principalmente relacionado con la significancia simbólica de los lugares intermedios y sin tocar el fenómeno de los pares de términos opuestos. Sus libros más relacionados son De la ciudad pantalla, a la ciudad escenario (2002) y el libro Hacía una Ciudad de los Umbrales (2010).

La investigación pertenece al grupo de investigación Hypermedia: Taller de Configuración y Comunicación Arquitectónica del departamento de Ideación Gráfica Arquitectónica de la E.T.S.A.M - en lo que participan los directores de la tesis Atxu Amann Alcocer y Javier Seguí de la Riva- así que los trabajos de la gente que lo construye y lo sigue están cerca de la tesis doctoral. De gran influencia y primer contacto con la noción de la mediación de la investigación fue la tesis doctoral de Polyxeni Mantzou realizada en 2000 con directores a Javier Seguí de la Riva bajo el título Utilización de 
medios audiovisuales como modificadores del espacio arquitectónico; estudio sobre la modificación del espacio arquitectónico por la mediación de los nuevos medios. Influencia importante en la realización de la tesis doctoral fue todo el trabajo literario de Polyxeni Mantzou. Las conferencias presentadas en Museo Bizantino de Atenas: The im-mediacy of contemporary architecture en 2003 y Architecture in the Digital Machine Age en 2014; 2ciones; es collage de líneas de investigación: Polyxeni Mantzou, Atxu Amman Alcocer, Javier Seguí de la Riva, François Jullien, Zygmunt Bauman, Bruce Bégout. Sin embargo la que más ha definido la línea de esta tesis doctoral las líneas de Javier Seguí de la Riva que ampliaron el concepto del "entre" e hicieron la tesis que saliera fuera de el "entre" físico que en las escuelas solo llamamos espacios intermedios. La nueva dualidad que introduzca Javier Seguí de la Riva proyectar desde dentro - proyectar desde fuera empujó a la investigación hacia la cuestión de si existe el modo del "proyectar desde el entre", pues las dualidades existen sólo porque existe el "entre". Además, la dualidad ya habitar desde dentro - habitar desde fuera (es decir, praxis - teoría) es la que conduzco a la clasificación de los estados del "entre" como estados tangibles físicos (puentes, puertas, pasillos, umbrales, proscenios, pórticos, puertos, etc.) y como estados inteligibles (lo que está entre los edificios, dialogo, encuentro, lenguaje, comunicación, el no - objeto); desde fuera el intermedio es un objeto que se puede ver, desde dentro no se ve sino solo se capta, es el no- objeto de François Jullien. Todos los cuadernos de Javier Seguí de la Riva publicados por la Editorial Mairea fueron de gran influencia a la investigación, empero los importantes son Dibujar, Proyectar (XXXIII). Vivir, hacer arte (2) de 2011, Dibujar, Proyectar (XXXII). Vivir, hacer arte (1) de 2011, después de los que el vacío fue visto como lleno de significación; Dibujar, Proyectar (VII). Envolturas de 2004, Dibujar, Proyectar (XVIII). Desde fuera y desde dentro. Del todo a la parte (2) de 2009. Dibujar, Proyectar (XVIII). Desde fuera y desde dentro. Del todo a la parte (1) de 2009 son las referencias más importantes de la investigación y más cercanas al tema de la investigación, pues sin entender esta clasificación no sería posible hablar del "entre" más allá que su matiz física. Dibujar, Proyectar (IX). El grado cero de la arquitectura de 2006 y Dibujar, Proyectar (XXXIX). Extrañeza (1) de 2011 son las referencias responsables para la presencia de la dualidad familiar - extraño del primer capítulo de la tesis. Los cuadernos Dibujar, Proyectar (L). Transitar-Atlas de 2012 que 
ayudó a la mejor compresión de Atlas, que es lo que la tesis quiere ser; Atlas de figuras intersticiales. La ponencia Arquitectura y Narración presentada en las Segundas Jornadas sobre Investigación en Arquitectura y Urbanismo - Comunicaciones, en Universitat Politècnica de Catalunya. Escola Tècnica Superior d'Arquitectura del Vallès de constituye el principio de la investigación de la tesis relacionada con los procesos de familiarización.

La Tesis de Pedro Burgaleta Mezo Residua. El valor de lo marginal, realizada en 1993 en E.T.S.A.M, es una tesis de 20 años adelantada de su época, pues de lo residual, del "entre", de lo marginal acaban de empezar de ser temas de interés de los últimos años. Una tesis que encuentra el "entre" en los partes de los procesos creativos artísticos que se resistan a la forma general. Parece a la lógica infraestructural que empezaron Smithson, según la que lo transitorio del vacío se usa como elemento constructivo, encontramos en La ciudad como espacio de relaciones dinámicas colección de trabajos de alumnos que trabajan con el flujo de los sistemas y las redes de la ciudad por Javier Raposo Grau, Miguel Paredes y Belén Butragueño publicado por la editorial Mairea en 2011. Angelique Trachana en Urbe Ludens, libro publicado por las ediciones Trea en 2014, habla del nuevo Homo Ludens que es el Urbe Ludens quien usando las facilidades de los nuevos medios puede con facilidad expresar sus ideas, crear colectivos y participar con sus actuaciones irregulares en la construcción del tejido urbano. La obra de Angelique Trachana es una investigación extendida de lo que el primer y segundo capítulo de la investigación que es la importancia de la participación del ciudadano en su entorno como también que lo importante que tiene lo irregular.

De los temas que la tesis toca - pero no profundiza - existen tesis doctorales del Departamento de Ideación Grafica de las que la investigación se ha influenciado y que profundizan cada una a otra parte del atlas del "entre". Por ejemplo. La tesis realizada por Laura Gallardo Frias, leída en 2012 bajo la dirección de Javier Seguí de la Riva, Lugar/ No-Lugar/Lugar en la Arquitectura Contemporánea es una extensa investigación de los lugares intermedios o no que la tesis considera como lugares del desencuentro. La tesis de Graziella Trovato, La fachada como lugar en la arquitectura contemporánea, con director a Javier Seguí de la Riva y leída en 2014 está dedicada a la fachada como un lugar intermedio. Habitar lo irreal. Aproximaciones a una arquitectónica de los mundos virtuales, presentada en 2014 por Emilio López-Galiacho Carrilero, bajo la dirección de 
Atxu Amman Alcocer y Javier Seguí de la Riva habla de lo que está entre lo virtual y lo real.

En tesis doctoral El Entorno Aumentado: Imperativo informacional para una ecología digital de lo arquitectónico por Eduardo Roig Segovia en 2014 con directora a Atxu Amman Alcocer se analiza el Entorno de Realidad Aumentada, que es un entorno hibrido, lugar del "entre", encontramos como la presencia del Entorno Aumentado ha cambiado los termino opuestos tradicionales y los pares de opuestos inventados después de su aparición. Un "entre" de tipo completamente distinto pero cerca a lo de Javier Seguí de la Riva y Pedro Burgaleta, lo del momento que el dibujo parece a Khora de Platón, el espacio donde una cosa es pero todavía no es, el dibujo y el dibujar entre lo abstracto y lo figurativo, siendo a la vez los dos pero ninguno de los dos, encontramos en la Tesis Doctoral de Anthi Kosma, Proyectar dibujando: Una aproximación fenomenológica al estado naciente del proyecto. Un estudio entre dos culturas arquitectónicas dirigida por Javier Seguí de la Riva y Paloma Ubeda Mansilla, leída en 2014. La tesis de Magdalini Grigoriadou El imaginario en la génesis del proyecto arquitectónico: La construcción de la realidad a través del mito, la utopía y la cibercultura dirigida por Atxu Amman Alcocer y Javier Seguí de la Riva leída en 2014, aproxima tanto el pensamiento binario con las dualidades hombre -mujer y cuerpo máquina, lo hibrido a partir del cuerpo de la cibercultura, como también al pensamiento metafórico a través del análisis del imaginario colectivo.

Sobre el intermedio encontramos la tesis que está en curso Tres bibliotecas de Rem Koolhaas como paradigmas de lo intermedio realizada por Antonio Lara Morcillo con Concepción Lapayese Luque, José Morales Sánchez como directores en departamento de Proyectos de ETSAM. En el mismo departamento se está realizando la investigación Espacios Inter-Medios del Forjado a la Entre-Planta por Ricardo Montoro Coso, con directora $\mathrm{M}^{\mathrm{a}}$ José Aranguren López. En el mismo departamento de Proyectos de ETSAM están en curso dos tesis más que tocan el concepto del intermedio: la de Ana Cristina Oliveira Vasconcelos con directores Félix Ruiz de la Puerta, Juana $\mathrm{M}^{\mathrm{a}}$ Sánchez González que enfoca en los procesos intersticiales de Eisenman bajo el titulo Lo intermedio como lugar. El tropo de lo intersticial en la arquitectura contemporánea. El 'monumento a las víctimas del holocausto' de Berlín. Peter Eisenman; y la de Luis Gil Guinea que con su director José Manuel López-Peláez Morales 
enfocan en el concepto del "entre" en el trabajo de Team X bajo el título Lugares intermedios. El pensamiento del Team X y su influencia en la arquitectura moderna.

Más cerca a la investigación están la tesis de Master que están realizando y no las tesis doctorales, hecho que, quizás, muestra que el "entre" en los procesos arquitectónicos acaba de empezar de tener cada vez más investigaciones dedicadas. Muy cerca está la tesis de Master de Sebastián Naranjo Cárdenas: El límite y su reversibilidad realizada con director Javier Seguí de la Riva en 2014. Habitar el Límite, por Óscar Martín Valdespino y como director José Miguel García Cortés leída en la Universitat Politècnica de València en 2013. Cerca de la investigación está Héctor Maestre Deltell con Polimatía prospectiva. De la incertidumbre a los sistemas complejos desde el pensamiento negativo, con directora la Atxu Amann Alcocer realizada en 2013 La tesis de Master de Marta Rabazo Martín realizada en 2013, con los directores Lucía Jalón y Javier Ruiz Sánchez, bajo el título, El vacío entre infraestructuras lineales y ciudad: espacios anómalos como oportunidad para lo colectivo. La tesis de Master de Mario Barrientos Moral, Espacios Duda. Topología, uso y velocidad del medio arquitectónico, realizada en 2013 con el director PedroFeduchi. La tesis de Master Aportaciones contemporáneas a la calle corredor. Análisis e interpretación del Linked Hybrid de Steven Holl realizada en 2013 por Luis Javier Aguilar Benavides con los directores a Nicolás Maruri González de Mendoza y Rafael Pina Lupiañez. Otras tesis de Master que acercan la tesis son por Ignacio García Martínez El límite difuso. Tectónica del límite en Toyo Ito 1971-2001 realizada en 2013 con los directores Rafael Pina Lupiañez y Nicolás Maruri González de Mendoza; Lo inacabado en la arquitectura. Herman Hertzberger por Clara Rodríguez Lorenzo con el director Jesús Ulargui. El retorno eterno, de João Quintela realizada en 2013 con el director a Alberto Campo Baeza. La espacialidad radical: transmutando espacios de acción y reacción de Ana Medina Gavilanes, realizada en 2013 con los directores Atxu Amann Alcocery Javier Ruiz Sánchez y por último La metáfora. Herramienta característica de renovación arquitectónica tras el movimiento moderno Ángela Teresa Rodríguez Fernández realizada en 2014 con los directores a Francisco Javier Maroto Ramos y Roberto Osuna Redondo. En Escuelas de Arquitecturas de España fuera de Madrid tesis dirigidas por Josep Muntañola i Thornberg como: Khora. El lugar: Desde la forma a la información. 
Lugares claves en el desarrollo urbano leída en 2005 en Universitat Politècnica de Catalunya, Barcelona Justin Ion Baroncea, En la penumbra: Sobre el umbral de la arquitectura leída en 2000 en Universitat Politècnica de Catalunya por Beatriz Ramírez Boscán, Ciudad formal - Ciudad informal: La frontera como encuentro por Yuraima Elena Martín Rodríguez en la Universitat Politècnica de Catalunya en 2007, Arquitectura inmaterial: La disolución de la forma y la imagen por Jaime Arturo Jofré Muñoz en la Universitat Politècnica de Catalunya en 2008, El espacio público como escenario / cinematográfico / - / La arquitectura como obscenidad por Ruth Marcela Díaz Guerrero en la Universitat Politècnica de Catalunya en 2001. Con otros directores, El Nudo y la Arquitectura. Aproximación crítica a Proyectos complejos por Boris Oswaldo Albornoz Vintimilla con director Antonio Armesto Aira en Universitat Politècnica de Catalunya leída en 2000. El afecto en la arquitectura. La relación arquitecto-lugarhabitante a través de la experiencia del proyecto por Fernando M Espósito Galarce y el director en 1 Luis Ángel Domínguez Moreno en Universitat Politècnica de Catalunya, Barcelona leída 2011. El diagrama en arquitectura. Una estrategia contemporánea de proyectos por Victor Manuel Martínez López leida en 2009 en Universitat Politècnica de Catalunya, Barcelona con el director Joan Puebla Pons, La Frontera Diluida. Arquitecturas efímeras en el cine. De Europa a Hollywood por Pedro Javier Molina Siles con los directores Ángela García Codoñer y Ana María Torres Barchino leida en la Universitat Politècnica de València en 2014. El balcón y el mirador en la arquitectura pre-moderna: el caso de la Valencia intramuros. Estudio histórico, compositivo y de cultura material por Paolo Privitera y los directores Camilla Mileto Fernando Vegas López-Manzanares leída en Universitat Politècnica de València en 2015. En los últimos años, se realizan cada vez más congresos, conferencias o jornadas que investigan el tema del "entre", cada vez de distinto puntos de vista. En 2014 el Tema de debate del Congreso EURAU: Composite Cities realizado en Estambul fue la ciudad compuesta: la ciudad hibrida, ciudad transformada, ciudad fragmentada, ciudad mutable, teniendo como palabras claves en su programa la de la mediación/intervención. Hybrid City II: Subtle rEvolutions en Grecia fue dedicada a lo híbrido y la de Hybrid City III: Data to the People se dedica a la mediación de las nuevas tecnologías para la mejora del urbanismo participativo. En la mayoría de los congresos y jornadas que se hacen en el 
campo de la arquitectura-urbanismo la mediación y el "entre" se limita en la mediación de los nuevos medios y los cambios que ellos provocan. El Congreso más cercano a la investigación que se ha encontrado fue el Congreso Científico Transparencia y Arquitectura: Vacío, lleno en la Universidad Aristóteles de Salónica en Grecia, realizado en 2001 y el de 2007,Congreso Científico Transparencia y Arquitectura: Desafíos y Limites.

\section{OBJETIVOS}

La tesis tiene tres objetivos: descubrir la relación que existe entre la vida y el diseño, aproximarse a la filosofía del Entre y analizar las influencias del pensamiento binario en el diseño. Mientras que la relación vida-diseño se observa a través de tres fenómenos sociales, objetivos más específicos es el encuentro con la aportación del arquitecto en dichos fenómenos y la aplicación de la teoría del entre en el apoyo de su resolución.

El objetivo principal de la tesis es encontrar los modos en los que la vida y la configuración arquitectónica se interrelacionan: averiguar si realmente las construcciones de los arquitectos influyen en la vida de los habitantes, investigar la causa de la distancia entre lo que los arquitectos imaginan y lo que los habitantes necesitan y de qué modo la vida influye en los proyectos arquitectónicos.

El acercamiento al primer objetivo de la tesis se hace a través de la compresión del concepto del Entre: de la distancia, lo intermedio, el medio, el intervalo, el intersticio, la relación; el lugar más adecuado porque hablar de la relación de dos conceptos es hablar de la distancia que las separa y las conecta. El segundo objetivo se resuelve en la realización de una especie de atlas de los distintos puntos de vista con los que filósofos y arquitectos enfrentan el Entre.

Del estudio del intermedio deriva otro objetivo que es aproximarse a las formas de pensar y al trabajo del pensamiento binario. Observando el Entre desde fuera como palabra y como lugar se revela que su existencia se debe al pensamiento binario, es decir, al hecho de que la mente se para el mundo en pares de términos opuestos. De este modo, tercer objetivo es encontrar los modos posibles de pensar y su influencia 
en la configuración arquitectónica. De la investigación relacionada a los tipos de pensamiento, la tesis observa que el pensamiento binario es lo que ha definido la filosofía y la arquitectónica occidental. Los modos con los que la sociedad se mueve entre ellos define los sistemas políticos y estos delimitan los proyectos de los arquitectos. En otras palabras, la manera con la que la sociedad enfrenta el Entre define su modos de vivir. En consecuencia, las formas que los arquitectos dan a los lugares intermedios revelan sus actividades políticas y escriben la historia y teoría de la arquitectura.

El experimento y la posible aplicación de la tesis está en los tres fenómenos sociales que destacan en el siglo XXI: la enfermedad del aburrimiento, las ciudades informales y las ciudades fantasmas, y el desencuentro. El análisis de dichos fenómenos permite la aproximación a la aportación de los arquitectos en su expansión y, a través de ella, se hace posible el encuentro de la relación de la vida con los proyectos arquitectónicos. La lectura de la historia del urbanismo muestra que los proyectos por arquitectos que proyectaban desde de la Filosofía del Entre han apoyado la solución de los fenómenos sociales analizados.

\section{METODOLOGÍA}

Si supiese qué es lo que estoy haciendo, no le llamaría investigación, verdad?, dijo una vez Einstein; y en otro momento afirmó que la investigación es lo que estoy haciendo cuando no sé qué estoy haciendo.

Sería mentir decir que su investigación tuvo una metodología. Fue consciente de su metodología después de haberse hecho y sólo porque alguien le pidió que la escribiera. La tesis doctoral, en su interior, propone un método de trabajo para la configuración arquitectónica: moverse $\sin$ plan; es decir, no planear, no tener autodisciplina, no tener una Idea previa sobre lo que uno quiere hacer, sino solo tener una intuición; no pensar en lo que está haciendo sino conocerlo después de haberlo hecho. Vivir y trabajar desde la quinta clase de ambigïedad que William Epson - citado mucho por Venturi - ha descrito; 
desde una confusión afortunada, como dice Epson, en la que el autor está descubriendo su idea mientras está escribiendo. O, también, es investigar y proyectar a partir de estados de epifanías o, de estados de serendipia, como los nombra el arquitecto Horace Walpole, o desde el trabajo preliminar del consciente, como lo describe Henri Poincaré; es decir, crear a partir de aquellos hallazgos valiosos que se producen de manera accidental o casual:

La metodología que la investigación ha seguido es el método de trabajo que ella propone: la estrategia de no actuar (wu wei), del concepto que está utilizado en la cultura china y atraviesa todas sus escuelas. No bay cosa más útil que no bacer nada, decía Lao Zi. La estrategia o arte de no actuar se base en la frase no hacerpero no dejar nada sin hacerse. El no hacer no se refiere en su sentido pasivo que en occidente lo entendemos, sino dejar que las cosas pasan de manera natural. Y la estrategia del no actuar es mucho más eficaz de las del occidente - según las que todo tiene que estar planificado y programado antes de su comienzo - si se observa que, a China, por esta estrategia de no actuar, nadie ha conseguido invadirla. Y es más, mientras que aparentemente no hay metodología, bajo esta metodología de no actuar, de repente, las cosas están hechas sin darse cuenta como se hicieron. Eso es lo que sucedió con la investigación.

La traducción de la estrategia del wu wei de la investigación en términos occidentales sería aquella que usa una investigación cualitativa que ha seguido un camino intuitivo - inductivo y que, observando los habitantes de la ciudad desde dentro con cuadernos de notas, es decir, con el método de la observación participante que principalmente usan los antropólogos, intenta llegar con la ayuda de notas bibliográficas a tener una visión holística de la distancia que existe entre el modo que los habitantes viven y el modo que los arquitectos creen que los habitantes viven. A partir de eso con el estudio de los tres fenómenos sociales que se analizan en la tesis, la investigación llega a sus conclusiones generales sobre el modo que el arquitecto influye en la vida.

La investigación es interdisciplinar-según Groaty Wang todas las investigaciones deben ser necesariamente interdisciplinares o aún más transdisciplinares ${ }^{6}$ - es decir, no se ha limitado en lecturas del campo arquitectónico sino, y principalmente, viene de los campos de la sociología, la filosofía, la neurociencia, la antropología ya que la investigación empieza con el estudio de tres fenómenos sociales. La investigación tiene 6 Groat, L. \& Wang, D. Architectural Research Methods. John Willey and Sons, Canada, 
dos fases: la primera es la de la observación participante que es un modo de trabajar que uno vive desde dentro el objeto de investigación y, de tal manera que no solo olvida que es un arquitecto que estudia la vida de los habitantes, sino olvida que está investigando. Y por eso, como en el método de wu wei, al final cuando entra en la segunda fase - la fase final - tiene la sensación que todo se ha hace solo. La segunda fase es la contraria de la primera; salir fuera de la ciudad y los libros y, aislado, con todo el material de las notas y lecturas llegar a escribir y cerrar la investigación.

Los títulos de los capítulos y subcapítulos de la tesis se deben a que precisamente están extraídos del diario de notas que los investigadores cualitativos utilizan mientras la observación participativa. ${ }^{7}$ La tesis doctoral es en realidad el diario de la investigadora en lo que apuntaba las conexiones absurdas - las serendipia, epifanías - que, de repente, sucedían cada vez que se encontraba en un estado inesperado pero intermedio. Ejemplos son el tedio y la ruptura de una relación amorosa que condujo a la investigación sobre el tedio urbano y los procesos de la familiarización; las series de fantasmas y vampiros que desencadenaron el estudio de las ciudades fantasmas y los slums. De este modo, los capítulos de la tesis se construyen por los lugares intermedios en los que la investigadora ha entrado; cuando decía Me Aburro, en el Tercer Espacio, con Fantasmas, Zombis y Vampiros, Entre la Espada y la Pared, Dentro de lo Innombrable, Sin Techo.

7 James P. Spradley, «Participant Observation,» (1980). 


\section{RESUMEN Y CONCLUSIONES EN GRIEGO}

mención internacional 

UNIVERSIDAD POLITÉCNICA DE MADRID

ESCUELA TÉCNICA SUPERIOR DE ARQUITECTURA

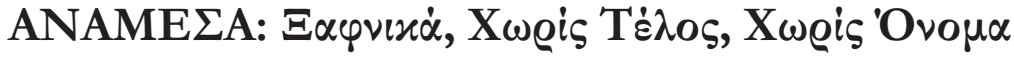

$\Delta \mathrm{I} \Delta$ AKTOPIKH $\triangle \mathrm{IATPIB}^{\prime} \mathrm{H}$

\section{ЕҮПРАЕIA ГIANNOПOY $\Lambda$ OY}

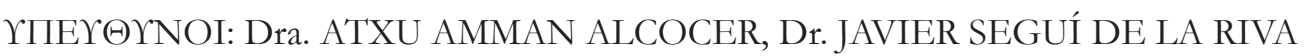





\section{ПЕРІАНЧН}

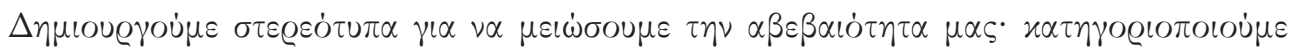

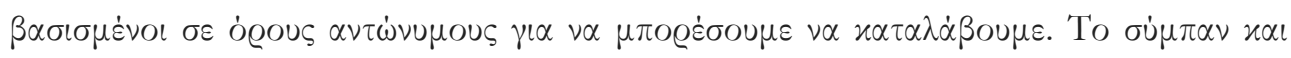

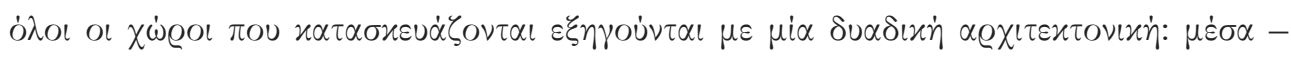

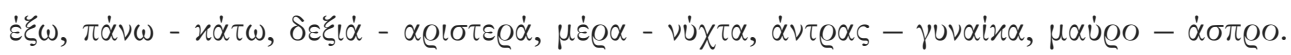

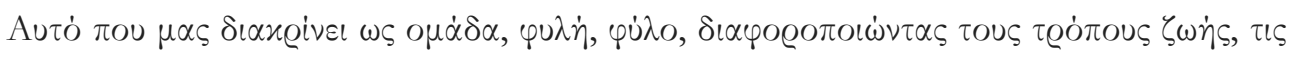

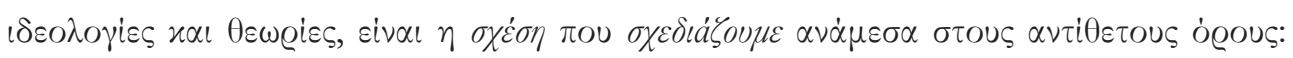

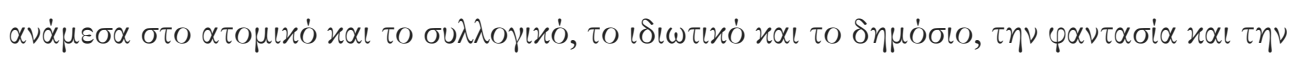

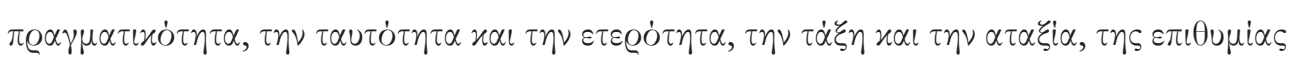

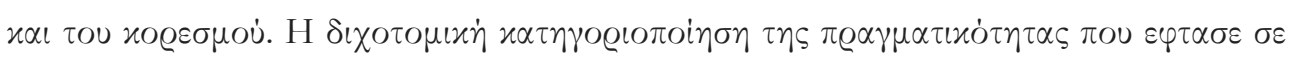

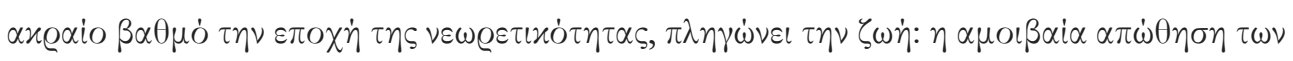

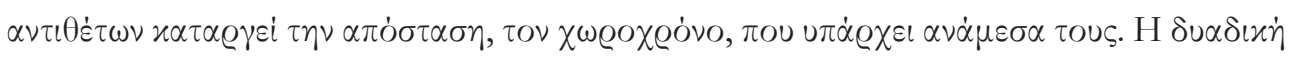

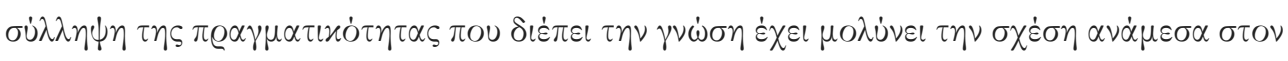

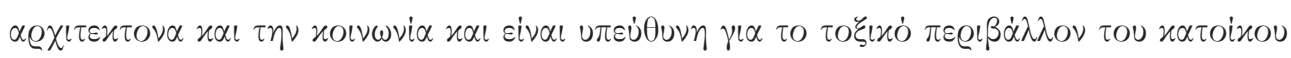

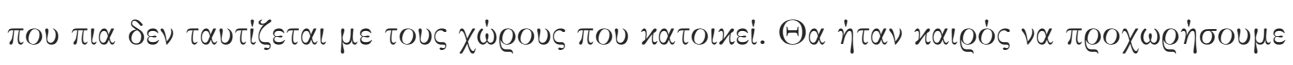

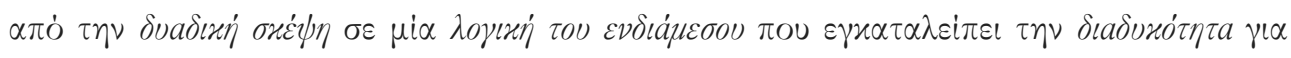

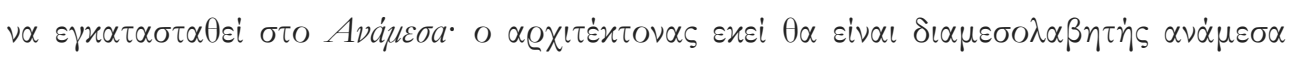

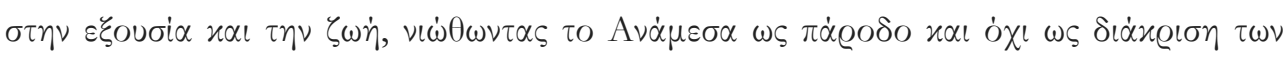

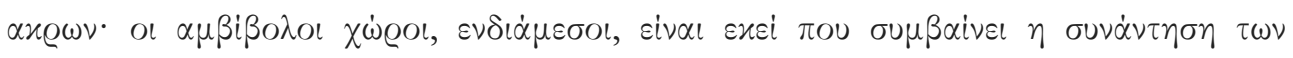

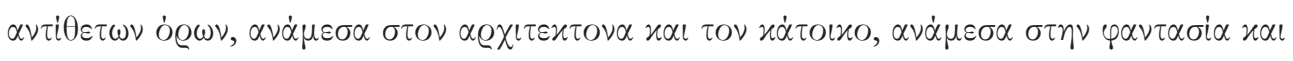

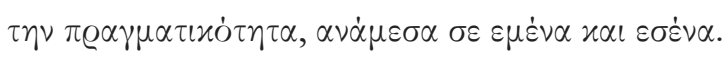





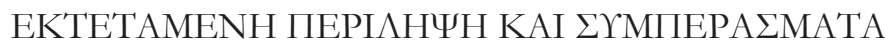

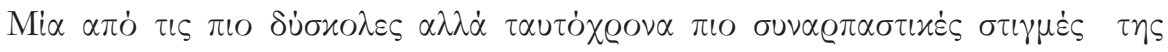

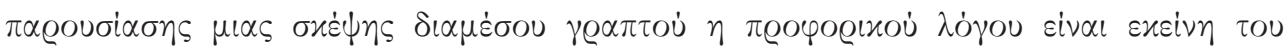

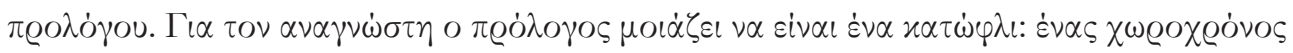

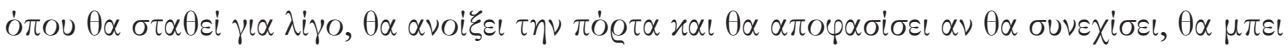

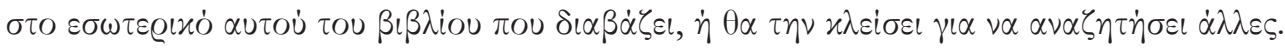

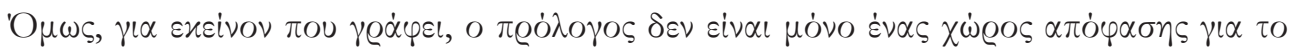

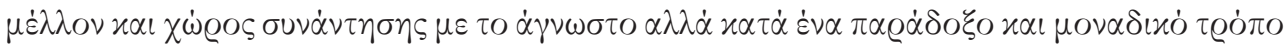

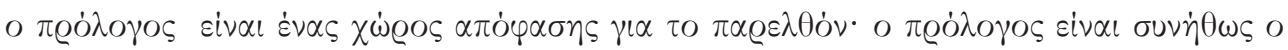

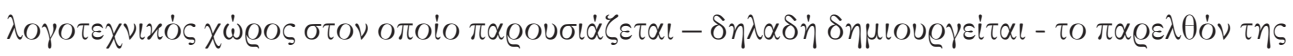

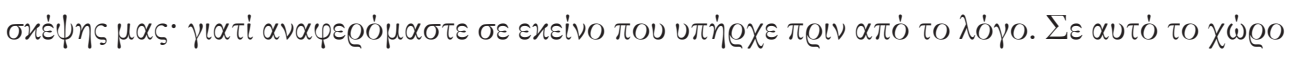

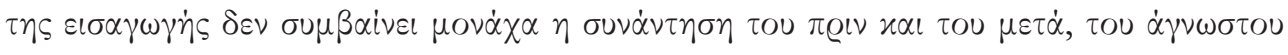

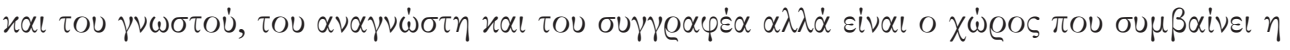

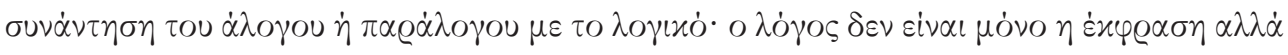

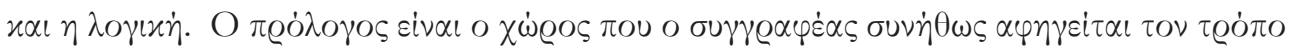

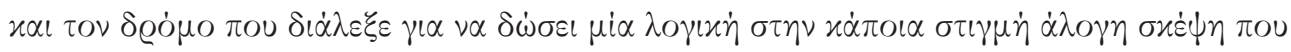

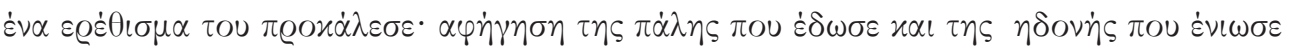

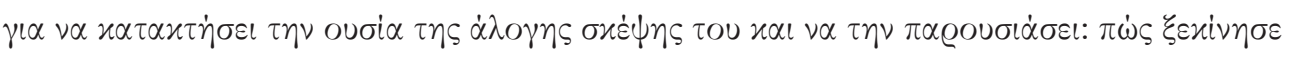
xal

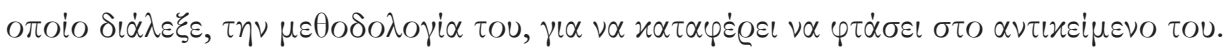

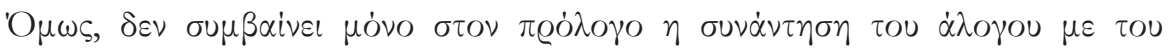

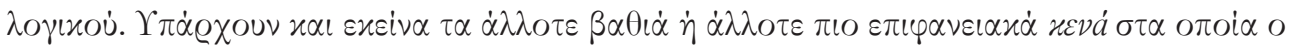

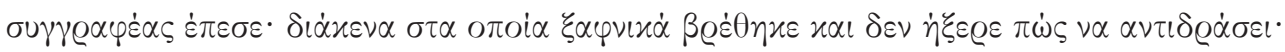

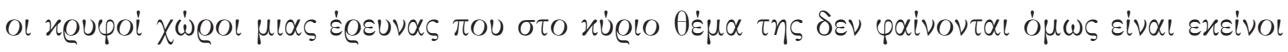

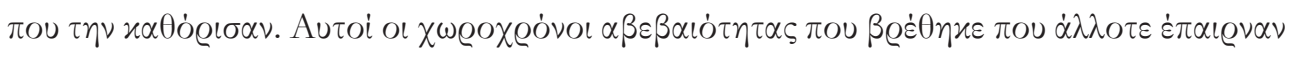




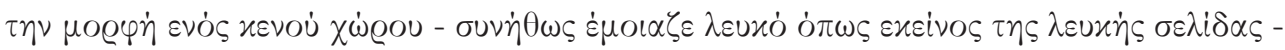

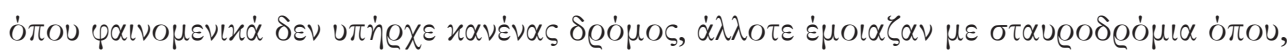

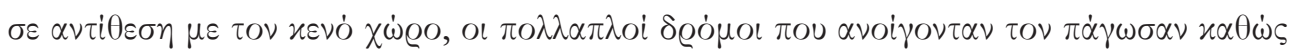

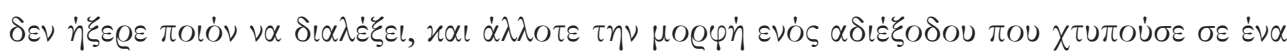

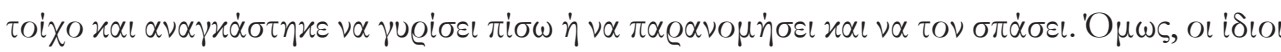

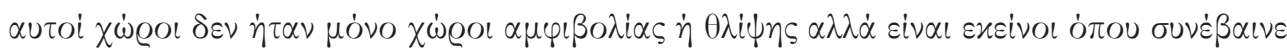

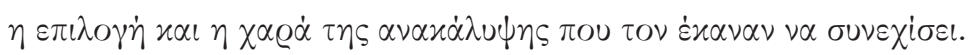

'O

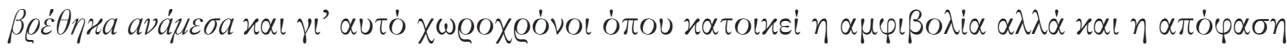

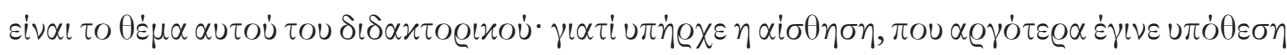

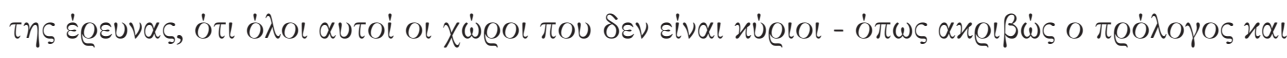

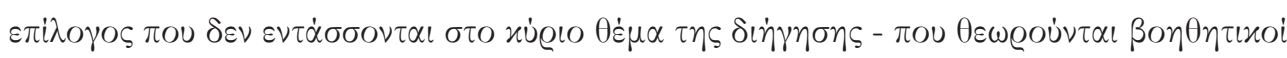

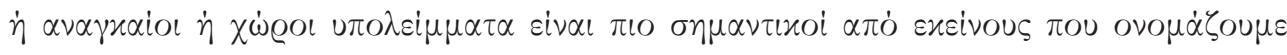

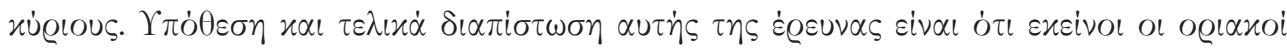

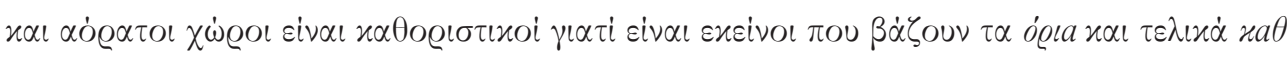

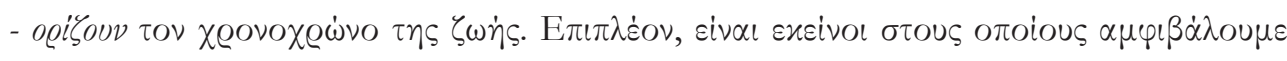

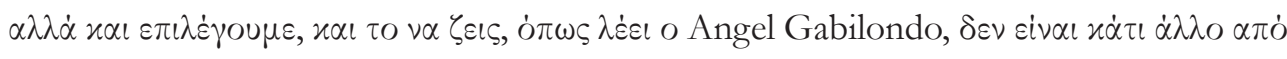
$\tau O \nu \alpha \varepsilon \pi i \lambda \dot{\varepsilon} \gamma \varepsilon \iota \varsigma$.

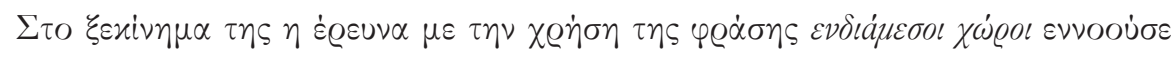

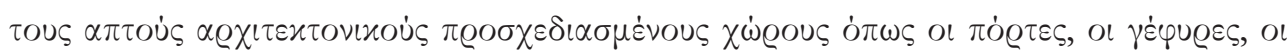

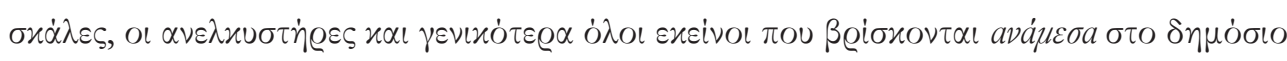

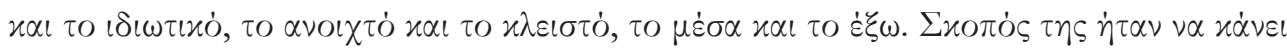

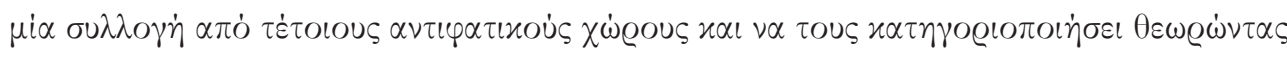

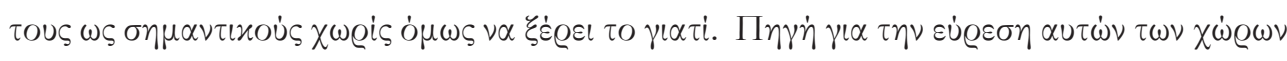

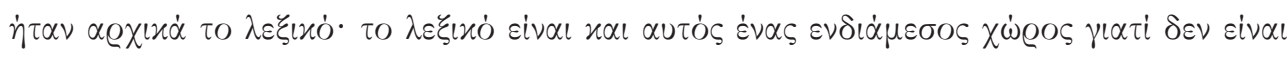

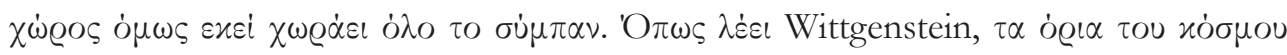

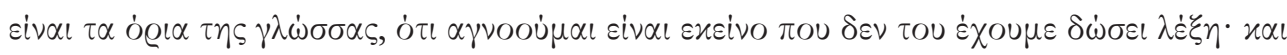

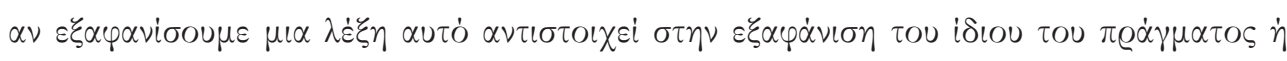

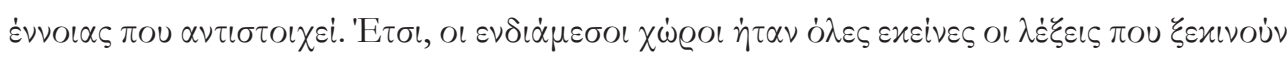

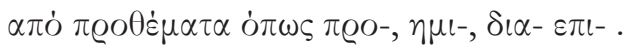




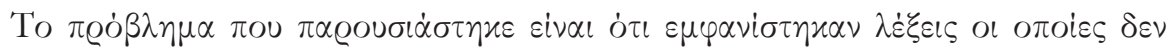

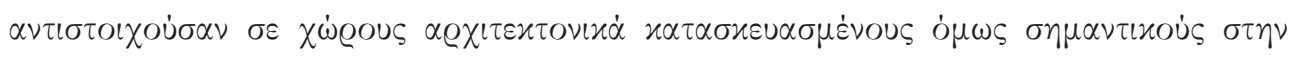

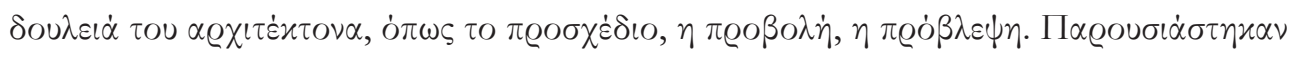

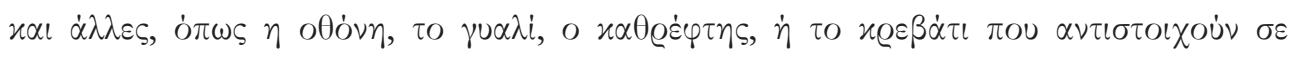

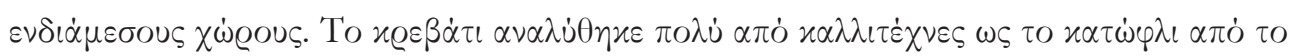

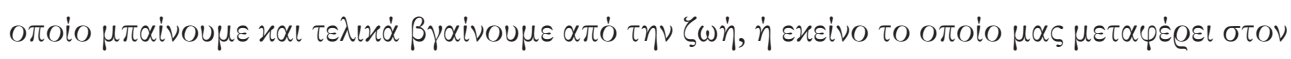

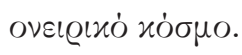

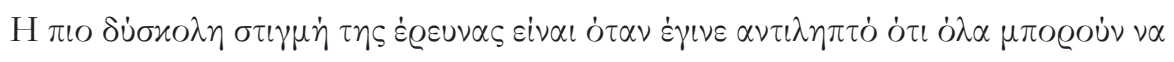

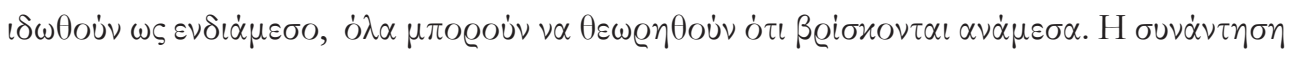

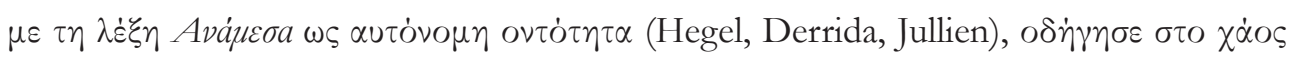

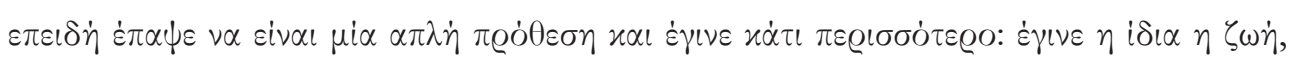

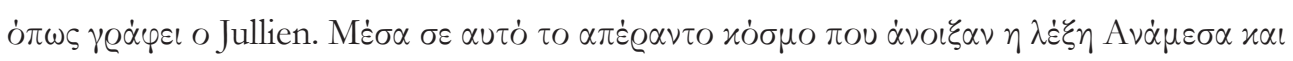

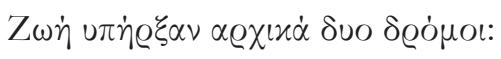

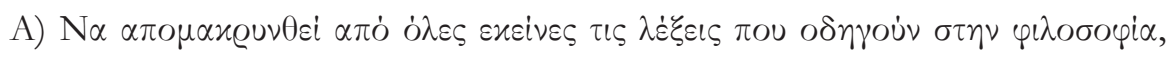

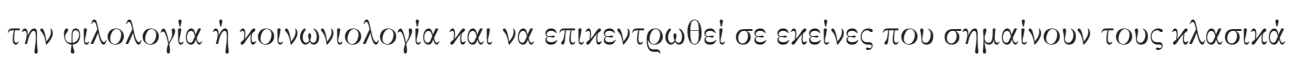

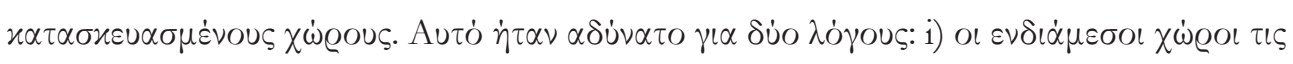

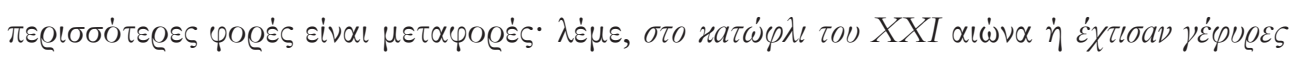

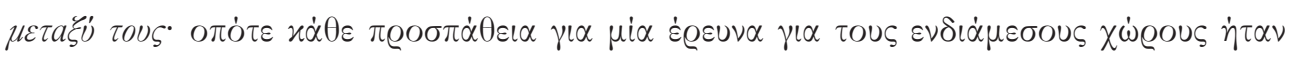

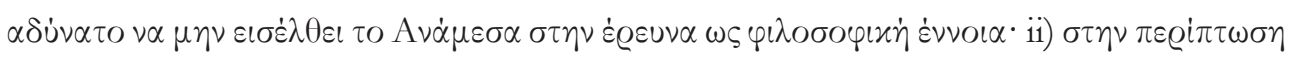

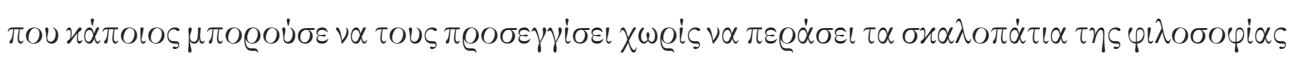

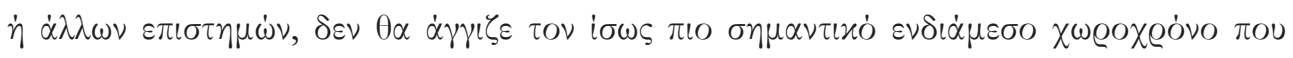

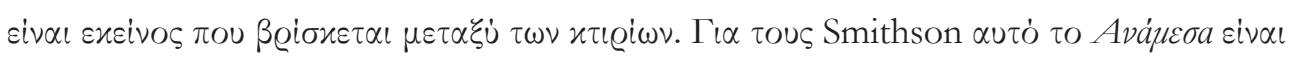

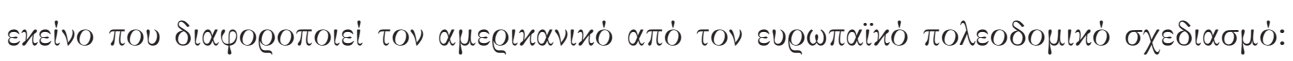

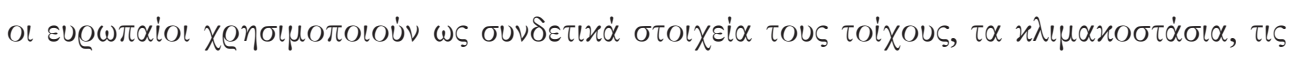

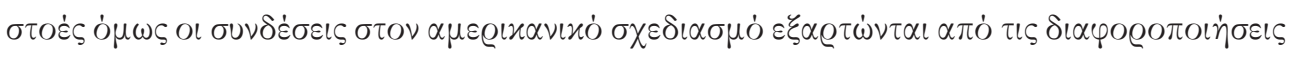

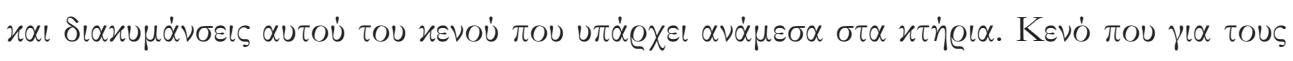

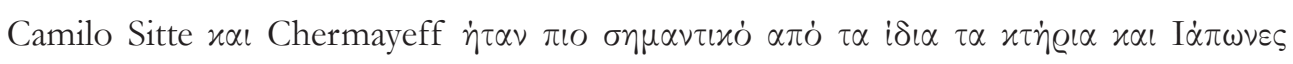

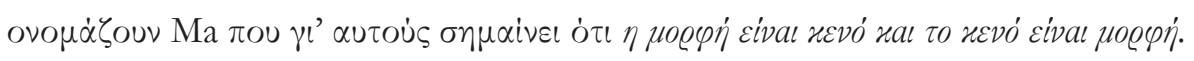

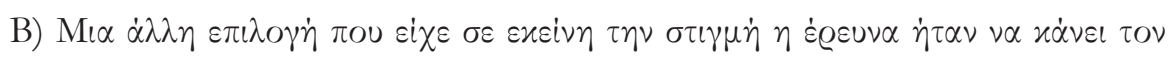

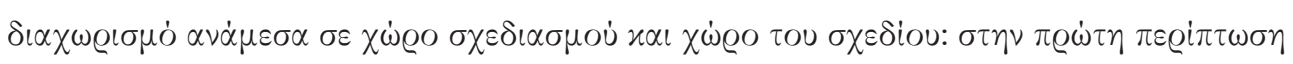

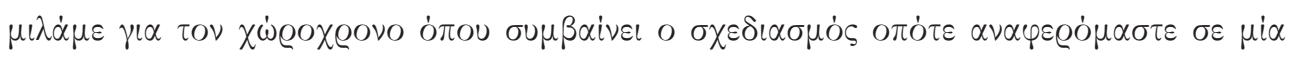




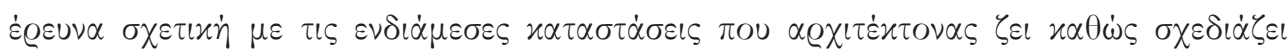

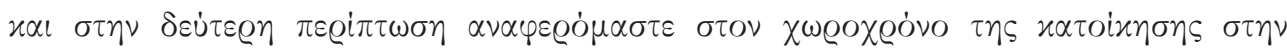

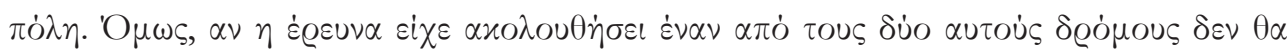

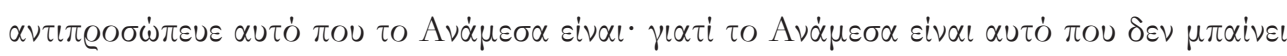

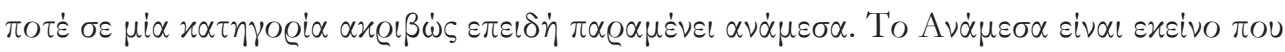

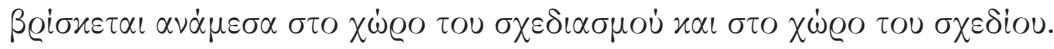

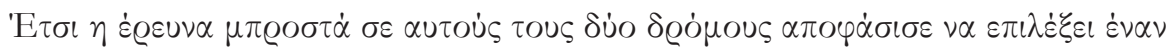

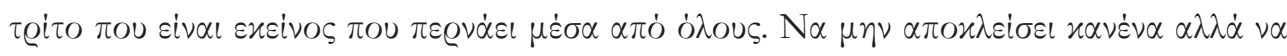

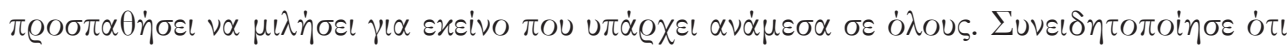

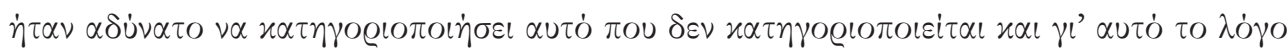

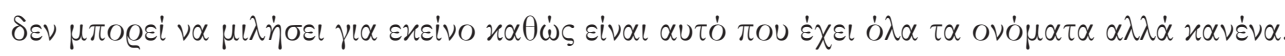

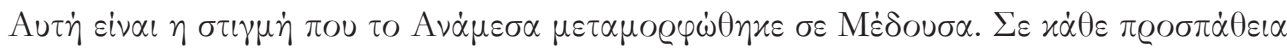

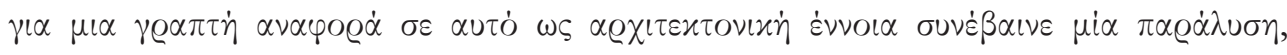

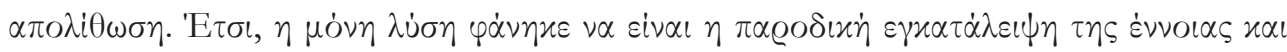

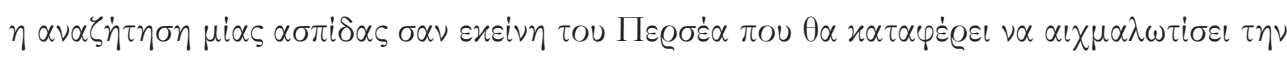

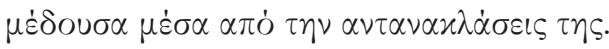

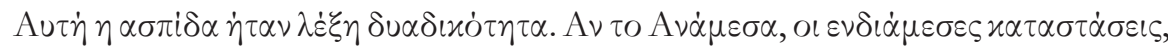

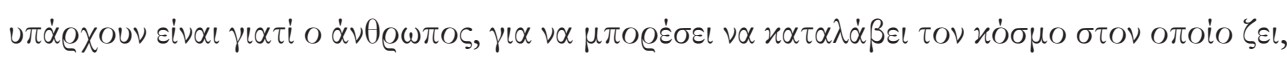

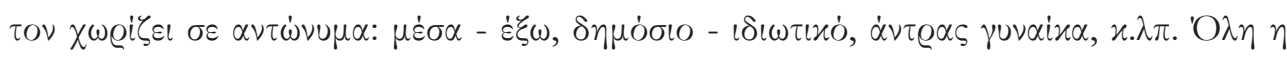

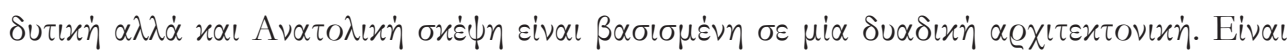

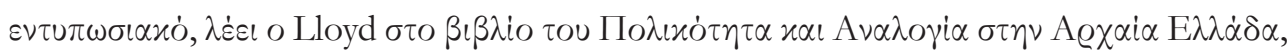

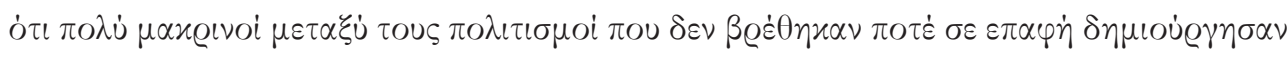

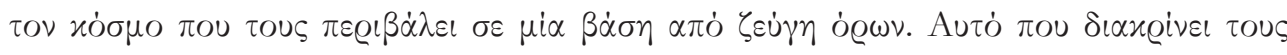

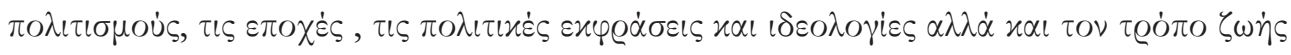

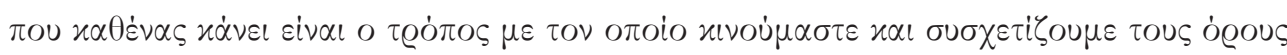

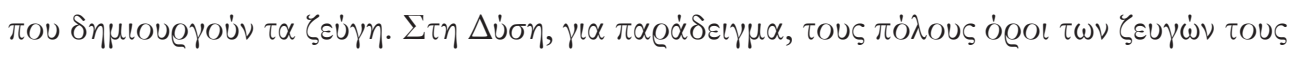

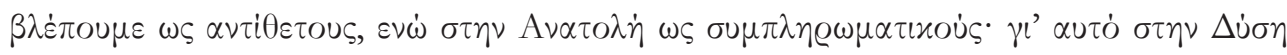

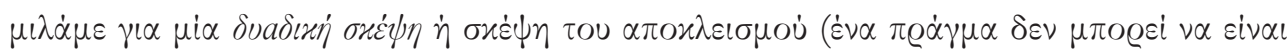

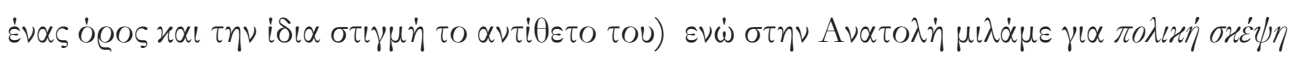

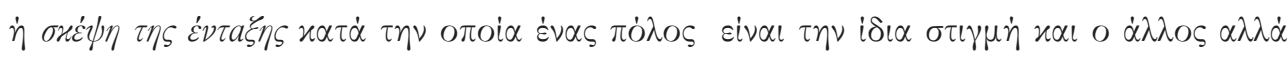

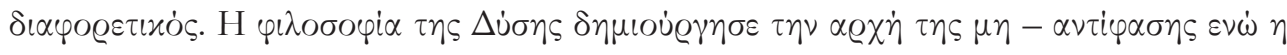




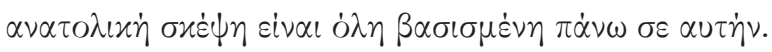

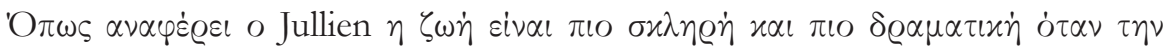

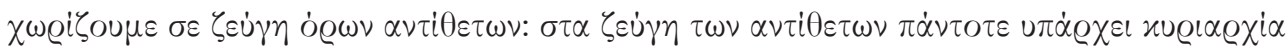

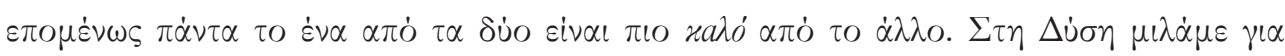

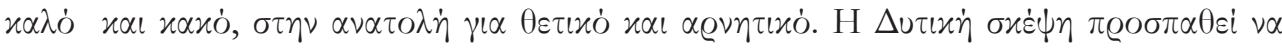

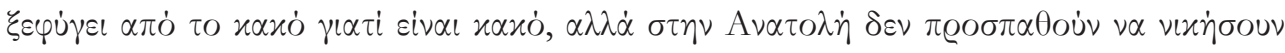

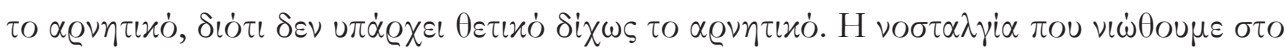

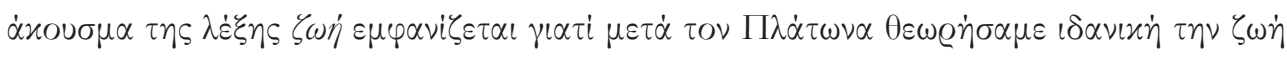

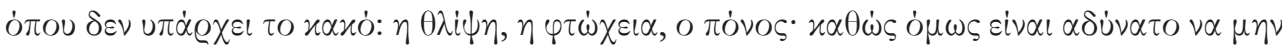

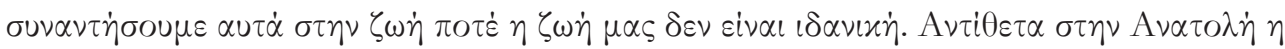

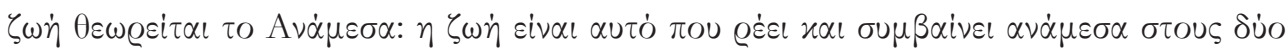

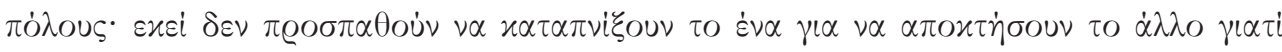

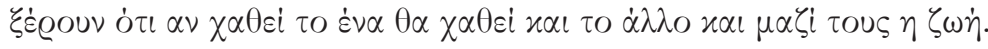

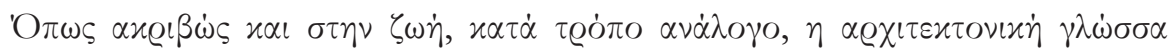

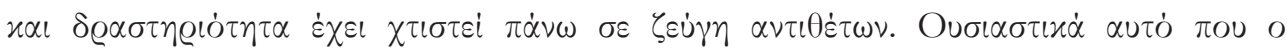

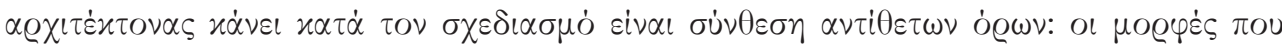

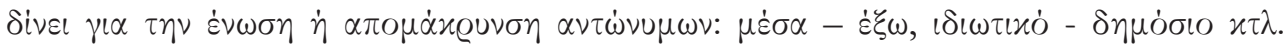

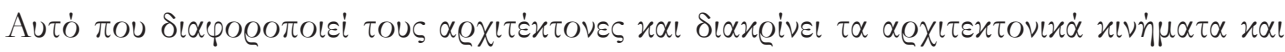

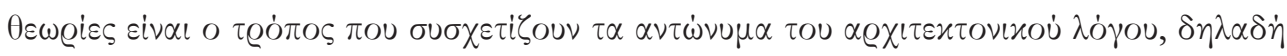

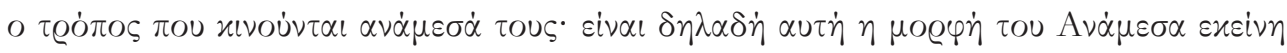

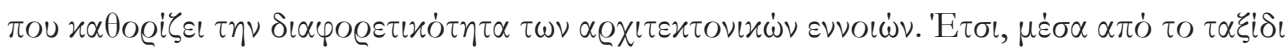

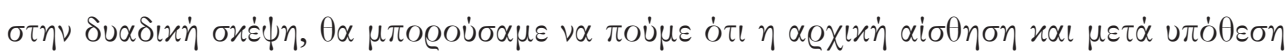

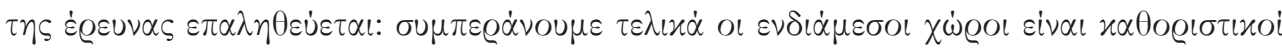

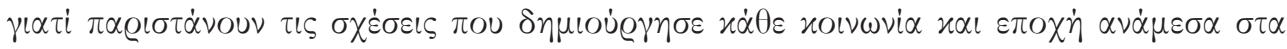

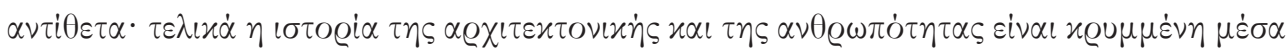
$\sigma \varepsilon \alpha u \tau \dot{~} \tau O A \nu \dot{\alpha} \mu \varepsilon \sigma \alpha$.

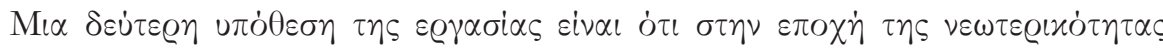

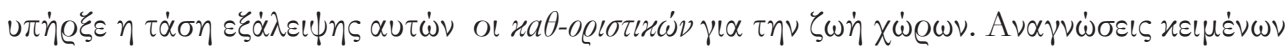

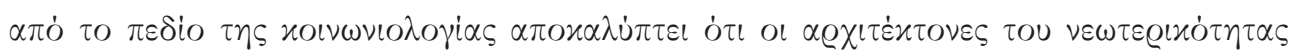

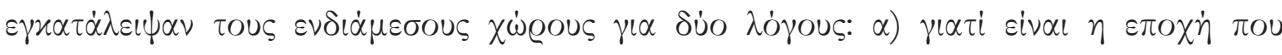

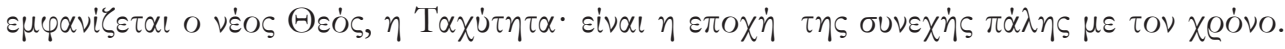




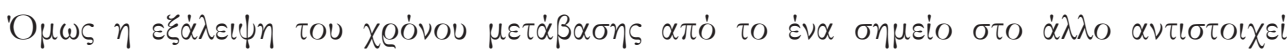

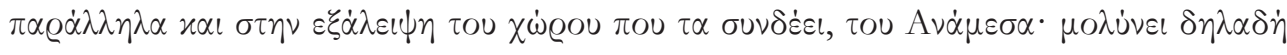

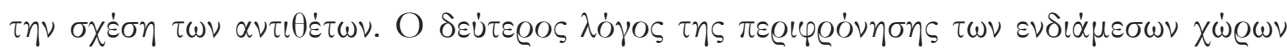

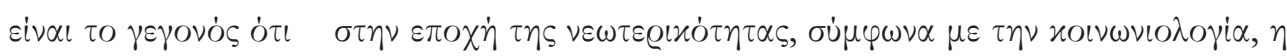

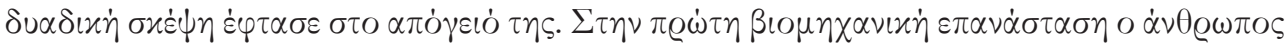

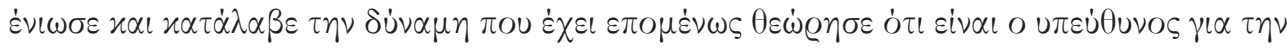

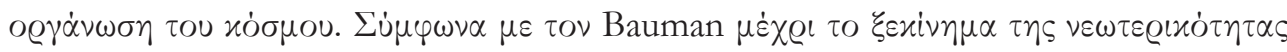

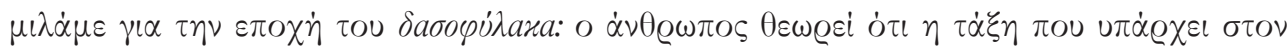

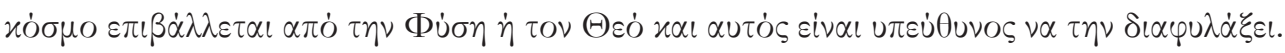

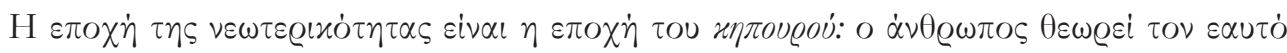

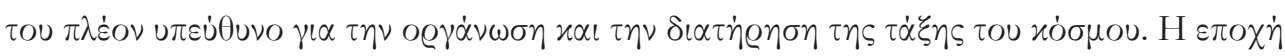

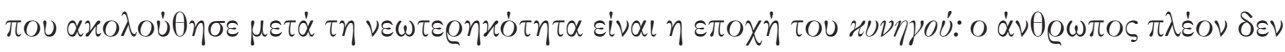

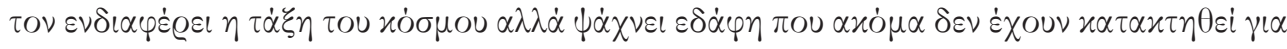

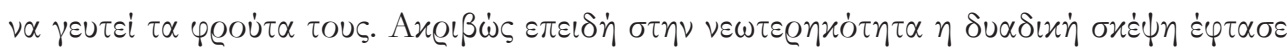

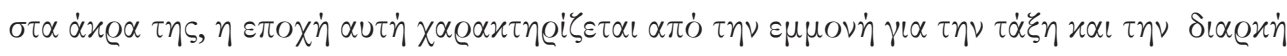

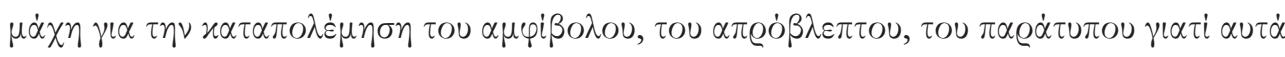

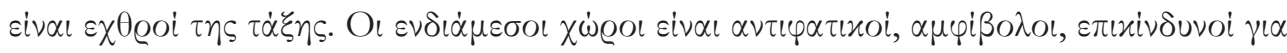

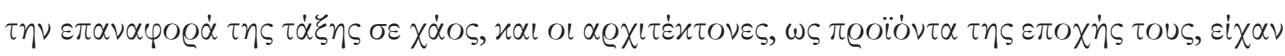

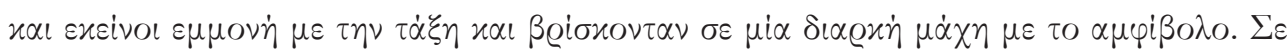

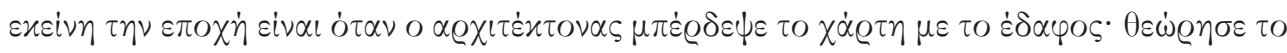

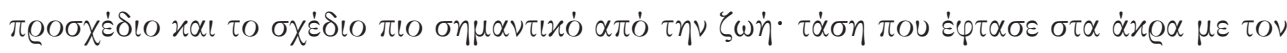

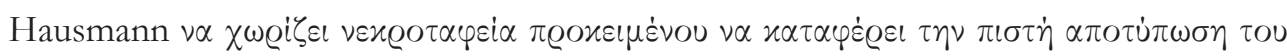

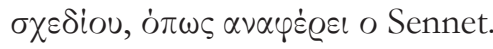

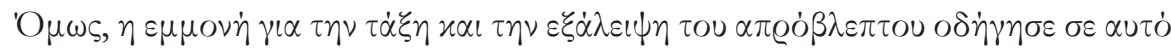

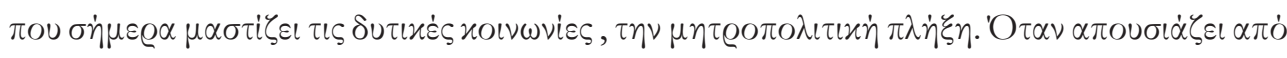

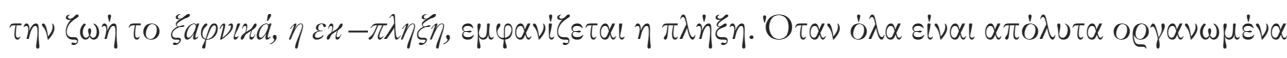

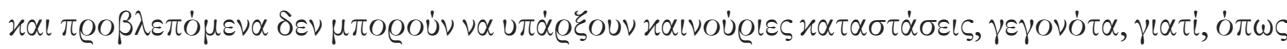

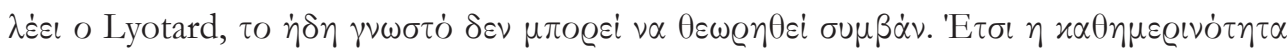

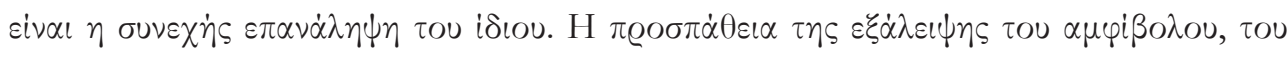

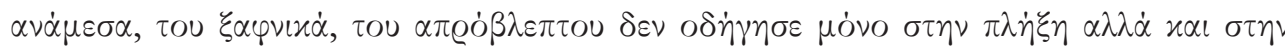

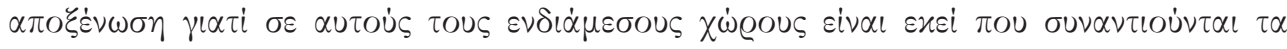




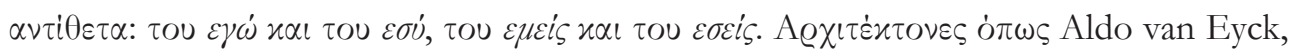

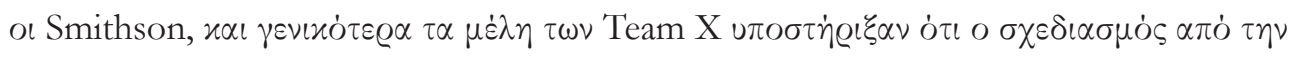

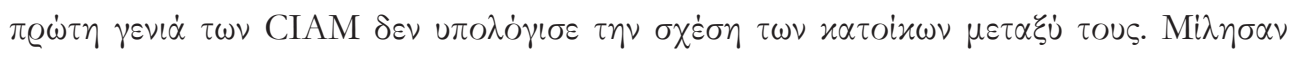

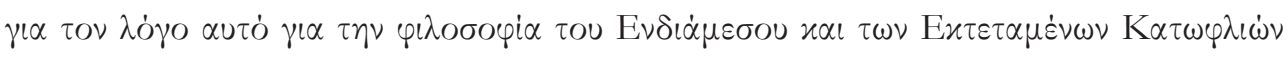

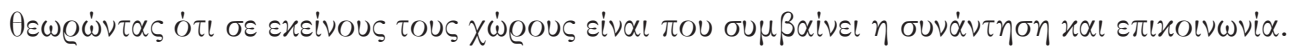

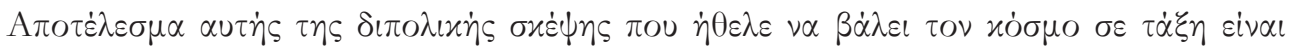

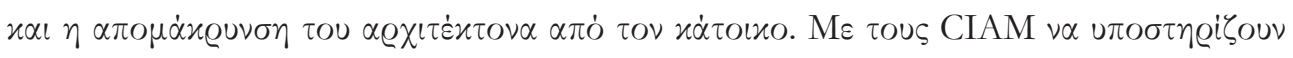

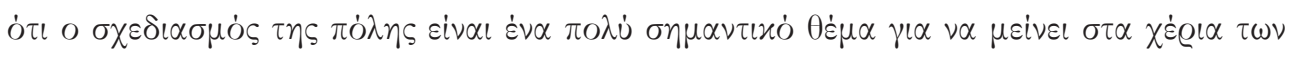

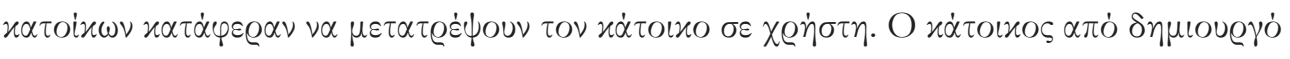

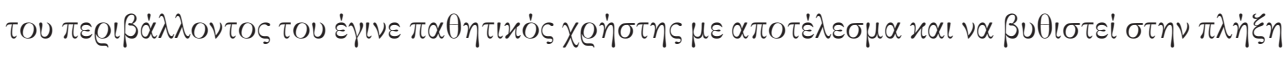

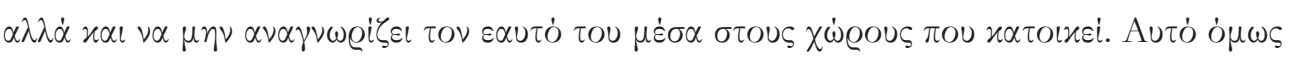

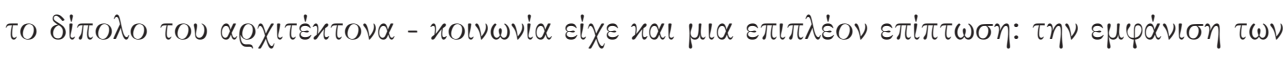

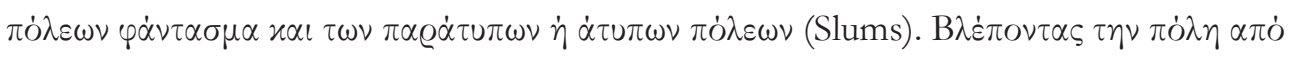

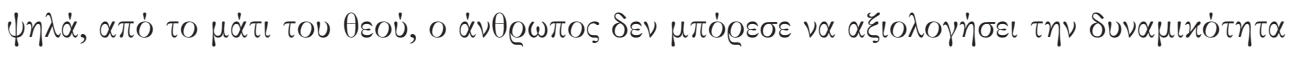

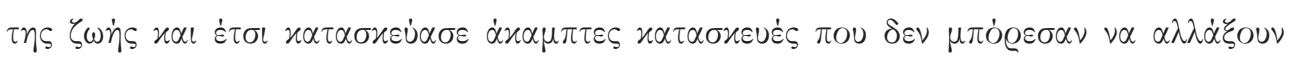

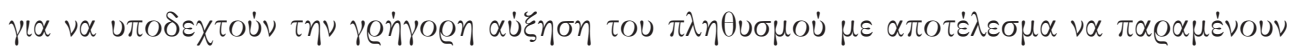

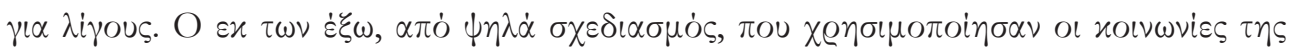

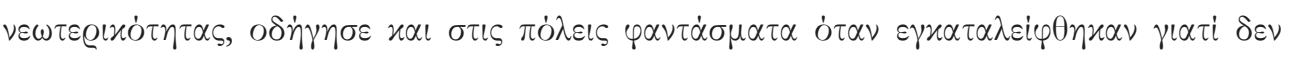

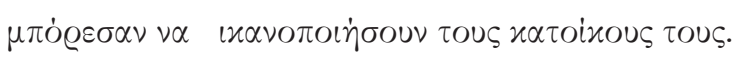

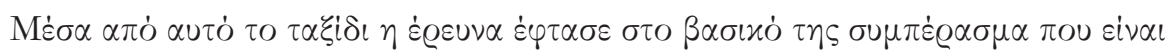

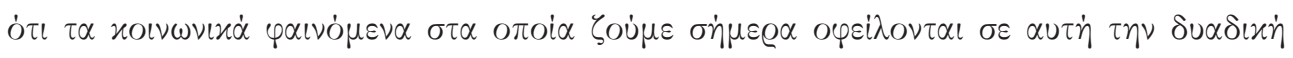

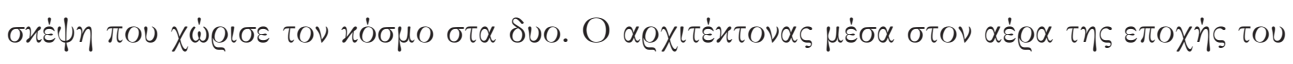

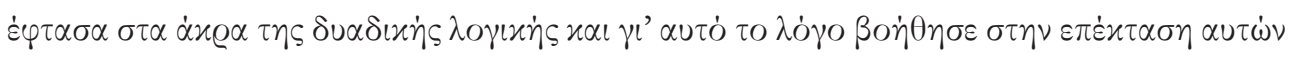

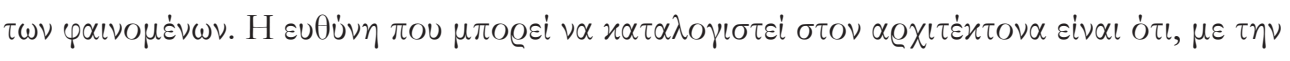

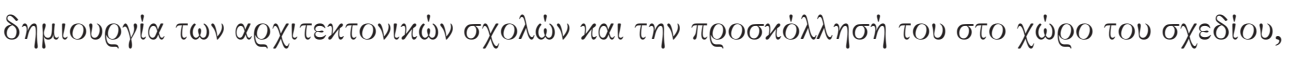

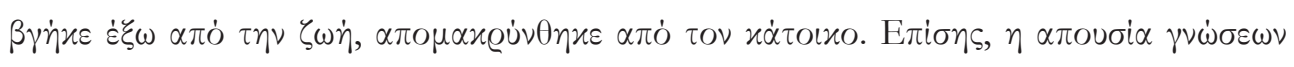

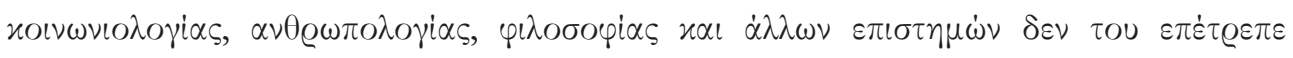

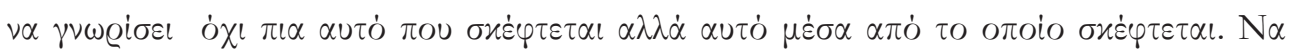

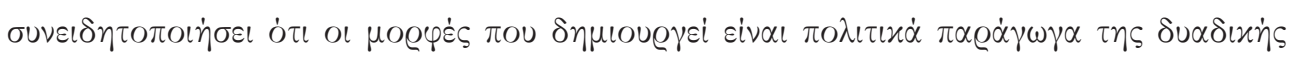

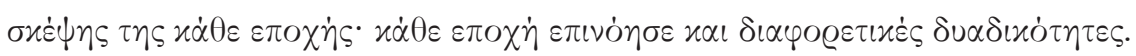

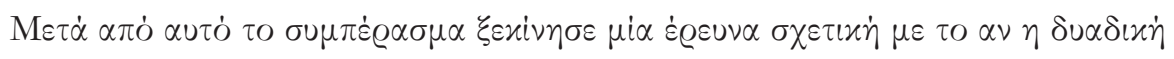




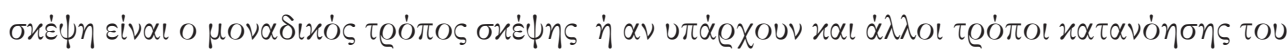

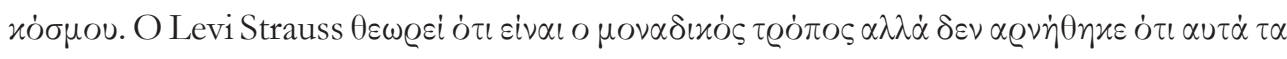

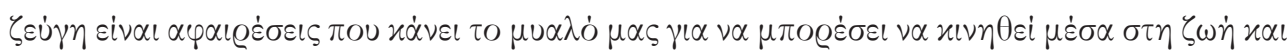

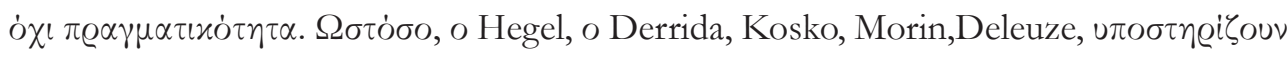

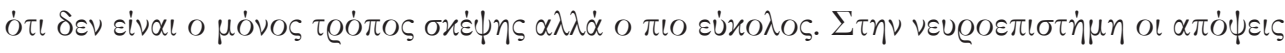

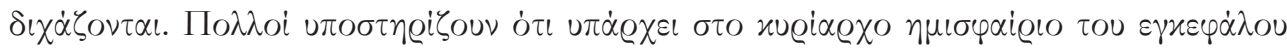

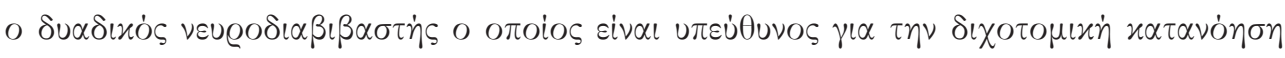

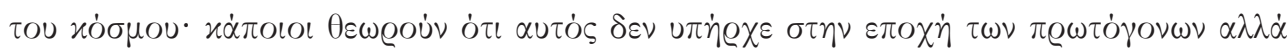

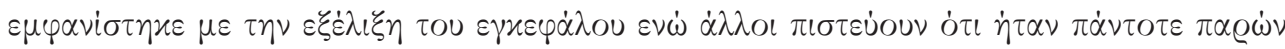

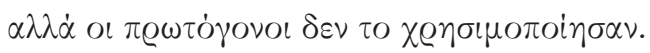

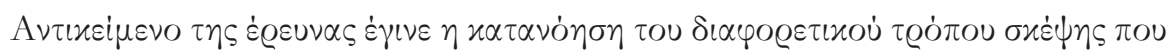

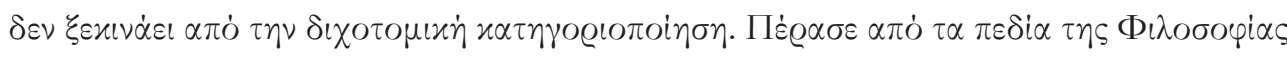

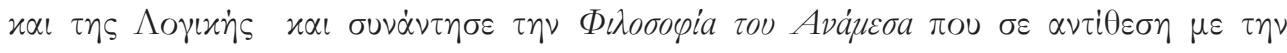

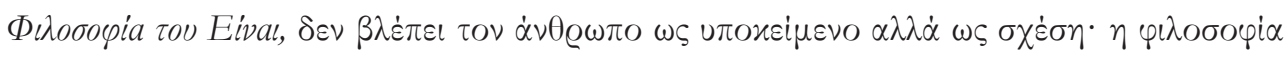

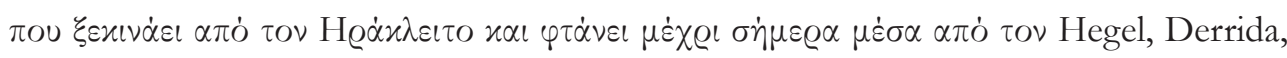

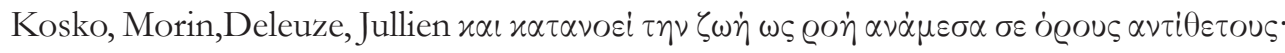

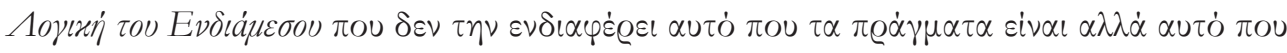

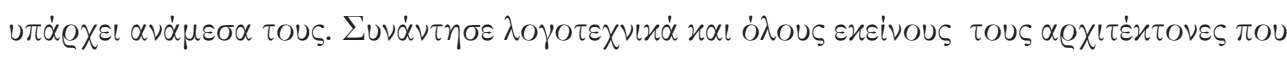

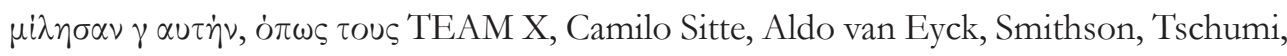

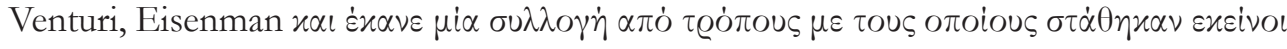

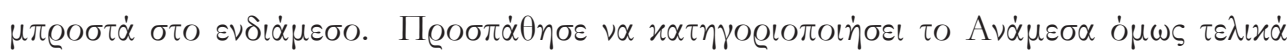

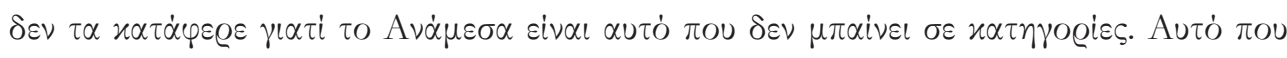

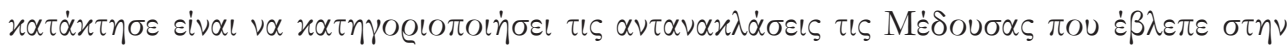

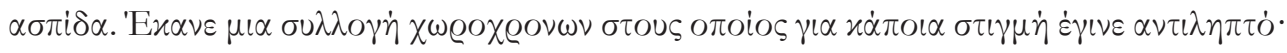

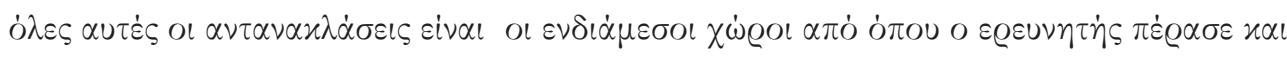

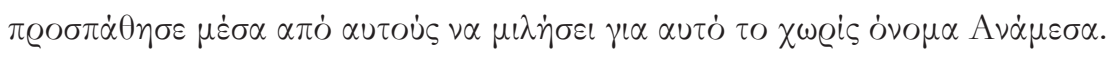

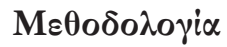

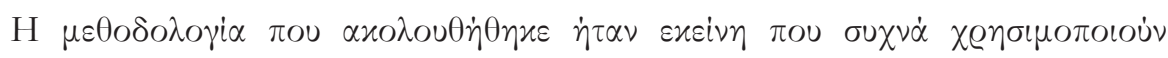

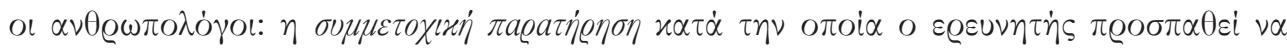

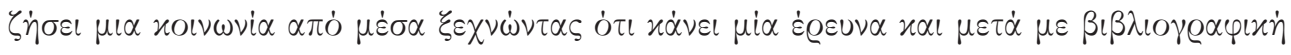




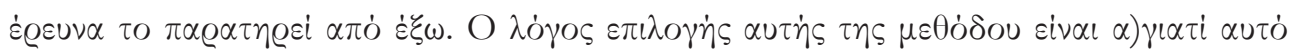

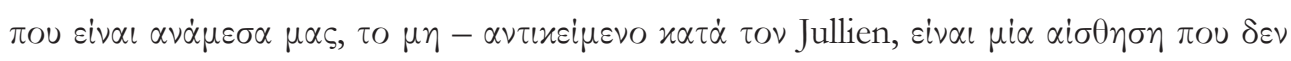

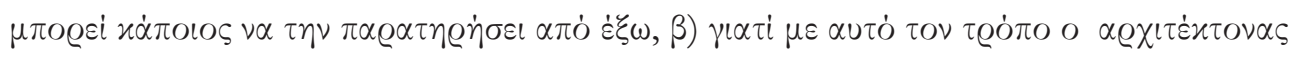

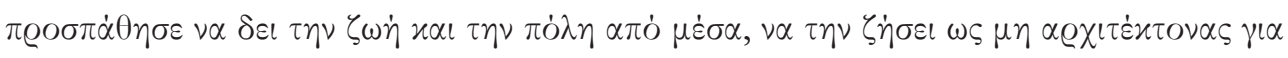

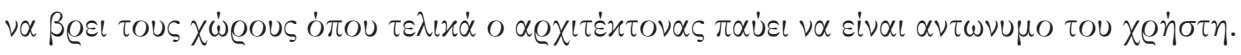

\section{- $\Delta o \mu \dot{\eta} \tau \eta \varsigma \delta \iota \alpha \varrho \ll \dot{\eta} \varsigma:$}

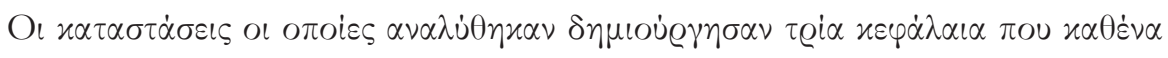

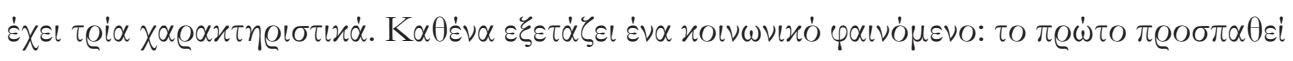

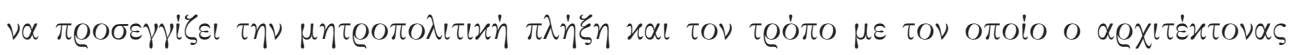

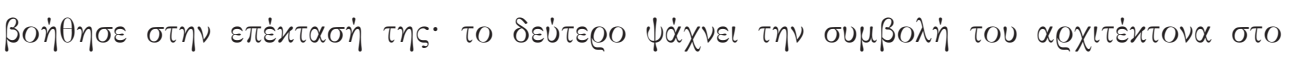

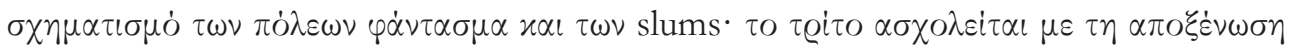

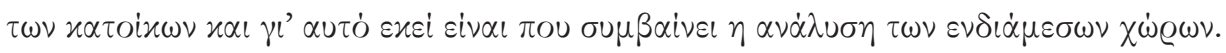

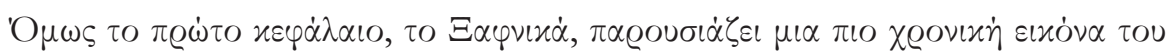

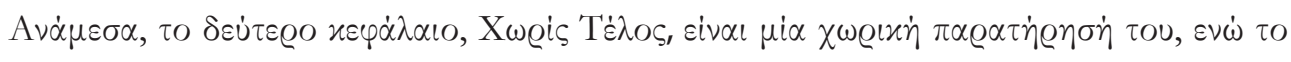

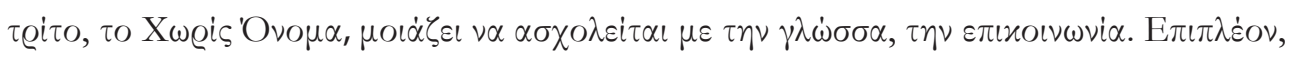

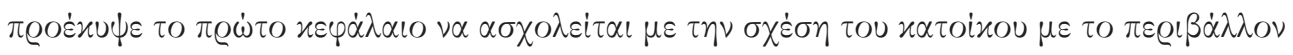

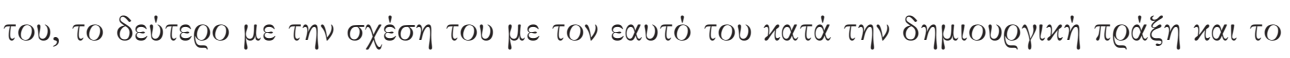

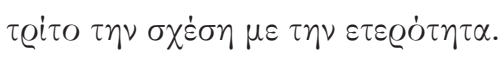

\section{$-\Sigma 0 \mu \pi \varepsilon \varrho \dot{\alpha} \sigma \mu \alpha \tau \alpha$}

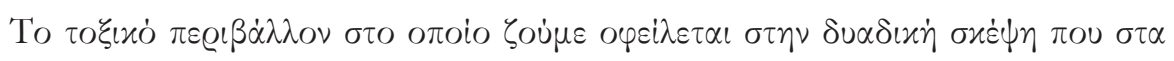

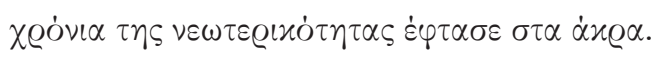

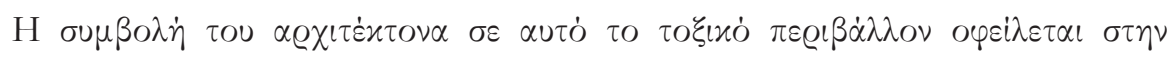

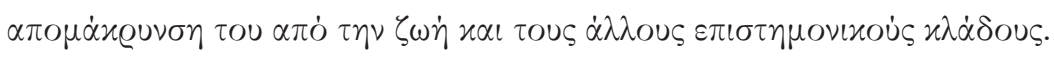

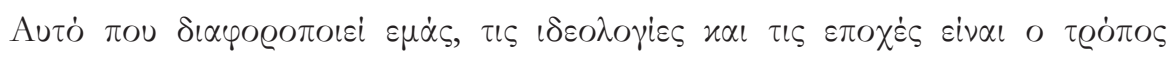

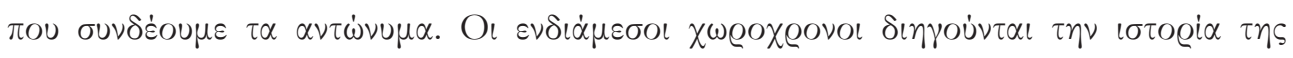

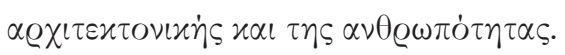



BIBLIOGRAFIA 

Agamben, Giorgio. "Estado De Excepción, Trad.” Flavia Costa e Ivana Costa.Buenos Aires (2003).

Agamben, Giorgio and Fabián Lebenglik. Infancia e Historia: Destrucción De La Experienciay Origen De La Historia. Buenos Aires, Argentina: Adriana Hidalgo, 2007. Aguirre Such, Jon. “El Urbanismo Participativo: Una Nueva Forma De Organizar La Ciudad." Periódico El País. Accessed 8/14/2015, 2015. http://blogs.elpais.com/ seres-urbanos/2015/06/el-urbanismo-participativo-una-nueva-forma-de-organizar-laciudad.html.

Agustín, San. Obras Completas. Madrid: BAC, 1975.

Alberti, Leon Battista. De Re Aedificatoria. Madrid: Ediciones Akal, 1991.

Alexander, Christopher. El Modo Intemporal De Construir Editorial Gustavo Gili, 1981.

Amann Alcocer, Atxu. El Espacio Doméstico: La Mujery La Casa (2005).

Amendola, Giandomenico. La Ciudad Postmoderna: Magia y Miedo De La Metrópolis

Contemporánea. Madrid España: Celeste Ediciones, 2000.

Argan, Giulio Carlo and Liliana Rainis. El Concepto Del Espacio Arquitectónico Desde El Barroco a Nuestros Días. Buenos Aires: Ediciones Nueva Visión, 1973.

Aristóteles. Física. Madrid: Gredos, 1995.

- Metafísica. Madrid: Editorial Gredos, 1994.

—. Metafísica. Madrid: Gredos, 1994.

—. Moral, a Nicómaco,. Translated by Patricio de Azcárate. Madrid: Espasa Calpe, 1992.

Ascher, François and María Hernández Díaz. Los Nuevos Principios Del Urbanismo: El Fin De Las Ciudades no Está a La Orden Del Día Alianza editorial, 2004.

Avia, Jorge Sáinz and Kenneth Frampton. Historia Crítica De La Arquitectura Moderna. Barcelona: Editorial Gustavo Gili, S.L., 2007.

Bachelard, Gaston. La Poética Del Espacio: Gaston Bachelard Fondo de Cultura Económica, 1983.

Bahtin, Mihail Mihajlovič. Estética De La Creación Verbal Siglo xxi, 1982.

—. Estética De La Creación Verbal Siglo xxi, 1982. 
Bajtin, Mijaíl. „El Autor y El Héroe En La Actividad Estética.“ M.Bajtin.Hacia Una Filosofía Del Acto Ético.De Los Borradores y Otros Escritos.Barcelona: Anthropos (1997).

Barthes, Roland. Ensayos Críticos Seix Barral, 2002.

Baudelaire, Charles. „Mi Corazón Al Desnudo.LXVI.“ In Diarios Íntimos. Translated by Alberti, Rafael. Buenos Aires: Editorial „Bajel“, 1943.

—_. El Pintor De La Vida Moderna Taurus, 2013.

Bauman, Zigmunt. La Posmodernidady Sus Descontentos Ediciones Akal, 2001.

Bauman, Zygmunt. Amor Líquido. Acerca De La Fragilidad De Los Vinculos Humanos.

Argentina: Fondo de Cultura Económica, 2005.

—. Arte, Liquido?. Translated by de Michelena, Francisco Ochoa Sequitur, 2007.

—. Ética Posmoderna Siglo XXI, 2005.

—. Modernidad Líquida. Argentina: Fondo de cultura económica, 2003.

—. „De Peregrino a Turista, o Una Breve Historia De La Identidad.“ In

Cuestiones De Identidad Cultural, 40-68. Buenos Aires: Amorrortu Editores, 2003. Vida De Consumo Fondo de cultura económica, 2008.

_. Vida Liquida. Barcelona: Austral, 2013.

Bauman, Zygmunt, Ulrich Beck, Anthony Giddens, and Niklas Luhmann.

„Modernidad y Ambivalencia.“ In Las Consecuencias Perversas De La Modernidad.

Modernidad Contingencia y Riesgo, 73 - 119. Barcelona, España: Anthropos, 1996.

—. Modernidady Ambivalencia. Barcelona, España: Anthropos, 1996.

Bauman, Zygmunt and de los Ángeles Boschiroli, Victoria. Trabajo, Consumismo y

Nuevos Pobres Gedisa Barcelona, 2003.

Bauman, Zygmunt and Tim May. Pensando Sociologicamente Ediciones Nueva Visión, 1994.

Bégout, Bruce. "La Potencia Discreta De Lo Cotidiano." Persona y Sociedad 23, no. 1 (2009): 9-20.

Beier, A. L. and Paul Ocobock. Cast Out: Vagrancy and Homelessness in Global and Historical Perspective. Athens, OH, Estados Unidos: Ohio University Press, 2009.

Benevolo, Leonardo. Historia Da Arquitetura Moderna (Tradução De Ana M. Goldberger)

São Paulo: Editora Perspectiva, 2001.

Benito, P. Ángel Peña and Agustino Recoleto. El Destino De Los Niños Muertos Sin 
Bautismo. Lima, Peru: 2003.

Benjamin, Walter. “Experiencia y Pobreza.” In Discursos Interrumpidos. Vol. I. Madrid, España: Taurus, 1989.

- Libro De Los Pasajes. Vol. 3 Ediciones Akal, 2005.

—. Libro De Los Pasajes. Vol. 3 Ediciones Akal, 2005.

BENJAMIN, Walter. "El París Del II Imperio En Baudelaire" y "París, Capital Del

Siglo XIX”, Ambos Incluidos En El Volumen.” Iluminaciones II (1972).

Benjamin, Walter. “Sobre Algunos Temas En Baudelaire." In Poesía y Capitalismo-

Iluminaciones II. Madrid, España: Taurus, 1998.

Berman, Marshall. Todo Lo Sólido Se Desvanece En El Aire: La Experiencia De La

Modernidad. Buenos Aires, Argentina: Siglo xxi, 1989.

Blanchot, Maurice. La Conversación Infinita. Madrid: Arena Libros, 2008.

—.El Diálogo Inconcluso, Trad. Caracas: Monte Ávila, 1970.

Borges, Jorge Luis. «Arte Poética.» Barcelona: Crítica (2001): 37-59.

- Obras Completas. Vol. 3. Buenos Aires: Emecé Editores, 1994.

Bourriaud, Nicolas. Radicante. Buenos Aires: Adriana Hidalgo, 2009.

Bourriaud, Nicolas and Michèle Guillemont. Radicante Adriana Hidalgo Buenos Aires, 2009.

Boutroux, Emile. De La Contingence Des Lois De La Nature(1874). 10.a ed ed. Paris:

Alcan, 1929.

Bradford, Peter and Richard Saul Wurman. Information Architects Graphis Press

Corporation, 1996.

Bregazzi, Daniel Mielgo. Construir Ficciones: Para Una Filosofía De La Arquitectura

Biblioteca Nueva, 2008.

Bruce, Bégout. «La Découverte Du Quotidien.» (2005).

Brun, Jean. Heráclito o El Filósofo Del Eterno Retorno. Madrid, España: Edaf, 1990.

Buber, Martin. Tuy Yo. Buenos Aires: Nueva Vision, 1984.

Buck-Morss, Susan and Mariano López Seoane. Walter Benjamin, Escritor Revolucionario.

Buenos Aires: Interzona, 2005.

Calvino, Italo. Las Ciudades Invisibles. Barcelona: Minotauro, 1983.

Canguilhem, Georges. Lo Normaly Lo Patológico. Buenos Aires: Siglo XXI, 1970. 
Casa Asia. Los Arquitectos De La Nada. Barcelona: Casa Asia, 2014.

Castro, Carmen. “La Ciudad Instantánea La Ciudad Cambiante...Los Arquitectos

Critican Sus Obras Jose Miguel De Prada y Poole.” Arquitectura-Revista Nacional De

Arquitectura 157, (1972): 26.

Charles, Baudelaire. Las Flores Del Mal. Madrid: Editorial Alianza, 1999.

Chermayeff, Serge and Christopher Alexander. Comunidad y Privacidad: Hacia Una Nueva Arquitectura Humanista. Buenos Aires: Nueva Visión, 1984.

Ching, Francis DK, Mark M. Jarzombek, and Vikramaditya Prakash. A Global History of Architecture. New Jersey: John Wiley \& Sons, 2010.

Cixous, Hélène, Keith Cohen, and Paula Cohen. "The Laugh of the Medusa." Signs 1, no. 4 (1976): 875-893.

Claude, Javeau. «La Société Au Jour Le Jour. Ecrits Sur La Vie Quotidienne.» Bruxelles: De Boeck-Wesmael (1991).

Collins, George R., Christiane C. Collins, and Camillo Sitte. Camillo Sitte y El Nacimiento Del Urbanismo Moderno: George R. Collins y Christiane C. Collins. Construcción De Ciudades Según Principios Artísticos Gustavo Gili, 1980.

Collins, Stephen L. "From Divine Cosmos to Sovereign State an Intellectual History of Consciousness and the Idea of Order in Renaissance England.” (1989).

Corbusier, Le. Precisiones Respecto a Un Estado Actual De La Arquitectura y El Urbanismo Trad. Barcelona, España: Apóstrofe, 1999.

Corbusier, Le and Josefina Martínez Alinari. Hacia Una Arquitectura. Barcelona, España: Ediciones Apóstrofe, 1998.

Cornford, Francis Macdonald. "From Religion to Philosophy." (1957).

Cortázar, Julio. “El Sentimiento De no Estar Del Todo.” In . Vol. 1. México: Siglo XXI, 1967.

Costa, Joan. Señalética Corporativa. Barcelona: Costa Punto Com, 2007.

Cox, Michael. Victorian Ghost Stories: An Oxford Anthology Oxford University Press, USA, 1991.

Cummings, Scott T. "Recent Writing on Interculturalism.” Performing Arts Journal 11/12, (1989): 240-242.

Dante, Alighieri. "Divina Comedia.” (2006). 
Davis, Mike. "Fortress Los Angeles: The Militarization of Urban Space." Variations on a Theme Park (1992): 154-180.

De Certeau, Michel and Luce Giard. La Invención De Lo Cotidiano: Artes De Hacer. I. Vol. 1 Universidad Iberoamericana, 2007.

de Efeso, Heráclito. Fragmentos Auténticos De Heráclito Según Diels-Kran₹y Walzer.

Alemania, Uruguay: Udelar, 1951,2004.

De la Lengua Española, Diccionario. "Real Academia Española." Vigésima 1, (2001).

de Unamuno, Miguel and Francisco Fernández Turienzo. En Torno Al Casticismo.

Madrid: Alcalá, 1971.

Delgado, Manuel. El Animal Público: Hacia Una Antropología De Los Espacios

Urbanos:[XXVII Premio Anagrama De Ensayo] Ed. Anagrama, 1999.

El Animal Público: Hacia Una Antropología De Los Espacios Urbanos:[XXVII

Premio Anagrama De Ensayo] Ed. Anagrama, 1999.

Delgado, Ruiz. "Manuel:“Ciudad Líquida, Ciudad Interrumpida".” Editorial Universidad

De Antioquia (1999).

Derrida, Jacques. La Diseminación. España: Seuil, 2007.

—. Dissemination. Translated by Johnson, Barbara. London: Athlone, 1981.

Positions. Translated by Bass, Alan. Chicago: University of Chicago Press, 1981.

"Positions. Trad. Alan Bass." (1987).

Dewey, J. El Arte Como Experiencia. Barcelona, España: Paidós, 2008.

Díaz, Carlos. Introducción Al Pensamiento De Martin Buber. Madrid: Instituto Emmanuel

Mounier, 1990.

Dixon-Kennedy, Mike. Encyclopedia of Greco-Roman Mythology. Santa Barbara, Califronia: Abc-Clio, 1998.

Doherty, Joe. "The Changing Role of the State: Homelessness and Exclusion:

Regulating Public Space." (2006).

Duhau, Emilio. Hábitat Populary Política Urbana Universidad Autonoma Metropolitana Unidad Azcapotzalco, 1998.

Eisenman, Peter. "Procesos De Lo Intersticial." Croquis no. 83 (1997): 21-35.

—_. "Procesos De Lo Intersticial." Croquis no. 83 (1997): 21-35. 
Elbow, Peter. "The Uses of Binary Thinking." Journal of Advanced Composition (1993): $51-78$

Empson, William. Seven Types of Ambiguity. London: Chatto and Windus, 1949. Seven Types of Ambiguity. Vol. 645 Random House, 2004.

Espinosa, Cinto Niqui. La Comunicación Es Vida: Reflexiones Eclécticas Sobre Tics y Contenidos Audiovisuales. Vol. 191 Editorial UOC, 2011.

Esquerra, Samper, Urdaneta Sáenz, Atelier Colombia, Korhonende Suiza, Correa Finlandia, Kurokaw Maki, Iñiguez de Onzoño Japón, Vásquez de Castro, Hansen España, and Christopher Alexander. "PREVI Lima: 35 Años Después." Arq no. 59 (2005): 72-76.

Felton, Debbie. Haunted Greece and Rome: Ghost Stories from Classical Antiquity University of Texas Press, 1999.

Fernández Corte, JC and A. Espinosa Pólit. Virgilio: Eneida. Madrid: Cátedra Madrid, 1993.

Fernandez Wagner, Raúl. "Elementos Para Una Revisión Crítica De Las Políticas Habitacionales En América Latina.” In Asentamientos Informais e Moradia Popular: Subsídios Para Políticas Habitacionais Más Inclusivas. Brasilia, Brasil: Instituto de Pesquisa Econômica Aplicada (IPEA), Ministério de Planejamento, Orçamento e Gestão., 2008. Fernández Wagner, Raúl. "Los Asentamientos Informales Como Cuestión. Revisión De Algunos Debates." Los Mil Barrios (in) Formales. Apuntes Para La Construcción De Un Observatorio Del Hábitat Popular Del Área Metropolitana De Buenos Aires, Cravino MC (Organizadora), UNGS, Provincia De Buenos Aires (2008).

Ferrero, Àngel and Saúl Roas. "El” Zombi” Como Metáfora Contracultural.” Nómadas. Revista Crítica De Ciencias Sociales y Jurídicas 32, no. 4 (2011): 97-220.

Fisk, Robert. "Secret Slaughter by Night, Lies and Blind Eyes by Day." Independent. September 14, (2003).

Flores Arancibia, Ivan. "Pensar El Entre, Contribuciones Para Una Crítica De La Razón Intersticial.”2010.

Flórez, Mercedes Arriaga. Mujeres, Espacio y Poder ArCiBel Editores, 2006.

Freeman, Lance. "Displacement Or Succession? Residential Mobility in Gentrifying Neighborhoods." Urban Affairs Review 40, no. 4 (2005): 463-491. 
Freud, Sigmund and Bertrand Féron. L'Inquiétante Étrangeté: Et Autres Essais. Vol. 85 Gallimard Paris, 1985.

Gabilondo, Ángel. Artesanos De La Belleza De La Propia Vida. España: Centro de Cultura Contemporánea de Barcelona, 2010.

—. Artesanos De La Belleza De La Propia Vida / Crafters of the Beanty of the Life itself. Barcelona: CCCB, 2010.

Ganivet, Ángel and Miguel de Unamuno. Granada La Bella: Seguido De Las Ruinas De Granada. Madrid: Círculo de Bellas Artes, 2011.

Ghiselin, Brewster. The Creative Process: Reflections on Invention in the Arts and Sciences.

California: Transformationial Book Circle, 2005.

Gibert, Javier García. Sobre El Viejo Humanismo: Exposición y Defensa De Una Tradición Marcial Pons Historia, 2010.

Giedion, Sigfried. Espacio, Tiempo y Arquitectura (Edición Definitiva): Origen y Desarrollo De Una Nueva Tradición. Vol. 17 Reverté, 2009. Espacio, Tiempo y Arquitectura (Edición Definitiva): Origen y Desarrollo De Una Nueva Tradición. Vol. 17. Barcelona: Reverté, 2009.

Glass, Ruth Lazarus. London: Aspects of Change. Vol. 3 MacGibbon \& Kee, 1964.

Goethe, Johann Wolfgang. Fausto. Madrid: Alianza Editorial, 2006.

Gonzalez, Francisco J. Plato and Heidegger: A Question of Dialogue. Pensilvania:

Pennsylvania State University Press, 2009.

Gonzalo, Jorge Fernández. Filosofía Zombi Anagrama, 2011.

Gosálvez, Patricia. “Arquitecto De Burbujas y Arcoíris.” El País, 28 Mar, 2011.

Gravagnuolo, Benedetto. Historia Del Urbanismo En Europa 1750-1960. Vol. 14. Madrid: Ediciones AKAL, 1998.

Greene, Brian. The Fabric of the Cosmos: Space, Time, and the Texture of Reality Vintage, 2007.

Fabric of the Cosmos: The Illusion of Time. 44. ——. 2011.

Groat, Linda and David Wang. "Architectural Research Methods.” New York (2002).

Gropius, Walter. The Scope of Total Architecture. New York, Estados Unidos: Collier, 1970.

Gubern, Román. Máscaras De La Ficción Anagrama, 2002. 
Gullón, Ricardo. Espacio y Novela Editorial Bosch, 1980.

Gutiérrez, Francisco Sierra. "Vida Cotidiana y Filosofía. Pertenencia y Distancia."

Universidad Iberoamericano. Ciudad de México, Junio 13 - 14, 2013.

Habicht, Christian. Pausanias' Guide to Ancient Greece. Vol. 50. California, USA: Univ of California Press, 1998.

Hall, Peter Geoffrey. Ciudades Del Mañana: Historia Del Urbanismo En El Siglo XX.

Barcelona, España: Ediciones del Serbal, 1996.

Hamnett, Chris and Drew Whitelegg. "Loft Conversion and Gentrification in London:

From Industrial to Postindustrial Land use." Environment and Planning A 39, no. 1 (2007): 106.

Hannah, Arendt. Los Origenes Del Totalitarismo. Madrid: Alianza, 1987.

Harvey, David and Martha Eguía. La Condición De La Posmodernidad: Investigación Sobre

Los Origenes Del Cambio Cultural. Buenos Aires: Amorrortu, 1998.

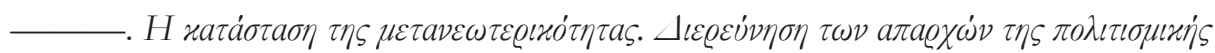

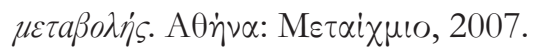

Heidegger, Martin. “La Doctrina De Platón Acerca De La Verdad.” Eikasia: Revista De

Filosofía no. 12 (2007): 261-284.

HEIDEGGER, Martín. CONSTRUIR, HABITAR, PENS AR.Traducción De

EUSTAQUIO BARJAU.Conferencias y Artículos, Serbal, Barcelona.1994 (.

Herzog, Thomas, Gernot Minke, and Hans Eggers. Construcciones Neumáticas: Manual

De Arquitectura Hinchable Editorial Gustavo Gili, 1977.

Holgado García, Eider. "La Casa Del Vacío. Espacios De Interacción En La

Arquitectura Doméstica De Sejima y Nishizawa.."Escuela Técnica Superior de Arquitectura, Universidad Politécnica de Madrid, 2016.

Hyman, Stanley Edgar. The Armed Vision: A Study in the Methods of Literary Criticism.

New York: Vintage Books, 1955.

Illich, Ivan. La Convivencialidad. México: Joaquín Mortiz /Planeta, 1985.

Jankélévitch, Vladimir. La Aventura, El Aburrimiento, Lo Serio. Madrid: Taurus, 1989.

—. La Aventura: El Aburrimiento. Lo Serio Taurus Ediciones, 1989.

Solo Los Amantes Sobreviven. Directed by Jarmusch, Jim. España: Paramount Television \& Digital Distribution SpainS.L, 2014. 
Jerome, Bruner. Realidad Mentaly Mundos Posibles. Barcelona, España: Editorial Gedisa, 2004.

Johnson, Philip. "Whence \& Whither: The Processional Element in Architecture." Perspecta (1965): 167-178.

Juárez Chicote, Antonio and Fernando Rodríguez Ramírez. "El Espacio Intermedio y Los Orígenes Del TEAM X.” (2014).

Jullien, Francois. "La Gran Imagen no Tiene Forma.” (2008).

Jullien, François. Conferencia Sobre La Eficacia. Buenos Aires: Katz Editores, 2007.

—. Filosofía Del Vivir. Barcelona, España: Octaedro, 2012.

—. La Sombra En El Cuadro. Del Mal o De Lo Negativo. Madrid: Arena Libros, 2009.

—. La Urdimbre y La Trama. Vol. 1009 Katz Editores, 2008.

Jullien, François and Miguel Lancho. Del" Tiempo": Elementos De Una Filosofía Del Vivir Arena Libros, 2005.

Jullien, Francois and José Miguel Marcén. Las Transformaciones Silenciosas Bellaterra, 2009.

Kanekar, Aarati Kumar. Celebration of Place: Processional Rituals and Urban Form (1992).

Kawash, Samira. “The Homeless Body.” Public Culture 10, no. 2 (1998): 319-339.

Kierkegaard, Søren. "La Rotación De Los Cultivos. Ensayo Para Una Doctrina De

Prudencia Social." In O Lo Uno o Lo Otro: Un Fragmento De Vida I. Madrid: Trotta, 2007.

Mauerhase. Directed by Konopka, Bartek, Piotr Rosolowski and Anna Wydra. Icarus

Films, 2009.

Kosko, Bart. Furzy Thinking, the New Science of Fuzay Logic. New York: Hyperion, 1993.

Kusko, Bart. Furzy Thinking: The New Science of Fuzay Logic. New York: Hyperion, 1993.

Kusmer, Kenneth L. Down \& Out, on the Road: The Homeless in American History Oxford University Press, 2003.

Lammers, Harm. "Potentially...Unravelling and Reconnecting Aldo Van Eyck in

Search of an Approach for Tomorrow.”Eindhoven University of Technology, 2012.

Le Corbusier. Towards a New Architecture. Londres: The Architectural Press, 1927.

Ledoux, Claude Nicolas. L'Architecture Considérée Sous Le Rapport De l'Art, Des Maurs Et 
De La Législation: Tome Premier. Vol. 1. París: A. Uhl, 1804.

Lees, Loretta. "Gentrification and Social Mixing: Towards an Inclusive Urban

Renaissance?" Urban Studies 45, no. 12 (2008): 2449-2470.

LEFEBVRE, Henri. "El Derecho a La Ciudad: Historia, Ciencia, Sociedad.” Barcelona. Penisula (1978).

Lennon, John. "Beautiful Boy (Darling Boy)." Song Lyrics.on Album Double Fantasy.New York: Geffen Records (1980).

Lizcano, Emmánuel. Metáforas Que Nos Piensan: Sobre Ciencia, Democracia y Otras Poderosas Ficciones (2006).

Lloyd, GER. Polaridady Analogía. Dos Tipos De Argumentacionen Los Albores Del Pensamiento Griego. Madrid: Taurus, 1987.

Loos, Adolf, Lourdes Cirlot, Pau Pérez, and Roland Schachel. Ornamento y Delito y Otros Escritos. Barcelona: Gustavo Gili, 1972.

López Martín, Ana Gemma. “Frontera. Criterios De Delimitación.” In Diccionario

Crítico De Ciencias Sociales. Vol. I. Madrid y México: Ed. Plaza \& Valdés, 2007.

Lowe, Sarah, Michael Browne, Souyad Boudjelas, and M. De Poorter. 100 of the World's Worst Invasive Alien Species: A Selection from the Global Invasive Species Database Invasive Species Specialist Group Auckland,, New Zealand, 2000.

Lucas, P., J. Salas, and R. Barrionuevo. "Cuarenta Años Del PREVI-LIMA:

Algunas Enseñanzas Para La Industrialización De La Vivienda De Bajo Coste En Latinoamérica." Informes De La Construcción 64, no. 525 (2012): 51-62.

Lucena, Jorge Martínez. Vampiros y Zombies Posmodernos Editorial GEDISA, 2011.

Lucendo Lacal, Santiago. "El Vampiro Como Imagen-Reflejo: Estereotipo Del Horror En La Modernidad.’Universidad Complutense de Madrid, Servicio de Publicaciones, 2009.

Luhmann, Niklas. Sożiologie Des Risikos. Berlin: Walter de Gruyter, 1991.

—. Soziologische Aufklärung. Vol. 4. Opladen: Westdeutscher Verlag, 1981.

Luiselli, Valeria. Papeles Falsos. Madrid: SextoPiso, 2010.

Lyotard, Jean-François. “The Inhuman: Reflections on Time, Trans. Geoffrey

Bennington and Rachel Bowlby." Cambridge, Polity Press (1991).

Madanipour, Ali. Public and Private Spaces of the City Routledge, 2003. 
Manning, Frank E. "The Celebration of Society." Perspectives on Contemporary Cultural

Performance.Bowling Green University Press: Obio (1983).

Mantzou, Polyxeni. "Utilización De Medios Audiovisuales Como Modificadores Del

Espacio Arquitectónico.”Arquitectura, 2000.

Markee, Patrick. War and Homelessness. how American Wars Create Homelessness among

United States Armed Forces Veterans. New York: Coalition for the Homeless, 2003.

Martin, Buber. “¿ Qué Es El Hombre.” México, Fondo De Cultura (1973).

Martine, Segalen. Ritos y Rituales Contemporáneos. Madrid: Colección El libro de bolsillo, Antropología, Alianza Editorial, SA, 2005.

Massey, Doreen. Space, Place and Gender John Wiley \& Sons, 2013.

Matsumoto, Michihiro. The Unspoken Way Kodansha International, 1988.

MELOGNO, Pablo. “La Cosmología y Teoría De Los Poliedros En Platón [En

Línea]. Cibernous. 2002. Disponible En Web: Ht Tp." Cibernous.com/autores/platon/

teoria/ ciencia/cosmolog.Html [Consultado En Linea: Febrero 2012] (.

Miguélez, Miguel Martínez. "El Desafío a La Racionalidad Científica Clásica."

Paradigma 21, no. 3 (2000): 187-200.

Millás, Juan José. El Orden Alfabético. España: Punto de Lectura, 2010.

Misetics, Bálint. "Criminalisation, Discourse and Symbolic Violence." Homeless in

Europe (Invierno 2012/2013): 12-14.

Mondolfo, Rodolfo. Heráclito: Textos y Problemas De Su Interpretación. México: Siglo XXI, 1981.

Montaner, José María. Después Del Movimiento Moderno, Arquitectura De La Segunda Mitad Del Siglo XX. Barcelona: Gustavo Gili, 1993.

Montaner, Josep Maria and Zaida Muxí. Arquitectura y Política: Ensayos Para Mundos

Alternativos Gustavo Gili, 2011.

Mora, José Ferrater. Dicionário De Filosofia. TOMO I (A-K). Vol. 1. Buenos Aires:

Editorial Sudamericana, 1971.

Morales, José Ricardo. Las Artes De La Vida: El Drama y La Arquitectura. Vol. 35

Anthropos Editorial, 1992.

Morris, William. News from Nowhere. Canada: Broadview Press, 2002.

Muñoz Carrera, Óscar. “Gentrificación, Segregación y Reestructuración Social En 
Madrid." Direito Da Cidade 6, no. 1 (2014).

Nancy, JL. El Intruso. Buenos Aires: Amorrortu, 2006.

NEGRETTE, Jorge A. “Utilización De La Cuadra y La Plaza Como Elementos De

Diseño Urbano." Trabajo De Ascenso.Universidad Simón Bolivar.Caracas, Venezuela (1986).

Neils, Jenifer. "Review: Architecture and Meaning on the Athenian Acropolis by

Robin Francis Rhodes." Journal of the Society of Architectural Historians 56, no. 2 (1997): 216-217.

Nietzsche, Friedrich. El Viajero y Su Sombra Edaf, 1999.

Ortega, José. La Rebelión De Las Masas. Santiago de Chile: Andres Bello, 1996.

Palacios, Rosario. "La Metrópolis Como Cultura Material / La Metrópolis y La Vida

Mental Como Propuesta Metodológica.” Bifurcaciones. Revista de Estudios Culturales

Urbanas. Accessed 5/31/2015, 2015. http://www.bifurcaciones.cl/2005/09/la-

metropolis-como-cultura-material/.

—_. "La Metrópolis Como Cultura Material: La Metrópolis y La Vida Mental

Como Propuesta Metodológica." Revista Bifurcaciones, Primavera no. 4 (2005).

Percy, Allan. Einstein Para Despistados: Soluciones Atómicas Para Problemas Relativamente

Graves. Madrid: DEBOLSILLO, 2014.

Perec, Georges. Especies De Espacios Editorial Montesinos, 2003.

—. Lo Infraordinario Editorial Verdehalago, 2008.

Pinkney, David H. Napoleon III and the Rebuilding of Paris. Vol. 78. Princeton, NJ:

Princeton University Press, 1958.

Platón. Diálogos III. Bogotá: Ed. Gráficas Modernas, 2005.

—. Diálogos IV, República. Translated by Eggers Lan, Conrado. Madrid: Editorial

Gredos, 1988.

—. Timeo, Introducción, Traducción y Comentarios, Kalfas Basilis, . Atenas: Polis, 1995.

Poe, Edgar Allan. "El Hombre De La Multitud." Cuentos Completos (2005): 247-254.

Prada Poole, José Miguel de. “Arquitectura Sensorial.” In Boden, Nº 13, 23. Madrid:

Unión Explosivos Rio Tinto, 1977.

Prada Poole, José Miguel de and Fabián López Ulloa. “José Miguel De Prada y

Las Estructuras Neumáticas En España, 1960-1980.” Geometría y Proporción En Las

Estructuras (2010): 374-387. 
Prada Poole, José Miguel de. "La Arquitectura Perecedera De Las Pompas De Jabón." El Urogallo 25, (Enero - Febrero 1974): 72-78.

PressReader - Periódicos de alrededor del mundo. "Le Corbusier, Uniformidad, Orden y Fascismo.” . Accessed 8/14/2015, 2015. http://www.pressreader.com/spain/lavanguardia-1a-edicion/20150503/281530814579619/TextView.

Punset, Elsa. Una Mochila Para El Universo. Barcelona: Destino, 2012.

quesada, Fernando. Comunidad Común Comuna. España: Asimétricas, 2015.

Quignard, Pascal. El Sexo y El Espanto 2005.

Rhodes, Robin Francis. Architecture and Meaning on the Athenian Acropolis. U.K:

Cambridge University Press, 1995.

Ruiz Barreto, Javier. "La Evolución De La Puerta En La Arquitectura Civil y Sus

Códigos En La Idiosincrasia De La China Imperial.”2015.

Ruskin, John. Las Siete Lámparas Dela Arquitectura. Barcelona: Alta Fulla, 1988.

Sagnier, Eugenio Trías. Los Límites Del Mundo Ariel, 1985.

Salas, María Cecilia. La Escritura Del Desasosiego: Una Poética Del Pensar En Fernando Pessoa. Colombia: Universidad de Antioquia, 2009.

Salingaros, Nikos A. and Federico Mena-Quintero. "Una Historia Breve Del

Urbanismo-P2P." (.

Salva y Pérez, Vicente. Grámatica De La Lengua Castellana. Según Ahora Se Habla.

Valencia, España: Librería de los SS Mallen y Sobrinos, 1854.

San Vicente, Félix. Reconstrucción De La Puerta De San Vicente Año 1994-1995.

Fraseología Contrastiva: Lexicografía, Traducción y Análisis De Corpus. Madrid:

Ayuntamiento, 1995.

Sassen, Saskia. The Global City: New York, London, Tokyo Princeton University Press, 2001.

Seguí de la Riva, Francisco Javier. “Arquitectura y Narración.” LAU 2006: Segundas Jornadas Sobre Investigación En Arquitectura y Urbanismo, 21-23 De Septiembre De 2006.Sant Cugat Del Vallès: Escuela De Arquitectura Del Vallès, 2006. (2006).

Seguí de la Riva, Javier. Desde Dentro y Desde Fuera. Del Todo a Las Parte. Dibujar,Proyectar XVII

. Madrid, España: Cuaderno del Instituto Juan de Herrera, 2009. 
Sennett, Richard. Carne y Piedra: El Cuerpo y La Ciudad En La Civilización Occidental Alianza editorial, 1997.

Sheringham, Michael. "Everyday Life: Theories and Practices from Surrealism to the Present." (2006).

Sica, Paolo, Vittorio Franchetti Pardo, Enrico Guidoni, Paolo Sica, Vioque Lozano, Ángela Marino, and Joaquín Hernández Orozco. "Historia Del Urbanismo.”INAP, 1981.

Silberman, Neil Asher. The Oxford Companion to Archaeology. U.S.A: Oxford University Press, 2012.

Simmel, Georg, Gustau Muñoz, Salvador Mas, and Jürgen Habermas. Sobre La Aventura: Ensayos Filosóficos Península, 2002.

Simmel, George. Cuestiones Fundamentales De Sociologia. Barcelona, Spain: Gedisa, 2002.

—. Cultura Femenina: Y Otros Ensayos. Barcelona: ALBA ETIDORIAL, 1999.

—. "La Metrópolis y La Vida Mental." Bifurcaciones: Revista De Estudios Culturales Urbanos no. 4 (2005): 7.

—. Sociologia II: Estudios Sobre Las Formas De Socialización. Madrid: Editorial Castilla, 1977.

Simmel, George and Esteban Vernik. Cuestiones Fundamentales De Sociología Gedisa, 2002.

Sitte, Camillo. Construcción De Ciudades Según Principios Artísticos. Translated by Canosa, Emilio. Barcelona: Editorial Canosa, 1926.

Skraparlis, Andreas. "Paisaje Urbano Contemporaneo, Espacio Público y Sin Techo." Programa Interdepartamental del curso de posgrado, Arquitectura de Paisaje, Escuela de Arquitectura - Facultad de Agricultura, Universidad Aristóteles de Salónica, 2013. Slater, Tom. "The Eviction of Critical Perspectives from Gentrification Research." International Journal of Urban and Regional Research 30, no. 4 (2006): 737-757.

__. "Gentrification of the City." The New Blackwell Companion to the City (2011):

$571-585$.

Smith, Neil. "On 'the Eviction of Critical Perspectives'." International Journal of Urban and Regional Research 32, no. 1 (2008): 195-197.

Smithson, Alison and Peter Smithson. "The Built World: Urban Re-Identification." 
Architectural Design.N6 (1955): 185-188.

Urban Structuring Studio Vista London, 1967.

Sparkes, B. A. "Decoding the Acropolis." The Classical Review 47, no. 1 (1997): 149-151.

Spivak, Gayartri Chakravorty. “Jacques Derrida of Grammatology.” (1974).

Spradley, James P. “Participant Observation.” (1980).

Stavridis, Stavros. De La Ciudad Pantalla a La Ciudad Escena. Atenas: Ellinika

Grammata, 2002.

Steiner, George. "El Gran Ennui.” In En El Castillo De Barba Azul. Barcelona, España: Editorial GEDISA, 2013.

Strauven, Francis. "Aldo Van Eyck. Shaping the New Reality from the in-between to the Aesthetics of Number." Study Centre Mellon Lectures.California: College of the Arts 24, (2007).

Svendsen, Lars Fr H. Filosofia Del Tedio. Barcelona: Tusquets, 2006.

Tennov, Dorothy. Love and Limerence: The Experience of being in Love. Maryland:

Scarborough House, 1998.

Todorov, Tzvetan. The Morals of History U of Minnesota Press, 1995.

Trachtenberg, Marvin and Isabelle Hyman. Arquitectura. Vol. 24. Madrid: Ediciones Akal, 1990.

Turner, John F. C. and Robert Fichter. Freedom to Build: Dweller Control of the Housing Process

. New York: The Macmillan Company, 1972.

Turner, Victor. "Frame, Flow and Reflection: Ritual and Drama as Public Liminality." Japanese Journal of Religious Studies (1979): 465-499.

"Liminality and Communitas." The Ritual Process: Structure and Anti-Structure (1969): 94-130.

Turner, Victor Witter. Dramas, Fields, and Metaphors: Symbolic Action in Human Society Cornell University Press, 1975.

Turner, Victor Witter and Beatriz García Ríos. El Proceso Ritual: Estructura y Antiestructura Taurus Ediciones, 1988.

Turner, John F. C. Vivienda, Todo El Poder Para Los Usuarios: Hacia La Economía En La Construcción Del Entorno. Madrid: Hermann Blume, 1977. 
Del Entorno. Madrid: Hermann Blume, 1977.

Valéry, Paul. El Alma y La Danza: Eupalinos o El Arquitecto. Buenos Aires: Losada, 1958.

van Eyck, Aldo, Vincent Ligtelijn, and Francis Strauven. Aldo Van Eyck: Writings.

Amsterdam: Sun, 2008.

Van Gennep, Arnold. Los Ritos De Paso Alianza, 2008.

Varelidou, Elisavet and Xanthoula Michail. "La "Ciudad De Los Sin Techo" -

Investigación Teórica / El Caso De Salónica." Geografías. Edición Bianual De Ciencias Del

Espacio. 24, (Otoño 2014): 136.

"La "Ciudad De Los Sin Techo" - Investigación Teórica / El Caso De

Salónica.” . Accessed 7/15/2015, 2015. http://akea2011.com/2014/03/04/

ipolitonastegon/\# ftnref2.

Venturi, Robert. Complejidady Contradicción En La Arquitectura Editorial Gustavo Gili, 1974.

Vitruvio, Marco Lucio. Los Diez Libros De Arquitectura. Madrid: Alianza Editorial, 1997.

Voloshinov, Valentin Nikólaievich and Rosa María Russovich. El Signo Ideológico y La

Filosofía Del Lenguaje. Buenos Aires, Argentina: Nueva Visión, 1976.

Whyte, William Hollingsworth. The Social Life of Small Urban Spaces. New York: Project for Public Spaces, 1980.

Wigley, Mark. White Walls, Designer Dresses: The Fashioning of Modern Architecture.

Cambridge MA, Estados Unidos: MIT Press, 2001.

Wikipedia contributors. “Generación Z.” Wikipedia, The Free Encyclopedia2015.

__. "Gerundio.” Wikipedia, The Free Encyclopedia2016. https://es.wikipedia. org/wiki/Gerundio.

__. "Holometabolismo." Wikipedia, The Free Encyclopedia2016. https:// es.wikipedia.org/wiki/Holometabolismo.

—_. "Transformación De París Durante El Segundo Imperio.” Wikipedia, The Free Encyclopedia2015.

Wikipedia Contributors. “Transformación De París Durante El Segundo Imperio.” . Accessed 1/12/2016, 2016. https://es.wikipedia.org/wiki/Transformaci\%C3\%B3n 
de $\mathrm{Par} \% \mathrm{C} 3 \% \mathrm{AD}$ s durante el Segundo Imperio.

Wood, Robert E. Martin Buber's Ontology: An Analysis of I and Thou Northwestern

University Press, 1969.

Wyly, Elvin K. and Daniel J. Hammel. "Gentrification, Segregation, and

Discrimination in the American Urban System." Environment and Planning A. 36, (2004): 1215-1242.

“Mapping Neo-Liberal American urbanism1.” In , 18: Routledge, 2004.

Young, David and Michiko Young. The Art of Japanese Architecture. Singapore: Tuttle Publishing, 2007.

Zanotto, Juliana M. Public Spaces, Homelessness, and Neo-Liberal Urbanism: A Study of'Anti-

Homeless' Strategies on Redeveloped Public Spaces (2012).

Zbinden, Karine. "El Yo, El Otro y El Tercero: El Legado De Bajtín En Todorov.”

Acta Poética 27, no. 1 (2006): 325-339.

Zizek, Slavoj. Viviendo En El Final De Los Tiempos Ediciones Akal, SA, 2012.

Zygmunt, Bauman. En Busca De La Política. Argentina: Fondo de Cultura Económica, 2001.

“"La Globalización. Consecuencias Humanas." Fondo De Cultura (1999).

“Tiempos Líquidos. Vivir En Una Época De Incertidumbre.” Argentina,

Editorial Tusquets (2007).

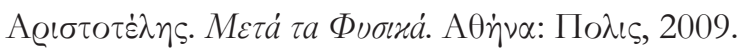

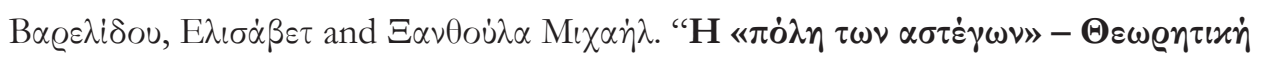

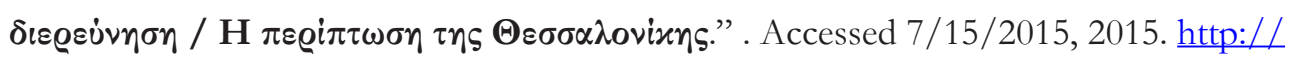
akea2011.com/2014/03/04/ipolitonastegon/\# ftnref2.

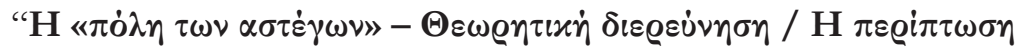

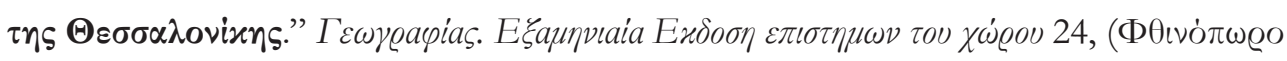

2014): 136.

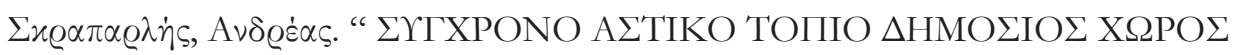

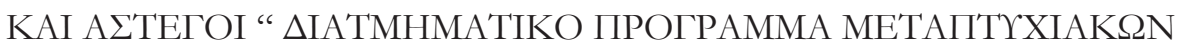

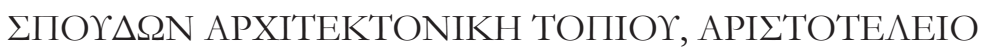

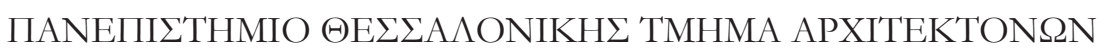




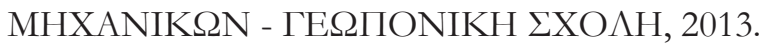

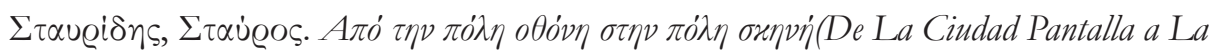

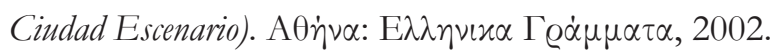

“- Arquitectura De La Información “. Accessed 1/12/2016, 2016. http://www.

bibliodigital.udec.cl/index.php?option $=$ com $\_$content\&task=view\&id $=39$.

“"'El Estado De Excepción Es Hoy La Norma” | Edición Impresa | EL

PAÍS “ . Accessed 1/13/2016, 2016. http://elpais.com/diario/2004/02/03/

cultura/1075762801 850215.html.

“(B)ORDOS 100 / Marcos Betanzos | Plataforma Arquitectura “. Accessed

5/16/2015, 2015. http://www.plataformaarquitectura.cl/cl/02-301410/b-ordos-100-

marcos-betanzos.

“iVive La Calle!” . Accessed 7/9/2015, 2015. https://vivelacalle.wordpress.com/.

“¿Es Esta La Primera Manifestación De Hologramas De La Historia? - BBC

Mundo “. Accessed 1/13/2016, 2016. http://www.bbc.com/mundo/

noticias/2015/04/150413 manifestacion_hologramas_espana_im.

“¿Tanto Urgía La Renovación De Las Marquesinas De Autobús? | Madrid | EL

MUNDO “ . Accessed 7/24/2015, 2015. http://www.elmundo.es/madrid/2014/09/

$\underline{01 / 54036144 \mathrm{e} 2704 \mathrm{ed} 8158 \mathrm{~b} 457 \mathrm{e} . \mathrm{html}}$.

“El ‘blindaje’ De Ceuta y Melilla | Política | EL PAÍS “. Accessed 1/13/2016, 2016.

http://politica.elpais.com/politica/2014/03/05/actualidad/1394046257 447524.

$\underline{\mathrm{html}}$.

““'Le Corbusier: Pensamiento Fascista y 'ciudad Radiante” De Joseph Confavreux,

Em infoLibro | Tiempos Canallas “. Accessed 5/22/2015, 2015. http://www.

tiemposcanallas.com/le-corbusier-pensamiento-fascista-y-ciudad-radiante-de-joseph-

confavreux-em-infolibro/.

“4,3 Millones Para El Centro De Acogida Juan Luis Vives - Ayuntamiento De Madrid

“. Accessed 6/13/2015, 2015. http://www.madrid.es/portales/munimadrid/es/

Inicio/Ayuntamiento/Medios-de-Comunicacion/Notas-de-prensa/4-3-millones-para-

el-Centro-de-Acogida-Juan-Luis-Vives?vgnextfmt $=$ default\&vgnextoid $=3$ ea14c1396a 0

3410VgnVCM1000000b205a0aRCRD\&vgnextchannel=6091317d3d2a7010VgnVCM1

00000dc0ca8c0RCRD. 
“The 97th Annual Meeting of the Archaeological Institute of America." American Journal of Archaeology 100, no. 2 (1996): 337-407.

"About - Design Other 90\% Network | Smithsonian Cooper-Hewitt National Design Museum “. Accessed 5/16/2015, 2015. http://www.designother90.org/about/. “Aguirre Quiere Sacar a Los ‘sin Hogar’ De La Calle Para Impulsar El Turismo | Madrid | EL PAÍS “. Accessed 6/7/2015, 2015. http://ccaa.elpais.com/ ccaa/2015/04/27/madrid/1430144657 879791.html.

“Anti Lugares.” . Accessed 7/24/2015, 2015. https://www.flickr.com/ photos/7211263@N02/.

“Arco Del Triunfo - El Monumento Más Representativo De París “. Accessed 1/13/2016, 2016. http://www.paris.es/arco-triunfo.

"Are Electricity Pylons really such a Blot on the Landscape? | Oliver Wainwright | Opinion | the Guardian “. Accessed 1/13/2016, 2016. http://www.theguardian. com/commentisfree/2014/nov/11/electricity-pylons-landscape-national-grid-bury. "Arqueólogos Descubren Cueva Donde Podría Haberse Ubicado El Hades, El Inframundo Griego." . Accessed 8/16/2015, 2015. http://pijamasurf.com/2012/11/ arqueologos-descurben-cueva-que-podria-haber-inspirado-el-hades-el-inframundogriego/.

“Arquitecto De Burbujas y Arcoíris | Edición Impresa | EL PAÍS “ . Accessed 7/13/2015, 2015. http://elpais.com/diario/2011/03/28/ madrid/1301311464 850215.html. “Arquitecto De Sueños, 'Biohacker'... y Otras Profesiones Del Futuro | Economía | EL MUNDO “. Accessed 1/12/2016, 2016. http://www.elmundo.es/economia/201 5/04/22/55368164e2704e7e608b4580.html.

“Arquitectura y Narración. Javier Seguí De La Riva.” . Accessed 5/30/2015, 2015. http://www.faud.unsi.edu.ar/descargas/LECTURAS/Arquitectura/EXTRA/1.pdf. "Arquitecturas Colectivas | Arquitecturas Colectivas Es Una Red De Personas y Colectivos Interesados En La Construcción Participativa Del Entorno Urbano. “ . Accessed 8/14/2015, 2015. http://arquitecturascolectivas.net/. “El Arte De no Actuar “. Accessed 1/13/2016, 2016. http://www.lavanguardia.com/ cultura/20140730/54412610993/arte-actuar.html. 
“Basurama “. Accessed 8/14/2015, 2015. http://basurama.org/\#2.

"Benedicto XVI: "El Purgatorio no Es Un Lugar Del Espacio, Sino Un Fuego Interior” - RTVE.Es “. Accessed 10/16/2015, 2015. http://www.rtve.es/ noticias/20110112/benedicto-xvi-purgatorio-no-lugar-del-espacio-sino-fuegointerior/394518.shtml.

"Berlin Wall Memorial “ . Accessed 1/13/2016, 2016. http://www.berliner-mauergedenkstaette.de/en/.

"Big Apple Spurns Chance of a New Beginning | Archive | Architects Journal " . Accessed 6/8/2015, 2015. http://www.architectsjournal.co.uk/home/big-applespurns-chance-of-a-new-beginning/142535.article.

"Boa Mistura “ . Accessed 8/14/2015, 2015. http://www.boamistura.com/. "Caldodecultivo ". Accessed 8/14/2015, 2015. http://caldodecultivo.com/. “El Caso Del Plan Cerdá | Opinión | EL PAÍS “ . Accessed 1/12/2016, 2016. http://elpais.com/elpais/2014/02/06/opinion/1391701528 507912.html. “El Círculo Del Vampiro Contemporáneo - Croco Magazine “. Accessed 1/13/2016, 2016. http://www.crocomag.com/item/el-circulo-del-vampiro-contemporaneo/. “Ciudades Divididas: Le Perthus y Els Limits - “ . Accessed 1/13/2016, 2016. http:// fronterasblog.com/2008/11/24/ciudades-divididas-le-perthus-y-els-limits/. “Ciudades Que Pinchan | Sociedad | EL PAÍS “ . Accessed 7/24/2015, 2015. http:// sociedad.elpais.com/sociedad/2014/06/13/actualidad/1402683725 100674.html. “Columbia GSAPP “ . Accessed 5/15/2015, 2015. http://www.arch.columbia.edu/ labs/more-labs.

“Conferencia_sobre_la_eficacia - conferencia_sobre_la_eficacia.Pdf “. Accessed 5/27/2015, 2015. https://cgrandola.files.wordpress.com/2008/04/conferencia sobre la eficacia.pdf.

“El Congreso Aprueba La Ley Antitabaco Que Prohíbe Fumar En Los Espacios Públicos Cerrados | Sociedad | EL PAÍS “. Accessed 1/13/2016, 2016. http:// sociedad.elpais.com/sociedad/2010/12/21/actualidad/1292886011 850215.html. “Uno De Cada Cuatro ‘sin Techo’ Tiene Estudios Universitarios | Madrid | EL PAÍS “. Accessed 6/8/2015, 2015. http://ccaa.elpais.com/ccaa/2013/02/22/ madrid/1361540246 338797.html. 
"Elemental - “. Accessed 5/15/2015, 2015. http://www.elementalchile.cl/.

“España Cuenta Con 40.000 Personas Sin Hogar" . Accessed 6/8/2015, 2015.

http://www.lavanguardia.com/vida/20140406/54404697303/espana-cuenta-con-40-

000-personas-sin-hogar-y-un-millon-y-medio-de-familias-en-infraviviendas.html.

"Esto no Es Un Solar “ . Accessed 8/14/2015, 2015. http://estonoesunsolar.com/.

“Flores En El Ático » Torres Eléctricas Como Soporte Artístico “. Accessed

1/13/2016, 2016. http://floresenelatico.es/torres-electricas-como-soporte-

artistico/11696.

“Georg Simmel, "La Metropolis y La Vida Mental” - Bifurcaciones 004 - Coleccion

Reserva." . Accessed 5/31/2015, 2015. http://www.bifurcaciones.cl/004/reserva.htm.

"El Gobierno Grecochipriota Comienza a Derribar El Muro Que Divide La Ciudad

De Nicosia | Internacional | EL PAÍS “. Accessed 1/13/2016, 2016. http://

internacional.elpais.com/internacional/2007/03/09/actualidad/1173394805 850215. $\underline{\mathrm{html}}$.

"La Gran Muralla Verde | Planeta Futuro | EL PAÍs “ . Accessed 1/13/2016, 2016. http://elpais.com/elpais/2014/08/08/planeta futuro/1407493132_336973.html.

"Hasta Que El Tedio Los Separe - Semana.Com “. Accessed 5/31/2015, 2015.

http://www.semana.com/vida-moderna/articulo/hasta-tedio-separe/246495-3.

“Hasta Que El Tedio Los Separe - Semana.Com “. Accessed 5/31/2015, 2015.

http://www.semana.com/vida-moderna/articulo/hasta-tedio-separe/246495-3.

“Homeless Homes Project “. Accessed 7/9/2015, 2015. http://www.

homelesshomesproject.org/.

"Human Brain Gets a Kick Out of Surprises “. Accessed 8/14/2015, 2015. http://

www.ccnl.emory.edu/Publicity/MSNBC.HTM.

"Human Brain Gets a Kick Out of Surprises “. Accessed 9/23/2015, 2015. http://

www.ccnl.emory.edu/Publicity/MSNBC.HTM.

"I+diseño “. Accessed 1/12/2016, 2016. http://www.diseno.uma.es/i diseno/i diseno $6 /$ carmen grisolia.htm.

“Imprescindibles - no Te Mueras Sin Ir a Ronchamp (Sáenz De Oíza), Imprescindibles

- RTVE.Es A La Carta “. Accessed 10/1/2015, 2015. http://www.rtve.es/alacarta/

videos/imprescindibles/imprescindibles-no-mueras-sin-ir-ronchamp-saenz- 
oiza/2929434/.

“Interpretando La Sociedad Desde La Arquitectura (I) | Arquitectura-Política “ . Accessed 5/25/2015, 2015. http://www.arquitectura-politica.org/?p=327.

“Jorge Mario Jáuregui “. Accessed 5/15/2015, 2015. http://www.jauregui.arq.br/.

“José Miguel De Prada y Las Estructuras Neumáticas En España, 1960 - 1980 -

Archivo Digital UPM “. Accessed 7/14/2015, 2015. http://oa.upm.es/4845/.

"De Las Abrumadoras Calles De Baudelaire a Los Fantasmagóricos Pasajes De

Benjamín (Página 2) - Monografias.Com “ . Accessed 1/12/2016, 2016. http://www.

monografias.com/trabajos55/baudelaire-y-benjamin/baudelaire-y-benjamin2.shtml.

“Left Hand Rotation.” . Accessed 8/14/2015, 2015. http://www.lefthandrotation.

$\mathrm{com} /$.

“Li-Fi, La Nueva Red Cien Veces Más Rápida Que El Wi-Fi.” .

Accessed 1/12/2016, 2016. http://www.lavanguardia.com/tecnologia/

innovacion/20151127/30426722928/red-lifi.html.

"Loved and Loathed - the Armoured Knights of the National Grid | Art and

Design | the Guardian “. Accessed 1/13/2016, 2016. http://www.theguardian.com/ artanddesign $/ 2011 / \mathrm{may} / 22 /$ national-grid-pylons-design.

"Metro Cable Caracas / Urban-Think Tank | Plataforma Arquitectura “. Accessed

5/15/2015, 2015. http://www.plataformaarquitectura.cl/cl/02-96696/metro-cable-

caracas-urban-think-tank.

“La Metrópolis Como Cultura Material | Bifurcaciones “. Accessed 5/31/2015, 2015.

http://www.bifurcaciones.cl/2005/09/la-metropolis-como-cultura-material/.

“Microsoft Word - Ivan Illich La Convivencialidad - Convivencial.Pdf “. Accessed

5/21/2015, 2015. http://www.ivanillich.org.mx/convivencial.pdf.

“Miguel Fuster Cuenta Sus 15 Años De Indigente En Cómic - RTVE.Es A La Carta “ . Accessed 7/21/2015, 2015. http://www.rtve.es/alacarta/videos/programa/miguelfuster-cuenta-15-anos-indigente-comic/763527/.

“La Mirada De Elsa » Te Quiero... Pero no Estoy Enamorado De Ti “ . Accessed

7/31/2015, 2015. http://www.inteligenciaemocionalysocial.com/828/elsa-escribe/te-

quiero-pero-no-estoy-enamorado-de-ti.

“El Misterio Del Otro | Actualidad | Móvil EL PAÍS “. Accessed 1/13/2016, 2016. 
http://elpais.com/m/diario/2009/08/06/revistaverano/1249509602 850215.html. “MP Calls for Robin Hood Gardens” Demolition After Failed Listing Bid “. Accessed 1/12/2016, 2016. http://www.dezeen.com/2015/08/05/politician-calls-immediatedemolition-robin-hood-gardens-listing-bid-fails-historic-england-brutalism/. “MP Calls for Robin Hood Gardens’ Demolition After Failed Listing Bid “. Accessed 1/12/2016, 2016. http://www.dezeen.com/2015/08/05/politician-calls-immediatedemolition-robin-hood-gardens-listing-bid-fails-historic-england-brutalism/. “Observatorio Metropolitano “. Accessed 7/24/2015, 2015. http://www. observatoriometropolitano.org $/$.

“Offlinecity | En Construcción “. Accessed 1/10/2016, 2016. https://offlinecity. wordpress.com/.

“Om - Tiny Houses \& More! “. Accessed 7/9/2015, 2015. http:/ /occupymadisoninc. $\underline{\mathrm{com} / .}$.

“ONU-HABITAT :: Oficina Regional Para América Latina y El Caribe “. Accessed 5/19/2015, 2015. http://www.onuhabitat.org/. "ORDOS - Skateboarding through a Modern Chinese Ghost Town : Salty Peaks “. Accessed 5/16/2015, 2015. http://www.saltypeaks.com/blog/2012/10/ordosskateboarding-through-a-modern-chinese-ghost-town.html.

“Otro Hábitat - Colectivo Interesado En Un Urbanismo Participativo y La Mejora Auto-Gestionada Del Hábitat “ . Accessed 8/14/2015, 2015. http://www.otrohabitat. org/.

"P2P Foundation “. Accessed 8/14/2015, 2015. http://p2pfoundation.net/Main

Page.

"Paisaje Transversal Porfolio “. Accessed 8/14/2015, 2015. http://www. paisajetransversal.com/.

“El Papa Cierra Las Puertas Del Limbo | Edición Impresa | EL PAÍS

“. Accessed 7/27/2015, 2015. http://elpais.com/diario/2006/10/07/ sociedad/1160172012 850215.html.

“Pirelli Presenta El Calendario Pirelli 2013, Fotografiado Por Steve McCurry “. Accessed 10/1/2015, 2015. http://www.pirelli.com/tyre/mx/es/news/2012/11/27/ pirelli-presenta-el-calendario-pirelli-2013-fotografiado-por-steve-mccurry/. 
“Portal De La Comunicación InCom-UAB · Dossiers · Vampiros En La Cultura Audiovisual · Tiempo y Vampirización: Del Asesino Al Superhéroe “. Accessed 1/13/2016, 2016. http://www.portalcomunicacion.com/monograficos txt. asp?id $=168 \& \mathrm{txt}=116$.

"Presentan Al Arquitecto Como "Intéprete Global” De Todas Las Disciplinas Artísticas - 20minutos.Es “. Accessed 1/12/2016, 2016. http://www.20minutos.es/ noticia/1614197/0/arquiecto/interprete-global/artes-exposicion/. "PREVI: The Metabolist Utopia “ . Accessed 5/15/2015, 2015. http://www. domusweb.it/en/architecture/2011/04/21/previ-the-metabolist-utopia.html. "Puntos Neutros De Internet: Presentamos a Los Grandes Desconocidos | Interxion “. Accessed 1/13/2016, 2016. http://www.interxion.com/es/blog/puntos-neutrosde-internet-presentamos-a-los-grandes-desconocidos/. “Quinta Monroy - Elemental “. Accessed 5/14/2015, 2015. http://www. elementalchile.cl/proyecto/quinta-monroy/. "Rabbits in Berlin's Death Zone | Film | the Guardian ". Accessed 1/13/2016, 2016. http://www.theguardian.com/film/2010/mar/11/rabbit-a-la-berlin.

"RAIS Fundación | RAIS Fundación “. Accessed 7/24/2015, 2015. https://www. raisfundacion.org $/$.

“Recetas Urbanas :: Santiago Cirugeda :: Arquitectura Social “ . Accessed 8/14/2015, 2015. http://www.recetasurbanas.net/v3/index.php/es/.

"La Reivindicación De La Casa | Edición Impresa | EL PAÍS “. Accessed 5/21/2015, 2015. http://elpais.com/diario/1983/06/05/ opinion/423612014 850215.html.

"Richard Saul Wurman: Technology, Entertainment, Design | Roy Christopher “. Accessed 1/12/2016, 2016. http://roychristopher.com/richard-saul-wurmantechnology-entertainment-design.

"Straddle3 “. Accessed 8/14/2015, 2015. http://straddle3.net/.

“Survival group/accueil “ . Accessed 7/24/2015, 2015. http://www.survivalgroup. $\operatorname{org} /$.

“TENDIENDO PUENTES ENTRE ARQUITECTURA Y SOCIEDAD «

La Ciudad Viva “ . Accessed 1/10/2016, 2016. http://www.laciudadviva.org/ 
$\underline{\operatorname{blogs} / ? \mathrm{p}=10859}$.

“TENDIENDO PUENTES ENTRE ARQUITECTURA Y SOCIEDAD «

La Ciudad Viva “ . Accessed 1/10/2016, 2016. http://www.laciudadviva.org/

blogs/?p=10859.

“TENDIENDO PUENTES ENTRE ARQUITECTURA Y SOCIEDAD «

La Ciudad Viva “. Accessed 1/12/2016, 2016. http://www.laciudadviva.org/ $\underline{\operatorname{blogs} / ? p=10859}$.

“Todo Por La Praxis “ . Accessed 8/14/2015, 2015. http://www.todoporlapraxis.es/.

“Torre David “. Accessed 5/15/2015, 2015. http://torredavid.com/.

“Urban Networks: Berlín Reunificado Tras La Caída Del Muro y El Final De La

Ciudad Doble. “. Accessed 1/13/2016, 2016. http://urban-networks.blogspot.com.

es/2013/04/berlin-reunificado-tras-la-caida-del.html\#more.

“Urban Networks: Rompiendo Moldes: Barcelona y Madrid Se "ensanchan”: El

Eixample De Cerdà y El Plan Castro (Paralelismos y Divergencias Entre Madrid y

Barcelona, 6) “. Accessed 1/12/2016, 2016. http://urban-networks.blogspot.com.

es/2012/11/rompiendo-moldes-barcelona-y-madrid-se.html.

“Urban-Think Tank - Interdisciplinary Design Studio “. Accessed 5/15/2015, 2015.

http://www.u-tt.com/.

"War and Homelessness. how American Wars Create Homelessness among United

States Armed Forces Veterans.”. Accessed 7/15/2015, 2015. http://www.csun.

edu/ bashforth/155 PDF/ME2 Fall SI/AmericanWarsCreateHomelessness.pdf.

"Warrior Square Gardens by Gillespies Landscape Architects « Landscape

Architecture Works | Landezine “. Accessed 7/23/2015, 2015. http://www.

landezine.com/index.php/2011/11/warrior-square-gardens-by-gillespies-landscape-

architects/.

"The Winner of a New Generation of Electricity Pylons is Announced |

Environment | the Guardian “. Accessed 1/13/2016, 2016. http://www.theguardian.

com/environment/gallery/2011/sep/14/shortlist-designs-electricity-pylons-in-

pictures.

"Works | Shigeru Ban Architects" . Accessed 7/9/2015, 2015. http://www.

shigerubanarchitects.com/works.html. 
“Zona Desmilitarizada De Turistas | Internacional | EL MUNDO “. Accessed

1/13/2016, 2016. http://www.elmundo.es/internacional/2015/05/13/5543ac23268e

3e70568b456b.html.

“Zuloark Zoohaus “. Accessed 8/14/2015, 2015. http://www.zuloark.com/zoohausthe-net/. 